Insights into Late Holocene climate of the Ross Sea region, Antarctica,

from high resolution ice core chemistry

by

Rachael H. Rhodes

\author{
A thesis \\ submitted to Victoria University of Wellington \\ in fulfilment of the requirements for the degree of \\ Doctor of Philosophy \\ in Geology
}

Victoria University of Wellington

2011 


\section{Abstract}

The Ross Sea is the most biologically productive sector of the Southern Ocean and a region of substantial bottom water formation. Modulation of these processes has the potential to influence both regional and global climate. Analysis of snow pit and ice core samples from Mt Erebus Saddle (MES) on Ross Island allows reconstruction of Late Holocene climate of this key region of Antarctica.

The biogenic sulphur species, methylsulphonate $\left(\mathrm{MS}^{-}\right)$, is shown to be a quantitative proxy for Ross Sea Polynya conditions. $\mathrm{MS}^{-}$concentrations of the snow pit, dating from 1999-2005 AD, strongly correlate $\left(R^{2}>0.9\right)$ with interannual changes in open water area and surface ocean primary productivity caused by the sea-ice-damming effect of large icebergs.

Trace element analysis of ice core samples allows delineation between: 1) terrestrial and marine sources, 2) anthropogenic $\mathrm{Pb}$ pollution, and 3) volcanic trace element deposition. To assess the contribution of mineral dust leaching to trace element concentrations, powdered rock standards were leached in 1 wt.\% $\mathrm{HNO}_{3}$ and periodically sampled for analysis. Results demonstrate that trace element leaching in acidified samples is time- and mineral-dependent. Incongruent leaching of trace elements from dust causes errors in crustal enrichment factors and produces trace element ratios, which do not reflect dust provenance.

Stable isotope $\left(\delta D, \delta^{18} \mathrm{O}\right.$, d-excess) and soluble chemistry records of the $120 \mathrm{~m}$ MES ice core document the climate of the Ross Sea region since 1446 AD. This includes the Little Ice Age (LIA) - the most recent global climate change event. Lithophile elements (e.g., Al), sourced from mineral dust, are proxies for katabatic wind speed whilst dexcess and marine elements (e.g., $\mathrm{Na}$ ) are related to the incursion of cyclonic systems into the Ross Sea. $\delta$ D values of $6.4 \%$ o below the $1950-2006$ mean characterise the LIA, suggesting a mean cooling of $1.6{ }^{\circ} \mathrm{C}$. An abrupt 5\%o d-excess increase provides evidence for enhanced cyclonic activity between 1625 and 1875 AD. Mean lithophile element concentrations, which are $>50 \%$ higher in the LIA than post-1850 AD, demonstrate that katabatic wind speeds $>57 \mathrm{~m} \mathrm{~s}^{-1}$ prevailed during the LIA. 
Furthermore, $\mathrm{MS}^{-}$concentrations indicate that the Ross Sea Polynya was larger and more productive prior to $1875 \mathrm{AD}$, relative to the ensuing time. As strong katabatic winds appear to have maintained a more extensive Ross Sea Polynya during the LIA, the associated increase in sea ice formation may have enhanced bottom water formation at this time. 


\section{Table of Contents}

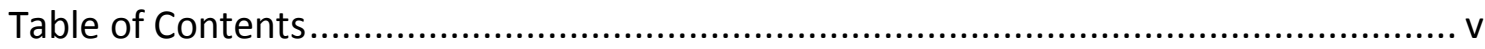

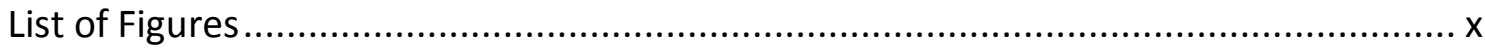

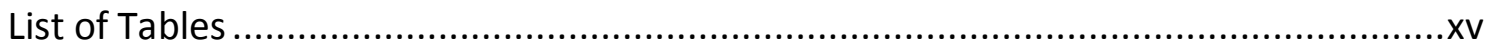

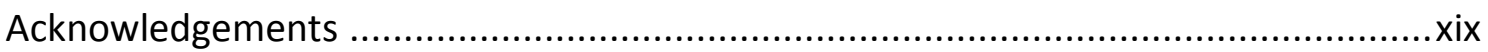

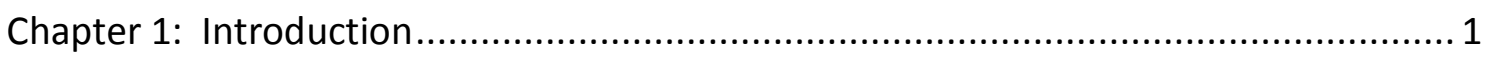

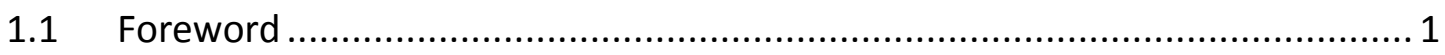

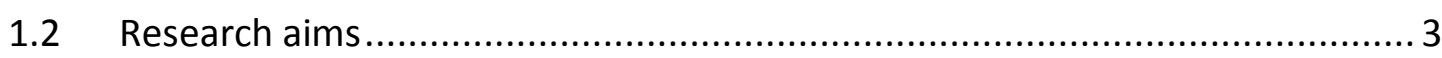

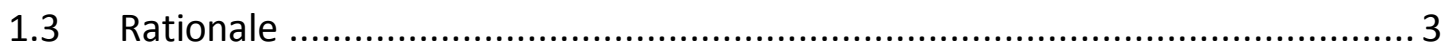

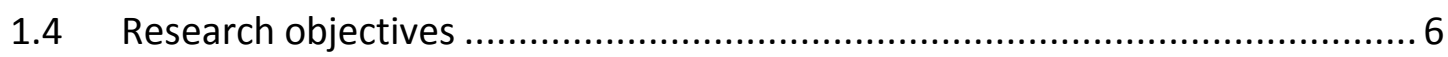

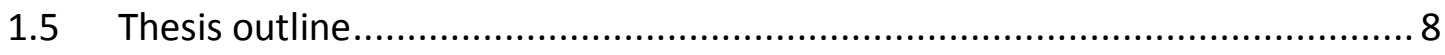

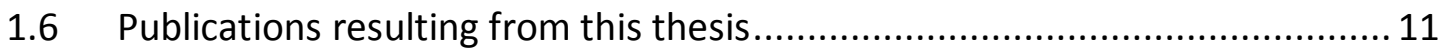

Chapter 2: Antarctic climate and ice core climate proxies ................................... 13

2.1 Antarctica and the global climate system ................................................. 14

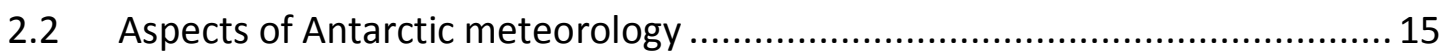

2.3 Decadal drivers of Antarctic and Southern Hemisphere climate variability.... 19

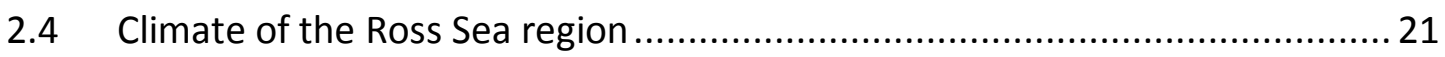

$2.5 \quad$ Ice core climate and environmental proxies........................................... 24

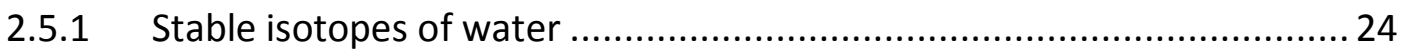

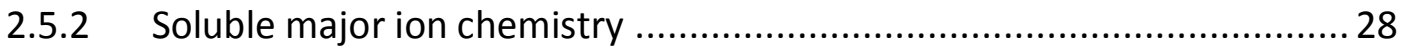

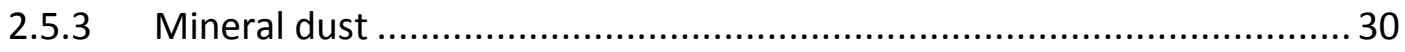

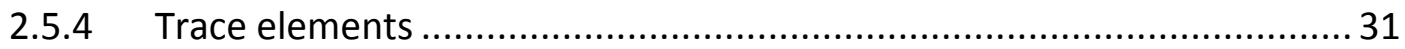

2.6 Ice core records of decadal-scale climate variability in the Antarctic............. 34

Chapter 3: Sea ice variability and primary productivity in the Ross Sea, Antarctica, from

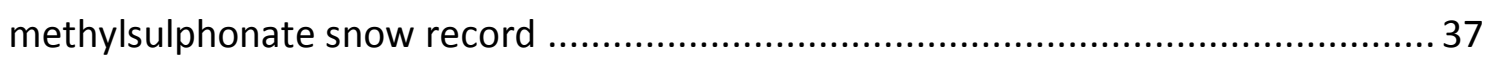




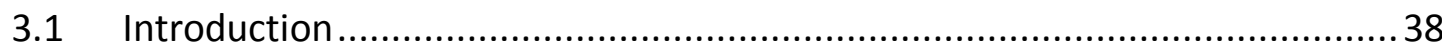

3.2 Sea ice behaviour in the Ross Sea region................................................. 40

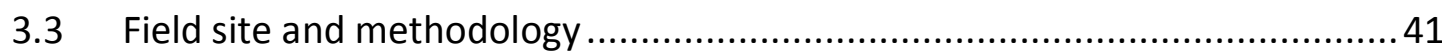

3.4 Sea ice extent, primary productivity and methylsulphonate .........................43

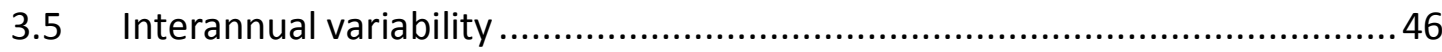

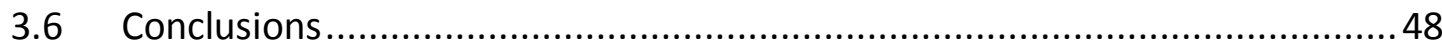

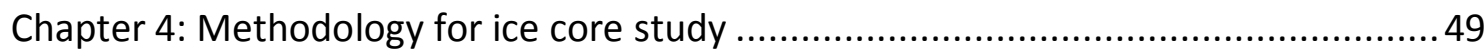

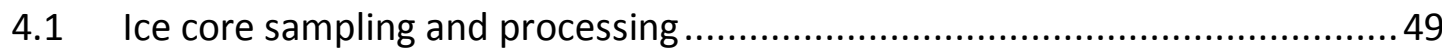

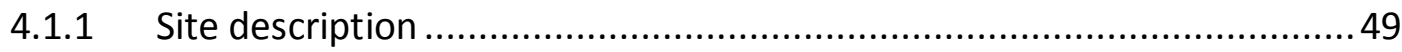

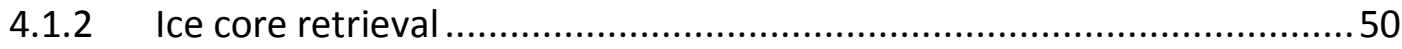

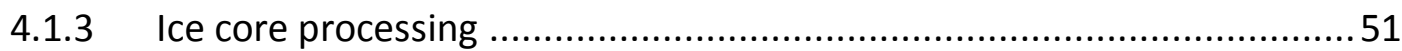

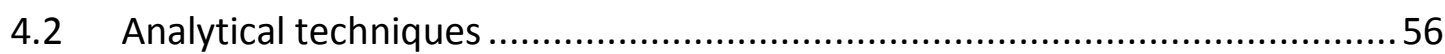

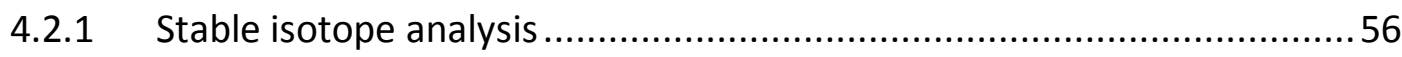

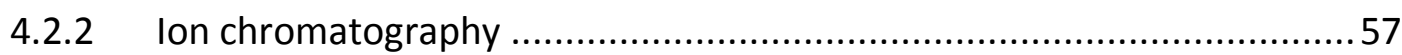

4.2.3 Inductively coupled plasma mass spectrometry ................................58

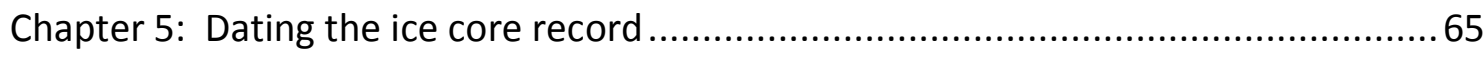

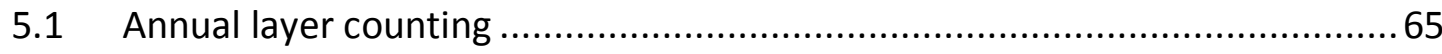

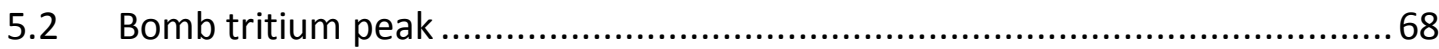

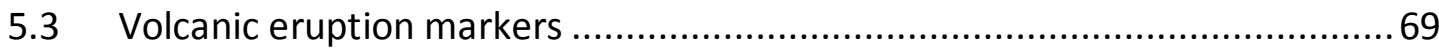

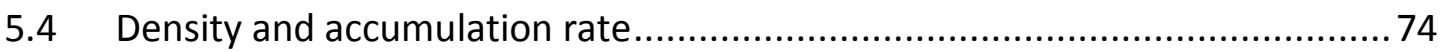

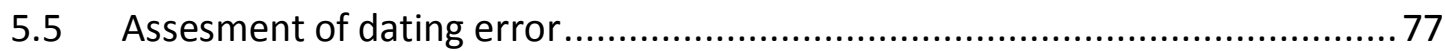

Chapter 6: Experimental investigation of the effects of mineral dust on the reproducibility and accuracy of ice core trace element analyses ..............................79

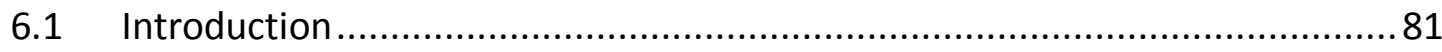

$6.2 \quad$ ICP-MS trace element analysis of ice cores ............................................. 83

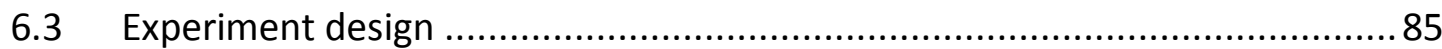
vi 


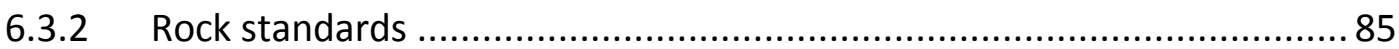

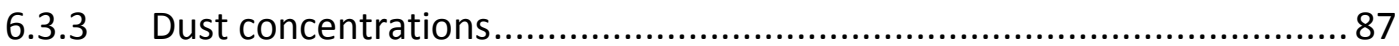

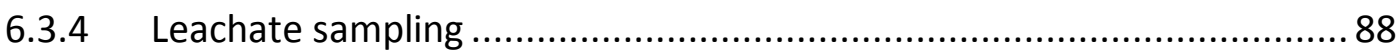

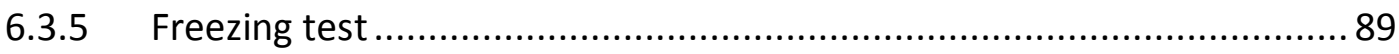

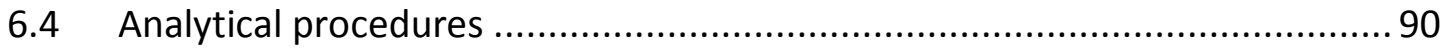

6.4.1 Hardware and operating conditions ............................................... 90

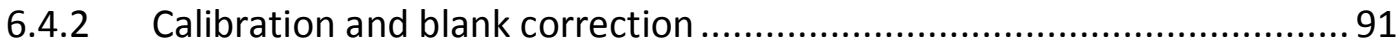

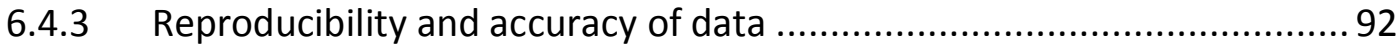

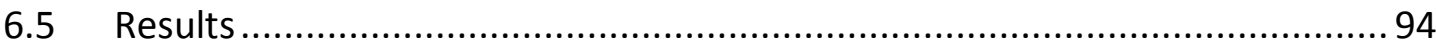

6.5.1 Effect of acidification time on trace element leachate concentration ....94

6.5.2 Variation in leaching characteristics between dust lithologies .............. 97

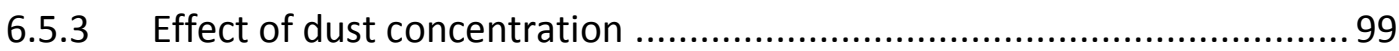

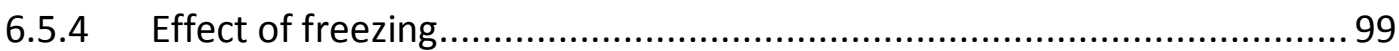

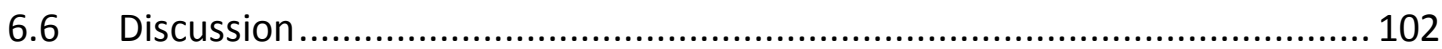

6.6.1 Implications for interpretation of trace element concentrations in ice

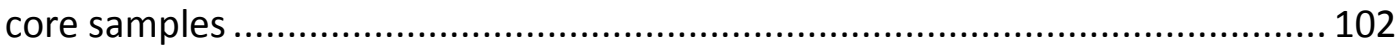

6.6.2 Implications for the interpretation of trace element ratios ................ 104

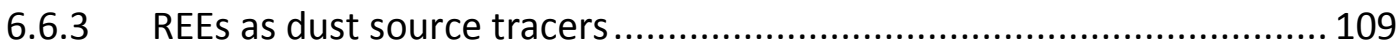

6.6.4 Redox-sensitive elements ...................................................... 110

6.7 Recommendations for future ice core trace element studies .................... 112

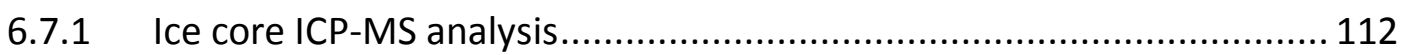

6.7.2 Ice core trace element data interpretation .................................. 113

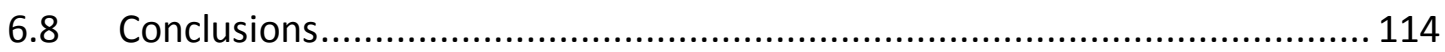

Chapter 7: Increased katabatic wind speeds and greater polynya extent in the Ross Sea

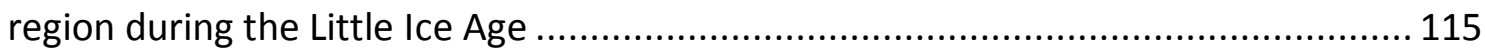




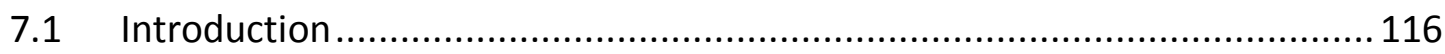

7.2 Study site, core processing and analytical methods.................................119

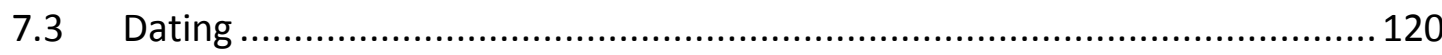

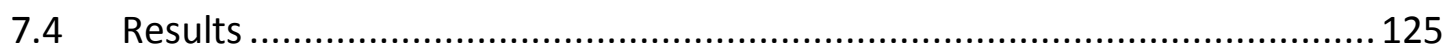

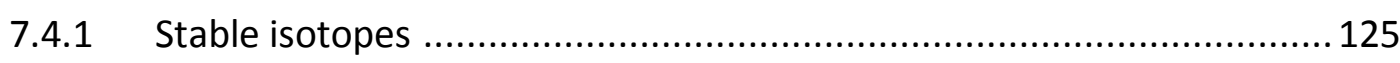

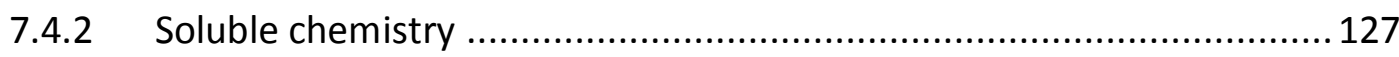

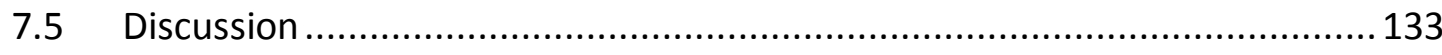

7.5.1 Linking the ice core record to climate parameters ........................... 133

7.5.2 Little Ice Age climate ............................................................ 137

7.5.3 Ross Sea Polynya in the Little Ice Age ............................................. 139

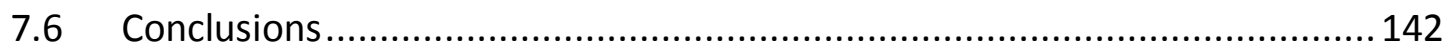

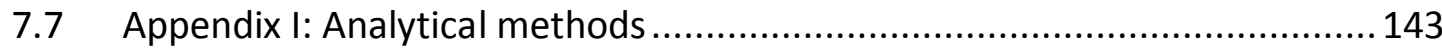

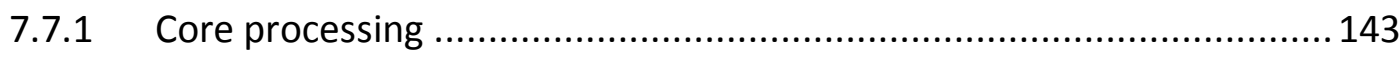

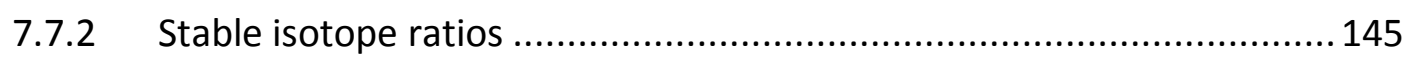

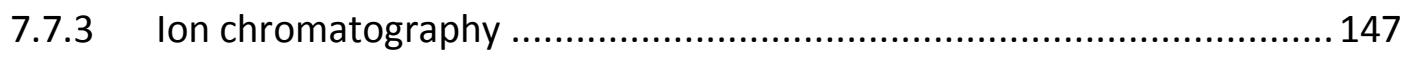

7.7.4 Inductively coupled plasma mass spectrometry ............................ 148

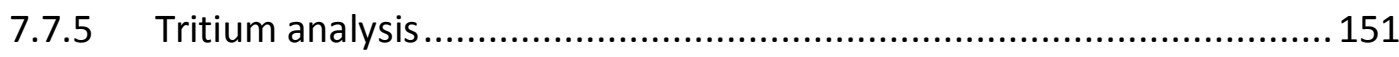

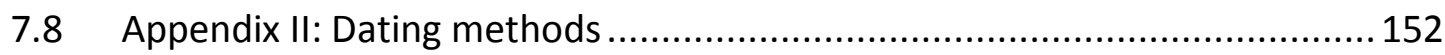

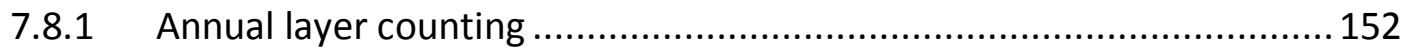

7.8.2 Back-diffusion of stable isotopes............................................... 152

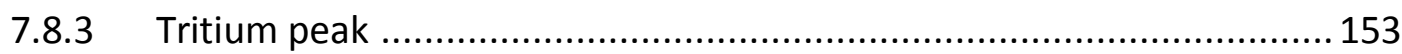

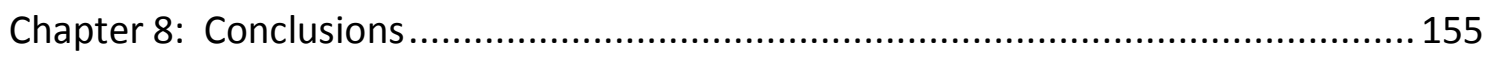

8.1 Interpretation of snow pit stable isotope and major ion data.................... 155

8.2 Core processing and ICP-MS method development............................... 155

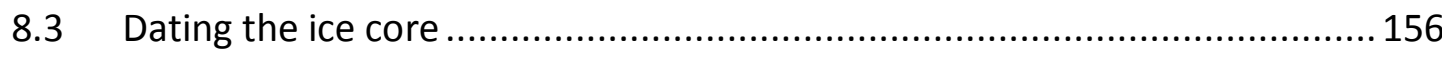


References

Appendices

Appendix I: Mt Erebus Saddle 2004/05 snow pit data

Appendix II: Procedural blanks for Mt Erebus Saddle ice core processing and sampling.

Appendix III: Accuracy, precision and detection limits of major ion concentration measurements

Appendix IV: Stable isotope data for Mt Erebus Saddle 2006/07 ice core

Appendix V: Dansgaard-Johnsen glacial flow model 205

Appendix VI: Back-diffusion of Mt Erebus Saddle 2006/07 ice core stable isotope ratios 206

Appendix VII: Mt Erebus Saddle tritium $\left({ }^{3} \mathrm{H}\right)$ measurements 207

Appendix VIII: Mt Erebus Saddle 2006/07 ice core density measurements 208

Appendix IX: Supplementary data tables for dust leaching investigation 210

Appendix X: Antarctic Little Ice Age climate

Appendix XI: Mt Erebus Saddle 2006/07 soluble chemistry data 223

Appendix XII: Mt Erebus Saddle ice core age model 225

References for appendices 230 
Figure 1.1: Reconstructed Antarctic surface temperature trends and observed changes in sea ice fractional area for 1979 to 2003 [Steig et al., 2009]...........................................4

Figure 1.2: Map of the Ross Sea region showing NZ-ITASE ice core sites......................5 Figure 2.1: Map of the Antarctic continent showing key locations and ice core sites referred to in the text. 13

Figure 2.2: Mean sea level pressure across Antarctica and the Southern Ocean for the time period Jan-1979 to Jan-2010. .16

Figure 2.3: Map of Antarctic showing the rate of accumulation of precipitation [Mayewski et al., 2009].

Figure 2.4: Major flowlines of katabatic winds off the Antarctic continent [Parish, 1988] .18

Figure 2.5: Thermal infra-red satellite image of the Ross Ice Shelf in mid-winter [Bromwich et al., 1992]..... 21

Figure 2.6: Effect of El Niño and La Niña events on the position and strength of the

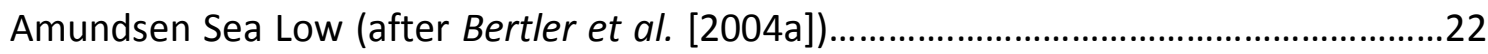

Figure 2.7: Global Meteoric Water Line (GMWL) of Craig [1961] .................................25 Figure 2.8: Deuterium excess as a function of temperature in the initial cloud vapour for relative humidities of $50 \%, 70 \%$ and $90 \%$ and wind speeds of $2 \mathrm{~ms}^{-1}, 4 \mathrm{~ms}^{-1}$ and 6 $\mathrm{ms}^{-1}$ [Merlivat and Jouzel, 1979] .26

Figure 2.9: Linear relationships between surface temperature and stable isotope ratios of snow and ice core samples from across Antarctica [Masson-Delmotte et al., 2008] .27

Figure 2.10: Na concentration records from Siple Dome (red) and Law Dome (blue) used as proxies for the Amundsen Sea Low (ASL) and East Antarctic High (EAH) respectively [Mayewski et al., 2009]. 35 Figure 3.1: Location of Mt Erebus Saddle on (a) Radarsat image of Antarctica and (b) on LIMA false colour satellite image, USGS. Rose diagram (C) displays wind direction and speed for summer months at nearby Scott Base 
Figure 3.2: (A) Mt Erebus Saddle snow pit $\mathrm{MS}^{-}$record (3-point running mean) plotted with $\delta^{18} \mathrm{O},(\mathrm{B})$ daily open water area of Ross Sea during summer, and (C) daily primary productivity of the Ross Sea polynya

Figure 3.3: $\mathrm{MS}^{-}$time series with images showing distribution of photosynthetic pigment, chlorophyll $a$, concentrations in the south-western Ross Sea (160-190 ${ }^{\circ} \mathrm{E}, 71$ $86^{\circ} \mathrm{S}$ ) in mid-December of each austral summer. .46

Figure 4.1: Ground penetrating radar (35 MHz frequency) profile from Mt Erebus Saddle showing bedrock topography, ice thickness and parallel isochrones (after Bertler [2004])....... 49

Figure 4.2: Map of annual precipitation in the McMurdo Sound region produced by the Antarctic Mesoscale Prediction System (AMPS) (after Monoghan et al. [2005]). 50 Figure 4.3: Plan view of the Mt Erebus Saddle ice core showing portion of core used in this study. 51

Figure 4.4: Photograph of nickel melt disk used on the continuous melter system......53 Figure 5.1: $\delta^{18} \mathrm{O}$ records from the Mt Erebus Saddle ice core (drilled summer 2006/07) and snow pit (sampled in 2004/05) on same age scale.

Figure 5.2: $\delta^{18} \mathrm{O}$ and $\mathrm{NO}_{3}{ }^{-}$profiles of a selected ice core section which display summer $\delta^{18} \mathrm{O}$ peaks and winter $\mathrm{NO}_{3}{ }^{-}$peaks. 66

Figure 5.3: Stable isotope data for 50-60 m section of the Mt Erebus Saddle core. .67

Figure 5.4: Tritium contents of six Mt Erebus Saddle ice core samples analysed plotted with tritium contents of precipitation from the Ross Ice Shelf, Halley Bay, Antarctic Peninsula and Kaitoke, New Zealand

Figure 5.5: The $\mathrm{nsSSO}_{4}{ }^{2-}$ concentration record and concentration ratios of $\mathrm{Pb}, \mathrm{Bi}$ and $\mathrm{TI}$ to $\mathrm{Al}$ for the period 1800 to $2007 \mathrm{AD}$ (65.5 m depth to surface) .70 Figure 5.6: Selected trace element ratio records for the time period including the proposed 1809 AD and Tambora eruption markers in $\mathrm{Bi}, \mathrm{Pb}$ and $\mathrm{TI}$...............................73

Figure 5.7: Density profile of the Mt Erebus Saddle ice core .74 Figure 5.8: Annual accumulation rates of the Mt Erebus Saddle ice core between 1950 and 2006 AD 75

Figure 5.9: Relationship between annual layer thickness and core depth for the age models produced by annual layer counting and the glacial flow model. .76 
Figure 5.10: Age-depth relationship of the Mt Erebus Saddle ice core age model compared to the glacial flow model output

Figure 6.1: A) Grain size distributions of BHVO-2, JG-2, W-2 and Nod-P-1. B) Horizontal bars indicate grain size ranges recorded at various Antarctic sites. 86

Figure 6.2: Relative concentration increases of trace elements in the leachates of $\mathrm{W}-2$, BHVO-2, JG-2 and Nod-P-1 at selected acidification times...........................................95 Figure 6.3: Concentrations of $\mathrm{Al}$ and $\mathrm{La}$ in BHVO-2 leachates plotted versus acidification time .96

Figure 6.4: Concentrations of $\mathrm{Al}, \mathrm{Mn}$ and $\mathrm{La}$ in JG-2 leachates plotted versus acidification time 96

Figure 6.5: Concentrations of $\mathrm{Na}, \mathrm{Al}$ and La in Nod-P-1 leachates plotted versus acidification time 97

Figure 6.6: Proportion of each element leached from BHVO-2, JG-2, W-2 and Nod-P-1 into leachate after $12 \mathrm{hr}$ acidification, expressed as \% recovery 98 Figure 6.7: Linear relationship between dust (W-2) concentration $(10,50,500$ ppm) and concentrations of $\mathrm{Sr}$ and Ce measured in the leachates after $12 \mathrm{hr}$....... .99 Figure 6.8: Recovery of $\mathrm{Zr}$ versus recovery of Ti for JG-2 and BHVO-2 samples that were either acidified and frozen, un-acidified and frozen, or not frozen prior to $12 \mathrm{hr}$ of acidleaching at room temperature. 101

Figure 6.9: Variation in the marine/terrestrial ratio with acidification time in BHVO-2 leachates using three different terrestrial tracers: $\mathrm{Mn}$, La and Al. 105 Figure 6.10: Variation in Na/Al ratio of BHVO-2, JG-2, W-2 and Nod-P-1 leachates acidification time 106 Figure 6.11: Variation in Al/La ratio of BHVO-2, JG-2, W-2 and Nod-P-1 leachate samples with acidification time. 106

Figure 6.12: Crustal enrichment factors for $\mathrm{Cu}, \mathrm{V}$, and $\mathrm{U}$ calculated for a dust lithology comprising 50\% JG-2, 24.5\% BHVO-2, 24.5\% W-2 and 1\% Nod-P-1 using Al, Mn and La as crustal reference elements. 108 Figure 6.13: Chondrite-normalised plot of REE concentrations in W-2 rock standard and REE concentrations in leachates of $W-2$ leached at a concentration of 500 ppm....110 
Figure 6.14: $\mathrm{Ce}$ anomaly ( $\mathrm{Ce} / \mathrm{Ce}{ }^{*}$ ) of Nod-P-1 rock standard and variation in $\mathrm{Ce} / \mathrm{Ce}$ * of Nod-P-1 leachate with acidification time.

Figure 7.1: A) Map of the Antarctic continent; B) Map of the Ross Sea region; C) Map of McMurdo Sound area

Figure 7.2: $\mathrm{Bi}, \mathrm{Pb}$ and $\mathrm{Tl}$ concentrations normalised to $\mathrm{Al}$ and selected trace element ratio records for the time period including the Mt Tambora eruption marker

Figure 7.3: Anthropogenic influence on Pb deposition at Mt Erebus Saddle since 1840 AD.

Figure 7.4: Mean seasonal cycles of $\delta D, d$-excess, marine and lithophile elements for 1970-2006 AD. 126

Figure 7.5: Stable isotope and soluble chemistry data for the time period 1970-2006 $A D$ of the Mt Erebus Saddle ice core. 130

Figure 7.6: Stable isotope and soluble chemistry records from the Mt Erebus Saddle ice core re-sampled to 2 samples $\mathrm{yr}^{-1}$...... 131

Figure 7.7: Deuterium excess and $\mathrm{MS}^{-}$time series from Mt Erebus Saddle ice core.

Figure 7.8: Scatterplot of $\mathrm{Na}^{+}$versus $\mathrm{SO}_{4}{ }^{2-}$ concentrations of all Mt Erebus Saddle samples measured by IC (surface-65.8 m; 1797-2006 AD). 134

Figure 7.9: A) NCEP/NCAR reanalysis $850 \mathrm{mb}$ meridional (positive values $=\mathrm{S}$ to $\mathrm{N}$ flow) wind composite mean for the winter months of period 1979-2006 across the Ross Sea region $\left(90-70^{\circ} \mathrm{S}, 150-220^{\circ} \mathrm{E}\right)$; B) Spatial correlation pattern between meridional wind (850 $\mathrm{mb}$ ) and Mt Erebus Saddle Al concentration record for the winter months of period $1990-2000$ across the Ross Sea region. 136

Figure 7.10: $\delta D$ measured on GVI mass spectrometer and LGR Liquid-Water Isotope Analyser (Laser)...... 146

Figure 7.11: Deuterium excess derived from $\delta^{18} \mathrm{O}$ and $\delta \mathrm{D}$ values measured on GVI mass spectrometer and LGR Liquid-Water Isotope Analyser (Laser).

Figure 7.12: Tritium content of six Mt Erebus Saddle ice core samples analysed plotted with tritium contents of precipitation from the Ross Ice Shelf, Halley Bay, Antarctic Peninsula, and Kaitoke, New Zealand .153 
Figure 8.1: Summary of relationship between $\mathrm{MS}^{-}$concentration, sea ice cover and primary productivity 156

Figure 8.2: Summary of time- and mineral-dependent leaching effects on A) trace element concentrations, B) crustal enrichment factors and C) terrestrial element ratios 158

Figure 8.3: Summary of the climatic and environmental changes recorded in the $\delta D, d$ excess, lithophile element (Al) and $\mathrm{MS}^{-}$records of the Mt Erebus Saddle ice core and diatom blooms of sediment cores [Leventer and Dunbar, 1988] .160 Figure A1: Scatterplots of annual mean $\mathrm{MS}^{-}$values against $A$ ) annual mean open water area and B) annual production 188

Figure A2: $\delta^{18} \mathrm{O}$ measured on GVI mass spectrometer and LGR Liquid-Water Isotope Analyser (Laser). 202

Figure $A 3: \delta D$ measured on GVI mass spectrometer and LGR Liquid-Water Isotope Analyser (Laser). .202

Figure A4: Deuterium excess calculated from $\delta^{18} \mathrm{O}$ and $\delta \mathrm{D}$ values measured on $\mathrm{GVI}$ mass spectrometer and LGR Liquid-Water Isotope Analyser (Laser) .203 Figure A5: Stable isotope ( $\delta D$ and d-excess) records of the MES ice core $A$ ) before, and B) after, a correction was applied to laser-measured data to account for the calibration difference between the mass spectrometer and laser instruments 204 Figure A6: Summary of conditions across Antarctica during the Little Ice Age (modified after Bertler et al. [in press]) .222

Figure A7: Identification and removal of anomalous IC data points .224 


\section{List of Tables}

Table 4.1: ICP-MS procedural blanks for ice core processing and sampling .55

Table 4.2: IC procedural blanks for ice core processing and sampling. .55

Table 4.3: Concentrations of major ions in IC calibration standards.

Table 4.4: Operating conditions of the ICP-MS and data acquisition parameters for the determination of selected elements in Mt Erebus Saddle ice core samples. .59

Table 4.5: Concentrations of elements in ICP-MS daily calibration standards. 60

Table 4.6: Major element concentrations determined by repeated measurement of SLRS-4 riverine water standard for each analytical session with precision and accuracy of measurements.

Table 4.7: Trace element concentrations determined by repeated measurement of SLRS-4 riverine water standard for each analytical session with precision and accuracy of measurements.

Table 4.8: Detection limits for elements determined in each analytical session of ICPMS analyses of the Mt Erebus Saddle ice core......

Table 6.1: Summary of sample preparation and storage procedures utilised in previously published ice core ICP-MS trace element studies.

Table 6.2: ICP-MS operating conditions and data acquisition parameters .90

Table 6.3: Element concentrations for BHVO-2, W-2, Nod-P-1 and JG-2 and dilution factors used to make up calibration standards from fully-digested rock standard powders

Table 6.4: Accuracy, precision and detection limits for ICP-MS analyses of rock standards.

Table 6.5: Mean recovery (\%) $(n=3)$ of trace elements from BHVO-2 and JG-2 leached at a dust concentration of $63 \mathrm{ppm}$ for $12 \mathrm{hr}$ after either being frozen acidified, frozen un-acidified or not frozen... 100

Table 7.1: Mean and range (in parentheses) of selected stable isotopic and soluble chemistry parameters within specified time intervals of the Mt Erebus Saddle ice core record 
Table 7.2: Correlation coefficients for major, minor and trace element concentrations (12 samples $\mathrm{yr}^{-1}$ ) during the 1970-2006 AD time period in Mt Erebus Saddle ice core. .128

Table 7.3: Correlation coefficients for lithophile element concentrations ( 2 samples $\mathrm{yr}^{-1}$ ) during the LIA recorded in Mt Erebus Saddle ice core (1446-1850 AD)..... 129

Table 7.4: Concentrations of elements and major ions determined in the procedural blanks sampled during processing and sampling of the ice core. .144

Table 7.5: Operating conditions of the ICP-MS and data acquisition parameters for the determination of selected elements in ice core samples. 149

Table 7.6: Detection limits for elements determined by ICP-MS analysis 149

Table 7.7: Element concentrations determined by repeated measurement of SLRS-4 riverine water standard $(n=82)$ with precision and accuracy of measurement 150

Table A1: Stable isotope ratios $\left(\delta^{18} \mathrm{O}\right)$ and major ion concentrations for Mt Erebus Saddle 04/05 snow pit. .184

Table A2: Concentrations of trace elements determined by ICP-MS in the procedural blanks 190

Table A3: Concentrations of major ions determined by IC in the procedural blanks...193

Table A4: Detection limits of major ions determined by IC .194

Table A5: Concentrations of major ions determined in two dilutions of the external standard ION-92 and the accuracy and precision of measurements. .195

Table A6: Stable isotope data for Mt Erebus Saddle 2006/07 ice core on disk Table A7: Mt Erebus Saddle 2006/07 ice core stable isotope samples with anomalously heavy values resulting from ethanol or ultra-pure water in the melter system.....on disk Table A8: Comparison of the stable isotope ratios $\left(\delta^{18} O\right.$ and $\left.\delta D\right)$ of selected ice core samples determined by GVI mass spectrometer (Mass spec.) and LGR Liquid-Water Isotope Analyser (Laser) 198

Table A9: Annual accumulation ( $\mathrm{m} \mathrm{yr}^{-1}$ ) model output of Dansgaard-Johnsen glacial flow model. on disk

Table A10: Depth-age result of Dansgaard-Johnsen glacial flow model......on disk Table A11: $\delta 180$ and $\delta D$ profiles re-sampled to $2.5 \mathrm{~cm}$ depth intervals........ disk xvi 
Table A12: Diffusion lengths of $\delta^{18} \mathrm{O}$ and $\delta \mathrm{D}$ calculated for the back-diffusion of stable isotope profiles on disk

Table A13: Modelled density profile used for back-diffusion of stable isotope profiles and glacial flow model. on disk

Table A14: Back-diffused stable isotope profiles and the derived d-excess profile. on disk

Table A15: Back-diffused stable isotope profiles and the derived d-excess profile calculated using increased diffusion lengths. .on disk

Table A16: Six tritium content measurements conducted on samples from selected depths in the ice core..... 207

Table A17: Field density measurements for the Mt Erebus Saddle ice core. .209

Table A18: Concentrations of trace elements in leachates of BHVO-2 at 10 ppm dust concentration.

Table A19: Concentrations of trace elements in leachates of W-2 at 10 ppm dust concentration.

Table A20: Concentrations of trace elements in leachates of JG-2 at 10 ppm dust concentration.

Table A21: Concentrations of trace elements in leachates of Nod-P-1 at 10 ppm dust concentration 214

Table A22: Concentrations of trace elements in leachates of $\mathrm{W}-2$ at $50 \mathrm{ppm}$ dust concentration 215

Table A23: Concentrations of trace elements in leachates of $\mathrm{W}-2$ at $500 \mathrm{ppm}$ dust concentration 216

Table A24: Concentrations of trace elements in leachate of BHVO-2 after $12 \mathrm{hr}$ acidification following storage under different conditions. 217

Table A25: Concentrations of trace elements in leachate of JG-2 after $12 \mathrm{hr}$ acidification following storage under different conditions 218

Table A26: Concentrations of trace elements recorded in freezing experiment procedural blanks 219 
Table A27: LREE/MREE and LREE/HREE ratios of BHVO-2, JG-2 and W-2 leachates and rock standards.

Table A28: Mt Erebus Saddle 2006/07 ice core major, minor and trace element concentrations .on disk Table A29: Mt Erebus Saddle 2006/07 ice core trace element concentrations determined by ICP-MS in collision cell (hydrogen-flushed) mode on disk Table A30: Mt Erebus Saddle 2006/07 major ion concentrations. on disk Table A31: Mt Erebus Saddle 2006/07 major ion concentrations with anomalously high concentration samples removed. on disk Table A32: Mt Erebus Saddle ice core age model. .226 


\section{Acknowledgements}

My sincere thanks go to my supervisors, Nancy Bertler and Joel Baker, for their valuable advice and support throughout this project. Thank you for creating such an exciting research opportunity, for allowing me to develop a wide range of skills, and for challenging me to achieve my potential.

I am truly indebted to Julia Bull for her significant contribution towards ICP-MS technique development, and for her friendship and laughter through the many weeks of vial washing. I would also like to acknowledge Monica Handler, Richard Wysoczanski, Marc-Alban Millet and many of the other students of the Volcanology, Geochemistry and Petrology (VGP) group for their assistance in the Geochemistry Laboratory.

The Antarctic Research Centre is a fantastic research group and I have very much enjoyed my time here. Lionel Carter, Warren Dickinson, Alex Pyne and Andrew Mackintosh have proved excellent sources of knowledge and advice. Melissa Bowen opened my eyes to the power of wavelet analysis and Gavin Dunbar introduced grain size analysis techniques. Infinite thanks must also go to Tamsin Falconer and Michelle Dow for their cheerful and efficient help with any problem at all. The technical expertise of Alex Pyne and the drill team of Webster Drilling made this research possible. Discussing ideas with my fellow 'ice core' students, Lana Cohen, Holly Winton and Bradley Markle, has been really useful and a lot of fun. To all my office mates, you really made the past few years special through your friendship, support and humour.

The opportunity to work at both Victoria University and GNS Science has proved a huge asset to this project. I thank all the GNS Science staff for embracing this research. In particular, I would like to acknowledge: Kate Sinclair for useful discussions on interpretation of stable isotopic data; Kate Sinclair and Julian Thompson for assistance in processing the ice core; Bruce Crothers and Ed Hutchinson for their electrical 
engineering expertise, and Stephen Mawdesley and Mechanical Engineering Workshop team for their production of components for the melter system. The staff of the Stable Isotope Laboratory at GNS Science, especially Andy Phillips, Cedric Douence and Valerie Claymore, analysed many samples for this project with care and dedication to data quality. I am grateful Uwe Morgenstern for meticulously measuring tritium contents of selected samples.

This project was generously supported by the Climate Change Institute at the University Maine. Sharon Sneed and Paul (Jay) Holweger not only analysed many samples from the Mt Erebus Saddle ice core, but also took time to train me in ion chromatograph operation. All the staff and students of Institute extended a warm welcome to me during my visit and I thank them for a truly enjoyable time.

Dating of the Mt Erebus Saddle ice core was greatly aided by Hans Christian SteenLarsen and Sigfus Johnsen (Center for Ice and Climate, Copenhagen), whose expertise in back-diffusion and glacial flow modelling has proved invaluable. I am also indebted to Kevin Arrigo (Stanford University) for Ross Sea primary productivity and open water data sets and to Hans Oerter (Alfred Wegener Institute) for stable isotopic measurements.

I am grateful to GNS Science for providing me with a scholarship for stipend and tuition fees. Additional funding for conference attendance was supplied by the TransAntarctic Association, the Antarctic Research Centre Endowment Fund, a Science Faculty Strategic Research Grant and the Postgraduate Students Association. My time on ice in the $2007 / 08$ season was an amazing experience and I thank Antarctica New Zealand for excellent logistical support.

Finally, to my family, and to Marc-Alban, your love and unconditional belief in me are a constant source of happiness, strength, and determination to achieve my goals. 


\section{Chapter 1: Introduction}

\subsection{Foreword}

Ice cores provide the most continuous and high resolution records of paleoclimate available for the past one million years of Earth's history [EPICA, 2004; Petit et al., 1999]. High profile, internationally acclaimed ice coring projects, such as the European Project for Ice Coring in Antarctica (EPICA), have provided a wealth of information about past global temperature and atmospheric greenhouse gas concentrations, which is fundamental to our understanding of global climate change [EPICA, 2004; IPCC, 2007].

To further our advance understanding of Earth's climate system and to allow for more accurate predictions of future climate response to continued anthropogenic greenhouse gas emissions, the International Trans-Antarctic Scientific Expedition (ITASE) identified the retrieval and interpretation of short term (past $200 \mathrm{yr}$ ), high resolution ice core records as a primary aim [Mayewski et al., 2005]. This goal was adopted by the International Partnership on Ice Coring Sciences (IPICS) and the targeted time period was extended to the past $2000 \mathrm{yr}$ to include Late Holocene climate variability including the Medieval Warm Period and Little Ice Age events [IPICS, 2008]. The New Zealand Ice Core Program contributes to ITASE and IPICS by obtaining ice core and snow pit samples from coastal locations in the Ross Sea region, Antarctica. Coastal Antarctica experiences higher rates of snow accumulation, and ice cores from coastal locations therefore provide subannual resolution climate records, which permit decadal-scale climate variability to be resolved [e.g. van Ommen and Morgan, 1997].

Advances in analytical capability, allowing the determination of trace element concentrations [e.g. Barbante et al., 1997], have introduced a new tool to ice core paleoclimatology. Trace element determination by inductively coupled plasma mass spectrometry (ICP-MS) is increasingly utilised alongside the conventional ice 
core climate proxies, stable isotope ratios and major ion chemistry and has the potential to provide additional insights into paleoclimate. 


\section{$1.2 \quad$ Research aims}

The aim of this thesis is to produce a record of the Late Holocene climate of the Ross Sea region, Antarctica, from glaciochemical proxies developed from a $2 \mathrm{~m}$ snow pit and $120 \mathrm{~m}$ ice core record. In order to achieve this, stable isotope ratios (oxygen and hydrogen), major ion, and major, minor and trace element concentrations, analysed at high temporal resolution, are correlated to instrumental and satellite data.

\subsection{Rationale}

The Ross Sea is a key region of Antarctica of which to understand past climate and to evaluate the potential future response to anthropogenically induced climate change. The Ross Sea is a principal site of sea ice production [Tamura et al., 2008] in the Southern Hemisphere and this drives substantial amounts of bottom water formation [Jacobs and Giulivi, 1998], which contributes to the global thermohaline circulation of the oceans [Broecker, 1997]. Additionally, the Ross Sea Polynya provides an excellent habitat for phytoplankton, making the Ross Sea the most biologically productive region of the Southern Ocean [Arrigo et al., 1998; Smith and Gordon, 1997] and a significant region of $\mathrm{CO}_{2}$ drawdown from the atmosphere [Arrigo et al., 1999]. Changes to any of these processes have the potential to create climate feedbacks which would affect not only regional climate, but also the global climate system.

Therefore, it is important to understand how the climate and environmental conditions of this region have varied in the past in order to provide a context in which to consider how the region may respond in the future. At present, there is a knowledge gap concerning the past climate variability of the Ross Sea region, the Antarctic continent, and the Southern Hemisphere as a whole, resulting from a lack of historical meteorological data from prior to the late-1950s and the restricted temporal coverage of satellite datasets (late-1970s onwards).

Ice core proxy records have the potential to extend our knowledge of past climate beyond the observational record. However, contrasting regional trends in temperature, sea ice cover, ocean temperatures and wind strength [Boning et al., 2008; 
Marshall et al., 2004; Steig et al., 2009; Zwally et al., 2002] have occurred in the Antarctic over the satellite era (Fig. 1.1), demonstrating that ice core climate proxy records from different locations in Antarctica will record regional signatures. The ITASE program takes this into account and aims to build up a network of climate proxy records from ice cores across the continent [Mayewski et al., 2005].

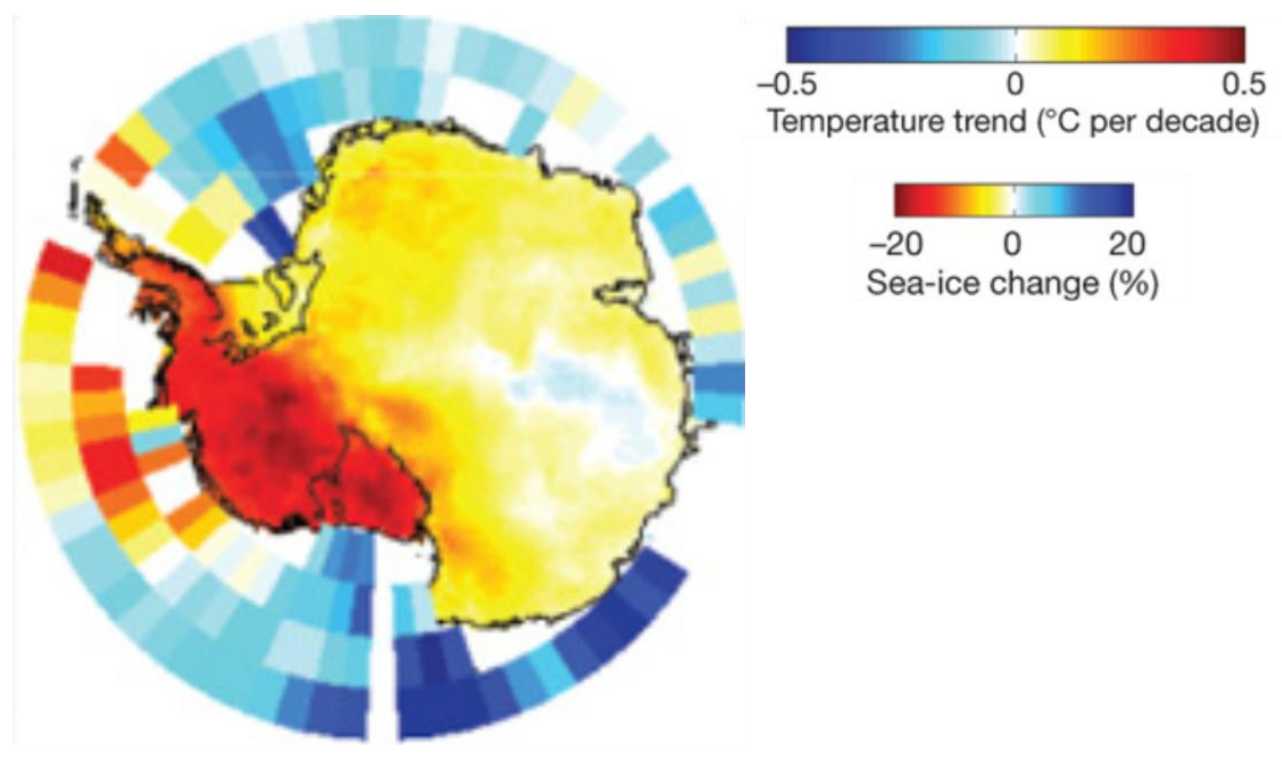

Figure 1.1: Reconstructed Antarctic surface temperature trends and observed changes in sea ice fractional area for 1979 to 2003 (modified after Steig et al. [2009]).

The snow pit and ice core records considered in this thesis were retrieved from Mt Erebus Saddle on Ross Island, Antarctica, as components of a wider sampling array in the Ross Sea region (Fig. 1.2), which comprises the New Zealand contribution to ITASE. Mt Erebus Saddle is situated at a boundary between two meteorological systems marine-based cyclones [Carrasco and Bromwich, 1993] and continental katabatic winds [Bromwich et al., 1992], characterised by air masses of contrasting geochemical signatures [Bertler et al., 2004a], facilitating climate reconstruction from the ice core record. In addition to this, Mt Erebus Saddle and other coastal Antarctic ice cores are also unique in that they have the potential to record local signatures of atmosphereocean interaction as a result of their proximity to seasonally open ocean and their low $(<2000 \mathrm{~m})$ elevations. 


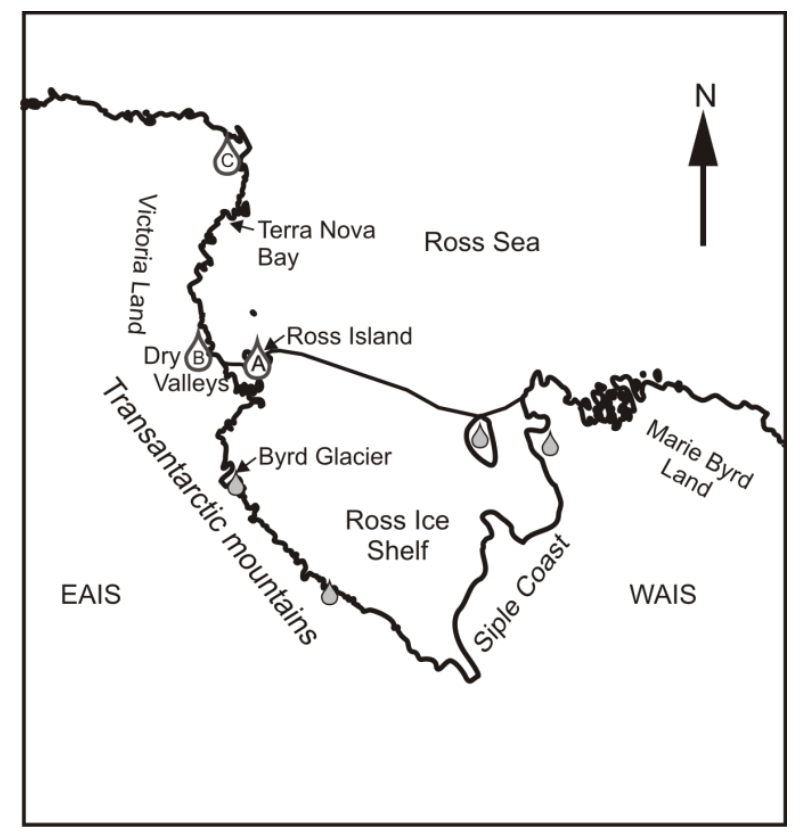

Figure 1.2: Map of the Ross Sea region showing NZ-ITASE ice core sites. White-filled drops indicate locations of ice core sites drilled. $A=$ Mt Erebus Saddle (this study), B = Evans Piedmont and Victoria Lower Glacier in the Dry Valleys, $C=$ Whitehall Glacier. Grey-filled drops are locations of proposed future drill sites.

Several ice core records from the ITASE program have utilised oxygen and hydrogen stable isotope ratios and major ion concentrations as glaciochemical proxies for climatic and environmental parameters. Major ions are predominantly sourced from the ocean [Legrand and Delmas, 1984] and can provide little information about terrestrial contributions. However, ICP-MS analysis can accurately determine the concentrations of a wide array of elements including lithophile, rare earth and heavy volatile elements. To date, there are no published studies which directly relate trace element concentrations in ice cores to climate parameters on decadal to multi-decadal timescales. 


\section{$1.4 \quad$ Research objectives}

Five research objectives were developed in order to fulfil the research aim of this thesis.

The first objective of this thesis was to date and interpret oxygen stable isotope and major ion concentration data from a snow pit sampled at Mt Erebus Saddle in order to examine the interannual variability of the climate record (Chapter 3). The oxygen isotope record proved suitable for annual layer counting and the record of methylsulphonate, a biogenic sulphur species, was developed as a proxy for both sea ice cover and primary productivity in the Ross Sea. This study is the first to directly link a snow or ice core record of methylsulphonate to variability in primary productivity and demonstrates the sensitivity of coastal ice core records to marine biogenic processes.

The Mt Erebus Saddle ice core was the first core to be processed and sampled the New Zealand Ice Core Laboratory, GNS Science, Lower Hutt and the first to be analysed for trace elements at the Victoria University of Wellington Geochemistry Laboratory. A second objective was therefore to set up a continuous melter system (after Osterberg et al. [2006]) to ensure a clean and effective sampling procedure and to develop an accurate, precise and efficient method for ICP-MS analysis of element concentrations ranging from several hundred ppb (parts per billion) to sub-ppt (parts per trillion) levels (Chapter 4).

A third objective was to date the glaciochemical record accurately (Chapter 5). The high snow accumulation rate at Mt Erebus Saddle $\left(22 \mathrm{~g} \mathrm{~cm}^{-3} \mathrm{yr}^{-1}\right)$ facilitated annual layer counting of the stable isotope ratio (oxygen and hydrogen) records. Development of the annual layer count model was aided by back-diffusion of the stable isotopic records, results of a glacial flow model and the identification of age tie points related to chemical deposition from thermonuclear bomb tests and major volcanic eruptions. 
A fourth objective of this thesis was to advance understanding of the controls on the trace element budget of ice cores (Chapter 6). In particular, a previous study by Bull [2009] had experienced reproducibility problems with ICP-MS measurements of snow samples, attributed to the presence of mineral dust particles within the samples which were acidified prior to analysis. A systematic experiment designed to assess the contribution of acid-leaching of mineral dust particles to trace element concentrations measured by ICP-MS was undertaken as a component of this study.

The fifth and principal objective of this thesis was to produce a paleoclimate record from glaciochemical proxies of the Mt Erebus ice core (Chapter 7). The stable isotopic and trace element record produced from the $120 \mathrm{~m}$ depth of ice core analysed encompasses the 1446 to 2006 AD time period and captures much of the Little Ice Age (LIA) climate event. Proxy relationships, identified through comparison between ice core chemistry (stable isotopes, marine chemical species and lithophile elements) and instrumental records, demonstrate that, compared to the present, cooler conditions with stronger katabatic winds and a larger, more productive Ross Sea Polynya prevailed during the LIA. 


\section{$1.5 \quad$ Thesis outline}

Chapters 3, 6 and 7 are each stand-alone papers, which are either, published or ready for submission to academic journals. A summary of the results obtained from this study is provided in Chapter 8. Additional information and all raw data obtained during the course of this study are contained in the Appendices. The content of each chapter is summarized briefly below. The chapters comprised of research papers include some contributions from co-authors other than thesis supervisors and these contributions are described.

\section{Chapter 1: Introduction}

Research aim, rationale and objectives

\section{Chapter 2: Antarctic climate and ice core climate proxies}

Background information concerning the climate of Antarctica and the Ross Sea region, glaciochemical proxies and ice core records of Late Holocene climate in Antarctica.

Chapter 3: Sea ice variability and primary productivity in the Ross Sea, Antarctica from methylsulphonate snow record

Snow pit study demonstrating the effectiveness of methylsulphonate (MS') concentration as a proxy for sea ice cover and primary productivity in the Ross Sea.

Paper published in Geophysical Research Letters (Section 1.6).

S. B. Sneed measured major ion concentrations and H. Oerter measured stable oxygen isotope ratios in the snow pit samples. K. R. Arrigo provided open water area and primary productivity time series data in addition to sharing his insight into the biochemistry of the Ross Sea. 


\section{Chapter 4: Methodology for ice core study}

Details of ice core drilling, processing and sampling procedures. Analytical techniques for determination of stable isotope ratios $\left(\delta^{18} O\right.$ and $\left.\delta D\right)$, major ion and trace element concentrations are provided and techniques used to date the ice core are summarised.

\section{Chapter 5: Dating the ice core record}

Dating of the ice core record by annual layer counting of stable isotope ratios, using thermonuclear bomb tritium fallout, and volcanic trace element deposition events as age tie points, is described.

Chapter 6: Factors affecting the reproducibility of trace element analyses of ice core samples

Series of laboratory experiments designed to quantify the effect of mineral dust leaching after sample acidification on the trace element budget of ice cores and its effect on measurement accuracy and reproducibility.

Paper accepted for publication in Chemical Geology (Section 1.6).

M-A. Millet provided input on experiment design and ideas for data interpretation.

Chapter 7: Increased katabatic wind speeds and greater Ross Sea Polynya extent in the Little Ice Age.

Climate proxy record of the ice core encompassing the time period 1446 to 2006 AD, including the Little Ice Age (LIA) and its termination. Comparisons between high resolution stable isotopic and geochemical records and the instrumental record develop a lithophile element proxy for katabatic wind strength. It is demonstrated that cooler, windier conditions and a larger, more productive Ross Sea Polynya prevailed during the LIA.

Paper prepared for submission to Climate of the Past (Section 1.6).

H. C. Steen-Larsen and S. J. Johnsen performed back-diffusion of the stable isotopic data and modelled the age-depth relationship down the ice core using a glacial flow model. S. B. Sneed measured some samples for major ion concentrations. $U$. 
Morgenstern measured samples for tritium contents and provided tritium content data for precipitation at other Antarctic sites.

\section{Chapter 8: Conclusions}

\section{Appendices}

Appendix I: Mt Erebus Saddle 2004/05 $2 \mathrm{~m}$ snow pit stable oxygen isotope ratios and major ion concentrations.

Appendix II: Procedural blanks for Mt Erebus Saddle ice core processing and sampling (ICP-MS and IC).

Appendix III: Accuracy, precision and detection limits of major ion concentration measurements on Mt Erebus Saddle 2006/07 ice core samples.

Appendix IV: Stable isotope data for Mt Erebus Saddle 2006/07 ice core.

Appendix V: Dansgaard-Johnsen glacial flow model.

Appendix VI: Back-diffusion of Mt Erebus Saddle 2006/07 ice core stable isotope ratios.

Appendix VII: Mt Erebus Saddle 2006/07 ice core tritium content measurements.

Appendix VIII: Mt Erebus Saddle 2006/07 ice core density measurements.

Appendix IX: Supplementary data tables for dust leaching investigation

Appendix X: Mt Erebus Saddle 2006/07 ice core major and minor element concentrations.

Appendix XI: Mt Erebus Saddle 2006/07 ice core age model. 


\subsection{Publications resulting from this thesis}

\section{Peer-reviewed journal articles}

Rhodes, R. H., Baker, J. A., Millet, M-A., Bertler, N. A. N., 2011. Experimental investigation of the effects of mineral dust on the reproducibility and accuracy of ice core trace element analyses. Chemical Geology, doi: 10.1016/j.chemgeo.2011.05.006.

Purdie, H., Bertler, N. A. N., Mackintosh, A., Baker, J. A. and Rhodes, R. H., 2010. Isotopic and elemental changes in winter snow accumulation on glaciers in the Southern Alps of New Zealand. Journal of Climate 23, doi: 10.1175/2010JCLI3701.1

Rhodes, R.H., Bertler, N. A. N., Baker, J. A., Sneed, S. B., Oerter, H., Arrigo, K. R., 2009. Sea ice variability and primary productivity in the Ross Sea, Antarctica, from methylsulphonate snow record. Geophysical Research Letters 36, L10704, doi:10.1029/2009GL037311.

\section{Journal articles in preparation for submission}

Rhodes, R. H., Bertler, N. A. N., Baker, J. A., Steen-Larsen, H. C., Sneed, S. B., Morgenstern, U., Johnsen, S. J., Increased katabatic wind speeds and greater Ross Sea Polynya extent in the Little Ice Age. In preparation for Climate of the Past.

\section{Selected conference and workshop presentations}

Rhodes, R. H., Baker, J. A., Millet, M-A., Bertler, N. A. N., Experimental investigation of the effects of mineral dust on the reproducibility and accuracy of ice core trace element analysis. American Geophysical Union, Fall Meeting 2010. San Francisco, USA. Abstract \#C13B-0548. 13-17 December 2010. (Poster)

Rhodes, R. H., Bertler, N. A. N., Baker, J. A., Trace elements reveal 'Little Ice Age' in an Antarctic ice core. European Research Course on Atmospheres. Grenoble, France. 11 January to 12 February 2010. 
Rhodes, R. H., Bertler, N. A. N., Baker, J. A., Trace elements reveal 'Little Ice Age' in an Antarctic ice core. New Zealand Postgraduate Conference. Victoria University of Wellington, Wellington, New Zealand, 20-21 November, 2009.

Rhodes, R. H., Bertler, N. A. N., Baker, J. A., Sneed, S. B., An ice core indicator of Ross Ice Shelf stability? Geological Society of New Zealand, New Zealand Geophysical Society and New Zealand Geochemical \& Mineralogical Society Joint Annual Conference. Te Papa, Wellington, New Zealand, 23-26 November, 2008.

Rhodes, R. H., Bertler, N. A. N., Baker, J. A., Sneed, S. B., High resolution climate reconstruction utilizing trace element geochemistry and stable isotopes from Mt. Erebus Saddle. SCAR/IASC IPY Open Science Conference, Polar Research - Arctic and Antarctic Perspectives in the International Polar Year. St. Petersburg, Russia, 8-11th July 2008. (Poster)

Rhodes, R. H., Bertler, N. A. N., Baker, J. A., and Sneed, S. B., Effects of large icebergs on sea ice and primary productivity in the Ross Sea. Annual Antarctic Conference International Polar Year and the Next Generation. Dunedin, New Zealand. July 2008 (Poster) 


\section{Chapter 2: Antarctic climate and ice core climate proxies}

This chapter presents a review of literature that is relevant to the research aim, rationale and objectives of this study. Geographical locations of places and ice core sites referred to in this chapter are displayed in Figure 2.1.

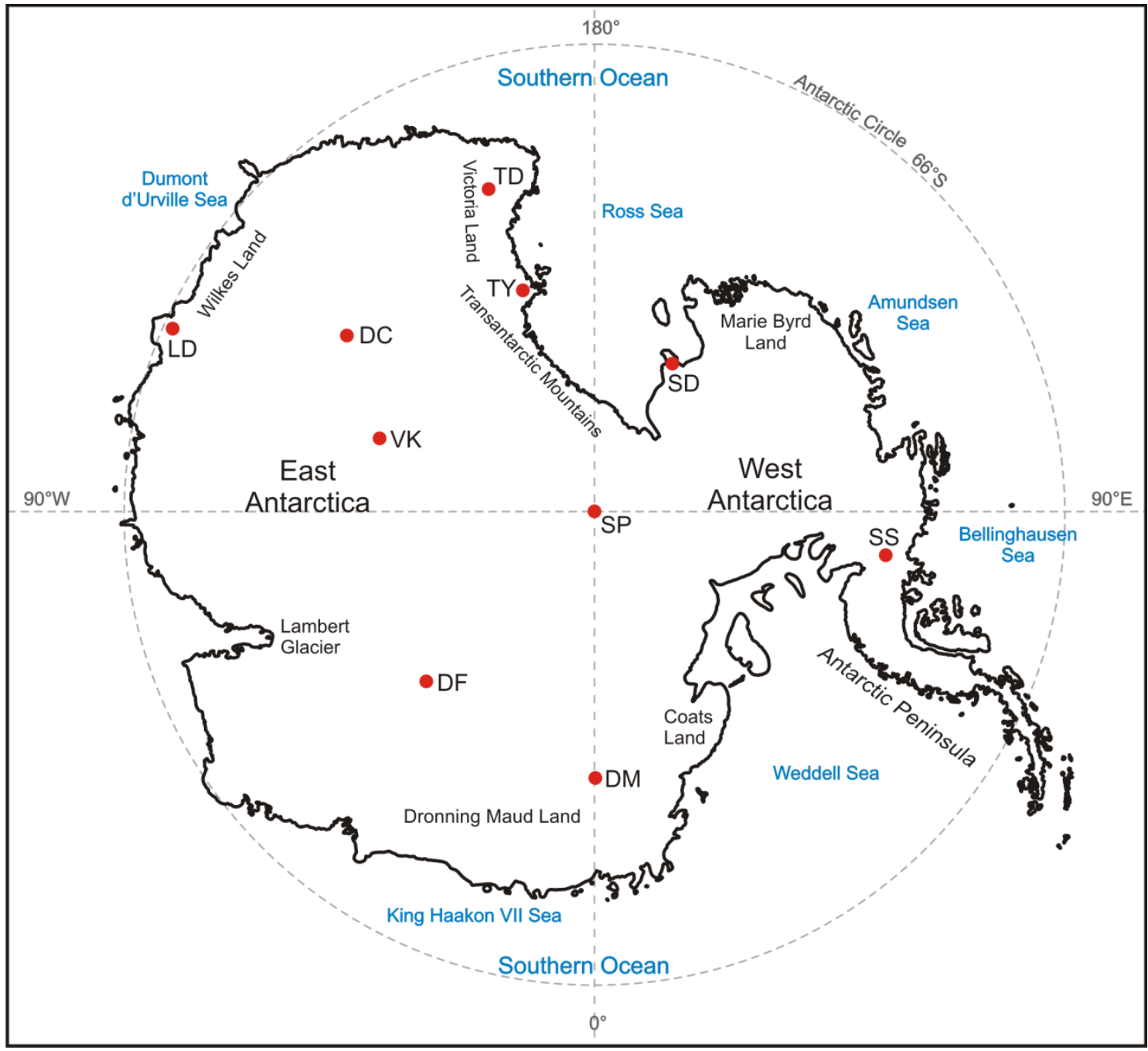

Figure 2.1: Map of the Antarctic continent showing key locations and ice core sites referred to in the text. Ice core sites are as follows: DC= EPICA Dome C, DF = Dome Fuji, DM = EPICA Dronning Maud Land, LD = Law Dome, SD = Siple Dome, SP = South Pole, SS = Siple Station, TD = Talos Dome, $\mathrm{TY}=$ Taylor Dome, $\mathrm{VK}=$ Vostok. All locations are approximate. 


\subsection{Antarctica and the global climate system}

Antarctica influences the global climate system primarily through its role as a sink for heat transported from the equator to high latitudes, mainly by extra-tropical cyclones [King and Turner, 1997] and ocean currents [Trenberth and Solomon, 2009]. The isolation of Antarctica within the Southern Ocean allows for the development of a persistent westerly circulation of cyclonic systems around the continent [King and Turner, 1997]. Another control on the Earth's energy budget is the high albedo of Antarctica and its associated sea ice, which cools the continent. It is the cooling of the air above the ice sheet surface which creates a temperature inversion causing persistent katabatic winds to flow off the continent [Parish, 1988] (Section 2.2). Katabatic winds are involved in the formation of polynyas [Bromwich et al., 1992], areas of open water within the sea ice cover, where new sea ice is generated. The formation of sea ice ejects brine, which along with cooling of the ocean by cold katabatic winds, causes the dense ocean waters to sink. This is the process of bottom water formation, a crucial step in the thermohaline circulation of the world's ocean which transports heat and nutrients, and ventilates the deep ocean [Broecker, 1997]. Arguably the most important interaction between Antarctica and the global climate system is the delicate mass balance of the ice sheets which hold $61 \%$ of the fresh water on the planet. A negative shift in the mass balance and resultant melting of the marine-based portion of the West Antarctic ice sheet would result in a global eustatic sea level rise of $3.3 \mathrm{~m}$ [Bamber et al., 2009]. 


\subsection{Aspects of Antarctic meteorology}

The meteorology of coastal Antarctica is dominated by the westerly-circulating belt of cyclones situated between $60-70^{\circ} \mathrm{S}$ which is called the Antarctic circum-polar trough. This low pressure belt consists of synoptic-scale ( $>1000 \mathrm{~km}$ diameter; $>1$ day lifetime) cyclones, which create strong westerly winds around the coast of Antarctica. These winds are important for cooling the ocean surface, promoting downwelling and bottom water formation [King and Turner, 1997]. The circum-polar trough is not perfectly circular in form because the path of the cyclones is obstructed by the Antarctic Peninsula, which obtrudes northwards from the continent into the Southern Ocean. As a result, three principal centres of low pressure form within the circumpolar trough (Fig. 2.2). The low pressure centre located off the coast of West Antarctica at $90-150^{\circ} \mathrm{W}$ is the Amundsen Sea Low. The circum-polar trough is subject to a semi-annual oscillation in its latitudinal position and strength. The trough contracts in spring and autumn, creating lower pressures close to Antarctica. Whereas, in summer and winter, the trough expands and moves further north, creating a positive pressure anomaly [King and Turner, 1997]. The circum-polar trough and its cyclones rarely penetrate into the interior of the Antarctic continent because elevation increases steeply from sea level to $3000 \mathrm{~m}$ on the plateau. This causes the rapid decrease in accumulation between coastal regions and the interior [King and Turner, 1997] (Fig. 2.3). 

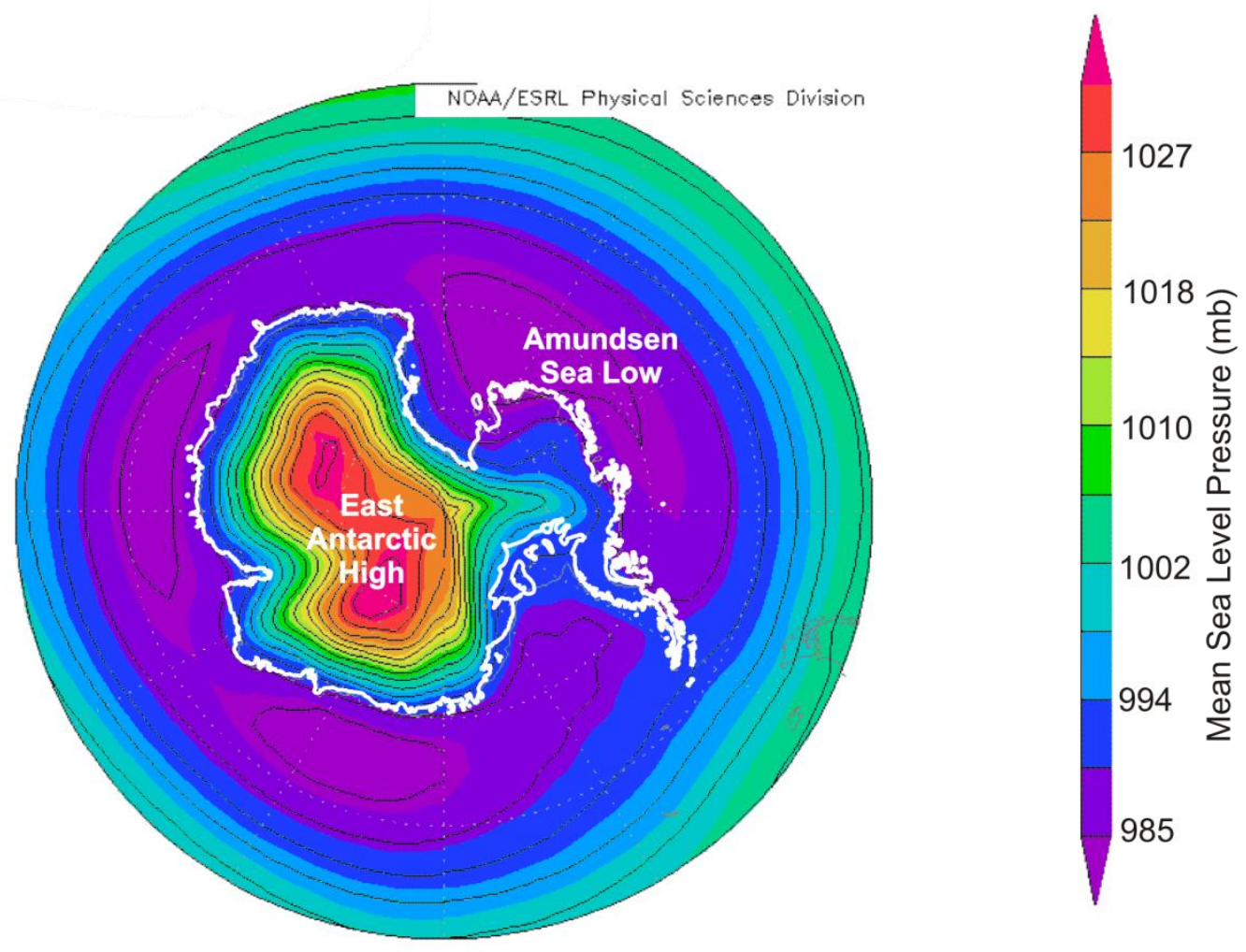

Figure 2.2: Mean sea level pressure across Antarctica and the Southern Ocean for the time period Jan-1979 to Jan-2010. The low pressure belt (purple colours) around the Antarctic continent is the circum-polar trough. Values were calculated from monthly averages of surface level NCEP (National Centres for Environmental Prediction) reanalysis data for latitude range $90^{\circ} \mathrm{S}$ to $50^{\circ} \mathrm{S}$ and plotted using the interactive plotting tool at NOAA (National Oceanographic and Atmospheric Administration) Earth System Research Laboratory http://www.esrl.noaa.gov/psd/cgi-bin/data/getpage.pl. 


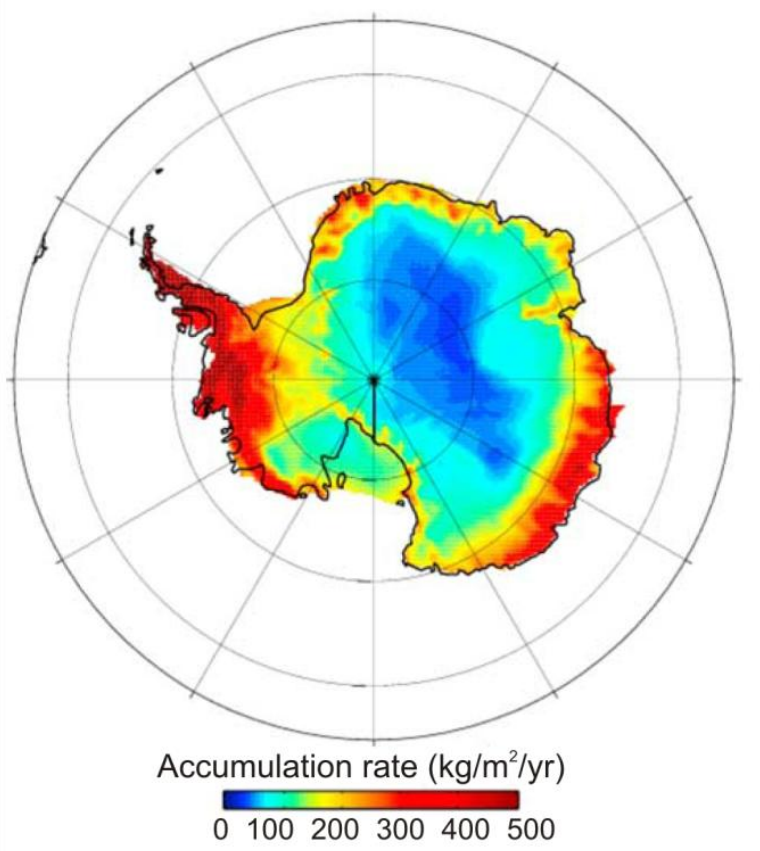

Figure 2.3: Map of Antarctica showing the rate of accumulation of precipitation (modified after Mayewski et al. [2009]).

The interior of the continent is dominated by a high pressure system and the wind regime is governed by katabatic winds. The high-elevation ice sheets cool radiatively and cool the layer of air just above the surface. This creates a temperature inversion, which causes the air to move down-slope under the pressure-gradient force [Parish, 1988; van den Broeke and van Lipzig, 2003]. Katabatic winds are therefore strongest during the winter months when the temperature inversion above the ice sheets is greatest. Their flow paths are strongly controlled by topography causing major outlet glaciers at the coast to funnel strong, cold winds down off the plateau (Fig. 2.4). Once katabatic winds have reached the relatively flat coastline or ice shelf the pressuregradient force is weak but interaction with synoptic scale cyclones can cause strong katabatic wind flow across the ice shelves (Section 2.4).

Cold katabatic winds descending from the interior are one cause of baroclinic instability around the Antarctic coast which leads to the formation of mesoscale $(<$ 1000 km diameter; < 24 hr lifetime) cyclones [Carrasco and Bromwich, 1993]. Baroclinic instability is caused by a thermal gradient which disrupts the stratification of the atmosphere. For this reason mesoscale cyclones also form at the northern edge of 
the sea ice cover or at the boundary between land and open ocean in summer [King and Turner, 1997].

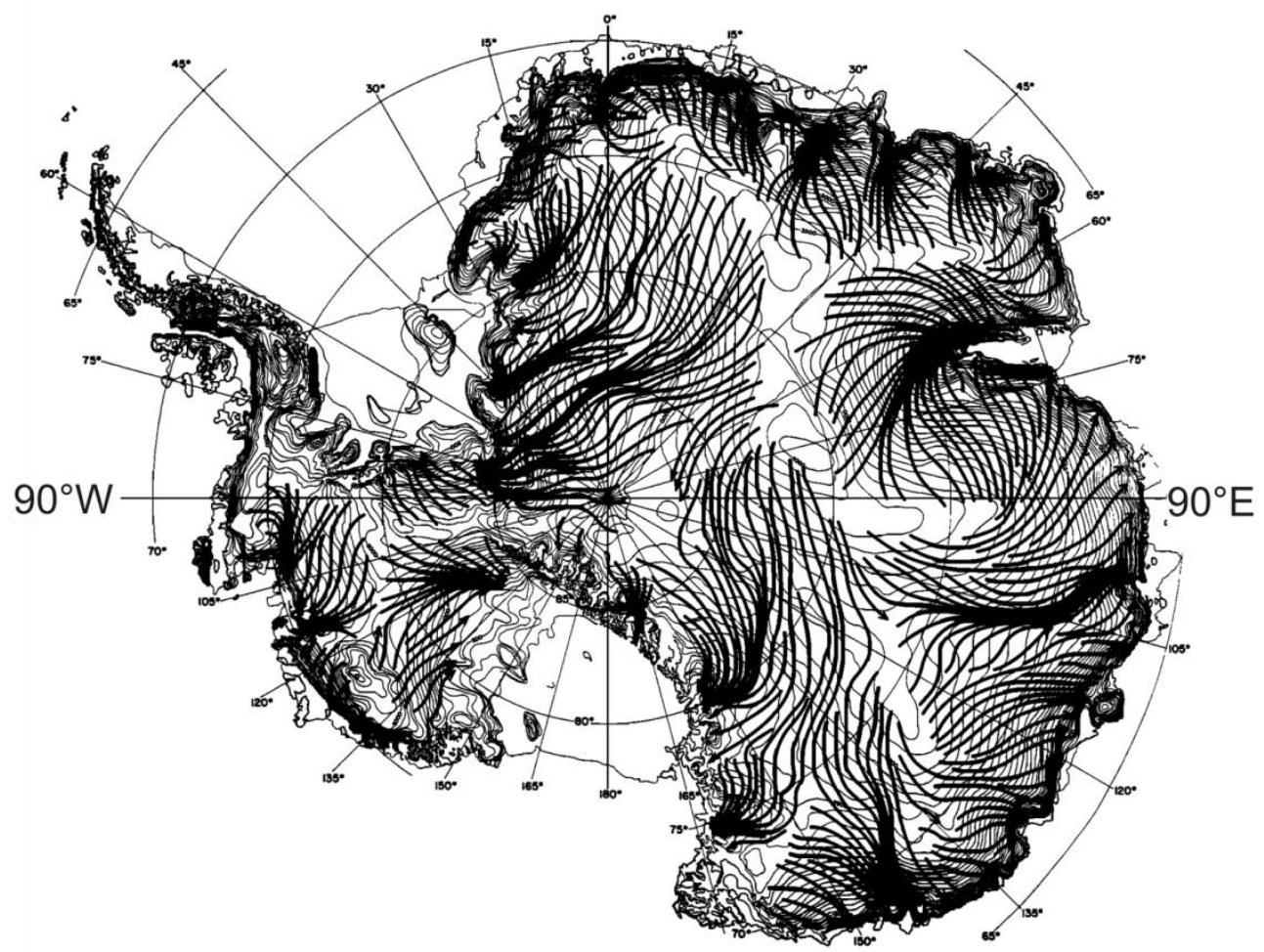

Figure 2.4: Major flowlines of katabatic winds off the Antarctic continent (modified after Parish [1988]). Thin black lines are ice sheet elevation contours. 


\subsection{Decadal drivers of Antarctic and Southern Hemisphere climate variability}

The dominant driver of the climate variability of the Southern Hemisphere on seasonal to decadal timescales is an atmospheric phenomenon called the Southern Annular Mode (SAM) [Kidson, 1999], which is also referred to as the Antarctic Oscillation (AAO). The SAM index explains the variability in atmospheric flow that is additional to the variability associated with the semi-annual oscillation of the circum-polar trough (Section 2.2) [Gong and Wang, 1999]. A strong positive SAM index corresponds to contraction of the circum-polar trough and Antarctica is subject to generally colder temperatures, lower pressures and stronger flow around latitude $60^{\circ} \mathrm{S}$ [Thompson and Solomon, 2002]. Over the last few decades SAM has moved into a more positive state causing intensified westerly winds [Marshall, 2003], a change that has been linked to the presence of the Antarctic ozone hole [Thompson and Solomon, 2002] or anthropogenic greenhouse gas forcing [Cai et al., 2003]. Model results suggest that stronger circum-polar circulation should result in higher temperatures over the Antarctic Peninsula, West Antarctica and the Weddell Sea, but cooler temperatures over East Antarctica, the Ross Ice Shelf and Marie Byrd Land [van den Broeke and van Lipzig, 2004]. These trends are appearing in Antarctic temperatures [van den Broeke, 2000]; $50 \%$ of the warming over the Antarctic Peninsula is attributed to the long-term trend in SAM [Thompson and Solomon, 2002]. Variations in SAM have also been linked to sea surface temperature (SST) across the Southern Ocean [Zhou and Yu, 2004], the distribution of sea ice around Antarctica [Hall and Visbeck, 2002] and change in ocean mixed layer depth [Sallee et al., 2010].

The second most important driver of Southern Hemisphere variability is the El Niño Southern Oscillation (ENSO) [Kidson, 1999; Turner, 2004], a coupled ocean-atmosphere climatic cycle. The term El Niño, and its counterpart La Niña, refer to anomalies in the sea surface temperature observed in the tropical eastern Pacific Ocean [Trenberth, 1997]. The Southern Oscillation is the coupled atmospheric response to the change in sea surface temperature and causes changes in air pressure across the Pacific. The Southern Oscillation Index (SOI) is the normalised difference in surface pressure between Darwin (West Pacific) and Tahiti (East Pacific). Extreme negative SOI values indicate El Niño conditions whereas positive values indicate La Niña [Trenberth, 1997]. 
During an El Niño event, SST is increased in the tropical Pacific and a strong anticyclone develops in the atmosphere above [Renwick, 1998]. This atmospheric anomaly is transmitted to the high southern latitudes via a wave train called the Pacific South American Pattern (PSA) in a process that is not completely understood (see Turner [2004] or Yuan and Martinson [2000] for reviews). The teleconnection causes an anti-cyclonic anomaly over the Amundsen-Bellinghausen Sea and movement of the Amundsen Sea Low pressure centre 1400 km eastwards towards the Marie-Byrd Land coast [Cullather et al., 1996] (Section 2.4). The opposite sequence of events occurs during La Niña periods and the Amundsen Sea Low intensifies.

The ENSO signal has been shown to affect the moisture budget of West Antarctica and the Weddell Sea - Ronne Ice Shelf region [Bromwich et al., 2004; Bromwich et al., 2000; Cullather et al., 1996]. Links between ENSO and sea ice extent around the Antarctic continent have also been established [Carleton, 1989; Kwok and Comiso, 2002; Simmonds and Jacka, 1995].

Recent research suggests that ENSO needs to be positively correlated with SAM to exert a strong influence on Antarctic climate. If both the SAM index and the SOI are in a positive phase then negative pressure anomalies and positive geopotential height anomalies in the South Pacific are augmented. However, if SAM and ENSO are out of phase, the effect of SAM will effectively cancel out any ENSO forcing from the tropics [Fogt and Bromwich, 2006]. 


\subsection{Climate of the Ross Sea region}

The climate of the Ross Sea region is characterised by the interaction between cyclonic systems of the circum-polar trough and katabatic winds from the continent. Synopticscale cyclones provide moisture to the Victoria Land coast by either remaining quasistationary over the Ross Sea or by effectively detaching from the cyclone belt and tracking around the inland edge of the Ross Ice Shelf [Sinclair et al., 2010].

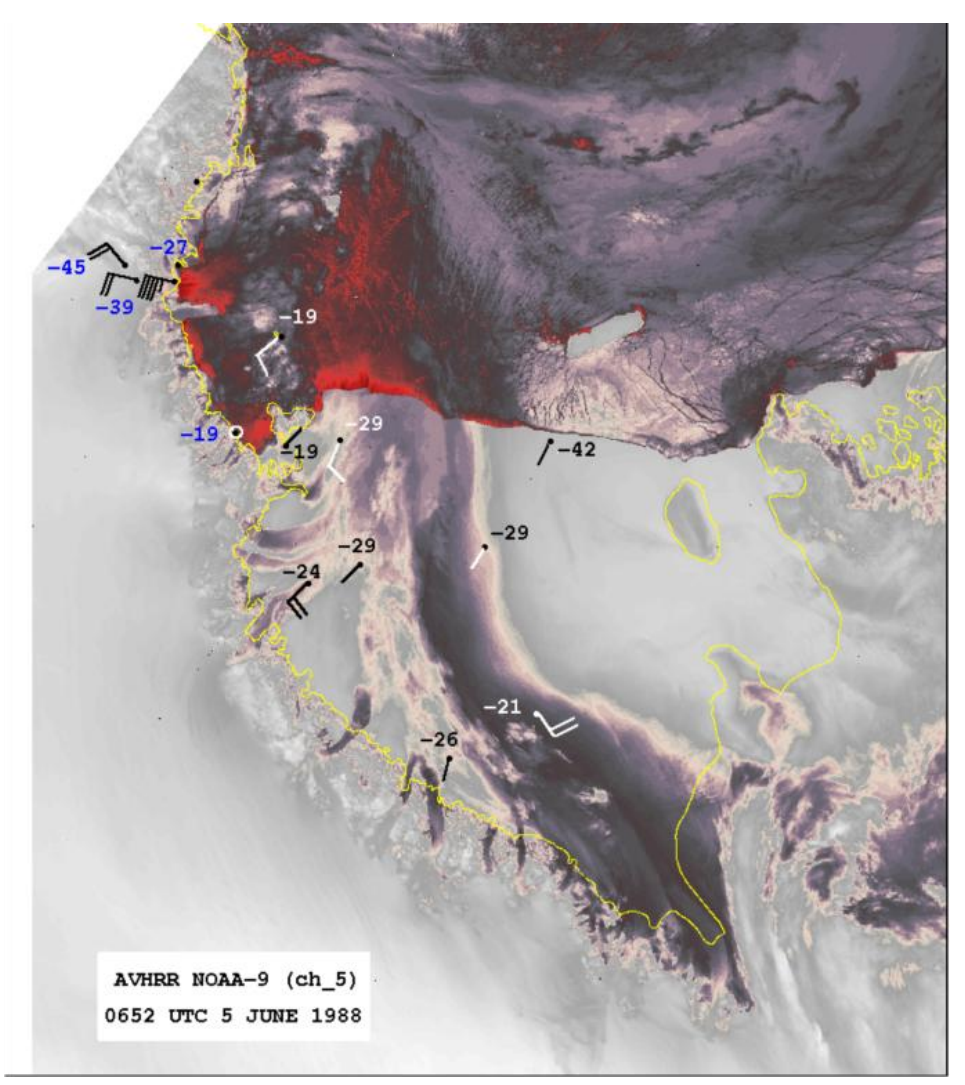

Figure 2.5: Thermal infra-red satellite image of the Ross Ice Shelf in mid-winter. Darker shades indicate a warmer surface and red patches are open water. Warm katabatic winds can be seen originating from glaciers draining the Transantarctic Mountains and a well-developed katabatic surge is seen flowing across the ice shelf from the Siple Coast. Automatic weather station observation of wind (wind barbs $=5 \mathrm{~ms}^{-1}$ ) and temperature $\left({ }^{\circ} \mathrm{C}\right.$ ) have been overlaid on the image (from study by Bromwich et al. [1992]).

Katabatic winds, originating from West Antarctica, via the Siple Coast, and East Antarctica via large outlet glaciers along the Transantarctic Mountains, such as the 
Byrd Glacier, propagate in a northwest direction across the Ross Ice Shelf [Bromwich et al., 1993]. The major katabatic flow path is diverted eastwards around Ross Island and is responsible for the formation of the Ross Sea Polynya at the edge of the Ross Ice Shelf (Fig. 2.5).

The cold air of the katabatic flows creates thermal gradients necessary for mesoscale cyclone formation. The region just to the north of Ross Island has a high rate of mesoscale cyclone formation [Carrasco and Bromwich, 1993] which contributes to the precipitation budget along the Victoria Land coast [Sinclair et al., 2010].

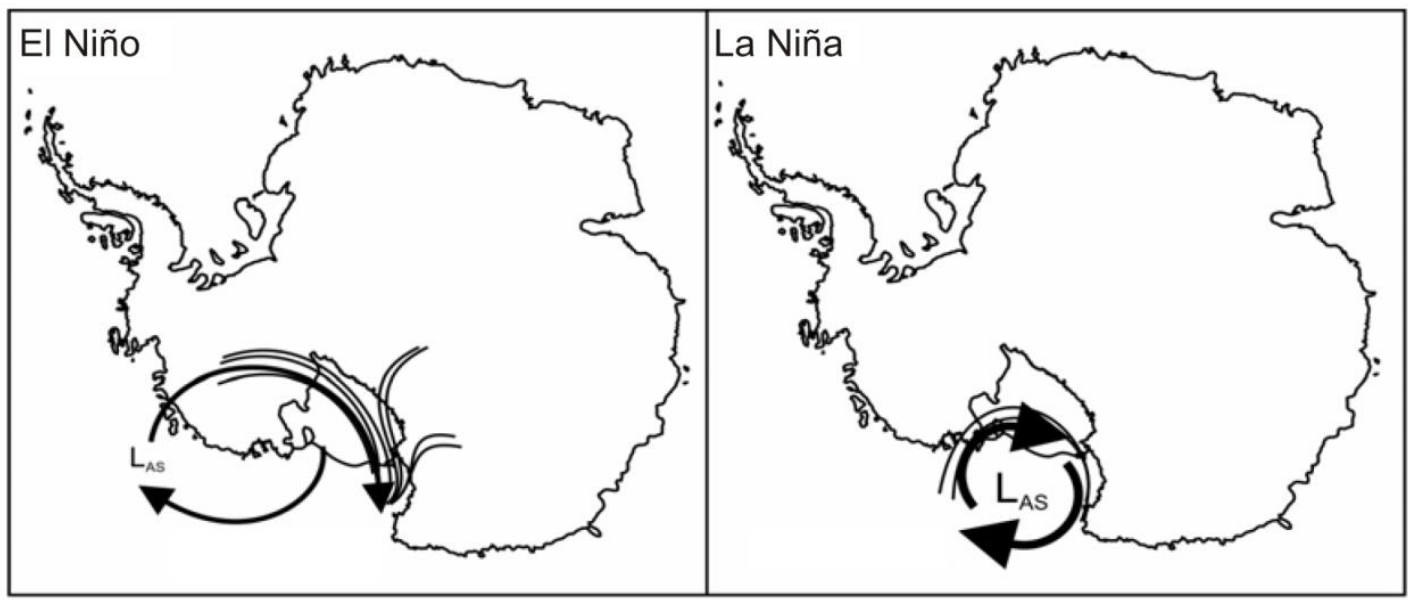

Figure 2.6: Effect of El Niño and La Niña events on the position and strength of the Amundsen Sea Low $\left(L_{A S}\right)$ pressure centre (modified after Bertler et al.[2004b]). Thickness of large arrows is indicative of the strength of the low pressure centre. Thin black lines depict the prevailing wind directions.

The southeast Pacific sector of Antarctica displays the strongest links to ENSO forcing from the tropics [Turner, 2004] through the modulation of the position of the Amundsen Sea Low (Fig. 2.6). The weakening and migration of the Amundsen Sea Low towards Marie Byrd Land during El Niño events causes the western Ross Sea to experience increase katabatic surges of cold, dry air from across the West Antarctic Ice Sheet [Bromwich et al., 1993]. Incursion of marine air masses onto the Ross Ice Shelf is reduced [Bertler et al., 2004b]. In contrast, during La Niña events the intensified 
Amundsen Sea Low brings strong cyclonic circulation and relatively warm, moist air to the Ross Sea [Bertler et al., 2004b]. In agreement with the later study of Fogt and Bromwich [2006], Bertler et al. [2004b] found that the ENSO influence on temperature in the Ross Sea region was more pronounced in the 1990s than the 1980s because SAM and ENSO were in-phase with one another. The advance and retreat of sea ice in the western Ross Sea is also associated with the interaction between SAM and ENSO [Stammerjohn et al., 2008]. 


\subsection{Ice core climate and environmental proxies}

Ice cores extracted from the Antarctic ice sheets have the potential to extend the meteorological record back in time via the development of geochemical proxies for climate parameters. The stable isotopes of water, soluble major ion chemistry, and dust content of ice cores are conventional ice core climate proxies and the applications of ice core trace element measurements are being developed. The basic principles of each are summarised in the following sections.

\subsubsection{Stable isotopes of water}

The stable isotope ratios of oxygen $\left(\delta^{18} \mathrm{O}\right)$ and hydrogen $(\delta D)$ are important proxies for ice core site temperature. The delta $(\delta)$ notation refers to the deviation of the ratio of the heavy isotope $\left({ }^{18} \mathrm{O}\right.$ or $\left.{ }^{2} \mathrm{H}\right)$ to the more abundant light isotope $\left({ }^{16} \mathrm{O}\right.$ or $\left.{ }^{1} \mathrm{H}\right)$ in the sample, from that of a standard, usually Vienna Standard Mean Ocean Water (VSMOW). The equation for the calculation of $\delta^{18} \mathrm{O}$ is:

$\delta^{18} \mathrm{O}(\%)=\left[\left({ }^{18} \mathrm{O} /{ }^{16} \mathrm{O}_{\text {sample }}-{ }^{18} \mathrm{O} /{ }^{16} \mathrm{O}_{\text {standard }}\right) /\left({ }^{18} \mathrm{O} /{ }^{16} \mathrm{O}_{\text {standard }}\right)-1\right] * 1000$

$(\%$ o per mil)

Isotopic fractionation of the stable isotopes of water occurs during phase changes as water molecules containing heavy isotopes $\left({ }^{1} \mathrm{H}^{2} \mathrm{HO}\right.$ and $\left.\mathrm{H}_{2}{ }^{18} \mathrm{O}\right)$ will preferentially remain in the liquid during evaporation and move into the liquid or solid during condensation or freezing [Araguas-Araguas et al., 2000]. When the two phase states of water are in equilibrium, the degree of fractionation between heavy and light isotopes (or the fractionation factor) will depend on the ratio of saturation vapour pressure of standard water $\left(\mathrm{H}_{2} \mathrm{O}\right)$ to 'heavy' water $\left({ }^{1} \mathrm{H}^{2} \mathrm{HO}\right.$ and $\left.\mathrm{H}_{2}{ }^{18} \mathrm{O}\right)[G a t, 2005]$. As the values of $\delta^{18} \mathrm{O}$ and $\delta \mathrm{D}$ in the same air mass are controlled by the same processes, a bivariate plot of the two ratios produces a linear trend (Fig. 2.7). The slope of the line equates to a value of 8 because the equilibrium fractionation of hydrogen isotopes is 8 times greater than that of oxygen isotopes [Jouzel, 2003]. The linear relationship displayed by this graph is consistent for samples from across the world and it is therefore named the Global Meteoric Water Line (GMWL) [Craig, 1961]. 


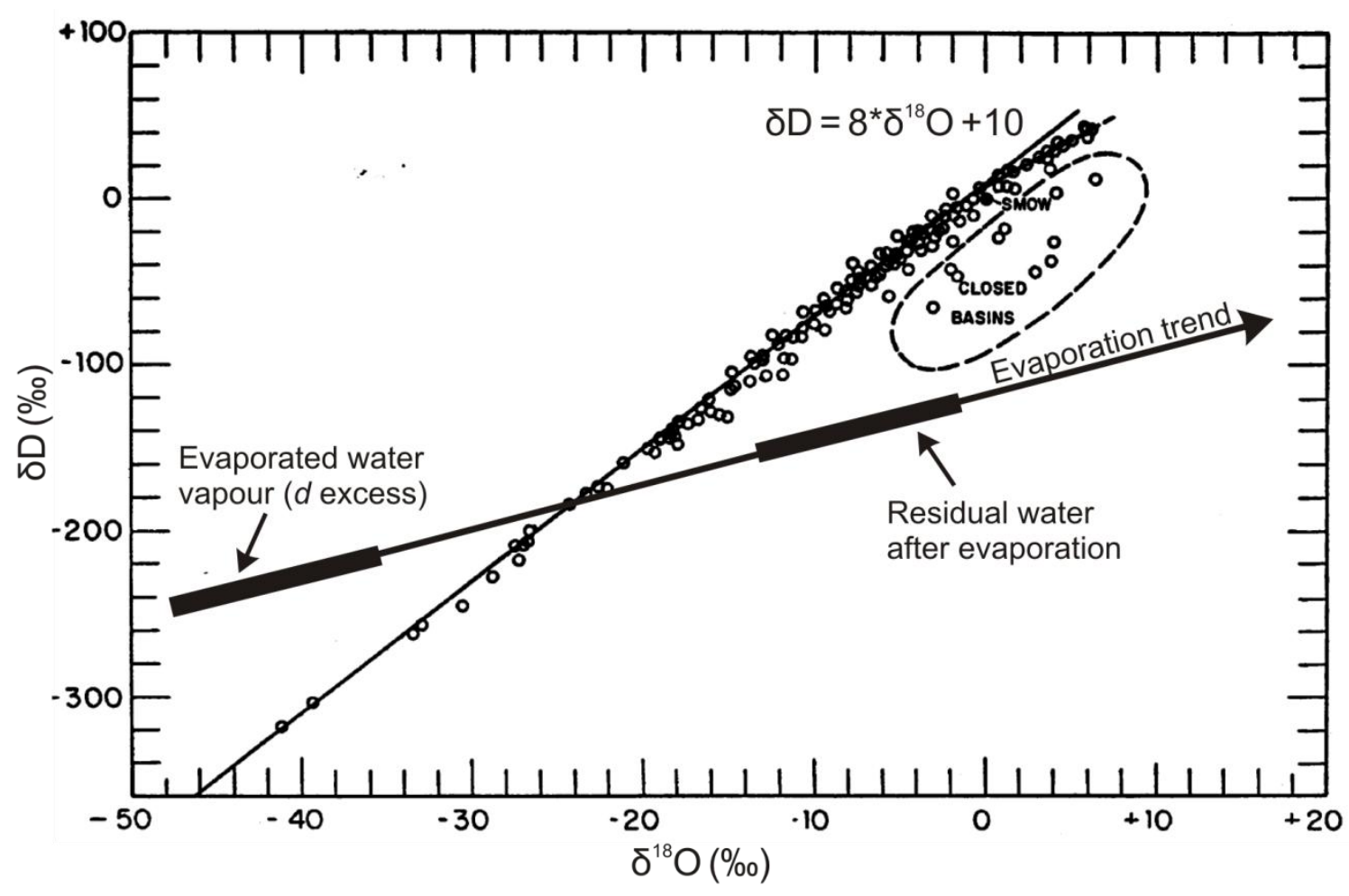

Figure 2.7: Global Meteoric Water Line (GMWL) of Craig [1961] with evaporation trend line of a moisture source located on the GMWL (after Gat [1996]). Samples with positive $\delta$ values that plot on the curved dashed line are from lakes and rivers in East Africa.

However, a state of equilibrium is usually not reached because vapour is often evaporated from open water into an atmosphere that is not fully saturated (relative humidity $<100 \%)$. In this case, the differences in the molecular diffusion of heavy and light water molecules through the water-air interface cause kinetic fractionation [Merlivat and Jouzel, 1979]. During evaporation of a moisture source which lies on the GMWL, the residual water of the moisture source moves to the right of the GMWL (Fig. 2.7) as the $\delta \mathrm{D} / \delta^{18} \mathrm{O}$ slope during kinetic fractionation is less than 8 . The vapour produced must therefore lie to the left of the GMWL producing a different value of $d$ excess. The extent of kinetic fractionation which occurs during evaporation and condensation determines the value of the second-order stable isotopic parameter, deuterium excess (d-excess) [Jouzel and Merlivat, 1984; Merlivat and Jouzel, 1979], as defined by Dansgaard [1964].

d-excess $=\delta D-8^{*} \delta^{18} \mathrm{O}$ 
The intercept of a meteoric water line is the value of $d$-excess. The GMWL has a $d$ excess value of $10 \%$ (Fig. 2.7 ) but this value varies considerably with the extent of kinetic fractionation.

Kinetic fractionation is principally controlled by the relative humidity at the surface temperature of the water and d-excess of an air mass will therefore increase with decreased relative humidity [Merlivat and Jouzel, 1979] (Fig. 2.8). Secondary effects on d-excess values include sea surface temperature (SST) of the moisture source and wind speed [Petit et al., 1991] (Fig. 2.8). Deuterium excess records from Antarctic ice cores can be used as proxies for a) vapour source temperature [Vimeux et al., 2002] b) relative humidity [Jouzel et al., 1982] and c) to identify abrupt changes in moisture source [Masson-Delmotte et al., 2010].

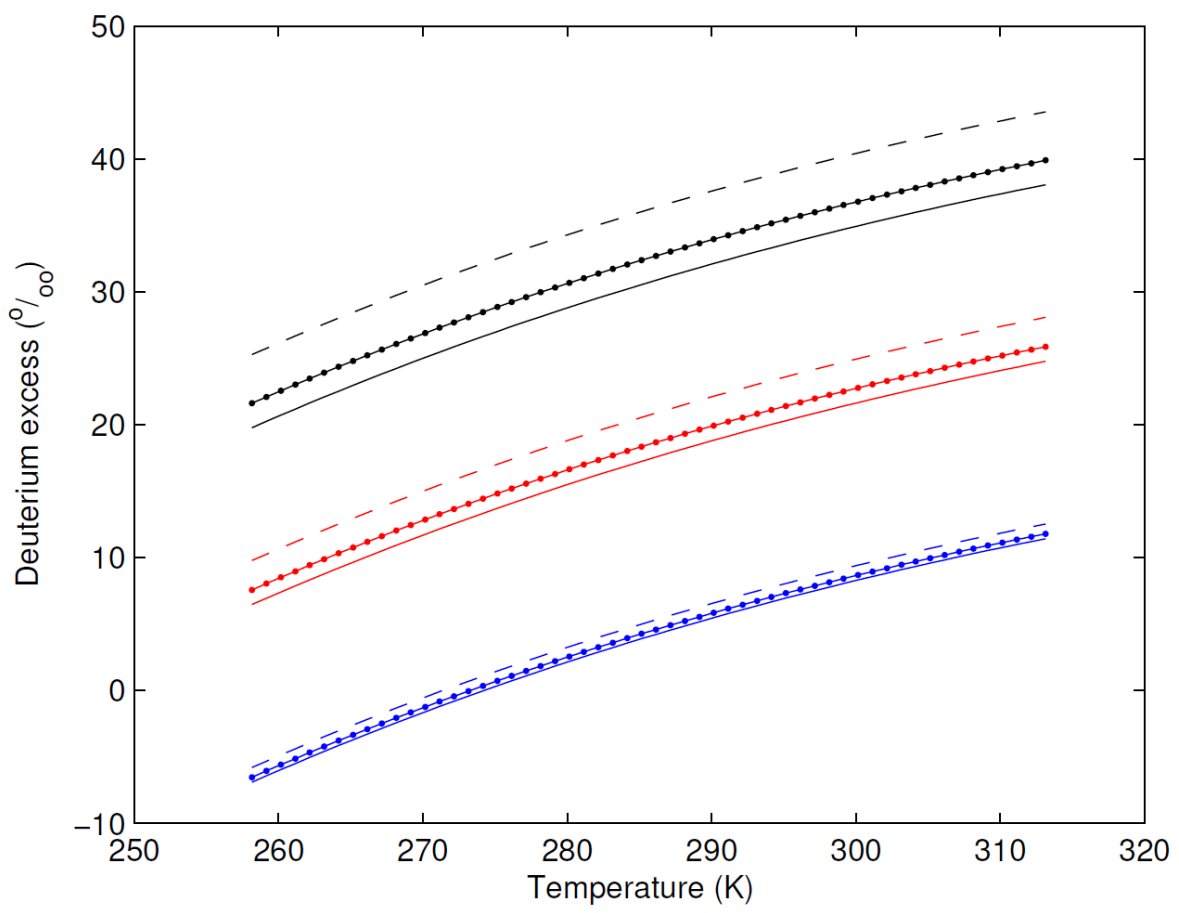

Figure 2.8: Deuterium excess as a function of temperature in the initial cloud vapour for relative humidities of $50 \%$ (black), 70\% (red) and 90\% (blue) and wind speeds of $2 \mathrm{~ms}^{-1}$ (dashed), $4 \mathrm{~ms}^{-1}$ (dotted) and $6 \mathrm{~ms}^{-1}$ (solid). Constructed from data of Merlivat and Jouzel [1979] (K. Sinclair, GNS Science, Personal communication). 

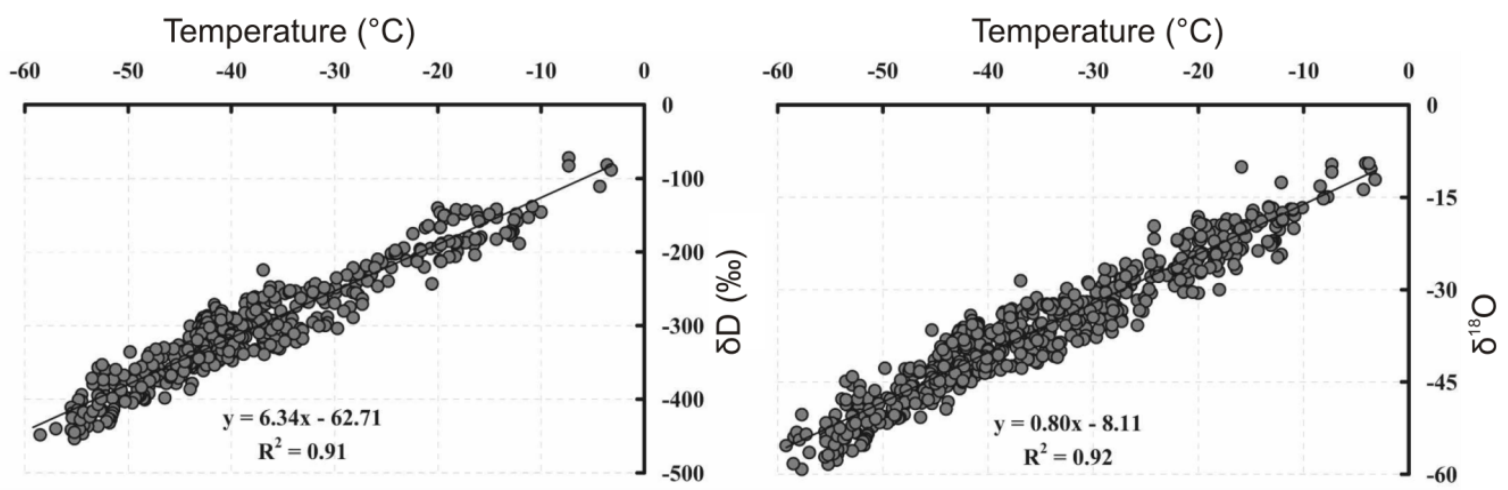

Figure 2.9: Linear relationships between surface temperature and stable isotope ratios of snow and ice core samples from across Antarctica (from Masson-Delmotte et al. [2008]).

Stable isotope ratios of oxygen $\left(\delta^{18} \mathrm{O}\right)$ and hydrogen $(\delta \mathrm{D})$ in Antarctic ice cores are well-established proxies for air temperature. Extensive spatial arrays that cover a wide range of temperatures have demonstrated strong correlations between mean temperature and $\delta^{18} \mathrm{O}$ and $\delta \mathrm{D}$ (Fig. 2.9) [Masson-Delmotte et al., 2008]. Several other factors including, elevation, distance from the coast and snow accumulation will also influence $\delta^{18} \mathrm{O}$ and $\delta \mathrm{D}$ so it is desirable to produce a $\delta$-temperature calibration from samples taken along a local spatial slope [Jouzel, 2003]. For coastal locations the calibration developed for Taylor Dome, West Antarctica, is applicable: $0.5 \% \circ \delta^{18} \mathrm{O} /{ }^{\circ} \mathrm{C}$ and $4 \%$ $\delta \mathrm{D} /{ }^{\circ} \mathrm{C}$ [Steig et al., 1998].

Ice core stable isotopic records from both West and East Antarctic exhibit sensitivity to both SAM and ENSO forcing. Gregory and Noone [2008] and Naik et al. [2010] studied records from West Antarctica and Dronning Maud Land respectively, and found that, in agreement with the theory of Fogt and Bromwich [2006], SAM is the dominant control on stable isotope ratios but ENSO influence is identifiable in periods when SAM and ENSO are in-phase. Patterson et al. [2005] also demonstrated that an ice core d-excess record from the Dry Valleys region reflected variations in moisture source and transport pathway caused by ENSO modulation of the position of the Amundsen Sea Low. 


\subsubsection{Soluble major ion chemistry}

Concentrations of major ions dissolved within an ice core are determined by ion chromatography (IC), an analytical technique which separates ions according to their ionic radius and charge [Curran and Palmer, 2001; Morganti et al., 2007]. The ions typically determined are $\mathrm{Na}^{+}, \mathrm{Mg}^{2+}, \mathrm{Ca}^{2+}, \mathrm{K}^{+}, \mathrm{Cl}^{-}$, sulphate $\left(\mathrm{SO}_{4}{ }^{2-}\right)$, nitrate $\left(\mathrm{NO}_{3}{ }^{-}\right)$and methylsulphonate $\left(\mathrm{MS}^{-}\right)$. Soluble $\mathrm{Na}^{+}, \mathrm{Mg}^{2+}, \mathrm{Ca}^{2+}, \mathrm{Cl}^{-}$and $\mathrm{SO}_{4}{ }^{2-}$ are principally sourced from the ocean whilst $\mathrm{K}^{+}$and $\mathrm{NO}_{3}{ }^{-}$have mixed sources [Legrand and Mayewski, 1997]. $\mathrm{MS}^{-}$and $\mathrm{SO}_{4}{ }^{2-}$ are produced by biogenic activity in the ocean [Legrand, 1997]. The following summary will only consider the source and transport of $\mathrm{Na}^{+}, \mathrm{Ca}^{2+}, \mathrm{SO}_{4}{ }^{2-}$ and $\mathrm{MS}^{-}$because they have been developed as climate proxies relevant to this study.

Atmospheric aerosol species are transferred from the atmosphere to the ice sheet by either, wet or dry deposition. Wet deposition involves scavenging of chemical species by precipitation, which includes snow, rain, fog and diamond dust, whereas dry deposition can occur without precipitation. It involves either gravitational settling, diffusion or impaction of aerosol particles onto the ice sheet surface [Buseck and Schwartz, 2003]. The latter process is often referred to as wind pumping [Legrand and Mayewski, 1997]. At coastal locations, where cyclones are active and the air is relatively humid, wet deposition is the dominant process for marine aerosol [Benassai et al., 2005].

There is considerable debate surrounding the mechanism by which $\mathrm{Na}^{+}$ions are transferred from the ocean into the polar atmosphere. Conventional understanding has favoured 'bubble bursting' which is the generation of marine aerosol droplets by breaking waves [Monahan et al., 1986]. According to this mechanism, production of marine aerosol should be increased at locations or time periods of more intense cyclonic activity over the ocean [Petit et al., 1981]. The alternative mechanism of transfer to the atmosphere is via the transport of frost flowers from the sea ice surface [Hall and Wolff, 1998]. Frost flowers are a well-documented feature on the surface of young sea ice and consist of salts precipitated from brine which migrates up through the sea ice [Rankin et al., 2000; Rankin et al., 2002]. $\mathrm{Na}^{+}$sourced from frost flowers can be differentiated from $\mathrm{Na}^{+}$from sourced bubble bursting by considering the 
$\mathrm{Na}^{+} / \mathrm{SO}_{4}{ }^{2-}$ in ice core samples because a major frost flower constituent is mirabalite $\left(\mathrm{Na}_{2} \mathrm{SO}_{4} 10 \mathrm{H}_{2} \mathrm{O}\right)$, a salt which is depleted in $\mathrm{SO}_{4}{ }^{2-}$ relative to $\mathrm{Na}^{+}$[Wagenbach et al., 1998]. Na has been developed as a proxy for cyclonic activity [Kaspari et al., 2005; Kreutz et al., 2000] assuming an open water bubble bursting source by relating ice core concentrations to sea level pressure. However, $\mathrm{Na}^{+}$has also been employed as a proxy for sea ice extent assuming a frost flower source and correlating $\mathrm{Na}^{+}$levels with sea ice area [Wolff et al., 2003].

Providing one assumes that all $\mathrm{Na}^{+}$present in ice cores is sourced from the ocean, the concentration of another ion (e.g. $\mathrm{Ca}^{2+}$ ) which originates from a different source (nonsea salt $=$ nss) can be calculated as follows,

$\left[\mathrm{nssCa}^{2+}\right]=\left[\mathrm{Ca}^{2+}\right]_{\mathrm{sample}}-\left[\mathrm{Ca}^{2+} / \mathrm{Na}^{+}\right]_{\mathrm{sw}}{ }^{*}\left[\mathrm{Na}^{+}\right]_{\mathrm{sw}}$

where $\left[\mathrm{Ca}^{2+}\right]_{\text {sample }}$ refers to the concentration of $\mathrm{Ca}^{2+}$ in the sample and $\left[\mathrm{Ca}^{2+}\right]_{s w}$ refers to the concentration of the ion in seawater [Legrand and Delmas, 1984].

Soluble $\mathrm{Ca}^{2+}$ ions can be sourced from the open ocean, terrestrial calcium carbonate $\left(\mathrm{CaCO}_{3}\right)$ dust [Banta et al., 2008] and anhydrous $\mathrm{CaCO}_{3}$ salts, such as ikarite, which are thought to form on the sea ice surface [Sala et al., 2008]. $\mathrm{NssCa}^{2+}$ has been used as a tracer of terrestrial dust transport to both Greenland and Antarctic ice core sites [Fischer et al., 2007; Mayewski et al., 1994; Wolff et al., 2006; Yan et al., 2005] but the merit of this approach is questionable for Antarctica because soluble $\mathrm{Ca}$ concentrations are unlikely to be representative of dust inputs that are dominated by alumino-silicate minerals [Ayling and McGowan, 2006; Gaudichet et al., 1988; Ruth et al., 2008].

There are three recognised sources of $\mathrm{nsSSO}_{4}{ }^{2-}$ in Antarctic ice cores: volcanic activity (Section 4.3.3), anthropogenic industrial activity and biogenic processes. $\mathrm{NssSO}_{4}{ }^{2-}$ and $\mathrm{MS}^{-}$are oxidation products of dimethlysulphide (DMS), which is produced by marine phytoplankton associated with seasonal sea ice cover [Saltzman et al., 1983]. Concentrations of both $\mathrm{nsSSO}_{4}{ }^{2-}$ [Dixon et al., 2005] and $\mathrm{MS}^{-}$[e.g. Abram et al., 2010; Curran et al., 2003; Welch et al., 1993] in Antarctic ice cores have been used as proxies for sea ice extent of different sectors of Antarctica. The effectiveness of the proxy and 
sign of correlation between $\mathrm{MS}^{-}$and sea ice extent varies between ice core records from different locations due to site-specific factors [Abram et al., 2007].

\subsubsection{Mineral dust}

In addition to marine salts, volcanic and biogenic aerosols, the atmosphere also contains wind-blown dust aerosol. Wind-blown dust is sourced from the entrainment of dust particles during dust storms over arid regions. In the Southern Hemisphere the dust aerosol load of the atmosphere is lower than that of the Northern Hemisphere because there are less arid areas and dust storms are less frequent [Prospero et al., 2002]. Only around $1 \%$ of the total available dust is carried in vertical suspension after a dust storm and the particles have a maximum diameter of 20-50 $\mu \mathrm{m}$ [Gillette et al., 1974]. In the Dry Valleys region of Antarctica there is a significant ice free area where a combination of mechanical weathering in the cold environment [Pye, 1987] and strong winds $\left(>5.5 \mathrm{~m} \mathrm{~s}^{-1}\right.$ ) cause entrainment of dust particles[Ayling and McGowan, 2006].

Dust particles can be carried in suspension for days or weeks, depending on size and composition. Larger particles have a much shorter lifetime in suspension because they are rapidly removed by gravitational settling leading to a mean particle size of 2-3 $\mu \mathrm{m}$ involved in long-range transport [Schulz et al., 1998]. Dust aerosols are transferred to the ice sheet by the same mechanisms as described in Section 2.5.2. On a global scale, wet deposition is the dominant removal process for smaller particles $(<2 \mu \mathrm{m})$ and dry deposition for larger particles [Buseck and Schwartz, 2003].

Where there are dust sources proximial to the ice core site, as is the case for sites close to the Dry Valleys, it is common practice to distinguish between 'global' dust, transported from elsewhere in the Southern Hemisphere, and 'local' dust, by grain size. 'Global' dusts have diameters of 2-6 $\mu \mathrm{m}$ [Delmonte et al., 2004], whereas 'local' dust particles are $>10 \mu \mathrm{m}$ in diameter [Atkins and Dunbar, 2009]. More diagnostic provenance is achieved either by study of the mineralogy of the mineral dust 
[Gaudichet et al., 1988] or by determining Sr and $\mathrm{Nd}$ isotope ratios, which fingerprint the samples to potential source regions [Bory et al., 2010; Delmonte et al., 2010].

\subsubsection{Trace elements}

Inductively coupled plasma mass spectrometry (ICP-MS) provides excellent analytical capability for determination of trace element concentrations in Antarctic ice core samples. Additionally, analysis is rapid, has the capability to determine many elements simultaneously and only a small amount of sample is consumed.

Analysis of melted ice samples involves introducing samples into an argon-generated plasma, which ionizes the elements present. The ion beam is focused by lenses which direct it towards the mass analyser where the ions are separated before colliding with the detector [Thomas, 2001]. Most ICP-MS systems have a quadrupole mass analyser which separate ions according to their mass to charge ratio [Thomas, 2001]. The disadvantage with this system is that the difference between two chemical species with the same mass to charge ratio, i.e., ${ }^{56} \mathrm{Fe}^{+}$and ${ }^{40} \mathrm{Ar}^{16} \mathrm{O}^{+}$, cannot be resolved. In response to this, several other mass analysers including collision cell technology and double focusing magnetic sector or sector field (SF) analysers were developed. Many Antarctic snow and ice trace element studies [e.g. Barbante et al., 1997; Gabrielli et al., 2006; Planchon et al., 2001] used SF-ICP-MS systems, but Grotti et al. [2008] and Bull [2009] have demonstrated that quadrupole ICP-MS is suitable for trace element determinations in coastal ice core samples.

Initial measurements of trace elements in Antarctic snow and ice were conducted before the advent of ICP-MS instruments and yet were able to define $20^{\text {th }}$ century baseline concentrations of several trace elements and classify these elements into three source groups: marine, terrestrial and another, speculated to be volcanism [Boutron and Lorius, 1979; Liu et al., 1988]. The development of analytical techniques for ICP-MS analysis of snow and ice samples [Barbante et al., 1997; Gabrielli et al., 2006; Krachler et al., 2004; Planchon et al., 2001; Townsend and Edwards, 1998] prompted a proliferation of trace element studies. 
Analyses of snow pit and ice core samples dating from the last few centuries have focused on assessing the level of anthropogenic pollution to reach the Antarctic ice sheets and on understanding the broad sources, i.e., marine, terrestrial, volcanic, anthropogenic, of the trace elements measured. Both of these objectives involve calculating crustal enrichment factors according to the following equation:

Crustal Enrichment Factor $\left(\mathrm{EF}_{\mathrm{c}}\right)$ for element $\mathrm{E} \quad E=\left(\left\lfloor E_{\text {sample }}\right\rfloor /\left[X_{\text {sample }}\right]\right) /\left(\left[E_{\text {crust }}\right] /\left[X_{\text {crust }}\right]\right)$

$[E]$ is the concentration of the element concerned and $[X]$ is the concentration of another element that is considered to be sourced solely from terrestrial dust. The ratio of these elements in the sample is normalised to the same ratio of elements in the upper continental crust, values for which are obtained from the literature. Any relative contribution from element $E$ above that of the terrestrial tracer, element $X$, is classed as being enriched i.e., from a source other than the crust, and any lower relative contribution from element $\mathrm{E}$ means that it is depleted relative to the crust. Anthropogenic pollution produces crustal enrichment factors greater than unity.

Wolff et al. [1999] identified only $\mathrm{Cu}$ as showing inputs from anthropogenic pollution in Coats Land, East Antarctica but Planchon et al. [2002b] added Cr, Zn, Ag, Pb, Bi and $\mathrm{U}$ to the list and attributed most these anthropogenic inputs to mining activities in the Southern Hemisphere. Anthropogenic input of $\mathrm{Cu}, \mathrm{Pb}$ and $\mathrm{As}$ has also been recorded on the opposite side of East Antarctica in the Lambert Glacier basin [Hur et al., 2007]. Both an increase in $\mathrm{Pb}$ pollution resulting from the use of leaded petrol and a decrease in $\mathrm{Pb}$ pollution since the 1980s due to heavily reduced leaded petrol use is recorded in Antarctic ice [Planchon et al., 2003].

Defining the sources of trace elements in Antarctic snow and ice has proven to be difficult and complex. Each element tends to exhibit large variations in concentration [Bull, 2009; Hur et al., 2007; Planchon et al., 2002b], and variability in behaviour between elements is high [Bull, 2009; Planchon et al., 2002b]. Where temporal resolution of the sampled time period is high enough, seasonal cycles have been noted in some trace elements (Ba and Mn, Hur et al. [2007]). Crustal enrichment factor values greater than unity can be interpreted as input from either anthropogenic or 
volcanic sources; this has led to $\mathrm{Cu}, \mathrm{Zn}$ and $\mathrm{Pb}$ being classified as both volcanic [Vallelonga et al., 2004] and anthropogenic [Planchon et al., 2002a] in origin.

Trace element concentrations have also been determined for sections of the deep ice cores from EPICA Dome C and Vostok which record glacial-interglacial climate cycles. Results from both cores show higher trace element concentrations in glacial periods than interglacial periods [Gabrielli et al., 2005a; Gabrielli et al., 2005b; Marteel et al., 2008; Marteel et al., 2009]. Peaks in mineral dust levels recorded in the Dome C core closely correspond to maxima in trace element concentrations indicating that elements such as $\mathrm{Li}, \mathrm{Mg}, \mathrm{Cr}, \mathrm{Mn}, \mathrm{Co}, \mathrm{Cu}, \mathrm{As}, \mathrm{Rb}, \mathrm{Ba}$ and $\mathrm{Bi}$ are sourced from terrestrial dust in glacial periods [Gabrielli et al., 2005a]. Gabrielli et al. [2005a; 2005b] argued that in interglacial periods, when both dust concentrations and trace element concentrations are reduced, input of $\mathrm{Cd}, \mathrm{Bi}$ and $\mathrm{As}$ from volcanic sources becomes important. Plots of trace element concentration against the stable isotope ratio $\delta^{18} \mathrm{O}$ suggest a threshold low temperature has to be reached before the transport to, and/or deposition of, trace elements on the ice sheet can increase [Gabrielli et al., 2005a; Gabrielli et al., 2005b]. Marteel et al. [2009] identified a trend of decreasing trace element concentrations in successive glacial periods which they tentatively relate to a "change in the size distribution of dust particles transported from the mid-latitudes."

A further study on the EPICA Dome C ice core considered only Fe concentrations measured after leaching the samples, which contain mineral dust particles, in acid for $24 \mathrm{hr}\left(\mathrm{pH} 1, \mathrm{HNO}_{3}\right)$. The relatively high concentration of $\mathrm{Fe}$ in the last glacial period is seen to decrease at the glacial termination as atmospheric $\mathrm{CO}_{2}$ concentration rises [Gaspari et al., 2006]. This adds some support to the 'biological pump hypothesis', which links iron availability to phytoplankton growth, $\mathrm{CO}_{2}$ uptake, and temperature decrease during glacial periods [Sigman and Boyle, 2000]. Gabrielli et al. [2010] also studied the transition from the Last Glacial Maximum to the Holocene and measured concentrations of rare earth elements by ICP-MS. Discrepancies in the rare earth element signatures of the samples between the two periods are interpreted as representing a change in the composition of aeolian dust transported to Antarctica, and therefore a possible source region shift. 


\subsection{Ice core records of decadal-scale climate variability in the Antarctic}

The study of Schneider et al. [2006] examined stable isotopic records from five ice cores across Antarctica to assess temperature changes since $1800 \mathrm{AD}$. The records showed that $17 \%$ of the variance in temperature, across time and space, could be explained by SAM. Additionally a cooler $\left(-0.2^{\circ} \mathrm{C}\right)$ period was identified between the mid- $19^{\text {th }}$ and early- $20^{\text {th }}$ centuries. High resolution sea salt concentration records from Law Dome, East Antarctica, revealed that this cool period was also characterised by increased sea salt deposition and stronger atmospheric circulation during the winter months [Souney et al., 2002]. Goodwin et al. [2004] expanded on this study by correlating the $\mathrm{Na}^{+}$record from Law Dome with winter sea level pressure to develop a proxy for the strength of SAM. The reconstructed SAM record shows that temporal variations in SAM became slower after $1500 \mathrm{AD}$ and the SAM index started to trend towards a weakly positive state. The Law Dome ice core record suggests that the positive shift in the SAM since 1970 is part of natural climate variability rather than the result of anthropogenic greenhouse gases or the ozone hole, as others have proposed [Thompson and Solomon, 2002].

Kreutz et al. [2000] correlated the marine aerosol record from Siple Dome, West Antarctica, with sea level pressure of the Amundsen Sea region to produce a proxy for the strength of the Amundsen Sea Low. ENSO periodicities of 2.2 and $7.1 \mathrm{yr}$ were identified in the marine aerosol spectrum between 1890 and 1994 AD, indicating that the ENSO teleconnection to Antarctica was effective during this period. Furthermore, evolutionary spectrum analysis of the sea salt record showed that a strong $45 \mathrm{yr}$ periodicity ended ca. $1600 \mathrm{AD}$, suggesting that a change in forcing of sea level pressure occurred.

Another ice core proxy for ENSO influence on Antarctica is the biogenic sulphur species methylsulphonate (MS'), which is linked to sea ice extent. Meyerson et al. [2002] found that the $\mathrm{MS}^{-}$record of an ice core from the South Pole correlated with the SOI and developed a proxy for the SOI. This record shows that between 1600 and 1800 AD the ENSO teleconnection to the Antarctic was weak and Pacific sector sea ice extent was 
reduced. At $1800 \mathrm{AD}$ a shift occurs in the proxy record towards higher frequency EI Niño events and the stable isotopic record also shows a cooling at this time.

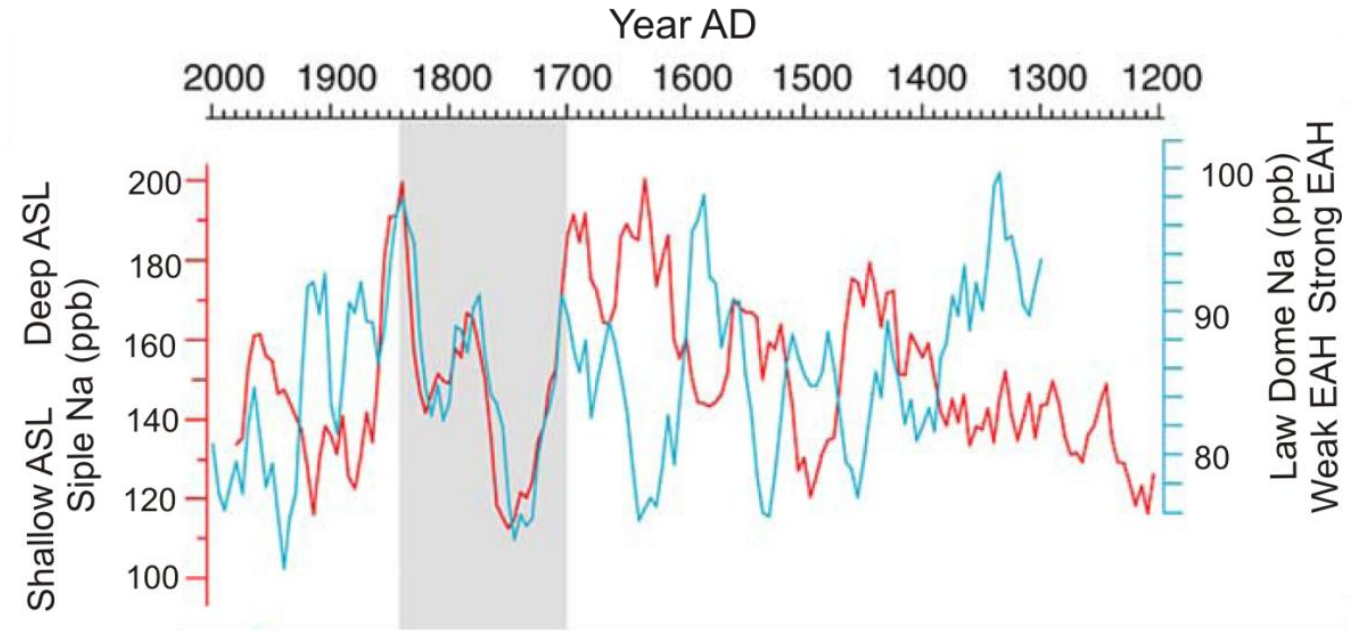

Figure 2.10: Na concentration records from Siple Dome (red) and Law Dome (blue) (25 year running means) used as proxies for the Amundsen Sea Low (ASL) and East Antarctic High (EAH) respectively (modified after Mayewski et al. [2009]) Grey shading highlights the anomalous period in which the records are in-phase.

Mayewski et al. [2004] combined the proxy records of Souney et al. [2002] (for the East Antarctic High, see Fig. 2.2)), Kreutz et al. [2000] (for the Amundsen Sea Low) and Meyerson et al. [2002] (for El Niño events) and argue that atmospheric circulation underwent a 'mode switch' during the period 1700 to 1850 AD in which the East Antarctic High and Amundsen Sea Low, which are normally out-of-phase, came into phase (Fig. 2.10). The authors also observe that this time period is coincident with a minimum in solar variability. The same time period sees the increased in El Niño activity identified by Meyerson et al. [2002]. Mayewski et al. [2009] propose a potential link between the termination of this anomalous period and the beginning of atmospheric $\mathrm{CO}_{2}$ concentration rise. 


\title{
Chapter 3: Sea ice variability and primary productivity in the Ross Sea, Antarctica, from methylsulphonate snow record
}

This chapter constitutes a paper published in Geophysical Research Letters (Section 1.6).

\begin{abstract}
The Ross Sea contains the most biologically productive continental shelf in Antarctica and is a region where the annual formation of sea ice drives substantial amounts of bottom water formation. We present snow pit chemistry data from Mt Erebus Saddle that provide a quantitative proxy to reconstruct summer sea ice conditions and rates of marine primary production. The methylsulphonate (MS') record is strongly correlated with changes in the area of open water $\left(R^{2}=0.903, p<0.05\right)$ caused by differences in atmospheric circulation and the sea-ice-damming effect of large icebergs, B-15 and C-19, which calved from the Ross Ice Shelf in 2000 and 2002 respectively. Furthermore, $\mathrm{MS}^{-}$and phytoplankton net primary production correlate significantly $\left(\mathrm{R}^{2}\right.$ $=0.927, p<0.01$ ). Our results demonstrate the potential of the Mt Erebus Saddle ice core to reconstruct sea ice and primary productivity variability in the Ross Sea beyond the observational record.
\end{abstract}




\subsection{Introduction}

Sea ice drives one of the strongest polar feedback mechanisms in the natural climate system, with reduced sea ice extent (SIE) causing amplification of greenhouse-gasinduced warming of the Earth. In addition, sea ice plays a key role in ocean circulation [Goose and Fichefet, 1999], ocean-atmosphere heat exchange and climate modulation [Yuan and Martinson, 2000], as well as providing a habitat for thriving marine ecosystems [Eicken, 1992]. Global temperature rise is predicted to continue at a rate of $0.2{ }^{\circ} \mathrm{C}$ per decade and climate models predict that sea ice will respond sensitively to increased sea surface temperature [IPCC, 2007]. Whilst Arctic sea ice is declining at a rapid and accelerating speed [Comiso et al., 2008], Antarctic sea ice trends are less discernable.

Large interannual variability caused by the oscillating nature of regional climate drivers [Turner, 2004] provides a complicated view showing either no trend or opposing trends in sea ice behaviour around Antarctica between adjacent ocean sectors [Liu et al., 2004; Zwally et al., 2002]. In addition, reliable satellite data are only available from 1979 onwards, complicating the delineation of a long-term trend. The current observational data set therefore limits the evaluation of a temporal Antarctic SIE trend, including the possible response to observed ocean and atmospheric changes, such as the warming of the Southern Ocean [Boning et al., 2008] and strong positive changes in the Southern Annular Mode [Stammerjohn et al., 2008]. An accurate sea ice proxy extending the observational data set is crucial in order to establish the response of Antarctic sea ice to oceanic and atmospheric forcings and to quantify its potential as a positive feedback mechanism.

Ice cores provide particularly high resolution and continuous records of environmental conditions at high latitudes. Several ice core studies have identified a statistical relationship between the biogenic sulphur species, methylsulphonate (MS'), and SIE [Abram et al., 2007; Curran et al., 2003; Meyerson et al., 2002; O'Dwyer et al., 2000; Pasteur et al., 1995; Sun et al., 2002; Welch et al., 1993] but the nature of this correlation is variable. 
$\mathrm{MS}^{-}$has a single source through the oxidation of dimethylsulphide (DMS) [Saltzman et al., 1983] that, in the Southern Ocean, is a by-product of the dimethylsulphoniopropionate (DMSP) produced by phytoplankton, such as Phaeocystis antarctica [DiTullio et al., 2003; Liss et al., 1994] and diatoms that are found in close association with sea ice [Bunt, 1963; Bunt and Wood, 1963; DiTullio et al., 2003]. Here we report a snow pit $\mathrm{MS}^{-}$record that demonstrates the causal link between $\mathrm{MS}^{-}$ emission, sea ice cover, and marine primary production in the Ross Sea, Antarctica. 


\subsection{Sea ice behaviour in the Ross Sea region}

The Ross Sea is a globally important site of sea ice production [Tamura et al., 2008] and bottom water formation [Jacobs and Giulivi, 1998]. However, current knowledge of sea ice behaviour in the Ross Sea is limited. Satellite data indicates that SIE has increased over the last 30 years [Stammerjohn et al., 2008; Zwally et al., 2002] despite a rise in the heat content of the Pacific sector of Southern Ocean [Levitus et al., 2005]. In contrast, analyses of whaling records suggest that sea ice cover was more extensive either in the summer [Cotté and Guinet, 2007], or in the winter and spring months [de la Mare, 2009], during the pre-satellite era. In addition, there is increasing evidence that the Ross Sea freshened between 1960 and 2000, with a decrease in salinity of about 0.1 psu observed along the western Ross Ice Shelf, causing the Ross Sea shelf water to now be less dense than that of the Weddell Sea [Jacobs et al., 2002].

The Ross Sea Polynya is maintained by katabatic winds that drive newly-formed ice offshore, allowing further sea ice formation [Bromwich et al., 1992]. During this process, dense brine is ejected into the ocean and sinks to form a precursor to Antarctic Bottom Water [Jacobs and Giulivi, 1998], a major contributor to the global thermohaline circulation.

As the Ross Sea Polynya is located on the Antarctic continental shelf, nutrient concentrations are relatively high [Sedwick and DiTullio, 1997]. Consequently, during the austral spring and summer, phytoplankton biomass reaches very high levels [Arrigo and McClain, 1994; Arrigo et al., 1999; Arrigo et al., 2000; Smith and Gordon, 1997] making the Ross Sea the most productive sector of the Southern Ocean [Arrigo et al., 1998; Smith and Gordon, 1997]. The Ross Sea Polynya itself is thought to be responsible for half the annual biological production on the entire Antarctic

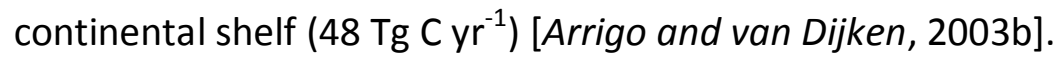




\subsection{Field site and methodology}

Mt Erebus Saddle is situated on Ross Island at the edge of the Ross Ice Shelf $\left(77^{\circ} 30.90^{\prime} \mathrm{S}, 167^{\circ} 40.59^{\prime} \mathrm{E}\right)$ (Fig. 3.1). As a result of its proximity ( $\left.15 \mathrm{~km}\right)$ to the seasonally open water of the Ross Sea Polynya, the snow accumulation rate at $\mathrm{Mt}$ Erebus Saddle is high (40 cm of snow per year). This allows sub-seasonal resolution of the snow and ice core record and limits post-depositional loss of $\mathrm{MS}^{-}$[Weller et al., 2004].

The predominant summer wind direction is north-easterly, entraining air masses that originate over the sea ice zone (Fig. 3.1). As a result, the marine aerosol signal in the Mt Erebus Saddle record is highly sensitive to the environmental conditions of the Ross Sea.

A 2 m deep snow pit was sampled in 2004/05, and a 180 m ice core was recovered from Mt Erebus Saddle in 2006/07. The snow pit was sampled at $1 \mathrm{~cm}$ resolution using methods reported previously [Bertler et al., 2004a]. Samples were analysed for $\delta^{18} \mathrm{O}$ at Alfred Wegener Institute for Polar and Marine Research to an accuracy of better than $\pm 0.1 \%$ o (MS Finnnigan DeltaE) and for $\mathrm{MS}^{-}$and major ions $\left(\mathrm{Na}^{+}, \mathrm{K}^{+}, \mathrm{Mg}^{2+}, \mathrm{Ca}^{2+}, \mathrm{Cl}^{-}, \mathrm{SO}_{4}{ }^{2-}\right.$, $\mathrm{NO}_{3}{ }^{-}$) by ion chromatography [Bertler et al., 2004a] at the Climate Change Institute, University of Maine. 


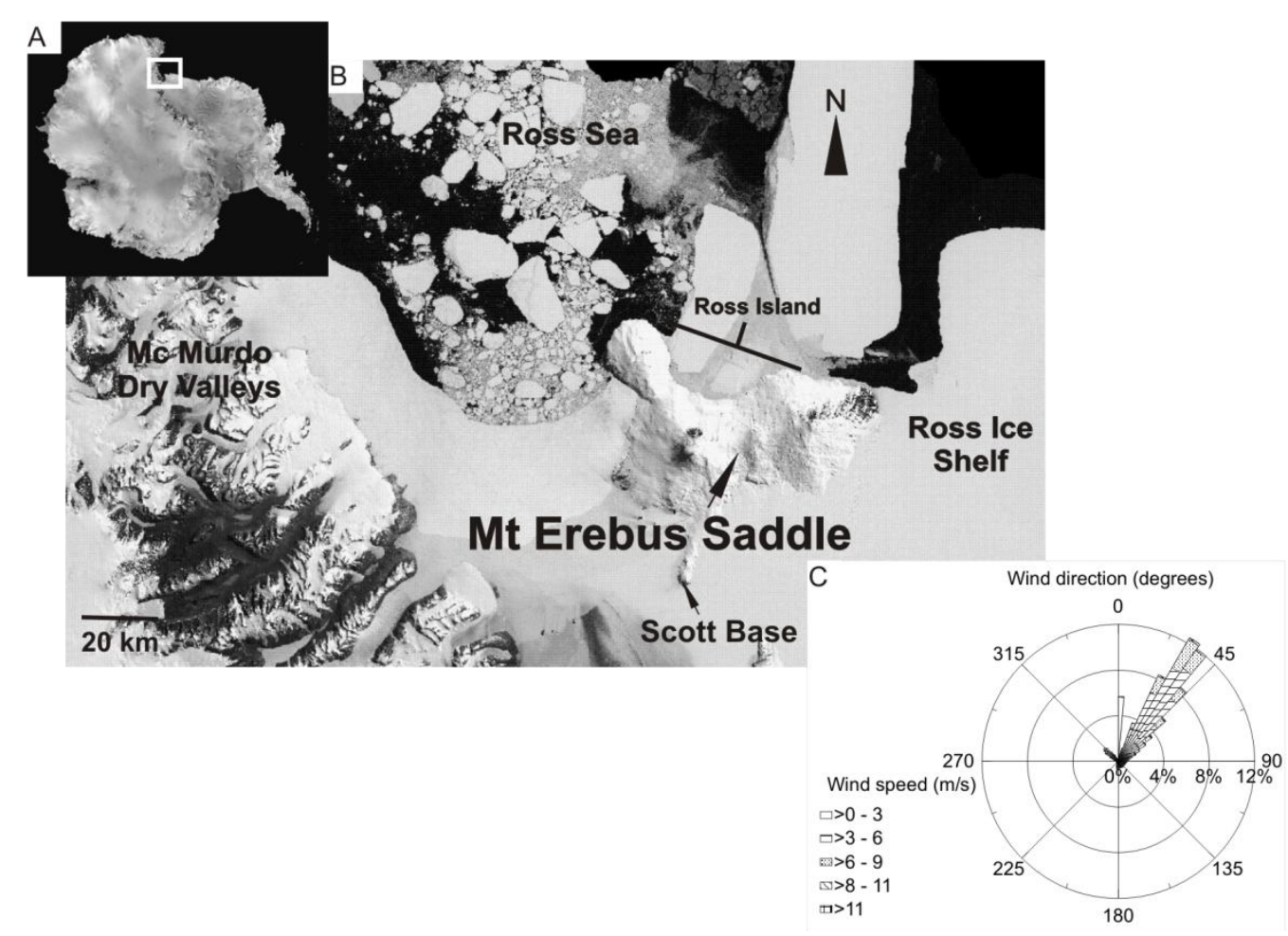

Figure 3.1: Location of Mt Erebus Saddle on (a) Radarsat Image of Antarctica (white box) and (b) on LIMA false colour satellite image, USGS. Rose diagram (C) displays wind direction and speed for summer months (Nov. to Feb.) at nearby Scott Base (available online at http://www.cliflo.niwa.co.nz).

Open water areas were determined using the algorithm of Markus and Burns [1995] from daily Special Sensor Microwave Imager (SSM/I) data obtained from the National Snow and Ice Data Center, University of Colorado, Boulder, CO. Sea-viewing Wide Field-of-view Sensor (SeaWiFS) chlorophyll a concentration data were acquired from the Goddard Earth Sciences (GES) Data and Information Services Center (DISC). Primary productivity was calculated using the algorithm of Arrigo et al. [2008]. Iceberg positions were projected from Moderate Resolution Imaging Spectroradiometer (MODIS) imagery. 


\subsection{Sea ice extent, primary productivity and methylsulphonate}

The Mt Erebus Saddle snow pit record (Fig. 3.2A) was dated utilising the $\delta^{18} \mathrm{O}$ record. $\delta^{18} \mathrm{O}$ maxima represent peak annual temperatures and were assigned the timing of January $1^{\text {st }}$. Corresponding discrete annual summer peaks in $\mathrm{MS}^{-}$concentration are clearly identifiable and vary between successive years of the record by almost an order of magnitude (11-68 ppb).

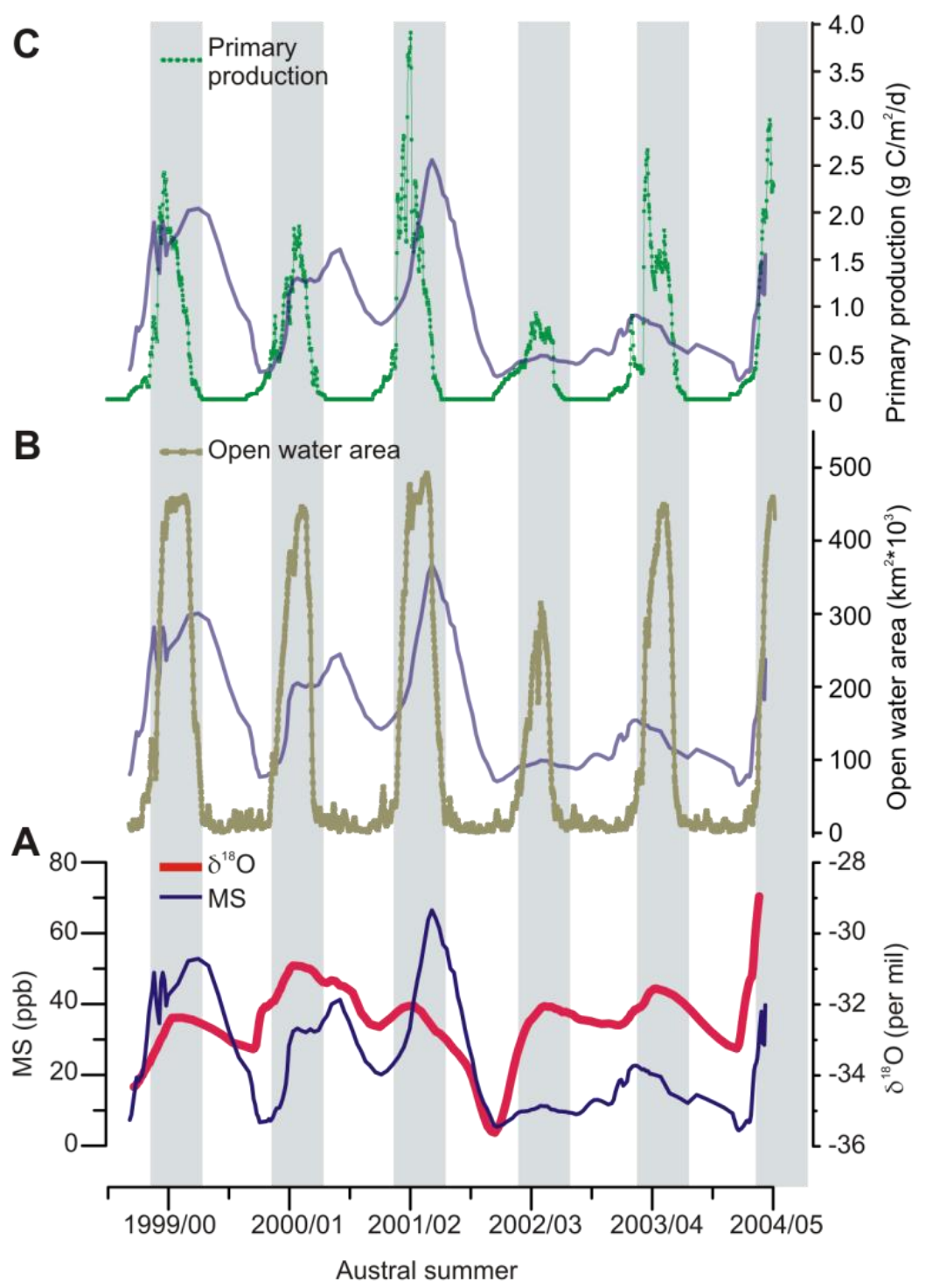

Figure 3.2: (A) Mt Erebus Saddle snow pit MS- record (3-point running mean) plotted with $\delta^{18} \mathrm{O}$ (3-point mean), (B) daily open water area of Ross Sea during summer (5-point running mean), and (C) daily primary productivity of the Ross Sea Polynya (3-point running mean). Grey shaded bars indicate summer (Nov. to Feb.). 
To test the sensitivity of our $\mathrm{MS}^{-}$record to sea ice conditions, for each year of the record, we compared $\mathrm{MS}^{-}$concentrations to the area of open water (rather than the more commonly used ice edge latitude) present in the Ross Sea during austral summer (Fig. 3.2B). We chose to use open water area because ice cover in the south-western Ross Sea is controlled by the dynamics of the Ross Sea Polynya, a feature whose size is not readily characterized by latitude. Additionally, open water area is effectively the inverse of SIE but is better able to account for the influence of the polynya. The interannual variability of open water area over the time period of the snow pit record is high (Fig. 3.2B), ranging between a mean annual value of $63,000 \mathrm{~km}^{2}$ in $2002 / 03$ and $141,000 \mathrm{~km}^{2}$ in 2001/02.

Austral summers that experienced increased open water area (decreased sea ice cover) in the Ross Sea (e.g., 2001/02) are associated with higher concentrations of $\mathrm{MS}^{-}$in the snow pit record (Fig. 3.2B). However, the $\mathrm{MS}^{-}$and open water area time series are both highly auto-correlated, which undermines the validity of direct cross-correlation. Therefore, we regressed annual mean $\mathrm{MS}^{-}$concentration against annual mean open water area (Appendix I). This analysis yielded a strong, positive correlation $\left(R^{2}=0.903\right.$, $p<0.05)$, indicating that an increase in open water area leads to a proportional increase in $\mathrm{MS}^{-}$concentration in the snow pit record and vice versa.

In addition, we were able to identify for the first time why increased MS concentrations in a snow or ice core record are associated with higher open water area. This was achieved by comparing the $\mathrm{MS}^{-}$record to the rate of marine primary production calculated for the Ross Sea over the same time period (Fig. 3.2C). In 2002/03, when the $\mathrm{MS}^{-}$concentration was low, the maximum rate of primary production reached was only $895 \mathrm{mg} \mathrm{C} \mathrm{m}^{-2} \mathrm{~d}^{-1}$ (Fig. 3.2C), less than a quarter of the rate reached in 2001/02, when the $\mathrm{MS}^{-}$concentration peaks. Annual primary production and mean annual $\mathrm{MS}^{-}$concentration correlate strongly $\left(\mathrm{R}^{2}=0.927, p<0.01\right)$ (Appendix I). This identifies $\mathrm{MS}^{-}$as a proxy for the mean annual rate of primary production. It also demonstrates that the $\mathrm{MS}^{-}$concentration in the Mt Erebus Saddle record is controlled by sea ice conditions via the modulation of open water area available for primary production, whereby reduced summer sea ice leads directly to 
greater marine primary productivity, higher DMS production, and elevated levels of $\mathrm{MS}^{-}$in the snow pit.

This is in contrast to several other ice core proxy studies [Curran et al., 2003; Meyerson et al., 2002; Welch et al., 1993], which identify a positive relationship between $\mathrm{MS}^{-}$and winter SIE. This difference is accounted for by considering the characteristics each site [cf. Abram et al., 2007]. At Law Dome, for example, Curran et al. [2003] recognised that the sea ice adjacent to Law Dome breaks out uniformly each summer and therefore the Law Dome $\mathrm{MS}^{-}$record is sensitive to differences in winter SIE. In contrast, Ross Sea summer sea ice conditions vary greatly. The range between maximum and minimum extent is almost twice that of the sector adjacent to Law Dome $\left(4.4 * 10^{6} \mathrm{~km}^{2}\right.$ compared to $\left.2.4 * 10^{6} \mathrm{~km}^{2}\right)$ [Zwally et al., 2002]. The influence of highly variable summer sea ice conditions on primary productivity and DMS production in the Ross Sea overrides any variability caused by changes in winter SIE. 


\subsection{Interannual variability}

The five-year period of the Mt Erebus Saddle snow pit is characterised by high variability in sea ice conditions and primary productivity (Fig. 3.3) in the Ross Sea. The anomalously high sea ice cover and consequent low primary productivity of austral summers 2000/01 and 2002/03 have been linked to the presence of icebergs B-15 and C-19. These were large icebergs $\left(10,000 \mathrm{~km}^{2}\right.$ and $6,400 \mathrm{~km}^{2}$ in areal extent respectively) and their slow drift across the Ross Sea restricted the summer breakout of sea ice [Arrigo and van Dijken, 2003a].

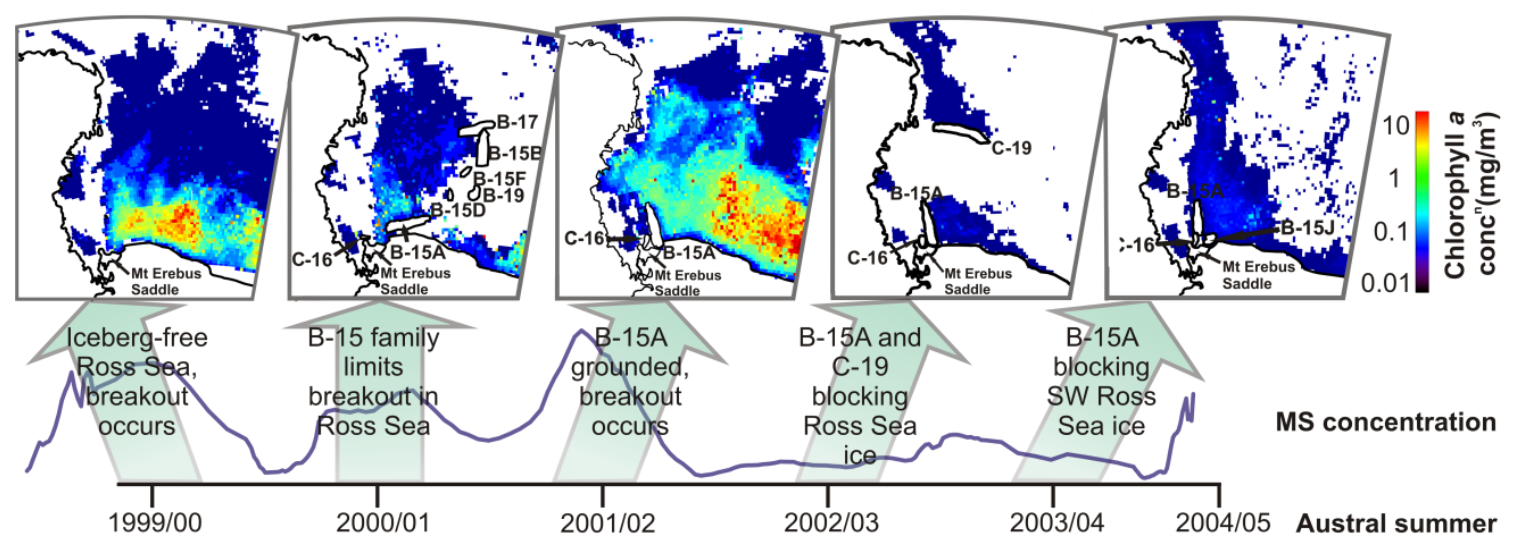

Figure 3.3: $\mathrm{MS}^{-}$time series with images showing distribution of photosynthetic pigment,

chlorophyll $a$, concentrations in the south-western Ross Sea $\left(160-190^{\circ} \mathrm{E}, 71-86^{\circ} \mathrm{S}\right)$ in midDecember of each austral summer. High concentrations of chlorophyll $a$ in the surface ocean indicate primary production is high. Iceberg locations are indicated and the effect on sea ice is described.

The impact of these icebergs on SIE is visible in satellite imagery and is also represented in our proxy record (Fig. 3.3). In 2000/01, (Fig. 3.3) a barrier formed by descendants of B-15 limited sea ice drift and restricted the open water area available for primary production [Arrigo et al., 2002] causing lower $\mathrm{MS}^{-}$concentrations than in the neighbouring years. The iceberg-effect is even greater in 2002/03 when C-19 was positioned perpendicular to the path of sea ice drift [Arrigo and van Dijken, 2003a]. The area of open water and primary productivity were severely limited (Fig. 3.3) and 46 
the concentration of $\mathrm{MS}^{-}$was reduced. Harangozo and Connolley [2006] show that weak atmospheric circulation during this summer also contributed to the heavy sea ice cover observed.

In 1999/00, neither of the large icebergs had yet calved, and in 2001/02, iceberg B-15A was grounded off the north of Ross Island (Fig. 3.3), to the west of the main polynya, and had little influence on sea ice behaviour. In both summers, complete sea ice breakout occurred across the entire Ross Sea area, phytoplankton biomass reached 10 $\mathrm{mg}$ chlorophyll $a \mathrm{~m}^{-3}$ over large areas (Fig. 3.3), resulting in high rates of primary production and peak $\mathrm{MS}^{-}$concentrations above 50 ppb (Fig. 3.2a). 


\subsection{Conclusions}

This snow pit study has identified the $\mathrm{MS}^{-}$record from Mt Erebus Saddle as a robust proxy for Ross Sea summer sea ice conditions via a strong, significant correlation with open water area. Furthermore, the annual mean $\mathrm{MS}^{-}$concentration at Mt Erebus Saddle is demonstrated to be a direct measure of the rate of marine primary productivity.

Strong, significant correlations between $\mathrm{MS}^{-}$, primary productivity, and open water area are established at Mt Erebus Saddle primarily as a result of the proximity of the Ross Sea Polynya and the predominant north-easterly wind direction, which directs $\mathrm{MS}^{-}$transport from the sea ice zone (Fig. 3.1). This ensures that atmospheric MS concentration is not depleted by a long transport distance [Preunkert et al., 2008]. It is also important that coastal Antarctic regions are strongly affected by regional cyclonic activity [Carrasco and Bromwich, 1993] and receive little stratospheric air, which carries a low latitude $\mathrm{MS}^{-}$signature [Minikin et al., 1998].

Future work will concentrate on the application of this proxy to the longer-term record of the $180 \mathrm{~m}$ deep Mt Erebus Saddle ice core. Through the use of a multi-proxy approach, involving stable isotopes, major ions, and trace elements, it is anticipated that a better understanding of the response of sea ice to drivers such as temperature and atmospheric circulation patterns will be established. Analysis of the ice core also has unique potential to produce a high-resolution record of Ross Sea primary production and its response to climatic change. Together, these longer-term records would improve our understanding of the past, and possible future, influence of ice dynamics on bottom water formation and of primary production on $\mathrm{CO}_{2}$ uptake in a key region of the Southern Ocean. 


\section{Chapter 4: Methodology for ice core study}

\subsection{Ice core sampling and processing}

\subsubsection{Site description}

Mt Erebus Saddle is located between the peaks of Mt Erebus and Mt Terra Nova at an altitude of $1600 \mathrm{~m}$ on Ross Island, western Ross Sea region, Antarctica (Fig. 3.1) $\left(77^{\circ} 30.90^{\prime} \mathrm{S}, 167^{\circ} 40.59^{\prime} \mathrm{E}\right)$. The average annual temperature determined by $15 \mathrm{~m}$ depth firn temperature at the site is $-25.6{ }^{\circ} \mathrm{C}$. A ground penetrating radar survey, conducted in late-2003, indicated a depth to bedrock of $220 \mathrm{~m}$ and suggested that ice flow off the saddle in NNW and SSE directions. The ice core was drilled at the centre of the ridge where ice flow is at a minimum. The radar survey imaged parallel isochrones or annual layers of snow deposition in the top 30-60 $\mathrm{m}$ and relatively flat bedrock topography, suggesting favourable glaciological conditions for the preservation of a continuous, annually-resolved ice core record (Fig. 4.1).

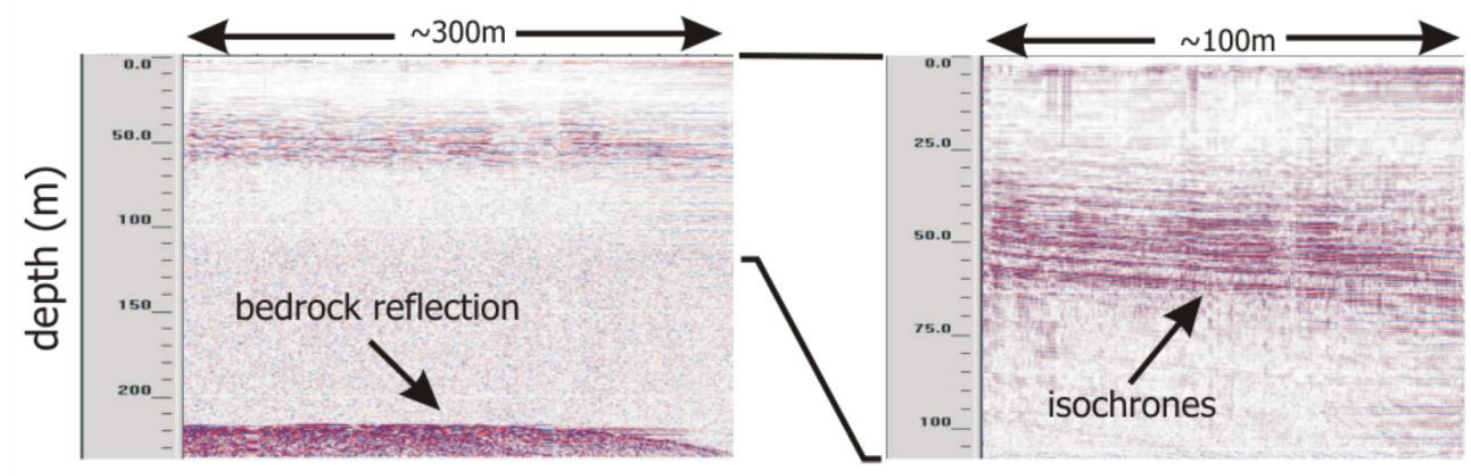

Figure 4.1: Ground penetrating radar (35 MHz frequency) profile from Mt Erebus Saddle showing bedrock topography, ice thickness and parallel isochrones (modified after Bertler [2004]).

This particular site was selected for ice core retrieval for two reasons. Firstly, the site was identified as having an anomalously high snow accumulation rate for coastal Antarctica (Fig. 4.2) [Bromwich, 1988; Monaghan et al., 2005], indicating that an ice 
core would capture a record of past climate at a high temporal resolution. Secondly, the firn-ice transition occurs between 60-67 m depth (Section 4.3.4), which is relatively shallow for an Antarctic ice core [Bender et al., 1997]. A shallow firn-ice transition causes the closure of gas bubbles in the firn to occur more rapidly, resulting in a reduced age difference between the ice and the gas trapped inside it and a higher resolution gas record [Bender et al., 2006]. Analysis of atmospheric gases trapped in the Mt Erebus Saddle ice core is being conducted by researchers at National Institute of Water and Atmospheric Research (NIWA), Wellington, New Zealand.

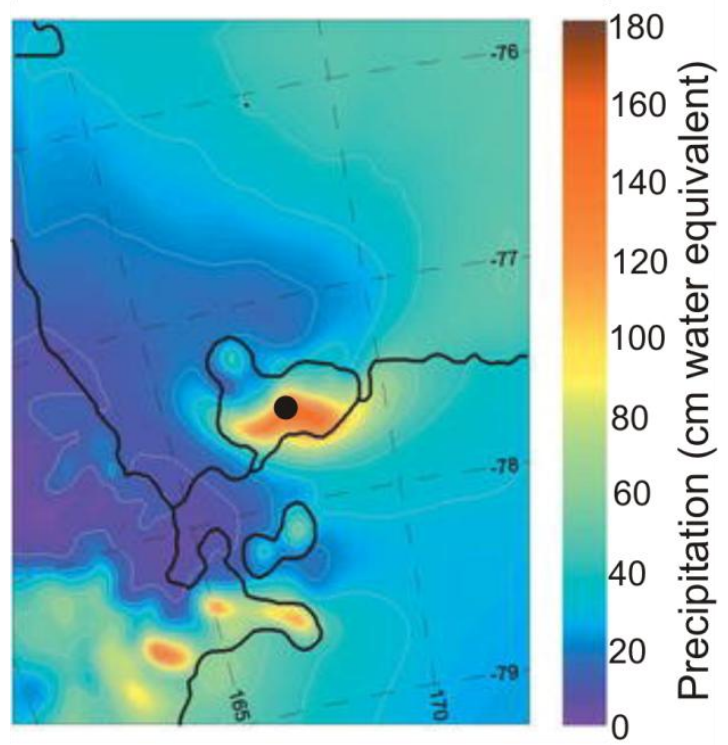

Figure 4.2: Map of annual precipitation in the McMurdo Sound region produced by the Antarctic Mesoscale Prediction System (AMPS) (modified after Monoghan et al. [2005]). The location of Mt Erebus Saddle is marked by a black circle. The $3.3 \mathrm{~km}$ domain model resolves the topography of Ross Island.

\subsubsection{Ice core retrieval}

The Mt Erebus Saddle ice core was drilled between $10^{\text {th }}$ and $27^{\text {th }}$ December 2006 using the Alfred Wegener Institute shallow drill and a drill depth of $168 \mathrm{~m}$ was reached. Once retrieved, the $10 \mathrm{~cm}$ diameter core was cut into sections of $1 \mathrm{~m}$ length using a band saw and each $1 \mathrm{~m}$ section was weighed in the field for calculation of density 50 
(Section 5.4). To minimise contamination of the core during the drilling operation, all core processing personnel in the drill trench wore Tyvek ${ }^{\circledast}$ clean suits with hoods, powder-free polyethene gloves and face masks. After processing, the core sections were transported at temperatures below $-18{ }^{\circ} \mathrm{C}$ to the New Zealand Ice Core Laboratory, GNS Science, Lower Hutt, New Zealand and stored at $-35^{\circ} \mathrm{C}$.

\subsubsection{Ice core processing}

\subsubsection{Ice core preparation}

The portion of ice core assigned to this study was prepared in the cold laboratory ($18^{\circ} \mathrm{C}$ ) of the New Zealand Ice Core Laboratory. Each $1 \mathrm{~m}$ length section of ice core was cut twice lengthways using a band saw to create a quasi-quarter sized portion (Fig. 4.3). Each exposed end surface was scraped with a ceramic knife to remove ice that may have been contaminated and this portion of core was then bagged into plastic lay flats for storage prior to melter processing. The remaining sections of core were also bagged into plastic lay flats and returned to storage.

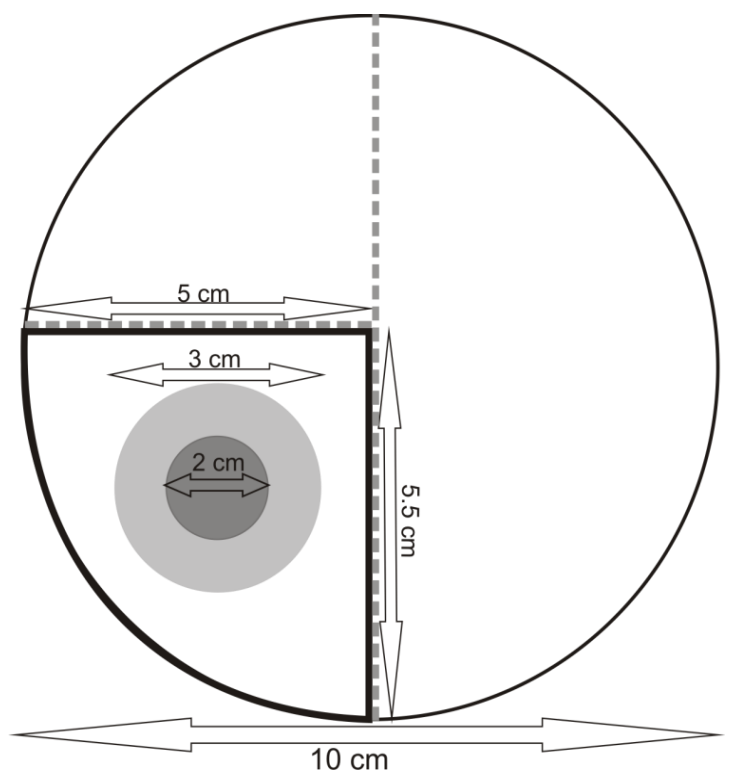

Figure 4.3: Plan view of the Mt Erebus Saddle ice core showing the portion of core used in this study, outlined by a thick black line. Concentric grey circles indicate the positions of the inner circles of each melt disk used in processing (see text). Grey dashed lines are band saw cut lines. 
The uppermost $120 \mathrm{~m}$ of the Mt Erebus Saddle ice core processed for this study were generally of good physical quality with few core breaks. The depths of all core breaks were recorded to check for chemical contamination or loss of material.

\subsubsection{Continuous-melter-discrete sampling system}

The ice core was processed in the clean laboratory of the New Zealand Ice Core Laboratory using a continuous-melter-discrete sampling system, described in detail by Osterberg et al. [2006], in order to obtain ultra-clean samples necessary for chemical analysis. To process the core each metre-length section was removed from the plastic lay flat and placed on a heated nickel disk situated inside a stand-alone freezer unit cooled to $-10{ }^{\circ} \mathrm{C}$. As the ice core melts on the nickel disk, sample is pumped away through radial slits on the surface of the disk. The melted sample is pumped to three Gilson fraction collectors which direct it into separate vials for three different types of analyses: determination of stable isotope ratios, ion chromatography (IC) and inductively coupled plasma mass spectrometry (ICP-MS). The fraction collector for the

IC samples controls the sampling sequence by monitoring the number of drops of sample it receives. Once a drop number equivalent to the required sample volume is reached, the IC fraction collector signals all the fraction collectors to move to the next sample vial simultaneously.

Material from the interior of the core which has had no contact with the atmosphere or processing equipment is sampled for IC and ICP-MS analysis. The surface of the nickel disk has a raised inner circle which acts to isolate material melted from the interior of the core (Figs. 4.3 and 4.4). Material from the outer region of the core is sampled for stable isotope analysis and for archival storage. The diameter of the inner circle on the nickel disk dictates the ratio of inner to outer material collected from a 1 $m$ length of core and therefore the sampling resolution that is achieved. A nickel disk with a $2 \mathrm{~cm}$ diameter inner circle was used to process the ice core down to a depth of $65 \mathrm{~m}$ with a mean sampling resolution of $2.3 \mathrm{~cm}$ depth. Each $2.3 \mathrm{~cm}$ depth of core melted equated to the following approximate sample volumes: $4 \mathrm{~mL}$ ICP-MS, $4 \mathrm{~mL} \mathrm{IC}$, $4.5 \mathrm{~mL}$ stable isotopes and up to $28 \mathrm{~mL}$ archive material. Between $66 \mathrm{~m}$ and $120 \mathrm{~m}$ 
depth, a nickel disk with an inner circle diameter of $3.0 \mathrm{~cm}$ was used to process the ice core. A larger inner circle diameter increased the ratio of inner material to outer material and allowed a higher mean sampling resolution of $1.6 \mathrm{~cm}$ to be achieved whilst still obtaining the sample volumes required for chemical analysis.

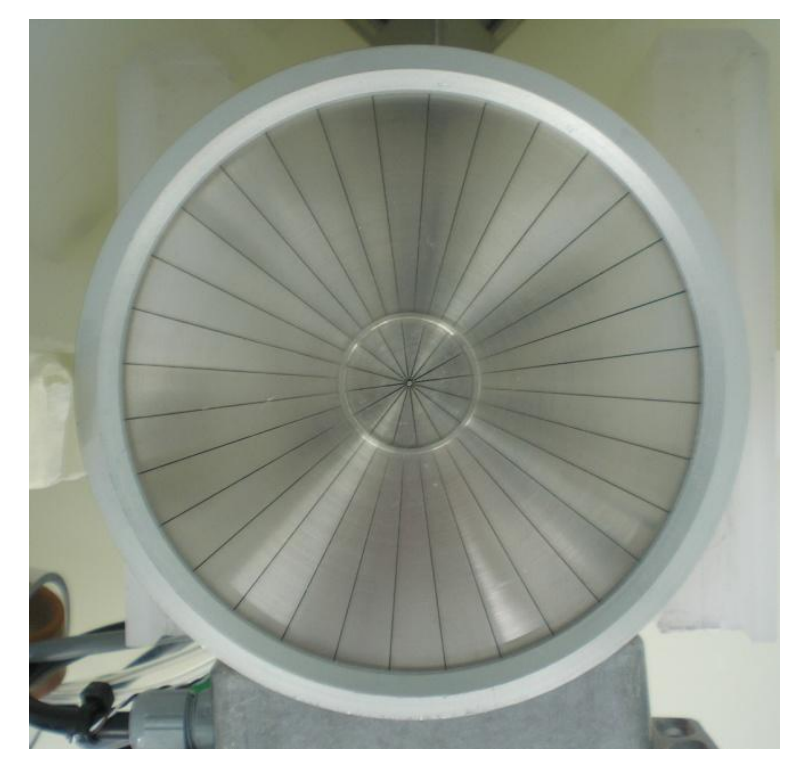

Figure 4.4: Photograph of nickel melt disk used on the continuous melter system. Raised inner circle ( $2 \mathrm{~cm}$ diameter) and radial slits can be seen.

\subsubsection{Improvements to the melter system}

The original design of the continuous-melter-discrete sampling system was improved in May 2010 by the development of software which monitors both the drop-counting sequence of the Gilson fraction collectors and the depth of core being sampled over time. This allows samples to be traced back to their original depth in the $1 \mathrm{~m}$ length of ice core melted. Another improvement was the addition of an optional setting which reduces the depth resolution of ICP-MS sampling by half; for every two stable isotope or IC samples produced, one ICP-MS sample is produced. This proved advantageous for this study because it was not practical or necessary to analyse every ICP-MS sample obtained and ICP-MS sample vials require a lengthy and laborious cleaning process. ICP-MS samples between 77 and $120 \mathrm{~m}$ were sampled at $3.2 \mathrm{~cm}$ resolution, whilst maintaining $1.64 \mathrm{~cm}$ resolution sampling for IC and stable isotope analysis. A total of 
6669 samples for IC and stable isotope analysis and 5225 samples for ICP-MS were obtained.

\subsubsection{Vial cleaning procedures}

All vials used to sample material intended for IC or ICP-MS analysis were rigorously cleaned prior to use to prevent chemical contamination. The polypropylene vials used for IC samples were triple-rinsed with ultra-pure water (>18.2 $\mathrm{M} \Omega$ ), soaked for a minimum of three days and triple-rinsed again. The polypropylene vials used for ICPMS samples were first triple-rinsed with ultra-pure water then soaked in 5 wt.\% analytical reagent grade $\mathrm{HNO}_{3}$ for a minimum of 10 days, triple-rinsed, soaked in ultrapure water for a minimum of 5 days and triple-rinsed with ultra-pure water. Vial cleaning was conducted under HEPA Class 100 clean room conditions whilst wearing a Tyvek $^{\circledR}$ clean suit with hood and powder-free polyethene gloves.

\subsubsection{Procedural blanks}

Procedural blanks monitor the potential contribution of the processing and sampling procedure to the concentrations of chemical species measured. Fabricated ice cores of frozen ultra-pure water (> 18.2 M $\Omega$ ) were processed, melted and sampled daily by the same methods as described above to provide procedural blanks. Chemical concentrations recorded in the procedural blanks are summarized in Tables 4.1 and 4.2. The procedural blank concentrations equate to: $<10 \%$ of the mean ice core concentrations of $\mathrm{Na}, \mathrm{Mg}, \mathrm{As}, \mathrm{Rb}, \mathrm{Sr}, \mathrm{Tl}, \mathrm{Bi} \mathrm{Th}, \mathrm{K}^{+}$and $\mathrm{SO}_{4}{ }^{2-} ;<15 \%$ of the mean ice core concentrations of $\mathrm{Al}, \mathrm{V}, \mathrm{Mn}, \mathrm{Cs}, \mathrm{Ce}$, La and $\mathrm{Pr} ;<20 \%$ of the mean ice core concentrations of $\mathrm{Y}, \mathrm{Zr}, \mathrm{U}, \mathrm{NO}_{3}{ }^{-}$and $\mathrm{Cl}^{-} ;<25 \%$ of the mean ice core concentrations of $\mathrm{Ti}$ and $\mathrm{Ba}$, and $<30 \%$ of the mean ice core concentration of $\mathrm{Pb}$. Contamination of $\mathrm{Ca}$ was a problem as the ICP-MS procedural blank accounts for $70 \%$ of the mean concentration. The $\mathrm{Ca}$ and $\mathrm{Zr}$ in the ICP-MS procedural blanks originate from the ceramic knives used to prepare the ice core for melting. The $\mathrm{Ca}^{2+}$ concentration of the procedural blanks measured by IC is significantly higher than the Ca concentration measured by ICP-MS. 
This is likely to be the result of interference from $\mathrm{Ni}$, sourced from the melt disk, which is known to elute close to $\mathrm{Ca}^{2+}$ on the CS-12A column [Osterberg et al., 2006]. During the processing of the ice core using the continuous melter system it was noted that dust particles can become lodged in connectors or tubing causing contamination of procedural blanks. It is recommended that connectors and tubing are checked for dust accumulation daily. Procedural blanks should also be sampled after several successive metres of ice core are melted to test whether the background concentrations increase.

Tables 4.1 and 4.2: Mean procedural blanks for Mt Erebus Saddle ice core processing and sampling. Raw data are provided in Appendix II.

Table 4.1: ICP-MS (ppt, except where indicated)

\begin{tabular}{cc}
\hline Element & Concentration \\
\hline $\mathrm{Na}^{\mathrm{a}}$ & 1.12 \\
$\mathrm{Mg}^{\mathrm{a}}$ & 0.29 \\
$\mathrm{Al}^{\mathrm{a}}$ & 0.56 \\
$\mathrm{Ca}^{\mathrm{a}}$ & 6.89 \\
$\mathrm{Ti}$ & 78.5 \\
$\mathrm{~V}$ & 0.70 \\
$\mathrm{Mn}$ & 10.9 \\
$\mathrm{As}$ & 0.29 \\
$\mathrm{Rb}$ & 0.47 \\
$\mathrm{Sr}$ & 4.50 \\
$\mathrm{Y}$ & 0.50 \\
$\mathrm{Zr}$ & 3.05 \\
$\mathrm{Cs}$ & 0.05 \\
$\mathrm{Ba}$ & 5.28 \\
$\mathrm{La}$ & 0.66 \\
$\mathrm{Ce}$ & 1.42 \\
$\mathrm{Pr}$ & 0.17 \\
$\mathrm{Tl}$ & 0.00 \\
$\mathrm{~Pb}$ & 4.67 \\
$\mathrm{Bi}$ & 0.09 \\
$\mathrm{Th}$ & 0.07 \\
$\mathrm{U}$ & 0.04 \\
\hline $\mathrm{Concentrations}$ & $\mathrm{ppb}$ \\
\end{tabular}

Table 4.2: IC (ppb)

\begin{tabular}{cc}
\hline Ion & Concentration \\
\hline $\mathrm{Na}^{+}$ & 0.34 \\
$\mathrm{Mg}^{2+}$ & 0.66 \\
$\mathrm{~K}^{+}$ & 0.10 \\
$\mathrm{Ca}^{2+}$ & 20.3 \\
$\mathrm{MS}^{-}$ & 0.00 \\
$\mathrm{Cl}^{-}$ & 26.6 \\
$\mathrm{SO}_{4}{ }^{2-}$ & 4.50 \\
$\mathrm{NO}_{3}{ }^{-}$ & 6.27 \\
\hline
\end{tabular}




\subsection{Analytical techniques}

\subsubsection{Stable isotope analysis}

The stable isotope ratios of oxygen $\left(\delta^{18} \mathrm{O}\right)$ and hydrogen $(\delta D)$ were measured at the Stable Isotope Laboratory, GNS Science, Lower Hutt. Two different systems were used to analyse samples from different sections of the $120 \mathrm{~m}$ depth of ice core processed for this study and both are described below.

Samples from the top $91 \mathrm{~m}$ depth of ice core were analysed by a conventional isotope ratio mass spectrometer instrument. $\delta^{18} \mathrm{O}$ measurement was conducted using a GVI AquaPrep system linked to a dual inlet GVI mass spectrometer. $400 \mu \mathrm{L}$ of sample was equilibrated with $300 \mu \mathrm{L}$ of $\mathrm{CO}_{2}$ for $24 \mathrm{hr}$ at $25.5^{\circ} \mathrm{C}$. The $\mathrm{CO}_{2}$ was then extracted and transferred to the mass spectrometer for analysis. $\delta D$ analyses were performed by directly reducing $100 \mu \mathrm{L}$ of sample to $\mathrm{H}_{2}$ gas in a PyrOH reaction column and measuring the gas on the same dual inlet GVI mass spectrometer. $\delta^{18} \mathrm{O}$ and $\delta \mathrm{D}$ are reported with respect to V-SMOW and normalized to internal standards: INS9 with reported values of $-17.4 \%$ for $\delta^{18} \mathrm{O}$ and, $-131.0 \%$ for $\delta \mathrm{D}$, and INS11 with reported values of $-0.4 \%$ o for $\delta^{18} \mathrm{O}$ and, $-4.6 \%$ o for $\delta \mathrm{D}$. The analytical precision is $\pm 0.1 \%$ ofor $\delta^{18} \mathrm{O}$ and $\pm 1.0 \%$ ofor $\delta \mathrm{D}$. Samples from $92 \mathrm{~m}$ to $120 \mathrm{~m}$ depth were analysed using a LGR Liquid-Water Isotope Analyser which measures $\delta^{18} O$ and $\delta D$ simultaneously by laser absorption spectroscopy. Laser absorption is measured within a cavity containing high-reflectivity mirrors to generate laser path lengths of several $\mathrm{km}$ resulting in clear separation of laser absorption lines of different water molecules. $\delta^{18} O$ and $\delta D$ are reported with respect to V-SMOW and normalized to the internal standards mentioned above. The analytical precision for this instrument is $\pm 0.2 \%$ o for $\delta^{18} \mathrm{O}$ and $\pm 0.6 \%$ o for $\delta D$. Tests were carried out to assess the degree of comparability between the measurements of the two analytical instruments. $\delta^{18} O$ and $\delta D$ values determined using the LGR LiquidWater Isotope Analyser were corrected to make them directly comparable to the mass spectrometer measurements (Appendix IV). 
Deuterium excess (d-excess) is a second order parameter derived from $\delta^{18} \mathrm{O}$ and $\delta \mathrm{D}$ values:

$\mathrm{d}-$ excess $=\delta D-8 * \delta^{18} O[$ Dansgaard, 1954$]$

Uncertainty $(u)$ resulting from analytical precision can be estimated as:

$u(\mathrm{~d}-$ excess $)=\sqrt{(u \delta D)^{2}+\left(8 * u \delta^{18} O\right)^{2}}$

Measurements conducted on the mass spectrometer result in an uncertainty of $1.3 \%$ o on d-excess, compared to $1.7 \%$ on the laser system. The combined uncertainty on $d$ excess values for the entire record is $2.14 \%$ o (Appendix IV).

\subsubsection{Ion chromatography}

Ion chromatography (IC) analysis for major ions $\left(\mathrm{Na}^{+}, \mathrm{K}^{+}, \mathrm{Mg}^{2+}, \mathrm{Ca}^{2+}, \mathrm{MS}^{-}, \mathrm{Cl}^{-}, \mathrm{NO}_{3}{ }^{-}, \mathrm{SO}_{4}{ }^{2-}\right)$ was conducted at the Climate Change Institute, University of Maine using Dionex ion chromatographs with chemical suppression and conductivity detectors. Two ion chromatographs paired to a Gilson 215 Liquid Handler autosampler allowed for simultaneous anion and cation analysis. Anions were measured using an AS-18 column, $400 \mu \mathrm{L}$ sample loop, and a Dionex Reagent Free Controller producing a $\mathrm{KOH}$ eluent concentration of $35 \mathrm{mM}$. Cations were measured using a CS-12A column and a $500 \mu \mathrm{L}$ loop with $25 \mathrm{mM}$ methanesulphonic acid eluent.

Table 4.3: Concentrations of major ions (ppb) in IC calibration standards

\begin{tabular}{lrrrrrrrr}
\hline $\begin{array}{l}\text { Calibration } \\
\text { std. }\end{array}$ & $\mathrm{Na}^{+}$ & $\mathrm{K}^{+}$ & $\mathrm{Mg}^{2+}$ & $\mathrm{Ca}^{2+}$ & $\mathrm{MS}^{-}$ & $\mathrm{Cl}^{-}$ & $\mathrm{NO}_{3}{ }^{2-}$ & $\mathbf{S O}_{4}{ }^{2-}$ \\
\hline 1 & 1200 & 50 & 150 & 250 & 100 & 2000 & 150 & 1200 \\
2 & 400 & 17 & 50 & 83 & 33 & 667 & 50 & 400 \\
3 & 133 & 6 & 17 & 28 & 11 & 222 & 17 & 133 \\
4 & 44 & 2 & 6 & 9 & 4 & 74 & 6 & 44 \\
5 & 15 & 1 & 2 & 3 & 1 & 25 & 2 & 15 \\
\hline
\end{tabular}


The chromatograph was calibrated at the beginning of each week by analyzing five calibration standards which bracketed the expected concentration range (Table 4.3). Correlation coefficients of $r^{2}>0.99$ were routinely achieved for all major ions. Calibration standard 2 was run daily to check the calibration. Calibration results were verified using the external standard ION-92 (National Water Research Institute, Canada), which was run at dilutions of 100 and 1000 times to reflect the range of concentrations measured in the ice core samples. The accuracy, precision and detection limits of major ion measurements are provided in Appendix III.

\subsubsection{Inductively coupled plasma mass spectrometry}

\subsubsection{Hardware and operating conditions}

ICP-MS analyses were conducted at the Geochemistry Laboratory of the School of Geography, Environment and Earth Sciences, Victoria University of Wellington using an Agilent 7500 cs Series instrument. Ice core samples were analysed for concentrations of 22 major, minor and trace elements ( $\mathrm{Na}, \mathrm{Mg}, \mathrm{Al}, \mathrm{Ca}, \mathrm{Ti}, \mathrm{V}, \mathrm{Mn}, \mathrm{As}, \mathrm{Rb}, \mathrm{Sr}, \mathrm{Y}, \mathrm{Zr}, \mathrm{Cs}, \mathrm{Ba}$, $\mathrm{La}, \mathrm{Ce}, \mathrm{Pr}, \mathrm{Tl}, \mathrm{Pb}, \mathrm{Bi}, \mathrm{Th}, \mathrm{U})$. The operating conditions employed for ICP-MS analysis are displayed in Table 4.4. The octopole collision cell was not used for this study because it inhibits the detection of very low (sub-ppt) concentrations of trace elements. An ASX-520 micro-volume autosampler linked to the ICP-MS introduced sample to the PFA Teflon nebuliser $\left(0.2 \mathrm{~mL} \mathrm{~min}^{-1}\right.$ flow rate) via a peristaltic pump. The temperature of the quartz spray chamber was maintained at $2{ }^{\circ} \mathrm{C}$ to reduce the water content of aerosol entering the plasma and limit molecular interferences [Hutton and Eaton, 1987]. The formation of oxides in the plasma was monitored by aspirating a $1 \mathrm{ppb}$ solution of $\mathrm{Ce}$. Tuning parameters were adjusted to maintain the proportion of the ${ }^{140} \mathrm{Ce}$ converted to ${ }^{140} \mathrm{Ce}{ }^{16} \mathrm{O}$ at below $2 \%$.

Nickel sampling and skimmer cones were cleaned and the sample introduction system was circulated with 5 wt.\% $\mathrm{HNO}_{3}$ (Seastar) for $1 \mathrm{hr}$ prior to each analytical session to reduce any possible memory effect from previous user's samples. 
Table 4.4: Operating conditions of the ICP-MS and data acquisition parameters for the determination of selected elements in Mt Erebus Saddle ice core samples.

\begin{tabular}{|c|c|}
\hline Parameter & Setting \\
\hline Forward power & $1500 \mathrm{~W}$ \\
\hline RF matching & $1.75-1.84 \mathrm{~V}$ \\
\hline Carrier gas & $1.04-1.10 \mathrm{~L} \mathrm{~min}^{-1}$ \\
\hline Makeup gas & $0 \mathrm{~L} \min ^{-1}$ \\
\hline Nebulizer pump & $0.12-0.16 \mathrm{rps}$ \\
\hline Spray chamber temperature & $2^{\circ} \mathrm{C}$ \\
\hline Sampling depth & $7 \mathrm{~mm}$ \\
\hline Torch position & Optimised daily to maximise sensitivity \\
\hline Ion lenses voltages & $\begin{array}{l}\text { Optimised daily to maximise sensitivity and signal } \\
\text { stability across mass range }\end{array}$ \\
\hline Isotopes measured & $\begin{array}{l}{ }^{23} \mathrm{Na},{ }^{24}{ }^{24} \mathrm{Mg},{ }^{27} \mathrm{Al},{ }^{43} \mathrm{Ca},{ }^{47} \mathrm{Ti},{ }^{51} \mathrm{~V},{ }^{55} \mathrm{Mn},{ }^{75} \mathrm{As},{ }^{85} \mathrm{Rb}, \\
{ }^{88} \mathrm{Sr},{ }^{89} \mathrm{Y},{ }^{90} \mathrm{Zr},{ }^{133} \mathrm{Cs},{ }^{138} \mathrm{Ba},{ }^{139} \mathrm{La},{ }^{140} \mathrm{Ce},{ }^{141} \mathrm{Pr},{ }^{205} \mathrm{Tl}, \\
{ }^{208} \mathrm{~Pb},{ }^{209} \mathrm{Bi}^{232}{ }^{23 h},{ }^{238} \mathrm{U}\end{array}$ \\
\hline Uptake and stabilization time & $50 \mathrm{~s}$ and $60 \mathrm{~s}$ \\
\hline Washing time between samples & $\begin{array}{l}10 \mathrm{~s} \mathrm{H}_{2} \mathrm{O}, 200 \mathrm{~s} 5 \text { wt. } \% \mathrm{HNO}_{3}, 220 \mathrm{~s} 1 \text { wt. } \% \mathrm{HNO}_{3} \\
\text { (total } 430 \mathrm{~s} \text { ) }\end{array}$ \\
\hline Integration time & $0.10 \mathrm{~s}$ or $0.15 \mathrm{~s}$ depending on element \\
\hline No. of runs and scan passes & $3 \times 26$ \\
\hline
\end{tabular}

\subsubsection{Calibration and external standards}

Two calibration standards were required to incorporate the large concentration range across all the elements measured in the samples. The first standard contained major and minor elements ( $\mathrm{Na}, \mathrm{Mg}, \mathrm{Al}, \mathrm{Mn}$ and $\mathrm{Ba}$ ) and the second standard contained lithophile trace elements ( $\mathrm{Ti}, \mathrm{V}, \mathrm{As}, \mathrm{Rb}, \mathrm{Sr}, \mathrm{Y}, \mathrm{Zr}, \mathrm{Cs}, \mathrm{La}, \mathrm{Ce}, \mathrm{Pr}, \mathrm{Tl}, \mathrm{Pb}, \mathrm{Bi}, \mathrm{Th}, \mathrm{U}$ ). The relative concentrations of the various elements in the calibration standards were chosen to reflect the ratio of element concentrations expected in the ice core samples. Stock calibration standards were made up in 5 wt. $\% \mathrm{HNO}_{3}$ from mono-elemental 1000 ppm standards. Daily calibration standards were gravimetrically diluted from the stock standards (Table 4.5). P/A factor tuning calibrates measurements made by the two modes of detection (pulse and analog) of a quadrupole-based ICP-MS. P/A factors were tuned for elements which recorded $>1,000,000$ counts $\mathrm{s}^{-1}(\mathrm{Na}, \mathrm{Mg}$ and $\mathrm{Al}$ ) every three days or when the sensitivity changed markedly. 
Table 4.5: Concentrations of elements in ICP-MS daily calibration standards.

\begin{tabular}{llrl}
\hline & Element(s) & Concentration \\
\hline & $\mathrm{Na}, \mathrm{Ca}$ & 10 & $\mathrm{ppb}$ \\
Calibration Std. 1 & $\mathrm{Mg}$ & 1 & $\mathrm{ppb}$ \\
& $\mathrm{Al}, \mathrm{Mn}, \mathrm{Ba}$ & 100 & $\mathrm{ppt}$ \\
\hline & $\mathrm{Ti}, \mathrm{Sr}$ & 100 & $\mathrm{ppt}$ \\
& $\mathrm{As}, \mathrm{Rb}, \mathrm{Pb}$ & 20 & $\mathrm{ppt}$ \\
Calibration Std. 2 & $\mathrm{V}, \mathrm{Zr}$ & 10 & $\mathrm{ppt}$ \\
& $\mathrm{Y}, \mathrm{Cs}, \mathrm{La}, \mathrm{Ce}, \mathrm{Tl}, \mathrm{Bi}, \mathrm{Th}, \mathrm{U}$ & 1 & $\mathrm{ppt}$ \\
\hline
\end{tabular}

Samples were stored frozen prior to analysis to minimise leaching of elements from the interior walls of the vials. Samples were defrosted and acidified to $1 \mathrm{wt} . \% \mathrm{HNO}_{3}$ with 68 wt.\% $\mathrm{HNO}_{3}$ (Seastar) in a Class 100 clean room at least $12 \mathrm{hr}$ prior to analysis. 1 wt.\% $\mathrm{HNO}_{3}$ blanks were run every 6 samples and counts recorded on the blanks were subtracted from those recorded on samples and standards to correct for background. Both calibration standards were run as bracketing standards every 12 samples to correct for instrumental drift. An external reference material, SLRS-4 (river water, National Research Council, Canada), was run at 10 times dilution with each batch of samples to test the accuracy and reproducibility of the measurements. All data processing including calibration and blank correction was performed offline.

\subsubsection{Precision, accuracy and detection limits of ICP-MS measurements}

The precision and accuracy of the MES ice core ICP-MS analyses are displayed in Tables 4.6 and 4.7. With the exception of only 3 elements, the concentrations determined in the external reference material are within error of the certified values. For several of these elements, notably $\mathrm{Ti}, \mathrm{As}, \mathrm{Sr}$ and $\mathrm{Th}$, the \% difference between the concentrations determined in this study and the certified values is greater than the precision of the measurements in this study. Ti, As, Sr and Th were consistently determined to be at higher concentrations than the certified values, suggesting that either poly-molecular interferences were consistently augmenting the signal or that the certified values are under-estimated. The certified values are determined by more than one independent analytical technique, although this does not always include ICP-MS. The 60 
concentrations of $\mathrm{V}, \mathrm{Cs}$ and $\mathrm{Pr}$ determined in this study are not within error of the certified values. The Pr concentration determined deviates from the certified value because $\operatorname{Pr}$ was not present in the calibration standard and $\operatorname{Pr}$ concentrations were determined using the sensitivity recorded on Ce. The $\mathrm{V}$ certified value is the product of 4 independent analytical techniques and the Cs is compiled from > 3 ICP-MS studies so it is likely that the measurements in this study are inaccurate. This could be the result of poly-atomic interferences (on $\mathrm{V}$ only) or an error made when adding monoelemental solutions to the calibration standard.

Detection limits are presented in Table 4.8 and demonstrate considerable improvement through the course of the analytical work undertaken for this study. The mean detection limits of all the analysis undertaken are consistently lower than achieved for other studies using quadrupole ICP-MS instruments and, for many elements, are comparable with those achieved with sector-field or double-focusing instruments. 
Table 4.6: Major element concentrations (ppb) determined by repeated ICP-MS measurement of SLRS-4 riverine water standard for each analytical session with precision and accuracy of measurements.

\begin{tabular}{cccccccc}
\hline $\begin{array}{c}\text { Analytical } \\
\text { session }\end{array}$ & $\mathbf{n}$ & $\mathbf{N a}$ & $\mathbf{M g}$ & $\mathbf{A l}$ & $\mathbf{C a}$ & $\mathbf{M n}$ & $\mathbf{B a}$ \\
\hline Nov-08 & 10 & 2362 & 1668 & 60.3 & 6363 & 3.66 & 12.7 \\
Feb-09 & 11 & 2285 & 1426 & 55.1 & 5933 & 3.60 & 13.2 \\
Mar-09 & 6 & 2263 & 1554 & 54.7 & 6068 & 3.48 & 13.0 \\
Apr-09 & 6 & 2232 & 1505 & 54.3 & 5874 & 3.46 & 12.7 \\
Jun-09 & 11 & 2295 & 1618 & 57.5 & 6149 & 3.55 & 13.2 \\
Aug-09 & 3 & 2288 & 1608 & 55.1 & 5952 & 3.63 & 13.3 \\
Oct-09 & 6 & 2265 & 1613 & 57.0 & 6111 & 3.52 & 13.0 \\
Dec-09 & 3 & 2340 & 1644 & 56.6 & 6747 & 3.60 & 13.1 \\
Jul, Aug-10 & 26 & 2270 & 1518 & 55.0 & 5986 & 3.49 & 12.8 \\
\hline Long-term mean & 82 & 2289 & 1573 & 56 & 6132 & 3.56 & 13.0 \\
2 SD & & 80 & 156 & 4 & 546 & 0.14 & 0.44 \\
\hline Certified values & & 2400 & 1600 & 54 & 6200 & 3.37 & 12.22 \\
2 SD & & 200 & 100 & 4 & 200 & 0.18 & 0.6 \\
\hline Accuracy & & 4.5 & 9.9 & 6.8 & 8.9 & 4.0 & 3.4
\end{tabular}

Certified values for SLRS-4 are GeoREM preferred values obtained from http://georem.mpch-mainz.gwdg.de.

$\mathrm{n}=$ number of SLRS-4 determinations in each analysis batch. 
Table 4.7: Trace element concentrations (ppt) determined by repeated ICP-MS measurement of SLRS-4 riverine water standard for each analytical session with precision and accuracy of measurements.

\begin{tabular}{|c|c|c|c|c|c|c|c|c|c|c|c|c|c|c|c|c|c|}
\hline $\begin{array}{l}\text { Analytical } \\
\text { session }\end{array}$ & $n$ & $\mathrm{Ti}$ & $\mathbf{V}$ & As & $\mathbf{R b}$ & $\mathrm{Sr}$ & $Y$ & $\mathrm{Zr}$ & Cs & La & $\mathrm{Ce}$ & $\mathrm{Pr}$ & TI & $\mathrm{Pb}$ & $\mathrm{Bi}$ & Th & $\mathbf{U}$ \\
\hline Nov-08 & 10 & 1564 & 380 & 774 & 1570 & 28630 & 139 & 135 & 6.83 & 285 & 347 & 70.6 & 6.98 & 76.7 & 2.55 & 20.0 & 45.9 \\
\hline Feb-09 & 11 & 1706 & 384 & 750 & 1640 & 30128 & 142 & 160 & 6.93 & 306 & 387 & 85.7 & 6.48 & 83.7 & 2.39 & 23.2 & 51.7 \\
\hline Mar-09 & 6 & 1696 & 401 & 763 & 1617 & 29806 & 146 & 120 & 6.77 & 308 & 379 & 83.9 & 7.21 & 82.6 & 2.40 & 22.2 & 54.0 \\
\hline Apr-09 & 6 & 1600 & 374 & 766 & 1590 & 29315 & 141 & 130 & 6.58 & 292 & 366 & 80.1 & $16.28^{\mathrm{a}}$ & 80.2 & 2.06 & 21.7 & 53.9 \\
\hline Jun-09 & 11 & 1559 & 385 & 757 & 1659 & 30701 & 146 & 121 & 6.90 & 306 & 384 & 85.8 & 9.49 & 83.2 & 2.58 & 22.0 & 52.3 \\
\hline Aug-09 & 3 & 1529 & 373 & 745 & 1653 & 30512 & 147 & 127 & 6.94 & 299 & 392 & 87.5 & 8.86 & 83.4 & 2.29 & 21.5 & 51.9 \\
\hline Oct-09 & 6 & 1491 & 371 & 758 & 1607 & 29628 & 144 & 125 & 6.70 & 295 & 378 & 86.9 & 8.99 & 82.0 & 2.52 & 20.5 & 50.1 \\
\hline Dec-09 & 3 & 1620 & 391 & 745 & 1616 & 29915 & 141 & 146 & 6.79 & 296 & 365 & 85.3 & $13.67^{\mathrm{a}}$ & 86.5 & $38.79^{a}$ & 20.9 & 50.3 \\
\hline Jul, Aug-10 & 26 & 1515 & 378 & - & 1597 & 29414 & 141 & 188 & 6.75 & 296 & 374 & 85.2 & 7.69 & 79.5 & 2.43 & 21.9 & 50.2 \\
\hline Long-term mean & 82 & 1587 & 382 & 757 & 1616 & 29783 & 143 & 139 & 6.80 & 298 & 375 & 83.4 & 7.96 & 82.0 & 2.40 & 21.5 & 51.1 \\
\hline $2 S D$ & & 152 & 19 & 21 & 59 & 1269 & 6 & 45 & 0.23 & 15 & 27 & 10.6 & 2.31 & 5.7 & 0.34 & 1.9 & 4.9 \\
\hline Certified values & & 1460 & 320 & 680 & 1530 & 26300 & 146 & 120 & 9 & 287 & 360 & 69.3 & 6.8 & 86 & 2.1 & 18 & 50 \\
\hline $2 \mathrm{SD}$ & & 80 & 30 & 60 & 50 & 3200 & 8 & 15 & 2 & 8 & 12 & 1.8 & 1.3 & 7 & 0.1 & 3 & 3 \\
\hline Precision 2 RSD (\%) & & 9.6 & 5.1 & 2.7 & 3.7 & 4.3 & 4.0 & 32.2 & 3.4 & 5.1 & 7.3 & 12.6 & 29.0 & 6.9 & 14.0 & 9.1 & 9.6 \\
\hline $\begin{array}{c}\text { Accuracy } \\
\text { (\% difference) }\end{array}$ & & 8.7 & 19.3 & 11.3 & 5.6 & 13.2 & 2.0 & 15.9 & 24.5 & 3.9 & 4.1 & 20.4 & 17.0 & 4.7 & 14.4 & 19.6 & 2.3 \\
\hline
\end{tabular}

Anomalous values excluded from long-term mean.

Certified values for SLRS-4 are GeoREM preferred values obtained from http://georem.mpch-mainz.gwdg.de.

$\mathrm{n}=$ number of SLRS-4 determinations in each analysis batch. 
Table 4.8: Detection limits (ppt) for elements determined in each analytical session of ICP-MS analyses of the MES ice core.

\begin{tabular}{|c|c|c|c|c|c|c|c|c|c|c|c|c|c|c|c|c|c|c|c|c|c|c|c|}
\hline $\begin{array}{l}\text { Analytical } \\
\text { session }\end{array}$ & $n$ & $\mathrm{Na}$ & $\mathrm{Mg}$ & Al & $\mathrm{Ca}$ & $\mathrm{Ti}$ & V & $M n$ & As & $\mathbf{R b}$ & Sr & $Y$ & $\mathrm{Zr}$ & Cs & $\mathrm{Ba}$ & La & $\mathrm{Ce}$ & $\mathrm{Pr}$ & $\mathrm{Tl}$ & $\mathrm{Pb}$ & $\mathrm{Bi}$ & Th & $\mathbf{U}$ \\
\hline Nov-08 & 11 & 107 & 3.8 & 12.1 & 3581 & 23 & 0.66 & 3.7 & 8.9 & 0.40 & $8.79^{d}$ & 0.14 & 0.52 & 0.25 & 0.46 & 0.19 & 0.26 & 0.22 & 0.60 & 1.04 & 0.69 & 0.58 & 0.53 \\
\hline Feb-09 & 13 & 185 & 5.2 & 11.1 & 1224 & 23 & 0.91 & 3.5 & 8.8 & 0.36 & 0.33 & 0.13 & 0.57 & 0.24 & 0.36 & 0.20 & 0.27 & 0.22 & 0.66 & 1.02 & 0.64 & 0.80 & 0.64 \\
\hline Mar-09 & 5 & 317 & 3.4 & 11.6 & 1265 & 20 & 1.03 & 3.9 & 9.5 & 0.39 & 0.30 & 0.12 & 0.49 & 0.24 & 0.28 & 0.18 & 0.23 & 0.22 & 0.54 & 0.85 & 0.55 & 0.53 & 0.53 \\
\hline Apr-09 & 7 & 209 & 6.2 & 11.4 & 812 & 22 & 0.76 & 3.4 & 13.5 & 0.31 & 0.25 & 0.09 & 0.39 & 0.20 & 0.29 & 0.16 & 0.22 & 0.18 & 0.60 & 0.98 & 0.57 & 0.62 & 0.61 \\
\hline Jun-09 & 12 & 310 & 6.3 & 9.2 & 755 & 26 & 0.88 & 3.1 & 1.8 & 0.29 & 0.28 & 0.07 & 0.80 & 0.13 & 0.25 & 0.09 & 0.13 & 0.27 & 0.27 & 0.46 & 0.25 & 0.23 & 0.25 \\
\hline Aug-09 & 3 & 201 & 5.7 & 8.4 & 815 & 24 & 0.77 & 2.1 & 1.5 & 0.32 & 0.44 & 0.08 & 0.36 & 0.16 & 0.26 & 0.10 & 0.13 & 0.11 & 0.30 & 0.52 & 0.28 & 0.27 & 0.26 \\
\hline Oct-09 & 5 & 42 & 2.5 & 8.5 & 446 & 24 & 0.85 & 2.1 & 2.1 & 0.20 & 0.42 & 0.07 & 0.40 & 0.11 & 0.18 & 0.09 & 0.10 & 0.09 & 0.23 & 0.45 & 0.21 & 0.18 & 0.18 \\
\hline Dec-09 & 3 & 57 & 5.7 & 5.1 & 647 & 23 & 1.04 & 3.2 & 1.8 & 0.20 & 0.74 & 0.07 & 0.39 & 0.09 & 0.44 & 0.08 & 0.09 & 0.08 & 0.21 & 0.49 & 0.17 & 0.11 & 0.11 \\
\hline Jul, Aug-10 & 13 & 52 & 5.3 & 6.9 & 655 & 18 & 0.78 & 3.1 & - & 0.21 & 0.25 & 0.09 & 0.72 & 0.13 & 0.28 & 0.11 & 0.12 & 0.11 & 0.25 & 0.42 & 0.24 & 0.25 & 0.21 \\
\hline $\begin{array}{c}\text { Mean } \\
\text { detection } \\
\text { limit }\end{array}$ & 72 & 167 & 5.0 & 9.7 & 1271 & 22 & 0.83 & 3.2 & 6.7 & 0.31 & 0.31 & 0.10 & 0.58 & 0.18 & 0.32 & 0.14 & 0.19 & 0.19 & 0.44 & 0.72 & 0.43 & 0.45 & 0.40 \\
\hline $1 \sigma$ & & 116 & 2.8 & 5.9 & 1955 & 6 & 0.19 & 0.8 & 4.8 & 0.10 & 0.18 & 0.03 & 0.74 & 0.06 & 0.13 & 0.05 & 0.08 & 0.23 & 0.22 & 0.34 & 0.23 & 0.27 & 0.22 \\
\hline \multicolumn{24}{|c|}{ Previous studies } \\
\hline $\begin{array}{c}\text { Grotti et al. } \\
{[2008]^{\mathrm{a}}}\end{array}$ & 60 & & & & & & 4.6 & 8.9 & & & & & & & & & & & 5.9 & & & & \\
\hline $\begin{array}{l}\text { Barbante et al. } \\
\text { [1999] }^{\mathrm{b}}\end{array}$ & 5 & & & & & 63 & 3 & 1.8 & & & & & & & 1.8 & & & & & 0.6 & 0.09 & & 0.03 \\
\hline $\begin{array}{c}\text { Osterberg et al. } \\
2006^{\mathrm{b}}\end{array}$ & 10 & & & 40 & 110 & 0.7 & 0.1 & 1 & & & 0.3 & & $\begin{array}{c}0.00 \\
7\end{array}$ & & 0.33 & 0.01 & 0.01 & $\begin{array}{c}0.00 \\
2\end{array}$ & 0.03 & 0.2 & 0.03 & & $\begin{array}{c}0.00 \\
6\end{array}$ \\
\hline $\begin{array}{c}\text { Krachler et al. } \\
{[2005]^{\mathrm{b}}}\end{array}$ & 15 & & & 93 & & & 0.14 & 0.28 & & 0.14 & 0.65 & & & & 0.38 & & & & $\begin{array}{c}0.00 \\
3\end{array}$ & 0.06 & 0.01 & & $\begin{array}{c}0.00 \\
5\end{array}$ \\
\hline $\begin{array}{l}\text { Correia et al. } \\
{[2003]^{c}}\end{array}$ & & 160 & 39 & 56 & 6600 & 23 & 9.5 & 5.2 & 28 & 1.6 & 1.5 & 0.37 & 5 & 0.89 & 5.2 & 0.57 & 0.66 & 0.26 & 1.1 & 2.1 & & 1.5 & 0.39 \\
\hline
\end{tabular}




\section{Chapter 5: Dating the ice core record}

The Mt Erebus Saddle ice core age model was developed by annual layer counting, using thermonuclear bomb tritium fallout, and volcanic trace element deposition events as age tie points, and further constrained by a glacial flow model.

\subsection{Annual layer counting}

For Antarctic ice cores, the term 'annual layer counting' refers to the process of identifying annual peaks in measured parameters [Steig et al., 2005]; there are no annual dust horizons visible to the naked eye, as are found in Greenland ice cores [Alley et al., 1997]. In the case of the Mt Erebus Saddle core, stable isotope ratios and soluble chemistry measurements were available for annual layer counting. As $\delta^{18} \mathrm{O}$ and $\delta D$ are controlled by site temperature (Section 2.5.1), it is assumed that values peak in summer (January $1^{\text {st }}$ ) and trough in winter. Dating of the record from the $2 \mathrm{~m}$ snow pit from Mt Erebus Saddle (Section 3.4) was conducted by counting peaks in $\delta^{18} \mathrm{O}$ and the $\delta^{18} \mathrm{O}$ record of the ice core was 'wiggle-matched' to it (Fig. 5.1). The derived isotopic parameter d-excess also exhibits an annual cycle with summer maxima in the Mt Erebus Saddle ice core record. In addition, the $\mathrm{NO}_{3}{ }^{-}$record was useful for annual layer counting because peaks regularly occurred in winter to spring (Fig. 5.2). This signal is preliminarily interpreted as originating from $\mathrm{NO}_{3}{ }^{-}$production in stratospheric clouds [Michalski et al., 2005]. 


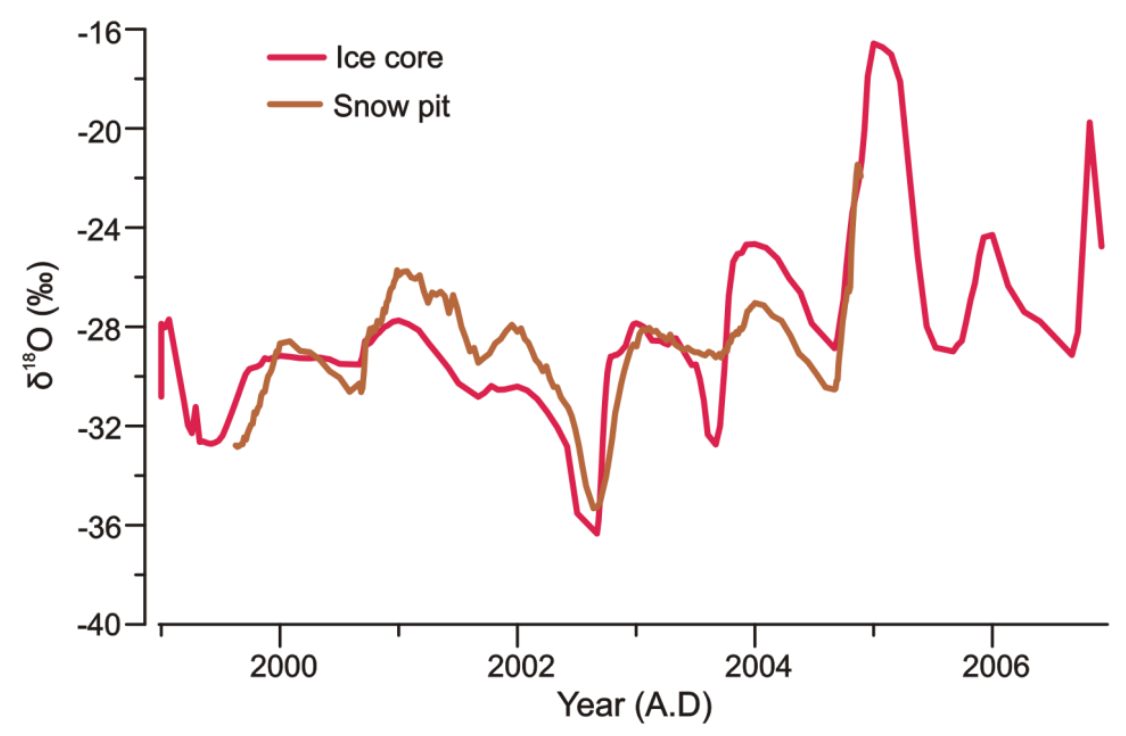

Figure 5.1: $\delta^{18} \mathrm{O}$ records from the Mt Erebus Saddle ice core (drilled summer 2006/07) and snow pit (sampled in 2004/05) on same age scale.

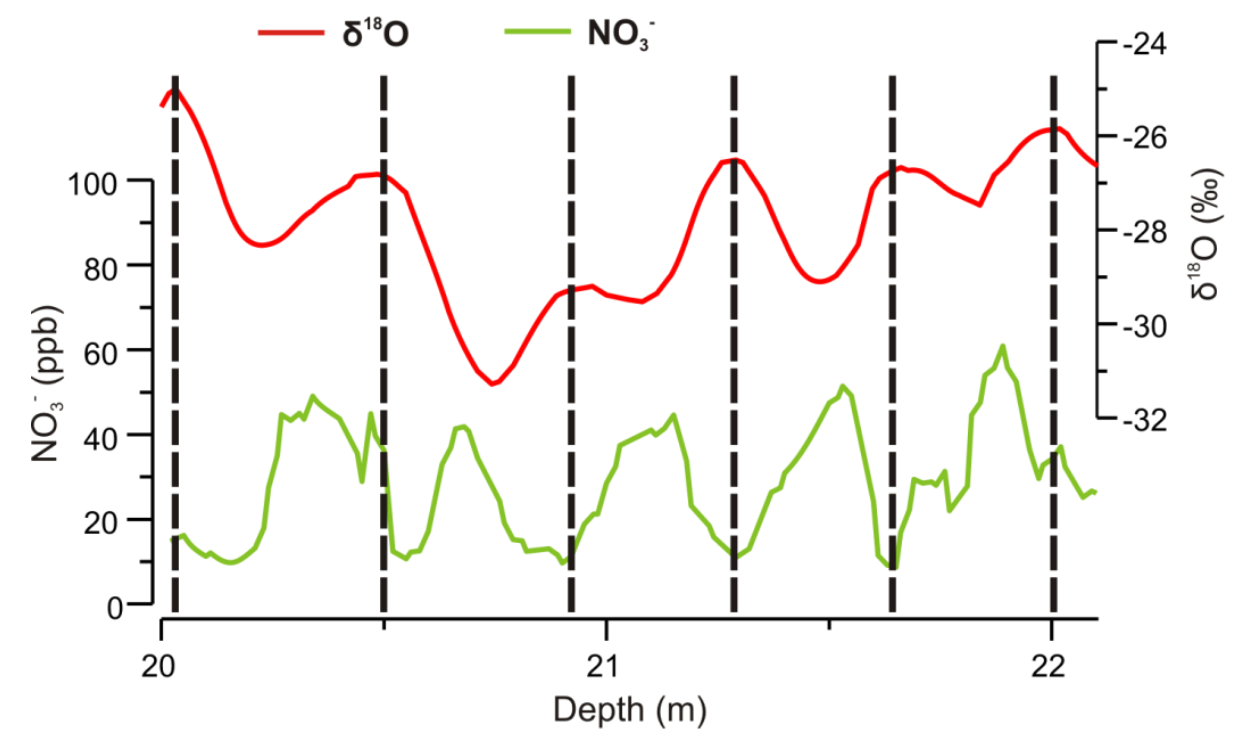

Figure 5.2: $\delta^{18} \mathrm{O}$ and $\mathrm{NO}_{3}{ }_{3}^{-}$profiles of a selected ice core section which display summer $\delta^{18} \mathrm{O}$ peaks and winter $\mathrm{NO}_{3}^{-}$peaks.

As the isotope record extended deeper down the core, the identification of annual peaks in the $\delta^{18} \mathrm{O}$ and $\delta \mathrm{D}$ records became more challenging. Diffusion of water molecules though the firn pore space, effectively smoothes the annual $\delta^{18} \mathrm{O}$ and $\delta \mathrm{D}$ 
peaks and causing loss of amplitude with depth. This phenomenon is well documented in both Antarctic and Greenland ice cores [Jouzel et al., 1989; Rasmussen et al., 2006; Steen-Larsen et al., 2011] and the diffusion coefficients of each of the isotopes involved have been calculated. The $\delta^{18} \mathrm{O}$ and $\delta \mathrm{D}$ signals can therefore be deconvolved or back-diffused in order to reconstruct the original signal [Johnsen, 1977; Johnsen et al., 2000]. Back-diffusion of the Mt Erebus Saddle stable isotopic record was performed to $108 \mathrm{~m}$ depth. A description of the method used and the back-diffused time series of $\delta^{18} \mathrm{O}$ and $\delta \mathrm{D}$ are provided in Appendix $\mathrm{VI}$. The back-diffused time series of $\delta^{18} \mathrm{O}$ and $\delta \mathrm{D}$ display well-defined annual peaks of a larger amplitude than the raw data. Therefore, a combination of these back-diffused time series and raw d-excess data was used to pick annual layers in the ice core to $108 \mathrm{~m}$ depth (Fig. 5.3).

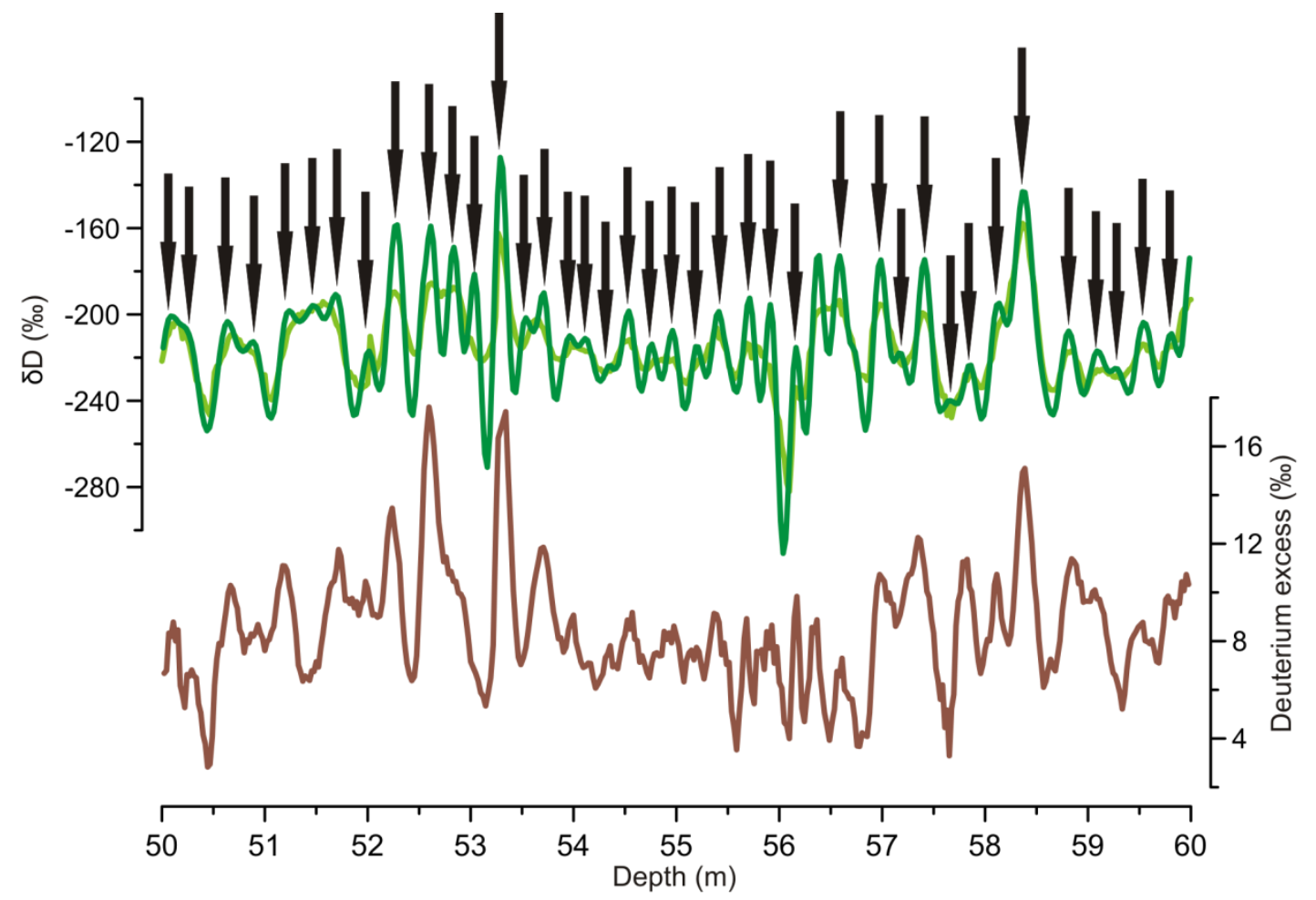

Figure 5.3: Stable isotope data for 50-60 m section of the Mt Erebus Saddle core. Both the raw $\delta \mathrm{D}$ data (light green) and back-diffused $\delta \mathrm{D}$ record (dark green) are displayed. Annual layers were identified at peaks in the back-diffused $\delta D$ record and corresponding peaks in the raw $d$-excess record (brown) were also identified to ensure peaks in the back-diffused $\delta \mathrm{D}$ record were not artifacts of processing. 
Due to time constraints back-diffused stable isotopic series were not available for annual layer counting between 108 and 120 m depth. Therefore, in order to date this section, a polynomial fit applied to the age model developed by annual layer counting was extrapolated to $120 \mathrm{~m}$.

\subsection{Bomb tritium peak}

Thermonuclear atmospheric bomb testing in the 1950s and 1960s emitted large quantities of short-lived radionuclides into Earth's atmosphere, including the radioactive hydrogen isotope, tritium ${ }^{3} \mathrm{H}$. ${ }^{3} \mathrm{H}$ was deposited worldwide and a peak in tritium levels characterises the 1964-1969 time period in Antarctic ice cores, providing a useful age marker [Oerter et al., 1999].

After the development of an initial age model via annual counting, determination of tritium contents of selected samples allowed independent verification of the annual layer counting method. Samples were taken from six sections of ice core from depths hypothesized to span the time characterised by the ${ }^{3} \mathrm{H}$ bomb peak. Tritium levels in Antarctic ice usually display a seasonal cycle that peaks in the austral winter (June to August) due to the incursion of stratospheric air masses [Jouzel et al., 1979]. Given this, each sample was taken over a depth range intended to include all four seasons of the year to remove seasonal bias. Direct measurement of ${ }^{3} \mathrm{H}$ content was conducted at the GNS Science Tritium and Water Dating Laboratory, Lower Hutt, New Zealand by ultra-low level liquid scintillation spectrometry (Quantulus ${ }^{\mathrm{TM}}$ ) in a monitored tritiumfree environment [Morgenstern and Taylor, 2009]. The results of tritium analysis display a clear ${ }^{3} \mathrm{H}$ peak (Fig. 5.4) which coincides with the ${ }^{3} \mathrm{H}$ peak measured in Antarctic and New Zealand precipitation. This validates the strategy of annual layer counting and provides an age tie point for the ice core age model. 


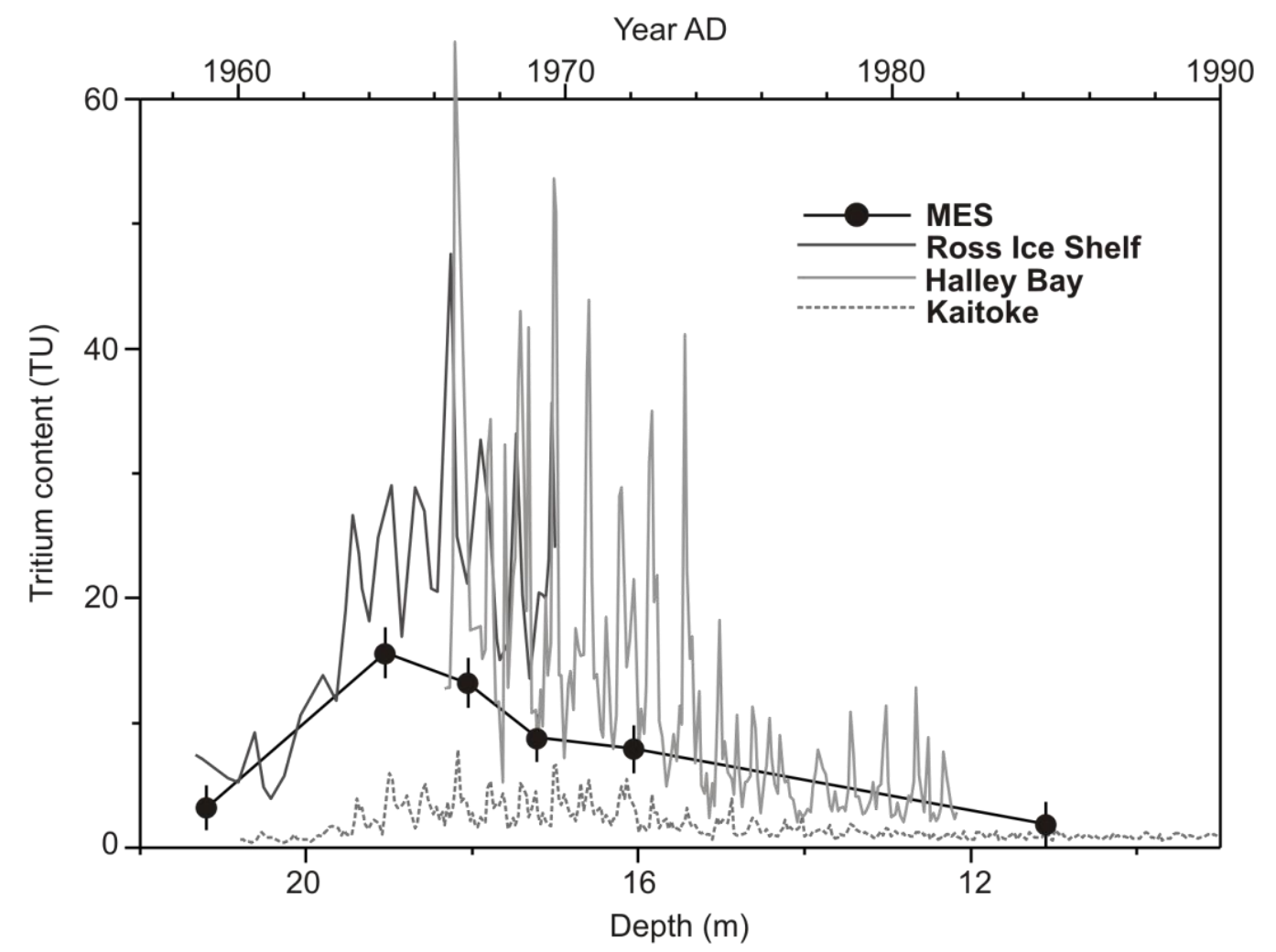

Figure 5.4: Tritium contents of six Mt Erebus Saddle ice core samples analysed (black circles) plotted with tritium contents of precipitation from the Ross Ice Shelf, Halley Bay on the Antarctic Peninsula, and Kaitoke, New Zealand, decay-corrected to December 2006 (U. Morgenstern, GNS Science, Personal communication). One tritium unit (TU) is defined as one atom of tritium per $10^{18}$ atoms of hydrogen, equivalent to 0.118 becquerels $(\mathrm{Bq})$ per litre of water. Error bars are $1 \sigma$. Raw data are provided in Appendix VII.

\subsection{Volcanic eruption markers}

The soluble chemistry of ice cores from Antarctica and Greenland can record the occurrence of historic volcanic eruptions which ejected large volumes of fine ash and gas into the stratosphere, providing useful age markers [e.g. Traufetter et al., 2004]. Sulphur dioxide that is emitted is oxidized to sulphate [Robock, 2000] and large amplitude peaks in ice core $\mathrm{nssSO}_{4}{ }^{2-}$ (Section 2.5.2) are therefore typically identified as volcanic eruption markers. However, for the Mt Erebus Saddle ice core, positive identification of $\mathrm{nsSSO}_{4}{ }^{2-}$ deposition from volcanic sources is difficult. Mt Erebus Saddle is located within $15 \mathrm{~km}$ of seasonally open water causing the $\mathrm{nssSO}_{4}{ }^{2-}$ signal to 
be dominated by biogenic nssSO ${ }_{4}{ }^{2-}$. As a result, the $\mathrm{nssSO}_{4}{ }^{2-}$ record does not exhibit isolated large amplitude peaks that can be attributed to volcanic eruptions (Fig. 5.5). This problem has been encountered in studies of other near-coastal ice cores, notably Siple Dome [Dixon et al., 2004].

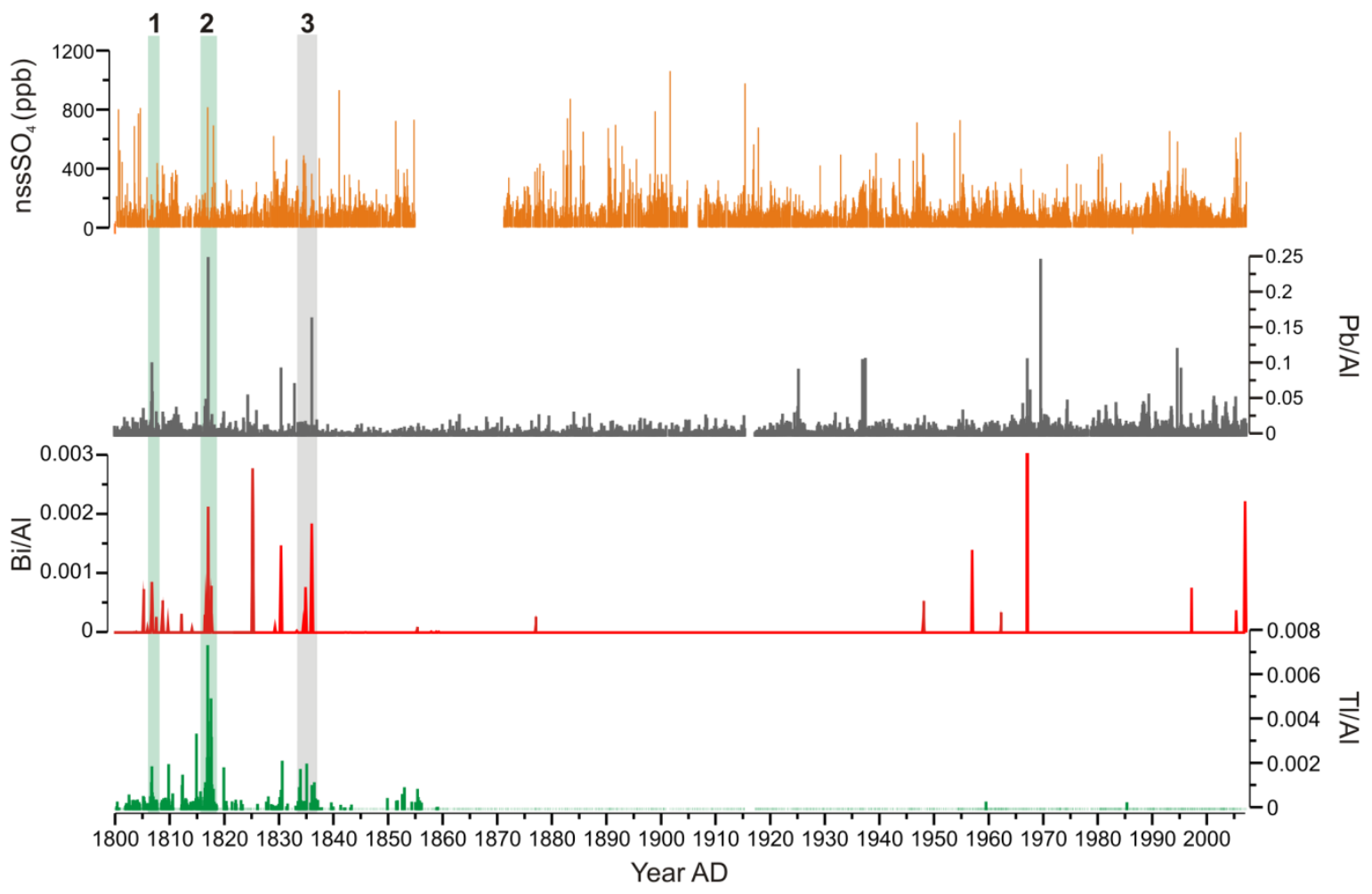

Figure 5.5: The nssSO ${ }_{4}{ }^{2-}$ concentration record and concentration ratios of $\mathrm{Pb}, \mathrm{Bi}$ and $\mathrm{Tl}$ to $\mathrm{Al}$ for the period 1800 to 2007 AD (65.5 m depth to surface). The pale green bars indicate positively identified volcanic eruptions: 1) 1809 AD \pm 2 yr unknown eruption [Traufetter et al., 2004], VEI (volcanic explosivity index) undefined, deposition year 1807 AD; 2) Tambora, Indonesia, VEI 7, eruption year 1815 AD [Simkin and Siebert, 1994]. The grey bar indicates a further possible volcanic eruption: 3) Coseguina, Nicaragua, VEI 5, eruption year 1835 AD [Simkin and Siebert, 1994].

Volcanoes may also emit heavy, volatile trace elements, such as $\mathrm{Pb}, \mathrm{Tl}$ and $\mathrm{Bi}$, in the vapour phase [Hinkley et al., 1994]. Concentrations of Bi [Kaspari et al., 2007] and TI [Kellerhals et al., 2010] enriched relative to terrestrial tracers in ice core samples have previously been used as indicators of stratospheric eruptions. $\mathrm{Pb}, \mathrm{Bi}$ and $\mathrm{TI}$ 70 
concentrations in the Mt Erebus Saddle ice core were determined by ICP-MS and are plotted in Figure 5.5 adjacent to the $\mathrm{nsSSO}_{4}{ }^{2-}$ record for comparison. Between 60.52 and $61.14 \mathrm{~m}$ depth, concentrations of $\mathrm{Pb}, \mathrm{Bi}$ and $\mathrm{Tl}$ are all strongly enriched relative to terrestrial element concentrations in at least 8 consecutive samples (Fig. 5.5, number 2). The annual layer count identifies this peak as deposition from the eruption of $\mathrm{Mt}$ Tambora of April 1815 AD. The deposition peak begins in mid-1816 AD, a similar timing to $\mathrm{nsSO}_{4}{ }^{2-}$ deposition from the eruption detected in other Antarctic ice cores [Dixon et al., 2004; Palmer et al., 2001; Stenni et al., 2002; Traufetter et al., 2004]. Furthermore, if this peak is tied to the Tambora eruption then the timing of another $\mathrm{Pb}$, $\mathrm{Bi}$ and TI peak (Fig. 5.5, number 1 ) coincides with the $1809 \pm 2 \mathrm{AD}$ eruption of an unknown volcano, which is detected in the $\mathrm{nsSSO}_{4}{ }^{2-}$ record of several Antarctic ice cores [Dixon et al., 2004; Palmer et al., 2001; Stenni et al., 2002; Traufetter et al., 2004]. The attribution of another trace element peak (Fig. 5.5 number 3 ) to the eruption of Coseguina is more uncertain because $\mathrm{Pb}, \mathrm{Bi}$ and $\mathrm{Tl}$ do not show the same enrichment pattern as each other and fewer samples are affected. This makes it less certain that the enrichments observed are due to volcanic activity. For this reason, this trace element peak is not used as a tie point in the ice core age model.

A detailed study of $\mathrm{Pb}$ isotopes and $\mathrm{Bi}$ and $\mathrm{Pb}$ concentrations across the $\mathrm{nssSO}_{4}{ }^{2-}$ peak attributed to Tambora in the Law Dome ice core found that although $\mathrm{Pb}$ and $\mathrm{Bi}$ were enriched relative to the terrestrial reference element across the $\mathrm{nssSO}_{4}{ }^{2-}$ peak, the $\mathrm{Pb}$ isotopic signatures measured were closer to that of Mt Erebus rather an Indonesian Arc volcano such as Tambora [Vallelonga et al., 2003]. As Mt Erebus Saddle is located adjacent to Mt Erebus it is plausible that the trace element record of the Mt Erebus Saddle ice core may record the eruption history of Mt Erebus rather than that of global-scale stratospheric eruptions. In order to test this hypothesis, trace element ratios measured across the suspected volcanic $\mathrm{Pb}, \mathrm{Tl}$ and $\mathrm{Bi}$ peaks were compared to trace element ratios measured in the plume of Mt Erebus (Fig. 5.6). None of the trace element ratios exhibit any marked deviation from the median value of the ice core record during the proposed 1809 and Tambora eruptions. The only possible exception is Cs/V but this deviates away from the Erebus plume value. This lends support to attribution of the $\mathrm{Bi}, \mathrm{Pb}$ and $\mathrm{TI}$ peaks at $63.2 \mathrm{~m}$ and $60.8 \mathrm{~m}$ to the 1809 eruption and 
Tambora respectively, and as a result, these peaks are used as age tie points in the age model. The most likely reason for the negligible contribution to the ice core trace element budget from Mt Erebus is the prevalence of southerly or northerly winds, which have been observed to transport the Erebus plume at altitudes $>3000 \mathrm{~m}$ for several $\mathrm{km}$ distance away from the crater [Oppenheimer et al., 2010]. Only one $2 \mathrm{~mm}$ thick tephra layer was observed in the $120 \mathrm{~m}$ of ice core at $90.2 \mathrm{~m}$ depth (1666 AD). 


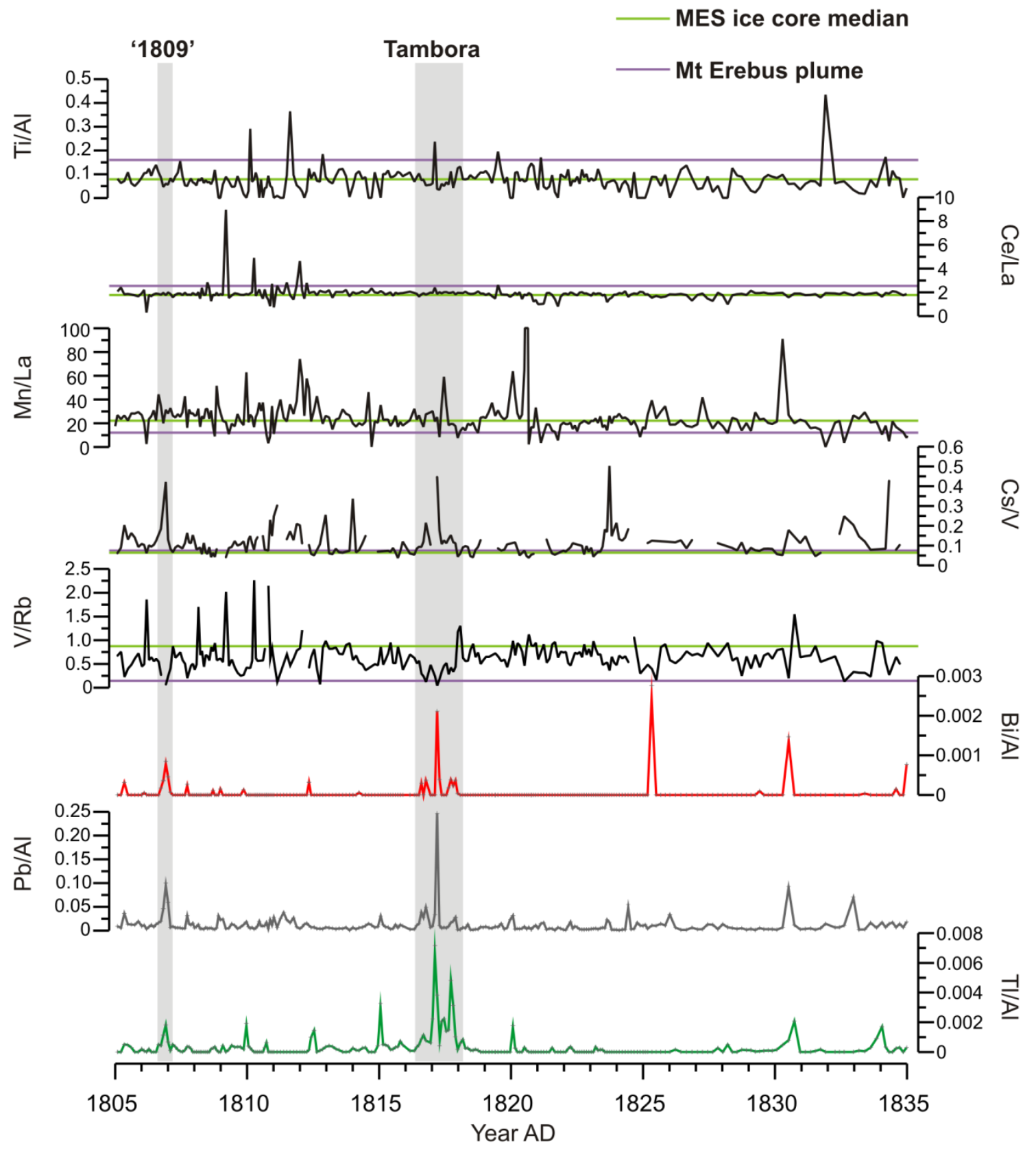

Figure 5.6: Selected trace element ratio records for the time period including the proposed $\mathbf{1 8 0 9}$ $\mathrm{AD}$ and Tambora eruption markers in $\mathrm{Bi}, \mathrm{Pb}$ and $\mathrm{Tl}$. The trace element ratios of the $\mathrm{Mt}$ Erebus plume are plotted where available [Zreda-Gostynska et al., 1997] and the median values for the entire Mt Erebus Saddle record are shown. Breaks in the record occur where the concentration of an element is below the ICP-MS detection limit. 


\subsection{Density and accumulation rate}

Density is an important parameter measured in ice cores because it allows sample depth to be related to snow accumulation. The density of each metre-length core section was calculated by assuming a core radius of $5 \mathrm{~cm}$ and a core length of $100 \mathrm{~cm}$ according to the equation:

Density $\left(\mathrm{g} \mathrm{cm}^{-3}\right)=$ mass of core section $(\mathrm{g}) /\left(\right.$ core radius $(\mathrm{cm})^{\wedge} 2 * \pi *$ core length $\left.(\mathrm{cm})\right)$

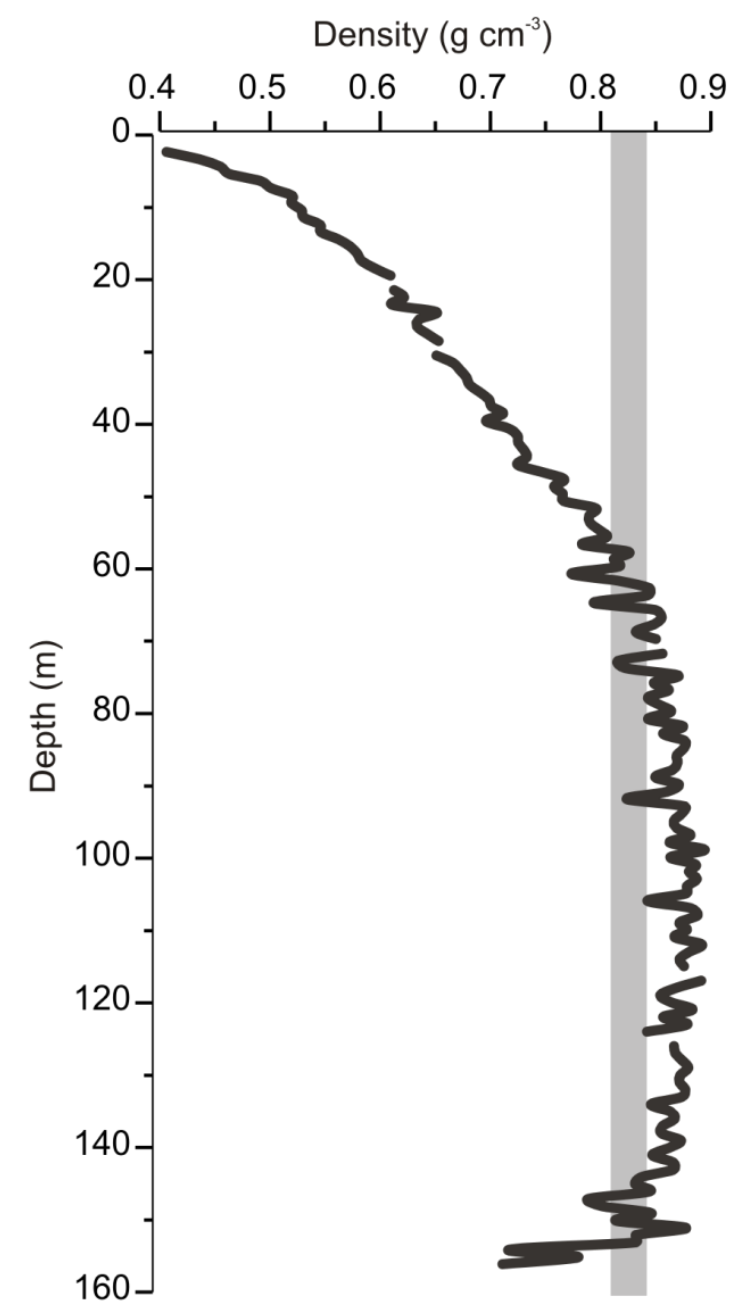

Figure 5.7: Density profile of the Mt Erebus Saddle ice core. Grey bar indicates the density range of the firn-ice transition (0.81-0.84 $\left.\mathrm{g} \mathrm{cm}^{-3}\right)$, as defined by Bender et al. [1997]. The apparent decrease in density after $\mathbf{1 2 0} \mathrm{m}$ depth is the result of poor core quality which reduces the actual core volume. Data are provided in Appendix VIII. 
Density increases with depth, reflecting the compaction of snow into firn and then into ice (Fig. 5.7). The firn-ice transition, the depth at which air bubbles are closed off to the atmosphere, is located around 60-67 m depth.

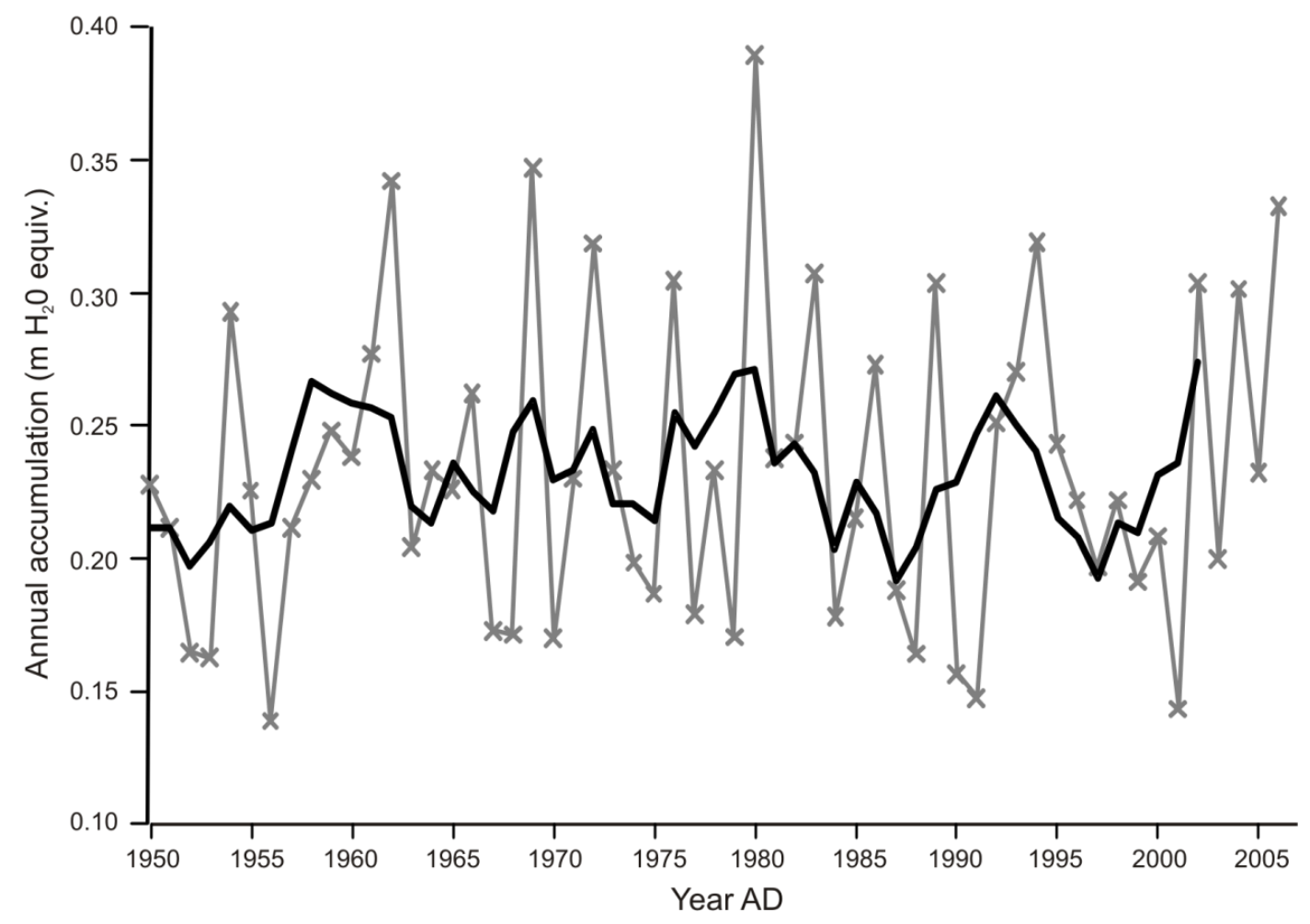

Figure 5.8: Annual accumulation rates of the Mt Erebus Saddle ice core (grey line) between 1950 and 2006 AD. Thick black line is the 5-year moving average.

Density is used to calculate accumulation rates in $\mathrm{m}\left(\mathrm{H}_{2} \mathrm{O}\right.$ equivalent) $\mathrm{yr}^{-1}$ which allows accumulation rates from sections of core with different densities to be compared. A 1 $\mathrm{m}$ depth section of $10 \mathrm{~cm}$ diameter ice core with a density of $0.42 \mathrm{~g} \mathrm{~cm}^{-3}$ is equivalent to a $10 \mathrm{~cm}$ diameter cylinder of water that has a depth of $0.42 \mathrm{~m}$. The annual accumulation rates calculated for 1950 to 2006 AD are displayed in Figure 5.8. The density profile and accumulation rate are parameters that must be included in the back-diffusion model (Appendix VI) and glacial flow model (Appendix V) used to model the age-depth profile of the core. The annual accumulation profile prior to 1950 AD 
has not yet been established as the layer thickness needs to be corrected for layer thinning caused by ice flow.

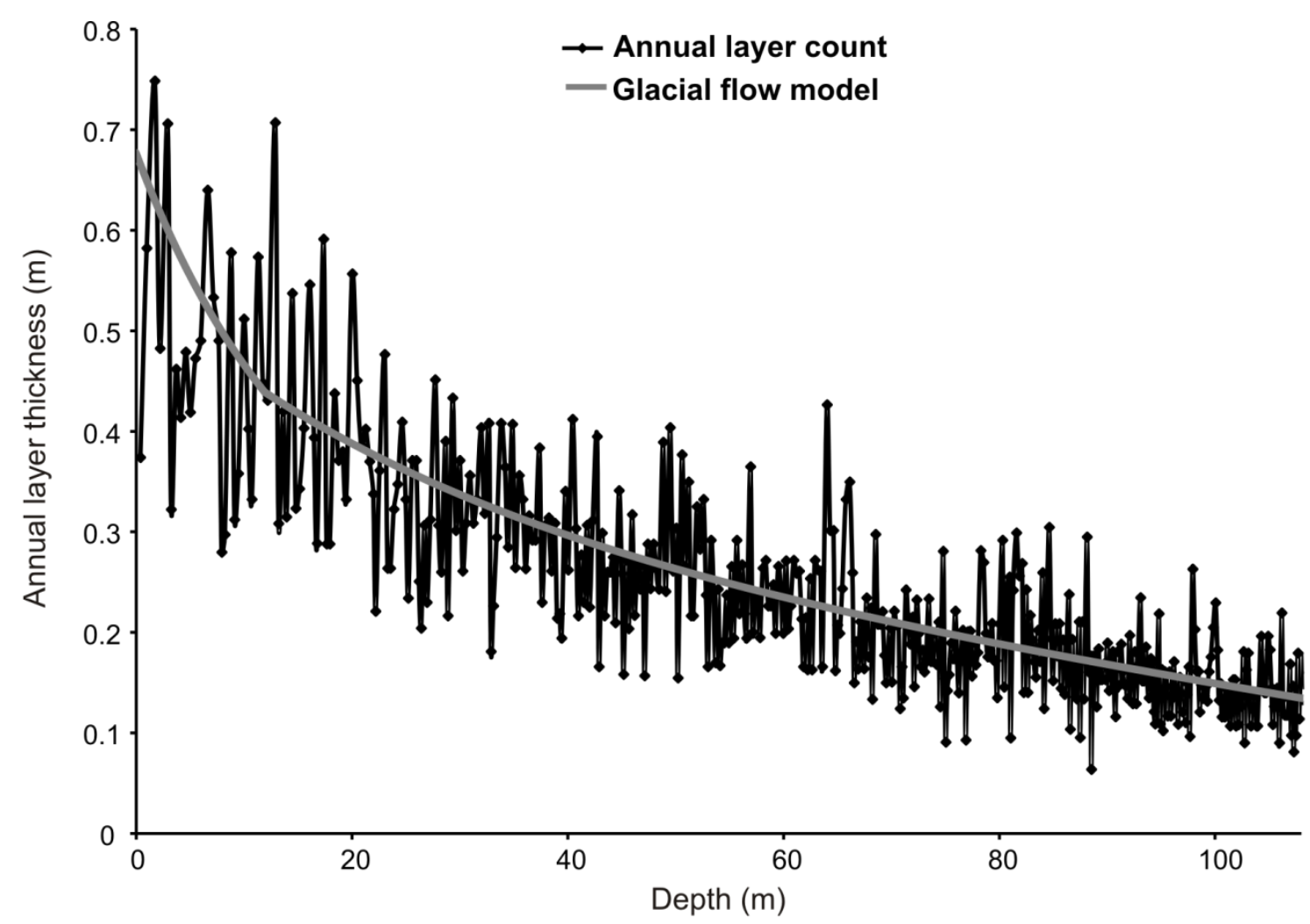

Figure 5.9: Relationship between annual layer thickness and core depth for the age models produced by annual layer counting and the glacial flow model. 


\subsection{Assesment of dating error}

A total of 561 annual layers are identified in the $120 \mathrm{~m}$ of core analysed. The incremental error on the dating of individual years or the duration of discrete time periods is $\pm 1 \mathrm{yr}$ between the surface and $61.1 \mathrm{~m}$ (1816 AD), the depth of the Mt Tambora eruption marker. The cumulative dating error, which is the difference between the age of the reference marker and the initial age indicated by the annual layer count is $\pm 1 \mathrm{yr}$ at $1964 \mathrm{AD}\left({ }^{3} \mathrm{H}\right.$ peak) and $\pm 9 \mathrm{yr}$ at $61.1 \mathrm{~m}$ (Mt Tambora). The dating uncertainty on the record below $61.1 \mathrm{~m}$ depth is difficult to constrain because no further age reference markers are identifiable.

A glacial flow model, developed by Dansgaard and Johnsen [1969], was used to model the age of the ice core as a function of depth (Appendix V). Outputs from the model are used in the back-diffusion of stable isotopic data (Appendix VI) so the flow model and the annual layer count are not independent assessments of the age-depth evolution. However, it is encouraging that the age model produced by annual layer counting shows excellent agreement with the glacial flow model (Fig. 5.10). 
Year A.D.

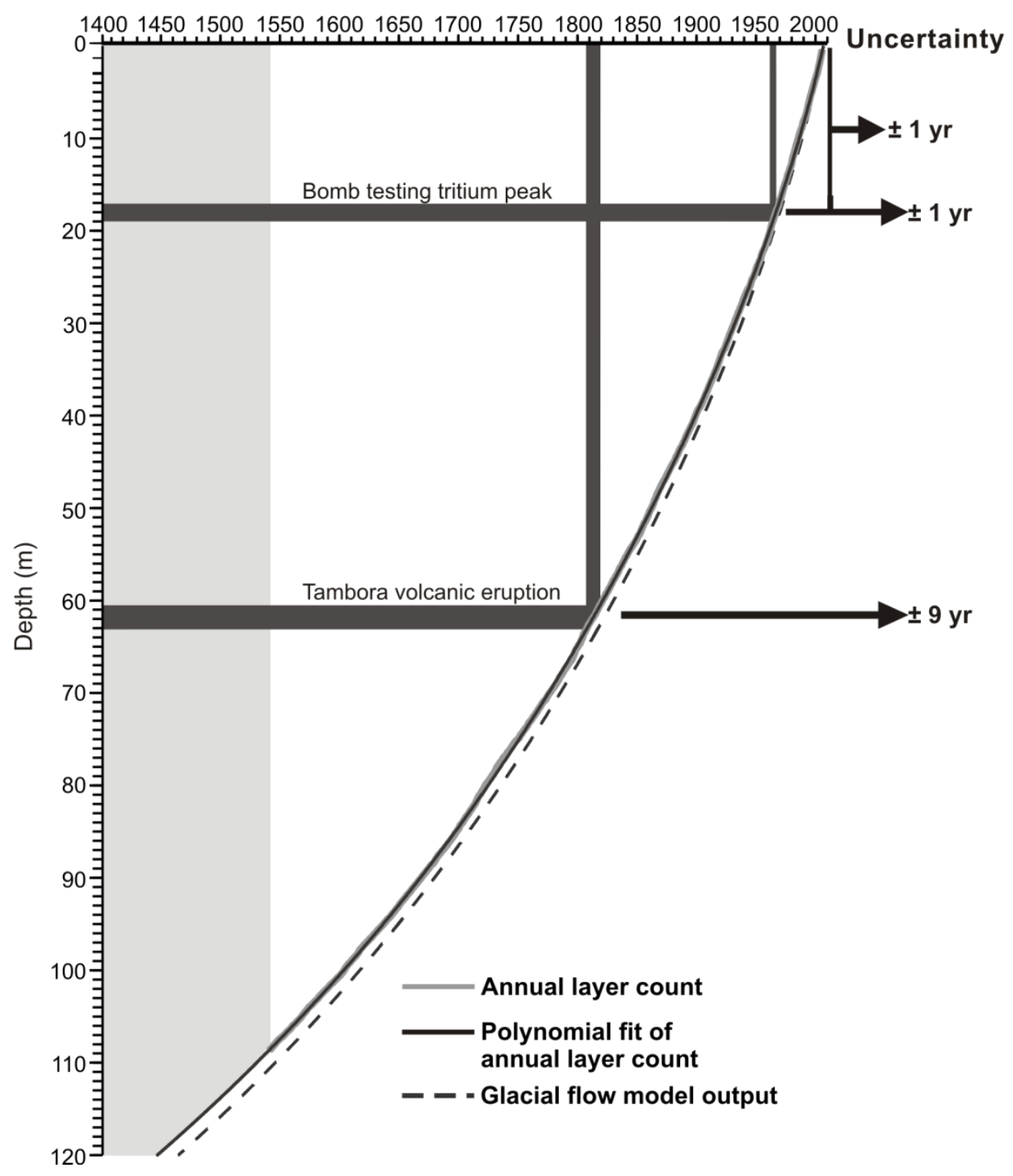

Figure 5.10: Age-depth relationship of the Mt Erebus Saddle ice core age model compared to the glacial flow model output. Age tie points used in the development of the age model are shown (dark grey bars). The section of core below $108 \mathrm{~m}$ depth (pale grey shading) was dated by extrapolation of the age model. 


\title{
Chapter 6: Experimental investigation of the effects of mineral dust on the reproducibility and accuracy of ice core trace element analyses
}

This chapter constitutes a paper accepted for publication in Chemical Geology (Section 1.6). Supplementary data tables are located in Appendix IX.

\begin{abstract}
Determination of trace element concentrations by inductively coupled plasma mass spectrometry (ICP-MS) can yield valuable information about paleoclimate from ice core records. Typically, ICP-MS analyses are performed on melted and acidified ice core samples which contain particulate material i.e., mineral dust. This particulate material is usually enriched in trace elements relative to ice core samples. Consequently, it is important to constrain the effect of acidification on mineral dust present in ice core samples and to assess the contribution of dust leaching to the trace element budget of ice cores.
\end{abstract}

We have conducted a systematic experimental investigation designed to replicate the conditions of conventional ice core trace element analyses. Powdered rock standards of various lithologies were leached in $1 \mathrm{wt} . \% \mathrm{HNO}_{3}$ and the leachates were sampled at regular time intervals. Oxides and sheet silicate minerals, in the ferromanganese nodule (Nod-P-1) and granite (JG-2) leachates respectively, released available trace elements into solution relatively quickly; trace element recovery reached $57 \%$ for $\mathrm{Mg}$ and $42 \%$ for $\mathrm{Mn}$ in the granite leachate and recoveries between 60 and $80 \%$ were reached for most elements in the ferromanganese nodule leachate after only $12 \mathrm{hr}$ of leaching. In contrast, mafic minerals in the basalt (BHVO-2) and dolerite (W-2) released trace elements slowly, achieving recoveries of $<20 \%$ for elements from Li to $\mathrm{Mn}$ after $12 \mathrm{hr}$ of leaching. The mafic minerals continued to release trace elements into solution over several weeks causing Al and Ti concentration increases $>4000 \%$. 
These results demonstrate that acidification of ice core samples containing mineral dust will cause time- and mineral-dependent leaching of trace elements. Leaching behaviour of trace elements remained constant with varying mineral dust concentration but freezing pre-acidified samples was found to promote leaching of some trace elements. Ideally, all ice core samples would be fully digested or filtered to eliminate the error introduced by partial dissolution of dust but this is time-consuming and impractical. We therefore recommend acidifying samples for as long as practical to reach a maximum leachable concentration. For datasets obtained by conventional methods, Al is identified as the most suitable element to use as a terrestrial tracer because it is leached to a uniform extent across all lithologies. Fundamental flaws are identified in the calculation of crustal enrichment factors which are likely to cause some elements to appear enriched as a result of incongruent leaching. Ratios of trace elements, in particular rare earth elements (REEs), leached from mineral dust will not reflect those of the dust and are not suitable as tracers of dust provenance. 


\subsection{Introduction}

Ice cores provide continuous, high-resolution records of past atmospheric and environmental conditions [e.g., Fischer et al., 2007]. Increasingly, conventional stable isotope and major ion analyses of ice cores are being complimented by determination of trace elements by inductively coupled plasma mass spectrometry (ICP-MS) [Barbante et al., 1997; Gabrielli et al., 2006; Planchon et al., 2001; Purdie et al., 2010]. The typical method of ICP-MS analysis involves analysing melted, acidified, ice core samples that have not been filtered or centrifuged to remove particulates [e.g. Barbante et al., 1997].

Sample acidification is a prerequisite for ICP-MS analysis of solutions but when particulates are present in the sample solution, acidification can cause particulate dissolution. The principal inorganic constituents of ice core samples are marine salts, and mineral dusts and whilst marine salts are readily soluble, mineral dusts are relatively insoluble. However, once the sample is acidified, typically to 1 wt.\% $\mathrm{HNO}_{3}$, trace elements can be leached, at least partially, from the mineral dust particles into solution. ICP-MS determinations of trace elements in ice core samples therefore do not solely measure the soluble chemical constituents but also an additional component resulting from the partial dissolution of mineral dust.

This has implications for understanding the trace element budget of ice cores because the contribution of mineral dust leaching to measured trace element concentrations in ice core samples has not been quantified previously and very little is known about how the leaching process varies for different trace elements, minerals or lithologies [Snäll and Liljefors, 2000]. Silicate minerals such as feldspars, clays and pyroxenes, which are commonly found in ice cores [Ayling and McGowan, 2006; Gaudichet et al., 1988], will only undergo partial dissolution because silicate mineral lattices can withstand $1 \mathrm{wt} . \%$ $\mathrm{HNO}_{3}$ solutions [Günzler and Williams, 2001]. Therefore, interpretation of ICP-MS data would be aided by an understanding of incongruent leaching i.e., which elements are leached in preference to others and whether the pattern is consistent between dust with different mineralogies. 
There are several further factors which may affect the extent and rate of mineral dust dissolution in an acidified ice core sample, thereby introducing uncertainty concerning the reproducibility and accuracy of trace element concentrations determined by ICPMS. The most important of these factors is the length of time that samples are acidified prior to analysis. Previous ICP-MS analysis of snow pit samples has shown that replicate analyses of the same sample measured at different time intervals can lead to trace element concentration increases of greater than $100 \%$ [Bull, 2009].

A further source of uncertainty in ice core trace element determinations lies in the uptake and incomplete ionisation of dust particles from within unfiltered ice core samples [Bull, 2009; Vallelonga et al., 2004]. The extent to which this occurs and its effect on signal intensity [Hobbs and Olesik, 1993] requires further investigation that is beyond the scope of this paper.

This study presents a systematic experimental investigation into the influence of partial dissolution of mineral dust particles on the reproducibility of trace element determinations in ice core samples. Leaching experiments were carried out on geochemically well-characterised, powdered international rock standards in 1 wt.\% $\mathrm{HNO}_{3}$ to examine how trace element measurements vary depending on the length of the acidification time, whether samples were frozen after acidification or not and variable dust lithologies and concentrations. These findings allow us make several recommendations for future ice core ICP-MS trace element studies and interpretation of ice core trace element data. 


\subsection{ICP-MS trace element analysis of ice cores}

The length of time that ice core samples are acidified prior to analysis varies widely between published studies of conventional ICP-MS trace element analyses (Table 6.1). It is typically $24 \mathrm{hr}$, but in many cases the length of time is not stated by the authors. The effects that resulting variable levels of mineral dust dissolution may have on the reproducibility of ICP-MS measurements ultimately limits the comparability of trace element records from different ice cores. Even if one specific acidification time is chosen, implemented and reported, the nature of ICP-MS analysis requires samples to be analysed in runs that can be $>12 \mathrm{hr}$ in length, causing the first sample to have experienced a considerably shorter acidification time than the final sample. An acidification time of $>3$ months was adopted by Townsend and Edwards [1998] because unpublished tests on ice core samples found the maximum leachable concentration of Fe was reached at this time, allowing all samples measured to be free of time-dependent leaching effects.

Trace element concentrations in ice cores can also be determined using coupled ice core melter and ICP-MS analysis systems where acidification occurs directly prior to analysis [Knusel et al., 2003; McConnell et al., 2002]. Many lithophile elements (e.g. Al and REEs) record significantly lower concentrations when analysed in this way compared to conventional methods [Knusel et al., 2003]. This is presumably because any mineral dust present in the sample is only exposed to acid for a short length of time, thereby minimising trace element leaching.

The type and molarity of acid used to acidify samples is also likely to affect the rate of which leaching occurs and also varies between published studies (Table 6.1). In some cases, samples from the same location were acidified to different strengths [Krachler et al., 2004; Krachler et al., 2005; Tao et al., 2001], creating a source of uncertainty for comparison of ice core trace element records. 
Table 6.1: Summary of sample preparation and storage procedures utilised in previously published ice core ICP-MS trace element studies.

\begin{tabular}{|c|c|c|c|c|c|}
\hline Reference & $\begin{array}{l}\text { Sampling } \\
\text { location }\end{array}$ & $\begin{array}{l}\text { Targeted } \\
\text { species }\end{array}$ & $\begin{array}{l}\text { Refrozen } \\
\text { after acid } \\
\text { addition? }\end{array}$ & $\begin{array}{l}\text { Acidification } \\
\text { used }\end{array}$ & Acidification time \\
\hline Barbante et al. [1997] & $\begin{array}{l}\text { Greenland and } \\
\text { Victoria Land, }\end{array}$ & $\begin{array}{l}\text { Heavy } \\
\text { metals }\end{array}$ & $\bar{Y}$ & 0.34 wt.\% $\mathrm{HNO}_{3}$ & Not stated \\
\hline $\begin{array}{l}\text { Townsend and Edwards } \\
\text { [1998] }\end{array}$ & Law Dome; & $\begin{array}{l}\text { Trace } \\
\text { elements }\end{array}$ & N & $0.1 \mathrm{M} \mathrm{HCl}^{\mathrm{a}}$ & $>3$ months \\
\hline Barbante et al. [1999] ${ }^{\mathrm{b}}$ & European Alps & $\begin{array}{l}\text { Trace } \\
\text { elements }\end{array}$ & N & 0.34 wt. $\% \mathrm{HNO}_{3}$ & Measured 'just after' acidification \\
\hline Planchon et al. [2001] ${ }^{\mathrm{b}}$ & $\begin{array}{l}\text { Coats Land, } \\
\text { Antarctica }\end{array}$ & $\begin{array}{l}\text { Heavy } \\
\text { metals }\end{array}$ & Y & 1 wt. $\% \mathrm{HNO}_{3}$ & Not stated \\
\hline Tao et al. [2001] & $\begin{array}{l}\text { Devon Ice Cap, } \\
\text { Canadian Arctic }\end{array}$ & $\begin{array}{l}\text { Heavy } \\
\text { metals }\end{array}$ & Y & $\mathrm{pH} 1.6 \mathrm{HNO}_{3}$ & Not stated \\
\hline Krachler et al. [2004] & $\begin{array}{l}\text { Devon Ice Cap, } \\
\text { Canadian Arctic }\end{array}$ & $\begin{array}{l}\text { Trace } \\
\text { elements }\end{array}$ & Y & $\mathrm{pH} 1.2 \mathrm{HNO}_{3}$ & Not stated \\
\hline Gabrielli et al. [2005a] & $\begin{array}{l}\text { EPICA Dome C, } \\
\text { Antarctica }\end{array}$ & $\begin{array}{l}\text { Trace } \\
\text { elements }\end{array}$ & $\mathrm{Y}$ & $\mathrm{pH} 1 \mathrm{HNO}_{3}$ & Not stated \\
\hline Gabrielli et al. [2005b] & Vostok, Antarctica & $\begin{array}{l}\text { Trace } \\
\text { elements }\end{array}$ & N & $\mathrm{pH} 1 \mathrm{HNO}_{3}$ & $>24 \mathrm{hr}$ \\
\hline Krachler et al. [2005] & $\begin{array}{l}\text { Devon Ice Cap, } \\
\text { Canadian Arctic }\end{array}$ & $\begin{array}{l}\text { Trace } \\
\text { elements }\end{array}$ & Y & 0.5 wt. $\% \mathrm{HNO}_{3}$ & $\sim 24 \mathrm{hr}$ \\
\hline Gabrielli et al.[2006] & European Alps & $\begin{array}{l}\text { Trace } \\
\text { elements }\end{array}$ & Not stated & 2 wt. $\% \mathrm{HNO}_{3}$ & Not stated \\
\hline Gaspari et al. [2006] ${ }^{\mathrm{b}}$ & $\begin{array}{l}\text { EPICA Dome C, } \\
\text { Antarctica }\end{array}$ & $\mathrm{Fe}$ & N & $\mathrm{pH} 1 \mathrm{HNO}_{3}$ & $>24 \mathrm{hr}$ \\
\hline Osterberg et al. [2006] ${ }^{\mathrm{b}}$ & $\begin{array}{l}\text { Mt Logan, Yukon, } \\
\text { Canada }\end{array}$ & $\begin{array}{l}\text { Trace } \\
\text { elements }\end{array}$ & Y & 1 wt.\% $\mathrm{HNO}_{3}$ & $24 \mathrm{hr}$ before freezing. \\
\hline Marteel et al. [2008] & $\begin{array}{l}\text { EPICA Dome C, } \\
\text { Antarctica }\end{array}$ & $\begin{array}{l}\text { Heavy } \\
\text { metals }\end{array}$ & $\mathrm{Y}$ & 1 wt. $\% \mathrm{HNO}_{3}$ & Not stated \\
\hline Marteel et al.[2009] & $\begin{array}{l}\text { EPICA Dome C, } \\
\text { Antarctica }\end{array}$ & $\begin{array}{l}\text { Trace } \\
\text { elements }\end{array}$ & Y & Not stated & Not stated \\
\hline Kaspari et al. [2009] & Mt Everest, Himalyas & $\begin{array}{l}\mathrm{Bi}, \mathrm{U}, \mathrm{Cs}, \mathrm{S} \\
\mathrm{Ca}\end{array}$ & Y & 1 wt. $\% \mathrm{HNO}_{3}$ & $\begin{array}{l}7 \mathrm{~d} \text { before freezing; time after } \\
\text { defrosting not stated }\end{array}$ \\
\hline Gabrielli et al. [2010] & $\begin{array}{l}\text { EPICA Dome C, } \\
\text { Antarctica }\end{array}$ & REES & Not stated & $\mathrm{pH} 1 \mathrm{HNO}_{3}$ & Not stated \\
\hline Purdie et al. [2010) & Southern Alps, & $\begin{array}{l}\text { Trace } \\
\text { elements }\end{array}$ & $\mathrm{N}$ & $1 \mathrm{wt} . \% \mathrm{HNO}_{3}$ & Not stated \\
\hline
\end{tabular}

The studies listed in Table 6.1 also vary widely in their approach to sample storage. It is generally accepted that ice core samples should be stored frozen prior to analysis, however samples were acidified before being refrozen in several studies. This could cause increased leaching of the mineral dust because when freezing takes place, dense acid sinks to the bottom of the vial where mineral dust is also located, causing the mineral dust to be exposed to more concentrated acid whilst freezing takes place. 


\subsection{Experiment design}

\subsubsection{Overview}

In order to replicate the partial dissolution of mineral dust in acidified ice core samples, small amounts of powdered international rock standards were leached in $1 \mathrm{wt} . \% \mathrm{HNO}_{3}$. Leachates were removed at selected times, and are considered to be analogous to ice core samples containing mineral dust which are acidified for different lengths of time prior to analysis. The use of rock standards for which bulk trace element concentrations are well characterised facilitates accurate measurement of the degree to which elements are leached from these standards as analogues of mineral dust.

Two experiments were conducted. The first tested how leachate composition changed with acidification time, dust lithology (rock standard type) and dust concentration. The second examined whether freezing samples after acidification affected leachate compositions.

\subsubsection{Rock standards}

The following four rock standards were selected to compare the leaching behaviour of different lithologies: BHVO-2 (Hawaiian Basalt, USGS); W-2 (Centerville Diabase, USGS); Nod-P-1 (Manganese Nodule, USGS) and JG-2 (Granite, Geological Survey of Japan). BHVO-2 is basalt comprised of clinopyroxene and plagioclase feldspar with minor amounts of magnetite. $\mathrm{W}-2$ is a diabase or a dolerite, comprised of plagioclase feldspar, clinopyroxene with minor amounts of muscovite mica, quartz, and opaque minerals (S. A. Wilson, USGS, Personal communication). JG-2 is a biotite-rich granite [Ando et al., 1989] and Nod-P-1 is a Pacific Ocean ferromanganese nodule which is 70\% Fe-Mn oxyhydroxide mineral phases and $30 \%$ quartz and plagioclase feldspar (S. A. Wilson, USGS, Personal communication). 


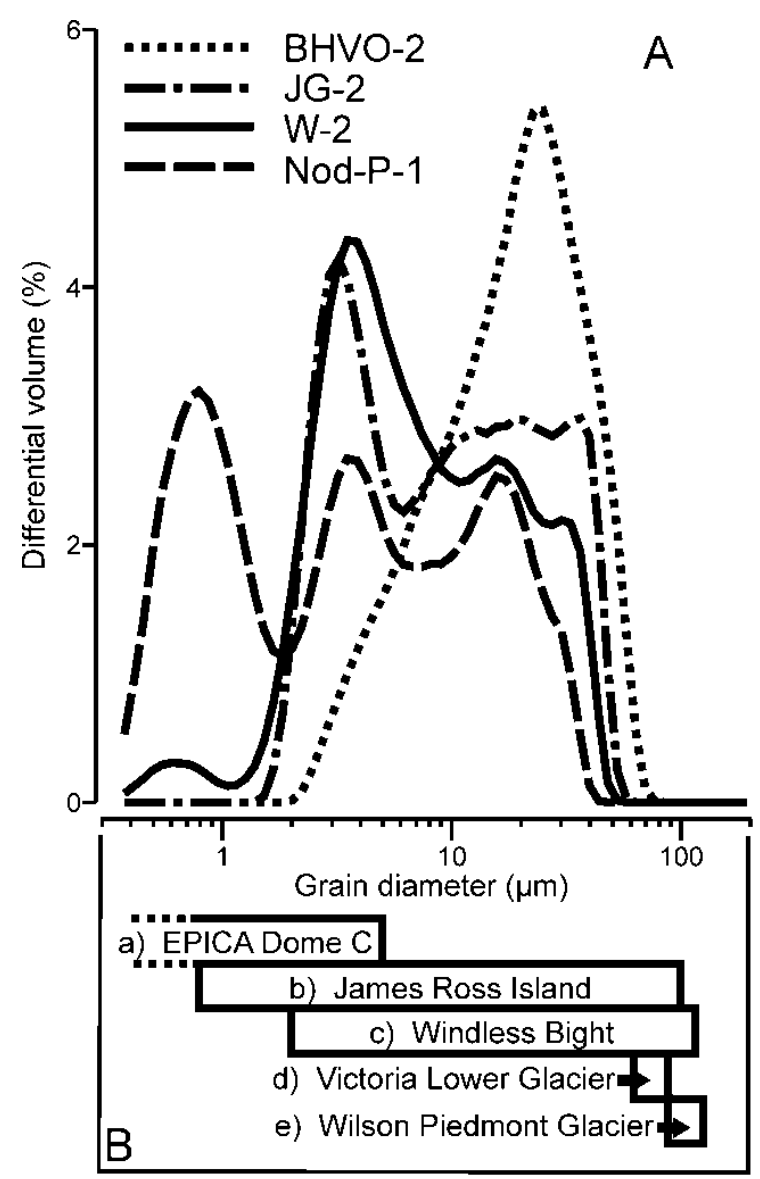

Figure 6.1: A) Grain size distributions of BHVO-2, JG-2, W-2 and Nod-P-1 measured by laser particle counter. B) Horizontal bars indicate grain size ranges recorded at various Antarctic sites:

a) EPICA Dome C [Delmonte et al., 2004] is located in East Antarctica, b) James Ross Island [McConnell et al., 2007] is near the Antarctic Peninsula, c) Windless Bight [Dunbar et al., 2009] is directly south of Ross Island, d \& e) Victoria Lower Glacier and Wilson Piedmont Glacier [Ayling and McGowan, 2006] are both in the McMurdo Dry Valleys.

These rock standards encompass a range of textures and mineralogies and contain minerals commonly found in ice core dust [Ayling and McGowan, 2006; Gaudichet et al., 1988]. The rock standard lithologies are also comparable to those exposed in the McMurdo Dry Valleys, Antarctica, where the New Zealand contribution to the International Trans-Antarctic Scientific Expedition focuses its snow pit and ice core sampling [Mayewski et al., 2005]. Nod-P-1 was selected because its predominantly Fe$\mathrm{Mn}$ oxyhydroxide mineralogy is similar to Fe-Mn oxides coatings on many aeolian particles [Post, 1999] and to desert varnish [Bauman, 1976], which coats the surface of 
a significant proportion of exposed rocks in the McMurdo Dry Valleys region [Bockheim, 2010].

The grain size distributions of the four rock standards, measured by laser particle counter (Beckman Coulter LS13 320), encompass the grain size range between $<1 \mu \mathrm{m}$ to $>80 \mu \mathrm{m}$ measured on ice core dust material (Fig. 6.1). As the grain size distributions vary between the four rock standards, the influence of grain size on the leaching process [Snäll and Liljefors, 2000] is also considered in the interpretation of our results.

\subsubsection{Dust concentrations}

Construction of a representative experiment necessitated that the powdered rock standards were leached at dust concentrations equivalent to those reported in ice core samples. The dust concentration of ice cores varies widely depending on geographical location and proximity to local dust sources. Ice cores from the interior of the Antarctic continent have dust concentrations as low as $0.015 \mathrm{ppm}$ in the Holocene and $0.65 \mathrm{ppm}$ in the last glacial period [Delmonte et al., 2004]. Where sources of aeolian dust are proximal, such as at ice core sites adjacent to the McMurdo Dry Valleys, Antarctica, maximum dust concentrations of between 470 ppm and 1900 ppm have been recorded [Ayling and McGowan, 2006]. Dust concentrations in South American ice cores range from $0.16 \mathrm{ppm}$ [Thompson et al., 1995] to $8.5 \mathrm{ppm}$ [Ramirez et al., 2003] and values as high as 243 ppm have been reported in northern China [Wu et al., 2009]. A dust concentration of $10 \mathrm{ppm}$, equivalent to that of Greenland ice cores from the Last Glacial Maximum [Ruth et al., 2003] was selected for this investigation because this mass of rock standard ( $5 \mathrm{mg}$ ) could be weighed precisely.

To test the effect of varying the starting dust concentration on leachate composition, rock standard W-2 was also leached at concentrations of $50 \mathrm{ppm}$ and $500 \mathrm{ppm}$. W-2 was selected because it has a broad grain size distribution (Fig. 6.1) and, unlike Nod-P1 , has a predominantly silicate mineralogy. 


\subsubsection{Leachate sampling}

Each of the four rock standards at dust concentrations of $10 \mathrm{ppm}$ and the two additional dust concentrations of $\mathrm{W}-2$ were leached with $1 \mathrm{wt} . \% \mathrm{HNO}_{3}$ (Seastar) in precleaned Teflon (PFA) bottles in a temperature-controlled, Class 100 clean room. The required mass of each rock standard was weighed precisely using an ultra microbalance (Mettler Toledo UMX2) and carefully added to each bottle. The actual dust concentration in the experiments was accurate to $< \pm 1 \%$. The time at which the weighed rock powder was added to each bottle was recorded and each bottle was immediately shaken for $30 \mathrm{~s}$ to mix the rock standard and acid.

Samples of the leachate were extracted at the following times after addition of the rock standard: $10 \mathrm{~min}, 1 \mathrm{hr}, 2 \mathrm{hr}, 4 \mathrm{hr}, 8 \mathrm{hr}, 12 \mathrm{hr}, 24 \mathrm{hr}, 36 \mathrm{hr}, 48 \mathrm{hr}, 72 \mathrm{hr}, 3 \mathrm{~d}, 5 \mathrm{~d}$, and $7 \mathrm{~d}$, followed by weekly to fortnightly sampling. Ten minutes prior to sampling, each bottle was shaken for $10 \mathrm{~s}$ to redistribute elements within solution. $7 \mathrm{~mL}$ of leachate was then pipetted from the top of each bottle into acid-cleaned vials. These leachate samples were then centrifuged for $5 \mathrm{~min}$ at $1000 \mathrm{rpm}$ to remove any remaining particles of rock standard and $5 \mathrm{~mL}$ of supernatant was pipetted off each into further acid-cleaned vials. After sampling, $7 \mathrm{~mL}$ of $1 \mathrm{wt} . \% \mathrm{HNO}_{3}$ was added to each bottle to replace the volume of leachate extracted, thus keeping the dust concentration effectively constant. All leachate samples were stored at room temperature before analysis to avoid any effects of freezing. Duplicate leachate samples taken at several sampling times showed a median concentration difference of 1.4\% across all elements and confirm the reproducibility of the leachate sampling method (Appendix IX, Tables A18 to A22). 


\subsubsection{Freezing test}

To quantify the effect of freezing pre-acidified samples on leachate composition, small amounts of rock standard powder were frozen in either $1 \mathrm{wt} . \% \mathrm{HNO}_{3}$ or ultra-pure water (> 18.2 M $\Omega$ ). Solutions were frozen in acid-cleaned vials and stored upright to replicate the conditions in which ice core samples are normally refrozen. $0.5 \mathrm{mg}$ of BHVO-2 was added to three vials containing $8 \mathrm{~mL}$ of $1 \mathrm{wt} . \% \mathrm{HNO}_{3}$ and three vials containing $8 \mathrm{~mL}$ of ultra-pure water. This experiment was repeated for JG-2. All 12 vials were then shaken and frozen for at least $48 \mathrm{hr}$. Once thawed, the ultra-pure water samples were acidified to $1 \mathrm{wt} . \% \mathrm{HNO}_{3}$ and all the vials were shaken to homogenise the sample again. Simultaneously, six fresh vials were made up containing the same concentration of BHVO-2 (3 vials) or JG-2 (3 vials) in 1 wt.\% $\mathrm{HNO}_{3}$. These vials acted as control samples and provided a means of testing whether the physical process of freezing itself had any effect on the concentrations leached from the mineral dust. The masses of both of the rock standard and the solution in each of the vials were weighed precisely and dust concentrations in the 18 sample vials ranged between $62 \mathrm{ppm}$ and $65 \mathrm{ppm}$. All samples were allowed to undergo dissolution for 12 $\mathrm{hr}$ at room temperature and then centrifuged and sampled as previously described (Section 6.3.4). Several additional vials containing only ultra-pure water or $1 \mathrm{wt} . \%$ $\mathrm{HNO}_{3}$ were frozen and sampled in the same manner to act as procedural blanks (Appendix IX, Table A26). 


\subsection{Analytical procedures}

\subsubsection{Hardware and operating conditions}

The leachate samples were analysed for concentrations of 29 elements ( $\mathrm{Li}, \mathrm{Na}, \mathrm{Mg}, \mathrm{Al}$, $\mathrm{Ca}, \mathrm{Ti}, \mathrm{V}, \mathrm{Cr}, \mathrm{Mn}, \mathrm{Cu}, \mathrm{Zn}, \mathrm{As}, \mathrm{Rb}, \mathrm{Sr}, \mathrm{Y}, \mathrm{Zr}, \mathrm{Cs}, \mathrm{Ba}, \mathrm{La}, \mathrm{Ce}, \mathrm{Pr}, \mathrm{Gd}, \mathrm{Er}, \mathrm{Yb}, \mathrm{Tl}, \mathrm{Pb}, \mathrm{Bi}, \mathrm{Th}, \mathrm{U})$ by ICP-MS (Agilent 7500cs Series). An ASX-520 micro-volume autosampler linked to the ICP-MS was used to introduce samples into the Teflon (PFA) nebuliser $(0.1 \mathrm{~mL} / \mathrm{min}$ flow rate) via a peristaltic pump. The ICP-MS operating conditions are given in Table 6.2. Tuning parameters were optimised to obtain high sensitivity across the mass range. The mass ratio ${ }^{156} \mathrm{CeO} /{ }^{140} \mathrm{Ce}$ was monitored and tuning parameters adjusted to maintain a level of cerium oxide formation below $2 \%$. Prior to analysis, the Ni sampling and skimmer cones were cleaned and the sample introduction system was aspirated with 5 wt.\% $\mathrm{HNO}_{3}$ for $1 \mathrm{hr}$ to reduce any possible memory effects from previous sample media.

Table 6.2: ICP-MS operating conditions and data acquisition parameters.

\begin{tabular}{|c|c|}
\hline Parameter & Setting \\
\hline Forward power & $1500 \mathrm{~W}$ \\
\hline RF matching & $1.75-1.84 \mathrm{~V}$ \\
\hline Carrier gas & 1.04-1.09 L. $\mathrm{min}^{-1}$ \\
\hline Makeup gas & 0 L. $\min ^{-1}$ \\
\hline Nebulizer pump & $0.11-0.14 \mathrm{rps}$ \\
\hline Spray chamber temperature & $2{ }^{\circ} \mathrm{C}$ \\
\hline Sampling depth & $7 \mathrm{~mm}$ \\
\hline Torch position & Optimised daily \\
\hline Ion lenses voltages & Optimised daily \\
\hline $\begin{array}{l}\text { Uptake and stabilisation } \\
\text { time }\end{array}$ & $50 \mathrm{~s}, 60 \mathrm{~s}$ \\
\hline \multirow[t]{2}{*}{ Wash time } & $10 \mathrm{~s} \mathrm{H}_{2} \mathrm{O}, 200$ s 5 wt. $\% \mathrm{HNO}_{3}$, \\
\hline & $220 \mathrm{~s} 1$ wt. $\% \mathrm{HNO}_{3}$, total $430 \mathrm{~s}$ \\
\hline Integration time per mass & $0.15 \mathrm{~s}$ \\
\hline No. of runs and scan passes & $3 \times 23$ \\
\hline
\end{tabular}




\subsubsection{Calibration and blank correction}

Dilutions of fully-digested BHVO-2, W-2, Nod-P-1 and JG-2 rock standards were run as calibration standards during ICP-MS analysis of the leachate samples. $50 \mathrm{mg}$ of each of the four rock standards were digested in ca. $2 \mathrm{~mL} 29 \mathrm{M} \mathrm{HF}$ (Seastar) and ca. $0.5 \mathrm{~mL} 16 \mathrm{M}$ $\mathrm{HNO}_{3}$ (Seastar) in pre-cleaned Savillex beakers heated to $120^{\circ} \mathrm{C}$ on a hotplate for $4 \mathrm{~d}$. The solution was then evaporated and the remaining sample was twice refluxed in $16 \mathrm{M} \mathrm{HNO}_{3}$, followed by reflux in $6 \mathrm{M} \mathrm{HCl}$ (Seastar). After checking that the rock standard powder had completely digested, the sample was dried down and brought back into solution with $1 \mathrm{M} \mathrm{HNO}_{3}$. Gravimetric dilutions of the fully-digested rock standard solutions were made prior to each ICP-MS analytical session to produce calibration standards close to the expected leachate trace element concentrations (Table 6.3). Furthermore, the use of fully-digested rock standards as calibration standards enabled the accurate assessment of the proportion of elements leached from the rock standard dust into the leachate.

Two W-2 calibration standards of different dilutions (Table 6.3) were made to bracket the concentration range of samples from the $10 \mathrm{ppm}, 50 \mathrm{ppm}$ and $500 \mathrm{ppm}$ dust concentration tests. Samples of the leachate from the W-2 500 ppm dust concentration test were diluted by a factor of 10 before analysis.

$1 \mathrm{wt} . \% \mathrm{HNO}_{3}$ blanks were run every 6-10 samples. Counts recorded on the blanks were subtracted from those measured on samples and standards to correct for background levels. Detection limits, defined as $3 \sigma$ of blank measurements, are presented in Table 6.4 . 
Table 6.3: Element concentrations (ppm) for BHVO-2, W-2, Nod-P-1 and JG-2 and dilution factors used to make up calibration standards from fully-digested rock standard powders.

\begin{tabular}{|c|c|c|c|c|}
\hline Element & BHVO-2 & $W-2$ & Nod-P-1 & JG-2 \\
\hline$\overline{\mathrm{Li}}$ & $4.8 \pm 0.2$ & $9.3 \pm 0.4$ & $140 \pm 1$ & $41.1 \pm 2.55^{\mathrm{a}}$ \\
\hline $\mathrm{Na}$ & $16471 \pm 594$ & $16323 \pm 275$ & $17100 \pm 240$ & $26200 \pm 3$ \\
\hline $\mathrm{Mg}$ & $43380 \pm 720$ & $38220 \pm 348$ & $20300 \pm 700$ & $480 \pm 208^{a}$ \\
\hline Al & $71470 \pm 1059$ & $81794 \pm 847$ & $24600 \pm 1000$ & $65400 \pm 1191^{a}$ \\
\hline $\mathrm{Ca}$ & $76000 \pm 1333$ & $72400 \pm 520$ & $22400 \pm 100$ & $4900 \pm 30$ \\
\hline $\mathrm{Ti}$ & $16300 \pm 2000$ & $6353 \pm 60$ & $2720 \pm 40$ & $240 \pm 60^{a}$ \\
\hline V & $317 \pm 11$ & $268 \pm 10$ & $510 \pm 3$ & $2.86 \pm 0.0778^{a}$ \\
\hline $\mathrm{Cr}$ & $280 \pm 19$ & $93 \pm 6$ & $13.3 \pm 0.01$ & $7.1 \pm 2.31^{a}$ \\
\hline $\mathrm{Mn}$ & $1317 \pm 39$ & $1294 \pm 31$ & $296000 \pm 13000$ & $129 \pm 45^{a}$ \\
\hline $\mathrm{Cu}$ & $127 \pm 7$ & $105 \pm 3$ & $11350 \pm 212^{a}$ & $0.53 \pm 0.13^{a}$ \\
\hline $\mathrm{Zn}$ & $103 \pm 6$ & $77 \pm 6$ & $1808 \pm 301^{a}$ & $13.5 \pm 1.56^{\mathrm{a}}$ \\
\hline As & nd & $1.1 \pm 0.1$ & $88.5 \pm 3.9$ & $0.75 \pm 0.03$ \\
\hline $\mathrm{Rb}$ & $9.11 \pm 0.04$ & $21 \pm 1$ & $660 \pm 14.8^{a}$ & $16.73 \pm 1.009^{a}$ \\
\hline $\mathrm{Sr}$ & $396 \pm 1$ & $196 \pm 5$ & $24.1 \pm 0.57^{a}$ & $299.3 \pm 7.869^{a}$ \\
\hline Y & $26 \pm 2$ & $22 \pm 1$ & $90.5 \pm 0.707^{a}$ & $88.6 \pm 9.12^{a}$ \\
\hline $\mathrm{Zr}$ & $172 \pm 11$ & $92 \pm 4$ & $289 \pm 12.7^{a}$ & $109.9 \pm 4.146^{a}$ \\
\hline Cs & $0.1 \pm 0.01$ & $0.92 \pm 0.07$ & $1.78 \pm 0.035^{a}$ & $7.4 \pm 0.53^{a}$ \\
\hline $\mathrm{Ba}$ & $131 \pm 1$ & $172 \pm 7$ & $2572 \pm 167.6^{a}$ & $62.6 \pm 7.22^{a}$ \\
\hline La & $15.2 \pm 0.1$ & $10.8 \pm 0.5$ & $108 \pm 3.54^{a}$ & $20.9 \pm 2.41^{a}$ \\
\hline $\mathrm{Ce}$ & $37.5 \pm 0.2$ & $23.4 \pm 0.7$ & $317 \pm 17^{a}$ & $49.7 \pm 3.65^{a}$ \\
\hline $\operatorname{Pr}$ & $5.35 \pm 0.17$ & $3 \pm 0.1$ & $32 \pm 1.4^{a}$ & $6.3 \pm 0.26^{a}$ \\
\hline Gd & $6.24 \pm 0.03$ & $3.66 \pm 0.12$ & $31.1 \pm 0.919^{a}$ & $8.7 \pm 1.1^{a}$ \\
\hline $\mathrm{Er}$ & $2.54 \pm 0.01$ & $2.22 \pm 0.1$ & $13.9 \pm 0.389^{\mathrm{a}}$ & $7.13 \pm 1.72^{a}$ \\
\hline $\mathrm{Yb}$ & $2 \pm 0.01$ & $2.05 \pm 0.04$ & $13.1 \pm 0.283^{a}$ & $8.79 \pm 2.01^{a}$ \\
\hline $\mathrm{Tl}$ & na & $0.132 \pm 0.002$ & $178 \pm 45.3^{a}$ & $1.56 \pm 5$ \\
\hline $\mathrm{Pb}$ & $1.6 \pm 0.3$ & $7.7 \pm 0.6$ & $494 \pm 54.5^{\mathrm{a}}$ & $31.27 \pm 1.704^{a}$ \\
\hline $\mathrm{Bi}$ & nd & $0.03 \pm$ & $5.8 \pm 0.4$ & $0.81 \pm 0.31^{a}$ \\
\hline Th & $1.22 \pm 0.06$ & $2.17 \pm 0.09$ & $16.7 \pm 0.07^{\mathrm{a}}$ & $30.58 \pm 2.173^{a}$ \\
\hline $\mathrm{U}$ & $0.403 \pm 0.001$ & $0.51 \pm 0.02$ & $4.11 \pm 0.148^{a}$ & $11.44 \pm 1.45^{a}$ \\
\hline $\begin{array}{l}\text { Dilution } \\
\text { factor(s) of } \\
\text { calibration } \\
\text { standard(s) }\end{array}$ & x 682205 & x 501957 & $\begin{array}{l}\times 984011 \\
\times 1261230^{b}\end{array}$ & x 948716 \\
\hline
\end{tabular}

Data for BHVO-2 and W-2 are GeoREM preferred values \pm 1 standard deviation (http://georem.mpchmainz.gwdg.de/ [Jochum et al., 2005]. Data for Nod-P-1 and JG-2 are GeoREM published values \pm 1 standard deviation.

na = data not available; nd = not detectable

${ }^{\text {a }}$ Mean of GeoREM published values \pm 1 standard deviation of GeoREM published values

${ }^{\mathrm{b}}$ Second dilution of Nod-P-1 (see Section 6.4.3)

\subsubsection{Reproducibility and accuracy of data}

Accuracy and precision of the ICP-MS trace element analyses of the leachate samples were assessed by calibrating the measurements on one fully-digested rock standard solution using another fully-digested rock standard solution, e.g., BHVO-2 measured 
using JG-2 as calibration standard. As the Nod-P-1 standard is widely different to the other three in terms of its mineral assemblage and element concentrations, a second dilution (Nod-P-1') was calibrated using the original dilution of the Nod-P-1 fullydigested standard. Reproducibility and accuracy of the ICP-MS analyses are reported in Table 5.4. All error bars displayed on figures referred to in Sections 6.5.1, 6.5.2, 6.6 .1 and 6.6 .2 represent $2 \sigma$ analytical precision.

Table 6.4: Accuracy, precision and detection limits for ICP-MS analyses of rock standards.

\begin{tabular}{|c|c|c|c|c|c|c|c|c|c|}
\hline \multirow{2}{*}{$\begin{array}{l}\text { Element } \\
\mathrm{Li}\end{array}$} & \multicolumn{4}{|c|}{ Accuracy (\% error) } & \multicolumn{4}{|c|}{ Precision (2*RSD (\%)) } & \multirow{2}{*}{$\begin{array}{l}\text { Detection } \\
\text { limit (ppt) } \\
0.6\end{array}$} \\
\hline & 2.6 & 3.5 & 2.1 & 4.4 & 1.2 & 6.1 & 4.2 & 2.6 & \\
\hline $\mathrm{Na}$ & 2.2 & 3.3 & 1.0 & 2.5 & 2.0 & 1.5 & 2.9 & 2.1 & 763.0 \\
\hline $\mathrm{Mg}$ & 0.8 & 56.0 & 1.6 & 1.5 & 1.4 & 6.9 & 4.0 & 0.8 & 49.1 \\
\hline $\mathrm{Al}$ & 0.8 & 1.7 & 1.2 & 0.8 & 2.3 & 0.7 & 3.2 & 0.9 & 48.6 \\
\hline $\mathrm{Ca}$ & 1.1 & 11.5 & 4.2 & 3.1 & 2.4 & 7.3 & 6.5 & 3.1 & 874.0 \\
\hline $\mathrm{Ti}$ & 2.5 & 2.6 & 1.1 & 3.1 & 1.0 & 6.1 & 2.4 & 3.7 & 23.5 \\
\hline V & 0.8 & 75.2 & 0.6 & 2.0 & 2.3 & 12.9 & 1.7 & 3.7 & 1.60 \\
\hline $\mathrm{Cr}$ & nd & nd & 3.4 & 4.0 & nd & nd & 12.1 & 4.4 & 8.8 \\
\hline $\mathrm{Mn}$ & 1.2 & 0.6 & 0.8 & 7.2 & 2.0 & 2.95 & 2.1 & 6.6 & 15.1 \\
\hline $\mathrm{Cu}$ & 0.4 & nd & 0.4 & 12.2 & 1.0 & nd & 1.2 & 13.5 & 37.7 \\
\hline $\mathrm{Zn}$ & 0.4 & nd & 0.8 & 2.0 & 0.8 & nd & 2.2 & 2.3 & 35.7 \\
\hline As & ndS & ndS & 1.6 & ndS & ndS & ndS & 3.2 & ndS & 1.2 \\
\hline $\mathrm{Rb}$ & 5.5 & 1.4 & 0.2 & 1.5 & 1.9 & 4.9 & 1.5 & 4.9 & 0.3 \\
\hline $\mathrm{Sr}$ & 1.1 & 1.0 & 0.3 & 4.2 & 1.8 & 5.4 & 0.7 & 5.2 & 0.9 \\
\hline Y & 1.4 & 9.1 & 0.7 & 1.7 & 2.6 & 4.3 & 1.3 & 5.2 & 0.1 \\
\hline $\mathrm{Zr}$ & 1.9 & 34.2 & 2.0 & 3.5 & 1.9 & 5.9 & 4.9 & 5.0 & 1.0 \\
\hline Cs & 1.4 & 0.4 & 2.8 & 9.0 & 2.1 & 31.0 & 6.6 & 6.7 & 0.1 \\
\hline $\mathrm{Ba}$ & 0.8 & 1.4 & 0.8 & 2.6 & 2.2 & 3.0 & 1.4 & 3.8 & 3.3 \\
\hline La & 1.8 & 5.9 & 1.1 & 0.0 & 2.3 & 2.1 & 2.1 & 3.9 & 0.1 \\
\hline $\mathrm{Ce}$ & 0.8 & 2.8 & 0.7 & 2.1 & 1.7 & 1.8 & 1.1 & 2.9 & 0.2 \\
\hline $\mathrm{Pr}$ & 1.2 & 0.5 & 0.4 & 2.5 & 1.3 & 3.4 & 1.1 & 3.1 & 0.1 \\
\hline $\mathrm{Gd}$ & 2.4 & 5.9 & 1.4 & 5.0 & 2.3 & 2.9 & 1.4 & 2.2 & 0.6 \\
\hline $\mathrm{Er}$ & 1.6 & $\mathrm{~nm}$ & 1.4 & 4.5 & 3.3 & $\mathrm{~nm}$ & 2.8 & 6.2 & 1.0 \\
\hline $\mathrm{Yb}$ & 0.6 & $\mathrm{~nm}$ & 1.5 & 4.2 & 2.0 & $\mathrm{~nm}$ & 4.0 & 10.8 & 0.5 \\
\hline $\mathrm{TI}$ & ndS & ndS & 0.3 & ndS & ndS & ndS & 0.5 & ndS & 0.3 \\
\hline $\mathrm{Pb}$ & 14.8 & nd & 1.0 & 12.6 & 3.8 & nd & 1.8 & 11.0 & 14.7 \\
\hline $\mathrm{Bi}$ & ndS & ndS & 1.1 & ndS & ndS & ndS & 4.0 & ndS & 0.3 \\
\hline Th & 1.0 & 7.0 & 0.8 & 4.7 & 2.7 & 6.1 & 2.0 & 6.5 & 0.2 \\
\hline U & 4.8 & 17.9 & 1.9 & 6.4 & 5.8 & 7.7 & 3.7 & 7.0 & 0.2 \\
\hline $\begin{array}{l}\text { Standard } \\
\text { measured }\end{array}$ & BHVO-2 & $J G-2$ & Nod-P-1 & $W-2$ & BHVO-2 & JG-2 & Nod-P-1 & $\mathrm{W}-2$ & $\begin{array}{l}\text { Standard } \\
\text { measured }\end{array}$ \\
\hline $\begin{array}{l}\text { Calibration } \\
\text { standard }\end{array}$ & $W-2$ & BHVO-2 & Nod-P-1' & BHVO-2 & $W-2$ & BHVO-2 & Nod-P-1' & BHVO-2 & $\begin{array}{l}\text { Calibration } \\
\text { standard }\end{array}$ \\
\hline
\end{tabular}




\section{$6.5 \quad$ Results}

\subsubsection{Effect of acidification time on trace element leachate concentration}

Similar trends in concentration increase over time were exhibited by many trace elements in the BHVO-2 and W-2 leachates (Fig. 6.2; Appendix IX, Tables A18 to A19). Large increases in leachate concentrations relative to the first sample, taken after 10 min of leaching, of $>80 \%$ after $12 \mathrm{hr}$ and $>200 \%$ after $7 \mathrm{wk}$ of leaching were recorded for elements from $\mathrm{Li}$ to $\mathrm{Mn}, \mathrm{Sr}$ and $\mathrm{Ba}$. The Al leachate concentration increased by $193 \%$ and $154 \%$ in BHVO-2 and W-2, respectively, over the first $12 \mathrm{hr}$ of leaching and did not stop increasing after 12 weeks (Fig. 6.3). REE and $Y$ concentration increases in both the BHVO-2 and W-2 leachates occurred during the first $2 \mathrm{hr}$ of leaching but larger increases over time were measured in the BHVO-2 leachate (Fig. 6.2 and 6.3).

The JG-2 leachates showed different trends in trace element concentrations as compared to the other silicate rock standards (Fig. 6.2; Appendix IX, Table A21). Only $\mathrm{Na}, \mathrm{Al}$ and As showed sustained increases in leachate concentration of a similar magnitude to those recorded in the BHVO-2 and W-2 leachates (Fig. 6.4). Aside from these elements, leachate concentration increases after $12 \mathrm{hr}$ of leaching were generally below $50 \%$ and after $7 \mathrm{wk}$ the concentration increase ranged from only $50 \%$ to $210 \%$. The Mn concentration rose only slightly in the first $48 \mathrm{hr}$ of the leaching test and then maintained a relatively constant leachate concentration over the longer-term, whereas the light REEs ( $L a$, Ce and Pr) showed a sustained increase in leachate concentration over the longer-term (Fig. 6.4).

In the Nod-P-1 leachates, $\mathrm{Na}, \mathrm{Li}, \mathrm{Ca}$ and $\mathrm{Sr}$ were at their highest concentrations after just 10 min of leaching and subsequent samples showed a slight ( 7 to $26 \%$ ), gradual decrease in concentration over time rather than an increase (Fig. 6.5). All other elements, excepting $\mathrm{Mn}$, showed a similar trend to Al which increased in concentration by $240 \%$ in the first $24 \mathrm{hr}$ but then remained relatively constant over time (Figs. 6.2 and 6.5; Appendix IX, Table A21). Mn was the only element which continued to increase in concentration in the Nod-P-1 leachates over the entire sampling period. 

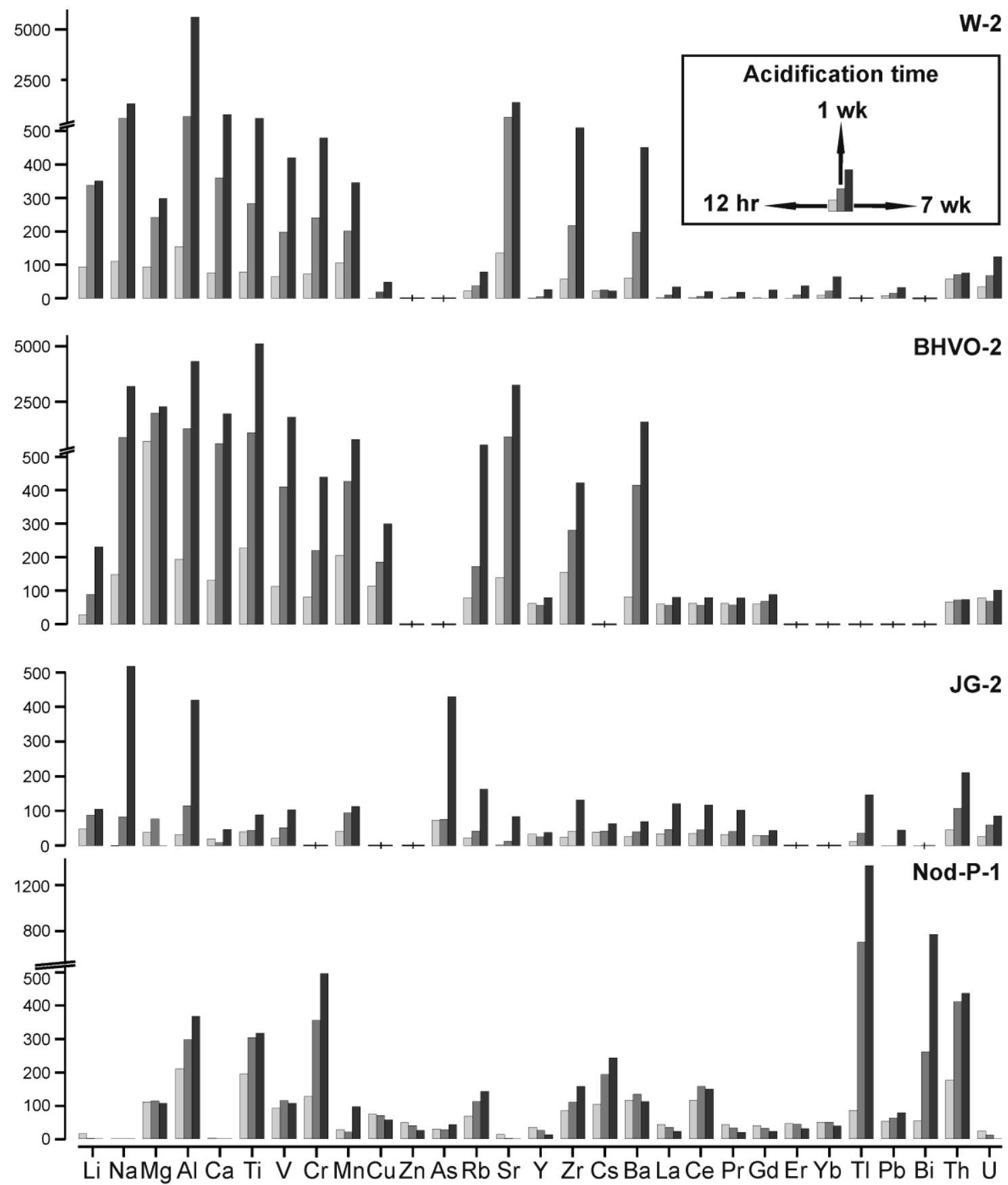

Figure 6.2: Relative concentration increases of trace elements in the leachates of W-2, BHVO-2, JG-2 and Nod-P-1 at selected acidification times. 

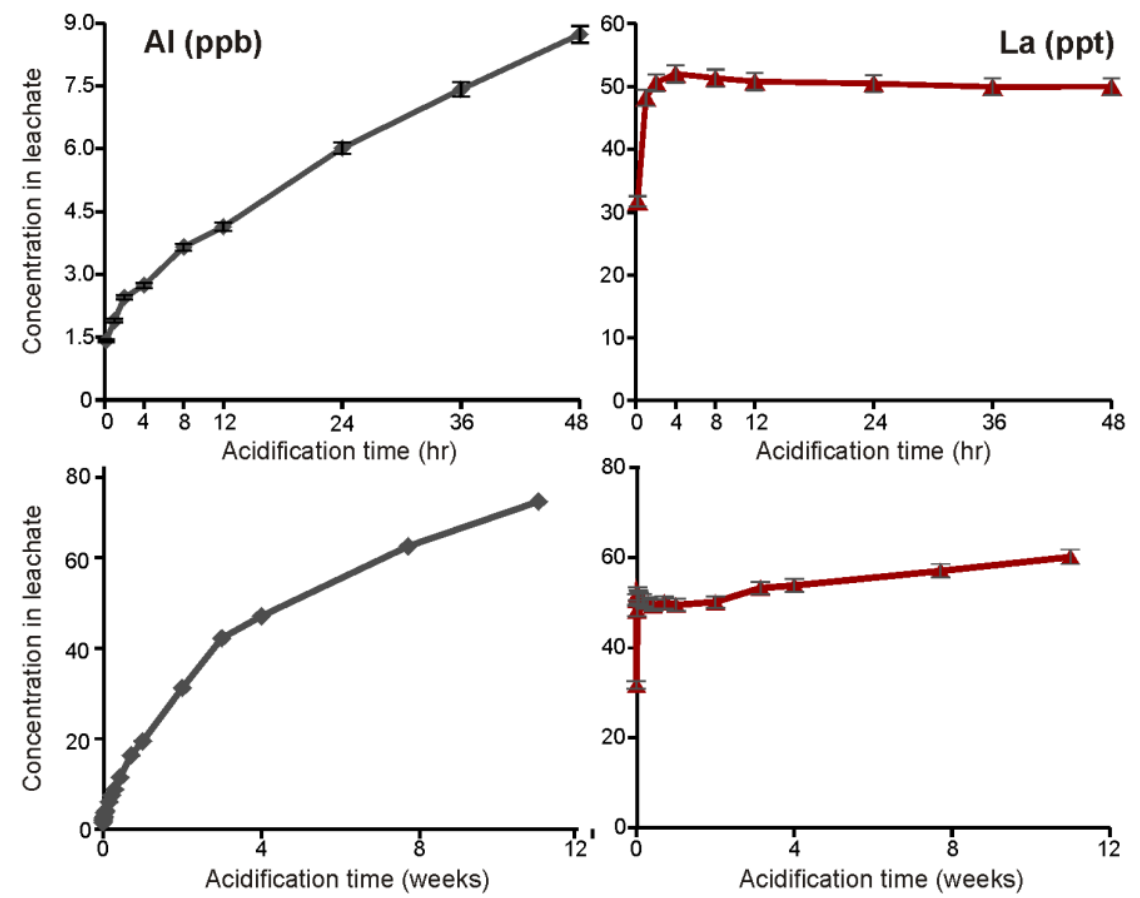

Figure 6.3: Concentrations of Al and La in BHVO-2 leachates plotted versus acidification time in $\mathrm{hr}$ (top panel) and weeks (bottom panel)
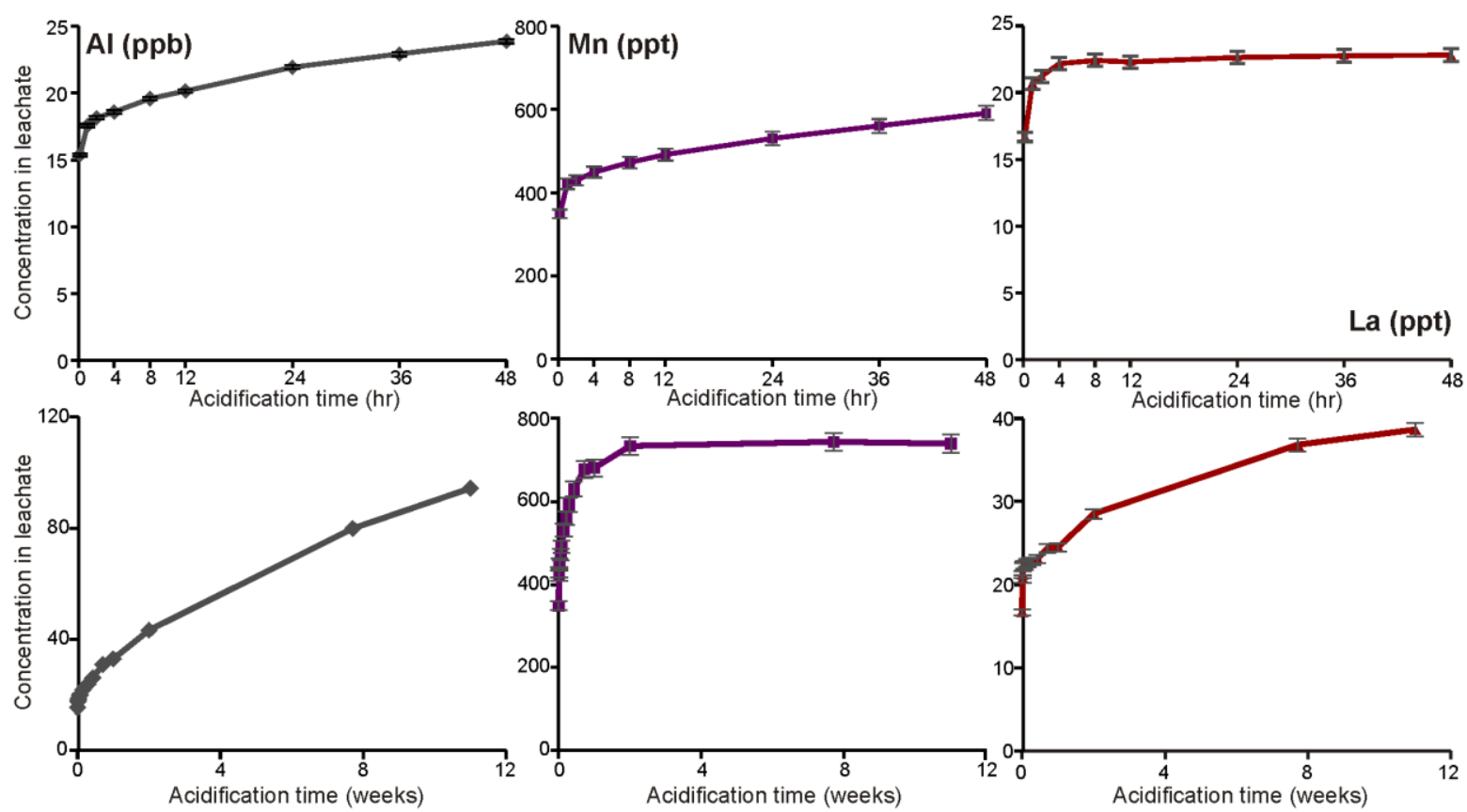

Figure 6.4: Concentrations of $\mathrm{Al}, \mathrm{Mn}$ and La in JG-2 leachates plotted versus acidification time in $\mathrm{hr}$ (top panel) and weeks (bottom panel). 

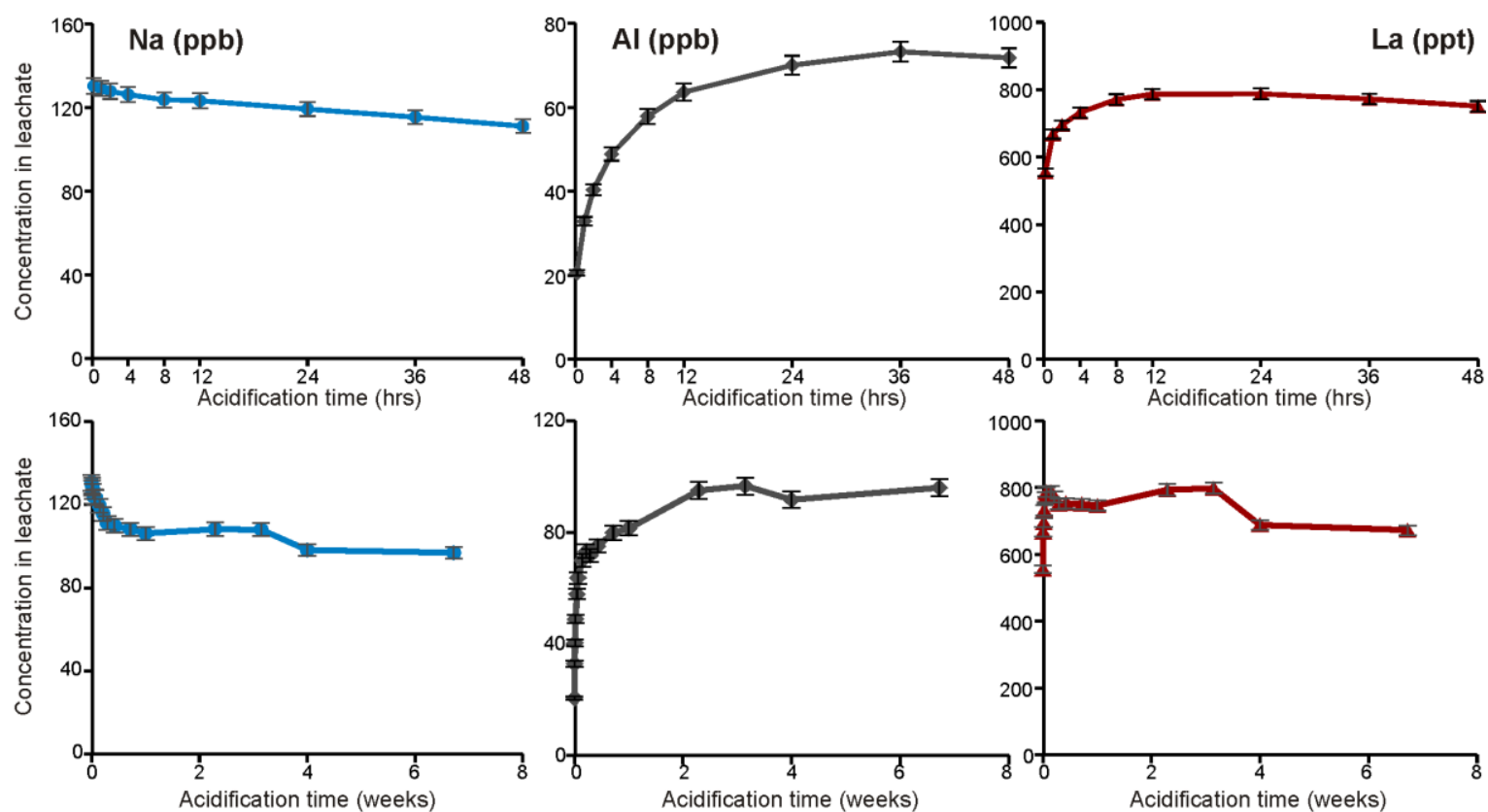

Figure 6.5: Concentrations of $\mathrm{Na}, \mathrm{Al}$ and $\mathrm{La}$ in Nod-P-1 leachates plotted versus acidification time in $\mathrm{hr}$ (top panel) and weeks (bottom panel).

\subsubsection{Variation in leaching characteristics between dust lithologies}

The relative amounts of each element leached from the rock standard dust into the leachate solution varied between elements and between dust lithologies (Fig. 6.6). The recovery of each element by mass was calculated according to the following equation:

$\%$ recovery of element $E=$ (mass of $E$ in leachate $/$ mass of $E$ in dust added $) * 100$

BHVO-2 and W-2 showed some similar trends in element recovery, which contrast with those exhibited by JG-2 and Nod-P-1. After $12 \mathrm{hr}$ of leaching, recovery of lighter elements from Li to Mn was consistently < 20\% for both BHVO-2 and W-2, whereas for JG-2, recovery was 58\% for $\mathrm{Mg}, 38 \%$ for $\mathrm{Ti}$ and $42 \%$ for $\mathrm{Mn}$. Light REEs showed some of the highest recoveries (31 to 33\%) in the BHVO-2 and W- 2 leachates, whereas in the JG-2 leachate, recoveries of only 11 to $12 \%$ were reached. Additionally, Y, which displayed similar time-dependent leaching trends to the REEs, showed different recovery values. Y recovery was highest (52\%) in the JG-2 leachate, which had the 
lowest recovery of light REEs after $12 \mathrm{hr}$ leaching, and $\mathrm{Y}$ recovery was lowest (12\%) in the W-2 leachate, which exhibited relatively high recoveries of light REEs. Zr was the only element which had a consistently low recovery ( 10\%) across all four rock standards.

Recovery was higher for the majority of elements in the Nod-P-1 leachate compared to the silicate rock standards (Fig. 6.6). Typical recoveries ranged between 57\% and $79 \%$ after $12 \mathrm{hr}$ of leaching. However, Mn which is the most abundant element in Nod-P-1, showed a recovery of only $4 \%$ after $12 \mathrm{hr}$ and $6 \%$ after 10 weeks (Appendix IX, Table A21).

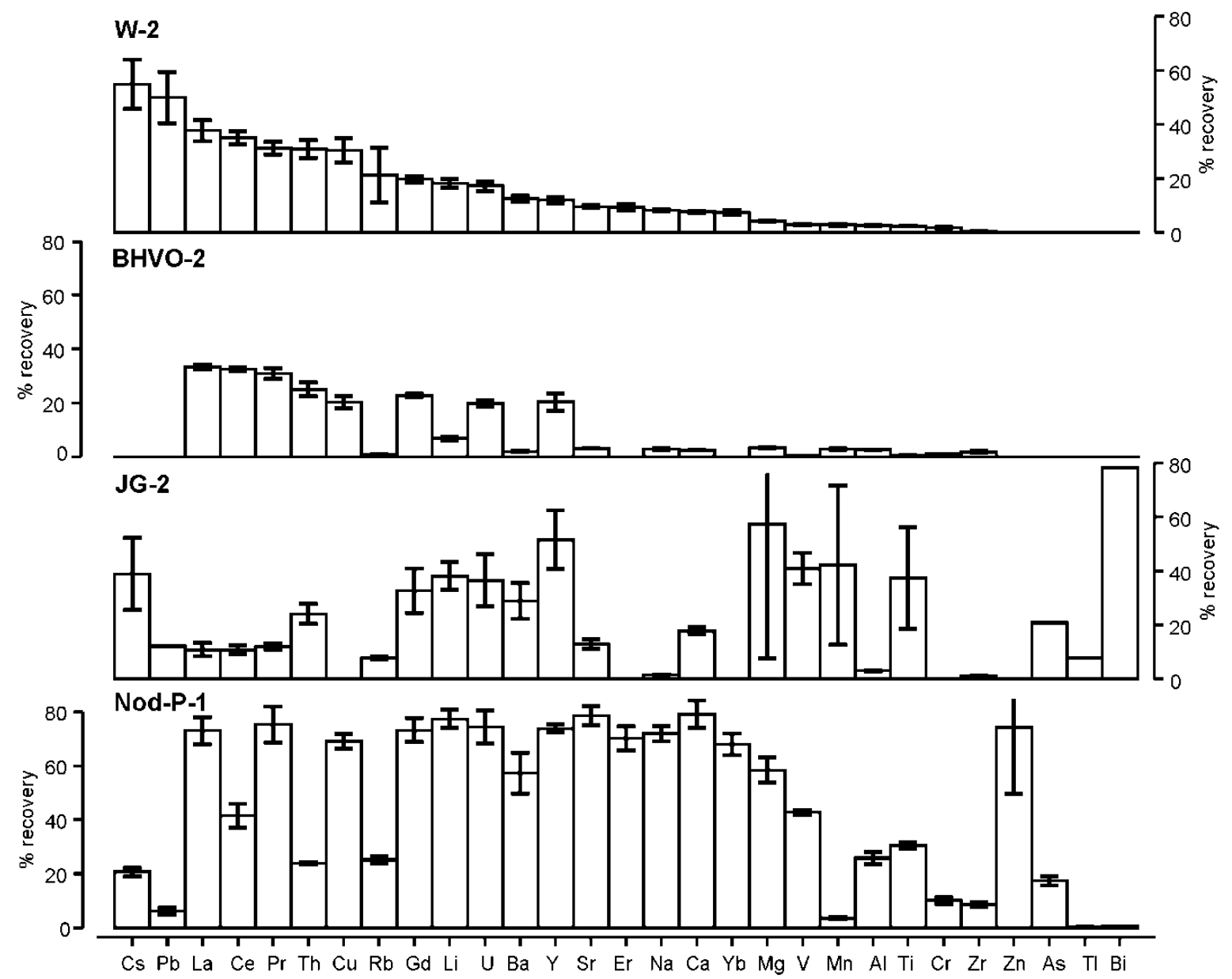

Figure 6.6: Proportion of each element leached from BHVO-2, JG-2, W-2 and Nod-P-1 into leachate after $12 \mathrm{hr}$ acidification, expressed as \% recovery. Elements which recorded concentrations below the detection limit are assumed to have $0 \%$ recovery. 


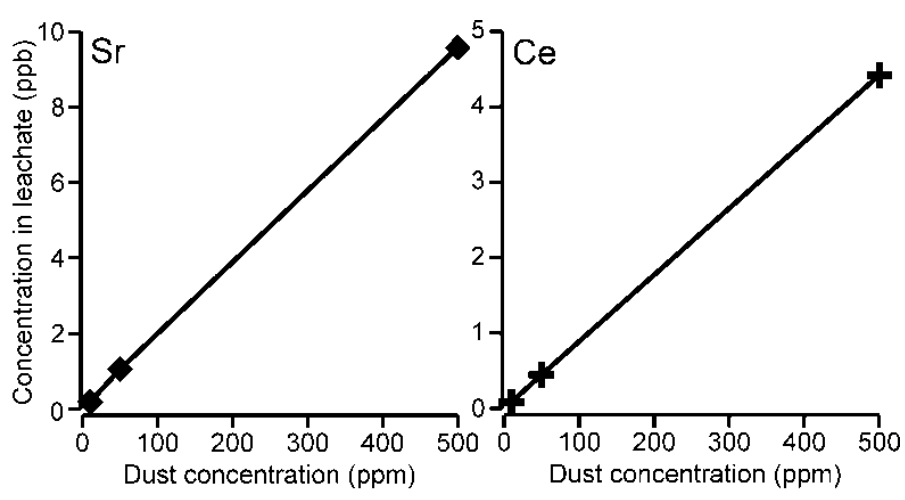

Figure 6.7: Linear relationship between dust ( $\mathrm{W}-2)$ concentration $(10,50,500 \mathrm{ppm})$ and concentrations of $\mathrm{Sr}$ and Ce measured in the leachates after $12 \mathrm{hr}$.

\subsubsection{Effect of dust concentration}

Results obtained by leaching W-2 at three different dust concentrations (10 ppm, 50 ppm and $500 \mathrm{ppm}$ ) demonstrate that a linear relationship exists between dust concentration and the leachate concentration of any element in the leachate (Appendix IX, Tables A19, A22, A23). Correlation coefficients ranging between 0.98 and 1.0 describe the linear relationship between dust concentration and leachate concentration of all the elements measured after $12 \mathrm{hr}$ of leaching (Fig. 6.7). The leachate did not become oversaturated even when 500 ppm of dust was leached for more than 6 weeks. The \% recovery of trace elements from the dust into the leachate was therefore consistent across all dust concentrations at any given acidification time.

\subsubsection{Effect of freezing}

Several elements (highlighted in Table 6.5) appear to have been more aggressively leached in the BHVO-2 or JG-2 mock ice core samples that were acidified to 1 wt.\% $\mathrm{HNO}_{3}$ prior to freezing compared to those which were acidified after freezing and thawing, and those which were not frozen prior to $12 \mathrm{hr}$ of leaching in $1 \mathrm{wt} . \% \mathrm{HNO}_{3}$. For those elements highlighted in Table 6.5 , the $2 \sigma$ of the leachate concentrations from acidified, frozen samples and the un-acidified, frozen samples do not overlap, which suggests that the two populations are different. This is illustrated in Figure 6.8 
which shows that recovery of $\mathrm{Ti}$ and $\mathrm{Zr}$ was increased in both the BHVO-2 and JG-2 mock ice core samples that were acidified before freezing. The difference in recovery between the acidified, frozen and un-acidified, frozen samples is acknowledged to be subtle but respective concentration increases in BHVO-2 and JG-2 samples of $23 \%$ and $31 \%$ for $\mathrm{Ti}$ and $34 \%$ and $71 \%$ for $\mathrm{Zr}$, are substantially higher than the limit of analytical precision (Table 6.4). Recovery was not significantly higher for any element in the samples that were frozen, un-acidified compared to those which were not frozen.

Table 6.5: Mean recovery (\%) $(n=3)$ of trace elements from BHVO-2 and JG-2 leached at a dust concentration of $63 \mathrm{ppm}$ for $12 \mathrm{hr}$ after either being frozen acidified, frozen un-acidified or not frozen. Grey shading and bold type indicates that the $2 \sigma$ of the acidified and un-acidified frozen samples do not overlap. Leachate concentrations have been scaled to a dust concentration of 63 ppm across all samples. Raw data are given in Appendix IX (Tables A24 and A25).

\begin{tabular}{|c|c|c|c|c|c|c|}
\hline & \multicolumn{3}{|c|}{ BHVO-2 } & \multicolumn{3}{|c|}{ JG-2 } \\
\hline & $\begin{array}{l}\text { Acidified } \\
\text { Frozen }\end{array}$ & $\begin{array}{l}\text { Un-acidified } \\
\text { Frozen }\end{array}$ & Not frozen & $\begin{array}{l}\text { Acidified } \\
\text { Frozen }\end{array}$ & $\begin{array}{l}\text { Un-acidified } \\
\text { Frozen }\end{array}$ & Not frozen \\
\hline $\mathrm{Li}$ & 4.9 & 5.2 & 5.4 & 50.6 & 38.6 & 44.0 \\
\hline $\mathrm{Na}$ & 2.9 & 4.0 & 3.7 & 1.8 & 1.6 & 1.7 \\
\hline $\mathrm{Mg}$ & 5.3 & 3.6 & 4.0 & 2.8 & 3.8 & 16.8 \\
\hline $\mathrm{Al}$ & 2.5 & 2.6 & 2.9 & 4.0 & 3.1 & 3.3 \\
\hline $\mathrm{Ca}$ & 2.5 & 2.6 & 2.8 & 9.3 & 11.0 & 14.6 \\
\hline $\mathrm{Ti}$ & 0.6 & 0.5 & 0.6 & 45.6 & 34.8 & 44.5 \\
\hline V & 0.6 & 0.5 & 0.6 & 66.9 & 61.2 & 61.0 \\
\hline $\mathrm{Cr}$ & 1.3 & 1.1 & 1.2 & nd & nd & nd \\
\hline $\mathrm{Mn}$ & 3.5 & 2.8 & 3.1 & 38.9 & 32.0 & 40.4 \\
\hline $\mathrm{Cu}$ & 20.4 & 18.8 & 20.0 & nd & nd & $\mathrm{Nd}$ \\
\hline $\mathrm{Rb}$ & 0.9 & 1.1 & 1.1 & 8.4 & 7.3 & 8.0 \\
\hline $\mathrm{Sr}$ & 3.1 & 3.2 & 3.5 & 14.1 & 12.8 & 13.3 \\
\hline Y & 20.4 & 20.3 & 21.7 & 67.9 & 52.9 & 56.3 \\
\hline $\mathrm{Zr}$ & 1.6 & 1.2 & 1.1 & 2.0 & 1.2 & 1.1 \\
\hline Cs & nd & nd & nd & 46.5 & 40.1 & 40.8 \\
\hline $\mathrm{Ba}$ & 2.1 & 2.2 & 2.3 & 38.0 & 33.5 & 34.3 \\
\hline La & 33.4 & 33.3 & 35.4 & 14.3 & 11.3 & 11.5 \\
\hline $\mathrm{Ce}$ & 32.4 & 32.3 & 34.6 & 14.1 & 11.1 & 11.4 \\
\hline $\mathrm{Pr}$ & 31.3 & 31.1 & 33.2 & 16.3 & 12.8 & 13.3 \\
\hline $\mathrm{Gd}$ & 23.5 & 23.3 & 24.4 & 42.0 & 34.5 & 36.8 \\
\hline $\mathrm{Er}$ & 19.5 & 19.4 & 20.5 & 43.3 & 33.1 & 34.5 \\
\hline $\mathrm{Yb}$ & 17.9 & 17.8 & 18.8 & 56.9 & 44.6 & 47.4 \\
\hline Th & 20.3 & 21.0 & 22.0 & 83.5 & 35.6 & 33.1 \\
\hline$U$ & 19.2 & 19.1 & 20.3 & 57.9 & 42.0 & 47.1 \\
\hline
\end{tabular}



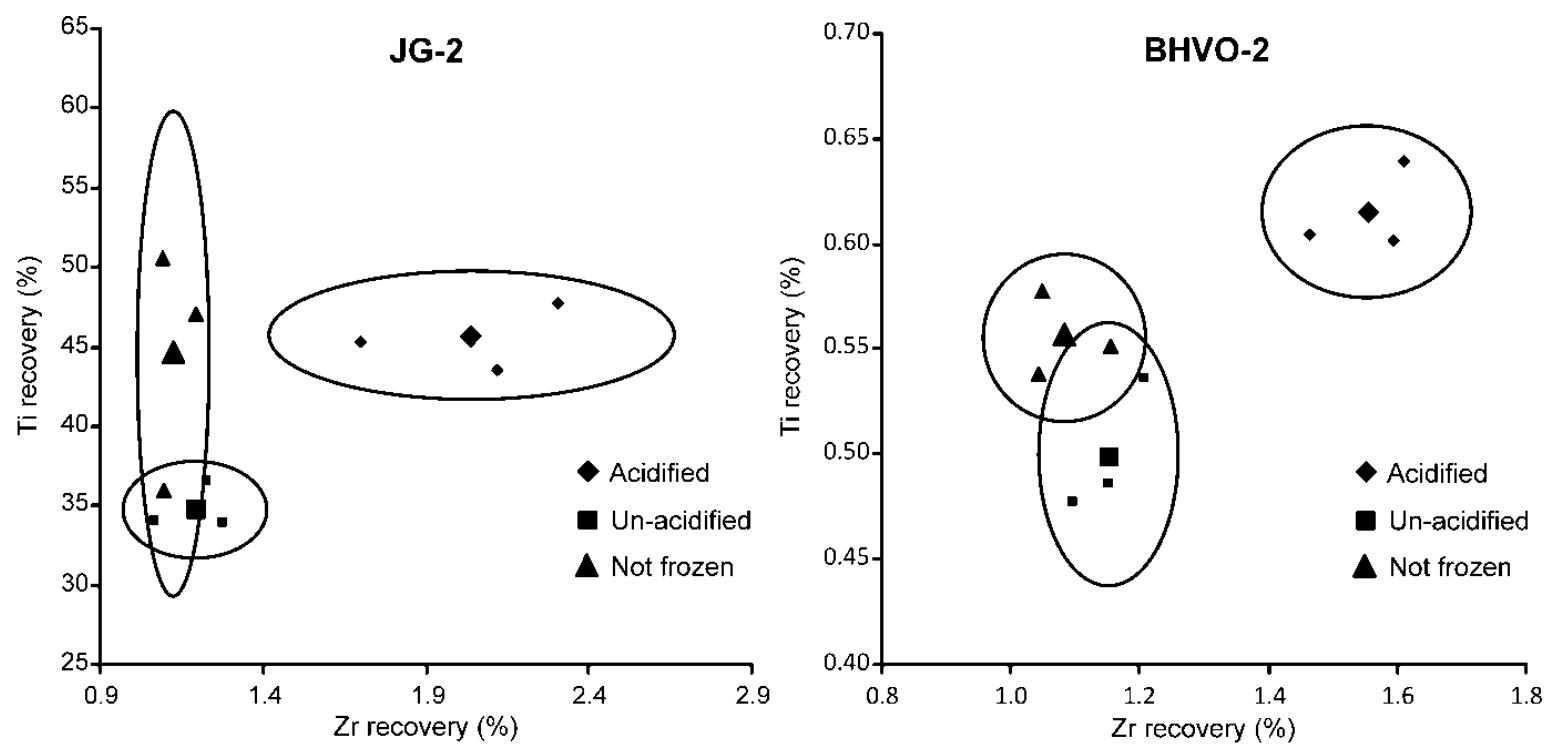

Figure 6.8: Recovery of Zr versus recovery of Ti for acid-leached JG-2 and BHVO-2 samples that were either acidified and frozen, un-acidified and frozen, or not frozen prior to $12 \mathrm{hr}$ of acidleaching at room temperature. Smaller symbols represent the 3 samples stored under each condition. Larger symbols represent the mean of 3 samples stored under each condition. Ellipses define $2 \sigma$ about the mean of each population. Analytical errors are within the extent of the ellipses. 


\subsection{Discussion}

6.6.1 Implications for interpretation of trace element concentrations in ice core samples

Trace element concentrations leached from mineral dust present in ice core samples will vary considerably (by more than an order of magnitude) depending on the length of acidification time prior to ICP-MS analysis. The rate of leaching differs widely between different elements in the same dust lithology and, in many cases, the same element leached from different lithologies (Fig. 6.2).

Leaching of trace elements from mineral dust is not only time-dependent but also dependent on the mineral constituents of the dust. The rock standards JG-2 (biotite granite) and W-2 (diabase/dolerite) have contrasting mineralogies and showed different patterns of trace element recovery or 'leachability' as a result. A major mineral constituent of JG-2 is biotite mica which is a sheet silicate, similar in structure to clay minerals common in ice cores [Gaudichet et al., 1988]. $\mathrm{K}^{+}$ions bond the silicate sheets together and trace elements, particularly mono- and di-valent cations, can substitute for the $\mathrm{K}^{+}$ions [Deer et al., 1966]. As the bonds holding the cations between the silicate sheets are relatively weak, trace elements were rapidly leached from the biotite mica of the JG-2 standard. The other dominant mineral constituent of JG-2 is quartz which contains very few trace element impurities and is unlikely to contribute to the leachate trace element budget. In contrast to JG-2, W-2 contains $<1 \%$ muscovite mica and its mineralogy is dominated by plagioclase feldspar and clinopyroxene (S. A. Wilson, USGS, Personal communication). Trace element impurities are held relatively tightly within the complex silicate structures of these minerals [Deer et al., 1966]. We interpret this contrast in mineralogy as the cause for the higher recovery values after $12 \mathrm{hr}$ of leaching and the reduced rates of leachate concentration increase with acidification time in the JG-2 leachates compared to the W-2 leachates. Rock standards W-2 and JG-2 have very similar grain size distributions (Fig. 6.1) so the differences in recovery cannot be attributed to a grain size effect. 
The BHVO-2 and W-2 leaching tests produced relatively similar trace element recovery profiles because both rock standards are mafic igneous rocks. The somewhat higher trace element recoveries of $\mathrm{W}-2$ could be the result of the lower modal grain size and broader grain size distribution of W-2 compared to BHVO-2 (Fig. 6.1). An increased relative surface area on which leaching can act is likely to result in an increased recovery of trace elements [Snäll and Liljefors, 2000]. This suggests that the reproducibility of ICP-MS trace element concentrations of ice cores with very low dust concentrations, such as EPICA Dome $\mathrm{C}$, will still be affected by mineral dust dissolution because the mean grain size is low ( $2 \mu \mathrm{m}$, Delmonte et al. [2004]) and provides a large relative surface area for leaching.

In contrast to silicate mineral lattices, which are relatively resistant to $\mathrm{HNO}_{3}$ attack, bonds in oxyhydroxide minerals, like those predominant in Nod-P-1 (Fe-Mn nodule), are easily broken down by $\mathrm{HNO}_{3}$. This explains the high proportions of trace elements released rapidly into solution in the Nod-P-1 leaching test. $100 \%$ recovery of trace elements was not achieved in the Nod-P-1 test because silicate minerals are present in the nodule. Recovery of $\mathrm{Mn}$ is anomalously low compared to other elements because it is present in some $\mathrm{Mn}$-oxyhydroxides as $\mathrm{Mn}^{4+}$ and $\mathrm{Mn}^{3+}$ ions [Post, 1999], which are more difficult to leach than $\mathrm{Mn}^{2+}$ ions [Zhang et al., 2001]. $\mathrm{Cr}$ and As may also be oxidised by $\mathrm{Mn}$ oxides to $\mathrm{Cr}^{4+}$ and $\mathrm{As}^{5+}$ [Post, 1999], which could explain the relatively low recovery of As and $\mathrm{Cr}$ in the Nod-P-1 leachates (Fig. 6.6). Significant decreases in the leachate concentration of trace elements relative to the first sample were only recorded in Nod-P-1 leachates and could be the result of re-adsorption onto the mineral structure.

If the leachate samples taken 10 min after acidification are considered analogous to ice core samples measured by coupled continuous melter and ICP-MS analysis systems then our results suggest that considerable trace element leaching from mineral dust occurs within the short acidification time of these systems ( $4.5 \mathrm{~min}$, Knusel et al. (2003)). Consequently, the reproducibility of trace element determinations will be poor. Furthermore, we suggest that not only lithophile elements [Knusel et al., 2003], 
but all trace elements will record lower concentrations on coupled continuous melter and ICP-MS analysis systems relative to conventional ICP-MS analysis methods.

\subsubsection{Implications for the interpretation of trace element ratios}

Trace element ratios are also affected by the time- and mineral-dependent leaching of trace elements from mineral dust which can influence how effective they are as tools for interpretation of ICP-MS data. Marine to terrestrial element ratios of ice core samples can be used to ascertain the relative contributions of marine and terrestrial sources [Bull, 2009], which may vary seasonally or in response to climate. This requires the choice of a conservative marine and conservative terrestrial tracer. $\mathrm{Na}$ is the standard choice for a marine tracer and is used here to investigate whether variability in mineral dust leaching can affect marine/terrestrial element ratios. Incidentally, if $\mathrm{Mg}$ or $\mathrm{Sr}$ are substituted for $\mathrm{Na}$ as marine tracers the results displayed here alter very little. Popular choices for terrestrial tracers are Al [Gabrielli et al., 2005b; Planchon et al., 2002a; Townsend and Edwards, 1998], Mn [Gabrielli et al., 2005a] and La [Wei et al., 2008], which we have shown to have variable leaching characteristics. The choice of terrestrial tracer therefore causes very different trends in the evolution of marine/terrestrial ratios (Fig. 6.9). The $\mathrm{Na} /$ La ratio of BHVO-2 leachate varied between 185 and 825 over $48 \mathrm{hr}$ and never achieved a constant value. La is identified as an unsuitable terrestrial tracer for the silicate rock standards (BHVO-2, W-2 and JG-2) as La and Na show strikingly different leaching behaviour in all three standards (Fig. 6.2). The $\mathrm{Na} / \mathrm{Mn}$ value also varied considerably with acidification time whereas the $\mathrm{Na} / \mathrm{Al}$ ratio in BHVO-2 leachate remained relatively constant after $2 \mathrm{hr}$ of leaching at a value close to that of the whole rock (Fig. 6.9). Therefore ice core samples analysed at acidification times $>2 \mathrm{hr}$ would not exhibit variation in the value of $\mathrm{Na} / \mathrm{Al}$ resulting from differential leaching rates of $\mathrm{Na}$ and $\mathrm{Al}$. As Al displayed similar leaching behaviour to $\mathrm{Na}$ in all four of the rock types tested, the $\mathrm{Na} / \mathrm{Al}$ quickly (after $~ 12 \mathrm{hr}$ ) reached a constant value in each of the leachates (Fig. 6.10) and is therefore identified as the most suitable terrestrial tracer to be employed in a marine/terrestrial ratio. However, $\mathrm{Na} / \mathrm{Al}$ ratios vary between dust lithologies (Fig. 6.10) and, therefore, if the 
dominant mineral dust lithology in an ice core changed then the value of the marine/terrestrial ratio would also change. Any major shift in the $\mathrm{Na} / \mathrm{Al}$ ratio should be interpreted with care because the relative marine and terrestrial input could be unchanged.
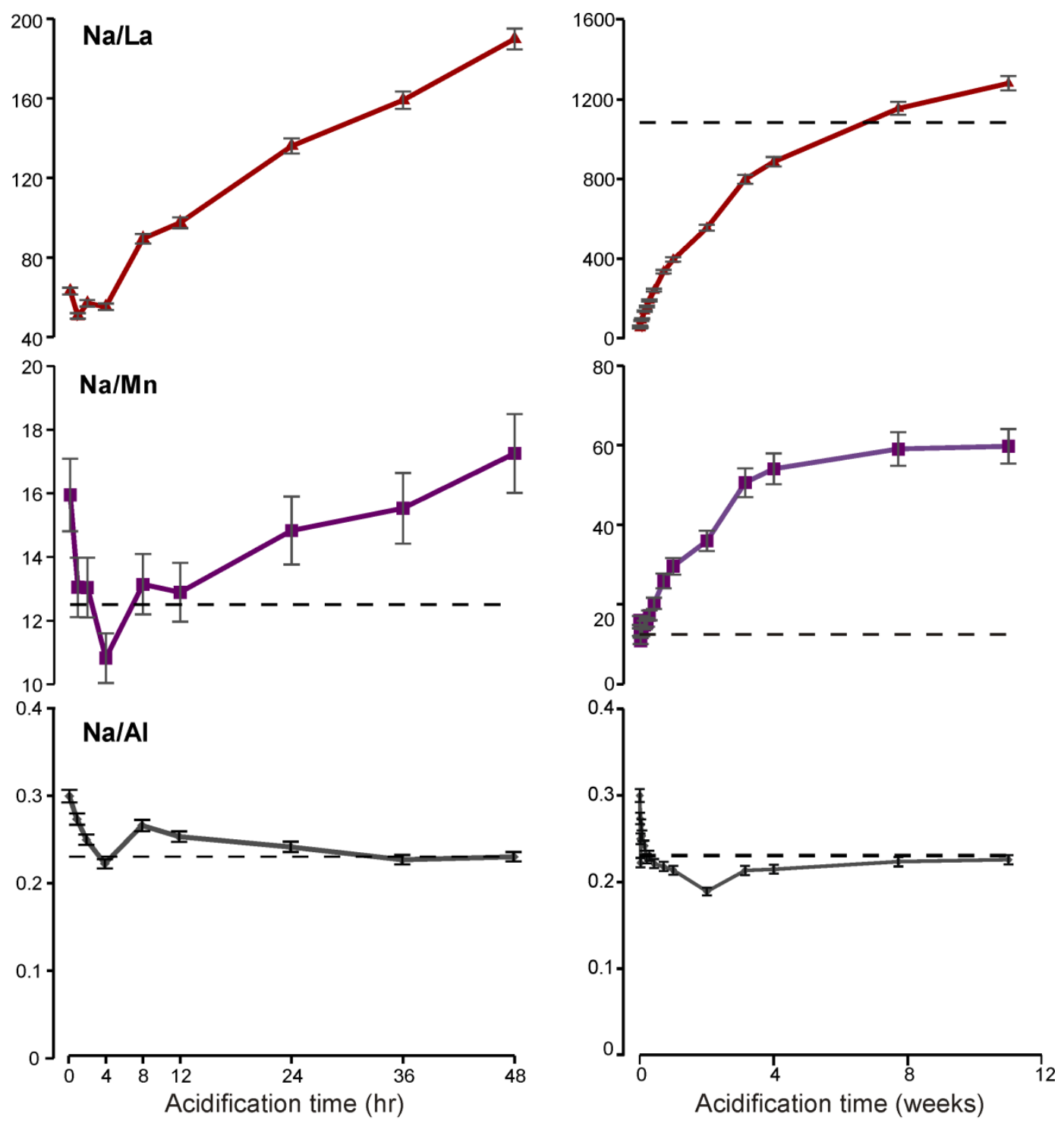

Figure 6.9: Variation in the marine/terrestrial ratio with acidification time in BHVO-2 leachates using three different terrestrial tracers: $\mathrm{Mn}$, La and Al. Dashed lines indicate BHVO-2 whole rock ratio. 

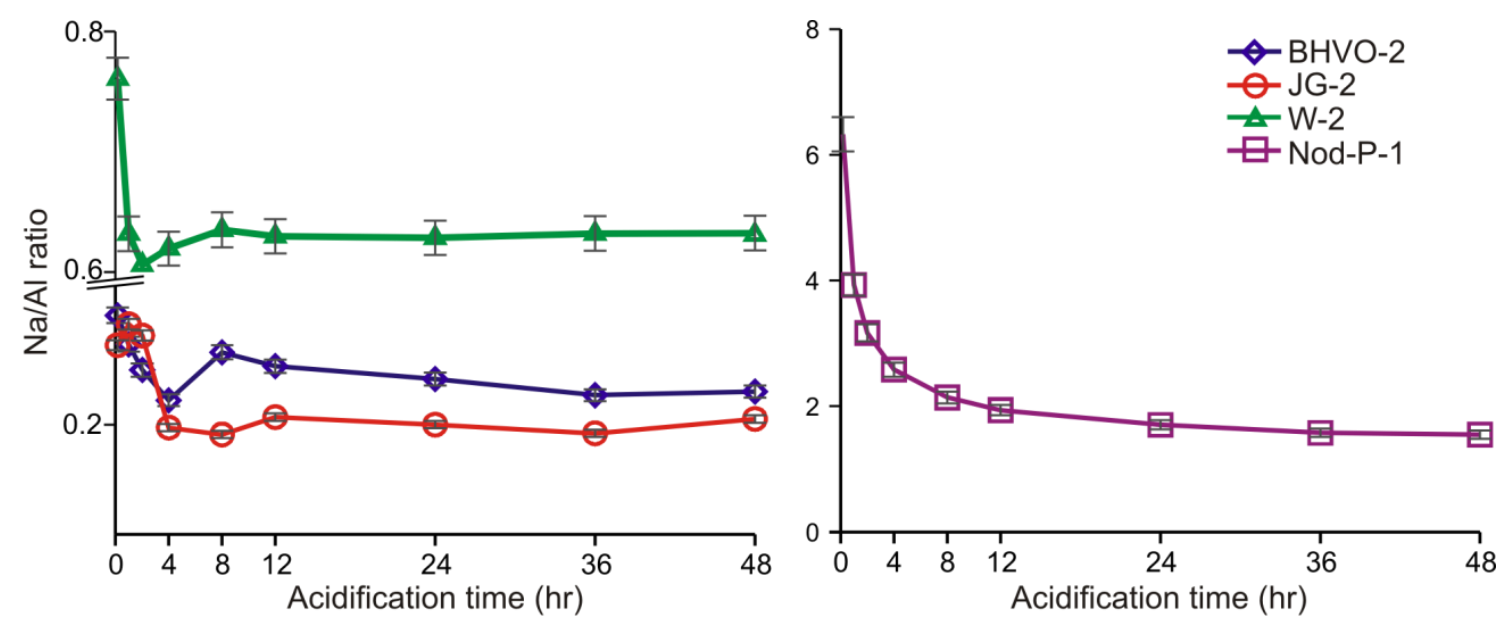

Figure 6.10: Variation in Na/Al ratio of BHVO-2, JG-2, W-2 and Nod-P-1 leachates versus acidification time. Actual Na/Al ratios of the rock standards are BHVO-2 (0.23), JG-2 (0.40), W-2 (0.20) and Nod-P-1 (0.70).

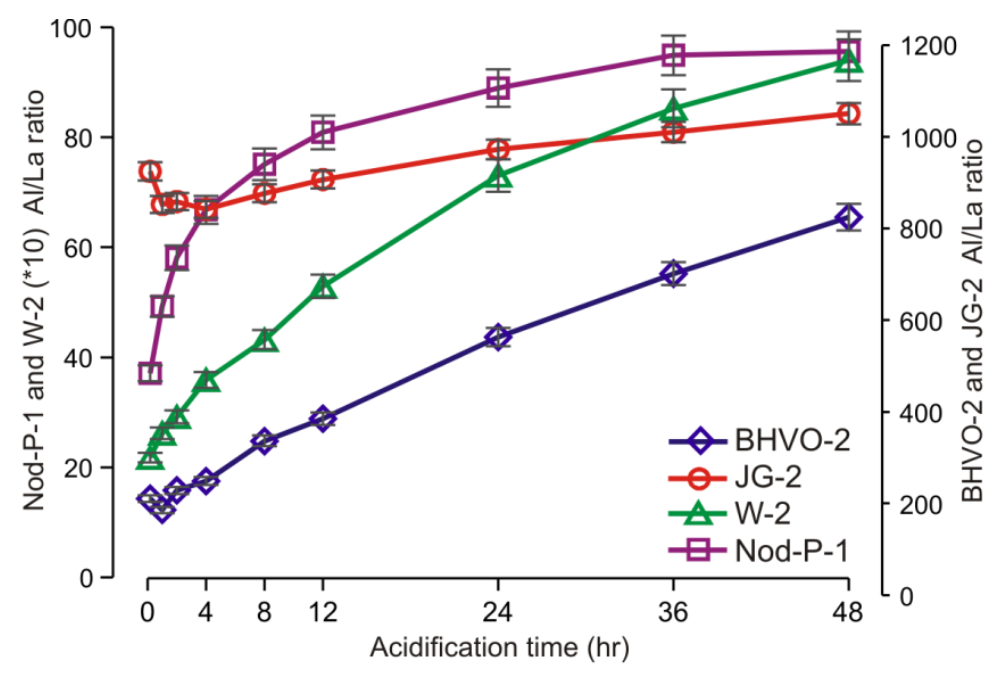

Figure 6.11: Variation in Al/La ratio of BHVO-2, JG-2, W-2 and Nod-P-1 leachate samples with acidification time. Actual Al/La ratios of the rock standards are BHVO-2 (4702), JG-2 (3132), W-2 (7574) and Nod-P-1 (229).

The $\mathrm{Al} /$ La ratio, the ratio of two potential conservative terrestrial tracers, varied with acidification time and dust lithology in our tests (Fig. 6.11). The Al/La ratio could potentially show changes between a predominantly silicate mineral assemblage with a high $\mathrm{Al} / \mathrm{La}$ ratio and an oxide-based mineral assemblage with a low Al/La ratio. 
However, the $\mathrm{Al} / \mathrm{La}$ ratio values in the four leachates of our tests did not reflect those of the rock standards and the use of terrestrial trace elements ratios as tracers of the provenance of mineral dust sources should also be treated with caution.. For example, the $\mathrm{Al} / \mathrm{La}$ ratio measured in the Nod-P-1 leachate was akin to that of the $\mathrm{W}-2$ leachate whereas their whole rock $\mathrm{Al} / \mathrm{La}$ ratios are 7574 and 229 respectively.

Element ratios are the basis of the calculation of enrichment factors, which are calculated by the following equation:

Crustal Enrichment Factor $E=\left(\left\lfloor E_{\text {sample }}\right\rfloor /\left[X_{\text {sample }}\right]\right) /\left(\left[E_{\text {crust }}\right] /\left[X_{\text {crust }}\right]\right)$

Ratios of element concentrations measured in the sample are divided through by element ratios reported for the continental crust. Any relative contribution from element $\mathrm{E}$ above that of the conservative terrestrial element $\mathrm{X}$ is classed as being enriched (from a source other than the crust) and any lower relative contribution from element $\mathrm{E}$ means that it is depleted relative to the crust. Crustal enrichment factors are used as a means of classifying trace elements in terms of their origin, usually defined as marine, terrestrial, anthropogenic or volcanic [Hur et al., 2007; Planchon et al., 2002b; Vallelonga et al., 2004]. As the calculation involves a ratio of two elements measured in the sample which may be leached incongruently from mineral dust the same caveats discussed above apply here too.

To test the sensitivity of crustal enrichment factors to incongruent mineral dust leaching crustal enrichment factors were calculated for $\mathrm{Cu}, \mathrm{V}$ and $\mathrm{U}$, which have been previously identified as having anthropogenic or volcanic inputs in some ice core samples [Hur et al., 2007; Planchon et al., 2002b; Vallelonga et al., 2004]. The calculations were conducted on leachate concentrations of an artificial ice core dust lithology comprising 50\% JG-2, 24.5\% BHVO-2, 24.5\% W-2 and 1\% Nod-P-1, leached at $10 \mathrm{ppm}$ dust concentration, using three different crustal reference elements, $\mathrm{Al}, \mathrm{Mn}$ and La (Fig. 6.12). Time-dependent trace element leaching causes the $\mathrm{EF}_{\mathrm{c}}$ values to vary with acidification time meaning values obtained for different samples or ice cores should only be compared with caution. This is especially applicable for calculations made using $\mathrm{Al}$ as a crustal reference element because $\mathrm{Al}$ is leached continuously and 
slowly over time, which causes the $\mathrm{EF}_{\mathrm{c}}$ values to decrease by more than $100 \%$ over the first week of leaching. Using Al as the crustal reference element produces the highest $\mathrm{EF}_{\mathrm{c}}$ values for $\mathrm{Cu}, \mathrm{V}$ and $\mathrm{U}$ because $\mathrm{Al}$ is more difficult to leach than $\mathrm{Mn}$ or La. In the case of $\mathrm{Cu}$ and $\mathrm{U}$, the $\mathrm{EF}_{\mathrm{c}}$ values are greater than 10 throughout the first week of leaching and this could be used to infer that $\mathrm{Cu}$ and $\mathrm{U}$ have anthropogenic or volcanic inputs, which is clearly not the case here. Ice core dust is rich in easily-transportable clay minerals which, as our JG-2 (biotite granite) test demonstrated, which quickly release many mono- and di-valent cations under leaching but release Al more slowly. Therefore, calculation of a crustal enrichment factor for an ice core sample using Al as the conservative terrestrial tracer could easily produce a misleading result which identifies cations, such as $\mathrm{Cu}, \mathrm{U}$ or other metals, as being enriched relative to the crust and therefore originating from another source, such as anthropogenic pollution.

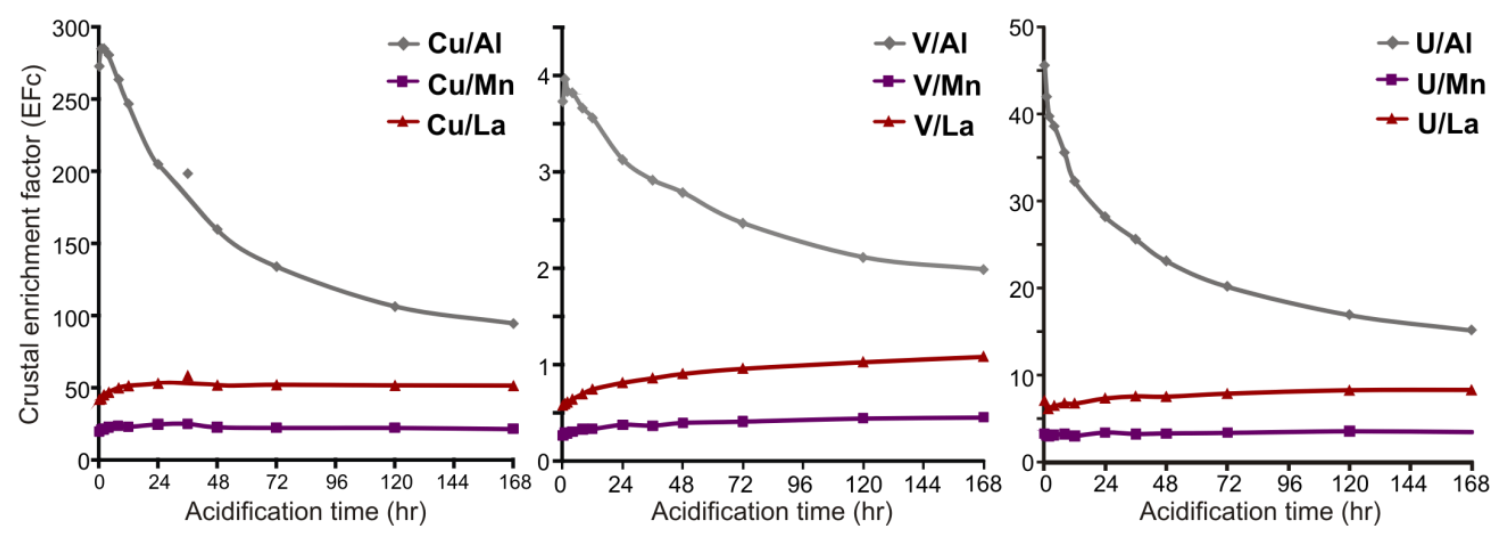

Figure 6.12: Crustal enrichment factors for $\mathrm{Cu}, \mathrm{V}$, and $\mathrm{U}$ calculated for a dust lithology comprising 50\% JG-2, 24.5\% BHVO-2, 24.5\% W-2 and 1\% Nod-P-1 using Al, Mn and La as crustal reference elements. Element ratios of the upper continental crust are from Wedepohl [1995].

Our tests have highlighted that the recovery of leached elements is dependent on the mineralogy of the dust present and that consequently, the leached concentrations rarely reflect those of the source dust. Yet, the crustal enrichment factor calculation normalises the element ratio measured in the ice core sample, which includes a component of partially dissolved mineral dust, to the element ratio of continental 
crust, which is derived from analysis of fully-digested rock [Reimann and De Caritat, 2000]. A more suitable approach towards the identification of $\mathrm{Cu}$ anthropogenic pollution, for example, would be to simply examine the evolution of the ice core $\mathrm{Cu} / \mathrm{Al}$, where Al could be replaced by any other terrestrial tracer. Providing that the sample acidification time allows a maximum leachable concentration to be reached, and that no major dust lithology change occurs, then an increase in $\mathrm{Cu} / \mathrm{Al}$ would suggest a contribution from anthropogenic pollution.

\subsubsection{REEs as dust source tracers}

Leaching the W-2 (diabase/dolerite) rock standard produced a REE concentration pattern in the $\mathrm{W}-2$ leachate that is significantly different to that of the $\mathrm{W}-2$ rock standard itself (Fig. 6.13). The W-2 leachates are enriched in light REEs (LREEs, La, Ce and $\mathrm{Pr}$ ) relative to middle REEs (MREEs, Gd) and heavy REEs (HREEs, Er and $\mathrm{Yb}$ ). The LREE/HREE ratio of the leachate is 11.7 compared to a ratio of 2.5 for the $\mathrm{W}-2$ rock standard. The magnitude of this enrichment remains constant with increasing acidification time causing the REE concentration pattern to not reflect that of the W-2 rock standard at any point in time. A similar pattern of LREE enrichment is seen in the BHVO-2 leachates (Appendix IX, Table A27) and was also identified as an artefact of ice core sample acidification by Gabrielli et al. [2010] in samples from EPICA Dome C, which have mineral dust concentrations several orders of magnitude lower than those used here (Section 6.3.3). In contrast, the JG-2 leachate is enriched in HREEs and MREEs relative to LREEs (Appendix IX, Table A27) because HREEs and MREEs are preferentially incorporated into biotite mica [Bea et al., 1994]. The geochemical characteristics of REEs mean they have the potential to be excellent tracers of mineral dust source region [Henderson, 1984] but REE concentration patterns derived by conventional ICP-MS analysis of ice core samples containing mineral dust will fractionate LREE/HREE and LREE/MREE ratios and will therefore not be representative of dust source region. A more robust approach would be to isolate and fully-digest mineral dust from ice core samples for analysis of REE concentrations. 


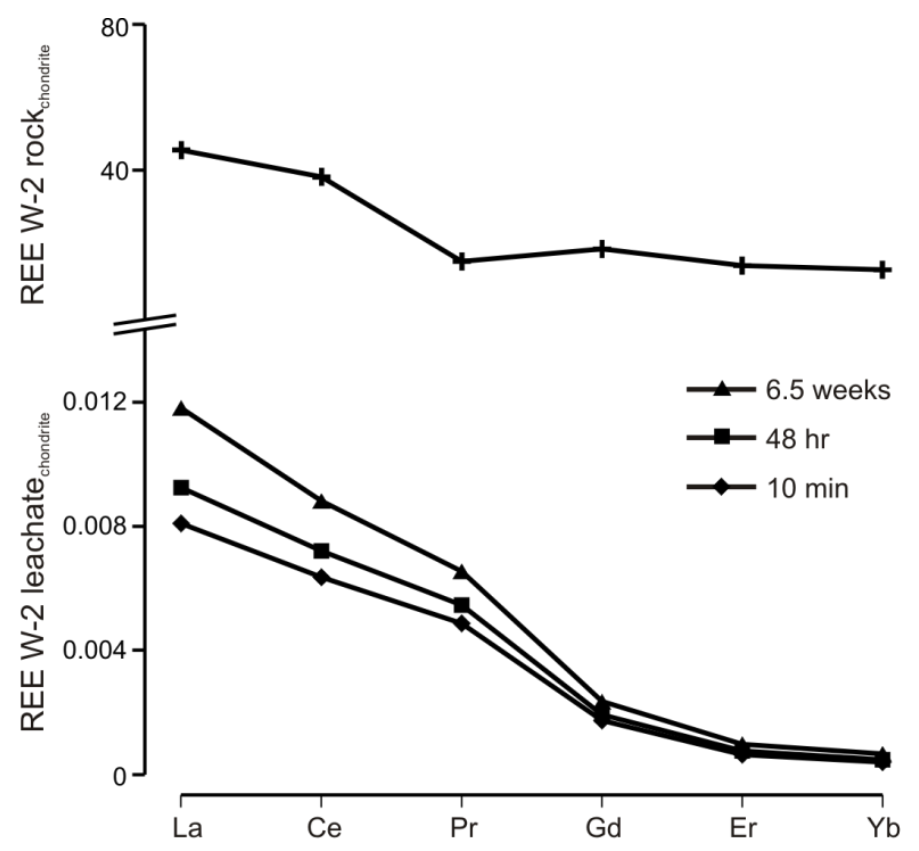

Figure 6.13: Chondrite-normalised plot of REE concentrations in W-2 rock standard and REE concentrations in leachates of W-2 leached at a concentration of $500 \mathrm{ppm}$. Leachate results from three different acidification times are displayed. Composition of $\mathrm{Cl}$ carbonaceous chondrite was taken from McDonough and Sun [1995].

\subsubsection{Redox-sensitive elements}

The Nod-P-1 rock standard has a Ce anomaly of 1.28 because Fe-Mn nodules are formed in an oxidised environment and incorporate $\mathrm{Ce}^{4+}$ scavenged from seawater, as well as $\mathrm{Ce}^{3+}$. In contrast, silicate rocks (BHVO-2, W-2 and JG-2) are formed in less oxidising magmatic environments and $\mathrm{Ce}$ is only present as $\mathrm{Ce}^{3+}$ resulting in no $\mathrm{Ce}$ anomaly. The Ce anomaly of the Nod-P-1 leachate was different to that of the Nod-P-1 rock standard throughout the leaching test (Fig. 6.14) because $\mathrm{Ce}^{3+}$ was leached in preference to $\mathrm{Ce}^{4+}$. This explains why the recovery of Ce after $12 \mathrm{hr}$ of leaching was significantly lower than that of the other LREEs (Fig. 6.6), which are only present as trivalent cations. As $\mathrm{Ce}^{3+}$ was leached, the $\mathrm{Ce}$ anomaly of the leachate progressively increased until a value of 1 was reached when all the $\mathrm{Ce}^{3+}$ present had been recovered. The Ce anomaly remained at 1 because $\mathrm{Ce}^{4+}$ was not leached into solution and the $\mathrm{Ce}$ anomaly did not therefore reflect the oxidised state of Fe-Mn nodule at any point 
during the leaching test. Ice core samples should be filtered to recover dust in order to provide useful information about the redox state of the environment.

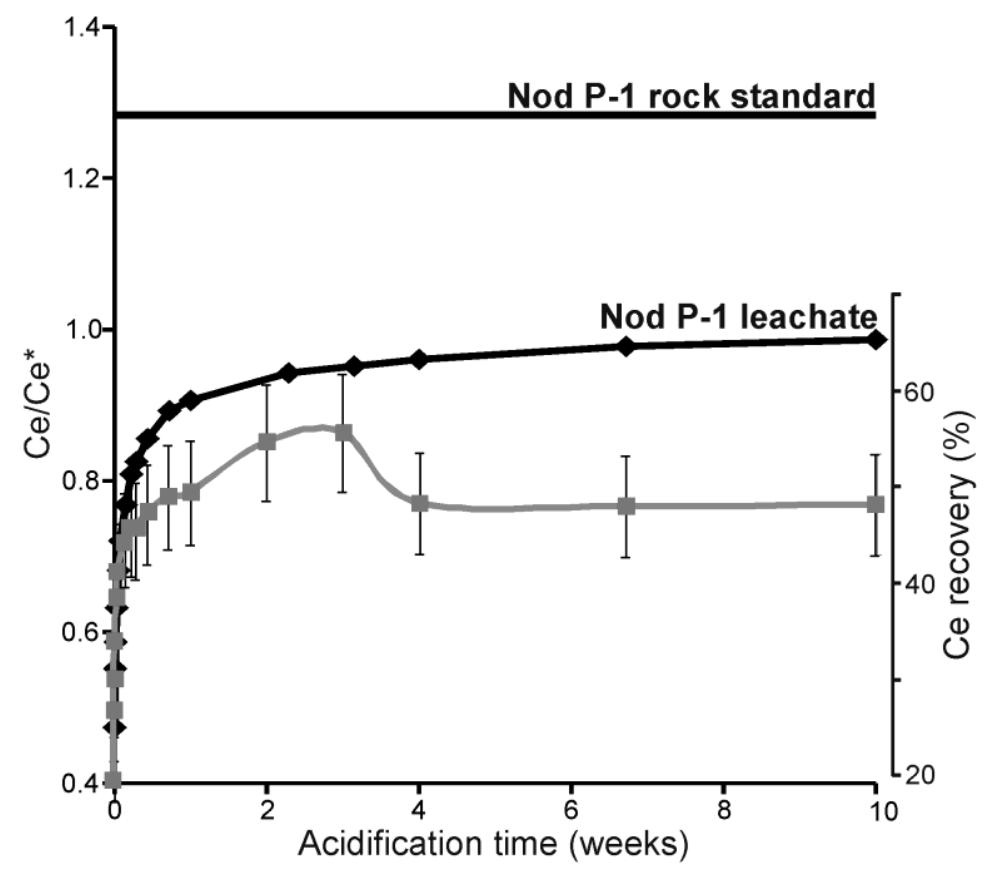

Figure 6.14: $\mathrm{Ce}$ anomaly ( $\left.\mathrm{Ce} / \mathrm{Ce}^{*}\right)$ of Nod-P-1 rock standard and variation in $\mathrm{Ce} / \mathrm{Ce}^{*}$ of Nod-P-1

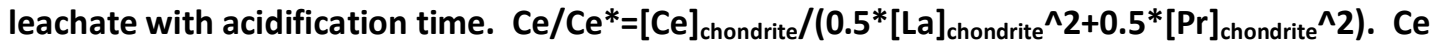
recovery versus acidification time is also displayed (grey line).

Fe and $\mathrm{Mn}$ are other redox-sensitive elements that are present at different oxidation states in Fe-Mn oxyhydroxide minerals. There is considerable scientific interest in determining the oxidation state of $\mathrm{Fe}$ in mineral dust that is a source of Fe to the surface ocean because $\mathrm{Fe}^{2+}$ is soluble in the ocean and therefore considered more bioavailable than $\mathrm{Fe}^{3+}$ [Schroth et al., 2009]. Our findings suggest that leaching of dust samples in 1 wt.\% $\mathrm{HNO}_{3}$ may yield a good first approximation of the concentration of Fe present as $\mathrm{Fe}^{2+}$. 


\subsection{Recommendations for future ice core trace element studies}

Based on the findings of this study a number of recommendations can be made regarding ICP-MS trace element analysis and the interpretation of ice core trace element data.

\subsubsection{Ice core ICP-MS analysis}

In order to eliminate the issue of partial dissolution of mineral dust, ice core samples could be fully-digested prior to ICP-MS analysis following the method of Correia et al. [2003]. Alternatively, samples could be filtered or centrifuged to remove the particulate phase and the soluble trace element budget could be accurately determined by ICP-MS. Complete digestion of the extracted dust would then allow determination of the partitioning of the ice core trace element budget between soluble and insoluble phases.

However, the process of dust separation and complete digestion is time-consuming and somewhat impractical for ice core projects involving large numbers of samples. In which case, unfiltered samples should be acidified and stored at room temperature for several months, prior to ICP-MS analysis in order to obtain the trace element concentrations of the maximum acid-leachable fraction. This longer acidification time will also significantly reduce any difference in leaching between the first and last sample an analytical session. Although our results indicate that refreezing samples after acidification promotes leaching of some elements, if samples are then allowed to leach for several months, as recommended, the freezing-enhanced leaching contribution will become negligible. 


\subsubsection{Ice core trace element data interpretation}

Trace element concentrations measured on samples acidified for varying lengths of time should not be directly compared without some assessment of the degree of uncertainty associated with incongruent mineral dust leaching.

Trace element concentrations originating from the partial dissolution of mineral dust will not reflect the composition of the dust itself and are not useful geochemical fingerprints of dust lithology. Assuming a uniform dust lithology, the trace element concentrations leached into solution will increase linearly with dust concentration. However, a change in the mineralogy of the source dust can cause considerable changes in the relative leaching of many mono- and di-valent trace elements.

$\mathrm{Al}$ is the most suitable element to use to assess the contribution of mineral dust partial dissolution because its rate of recovery from mineral dust tends not to vary between different dust lithologies. $\mathrm{Na} / \mathrm{Al}$ is identified as the marine/terrestrial ratio least affected by partial dissolution of mineral dust and therefore most likely to record changes in relative contributions of marine and terrestrial air masses. However, a change in dust lithology will alter the $\mathrm{Na} / \mathrm{Al}$ ratio of the ice core sample so other trace element ratios should be also examined to decipher the cause of any change.

In general, calculation of crustal enrichment factors should be carried out with caution because it normalises dust-leached concentrations to concentrations of bulk continental crust. If $\mathrm{Al}$ is used as a conservative terrestrial tracer in the calculation of crustal enrichment factors many elements will appear enriched purely as a result of incongruent leaching. This could lead to misleading conclusions regarding the input of trace elements from non-terrestrial sources such as volcanic degassing or anthropogenic pollution. REE concentration patterns obtained from samples containing leached mineral dust have fractionated LREE/MREE and LREE/HREE ratios and are therefore not suitable as tracers of dust source. 


\subsection{Conclusions}

We have conducted experiments to systematically assess the effects of mineral dust partial dissolution resulting from sample acidification on the trace element budget of ice core samples. The main conclusions of this investigation are:

- Leaching of trace elements from mineral dust in acidified samples is both timeand mineral-dependent.

- Oxide and sheet silicate minerals, such as micas and clays, release trace elements into solution relatively quickly whereas mafic minerals continue to release trace elements into solution over several weeks causing concentration increases of several orders of magnitude.

- The concentration of trace elements leached from mineral dust is proportional to the mineral dust concentration in the sample.

- We recommend acidifying samples for as long as practical to reach a maximum leachable concentration.

- Incongruent leaching of trace elements from mineral dust is likely to produce misleading crustal enrichment factor values.

- Ratios of trace elements, in particular REEs, leached from mineral dust will not reflect those of the dust and are not suitable as tracers of dust provenance. 


\title{
Chapter 7: Increased katabatic wind speeds and greater polynya extent in the Ross Sea region during the Little Ice Age
}

This chapter constitutes a paper prepared for submission to Climate of the Past (Section 1.6). Supplementary information is provided in appendices, which are located in Sections 7.7 and 7.8 of this chapter.

\begin{abstract}
Processes of bottom water formation and primary production in the Ross Sea region of Antarctica have the potential to create feedbacks in the global climate system. We present an ice core stable isotopic and soluble chemistry record, which captures the climate of the Little Ice Age (LIA), the most recent abrupt climate change, in this key region of Antarctica. Lithophile elements (e.g., Al), sourced from mineral dust are developed as proxies for katabatic wind speed, whilst deuterium excess (d-excess) and marine elements (e.g., $\mathrm{Na}$ ) are related to the incursion of cyclonic systems into the Ross Sea. The LIA record is characterised by relatively low $\delta D$ values and high concentrations of lithophile elements, compared to the ensuing time, suggesting that temperatures were $\sim 1.6{ }^{\circ} \mathrm{C}$ colder and that strong $\left(>57 \mathrm{~m} \mathrm{~s}^{-1}\right)$ katabatic winds prevailed. $\mathrm{Al}, \mathrm{Ti}$ and $\mathrm{Pb}$ concentration increases of an order of magnitude $>120 \mathrm{ppb}$ Al) mark the strongest wind events of the LIA and a >50\% decrease in mean concentrations signals the LIA termination. Furthermore, an abrupt 5\%o d-excess increase at 1625 AD suggests that cyclonic activity was enhanced between 1625 and 1875 AD. Methylsulphonate (MS) concentrations indicate that the Ross Sea Polynya was larger and more productive prior to $1875 \mathrm{AD}$, relative to the subsequent time. We suggest that a more extensive Ross Sea Polynya, maintained by strong katabatic winds, resulted in increased sea ice formation driving higher rates of bottom water formation during the LIA.
\end{abstract}




\subsection{Introduction}

The Little Ice Age (LIA) terminated only ca. $150 \mathrm{yr}$ ago and is the most recent of several cooling events that punctuated the Holocene [Domack and Mayewski, 1999; Masson et al., 2000]. The cause of the LIA has been widely speculated upon [e.g., Ammann et al., 2007; Broecker, 2000; Crowley, 2000], but no consensus has been reached despite the multitude of meteorological instrumental and proxy records available from the Northern Hemisphere [Jones et al., 2009]. Considerable variability exists globally in the timing, magnitude and character of the regional climate response [Matthews and Briffa, 2005]. In particular, it is unclear whether or not the two hemispheres experienced synchronous climate perturbations and what role the thermohaline circulation of the world's oceans may have played in instigating or amplifying the climate response [Broecker, 2000]. One vital aspect to understanding this event is the interpretation of Southern Hemisphere paleoclimate records, but few are currently available [Jones and Mann, 2004].

Antarctic ice cores are important archives of past climate and recently several have been obtained with sufficient temporal resolution to record the LIA [Bertler et al., in press; Stenni et al., 2002]. Whilst significant spatial and temporal variability exists [Masson et al., 2000; Morgan and van Ommen, 1997; Mosley-Thompson and Thompson, 1990; Stenni et al., 2002], Antarctica appears to have experienced cooler conditions during the LIA, synchronous with the Northern Hemisphere [Bertler et al., in press]. This suggests that reorganisation of the thermohaline circulation was not the driver of the LIA climate change and that further investigation is required.

In this study, we examine ice core glaciochemical records to reconstruct LIA climate in a key region of Antarctica - the Ross Sea region. The Ross Sea, in particular the Ross Sea Polynya, located along the edge of the Ross Ice Shelf, is a major site of Southern Ocean sea ice generation [Tamura et al., 2008], which drives bottom water formation [Jacobs and Giulivi, 1998]. Additionally, the region is the most biologically productive area of the Southern Ocean [Arrigo and van Dijken, 2003b]. Consequently, climatic changes occurring here have the potential to produce feedbacks, which influence both regional conditions and the global climate system [Turner et al., 2009]. 
A sub-annual resolution ice core record was retrieved from Mt Erebus Saddle (MES) on Ross Island, south-western Ross Sea (Fig. 7.1). The MES ice core site is located at the edge of the Ross Ice Shelf, at a boundary between the influences of two dominant meteorological regimes. Air masses originate from both the Southern Ocean, in the form of cyclones [Sinclair et al., 2010], and the interior of Antarctica, in the form of katabatic flow [Bromwich et al., 1992; Sinclair et al., 2010]. The two dominant air masses have different geochemical characteristics that allow them to be identified [Bertler et al., 2004a]. Thus, the location of the MES ice core site allows the meteorological regimes of the interior of Antarctica and the Ross Sea region to be traced back through time in the same ice core record.

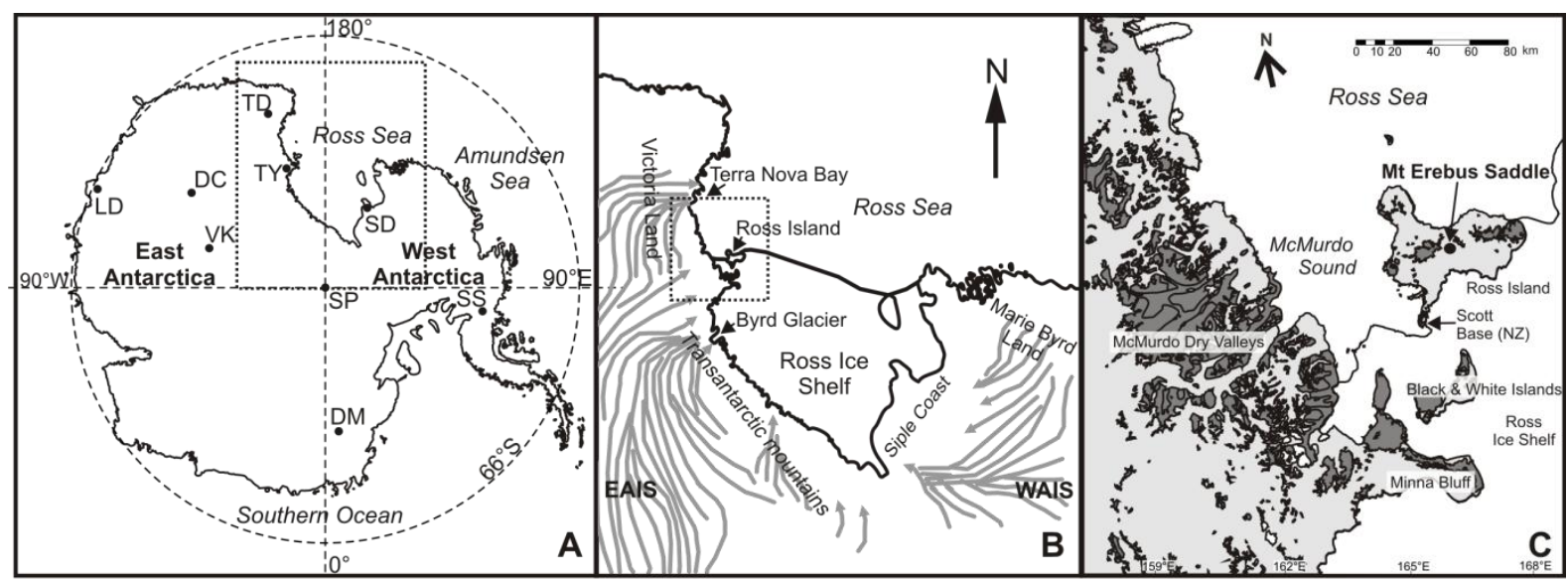

Figure 7.1: A) Map of the Antarctic continent. Locations of ice core sites referred to in the text are marked by solid black circles and are labeled as follows: DC $=$ EPICA Dome C, DM = EPICA Dronning Maud Land, LD = Law Dome, SD = Siple Dome, SP = South Pole, SS = Siple Station, TD = Talos Dome, TY = Taylor Dome. The dashed rectangle defines the area of map B. B) Map of the Ross Sea region bound by the East Antarctic Ice Sheet (EAIS) and the West Antarctic Ice Sheet (WAIS). Approximate katabatic flow paths are indicated by grey arrows (modified after Parish [1988]). The dashed rectangle defines the area of map C. C) Map of McMurdo Sound area. The location of Mt Erebus Saddle (MES) is shown. Dark grey shading indicates areas of exposed rock outcrop. 
A 550 yr continuous record of ice core lithophile element concentrations from this site provides a proxy for katabatic wind speeds, which were stronger prior to 1850 AD than at any ensuing time. A substantial decrease in katabatic flow speeds is identified at the LIA termination. Furthermore, by linking the katabatic wind proxy to d-excess, which is associated with the incursion of cyclonic systems, and methylsulphonate (MS'), a proxy for primary productivity, we demonstrate that stronger offshore winds caused a larger or more persistent Ross Sea Polynya between 1625 and 1875 AD. 


\subsection{Study site, core processing and analytical methods}

MES is a local snow accumulation zone situated at an altitude of $1600 \mathrm{~m}$ between Mt

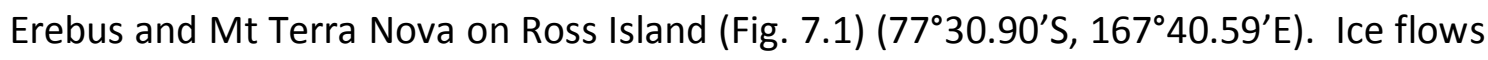
off the saddle in NNW and SSE directions. Ground penetrating radar indicated a depth to bedrock of $220 \mathrm{~m}$ and imaged parallel isochrones, suggesting favourable glaciological conditions for the preservation of a continuous, annually-resolved ice core record. A $168 \mathrm{~m}$ deep ice core was drilled at the centre of the ridge, in the zone of minimum ice flow, in December 2006. Annual temperature at the site, ascertained from firn temperature logging, is $-25.6{ }^{\circ} \mathrm{C}$ and the accumulation rate calculated from the annual layer count is $0.22 \mathrm{~m}\left(\mathrm{H}_{2} \mathrm{O}\right.$ equivalent $) \mathrm{yr}^{-1}$.

A brief summary of the processing and analysis of the ice core is only provided here, with full details of the analytical methods including precision, accuracy and detection limits given in Appendix I (Section 7.7). Here, we present data from the uppermost $120 \mathrm{~m}$ of the ice core, which was processed for chemical analysis using a continuous melter-discrete sampling system [Osterberg et al., 2006]. Pristine samples from the interior of the core were analysed by ion chromatography (IC) for major ions and by inductively coupled plasma mass spectrometry (ICP-MS) for 22 major, minor and trace elements. Stable isotope ratios $\delta^{18} \mathrm{O}$ and $\delta D$ were determined on samples from corresponding depths obtained from the outer section of core. In addition, the tritium $\left({ }^{3} \mathrm{H}\right)$ contents of six samples were measured. 


\subsection{Dating}

The MES ice core was dated by annual layer counting of stable isotopic and soluble chemistry signals, using key reference horizons as age tie points. A back-diffusion model [Johnsen, 1977; Johnsen et al., 2000] was applied to the stable isotope ratio profiles to recover the annual signal at depth, facilitating annual layer counting. A glacial flow model provided further constraint on the evolution of the age model [Dansgaard and Johnsen, 1969]. Detailed description of the parameters used for annual layer counting is provided in Appendix II (Section 7.8).

A peak in levels of ${ }^{3} \mathrm{H}$, relating to thermonuclear bomb testing, provides an age tie point for the age model and confirms reliability of the annual layer counting technique. Elevated tritium contents were determined in the MES ice core between 1964 and $1972 A D$, in line with measurements reported in Antarctic and New Zealand precipitation (Appendix II (Section 7.8)) and other Antarctic ice core records [Jouzel et al., 1979; Oerter et al., 1999; Stenni et al., 2002].

Large amplitude peaks in non-sea salt (nss) $\mathrm{SO}_{4}{ }^{2-}$ determined in ice core records are typically attributed to major volcanic eruptions and are often used as age tie points in age model development [Dixon et al., 2004; Legrand and Delmas, 1987; Palmer et al., 2001; Stenni et al., 2002; Traufetter et al., 2004]. However, positive identification of volcanic nssSO ${ }_{4}{ }^{2-}$ deposition in the MES ice core is difficult because the $\mathrm{nsSSO}_{4}{ }^{2-}$ signal is dominated by biogenic $\mathrm{nsSO}_{4}{ }^{2-}$ from the seasonally open ocean (Section 7.5.1).

As an alternative, we examined the deposition history of heavy, volatile trace elements, which are emitted by volcanoes [Hinkley et al., 1994] and can be deposited on ice sheets [Kaspari et al., 2007; Kellerhals et al., 2010]. In the MES ice core, Pb, Bi and TI are all strongly enriched relative to terrestrial element concentrations in at least 8 consecutive samples between 60.5 and $61.1 \mathrm{~m}$ depth (Fig. 7.2). The annual layer count suggests this signal is deposition from the eruption of Mt Tambora, Indonesia in April 1815 AD [Simkin and Siebert, 1994]. However, Vallelonga et al. [2003] attributed elevated $\mathrm{Pb}$ and $\mathrm{Bi}$ concentrations in a Law Dome (Fig. $1 \mathrm{~A}$ ) ice core at this time to emissions from Mt Erebus, on the basis of Pb isotopic signatures. As MES is located 
adjacent to Mt Erebus it is plausible that the trace element record of the MES ice core may record the eruption history of $\mathrm{Mt}$ Erebus rather than that of global-scale stratospheric eruptions. To test this hypothesis, trace element ratios measured across the $\mathrm{Pb}, \mathrm{Tl}$ and $\mathrm{Bi}$ peaks were compared to trace element ratios measured in the plume of Mt Erebus (Fig. 7.2). None of the trace element ratios exhibit any marked deviation from the median value of the ice core record (green line) during the proposed $\mathrm{Mt}$ Tambora eruption. This lends support to attribution of the $\mathrm{Bi}, \mathrm{Pb}$ and $\mathrm{Tl}$ peaks at 61.1 $\mathrm{m}$ to the Mt Tambora eruption. Moreover, the median values (Fig. 7.2, green line) of the MES ice core trace element ratios are different from those of the Mt Erebus plume (Fig. 7.2, purple line) providing evidence that the ice core trace element budget is predominantly influenced by input from other sources. 


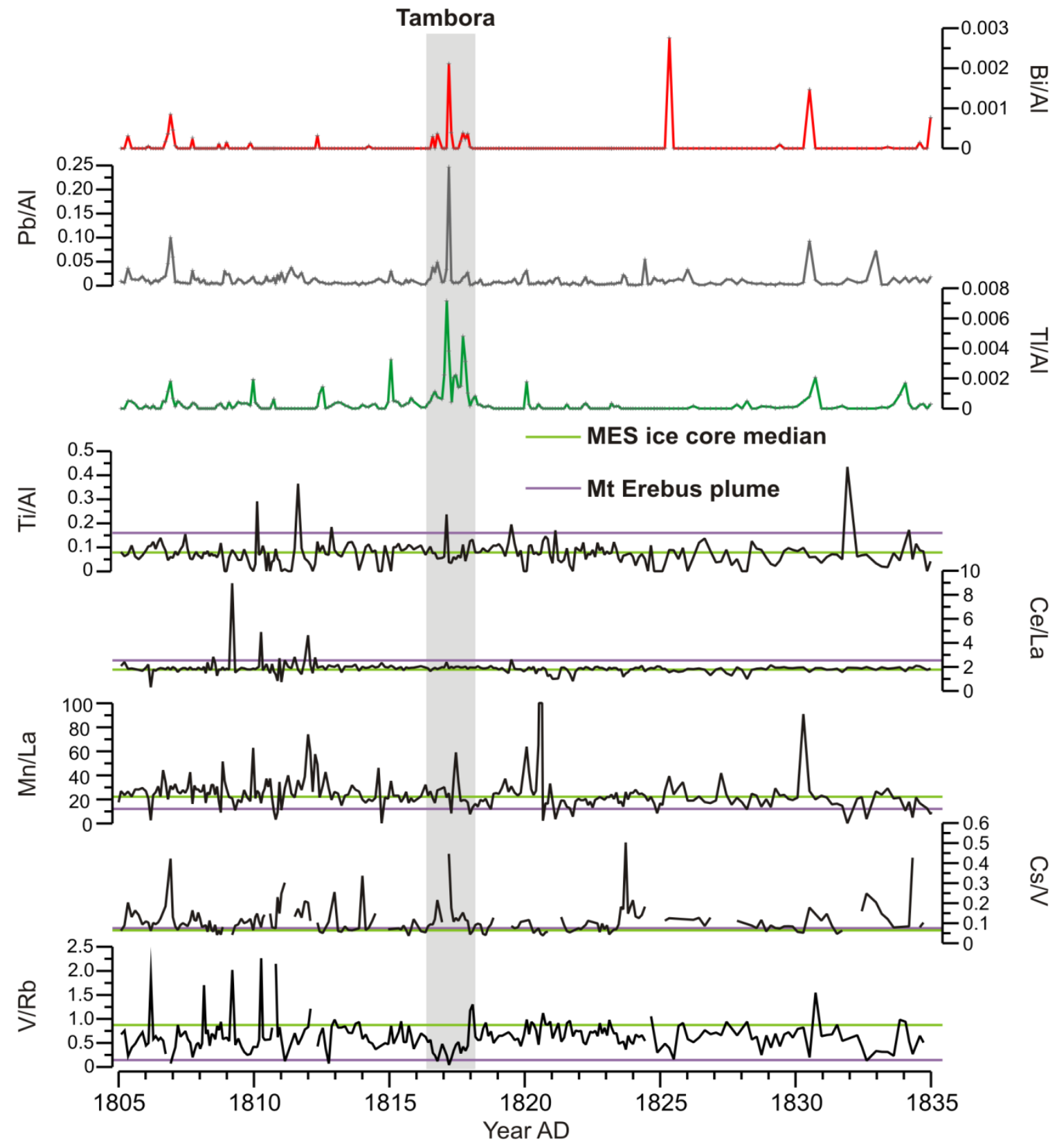

Figure 7.2: $\mathrm{Bi}, \mathrm{Pb}$ and $\mathrm{Tl}$ concentrations normalised to $\mathrm{Al}$ and selected trace element ratio records for the time period including the Mt Tambora eruption marker. The trace element ratios of the Mt Erebus plume are plotted where available [Zreda-Gostynska et al., 1997] and the median values for the entire MES ice core record are shown. Breaks in the record occur where the concentration of an element is below the ICP-MS detection limit. 
Further support for the accuracy of the age model can be drawn from comparison of $\mathrm{Pb}$ concentrations determined in the MES ice core with the history of anthropogenic $\mathrm{Pb}$ contamination recorded in an ice core from Law Dome (Fig. 7.3). A rise in $\mathrm{Pb} / \mathrm{Al}$ is seen at $1893 \mathrm{AD}$ in the MES record, within $9 \mathrm{yr}$ of the increase in $\mathrm{Pb}$ concentrations at Law Dome, which is attributed to anthropogenic activity [Vallelonga et al., 2002].

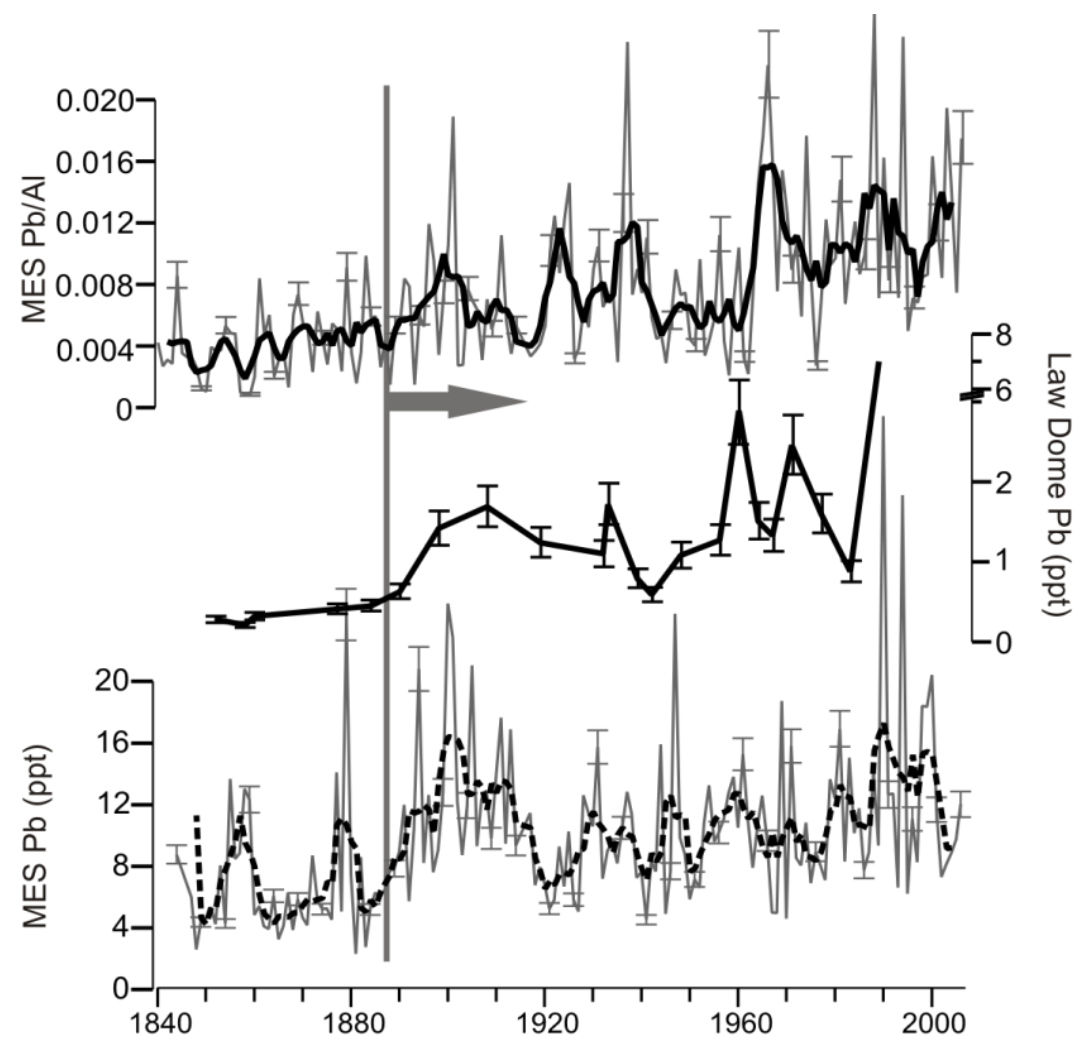

Figure 7.3: Anthropogenic influence on Pb deposition at MES since 1840 AD. All MES data plotted are annual means to remove seasonal variability. A $5 \mathrm{yr}$ running mean is plotted through the MES Pb concentration data (dash line). MES Pb concentrations are also shown normalised to $\mathrm{Al}$ to remove the influence of variable mineral dust contributions. $\mathrm{Pb}$ concentrations determined at Law Dome are plotted for comparison [Vallelonga et al., 2002]. Grey arrow indicates onset of anthropogenic $\mathrm{Pb}$ pollution determined at Law Dome. All error bars are $\pm 2 \sigma$. 
A total of 561 annual layers are identified in the $120 \mathrm{~m}$ of core analysed. A sub-annual sampling resolution is maintained throughout the core; in the deepest $10 \mathrm{~m}$ section of core $84 \mathrm{yr}$ are preserved and each year has $\geq 4$ stable isotope samples and $\geq 2$ ICP-MS samples. The incremental error on the dating of individual years or the duration of discrete time periods is $\pm 1 \mathrm{yr}$ between the surface and $61.1 \mathrm{~m}$ (1816 AD), the depth of the Mt Tambora eruption marker. The cumulative dating error, which is the difference between the age of the reference marker and the initial age indicated by the annual layer count is $\pm 1 \mathrm{yr}$ at $1964 \mathrm{AD}\left({ }^{3} \mathrm{H}\right.$ peak) and $\pm 9 \mathrm{yr}$ at $61.1 \mathrm{~m}$ (Mt Tambora). The dating uncertainty on the record below $61.1 \mathrm{~m}$ depth is difficult to constrain because no further age reference markers are identifiable. 


\subsection{Results}

\subsubsection{Stable isotopes}

The MES ice core $\delta D$ record displays well-developed seasonal cycles between a mean summer (Jan $1^{\text {st }}$, fixed by dating) maximum of $-202 \%$ and a mean winter (July $1^{\text {st }}$ ) minimum of $-221 \%$ in the $1970-2006$ AD time period (Fig. 7.4). Only the $\delta D$ record will be referred to in the following sections because the $\delta^{18} \mathrm{O}$ displays essentially the same variability. The second order stable isotopic parameter d-excess also shows a welldeveloped seasonal cycle with early-summer maxima and a mean annual oscillation of $2.1 \%$ o between summer and winter values (Fig. 7.4). Although $\delta D$ and d-excess show similar seasonality, by plotting both time series about their respective long term means, it is demonstrated that they have different interannual variability (Fig. 7.5). Regression of $\delta D$ and $d$-excess annual mean or maximum values produces no significant correlation.

The long term $\delta D$ record of MES ice core is characterised by frequent oscillations about the 1950-2006 AD mean (Fig. 7.7). The only deviations in $\delta D$ below this mean of $>4 \mathrm{yr}$ duration occur prior to $1850 \mathrm{AD}$. The most notable of these low $\delta \mathrm{D}$ periods are $1470-$ 1535 AD, 1560-1580 AD, 1605-1630 AD, 1670-1700 AD, 1760-1780 AD and 1835-1850 $A D$. The mean $\delta D$ of the pre- 1850 AD period is $5.6 \%$ lower than that of the post -1850 $A D$ period (Table 7.1). In contrast, the d-excess record of the MES ice core is dominated by an abrupt shift towards a consistently elevated d-excess state at 1625 AD. The preceeding time period (1446-1625 AD) is characterised by d-excess values 3.1\%o lower than the 1950-2006 mean. Between 1625 and 1875 AD the d-excess $5 \mathrm{yr}$ running mean only deviates below the 1950-2006 mean once, at ca. 1800 AD. The mean d-excess value of the $1625-1875 \mathrm{AD}$ time period is $5.1 \%$ o higher than that of the preceeding time and 1.5\% higher than the following time (Table 7.1). 


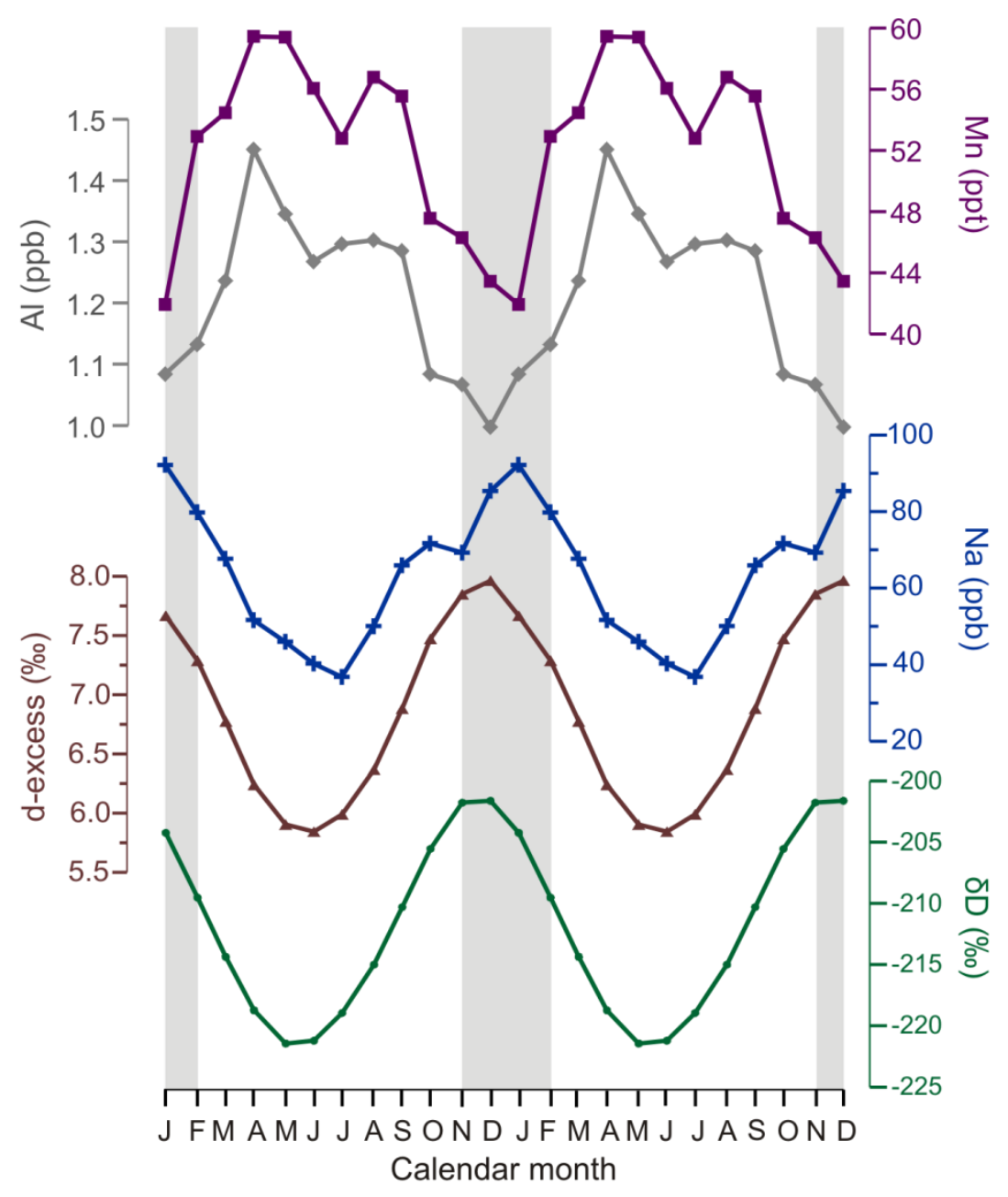

Figure 7.4: Mean seasonal cycles of $\delta \mathrm{D}, \mathrm{d}$-excess, marine aerosol $(\mathrm{Na})$ and lithophile elements (AI and $\mathrm{Mn}$ ) for 1970-2005 AD. Two cycles are plotted to aid viewing. Data points are plotted at the end of each month, i.e., peak $\delta D$ is plotted at end of December, equivalent to January $1^{\text {st }} . \delta D$ and d-excess are back-diffused to correct for changes in amplitude and phasing of seasonal cycles resulting from molecular diffusion (Appendix II, Section 7.8). 
Table 7.1: Mean and range (in parentheses) of selected stable isotopic and soluble chemistry parameters within specified time intervals of the MES ice core record.

\begin{tabular}{c|cccccc} 
& SD (\%o) & d-excess $(\%)$ & Na (ppb) & Al (ppb) & Mn (ppt) & Ce (ppt) \\
\hline $\mathbf{1 9 5 0 - 2 0 0 6}$ & -211.6 & 7.0 & 76.5 & 1.33 & 61.9 & 3.95 \\
& $(-254.1$ to -130.4$)$ & $(0.2$ to 21.8$)$ & $(2.15$ to 506$)$ & (0.09 to 7.06$)$ & (0 to 301) & (0 to 24.3) \\
$\mathbf{1 8 5 0 - 2 0 0 6}$ & -209 & 7.7 & 95.7 & 1.64 & 55.7 & 4.1 \\
(post-LIA) & $(-255$ to -130.4$)$ & $(0.2$ to 21.8$)$ & $(2.15$ to 853$)$ & $(2.02$ to 18.9$)$ & (0 to 472$)$ & (0 to 26.6) \\
$\mathbf{1 4 4 6 - 1 8 5 0}$ & -215.4 & 6.81 & 89.5 & 3.45 & 90.5 & 15.7 \\
(LIA) & $(-266.5$ to -147.2$)$ & $(-3.66$ to 20.5$)$ & $(2.48$ to 1111$)$ & $(0.20-125)$ & (0 to 940$)$ & (0.25-294) \\
$\mathbf{1 6 2 5 - 1 8 7 5}$ & -213.7 & 9.1 & 97.1 & 5.02 & 85.3 & 15.3 \\
& $(-266.5$ to -157.6$)$ & $(1.6$ to 20.5$)$ & $(2.48$ to 1110$)$ & $(0.20$ to 125$)$ & (0 to 940$)$ & (0.10 to 294) \\
1446-1625 & -216.5 & 3.9 & 89.5 & 3.45 & 90.5 & 15.7
\end{tabular}

\subsubsection{Soluble chemistry}

A Pearson's correlation shows the degree of co-variability between the concentrations of the elements determined by ICP-MS (Table 7.2). $\mathrm{Na}, \mathrm{Mg}$ and $\mathrm{Sr}$ are highly correlated $\left(R^{2}>0.86, p<0.01\right)$ in the MES ice core record. Bivariate plots place the samples onto straight lines corresponding to seawater concentration ratios, indicating a marine source for these elements. We focus on the Na record but consideration of the $\mathrm{Mg}$ or $\mathrm{Sr}$ record would produce similar results. Annual maximum Na concentrations $(92 \mathrm{ppb}$ mean) generally occur in summer, coincident with the annual peaks in $\delta D$ (Fig. 7.4) between 1970 and 2006 AD. The Na record exhibits significant interannual variability (Fig. 7.5) and concentrations range from 2 to $506 \mathrm{ppb}$ in the 1950-2006 AD record (Table 7.1). Na concentrations remain relatively constant with no abrupt changes over the long term record (Fig. 7.6). However, the mean Na concentration increased by $8.5 \%$ (Table 7.1) after the abrupt positive shift in d-excess observed at 1625 AD. 
Table 7.2: Correlation coefficients for major, minor and trace element concentrations (12 samples $\mathrm{yr}^{-1}$ ) during the 1970-2006 AD time period in the MES ice core. All values shown are significant at the $99 \%$ level, $n=439$.

\begin{tabular}{|c|c|c|c|c|c|c|c|c|c|c|c|c|c|}
\hline $\mathbf{R}^{2}$ & $\mathrm{Na}$ & $\mathrm{Mg}$ & Al & $\mathrm{Ti}$ & v & $M n$ & $\mathbf{R b}$ & $\mathrm{Sr}$ & $Y$ & $\mathrm{Ba}$ & La & $\mathrm{Ce}$ & $\mathrm{Pb}$ \\
\hline $\mathrm{Na}$ & 1 & & & & & & & & & & & & \\
\hline Mg & 0.86 & 1 & & & & & & & & & & & \\
\hline Al & - & 0.02 & 1 & & & & & & & & & & \\
\hline $\mathrm{Ti}$ & - & - & 0.51 & 1 & & & & & & & & & \\
\hline V & 0.36 & 0.38 & 0.44 & 0.52 & 1 & & & & & & & & \\
\hline$M n$ & - & 0.02 & 0.75 & 0.55 & 0.39 & 1 & & & & & & & \\
\hline $\mathbf{R b}$ & 0.15 & 0.15 & 0.61 & 0.58 & 0.73 & 0.47 & 1 & & & & & & \\
\hline $\mathrm{Sr}$ & 0.90 & 0.90 & 0.06 & 0.06 & 0.50 & 0.06 & 0.27 & 1 & & & & & \\
\hline $\mathbf{Y}$ & - & - & 0.42 & 0.43 & 0.29 & 0.44 & 0.46 & 0.02 & 1 & & & & \\
\hline $\mathrm{Ba}$ & - & - & 0.12 & 0.18 & 0.08 & 0.13 & 0.13 & 0.03 & 0.12 & 1 & & & \\
\hline La & - & - & 0.75 & 0.69 & 0.53 & 0.62 & 0.71 & 0.05 & 0.52 & 0.10 & 1 & & \\
\hline $\mathrm{Ce}$ & - & - & 0.74 & 0.68 & 0.51 & 0.64 & 0.68 & 0.05 & 0.54 & 0.09 & 0.97 & 1 & \\
\hline $\mathrm{Pb}$ & - & - & 0.11 & 0.21 & 0.06 & 0.16 & 0.13 & 0.03 & 0.13 & 0.49 & 0.10 & 0.09 & 1 \\
\hline
\end{tabular}

Al, Ti, Mn, Rb, Y, La and Ce concentrations all correlate at $\mathrm{R}^{2}>0.5(\mathrm{p}<0.01)$ and display similar temporal variability between 1970 and 2006 AD (Fig. 7.5). This group of elements is hereafter referred to as 'lithophile elements'. Cs, Pr, $\mathrm{Tl}, \mathrm{Bi}$, Th and $\mathrm{U}$ were excluded from the correlation because they frequently registered at below the ICP-MS detection limit. In addition, $\mathrm{Ca}$ and $\mathrm{Zr}$ were excluded due to evidence of contamination from ceramic tools used in processing of the ice core. $\mathrm{Pb}$ is only weakly correlated $\left(R^{2}<0.2\right)$ with the lithophile elements because substantial anthropogenic input occurs during the time period considered (Fig. 7.3). Maximum concentrations of lithophile elements in the MES ice core occur during autumn and winter months (Fig. 7.4, $\mathrm{Al}$ and $\mathrm{Mn}$ shown), the opposite to the seasonal cycles of $\mathrm{Na}, \delta \mathrm{D}$ and d-excess. The Al mean seasonal cycle of 1970-2006 AD shows a 45\% concentration increase in winter relative to summer.

The long term ice core record reveals that lithophile element concentrations decreased significantly around 1850 AD (Fig. 7.6). The mean concentrations of Al, Mn and Ce are all $>60 \%$ higher in the period prior to 1850 AD compared to post-1850 AD (Table 7.1). Furthermore, significant variability between the behaviour of different lithophile elements, not observable in the record of the last $35 \mathrm{yr}$ (Figure 7.5), can be discerned 128 
in the long term record (Figure 7.6). For example, the mean $\mathrm{Mn}$ concentration decreased by $38 \%$ after $1850 \mathrm{AD}$, whereas the Ce mean concentrations decreased by 74\%. The lithophile elements can be categorised by the extent of inter-correlation in the pre-1850 AD period (Table 7.3). Three discrete groups are identifiable: correlation coefficients of $\mathrm{R}^{2}>0.52$ are produced between $\mathrm{Al}, \mathrm{Ti}$ and $\mathrm{Pb}, \mathrm{R}^{2}>0.63$ between $\mathrm{Mn}$ and $\mathrm{Rb}$, and $\mathrm{R}^{2}>0.92$ between $\mathrm{Y}, \mathrm{La}$, and Ce. Figures 7.5 and 7.6 both display the concentration record of one element from each of these groups.

$\mathrm{MS}^{-}$concentrations vary between 1 and $187 \mathrm{ppb}$ about a mean of $54 \mathrm{ppb}$ (Fig. 7.7). A period of significantly higher concentrations, equating to a $81 \%$ increase in mean concentration, is identifiable between 1825 and 1875 AD. MS $^{-}$data are only available for the section of MES core dating from 1797 to 2006 AD.

Table 7.3: Correlation coefficients for lithophile element concentrations ( 2 samples $\mathrm{yr}^{-1}$ ) during the LIA recorded in MES ice core (1446-1850 AD).

All values shown are significant at the $99 \%$ level, $n=809$.

\begin{tabular}{l|rrrrrrrr}
$\mathbf{R}^{2}$ & \multicolumn{1}{|c}{$\boldsymbol{A l}$} & \multicolumn{1}{c}{$\boldsymbol{T i}$} & \multicolumn{1}{c}{$\boldsymbol{M n}$} & $\boldsymbol{R} \boldsymbol{b}$ & $\boldsymbol{Y}$ & $\boldsymbol{L} \boldsymbol{a}$ & $\mathbf{C e}$ & $\mathbf{P b}$ \\
\hline $\mathbf{A l}$ & 1 & & & & & & & \\
$\mathrm{Ti}$ & 0.81 & 1 & & & & & & \\
$\mathbf{M n}$ & 0.13 & 0.12 & 1 & & & & & \\
$\mathbf{R b}$ & 0.07 & 0.06 & 0.63 & 1 & & & & \\
$\mathbf{Y}$ & 0.08 & 0.06 & 0.52 & 0.43 & 1 & & & \\
$\mathbf{L a}$ & 0.06 & 0.05 & 0.45 & 0.38 & 0.92 & 1 & & \\
$\mathbf{C e}$ & 0.10 & 0.08 & 0.45 & 0.36 & 0.94 & 0.98 & 1 & \\
$\mathbf{P b}$ & 0.59 & 0.52 & - & - & - & - & - & 1
\end{tabular}



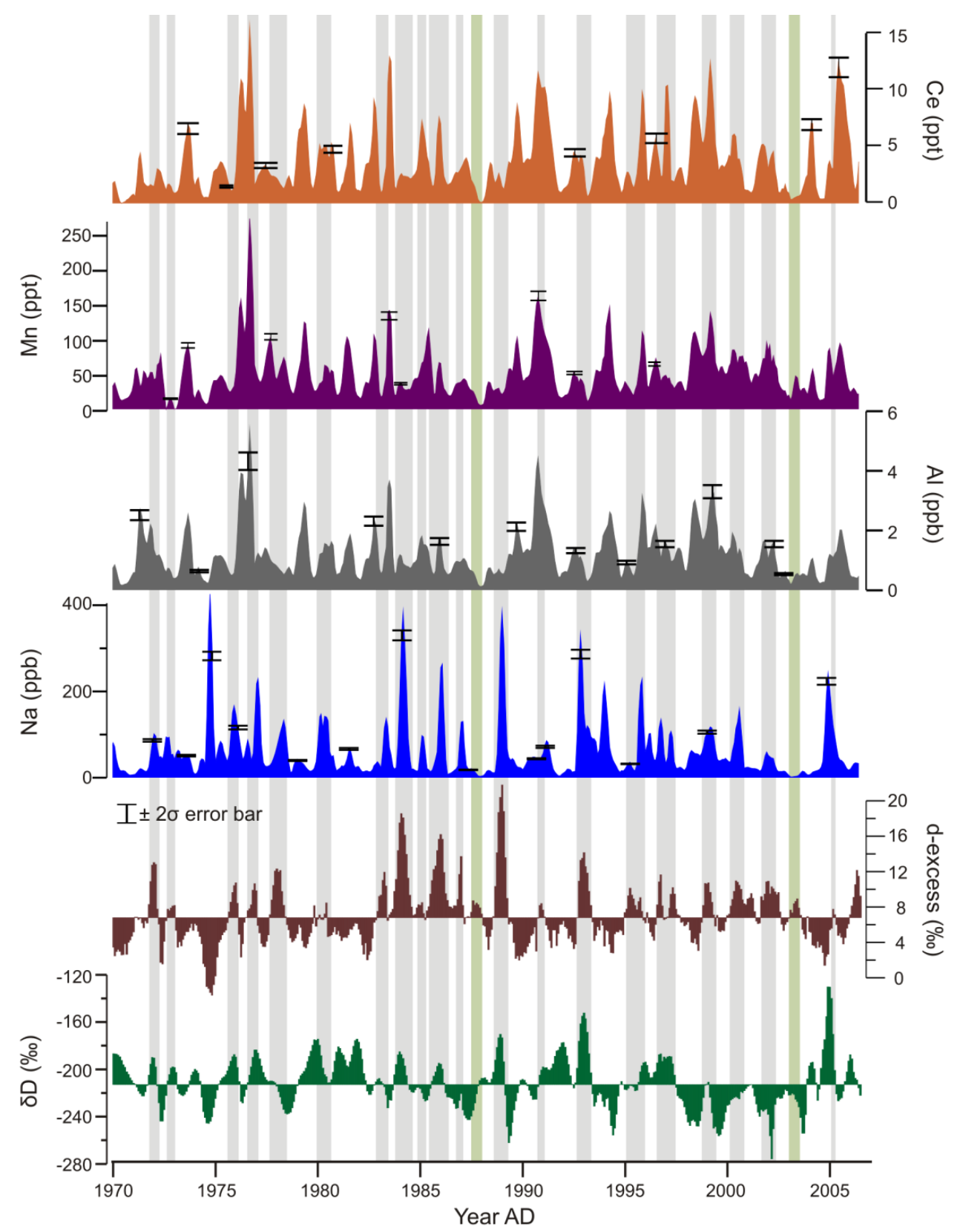

Figure 7.5: Stable isotope and soluble chemistry data for the period 1970-2006 AD of the MES ice core. All the time series have been re-sampled to monthly resolution and a 3 month running mean has then been applied to the soluble chemistry time series. $\delta \mathrm{D}$ and $d$-excess are plotted around 1970-2006 mean values. Representative analytical error bars $( \pm 2 \sigma)$ are displayed on selected points. $\delta D$ analytical error bars are too small to plot and the d-excess analytical error is indicated. Shaded bars highlight d-excess values exceeding the 1970-2006 mean with associated Na peaks (grey shading) or without associated Na peaks (green shading). 


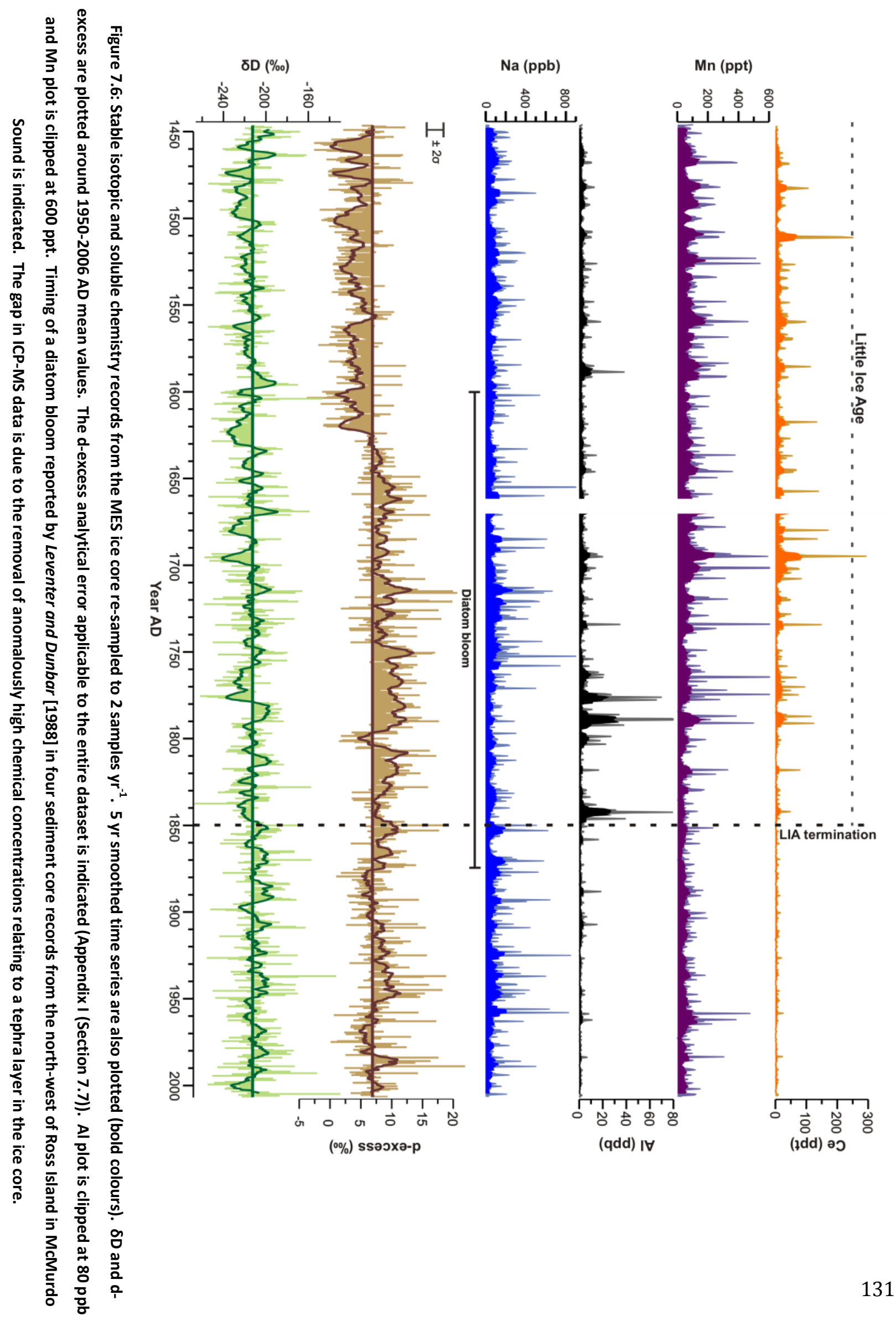




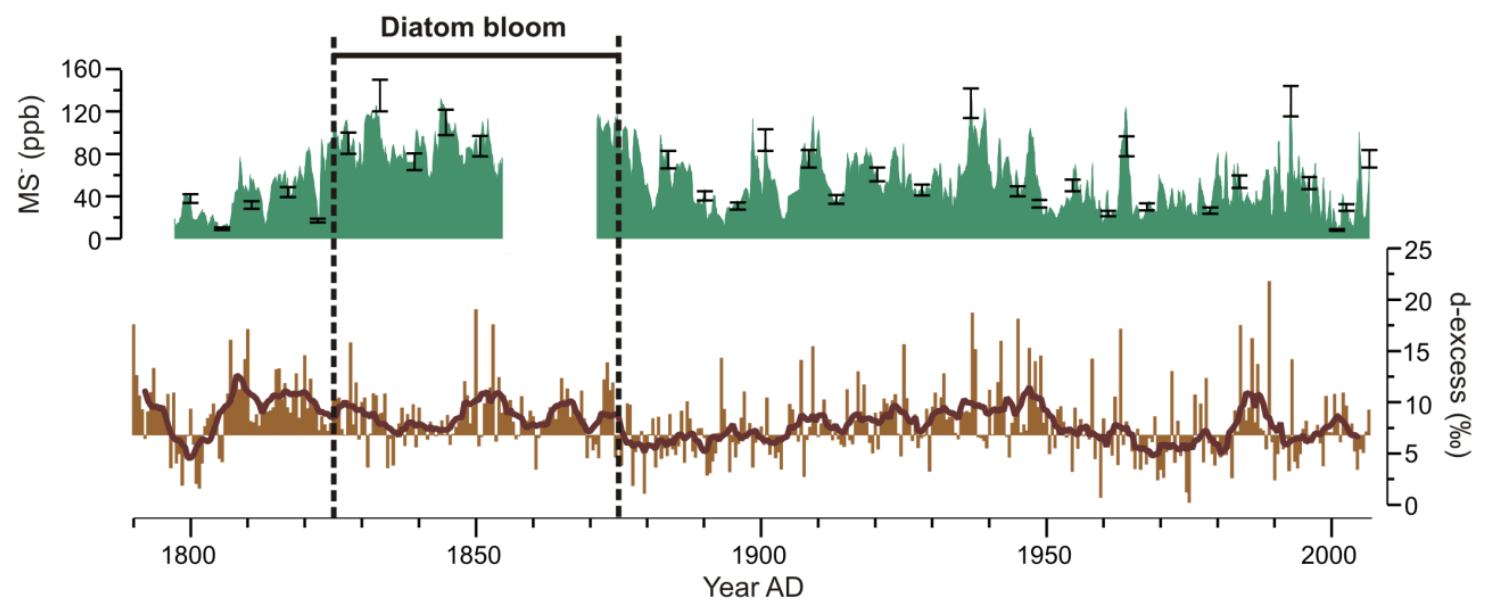

Figure 7.7: Deuterium excess and MS ${ }^{-}$time series from MES ice core. MS $^{-}$is raw data smoothed

by 5-point running mean. Deuterium excess time series re-sampled to 2 samples $\mathrm{yr}^{-1}$ and smoothed by 5 yr running mean (as Fig. 7.6). Timing of a diatom bloom reported by Leventer and Dunbar [1988] in two sediment core records from the west of Ross Island in McMurdo Sound is indicated. Representative analytical error bars $( \pm 2 \sigma)$ are displayed on selected points. The gap in MS' time series exists because some samples have not been analysed for $\mathrm{MS}^{-}$concentration. 


\subsection{Discussion}

\subsubsection{Linking the ice core record to climate parameters}

Stable isotopic ratios ( $\delta \mathrm{D}$ and $\delta^{18} \mathrm{O}$ ) in ice cores are well-established proxies of Antarctic air temperature [Craig, 1961; Dansgaard, 1964]. However, for the MES ice core record direct calibration of the stable isotopic paleothermometer is challenging. No statistically significant relationship can be established with air temperature recorded at Scott Base (Fig. 7.1C) or gridded reanalysis data, most likely because neither data set provides an acccurate representation of conditions at MES. The effects of the extreme topography of Ross Island are not well represented in the gridded dataset, and MES experiences significantly different weather conditions to Scott Base (N. A. Bertler, Personal communication).

Two different mechanisms of aerosol generation are advocated for marine chemistry in ice core records: aerosol generated via bubble bursting over the open ocean [Curran et al., 1998; Legrand and Mayewski, 1997] and the entrainment of frost flowers from the sea ice surface [Rankin et al., 2002]. The growth of frost flowers on the sea ice surface involves precipitation of miribalite $\left(\mathrm{Na}_{2} \mathrm{SO}_{4} \cdot 10 \mathrm{H}_{2} \mathrm{O}\right)$, which is depleted in $\mathrm{SO}_{4}{ }^{2-}$ relative to $\mathrm{Na}^{+}$[Rankin et al., 2000]. This leads to a fractionated $\mathrm{Na}^{+} / \mathrm{SO}_{4}{ }^{2-}$ ratio in ice core marine aerosol records with a frost flower source [Kaspari et al., 2005; Rankin et al., 2004]. However, the $\mathrm{Na}^{+} / \mathrm{SO}_{4}{ }^{2-}$ ratio of MES ice core samples exhibits no depletion in $\mathrm{SO}_{4}{ }^{2-}$ (Fig. 7.8). $\mathrm{SO}_{4}{ }^{2-}$ concentrations are actually enriched relative to seawater concentrations due to additional input from biogenic $\mathrm{SO}_{4}{ }^{2-}$. The absence of $\mathrm{Na}^{+} / \mathrm{SO}_{4}{ }^{2-}$ values higher than the seawater value, together with the predominance of summer maxima in $\mathrm{Na}$ concentrations (Fig. 7.5), is indicative of an open water source for marine aerosol at MES [Rankin et al., 2004]. 


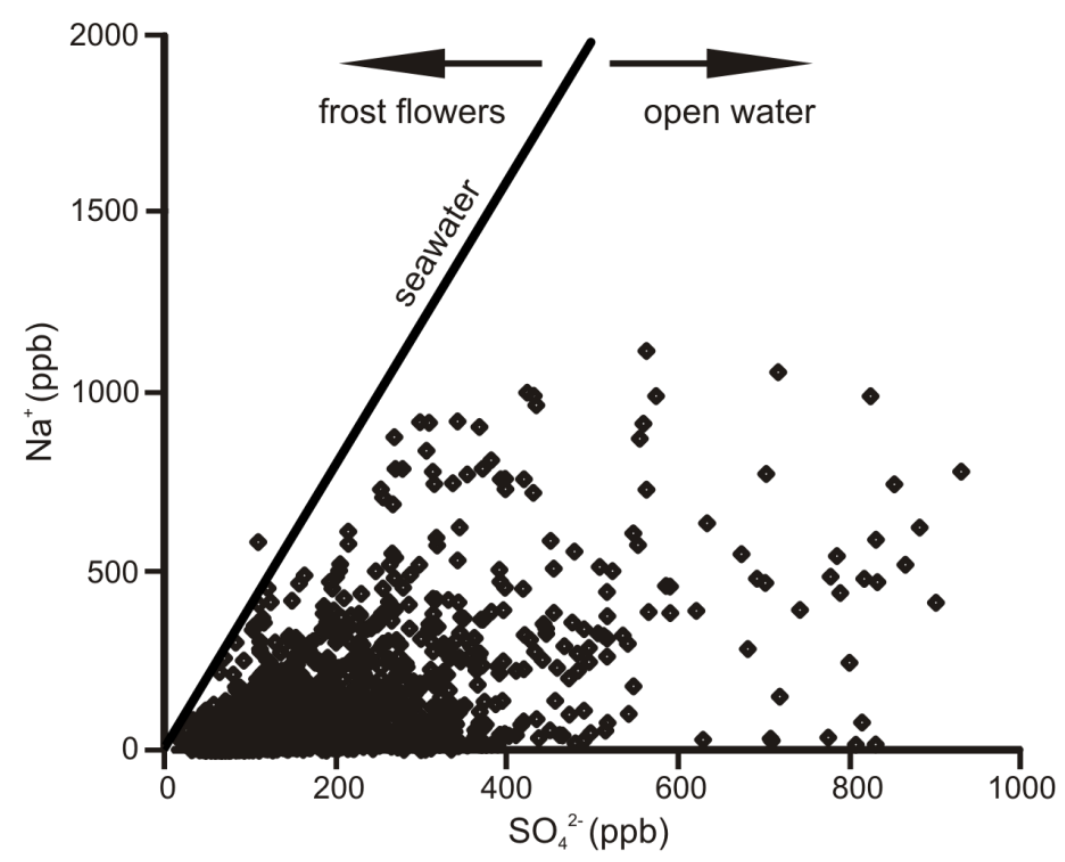

Figure 7.8: Scatterplot of $\mathrm{Na}^{+}$versus $\mathrm{SO}_{4}{ }^{2-}$ concentrations of all MES samples measured by IC (surface-65.8 m; 1797-2006 AD). ICP-MS Na concentrations are plotted for 59.6-65.8 $\mathrm{m}$ because IC cation data is not available. Black line is the $\mathrm{Na}^{+} / \mathrm{SO}_{4}{ }^{2-}$ of seawater and all samples, except one, plot below this line. $\mathrm{Na}^{+} / \mathrm{SO}_{4}{ }^{2-}$ values indicate $\mathrm{Na}^{+}$is sourced from the open ocean.

The d-excess and marine element records show similar interannual trends; in the 1970-2006 AD record, $90 \%$ of $d$-excess peaks greater than the long term mean have corresponding peaks in marine element concentrations (Fig. 7.5, grey shaded bars). Furthermore, the maximum summer values of $\mathrm{Na}$ and d-excess between 1970 and $2006 A D$ are significantly correlated $\left(R^{2}=0.58, p<0.01\right)$, suggesting a common forcing. Deuterium excess is primarily controlled by factors associated with the moisture source, principally relative humidity [Merlivat and Jouzel, 1979; Petit et al., 1991]. We speculate that high d-excess values in the MES record are related to the advection of air masses from low latitude source regions, of low relative humidity, by cyclonic activity. Synoptic-scale cyclones are known to provide precipitation to the southwestern Ross Sea by either remaining stationary to the north of the Ross Sea and promoting the incursion of marine air or by tracking around the interior of the Ross Ice Shelf [Sinclair et al., 2010]. Either mechanism would cause the entrainment of $\mathrm{Na}$ from 
the seasonally open water of the Ross Sea, leading to the relationship between $d$ excess and $\mathrm{Na}$ observed.

Seasonal cycles in d-excess, as observed in the MES core, have also been reported in Antarctic ice core records from Law Dome [Delmotte et al., 2000], South Pole and Adelie Land [Ciais et al., 1995]. Detailed delineation of potential oceanic moisture source regions, coupled with isotopic modelling, is required to understand the origin of the seasonality in the MES d-excess signal.

Lithophile elements are tracers of mineral dust transport to an ice core site [Rhodes et al., 2011]. Several areas of outcropping rock are located within $160 \mathrm{~km}$ of MES in the Dry Valleys and along the Transantarctic Mountains (Fig. 7.1), and these are likely source areas for mineral dust in the ice core. Furthermore, with such abundant local dust sources it can be assumed that the variability of lithophile element concentrations in the MES ice core is primarily controlled by input from these local (100s of km distance away), rather than global (1000s of km distance away) dust sources. Previous studies of dust transport and deposition in the south-western Ross Sea region support this conclusion [Ayling and McGowan, 2006; Dunbar et al., 2009]. We do not attempt to relate the lithophile element signatures recorded in the ice core to the various dust lithologies of the region as previous work [Rhodes et al., 2011] has shown that no reliable indication of provenance would be produced (Section 6.6.2). Rather, the lack of perfect positive correlation between $\mathrm{Al}, \mathrm{Ti}, \mathrm{Mn}, \mathrm{Rb}, \mathrm{Y}, \mathrm{La}$ and $\mathrm{Ce}$ is likely to reflect mineral-specific differential rates of weathering and transport efficiency [Caquineau et al., 1998; Reimann and De Caritat, 2000], and incongruent leaching of trace elements from mineral dust in acidified samples [Rhodes et al., 2011].

Increased lithophile element concentrations during autumn and winter months (Fig. 7.4) indicate that strong (>35 $\mathrm{m} \mathrm{s}^{-1}$ ) southerly winds, which are recorded at Scott Base (data available at www.cliflo.co.nz), are required to transport sufficient mineral dust material to MES to produce the concentration maxima. The strong southerly flows recorded at Scott Base result from katabatic winds, which originate from the West and East Antarctic Ice Sheets [Parish, 1988] and propagate across the Ross Ice Shelf [Bromwich et al., 1992]. It is also important to note that the opposite seasonal cycle of lithophile and marine element concentrations at MES (Fig. 7.4) supports the 
assignment of two different meteorological systems, katabatic winds and marine cyclones respectively, as transport mechanisms for these chemical species.
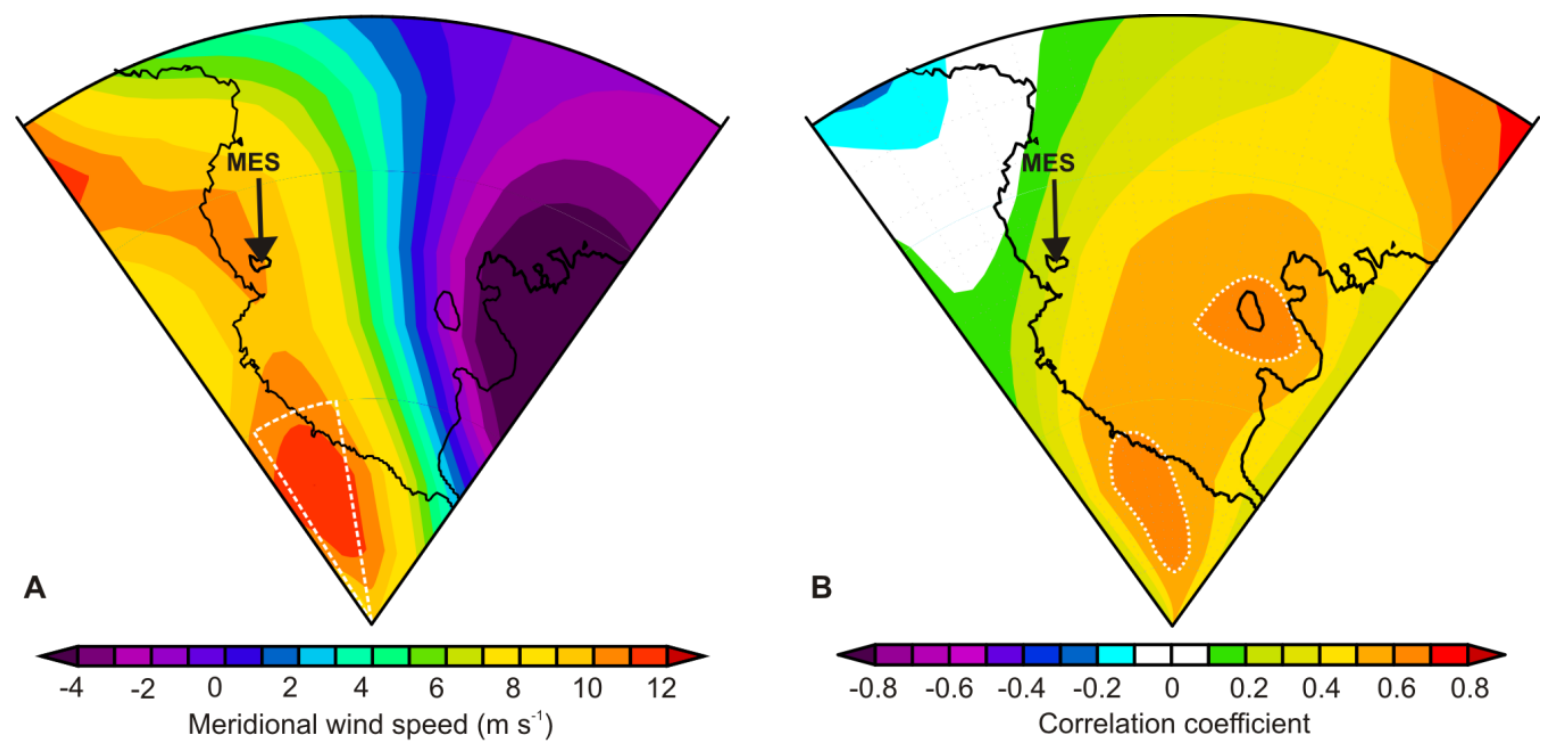

Figure 7.9: A) NCEP/NCAR reanalysis $850 \mathrm{mb}$ meridional wind composite mean for the winter months (JJA) of 1979-2006 AD across the Ross Sea region (90-70 $\left.\mathrm{S}, 150-220^{\circ} \mathrm{E}\right)$. White dashed line defines the source region of meridional winds arriving at MES. B) Spatial correlation pattern between meridional wind $(850 \mathrm{mb})$ and MES Al concentration record for the winter months (JJA) of 1990-2000 AD across the Ross Sea region. White dashes outline region of significant correlation $(p<0.025, n=10)$.

To further investigate the relationship between lithophile element concentrations and katabatic winds, we correlate MES ice core data with NCEP/NCAR reanalysis meridional wind strength [Kalnay et al., 1996]. In this region of Antarctica, the meridional (south to north) component of the wind field is an approximation of katabatic wind flow (Fig. 7.9). No significant correlation between wind speed and lithophile element concentration could be achieved for the entire time period for which reliable Antarctic NCEP/NCAR data are available (1979-2006 AD). However, when individual decades are studied, a significant correlation with Al concentration is observed between 1990 and $2000 \mathrm{AD}$ (Fig. 7.9). In contrast to the 1980s, the 1990s were characterised by a relatively strong teleconnection between the El Niño Southern Oscillation and 136 
Antarctica [Fogt and Bromwich, 2006]. This led to enhanced katabatic flow speeds in the Ross Sea region [Bertler et al., 2004b], and a stronger signal in the MES katabatic wind proxy. The area of significant correlation includes the Transantarctic Mountains to the south of MES, a source region for katabatic winds to the site, which further confirms katabatic flow as the mechanism for mineral dust transport to MES.

\subsubsection{Little Ice Age climate}

The portion of the LIA captured in the MES ice core (1446-1850 AD) is characterised by elevated lithophile element concentrations (Fig. 7.6, Table 7.1) and the rapid decrease in lithophile element concentrations between 1848 and 1850 AD marks the termination of the LIA. The ice core record currently dates back to $1446 \mathrm{AD}$ and there is no indication that the onset of the LIA is captured. A frequently cited date for the onset of the LIA in the Northern Hemisphere is 1450 AD [Grove, 1988] but estimates vary; an ice core record from the Antarctic Dry Valleys [Bertler et al., in press], and a tree ring climate reconstruction from South America [Villalba, 1994], have suggested the onset was ca. 150 yr earlier in the Southern Hemisphere.

As lithophile element concentrations in the MES ice core are proxies for katabatic wind strength, the elevated concentrations suggest that katabatic wind speeds were considerably stronger during the LIA. As a threshold wind velocity must be exceeded to transport particles in suspension [Bagnold, 1941], it is likely that increased maximum wind speed, as opposed to relatively prolonged katabatic flow events, led to the increased transport of mineral dust revealed by higher lithophile element concentrations during the LIA. Formulating an approximation of how much stronger katabatic winds were is challenging, principally because the relationship between dust entrainment and wind speed is not linear [Bagnold, 1941; Pye, 1987; Schulz et al., 1998]. However, as the elevated lithophile element concentrations of the LIA are not repeated in the post-1850 AD ice core record, we can assume that wind speeds did not reach such strength again. At Scott Base the maximum daily gust speed recorded since 1972 was $57.7 \mathrm{~ms}^{-1}$ from due south, so LIA maximum wind speeds must have exceeded this value. 
By examining the behaviour of the three groups of lithophile elements identified in Section 6.4.2 and their links to mineralogy and wind speed, considerable climate variability within the LIA is revealed. $\mathrm{Al}, \mathrm{Ti}$ and $\mathrm{Pb}$ show increased mean concentrations (Table 7.1, Al shown), coupled with discrete periods of dramatic concentration increases of several orders of magnitude, during the LIA (Fig. 7.6, AI shown). These elements are predominantly sourced from complex silicate minerals, such as feldspars, which have relatively high densities and large grain sizes, causing the threshold wind velocity required to transport them in suspension to be high [Bagnold, 1941]. The discrete periods of increased Al, Ti and Pb concentrations (1760-1805 AD and 1838-1850) represent the most extreme wind speeds of the LIA period. In contrast, the lithophile elements of the second group, $\mathrm{Mn}$ and $\mathrm{Rb}$, which show more muted concentration increases during the LIA, are common in Fe-Mn oxyhydroxides and sheet silicate minerals such as clays and micas, respectively. All of these minerals have relatively low densities and are easily weathered, forming flake-like particles of a low, uniform grain size, which require a lower threshold wind velocity to initate transport in suspension [Bagnold, 1941]. Thus, $\mathrm{Mn}$ and $\mathrm{Rb}$ concentrations are not a reflection maximum wind strength. The third group of lithophile elements, consisting of La, Ce and Y, show characteristics of both the other two groups. Similarly to Mn, La, $\mathrm{Ce}$ and $\mathrm{Y}$ are abundant in oxyhydroxide minerals but they are also common impurities in silicate minerals, particularly apatite. During discrete time periods of the LIA, concentrations increase by an order of magnitude but the timing of these extreme events does not not always match that of the large increases in Al and Ti (Fig. 7.6).

The MES $\delta D$ record suggests that colder temperatures, as well as stronger winds, than those experienced in the past $50 \mathrm{yr}$ prevailed during the LIA. The significant negative deviations in $\delta D$ from the 1950 to 2006 AD mean identified in Section 7.4.1 all date from the LIA. In the absence of representative weather station data with which to calculate a local $\delta$-temperature slope, we employ the Taylor Dome $\delta$ - temperature calibration of $4 \% \mathrm{oD} /{ }^{\circ} \mathrm{C}$ [Steig et al., 1998] to estimate the degree of cooling experienced at MES during the LIA. Taylor Dome, located in the Ross Sea region (Fig. $7.1 \mathrm{~A})$, is the most proximal ice core for which a local $\delta$ - temperature slope has been established. The difference between the mean $\delta D$ of the LIA and the post-LIA period is 138 
6.4\%o (Table 7.1), which equates to a mean cooling of $1.6^{\circ} \mathrm{C}$ during the LIA. The difference in the minimum $\delta D$ values suggests that temperatures could have been $2.5^{\circ} \mathrm{C}$ colder during discrete time periods of the LIA.

Furthermore, the increase in d-excess at 1625 AD suggests that either a change occurred at the oceanic moisture source to reduce relative humidity or the moisture source switched to one of a lower relative humidity [Petit et al., 1991]. The abrupt nature of the transition seems to make a moisture source change the more likely explanation. The elevated d-excess values between 1625 and 1875 AD could indicate that intrusion of marine cyclones from lower latitiude (low relative humdity) oceanic moisture source regions was more frequent during this time. An increased level of storminess during this time period is also supported by the presence of higher marine aerosol concentrations in the post-1625 AD MES ice core record.

\subsubsection{Ross Sea Polynya in the Little Ice Age}

Although the $\mathrm{MS}^{-}$record has limited temporal coverage, it indicates that primary productivity and polynya area, were greater prior to 1875 AD than in the following years (Fig. 7.7). The effectiveness of the biogenic sulphur species $\mathrm{MS}^{-}$as a primary productivity proxy relating to the area of the Ross Sea Polynya has been demonstrated previously [Rhodes et al., 2009]. Polynya size exerts a direct influence on rates of marine primary productivity [Arrigo and van Dijken, 2004] because primary productivity is stimulated by increased the sunlight availability when polynya size is enhanced [Arrigo and McClain, 1994]. By extrapolating the linear relationship between $\mathrm{MS}^{-}$concentration ( $\mathrm{x}$ ) and primary production ( $\mathrm{y}$ ) established by Rhodes et al. [2009] ( $y=1.35 x-3.41)$, we calculate that between 1825 and 1875 AD primary productivity rates were approximately $80 \%$ higher than post- 1875 AD levels.

Independent evidence for heightened primary productivity in the Ross Sea at this time is found in increased diatom abundances in sediment cores from McMurdo Sound [Leventer and Dunbar, 1988]. Records of diatom abundance from two sediment cores from the west of Ross Island reveal a period of increased primary productivity between 
1825 and 1880 AD [Leventer and Dunbar, 1988] corresponding almost precisely to the interval of higher $\mathrm{MS}^{-}$concentrations observable in the MES record (Fig. 7.7). A further prolonged time period (1600-1875 AD) of increased open water diatom populations is identified in a four sediment cores retrieved from the north and northwest of Ross Island. Taking into account dating errors, this corresponds remarkably well to the period of high d-excess values recorded in the MES ice core (1652-1875 AD) (Fig. 7.6).

Heightened primary productivity, and therefore greater polynya extent, appears to be linked to increased cyclonic activity. This can be explained by considering the controls on polynya formation and size. The Ross Sea Polynya (and other minor polynyas in the Ross Sea region) are mechanically-driven and are maintained by strong offshore katabatic winds [Bromwich et al., 1998; Morales Maqueda et al., 2004]. For katabatic winds to propagate across the relatively flat Ross Ice Shelf a strong pressure gradient is required and this is created by the presence of cyclonic (low pressure) systems [Bromwich et al., 1992; Bromwich et al., 1993]. As variability in the size of the Ross Sea Polynya over recent decades has been linked to katabatic wind strength [Morales Maqueda et al., 2004], we propose that the combination of colder temperatures and increased cyclonic activity in the Ross Sea region led to stronger katabatic flows, which maintained a spatially larger and/or more temporally persistent polynya between 1625 and 1875 AD. Supporting evidence for stronger katabatic winds across East Antarctica during this interval of the LIA is found in an ice core micro-particle record from South Pole [Mosley-Thompson, 1995].

As the MES ice core provides evidence for a greater polynya extent between 1625 and 1875 AD, we now consider that greater polynya size led not only to increased primary productivity but also to increased rates of sea ice production [Morales Maqueda et al., 2004]. Sea ice formation drives the formation of deep water masses by ejecting dense, saline brine which sinks to depth. In the Ross Sea, an intermediate water mass called High Salinity Shelf Water (HSSW) is formed, which contributes to Antarctic Bottom Water [Jacobs and Giulivi, 1998]. Therefore, it is feasible that increased sea ice production in the polynya amplified bottom water formation rates during the 16251875 AD period. Furthermore, it is conceivable that the increased katabatic wind 
strength recorded in the MES and South Pole ice cores affected the other wind-driven polynyas around the Antarctic continent [Morales Maqueda et al., 2004]. Increased bottom water formation in Antarctic coastal polynyas may have driven the increase in Southern Hemisphere bottom water formation during in the LIA, identified by Broecker et al. [1999]. Combined with enhanced primary productivity, this could have resulted in stronger drawdown of atmospheric $\mathrm{CO}_{2}$ into the ocean, contributing to the 6-8 ppm decrease in atmospheric $\mathrm{CO}_{2}$ concentration observed in other Antarctic ice cores, which occurred ca. 1600 AD and persisted until ca. 1800 AD [Etheridge et al., 1996; Indermuhle et al., 1999]. 


\subsection{Conclusions}

Ice core stable isotope and soluble chemistry document the last $550 \mathrm{yr}$ of climate in the south-western Ross Sea region of Antarctica at sub-annual resolution. Dating of the record is accomplished by a combination of annual layer counting and a glacial flow model, with the timing of anthropogenic $\mathrm{Pb}$ deposition in Antarctica providing support for accuracy of the age model. Examination of the monthly resolution record of the last $35 \mathrm{yr}$ allowed climate proxies to be developed. Lithophile elements concentrations are related to mineral dust transport by katabatic winds whilst more positive d-excess values appear to be linked to the incursion of marine cyclones into the Ross Sea.

The MES ice core record suggests that the Ross Sea region experienced colder temperatures $\left(\right.$ by $\left.\sim 1.6^{\circ} \mathrm{C}\right)$ and stronger $\left(>57 \mathrm{~m} \mathrm{~s}^{-1}\right)$ katabatic winds during the LIA. The termination of the LIA between 1848 and 1850 AD is marked by a decrease in lithophile elements concentrations indicating a substantial reduction in katabatic wind speed. Furthermore, the d-excess record suggests incursion of marine cyclones into the Ross Sea was more frequent between 1625 and 1875 AD. The MS $^{-}$record demonstrates that marine primary productivity increased during this time and suggests that polynya area was greater. The occurrence of diatom blooms recorded in sediment cores [Leventer and Dunbar, 1988] support this interpretation. It is hypothesised that colder temperatures and increased cyclonic activity promoted stronger katabatic winds across the Ross Ice Shelf, causing sea ice divergence and creating a greater polynya area in the Ross Sea.

We suggest that increased sea ice formation resulting from greater polynya extent caused enhanced rates of bottom water formation at this time. Change in the thermohaline circulation of the oceans could therefore be a response to, rather than the initial driver of, climate change at the LIA [cf. Broecker, 2000]. 


\subsection{Appendix I: Analytical methods}

\subsubsection{Core processing}

The continuous-melter-discrete sampling system [Osterberg et al., 2006] allowed the pristine ice of the inner core to be continuously sampled for chemical analysis (IC and ICP-MS). From the surface to $66 \mathrm{~m}$ depth the mean sampling resolution was 43 samples $\mathrm{m}^{-1}$ and between $66 \mathrm{~m}$ and $120 \mathrm{~m}$ depth the mean sampling resolution was increased to 61 samples $\mathrm{m}^{-1}$. Between $77 \mathrm{~m}$ and $120 \mathrm{~m}$ depth, an alteration to the continuous-melter-discrete sampling system enabled material for ICP-MS to be sampled at half the depth resolution relative to the stable isotope and IC samples to improve processing efficiency.

All vials used to sample material intended for IC or ICP-MS analysis were rigorously cleaned to prevent chemical contamination. Polypropylene vials used for IC samples were triple-rinsed with ultra-pure water $(>18.2 \mathrm{M} \Omega)$, soaked for $>3$ days and triplerinsed again. Polypropylene vials used for ICP-MS samples were first triple-rinsed with ultra-pure water then soaked in 5 wt.\% analytical reagent grade $\mathrm{HNO}_{3}$ for $>10$ days, triple-rinsed, soaked in ultra-pure water for $>5$ days and triple-rinsed with ultra-pure water. Vial cleaning was conducted under HEPA Class 100 clean room conditions whilst wearing Tyvek $^{\circledR}$ clean suits with hoods and powder-free polyethene gloves.

Procedural blanks monitor the potential contribution of the processing and sampling procedure to the concentrations of chemical species measured. Fabricated ice cores of frozen ultra-pure water ( $>18.2 \mathrm{M} \Omega$ ) were processed, melted and sampled daily by the methods described above to provide procedural blanks. Chemical concentrations recorded in the procedural blanks are summarized in Table 7.4. The procedural blank concentrations equate to: $<10 \%$ of the mean ice core concentrations of $\mathrm{Na}, \mathrm{Mg}, \mathrm{As}, \mathrm{Rb}$, $\mathrm{Sr}, \mathrm{Tl}, \mathrm{Bi} \mathrm{Th}, \mathrm{K}^{+}$and $\mathrm{SO}_{4}{ }^{2-} ;<15 \%$ of the mean ice core concentrations of $\mathrm{Al}, \mathrm{V}, \mathrm{Mn}, \mathrm{Cs}$, $\mathrm{Ce}$, La and $\mathrm{Pr} ;<20 \%$ of the mean ice core concentrations of $\mathrm{Y}, \mathrm{Zr}, \mathrm{U}, \mathrm{NO}_{3}{ }^{-}$and $\mathrm{Cl}^{-} ;<25 \%$ of the mean ice core concentrations of $\mathrm{Ti}$ and $\mathrm{Ba}$, and $<30 \%$ of the mean ice core concentration of $\mathrm{Pb}$. Contamination of $\mathrm{Ca}$ was a problem as the procedural blank 
accounts for $70 \%$ of the mean concentration. The $\mathrm{Ca}$ and $\mathrm{Zr}$ in the procedural blanks likely originate from ceramic knives used to prepare the ice core for melting.

Table 7.4: Concentrations of elements and major ions determined by ICP-MS and IC in the procedural blanks sampled during processing of the MES ice core.

\begin{tabular}{cccc}
\hline Element & Concentration & Major ion & $\begin{array}{c}\text { Concentration } \\
\text { (ppb) }\end{array}$ \\
\hline $\mathrm{Na}$ & 1120 & $\mathrm{Na}^{+}$ & 0.34 \\
$\mathrm{Mg}$ & 290 & $\mathrm{Mg}^{2+}$ & 0.66 \\
$\mathrm{Al}$ & 560 & $\mathrm{~K}^{+}$ & 0.10 \\
$\mathrm{Ca}$ & 6890 & $\mathrm{Ca}^{2+}$ & 20.3 \\
$\mathrm{Ti}$ & 78.5 & $\mathrm{MS}^{-}$ & 0.00 \\
$\mathrm{~V}$ & 0.70 & $\mathrm{Cl}^{-}$ & 26.6 \\
$\mathrm{Mn}$ & 10.9 & $\mathrm{SO}_{4}{ }^{2-}$ & 4.50 \\
$\mathrm{As}$ & 0.29 & $\mathrm{NO}_{3}{ }^{-}$ & 6.27 \\
$\mathrm{Rb}$ & 0.47 & & \\
$\mathrm{Sr}$ & 4.50 & & \\
$\mathrm{Y}$ & 0.50 & & \\
$\mathrm{Zr}$ & 3.05 & & \\
$\mathrm{Cs}$ & 0.05 & & \\
$\mathrm{Ba}$ & 5.28 & & \\
$\mathrm{La}$ & 0.66 & & \\
$\mathrm{Ce}$ & 1.42 & \\
$\mathrm{Pr}$ & 0.17 & & \\
$\mathrm{Tl}$ & 0.00 & \\
$\mathrm{~Pb}$ & 4.67 & \\
$\mathrm{Bi}$ & 0.09 & \\
$\mathrm{Th}$ & 0.07 & \\
$\mathrm{U}$ & 0.04 & & \\
\hline
\end{tabular}




\subsubsection{Stable isotope ratios}

The stable isotope ratios $\delta^{18} \mathrm{O}$ and $\delta \mathrm{D}\left(\right.$ where $\delta^{18} \mathrm{O}=\left(\left[\left({ }^{18} \mathrm{O} /{ }^{16} \mathrm{O}\right)\right.\right.$ sample $/\left({ }^{18} \mathrm{O} /{ }^{16} \mathrm{O}\right) \mathrm{v}$-smow) $]$ -1) * 1000) were measured at the Stable Isotope Laboratory, GNS Science using both traditional mass spectrometry and laser absorption spectroscopy. Samples from the first $91 \mathrm{~m}$ depth of ice core were analysed by a conventional isotope ratio mass spectrometer instrument. $\delta^{18} \mathrm{O}$ measurements were conducted using a GVI AquaPrep system linked to a dual inlet GVI mass spectrometer. $400 \mu \mathrm{L}$ of sample was equilibrated with $300 \mu \mathrm{L}$ of $\mathrm{CO}_{2}$ for $24 \mathrm{hr}$ at $25.5^{\circ} \mathrm{C}$. The $\mathrm{CO}_{2}$ was then extracted and transferred to the mass spectrometer for analysis. $\delta D$ analyses were performed by directly reducing $100 \mu \mathrm{L}$ of sample to $\mathrm{H}_{2}$ gas in a $\mathrm{PyrOH}$ reaction column and measuring the gas on the same dual inlet GVI mass spectrometer. $\delta^{18} \mathrm{O}$ and $\delta \mathrm{D}$ are reported with respect to V-SMOW and normalized to internal standards: INS9 with reported values of $-17.4 \%$ o for $\delta^{18} \mathrm{O}$ and, $-131.0 \%$ for $\delta \mathrm{D}$, and INS11 with reported values of $-0.4 \%$ o for $\delta^{18} \mathrm{O}$ and, $-4.6 \%$ o for $\delta \mathrm{D}$. The analytical precision of this instrument is $\pm 0.1 \%$ o for $\delta^{18} \mathrm{O}$ and $\pm 1.0 \%$ for $\delta \mathrm{D}$, resulting in an uncertainty of $\pm 1.3 \%$ on the second order parameter d-excess [Dansgaard, 1954].

Samples from $92 \mathrm{~m}$ to $120 \mathrm{~m}$ depth (1655-1446 AD) were analysed using a LGR LiquidWater Isotope Analyser which measures $\delta^{18} O$ and $\delta D$ simultaneously by laser absorption. Path lengths of several $\mathrm{km}$ are generated within a mirrored-cavity resulting in clear separation of laser absorption lines of different water molecules. $\delta^{18} \mathrm{O}$ and $\delta \mathrm{D}$ are normalized to the internal standards stated above. The analytical precision for this instrument is $\pm 0.2 \%$ o for $\delta^{18} \mathrm{O}$ and $\pm 0.6 \%$ o for $\delta \mathrm{D}$, resulting in an uncertainty of $\pm 1.7 \%$ o on d-excess.

To test the comparability of measurements conducted on the two instruments a batch of samples $(n=187)$ was analysed by both instruments. Comparison of the stable isotope ratios measured on the two instruments identifies offsets between the datasets (Fig. 7.10). The offsets between the $\delta D$ and $\delta^{18} O$ values produced a significant offset between the calculated values of d-excess (Fig. 7.11). Therefore, the $\delta \mathrm{D}$ and $\delta^{18} \mathrm{O}$ values measured on the LGR Liquid-Water Isotope Analyser $\left(\delta \mathrm{D}_{\text {laser }}\right)$ were corrected to make them comparable to the GVI mass spectrometer values $\left(\delta D_{\text {mass spec. }}\right.$ 
equiv.) using the linear relationships established by analysing samples on both instruments (e.g., Fig. 7.10).

$\left.\delta D_{\text {mass spec. equiv. }}=\left(\delta D_{\text {laser }}+1.6576\right) / 0.9809\right)$

$\left.\delta^{18} \mathrm{O}_{\text {mass spec. equiv. }}=\left(\delta^{18} \mathrm{O}_{\text {laser }}-0.1577\right) / 0.1 .0034\right)$

Deuterium excess values were then calculated from the corrected $\delta D$ and $\delta^{18} O$ datasets. A revised analytical uncertainty $(u)$ for d-excess, which takes into account the errors on both instruments, is calculated as: $\sqrt{1.3^{2}+1.7^{2}}=2.14 \%$. This value is applied when the entire record encompassing stable isotope ratios measured by both instruments is considered.

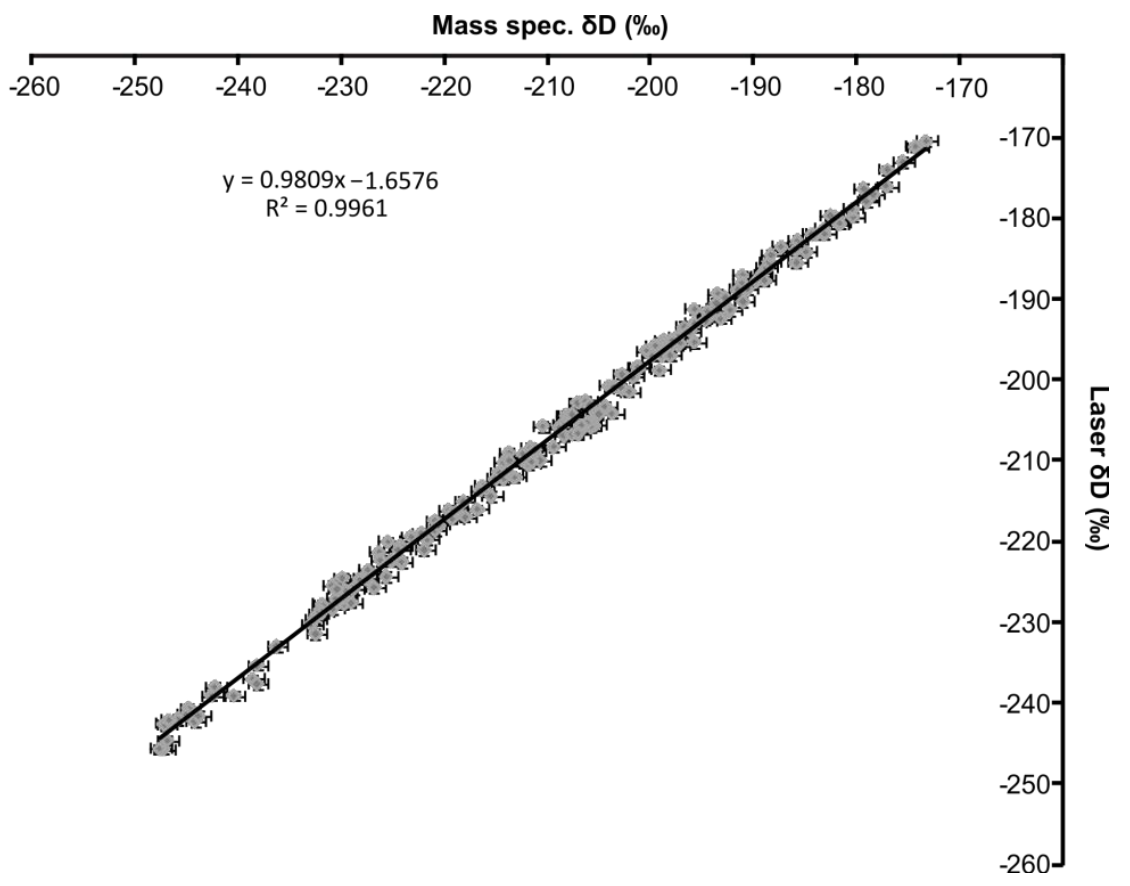

Figure 7.10: $\delta D$ measured on GVI mass spectrometer and LGR Liquid-Water Isotope Analyser (Laser). Error bars are $2 \sigma$. 


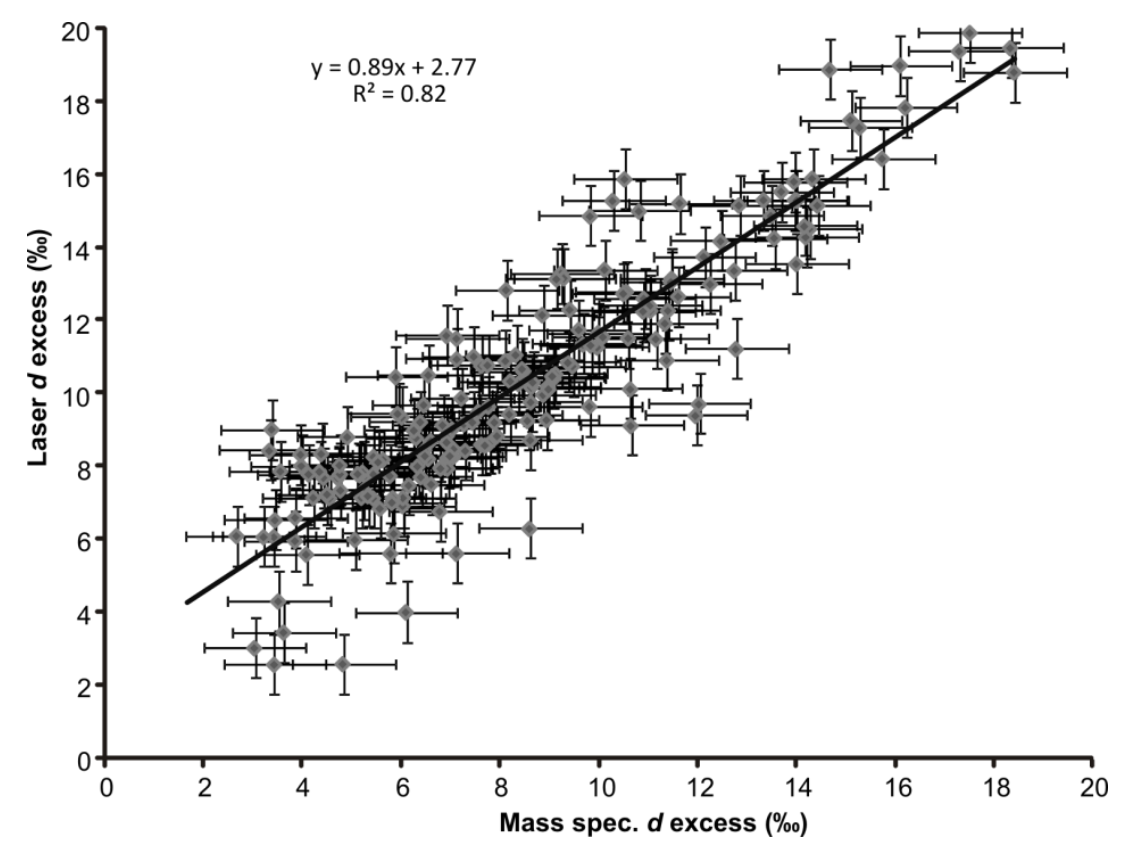

Figure 7.11: Deuterium excess derived from $\delta^{18} O$ and $\delta D$ values measured on GVI mass spectrometer and LGR Liquid-Water Isotope Analyser (Laser). Error bars are analytical uncertainty $(u)\left(u=v\left(a^{2}+\left(8^{*} b^{2}\right)\right)\right.$, where $a=$ precision on $\delta^{18} O$ and $b=$ precision on $\left.\delta D\right)$.

\subsubsection{Ion chromatography}

Ion chromatography analysis for major ions $\left(\mathrm{Na}^{+}, \mathrm{K}^{+}, \mathrm{Mg}^{2+}, \mathrm{Ca}^{2+}, \mathrm{MS}^{-}, \mathrm{Cl}^{-}, \mathrm{NO}_{3}{ }^{-}, \mathrm{SO}_{4}{ }^{2-}\right)$ was conducted at the Climate Change Institute, University of Maine using Dionex ion chromatographs with chemical suppression and conductivity detectors paired to a Gilson 215 Liquid Handler autosampler. Anions were measured using an AS-18 column, $400 \mu \mathrm{L}$ sample loop, and a Dionex Reagent Free Controller producing a $\mathrm{KOH}$ eluent concentration of $35 \mathrm{mM}$. Cations were measured using a CS-12A column and a $500 \mu \mathrm{L}$ loop with $25 \mathrm{mM}$ methanesulphonic acid eluent. Calibration using five calibration standards bracketing the anticipated concentration range routinely achieved correlation coefficients of $\mathrm{R}^{2}>0.99$ for all major ions. The external reference material ION-92 (National Water Research Institute, Canada) was analysed at dilutions of 100 and 1000 times to verify the calibration and to calculate the accuracy and precision of the measurements. $\mathrm{Na}^{+}, \mathrm{Mg}^{2+}, \mathrm{Ca}^{2+}, \mathrm{MS}^{-}, \mathrm{Cl}^{-}$and $\mathrm{SO}_{4}{ }^{2-}$ measurements are accurate to within $5 \%$. The reproducibility, calculated as $2 *$ RSD (relative standard deviation), of 
$\mathrm{Na}^{+}, \mathrm{Mg}^{2+}, \mathrm{Ca}^{2+}$ and $\mathrm{MS}^{-}$measurements is $< \pm 11 \%$ and $< \pm 4 \%$ for $\mathrm{Cl}^{-}$and $\mathrm{SO}_{4}{ }^{2-}$. $\mathrm{NO}_{3}{ }^{-}$is not detectable in ION-92 and $\mathrm{K}^{+}$measurements were not reproducible.

\subsubsection{Inductively coupled plasma mass spectrometry}

Ice core samples were analysed for concentrations of 22 major, minor and trace elements ( $\mathrm{Na}, \mathrm{Mg}, \mathrm{Al}, \mathrm{Ca}, \mathrm{Ti}, \mathrm{V}, \mathrm{Mn}, \mathrm{As}, \mathrm{Rb}, \mathrm{Sr}, \mathrm{Y}, \mathrm{Zr}, \mathrm{Cs}, \mathrm{Ba}, \mathrm{La}, \mathrm{Ce}, \mathrm{Pr}, \mathrm{Tl}, \mathrm{Pb}, \mathrm{Bi}, \mathrm{Th}, \mathrm{U}$ ) by ICP-MS (Agilent 7500cs Series) at the Geochemistry Laboratory of the School of Geography, Environment and Earth Sciences, Victoria University of Wellington. The operating conditions adopted for ICP-MS analysis are displayed in Table 7.5. An ASX520 micro-volume autosampler linked to the ICP-MS introduced sample to the PFA

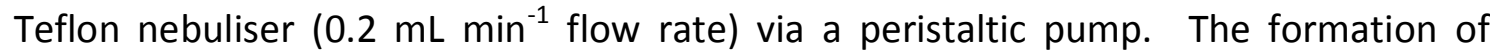
oxides in the plasma was monitored by aspirating a $1 \mathrm{ppb}$ solution of $\mathrm{Ce}$ and tuning parameters were adjusted to maintain the proportion of the ${ }^{140} \mathrm{Ce}$ converted to ${ }^{140} \mathrm{Ce}^{16} \mathrm{O}$ at below $2 \%$. Nickel sampling and skimmer cones were cleaned, and the sample introduction system was circulated with 5 wt.\% $\mathrm{HNO}_{3}$ (Seastar) for $1 \mathrm{hr}$ prior to each analytical session to reduce any possible memory effect from the samples of previous users.

Calibration standards were gravimetrically diluted daily from stock multi-element standards made up from mono-elemental $1000 \mathrm{ppm}$ standards. The element concentrations in the calibration standards varied between elements according to the relative concentrations expected in the ice core samples. P/A factor tuning was required to calibrate measurements conducted by the two different mass detectors (pulse and analogue) on elements which recorded $>1,000,000$ counts $\mathrm{s}^{-1}$ ( $\mathrm{Na}, \mathrm{Mg}$ and Al). 
Table 7.5: Operating conditions of the ICP-MS and data acquisition parameters for the determination of selected elements in MES ice core samples

\begin{tabular}{|c|c|}
\hline Parameter & Setting \\
\hline $\begin{array}{l}\text { Forward power } \\
\text { RF matching }\end{array}$ & $\begin{array}{l}1500 \mathrm{~W} \\
1.75-1.84 \mathrm{~V}\end{array}$ \\
\hline Carrier gas & $1.04-1.10 \mathrm{~L} \mathrm{~min}^{-1}$ \\
\hline Makeup gas & $0 \mathrm{~L} \mathrm{\operatorname {min } ^ { - 1 }}$ \\
\hline Nebulizer pump & $0.12-0.16 \mathrm{rps}$ \\
\hline Spray chamber temperature & $2^{\circ} \mathrm{C}$ \\
\hline Sampling depth & $7 \mathrm{~mm}$ \\
\hline Torch position & Optimised daily to maximise sensitivity \\
\hline Ion lenses voltages & $\begin{array}{l}\text { Optimised daily to maximise sensitivity and signal stability } \\
\text { across mass range }\end{array}$ \\
\hline Isotopes measured & $\begin{array}{l}{ }^{23} \mathrm{Na},{ }^{24} \mathrm{Mg},{ }^{27} \mathrm{Al},{ }^{43} \mathrm{Ca},{ }^{47} \mathrm{Ti},{ }^{51} \mathrm{~V},{ }^{55} \mathrm{Mn},{ }^{75} \mathrm{As},{ }^{85} \mathrm{Rb},{ }^{88} \mathrm{Sr},{ }^{89} \mathrm{Y}, \\
{ }^{90} \mathrm{Zr},{ }^{133} \mathrm{Cs},{ }^{138} \mathrm{Ba},{ }^{139} \mathrm{La},{ }^{140} \mathrm{Ce},{ }^{141} \mathrm{Pr},{ }^{205} \mathrm{Tl},{ }^{208} \mathrm{~Pb},{ }^{209} \mathrm{Bi}^{232} \mathrm{Th}, \\
{ }^{238} \mathrm{U}\end{array}$ \\
\hline Uptake and stabilization time & $50 \mathrm{~s}$ and $60 \mathrm{~s}$ \\
\hline \multirow[t]{2}{*}{ Washing time between samples } & $10 \mathrm{~s} \mathrm{H}_{2} \mathrm{O}, 200$ s 5 wt. $\% \mathrm{HNO}_{3}$ (Seastar), \\
\hline & $220 \mathrm{~s} 1$ wt. $\% \mathrm{HNO}_{3}$ (total $430 \mathrm{~s}$ ) \\
\hline Integration time & $0.10 \mathrm{~s}$ or $0.15 \mathrm{~s}$ depending on element \\
\hline No. of runs and scan passes & $3 \times 26$ \\
\hline
\end{tabular}

Table 7.6: Detection limits (ppt) for elements determined by ICP-MS analysis.

\begin{tabular}{lc}
\hline Element & $\begin{array}{l}\text { Detection } \\
\text { limit }\end{array}$ \\
\hline $\mathrm{Na}$ & 167 \\
$\mathrm{Mg}$ & 5.0 \\
$\mathrm{Al}$ & 9.7 \\
$\mathrm{Ca}$ & 1271 \\
$\mathrm{Ti}$ & 22 \\
$\mathrm{~V}$ & 0.83 \\
$\mathrm{Mn}$ & 3.2 \\
$\mathrm{As}$ & 6.7 \\
$\mathrm{Rb}$ & 0.31 \\
$\mathrm{Sr}$ & 0.31 \\
$\mathrm{Y}$ & 0.1 \\
$\mathrm{Zr}$ & 0.58 \\
$\mathrm{Cs}$ & 0.18 \\
$\mathrm{Ba}$ & 0.32 \\
$\mathrm{La}$ & 0.14 \\
$\mathrm{Ce}$ & 0.19 \\
$\mathrm{Pr}$ & 0.19 \\
$\mathrm{Tl}$ & 0.44 \\
$\mathrm{~Pb}$ & 0.72 \\
$\mathrm{Bi}$ & 0.43 \\
$\mathrm{Th}$ & 0.45 \\
$\mathrm{U}$ & 0.4 \\
\hline
\end{tabular}


Samples were stored frozen prior to analysis then thawed and acidified to $1 \mathrm{wt} . \%$ $\mathrm{HNO}_{3}$ with 68 wt.\% $\mathrm{HNO}_{3}$ (Seastar) at least $12 \mathrm{hr}$ prior to analysis. Counts recorded on 1 wt.\% $\mathrm{HNO}_{3}$ blanks were subtracted from those recorded on samples and standards to correct for background. Detection limits are calculated as $3 \sigma$ on the blank measurements (Table 7.6). The calibration standards were run as bracketing standards every 12 samples to correct for instrumental drift. An external reference material, SLRS-4 (river water, National Research Council, Canada), was run at 10 times dilution during each analytical session to test the accuracy and reproducibility of the measurements (Table 7.7).

Table 7.7: Element concentrations (ppt) determined by repeated measurement of SLRS-4 riverine water standard $(n=82)$ with precision and accuracy of measurements.

\begin{tabular}{|c|c|c|c|c|}
\hline Element & This study & $\begin{array}{l}\text { Certified } \\
\text { values }\end{array}$ & $\begin{array}{l}\text { Precision } \\
2 \text { RSD (\%) }\end{array}$ & $\begin{array}{c}\text { Accuracy } \\
\text { (\% difference) }\end{array}$ \\
\hline $\mathrm{Na}^{\mathrm{a}}$ & $2289 \pm 80$ & $2400 \pm 200$ & 3.5 & 4.6 \\
\hline $\mathrm{Mg}^{\mathrm{a}}$ & $1573 \pm 156$ & $1600 \pm 100$ & 9.9 & 1.7 \\
\hline $\mathrm{Al}^{\mathrm{a}}$ & $56 \pm 4$ & $54 \pm 4$ & 6.8 & 4.0 \\
\hline $\mathrm{Ca}^{\mathrm{a}}$ & $6132 \pm 546$ & $6200 \pm 200$ & 8.9 & 1.1 \\
\hline $\mathrm{Mn}^{\mathrm{a}}$ & $3.56 \pm 0.14$ & $3.37 \pm 0.18$ & 4.0 & 5.5 \\
\hline $\mathrm{Ba}^{\mathrm{a}}$ & $13 \pm 0.44$ & $12.22 \pm 0.6$ & 3.4 & 6.4 \\
\hline $\mathrm{Ti}$ & $1587 \pm 152$ & $1460 \pm 80$ & 9.6 & 8.7 \\
\hline V & $382 \pm 19$ & $320 \pm 30$ & 5.1 & 19.3 \\
\hline As & $757 \pm 21$ & $680 \pm 60$ & 2.7 & 11.3 \\
\hline $\mathrm{Rb}$ & $1616 \pm 59$ & $1530 \pm 50$ & 3.7 & 5.6 \\
\hline $\mathrm{Sr}$ & $29.8 \pm 1.27$ & $26300 \pm 3200$ & 4.3 & 13.2 \\
\hline Y & $143 \pm 6$ & $146 \pm 8$ & 4.0 & 2.0 \\
\hline $\mathrm{Zr}$ & $139 \pm 45$ & $120 \pm 15$ & 32.2 & 15.9 \\
\hline Cs & $6.8 \pm 0.23$ & $9 \pm 1$ & 3.4 & 24.5 \\
\hline La & $298 \pm 15$ & $287 \pm 8$ & 5.1 & 3.9 \\
\hline $\mathrm{Ce}$ & $375 \pm 27$ & $360 \pm 12$ & 7.3 & 4.1 \\
\hline $\operatorname{Pr}$ & $83.4 \pm 10.6$ & $69.3 \pm 1.8$ & 12.6 & 20.4 \\
\hline $\mathrm{TI}$ & $7.96 \pm 2.31$ & $6.8 \pm 1.3$ & 29.0 & 17.0 \\
\hline $\mathrm{Pb}$ & $82 \pm 5.7$ & $86 \pm 7$ & 6.9 & 4.7 \\
\hline $\mathrm{Bi}$ & $2.4 \pm 0.34$ & $2.1 \pm 0.1$ & 14.0 & 14.4 \\
\hline Th & $21.5 \pm 1.9$ & $18 \pm 3$ & 9.1 & 19.6 \\
\hline U & $51.1 \pm 4.9$ & $50 \pm 3$ & 9.6 & 2.3 \\
\hline
\end{tabular}

Certified values for SLRS-4 are GeoREM [Jochum et al., 2005] preferred values obtained from http://georem.mpch-mainz.gwdg.de. 


\subsubsection{Tritium analysis}

Tritium $\left({ }^{3} \mathrm{H}\right)$ content was measured at the GNS Science Tritium and Water Dating Laboratory, Lower Hutt, New Zealand by ultra-low-level liquid scintillation spectrometry (Quantulus ${ }^{\mathrm{TM}}$ ). Measurements were conducted on six samples from a depth range of $11 \mathrm{~m}$ to $21.3 \mathrm{~m}$ which were sampled from the ice core in the cold laboratory $\left(-20^{\circ} \mathrm{C}\right)$ using a band saw. The water samples were purified in a vacuum distillation system to exclude tritium contamination and measured without prior tritium enrichment in a monitored tritium-free environment. Details of the tritium analysis procedure are described in [Morgenstern and Taylor, 2009]. 


\subsection{Appendix II: Dating methods}

\subsubsection{Annual layer counting}

A snow pit sampled at Mt Erebus Saddle 2 yr prior to drilling of the ice core was dated by identifying annual peaks in $\delta^{18} \mathrm{O}$ for the time period 2000 to $2005 \mathrm{AD}$ [Rhodes et al., 2009]. The equivalent section of the $\delta^{18} \mathrm{O}$ record was located in the ice core to facilitate dating of the uppermost section. The annual signals of $\delta^{18} \mathrm{O}, \delta \mathrm{D}$ and d-excess were well-preserved in the top $25 \mathrm{~m}$ of the ice core and maximum values were identified as mid-summer ( $\left.\operatorname{Jan} 1^{\text {st }}\right) . \quad \mathrm{NO}_{3}{ }^{-}$displayed a well-defined annual signal with maximum values in winter-spring. This $\mathrm{NO}_{3}{ }^{-}$signal is preliminarily interpreted as originating from production in stratospheric clouds [Michalski et al., 2005]. A combination of $\delta^{18} \mathrm{O}, \delta \mathrm{D}, \mathrm{d}$-excess and $\mathrm{NO}_{3}{ }^{-}$were utilised for annual layer counting.

\subsubsection{Back-diffusion of stable isotopes}

$\delta^{18} \mathrm{O}$ and $\delta \mathrm{D}$ peaks were difficult to identify deeper down the core because molecular diffusion in the firn pore space effectively blurs the annual $\delta^{18} O$ and $\delta D$ cycles into each other and removes the high frequency annual signal [Steen-Larsen et al., 2011]. The $\delta^{18} \mathrm{O}$ and $\delta \mathrm{D}$ signals can be deconvolved or back-diffused in order to obtain the original signal using calculated diffusion coefficients of each of the isotopes involved [Johnsen, 1977; Johnsen et al., 2000]. Back-diffusion of the Mt Erebus Saddle stable isotopic record was performed to $108 \mathrm{~m}$ depth. The back-diffused time series of $\delta^{18} \mathrm{O}$ and $\delta D$ display well-defined annual signals of a larger amplitude than in the raw data. Therefore, a combination of these back-diffused time series and the raw d-excess signal, which appears to remain sensitive to seasonality, was used to identify annual layers in the ice core to $108 \mathrm{~m}$ depth (1545 AD). As back-diffused stable isotope series were not available for annual layer counting between 108 and $120 \mathrm{~m}$ depth, a polynomial fit applied to the age model developed by annual layer counting was extrapolated to $120 \mathrm{~m}$ depth. 


\subsubsection{Tritium peak}

Elevated tritium content is observed between 1964 and 1972 AD, in line with that observed in Antarctic and New Zealand precipitation (Fig. 7.12).

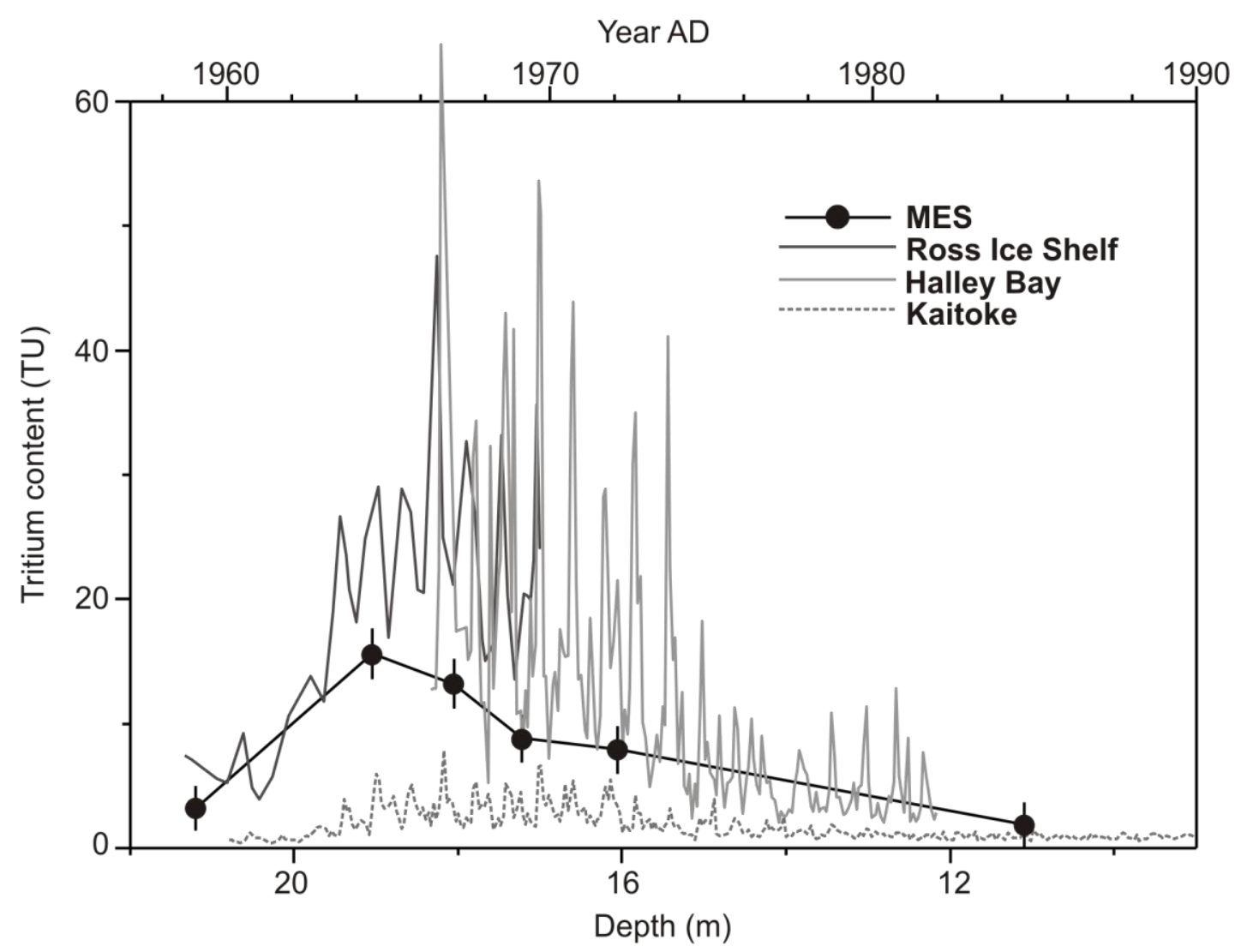

Figure 7.12: Tritium contents of six MES ice core samples analysed (black circles) plotted with tritium contents of precipitation from the Ross Ice Shelf, Halley Bay on the Antarctic Peninsula, and Kaitoke, New Zealand, decay-corrected to December 2006. One tritium unit (TU) is defined as one atom of tritium per $10^{18}$ atoms of hydrogen, equivalent to 0.118 becquerels $(\mathrm{Bq})$ per litre of water. Error bars are $1 \sigma$. 


\section{Chapter 8: Conclusions}

The principal aim of this thesis was to construct a paleoclimate record of the Late Holocene in the Ross Sea region, Antarctica, utilising climate proxies developed from ice core stable isotopic and soluble chemistry records of the Mt Erebus Saddle snow pit and ice core.

\subsection{Interpretation of snow pit stable isotope and major ion data}

A $2 \mathrm{~m}$ snow pit record of stable isotope ratios and major ion concentrations demonstrated that the glaciochemical records preserved in the snow and ice at Mt Erebus Saddle held seasonally resolvable signals related to climatic and environmental factors. $\delta^{18} \mathrm{O}$ was utilised for annual layer counting of the $5 \mathrm{yr}$ record. $\mathrm{MS}^{-}$, a biogenic sulphur species, displayed an annual signal related to the area of open water available for primary production during summer in the south-western Ross Sea (Fig. 8.1). Interannual variability in the annual $\mathrm{MS}^{-}$concentration was shown to be the result of large icebergs, which carved from the Ross Ice Shelf and restricted the area of the Ross Sea Polynya for several years of the record. $\mathrm{MS}^{-}$was developed as a proxy for both open water area and the rate of primary productivity in the Ross Sea. This is the only study to-date to statistically link the level of primary productivity, and hence MS production, to the concentration of $\mathrm{MS}^{-}$recorded in a snow pit or ice core record. Furthermore, this work demonstrates the sensitivity of coastal ice core chemistry records to local marine biogenic processes.

\subsection{Core processing and ICP-MS method development}

The MES ice core was processed at the New Zealand Ice Core Laboratory at GNS Science using a continuous melter system to produce samples suitable for analysis of ultra-low concentrations of trace elements. An accurate, precise and efficient method 
for ICP-MS analysis of major, minor and trace element concentrations was refined over the course of the analytical work involved in this thesis.

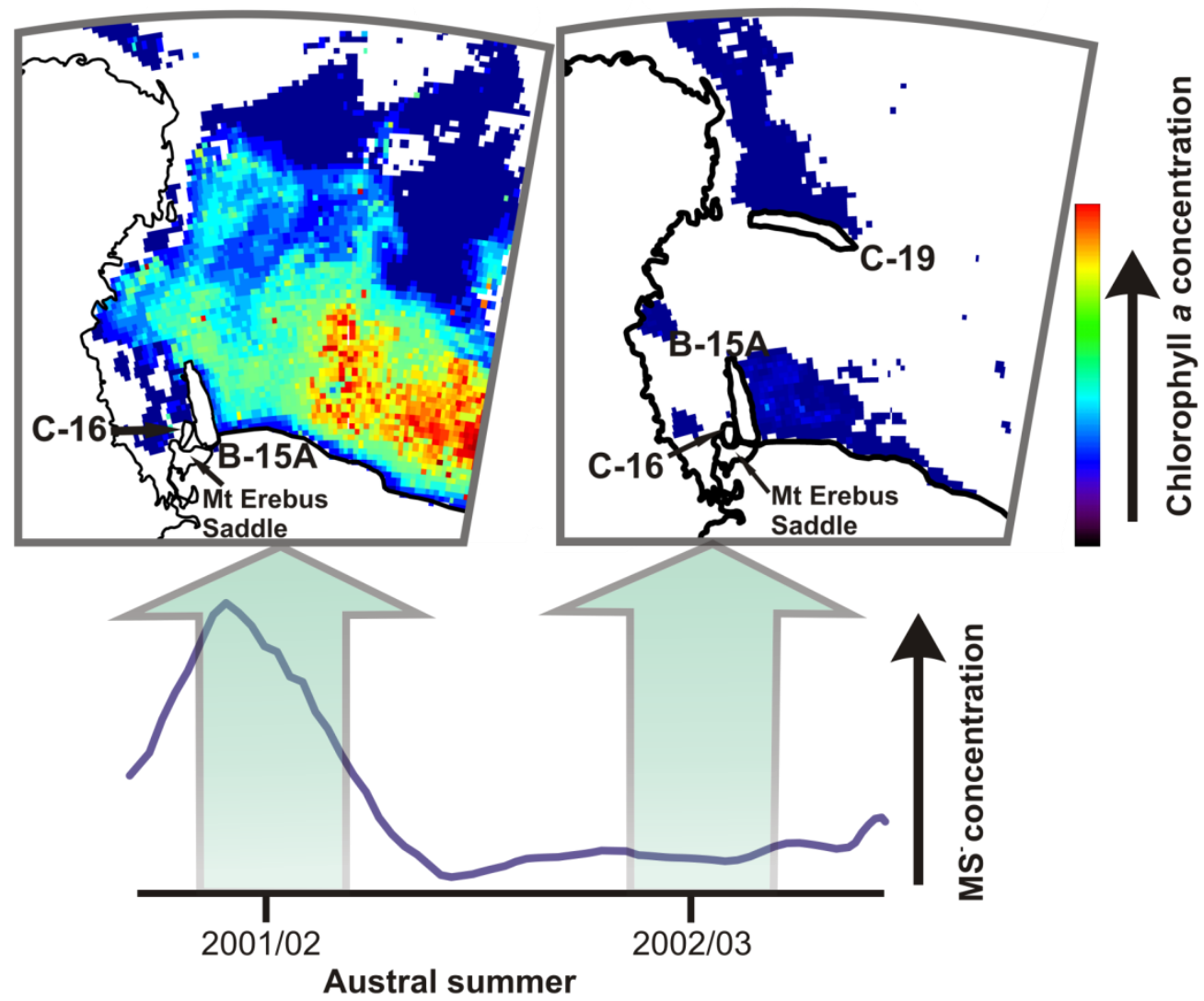

Figure 8.1: Summary of the relationships between $\mathrm{MS}^{-}$concentration, sea ice cover and primary productivity. High $\mathrm{MS}^{-}$concentrations result from extensive open water and high primary productivity (high chlorophyll a concentrations). Low $\mathrm{MS}^{-}$concentrations result from restricted open water and low primary productivity (low chlorophyll $a$ concentrations).

\subsection{Dating the ice core}

The ice core was dated by annual layer counting, predominantly of stable isotope ratios $\delta \mathrm{D}$ and $\delta^{18} \mathrm{O}$, as for the snow pit record. The relatively high accumulation rate at MES (23 cm water equivalent $\mathrm{yr}^{-1}$ ) and mean annual temperature of $-28^{\circ} \mathrm{C}$ preserved an annual signal in stable isotope ratios and other geochemical parameters measured in the ice core. Back-diffusion modelling of the stable isotopic records was used to 156 
correct for molecular diffusion, which dampened the annual signal below $25 \mathrm{~m}$ depth in the ice core. Age tie points in the form of thermonuclear bomb tritium fallout (1964 $A D$ ) and heavy, volatile element deposition from the eruption of Mt Tambora (1816 AD) helped to constrain the age model. Additional support for the dating method was identified in the anthropogenic $\mathrm{Pb}$ deposition history recorded in the MES ice core, which was similar in timing to that recorded at Law Dome, East Antarctica [Vallelonga et al., 2002]. Finally, a Dansgaard-Johnsen glacial flow model provided further confidence in the age-depth relationship produced by the annual layer counting technique. The maximum age uncertainty of the MES ice core age model is $\pm 1 \mathrm{yr}$ between 2006 and 1964 AD, \pm 9 yr between 1964 and 1816 AD, \pm 1 yr at $1816 A D$ and \pm 18 yr between 1816 and 1446 AD.

\subsection{Dust leaching experiment}

A systematic experiment was designed and implemented to assess the contribution of acid-leaching of mineral dust particles to trace element concentrations measured in ice core samples by ICP-MS. Before ICP-MS analysis ice core samples must be acidified and mineral dust particulates are generally not removed prior to this. The contribution of dust leaching to soluble ice core chemistry and the factors which could affect the magnitude of this contribution had not previously been considered in detail. The experiment involved leaching powdered international rock standards of different lithologies and concentrations in 1 wt.\% $\mathrm{HNO}_{3}$ for variable lengths of time. The leachates were periodically sampled and analysed by ICP-MS to ascertain the extent of leaching that had occurred.

The results showed that leaching of trace elements from mineral dust in acidified samples is both time- and mineral-dependent (Fig. 8.2A). Oxide and sheet silicate minerals, such as micas and clays, released trace elements into solution relatively quickly, whereas mafic minerals continued to release trace elements into solution over several weeks causing concentration increases of several orders of magnitude in the 
leachates. Additionally, the concentration of trace elements leached from mineral dust was found to be proportional to the mineral dust concentration in the sample.

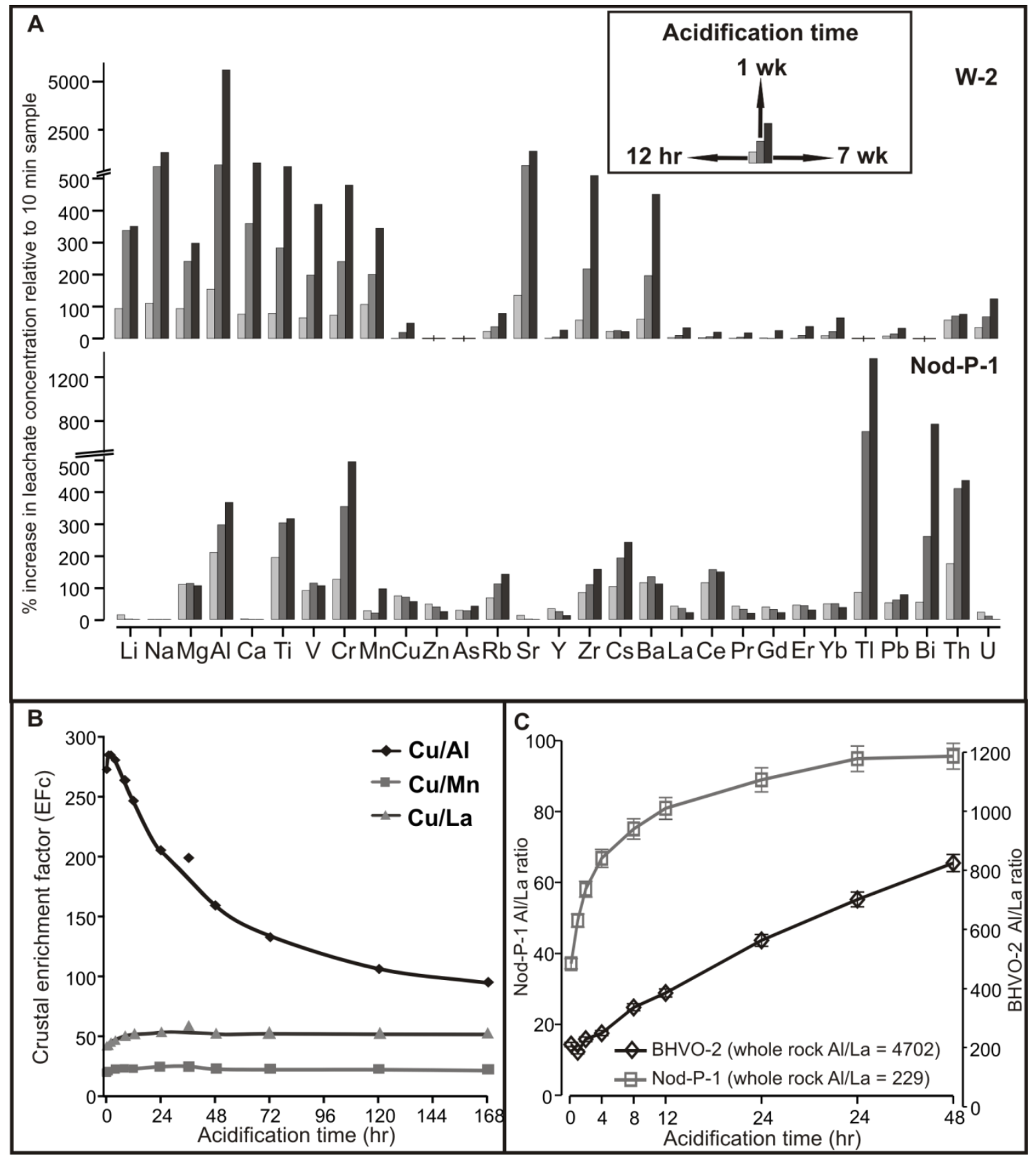

Figure 8.2: Summary of time- and mineral-dependent leaching effects on A) trace element concentrations, B) crustal enrichment factors and C) terrestrial element ratios. 
The findings of this study have important implications, both for the methods by which ICP-MS analyses of ice core samples are conducted, and the assumptions made during interpretation. To minimise the effects of time-dependent leaching, it is recommended to acidify samples for as long as practical or to use a system of continuous melting and immediate analysis. It also is demonstrated that incongruent leaching of trace elements from mineral dust is likely to produce misleading crustal enrichment factor values that may cause contributions of some trace elements to the ice core chemistry budget to be incorrectly attributed to anthropogenic or volcanic sources (Fig. 8.2B). Furthermore, it is evident that some ratios of trace elements, in particular REEs, leached from mineral dust will not reflect those of the dust and are therefore not suitable as tracers of dust provenance (Fig. 8.2C).

\subsection{Reconstruction of Late Holocene climate in the Ross Sea region}

The MES ice core record dates from 1446 to 2006 AD and therefore captures much of the Little Ice Age (LIA) climate event. To develop climate proxies to apply to the LIA climate record, the monthly resolution record of the last $30 \mathrm{yr}$ was compared to gridded reanalysis data [Kalnay et al., 1996]. Lithophile element concentrations were found to reflect mineral dust transport from local sources by katabatic winds. A significant positive correlation $\left(R^{2}>0.6, p<0.025\right)$ between Al concentration and wind speed in a katabatic source region was found for the 1990s decade, when katabatic winds were particularly strong [Bertler et al., 2004b]. The lithophile elements showed some contrasting trends further back in time, suggestive of a change in dust source region or transport mechanism. However, results from the dust leaching experiment had demonstrated that element ratios were not likely to be diagnostic of dust source region. The variability between the elements was instead related to the weathering, transport and leaching characteristics of the dominant minerals in which the elements occur.

The MES ice core paleoclimate record is summarised in Figure 8.3. The $\delta D$ record suggests that the Ross Sea region experienced colder temperatures, and elevated 
lithophile element concentrations indicate greater transport of mineral dust resulting from stronger katabatic winds, during the LIA. Al, $\mathrm{Ti}$ and $\mathrm{Pb}$ concentration increases of an order of magnitude mark the strongest wind events of the LIA, where wind speed exceeded the threshold velocity required to transport relatively dense silicate minerals of relatively large grain size to MES. The termination of the LIA between 1848 and $1850 \mathrm{AD}$ is marked by an abrupt decrease in the lithophile element concentrations, equivalent to $>50 \%$ reduction in mean $\mathrm{Al}$ concentration, indicating a reduction in katabatic wind speed. Furthermore, d-excess values consistently higher than the 19502006 AD mean provide evidence for enhanced cyclonic activity, which advected moisture sourced from lower latitudes, over the Ross Sea region between 1625 and 1875 AD.

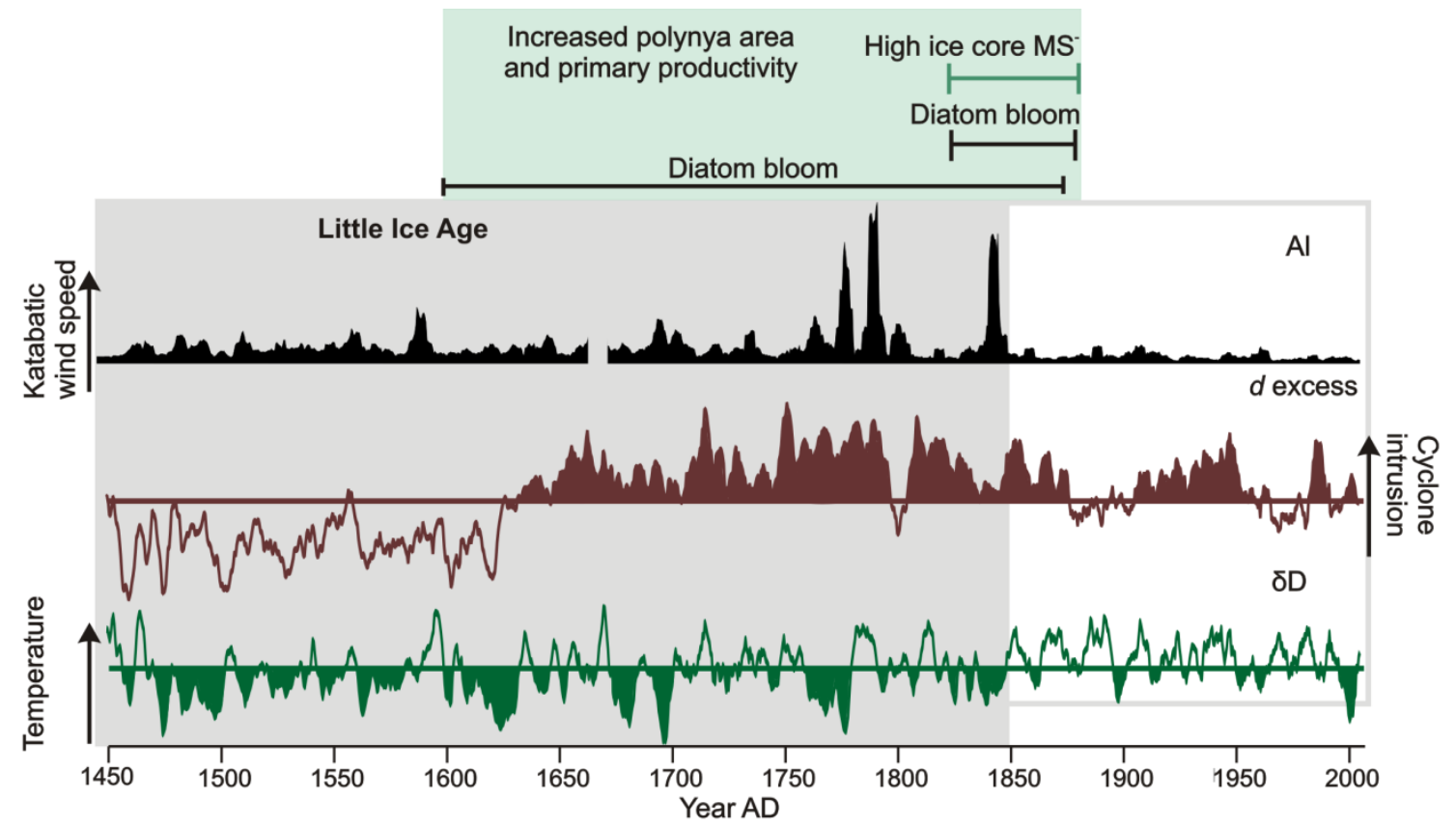

Figure 8.3: Summary of the climatic and environmental changes recorded in the $\delta D, d$-excess, lithophile element (AI) and $\mathrm{MS}^{-}$records of the MES ice core and diatom blooms of sediment cores [Leventer and Dunbar, 1988].

The snow pit study of $\mathrm{MS}^{-}$demonstrated that the $\mathrm{MS}^{-}$record preserved at MES was an effective proxy for primary productivity and the summer area of the Ross Sea Polynya. 
This allowed the identification of the 1820 and 1875 AD period as one of greater polynya area and $80 \%$ higher primary productivity (Fig. 8.3). Independent evidence for heightened primary productivity between 1825 and 1880 AD is found in sediment core diatom abundances [Leventer and Dunbar, 1988]. The timing of a more prolonged period (1600-1875 AD) of increased open water diatom populations identified in a further four sediment cores to the north and northwest of Ross Island [Leventer and Dunbar, 1988] corresponds with the period of increased cyclonicity recorded in the dexcess of the MES ice core.

It is proposed that the combination of colder temperatures and increased cyclonic activity in the Ross Sea region led to stronger katabatic flows which maintained a spatially larger and/or more temporally persistent polynya between 1625 and 1875 AD. Moreover, it is likely that larger polynya area led to increased sea ice formation, driving increased rates of bottom water formation. Combined with enhanced primary productivity, this could have resulted in stronger drawdown of atmospheric $\mathrm{CO}_{2}$ into the ocean, contributing to the atmospheric $\mathrm{CO}_{2}$ concentration reduction observed in other Antarctic ice cores [Etheridge et al., 1996; Indermuhle et al., 1999] between 1600 and $1800 \mathrm{AD}$.

This paleoclimate record is significant because a reorganisation of the thermohaline circulation of the oceans has been proposed as a driver of the LIA [Broecker, 2000]. Alternatively, the MES ice core record suggests that increased bottom water formation, at least in the Ross Sea region, resulted from the stronger atmospheric circulation of the LIA, and was therefore a response to, rather than the initial driver, of LIA climate change. 


\section{References}

Abram, N. J., R. Mulvaney, E. W. Wolff, and M. Mudelsee (2007), Ice core records as sea ice proxies: an evaluation from the Weddell Sea region of Antarctica, Journal of Geophysical Research, 112, doi:10.1029/2006JD008139.

Abram, N. J., E. R. Thomas, J. R. McConnell, R. Mulvaney, T. Bracegirdle, L. C. Sime, and A. Aristarain (2010), Ice core evidence for a 20th century decline of sea ice in the Bellingshausen Sea, Antarctica, Journal of Geophysical Research, 115, doi:10.1029/2010JD014644.

Alley, R. B., et al. (1997), Visual-stratigraphic dating of the GISP2 ice core: basis, reproducibility, and application, Journal of Geophysical Research, 102, 26367-26381.

Ammann, C. M., F. Joos, D. S. Schimel, B. L. Otto-Bliesner, and R. A. Tomas (2007), Solar influence on climate during the past millennium: results from transient simulations with the NCAR Climate System Model, Proceedings of the National Academy of Sciences, 104, 3713-3718.

Ando, A., N. Mita, and A. Matsumoto (1989), 1987 compilation of $\mathrm{K}_{2} \mathrm{O}$ concentrations in seventeen GSJ geochemical reference samples, "Igneous rock series", Bulletin of the Geological Survey of Japan, 40, 19-45.

Araguas-Araguas, L., K. Froelich, and K. Rozanski (2000), Deuterium and oxygen-18 isotope composition of precipitation and atmospheric moisture, Hydrological Processes, 14, 1341-1355.

Arrigo, K. R., and C. R. McClain (1994), Spring phytoplankton production in the western Ross Sea, Science, 266, 261-263.

Arrigo, K. R., and G. L. van Dijken (2003a), Impact of iceberg C-19 on Ross Sea primary production, Geophysical Research Letters, 30, doi:10.1029/2003GL017721.

Arrigo, K. R., and G. L. van Dijken (2003b), Phytoplankton dynamics within 37 Antarctic coastal polynya systems, Journal of Geophysical Research, 108, doi:10.1029/2002JC001739.

Arrigo, K. R., and G. L. van Dijken (2004), Annual changes in sea-ice, chlorophyll $a$ and primary production in the Ross Sea, Antarctica, Deep Sea Research II, 51, 117-138.

Arrigo, K. R., G. L. van Dijken, and S. Bushinsky (2008), Primary production in the Southern Ocean, 1997-2006, Journal of Geophysical Research, 113, doi:10.1029/2007JC004551.

Arrigo, K. R., A. Schnell, D. L. Worthen, and M. P. Lizotte (1998), Primary production in Southern Ocean waters, Journal of Geophysical Research, 103, 15587-15600. 
Arrigo, K. R., G. L. van Dijken, D. G. Ainley, M. A. Fahnestock, and T. Markus (2002), Ecological impact of a large Antarctic iceberg, Geophysical Research Letters, 29, doi:10.1029/2001GL014160.

Arrigo, K. R., D. H. Robinson, D. L. Worthen, R. B. Dunbar, G. R. DiTullio, M. VanWoert, and M. P. Lizotte (1999), Phytoplankton community structure and the drawdown of nutrients and $\mathrm{CO}_{2}$ in the Southern Ocean, Science, 283, 365-367.

Arrigo, K. R., G. R. DiTullio, R. B. Dunbar, M. P. Lizotte, D. H. Robinson, M. VanWoert, and D. L. Worthen (2000), Phytoplankton taxonomic variability and nutrient utilization and primary production in the Ross Sea, Journal of Geophysical Research, 105, 88278846.

Atkins, C. B., and G. B. Dunbar (2009), Aeolian sediment flux from sea ice into Southern McMurdo Sound, Antarctica, Global and Planetary Change, 69, 133-141.

Ayling, B. F., and H. A. McGowan (2006), Niveo-eolian sediment deposits in coastal South Victoria Land, Antarctica: indicators of regional variability in weather and climate, Arctic Antarctic and Alpine Research, 38, 313-324.

Bagnold, R. A. (1941), The physics of blown sand and desert dunes, 265 pp., Methuen, New York.

Bamber, J. L., R. E. M. Riva, B. L. A. Vermeersen, and A. M. LeBrocq (2009), Reassessment of the potential sea-level rise from a collapse of the West Antarctic Ice Sheet, Science, 324, 901-903.

Banta, J. R., J. R. McConnell, R. Edwards, and J. P. Engelbrecht (2008), Delineation of carbonate dust, aluminous dust, and sea salt deposition in a Greenland glaciochemical array using positive matrix factorization, Geochemistry Geophysics Geosystems, 9, doi:10.1029/2007GC001908.

Barbante, C., G. Cozzi, G. Capodaglio, K. van de Velde, C. Ferrari, C. F. Boutron, and P. Cescon (1999), Trace element determination in alpine snow and ice by double focusing inductively coupled plasma mass spectrometry with microconcentric nebulization, Journal of Analytical Atomic Spectrometry, 14, 1433-1438.

Barbante, C., T. Bellomi, G. Mezzadri, P. Cescon, G. Scarponi, C. Morel, S. Jay, K. Van De Velde, C. Ferrari, and C. F. Boutron (1997), Direct determination of heavy metals at picogram per gram levels in Greenland and Antarctic snow by double focusing inductively coupled plasma mass spectrometry, Journal of Analytical Atomic Spectrometry, 12, 925-931.

Bauman, A. J. (1976), Desert varnish and marine ferromanganese oxide nodules: congeneric phenomena, Nature, 259, 387-388.

Bea, F., M. D. Pereira, L. G. Corretgé, and G. B. Fershtater (1994), Differentiation of strongly peraluminous, perphosphorus granites: the pedrobernardo pluton, central Spain, Geochimica et Cosmochimica Acta, 58, 2609-2627. 
Benassai, S., R. Gragnani, O. Magand, M. Proposito, I. Fattori, R. Traversi, and R. Udisti (2005), Sea-spray deposition in Antarctic coastal and plateau areas from ITASE traverses, Annals of Glaciology, 41, 32-40.

Bender, M. L., T. Sowers, and E. Brook (1997), Gases in ice cores, Proceedings of the National Academy of Science USA, 94, 8343-8349.

Bender, M. L., G. Floch, J. Chappellaz, M. Suwa, J. M. Barnola, T. Blunier, G. Dreyfus, J. Jouzel, and F. Parrenin (2006), Gas age-ice age differences and the chronology of the Vostok ice core, 0-100 ka, Journal of Geophysical Research, 111, doi:10.1029/2005jd006488.

Bertler, N. A. N. (2004), K049 NZ ITASE - Holocene climate variability along the Victoria Land Coast, Immediate Science Report, Antarctica New Zealand.

Bertler, N. A. N., P. Mayewski, and L. Carter (in press), Cold conditions in Antarctica during the Little Ice Age - implications for abrupt climate change mechanisms, Earth and Planetary Science Letters.

Bertler, N. A. N., P. A. Mayewski, P. J. Barrett, S. B. Sneed, M. J. Handley, and K. J. Kreutz (2004a), Monsoonal circulation of the McMurdo Dry Valleys, Ross Sea Region, Antarctica: signal from the snow chemistry, Annals of Glaciology, 39, 139-145.

Bertler, N. A. N., P. J. Barrett, P. A. Mayewski, R. L. Fogt, K. J. Kreutz, and J. Shulmeister (2004b), El Niño suppresses Antarctic warming, Geophysical Research Letters, 31, doi:10.1029/2004GL020749.

Bockheim, J. G. (2010), Evolution of desert pavements and the vesicular layer in soils of the Transantarctic Mountains, Geomorphology, 118, 433-443.

Boning, C. W., A. Dispert, M. Visbeck, S. R. Rintoul, and F. U. Schwarzkopf (2008), The response of the Antarctic Circumpolar Current to recent climate change, Nature Geoscience, 1, 864-869.

Bory, A., E. Wolff, R. Mulvaney, E. Jagoutz, A. Wegner, U. Ruth, and H. Elderfield (2010), Multiple sources supply eolian mineral dust to the Atlantic sector of coastal Antarctica: Evidence from recent snow layers at the top of Berkner Island ice sheet, Earth and Planetary Science Letters, 291, 138-148.

Boutron, C. F., and C. Lorius (1979), Trace metals in Antarctic snows since 1914, Nature, 277, 551-554.

Broecker, W. S. (1997), Thermohaline circulation, the Achilles Heel of our climate system: will man-made $\mathrm{CO}_{2}$ upset the current balance?, Science, 278, 1582-1588.

Broecker, W. S. (2000), Was a change in thermohaline circulation responsible for the Little Ice Age?, Proceedings of the National Academy of Sciences of the United States of America, 97, 1339-1342. 
Broecker, W. S., S. Sutherland, and T. Peng (1999), A possible 20th-century slowdown of Southern Ocean deep water formation, Science, 286, 1132-1135.

Bromwich, D. H. (1988), Snowfall in high southern latitudes, Reviews of Geophysics, 26, 149-168.

Bromwich, D. H., J. F. Carrasco, and C. R. Stearns (1992), Satellite observations of katabatic-wind propagation for great distances across the Ross Ice Shelf, Monthly Weather Review, 120, 1940-1949.

Bromwich, D. H., A. J. Monaghan, and Z. C. Guo (2004), Modeling the ENSO modulation of Antarctic climate in the late 1990s with the Polar MM5, Journal of Climate, 17, 109132.

Bromwich, D. H., J. F. Carrasco, Z. Liu, and R. Tzeng (1993), Hemispheric moisture variations and oceanographic impacts associated with katabatic surges across the Ross Ice Shelf, Antarctica, Journal of Geophysical Research, 98, 13045-13062.

Bromwich, D. H., Z. Liu, A. N. Rogers, and M. L. Van Woert (1998), Winter atmospheric forcing of the Ross Sea Polynya, in Ocean, Ice, and Atmosphere: Interactions at the Antarctic Continental Margin, Antarctic Research Series, edited by S. S. Jacobs and R. F. Weiss, pp. 101-133, AGU, Washington D. C.

Bromwich, D. H., A. N. Rogers, P. Kallberg, R. I. Cullather, J. W. C. White, and K. J. Kreutz (2000), ECMWF analyses and reanalyses depiction of ENSO signal in Antarctic precipitation, Journal of Climate, 13, 1406-1420.

Bull, J. R. (2009), Stable isotope, major and trace element chemistry of modern snow from Evans Piedmont Glacier, Antarctica: insights into potential source regions and relationship of glaciochemistry to atmospheric circulation and vigour. Thesis submitted for Master of Science in Geology., Victoria University of Wellington, Wellington.http://hdl.handle.net/10063/1124.

Bunt, J. F. (1963), Diatoms of Antarctic sea-ice as agents of primary production, Nature, $199,1255-1257$.

Bunt, J. F., and E. F. J. Wood (1963), Microbiology of Antarctic sea ice, Nature, 199, 1254-1255.

Buseck, P. R., and S. E. Schwartz (2003), Troposheric aerosols, in Treatise on Geochemistry, edited by K. K. Turekian and H. D. Holland, pp. 91-129, Elsevier.

Cai, W., P. H. Whetton, and D. J. Karoly (2003), The response of the Antarctic Oscillation to increasing and stabilized atmospheric $\mathrm{CO}_{2}$, Journal of Climate, 16, 15251538.

Caquineau, S., A. Gaudichet, L. Gomes, M. Magonthier, and B. Chatenet (1998), Saharan dust: clay ratio as a relevant tracer to assess the origin of soil-derved aerosols, Geophysical Research Letters, 25, 983-986. 
Carleton, A. M. (1989), Antarctic sea-ice relationships with indices of the atmospheric circulation of the Southern Hemisphere, Climate Dynamics, 3, 207-220.

Carrasco, J. F., and D. H. Bromwich (1993), Mesoscale cyclogenesis dynamics over the southwestern Ross Sea, Antarctica, Journal of Geophysical Research, 98 12,973912,995 .

Ciais, P., J. White, J. Jouzel, and J. R. Petit (1995), The origin of present-day Antarctic precipitation from surface snow deuterium excess data, Journal of Geophysical Research, 100, 18917-18927.

Comiso, J. C., C. L. Parkinson, R. Gersten, and L. Stock (2008), Accelerated decline in the Arctic sea ice cover, Geophysical Research Letters, 35, doi:10.1029/2007GL031972.

Correia, A., R. Freydier, R. J. Delmas, J. C. Simoes, J. D. Taupin, B. Dupre, and P. Artaxo (2003), Trace elements in South America aerosol during 20th century inferred from a Nevado Illimani ice core, Eastern Bolivian Andes (6350m asl), Atmospheric Chemistry and Physics, 3, 1337-1352.

Cotté, C., and C. Guinet (2007), Historical whaling records reveal major regional retreat of Antarctic sea ice, Deep-Sea Research I, 54, 243-252.

Craig, H. (1961), Isotopic variations in meteoric waters, Science, 133, 1702-1703.

Crowley, T. J. (2000), Causes of climate change over the past 1000 years, Science, 289, 270-277.

Cullather, R. I., D. H. Bromwich, and M. L. Van Woert (1996), Interannual variations in Antarctic precipitation related to El Niño-Southern Oscillation, Journal of Geophysical Research, 101, 19109-19118.

Curran, M. A. J., and A. S. Palmer (2001), Suppressed ion chromatography methods for the routine determination of ultra low level anions and cations in ice cores, Journal of Chromatography A, 919, 107-113.

Curran, M. A. J., T. D. van Ommen, and V. I. Morgan (1998), Seasonal characteristics of the major ions in the high-accumulation Dome Summit South ice core, Law Dome, Antarctica, Annuals of Glaciology, 27, 385-390.

Curran, M. A. J., T. D. van Ommen, V. I. Morgan, K. L. Phillips, and A. S. Palmer (2003), Ice core evidence for Antarctic sea ice decline since the 1950s, Science, 302, 1203-1206.

Dansgaard, W. (1954), The ${ }^{18} \mathrm{O}$ abundance in fresh water, Geochimica et Cosmochimica Acta, 6, 241-260.

Dansgaard, W. (1964), Stable isotopes in precipitation, Tellus, 16, 436-468.

Dansgaard, W., and S. J. Johnsen (1969), A flow model and a time scale for the ice core from Camp Century, Greenland, Journal of Glaciology, 8, 215-223. 
de la Mare, W. K. (2009), Changes in Antarctic sea-ice extent from direct historical observations and whaling records, Climatic Change, 92, 461-493.

Deer, W. A., R. A. Howie, and J. Zussman (1966), An introduction to rock forming minerals, 528 pp., John Wiley and Sons, New York.

Delmonte, B., I. Basile-Doelsch, J. R. Petit, V. Maggi, M. Revel-Rolland, A. Michard, E. Jagoutz, and F. Grousset (2004), Comparing the EPICA and Vostok dust records during the last 220,000 years: stratigraphical correlation and provenance in glacial periods, Earth-Science Reviews, 66, 63-87.

Delmonte, B., P. S. Andersson, H. Schoberg, M. Hansson, J. R. Petit, R. Delmas, D. M. Gaiero, V. Maggi, and M. Frezzotti (2010), Geographic provenance of aeolian dust in East Antarctica during Pleistocene glaciations: preliminary results from Talos Dome and comparison with East Antarctic and new Andean ice core data, Quaternary Science Reviews, 29, 256-264.

Delmotte, M., V. Masson, and J. Jouzel (2000), A seasonal deuterium excess signal at Law Dome, coastal eastern Antarctica: a Southern Ocean signature, Journal of Geophysical Research, 105, 7187-7197.

DiTullio, G. R., D. R. Jones, and M. E. Geesey (2003), Dimethylsulfide dynamics in the Ross Sea during austral summer. , in Antarctic Research Series, edited by G. R. DiTullio and R. B. Dunbar, pp. 279-294.

Dixon, D., P. A. Mayewski, S. Kaspari, S. Sneed, and M. Handley (2004), A 200 year subannual record of sulfate in West Antarctica, from 16 ice cores, Annals of Glaciology, 39, 545-556.

Dixon, D., P. A. Mayewski, S. Kaspari, K. J. Kreutz, G. S. Hamilton, K. Maasch, S. Sneed, and M. Handley (2005), A 200 year sulfate record from 16 Antarctic ice cores and associations with Southern Ocean sea-ice extent, Annals of Glaciology, 41, 155-166.

Domack, E. W., and P. A. Mayewski (1999), Bi-polar ocean linkages: evidence from lateHolocene Antarctic marine and Greenland ice-core records, Holocene, 9, 247-251.

Dunbar, G. B., N. A. N. Bertler, and R. M. McKay (2009), Sediment flux through the McMurdo Ice Shelf in Windless Bight, Antarctica, Global and Planetary Change, 69, 8793.

Eicken, H. (1992), The role of sea ice in structuring Antarctic ecosystems, Polar Biology, 12, 3-12.

EPICA (2004), Eight glacial cycles from an Antarctic ice core, Nature, 429, 623-628.

Etheridge, D. M., L. P. Steele, R. L. Langenfelds, R. J. Francey, J. M. Barnola, and V. I. Morgan (1996), Natural and anthropogenic changes in atmospheric $\mathrm{CO}_{2}$ over the last 1000 years from air in Antarctic ice and firn, Journal of Geophysical Research, 101, 4115-4128. 
Fischer, H., et al. (2007), Reconstruction of millennial changes in dust emission, transport and regional sea ice coverage using the deep EPICA ice cores from the Atlantic and Indian Ocean sectors of Antarctica, Earth and Planetary Science Letters, $260,340-354$.

Fogt, R. L., and D. H. Bromwich (2006), Decadal variability of the ENSO teleconnection to the high-latitude South Pacific governed by coupling with the Southern Annular Mode, Journal of Climate, 19, 979-998.

Gabrielli, P., C. Barbante, C. Turetta, A. Marteel, C. F. Boutron, G. Cozzi, W. Cairns, C. Ferrari, and P. Cescon (2006), Direct determination of rare earth elements at the subpicogram per gram level in Antarctic ice by ICP-SFMS using a desolvation system, Analytical Chemistry, 78, 1883-1889.

Gabrielli, P., C. Barbante, C. F. Boutron, G. Cozzi, V. Gaspari, F. A. M. Planchon, C. Ferrari, C. Turetta, S. M. Hong, and P. Cescon (2005a), Variations in atmospheric trace elements in Dome C (East Antarctica) ice over the last two climatic cycles, Atmospheric Environment, 39, 6420-6429.

Gabrielli, P., et al. (2005b), Trace elements in Vostok Antarctic ice during the last four climatic cycles, Earth and Planetary Science Letters, 234, 249-259.

Gabrielli, P., et al. (2010), A major glacial-interglacial change in aeolian dust composition inferred from rare earth elements in Antarctic ice, Quaternary Science Reviews, 29, 265-273.

Gaspari, V., C. Barbante, G. Cozzi, P. Cescon, C. F. Boutron, P. Gabrielli, G. Capodaglio, C. Ferrari, J. R. Petit, and B. Delmonte (2006), Atmospheric iron fluxes over the last deglaciation: climatic implications, Geophysical Research Letters, 33, doi:10.1029/2005GL024352.

Gat, J. R. (1996), Oxygen and hydrogen isotopes in the hydrologic cycle, Annual Review of Earth and Planetary Sciences, 24, 225-262.

Gat, J. R. (2005), Some classical concepts of isotope hydrology, 127-137 pp., Springer, Netherlands.

Gaudichet, A., M. De Angelis, R. Lefevre, J. R. Petit, Y. S. Korotkevitcha, and V. N. Petro (1988), Mineralogy of insoluble particles in the Vostok Antarctic ice core over the last climatic cycle (150 kyr), Geophysical Research Letters, 15, 1471-1474.

Gillette, D. A., I. H. J. Blifford, and D. W. Fryrear (1974), The influence of wind velocity on the size distributions of aerosols generated by the wind erosion of soils, Journal of Geophysical Research, 79, 4068-4075.

Gong, D., and S. Wang (1999), Definition of Antarctic Oscillation index, Geophysical Research Letters, 26, 459-462. 
Goodwin, I., T. D. Van Ommen, M. A. J. Curran, and P. A. Mayewski (2004), Mid latitude winter climate variability in the south Indian and southwest Pacific regions since 1300 AD, Climate Dynamics, 22, 783-794.

Goose, H., and T. Fichefet (1999), Importance of the ice-ocean interactions for the global ocean circulation: a model study, Journal of Geophysical Research, 40, 2333723355.

Gregory, S., and D. Noone (2008), Variability in the teleconnection between the El Niño-Southern Oscillation and West Antarctic climate deduced from West Antarctic ice core isotope records, Journal of Geophysical Research, 113, doi:10.1029/2007jd009107.

Grotti, M., F. Soggia, and J. Todoli (2008), Ultra-trace analysis of Antarctic snow samples by reaction cell inductively coupled plasma mass spectrometry using a totalconsumption micro-sample-introduction system, Analyst, 133, 1388-1394.

Grove, J. M. (1988), The Little Ice Age, Methuen, London.

Günzler, H., and A. Williams (Eds.) (2001), Handbook of Analytical Techniques, 1198 pp., Wiley-VCH.

Hall, A., and M. Visbeck (2002), Synchronous variability in the Southern Hemisphere atmosphere, sea ice, and ocean resulting from the Annular Mode, Journal of Climate, 15, 3043-3057.

Hall, J. S., and E. W. Wolff (1998), Causes of seasonal and daily variations in aerosol sea-salt concentrations at a coastal Antarctic station, Atmospheric Environment, 32, 3669-3677.

Harangozo, S. A., and W. M. Connolley (2006), The role of the atmospheric circulation in the record minimum extent of open water in the Ross Sea in the 2003 austral summer, Atmosphere-Ocean, 44, 83-97.

Henderson, P. (1984), General geochemical properties and abundances of the rare earth elements, in Rare Earth Element Geochemistry, edited, Elsevier.

Hinkley, T. K., M. F. Le Cloarec, and G. Lambert (1994), Fractionation of families of major, minor, and trace metals across the melt-vapor interface in volcanic exhalations, Geochimica et Cosmochimica Acta, 58, 3255-3263.

Hobbs, S. E., and J. W. Olesik (1993), The effect of desolvating droplets and vaporizing particles on ionization and excitation in Ar inductively coupled plasmas, Spectrochimica Acta Part B: Atomic Spectroscopy, 48, 817-833.

Hur, S., X. Cunde, S. Hong, C. Barbante, P. Gabrielli, K. Lee, C. Bouton, and Y. Ming (2007), Seasonal patterns of heavy metal deposition to the snow on Lambert Glacier basin, East Antarctica, Atmospheric Environment, 41, 8567-8578. 
Hutton, R. C., and A. N. Eaton (1987), Role of aerosol water vapour loading in inductively coupled plasma mass spectrometry, Journal of Analytical Atomic Spectrometry, 2, 595-598.

Indermuhle, A., et al. (1999), Holocene carbon-cycle dynamics based on $\mathrm{CO}_{2}$ trapped in ice at Taylor Dome, Antarctica, Nature, 398, 121-126.

IPCC (2007), Summary for policymakers Rep., Cambridge University Press, Cambridge, United Kingdom and New York, USA.

IPICS (2008), The IPICS 2K Array: A network of ice core climate and climate forcing records for the last two millennia, edited by E. Brook and E. W. Wolff.

Jacobs, S. S., and C. F. Giulivi (1998), Interannual ocean and sea ice variability in the Ross Sea., in Antarctic Research Series, edited by S. S. Jacobs and R. Weiss, pp. 135-150, AGU, Washington, D.C.

Jacobs, S. S., C. F. Giulivi, and P. A. Mele (2002), Freshening of the Ross Sea during the late 20th century, Science, 297, 386-389.

Jochum, K. P., U. Nohl, K. Herwig, E. Lammel, B. Stoll, and A. W. Hofmann (2005), GeoReM: a new geochemical database for reference materials and isotopic standards, Geostandards and Geoanalytical Research, 29, 333-338.

Johnsen, S. J. (1977), Stable isotope homogenisation of polar firn and ice, paper presented at International Symposium on Isotopes and Impurities in Snow and Ice, General Assembly XVI, Int. Assoc. of Hydrol. Sci., Washington, D.C.

Johnsen, S. J., H. B. Clausen, K. M. Cuffey, G. Hoffmann, J. Schwander, and T. Creyts (2000), Diffusion of stable isotopes in polar firn and ice : the isotope effect in firn diffusion, Physics of Ice Core Records, 121-140.

Jones, P. D., and M. E. Mann (2004), Climate over past millennia, Reviews of Geophysics, 42, doi:10.1029/2003RG000143.

Jones, P. D., et al. (2009), High-resolution palaeoclimatology of the last millennium: a review of current status and future prospects, The Holocene, 19, 3-49.

Jouzel, J. (2003), Water stable isotopes: atmospheric composition and applications in polar ice core studies, in Treatise of Geochemistry, edited by K. K. Turekian and H. D. Holland, pp. 213-243, Elsevier.

Jouzel, J., and L. Merlivat (1984), Deuterium and oxygen 18 in precipitation: modelling of the isotopic effect during snow formation, Journal of Geophysical Research, 89, 11749-11757.

Jouzel, J., L. Merlivat, and C. Lorius (1982), Deuterium excess in an East Antarctic ice core suggests higher relative humidity at the oceanic surface during the last glacial maximum, Nature, 299, 688-691. 
Jouzel, J., L. Merlivat, M. Pourchet, and C. Lorius (1979), A continuous record of artificial tritium fallout at the South Pole (1954-1978), Earth and Planetary Science Letters, 45, 188-200.

Jouzel, J., G. Raisbeck, J. P. Benoist, F. Yiou, C. Lorius, D. Raynaud, J. R. Petit, N. I. Barkov, Y. S. Korotkevitch, and V. M. Kotlyakov (1989), A comparison of deep Antarctic ice cores and their implications for climate between 65,000 and 15,000 years ago, Quaternary Research, 31, 135-150.

Kalnay, E., et al. (1996), The NCEP/NCAR reanalysis 40-year project, Bulletin of the American Meteorological Society, 77, 437-471.

Kaspari, S., D. Dixon, S. Sneed, and M. Handley (2005), Sources and transport pathways of marine aerosol species into West Antarctica, Annals of Glaciology, 41, 1-9.

Kaspari, S., P. A. Mayewski, M. Handley, S. Kang, S. Hou, S. Sneed, K. Maasch, and D. Qin (2009), A high-resolution record of atmospheric dust composition and variability since AD 1650 from a Mount Everest ice core, Journal of Climate, 22, 3910-3925.

Kaspari, S., et al. (2007), Reduction in northward incursions of the South Asian monsoon since 1400 AD inferred from a Mt. Everest ice core, Geophysical Research Letters, 34, doi:10.1029/2007GL030440.

Kellerhals, T., L. Tobler, S. Brütsch, M. Sigl, L. Wacker, H. W. Gäggeler, and M. Schwikowski (2010), Thallium as a tracer for preindustrial volcanic eruptions in an ice core record from Illimani, Bolivia, Environmental Science \& Technology, 44, 888-893.

Kidson, J. W. (1999), Principal modes of Southern Hemisphere low-frequency variability obtained from NCEP-NCAR reanalyses, Journal of Climate, 12, 2808-2830.

King, J. C., and J. Turner (1997), Antarctic meterology and climatology, Cambridge University Press, Cambridge.

Knusel, S., D. E. Piguet, M. Schwikowski, and H. W. Gaggeler (2003), Accuracy of continuous ice-core trace-element analysis by inductively coupled plasma sector field mass spectrometry, Environmental Science \& Technology, 37, 2267-2273.

Krachler, M., J. Zheng, D. Fisher, and W. Shotyka (2004), Novel calibration procedure for improving trace element determinations in ice and water samples using ICP-SMS, Journal of Analytical Atomic Spectrometry, 19, 1017-1019.

Krachler, M., J. Zheng, D. Fisher, and W. Shotyk (2005), Analytical procedures for improved trace element detection limits in polar ice from Arctic Canada using ICP-SMS, Analytica Chimica Acta, 530, 291-298.

Kreutz, K. J., P. A. Mayewski, I. I. Pittalwala, L. D. Meeker, M. S. Twickler, and S. I. Whitlow (2000), Sea level pressure variability in the Amundsen Sea region inferred from a West Antarctic glaciochemical record., Journal of Geophysical Research, 105, 4047-4059. 
Kwok, R., and J. C. Comiso (2002), Southern Ocean climate and sea ice anomalies associated with the Southern Oscillation, Journal of Climate, 15, 487-501.

Legrand, M. R. (1997), Ice-core records of atmospheric sulphur, Philosophical Transactions of the Royal Society of London Series B, 352, 241-250.

Legrand, M. R., and R. J. Delmas (1984), The ionic balance of Antarctic snow: a 10-year detailed record, Atmospheric Environment (1967), 18, 1867-1874.

Legrand, M. R., and R. J. Delmas (1987), A 220-yr continuous record of volcanic $\mathrm{H}_{2} \mathrm{SO}_{4}$ in the Antarctic ice sheet, Nature, 327, 671-676.

Legrand, M. R., and P. A. Mayewski (1997), Glaciochemistry of polar ice cores: a review, Reviews of Geophysics, 35, 219-243.

Leventer, A., and R. B. Dunbar (1988), Recent diatom record of McMurdo Sound, Antarctica: implications for history of sea ice extent, Paleoceanography, 3, 259-274.

Levitus, S., J. Antonov, and T. Boyer (2005), Warming of the world ocean, 1955-2003, Geophysical Research Letters, 32, doi:10.1029/2004GL021592.

Liss, P. S., G. Malin, S. M. Turner, and P. M. Holligan (1994), Dimethyl sulphide and phaeocystis: a review, Journal of Marine Systems, 5, 41-53.

Liu, J. P., J. A. Curry, and D. G. Martinson (2004), Interpretation of recent Antarctic sea ice variability, Geophysical Research Letters, 31, doi:10.1029/2003GL018732.

Liu, Y., Y. Zhang, G. Li, and L. Xiao (1988), Analysis of trace elements in the BHQ ice core Law Dome, Antarctica, Journal of Glaciology, 34, 297-300.

Markus, T., and B. A. Burns (1995), A method to estimate subpixel-scale coastal polynyas with satellite passive microwave data, Journal of Geophysical Research, 100, 4473-4487.

Marshall, G. J. (2003), Trends in the Southern Annular Mode from observations and reanalyses, Journal of Climate, 16, 4134-4143.

Marshall, G. J., P. A. Stott, J. Turner, W. M. Connolley, J. C. King, and T. A. Lachlan-Cope (2004), Causes of exceptional atmospheric circulation changes in the Southern Hemisphere, Geophysical Research Letters, 31, doi:10.1029/2004gl019952.

Marteel, A., et al. (2008), Changes in atmospheric heavy metals and metalloids in Dome C (East Antarctica) ice back to $672.0 \mathrm{kyr}$ BP (Marine Isotopic Stages 16.2), Earth and Planetary Science Letters, 272, 579-590.

Marteel, A., et al. (2009), Climate-related variations in crustal trace elements in Dome C (East Antarctica) ice during the past 672 kyr, Climatic Change, 92, 191-211. 
Masson-Delmotte, V., et al. (2010), Abrupt change of Antarctic moisture origin at the end of Termination II, Proceedings of the National Academy of Sciences, 107, 1209112094.

Masson-Delmotte, V., et al. (2008), A review of Antarctic surface snow isotopic composition: observations, atmospheric circulation, and isotopic modeling, Journal of Climate, 21, 3359-3387.

Masson, V., et al. (2000), Holocene climate variability in Antarctica based on 11 icecore isotopic records, Quaternary Research, 54, 348-358.

Matthews, J. A., and K. R. Briffa (2005), The 'Little Ice Age': reevaluation of an evolving concept, Geografiska Annaler, 87A, 17-36.

Mayewski, P. A., et al. (2004), A 700 year record of Southern Hemisphere extratropical climate variability, Annals of Glaciology, 39, 127-132.

Mayewski, P. A., et al. (1994), Changes in atmospheric circulation and ocean ice cover over the North Atlantic during the last 41,000 years, Science, 263, 1747-1751.

Mayewski, P. A., et al. (2009), State of the Antarctic and Southern Ocean climate system, Reviews of Geophysics, 47, doi:10.1029/2007rg000231.

Mayewski, P. A., et al. (2005), The International Trans-Antarctic Scientific Expedition (ITASE): an overview, Annals of Glaciology, 41, 180-185.

McConnell, J. R., G. W. Lamorey, S. W. Lambert, and K. W. Taylor (2002), Continuous ice-core chemical analyses using inductively coupled plasma mass spectrometry, Environmental Science \& Technology, 36, 7-11.

McConnell, J. R., A. J. Aristarain, J. R. Banta, P. R. Edwards, and J. C. Simoes (2007), 20th-century doubling in dust archived in an Antarctic Peninsula ice core parallels climate change and desertification in South America, Proceedings of the National Academy of Sciences, 104, 5743-5748.

McDonough, W. F., and S. Sun (1995), The composition of the Earth, Chemical Geology, 120, 223-253.

Merlivat, L., and J. Jouzel (1979), Global climatic interpretation of the deuteriumoxygen 18 relationship for precipitation, Journal of Geophysical Research, 84, 50295033.

Meyerson, E. A., P. A. Mayewski, K. J. Kreutz, L. D. Meeker, S. I. Whitlow, and M. S. Twickler (2002), The polar expression of ENSO and sea-ice variability as recorded in a South Pole ice core, Annals of Glaciology, 35, 430-436.

Michalski, G., J. G. Bockheim, C. Kendall, and M. Thiemens (2005), Isotopic composition of Antarctic Dry Valley nitrate: implications for NOy sources and cycling in Antarctica, Geophysical Research Letters, 32, doi:10.1029/2004gl022121. 
Minikin, A., M. Legrand, J. S. Hall, D. Wagenbach, C. Kleefeld, E. W. Wolff, E. C. Pasteur, and F. Ducroz (1998), Sulfur-containing species (sulfate and methanesulfonate) in coastal Antarctic aerosol and precipitation, Journal of Geophysical Research, 103, 10975-10990.

Monaghan, A. J., D. H. Bromwich, J. G. Powers, and K. W. Manning (2005), The climate of the McMurdo, Antarctica, region as represented by one year of forecasts from the Antarctic Mesoscale Prediction System, Journal of Climate, 18, 1174-1189.

Monahan, E. C., D. E. Spiel, and K. L. Davidson (1986), A model of marine aerosol generation via whitecaps and wave disruption, in Oceanic Whitecaps and Their Role in Air-Sea Exchange Processes, edited by E. C. Monahan and G. Niocaill, pp. 167-174, Springer, New York.

Morales Maqueda, M. A., A. J. Willmott, and N. R. T. Biggs (2004), Polynya dynamics: a review of observation and modeling, Reviews of Geophysics, 42, doi:10.1029/2002RG000116.

Morgan, V. I., and T. D. van Ommen (1997), Seasonality in late-Holocene climate from ice-core records, Holocene, 7, 351-354.

Morganti, A., S. Becagli, E. Castellano, M. Severi, R. Traversi, and R. Udisti (2007), An improved flow analysis-ion chromatography method for determination of cationic and anionic species at trace levels in Antarctic ice cores, Analytica Chimica Acta, 603, 190198.

Morgenstern, U., and C. B. Taylor (2009), Ultra low-level tritium measurement using electrolytic enrichment and LSC, Isotopes in Environmental and Health Studies, 45, 96117.

Mosley-Thompson, E. (1995), Paleoenvironmental conditions in Antarctica since A. D. 1500: ice core evidence, in Climate Since A. D. 1500 edited by R. S. Bradley and P. D. Jones, p. 572, Routledge.

Mosley-Thompson, E., and L. G. Thompson (1990), Little Ice Age (neoglacial) paleoenvironmental conditions at Siple Station, Antarctica, Annals of Glaciology, 14, 199-204.

Naik, S. S., M. Thamban, C. M. Laluraj, B. L. Redkar, and A. Chaturvedi (2010), A century of climate variability in central Dronning Maud Land, East Antarctica, and its relation to Southern Annular Mode and El Niño-Southern Oscillation, Journal of Geophysical Research, 115, doi:10.1029/2009jd013268.

O'Dwyer, J., E. Isaksson, T. Vinje, T. Jauhiainen, J. Moore, V. Pohjola, R. Vaikmae, and R. S. W. van de Wal (2000), Methanesulfonic acid in a Svalbard ice core as an indicator of ocean climate, Geophysical Research Letters, 27, 1159-1162.

Oerter, H., W. Graf, F. Wilhelms, A. Minikin, and H. Miller (1999), Accumulation studies on Amundsenisen, Dronning Maud Land, Antarctica, by means of tritium, dielectric 
profiling and stable-isotope measurements: first results from the 1995-96 and 1996-97 field seasons, Annals of Glaciology, 29, 1-9.

Oppenheimer, C., et al. (2010), Atmospheric chemistry of an Antarctic volcanic plume, Journal of Geophysical Research, 115, doi:10.1029/2009JD011910.

Osterberg, E. C., M. J. Handley, S. B. Sneed, P. A. Mayewski, and K. J. Kreutz (2006), Continuous ice core melter system with discrete sampling for major ion, trace element, and stable isotope analyses, Environmental Science \& Technology, 40, 3355-3361.

Palmer, A. S., T. D. van Ommen, M. A. J. Curran, V. I. Morgan, J. M. Souney, and P. A. Mayewski (2001), High-precision dating of volcanic events (A.D. 1301 - 1995) using ice cores from Law Dome, Antarctica, Journal of Geophysical Research, 106, 28089-28095.

Parish, T. (1988), Surface winds over the Antarctic continent: a review, Reviews of Geophysics, 26, 169-180.

Pasteur, E. C., R. Mulvaney, D. A. Peel, E. S. Saltzman, and P. Y. Whung (1995), A 340 year record of biogenic sulphur from the Weddell Sea area, Antarctica, Annals of Glaciology, 21, 169-174.

Patterson, N. G., N. A. N. Bertler, T. R. Naish, and U. Morgenstern (2005), ENSO variability in the deuterium-excess record of a coastal Antarctic ice core from the McMurdo Dry Valleys, Victoria Land, Annals of Glaciology, 41, 140-146.

Petit, J. R., M. Briat, and A. Royer (1981), Ice age aerosol content from East Antarctic ice core samples and past wind strength., Nature, 293, 391-394.

Petit, J. R., J. White, N. W. Young, J. Jouzel, and Y. S. Korotkevitch (1991), Deuterium excess in Antarctic snow, Journal of Geophysical Research, 96, 5113-5122.

Petit, J. R., et al. (1999), Climate and atmospheric history of the past 420,00- years from the Vostok ice core, Antarctica, Nature, 399, 429-436.

Planchon, F. A. M., K. Van de Velde, K. Rosman, E. W. Wolff, C. Ferrari, and C. F. Boutron (2003), One hundred fifty-year record of lead isotopes in Antarctic snow from Coats Land, Geochimica et Cosmochimica Acta, 67, 693-708.

Planchon, F. A. M., C. F. Boutron, C. Barbante, E. W. Wolff, G. Cozzi, V. Gaspari, C. P. Ferrari, and P. Cescon (2001), Ultrasensitive determination of heavy metals at the subpicogram per gram level in ultraclean Antarctic snow samples by inductively coupled plasma sector field mass spectrometry, Analytica Chimica Acta , 450, 193-205.

Planchon, F. A. M., C. F. Boutron, C. Barbante, G. Cozzi, V. Gaspari, E. W. Wolff, C. P. Ferrari, and P. Cescon (2002a), Changes in heavy metals in Antarctic snow from Coats Land since the mid-19th to the late-20th century, Earth and Planetary Science Letters, 200, 207-222. 
Planchon, F. A. M., C. F. Boutron, C. Barbante, G. Cozzi, V. Gaspari, E. W. Wolff, C. P. Ferrari, and P. Cescon (2002b), Short-term variations in the occurrence of heavy metals in Antarctic snow from Coats Land since the 1920s, Science of the Total Environment, $300,129-142$

Post, J. E. (1999), Manganese oxide minerals: crystal structures and economic and environmental significance, paper presented at Proceedings of National Academy of Science, USA.

Preunkert, S., B. Jourdain, M. Legrand, R. Udisti, S. Becagli, and O. Cerri (2008), Seasonality of sulfur species (dimethyl sulfide, sulfate, and methanesulfonate) in Antarctica: inland versus coastal regions, Journal of Geophysical Research, 113, doi: 10.1029/2008JD009937.

Prospero, J. M., P. Ginoux, O. Torres, S. E. Nicholson, and T. E. Gill (2002), Environmental characterization of global sources of atmospheric soil dust identified with the Nimbus 7 total ozone mapping spectrometer (TOMS) absorbing aerosol product, Reviews of Geophysics, 40, doi:10.1029/2000RG000095.

Purdie, H., N. A. N. Bertler, A. Mackintosh, J. A. Baker, and R. H. Rhodes (2010), Isotopic and elemental changes in winter snow accumulation on glaciers in the Southern Alps of New Zealand, Journal of Climate, 23, doi: 10.1175/2010JCLI3701.1171.

Pye, K. (1987), Aeolian dust and dust deposits, Academic Press, London.

Ramirez, E., et al. (2003), A new Andean deep ice core from Nevado Illimani (6350 m), Bolivia, Earth and Planetary Science Letters, 212, 337-350.

Rankin, A. M., V. Auld, and E. W. Wolff (2000), Frost flowers as a source of fractionated sea salt aerosol in the polar regions, Geophysical Research Letters, 27, 3469-3472.

Rankin, A. M., E. W. Wolff, and S. Martin (2002), Frost flowers: implications for tropospheric chemistry and ice core interpretation, Journal of Geophysical Research, 107, doi:10.1029/2002JD002492.

Rankin, A. M., E. W. Wolff, and R. Mulvaney (2004), A reinterpretation of sea-salt records in Greenland and Antarctic ice cores?, Annals of Glaciology, 39, 276-282.

Rasmussen, S. O., et al. (2006), A new Greenland ice core chronology for the last glacial termination, Journal of Geophysical Research, 111, doi:10.1029/2005jd006079.

Reimann, C., and P. De Caritat (2000), Intrinsic flaws of element enrichment factors (EFs) in environmental geochemistry, Environmental Science \& Technology, 34, 50845091.

Renwick, J. A. (1998), ENSO-related variability in the frequency of South Pacific blocking, Monthly Weather Review, 126, 3117-3123. 
Rhodes, R. H., J. A. Baker, M.-A. Millet, and N. A. N. Bertler (2011), Experimental investigation of the effects of mineral dust on the reproducibility and accuracy of ice core trace element analyses, Chemical Geology, doi: 10.1016/j.chemgeo.2011.05.006.

Rhodes, R. H., N. A. N. Bertler, J. A. Baker, S. B. Sneed, H. Oerter, and K. R. Arrigo (2009), Sea ice variability and primary productivity in the Ross Sea, Antarctica, from methylsulphonate snow record, Geophysical Research Letters, 36, doi:10.1029/2009GL037311.

Robock, A. (2000), Volcanic eruptions and climate, Reviews of Geophysics, 38, 191-219.

Ruth, U., D. Wagenbach, J. P. Steffensen, and M. Bigler (2003), Continuous record of microparticle concentration and size distribution in the central Greenland NGRIP ice core during the last glacial period, Journal of Geophysical Research, 108, doi:10.1029/2002JD002376.

Ruth, U., et al. (2008), Proxies and measurement techniques for mineral dust in Antarctic ice cores, Environmental Science \& Technology, 42, 5675-5681.

Sala, M., et al. (2008), Evidence of calcium carbonates in coastal (Talos Dome and Ross Sea area) East Antarctica snow and firn: environmental and climatic implications, Earth and Planetary Science Letters, 271, 43-52.

Sallee, J. B., K. G. Speer, and S. R. Rintoul (2010), Zonally asymmetric response of the Southern Ocean mixed-layer depth to the Southern Annular Mode, Nature Geoscience, 3, 273-279.

Saltzman, E. S., G. W. Brass, and D. A. Price (1983), Mechanism of sulfate aerosol formation: chemical and sulfur isotopic evidence, Geophysical Research Letters, 10, 513-516.

Schneider, D. P., E. J. Steig, T. D. van Ommen, D. Dixon, P. A. Mayewski, J. M. Jones, and C. M. Bitz (2006), Antarctic temperatures over the past two centuries from ice cores, Geophysical Research Letters, 33, doi:10.1029/2006GL027057.

Schroth, A. W., J. Crusius, E. R. Sholkovitz, and B. C. Bostick (2009), Iron solubility driven by speciation in dust sources to the ocean, Nature Geoscience, 2, 337-340.

Schulz, M., Y. Balkanski, W. Guelle, and F. Dulac (1998), Role of aerosol size distribution and source location in a three-dimensional simulation of a Saharan dust episode tested against satellite derived optical thickness, Journal of Geophysical Research, 103, $10,579-510,592$.

Sedwick, P. N., and G. R. DiTullio (1997), Regulation of algal blooms in Antarctic shelf waters by the release of iron from melting sea ice, Geophysical Research Letters, 24, 2515-2518.

Sigman, D. M., and E. A. Boyle (2000), Glacial/interglacial variations in atmospheric carbon dioxide, Nature, 407, 859-869. 
Simkin, T., and L. Siebert (1994), Volcanoes of the world, 2nd ed., 349 pp., Geoscience Press, Tuscon, Arizona.

Simmonds, I., and T. H. Jacka (1995), Relationships between the interannual variability of Antarctic sea ice and the Southern Oscillation, Journal of Climate, 8, 637-647.

Sinclair, K. E., N. A. N. Bertler, and W. J. Trompetter (2010), Synoptic controls on precipitation pathways and snow delivery to high-accumulation ice core sites in the Ross Sea region, Antarctica, Journal of Geophysical Research, 115, doi:10.1029/2010jd014383.

Smith, W. O., and L. I. Gordon (1997), Hyperproductivity of the Ross Sea (Antarctica) Polynya during austral spring, Geophysical Research Letters, 24, 233-236.

Snäll, S., and T. Liljefors (2000), Leachability of major elements from minerals in strong acids, Journal of Geochemical Exploration, 71, 1-12.

Souney, J. M., P. A. Mayewski, I. D. Goodwin, L. D. Meeker, V. I. Morgan, M. A. J. Curran, T. D. Van Ommen, and A. S. Palmer (2002), A 700-year record of atmospheric circulation developed from the Law Dome ice core, East Antarctica, Journal of Geophysical Research, 107, doi:10.1029/2002JD002104.

Stammerjohn, S. E., D. G. Martinson, R. C. Smith, X. Yuan, and D. Rind (2008), Trends in Antarctic annual sea ice retreat and advance and their relation to El Niño-Southern Oscillation and Southern Annular Mode variability. , Journal of Geophysical Research, 113, doi:10.1029/2007JC004269.

Steen-Larsen, H. C., et al. (2011), Understanding the climatic signal in the water stable isotope records from the NEEM shallow firn/ice cores in North-West Greenland, Journal of Geophysical Research, in press.

Steig, E. J., D. P. Schneider, S. D. Rutherford, M. E. Mann, J. C. Comiso, and D. T. Shindell (2009), Warming of the Antarctic ice-sheet surface since the 1957 International Geophysical Year, Nature, 457, 459-462.

Steig, E. J., E. J. Brook, J. W. C. White, C. M. Sucher, M. L. Bender, S. J. Lehman, D. L. Morse, E. D. Waddington, and G. D. Clow (1998), Synchronous climate changes in Antarctica and the North Atlantic, Science, 282, 92-95.

Steig, E. J., et al. (2005), High-resolution ice cores from US ITASE (West Antarctica): development and validation of chronologies and determination of precision and accuracy, Annuals of Glaciology, 41, 77-84.

Stenni, B., M. Proposito, R. Gragnani, O. Flora, J. Jouzel, S. Falourd, and M. Frezzotti (2002), Eight centuries of volcanic signal and climate change at Talos Dome (East Antarctica), Journal of Geophysical Research, 107, doi:10.1029/2000jd000317.

Sun, J. Y., J. W. Ren, and D. H. Qin (2002), 600 years record of biogenic sulfur from Lambert Glacier basin firn core, East Antarctica, Annals of Glaciology, 35, 362-367. 
Tamura, T., K. I. Ohshima, and S. Nihashi (2008), Mapping of sea ice production for Antarctic coastal polynyas, Geophysical Research Letters, 35, doi:10.1029/2007GL032903.

Tao, G. H., R. Yamada, Y. Fujikawa, A. Kudo, J. Zheng, D. A. Fisher, and R. M. Koerner (2001), Determination of trace amounts of heavy metals in Arctic ice core samples using inductively coupled plasma mass spectrometry, Talanta, 55, 765-772.

Thomas, R. (2001), A beginners guide to ICP-MS, Spectroscopy, 14, 38-42.

Thompson, D. W. J., and S. Solomon (2002), Interpretation of recent Southern Hemisphere climate change, Science, 296, 895-899.

Thompson, L. G., E. Mosley-Thompson, M. E. Davis, P.-N. Lin, K. A. Henderson, J. ColeDai, J. F. Bolzan, and K.-B. Liu (1995), Late Glacial stage and Holocene tropical ice core records from Huascaran, Peru, Science, 269, 46-50.

Townsend, A. T., and R. Edwards (1998), Ultratrace analysis of Antarctic snow and ice samples using high resolution inductively coupled plasma mass spectrometry, Journal of Analytical Atomic Spectrometry, 13, 463-468.

Traufetter, F., H. Oerter, H. Fischer, R. Weller, and H. Miller (2004), Spatio-temporal variability in volcanic sulphate deposition over the past $2 \mathrm{kyr}$ in snow pits and firn cores from Amundsenisen, Antarctica, Journal of Glaciology, 50, 137-146.

Trenberth, K. E. (1997), The definition of El Niño, Bulletin of the American Meterological Society, 78, 2771-2777.

Trenberth, K. E., and S. Solomon (2009), The global heat balance: heat transport in the atmosphere and ocean, Climate Dynamics, 10, 107-134.

Turner, J. (2004), The El Niño-Southern Oscillation and Antarctica, International Journal of Climatology, 24, 1-31.

Turner, J., R. Bindschadler, P. Convey, G. di Prisco, E. Fahrbach, J. Gutt, D. Hodgson, P. A. Mayewski, and C. P. Summerhayes (2009), Antarctic Climate Change and the Environment, Scientific Committee on Antarctic Research, Scott Polar Research Institute, Cambridge, UK.526 pp.

Vallelonga, P., K. Van de Velde, J. Candelone, V. I. Morgan, C. F. Boutron, and K. Rosman (2002), The lead pollution history of Law Dome, Antarctica, from isotopic measurements on ice cores: 1500 AD to 1989 AD, Earth and Planetary Science Letters, 204, 291-306.

Vallelonga, P., J. P. Candelone, K. Van de Velde, M. A. J. Curran, V. I. Morgan, and K. J. R. Rosman (2003), Lead, Ba and Bi in Antarctic Law Dome ice corresponding to the 1815 AD Tambora eruption: an assessment of emission sources using $\mathrm{Pb}$ isotopes, Earth and Planetary Science Letters, 211, 329-341. 
Vallelonga, P., C. Barbante, G. Cozzi, V. Gaspari, J. Candelone, K. Van de Velde, V. I. Morgan, K. Rosman, C. F. Bouton, and P. Cescon (2004), Elemental indicators of natural and anthropogenic aerosol inputs to Law Dome, Antarctica, Annals of Glaciology, 39, 169-174.

van den Broeke, M. R. (2000), On the interpretation of Antarctic temperature trends, Journal of Climate, 13, 3885-3889.

van den Broeke, M. R., and N. P. M. van Lipzig (2003), Factors controlling the nearsurface wind field in Antarctica, Monthly Weather Review, 131, 733-743.

van den Broeke, M. R., and N. P. M. van Lipzig (2004), Changes in Antarctic temperature, wind and precipitation in response to the Antarctic Oscillation, Annals of Glaciology, 39, 119-126.

van Ommen, T., and V. I. Morgan (1997), Calibrating the ice core paleothermometer using seasonality, Journal of Geophysical Research, 102, 9351-9357.

Villalba, R. (1994), Tree-ring and glacial evidence for the Medieval Warm Epoch and the Little Ice Age in southern South America, Climatic Change, 26, 183-197.

Vimeux, F., K. M. Cuffey, and J. J. (2002), New insights into Southern Hemisphere temperature changes from Vostok ice cores using deuterium excess correction, Earth and Planetary Science Letters, 203, 829-843.

Wagenbach, D., F. Ducroz, R. Mulvaney, L. Keck, A. Minikin, M. Legrand, J. S. Hall, and E. W. Wolff (1998), Sea-salt aerosol in coastal Antarctic regions, Journal of Geophysical Research, 103, 10,961-910,974.

Wedepohl, K. H. (1995), The composition of the continental crust, Geochimica et Cosmochimica Acta, 59, 1217-1232.

Wei, L., E. Mosley-Thompson, P. Gabrielli, L. G. Thompson, and C. Barbante (2008), Synchronous deposition of volcanic ash and sulfate aerosols over Greenland in 1783 from the Laki eruption (Iceland), Geophysical Research Letters, 35, doi:10.1029/2008GL035117.

Welch, K. A., P. A. Mayewski, and S. I. Whitlow (1993), Methanesulphonic-acid in coastal Antarctic snow related to sea-ice extent, Geophysical Research Letters, 20, 443446.

Weller, R., F. Göktas, H. Fischer, Oerter, C. Piel, and H. Miller (2004), Post depositional losses of methane sulfonate, nitrate, and chloride at the EPICA deep-drilling site in Dronning Maud Land, Antarctica, Journal of Geophysical Research, 109, doi:10.1029/2003JD004189.

Wolff, E. W., E. D. Suttie, and D. A. Peel (1999), Antarctic snow record of cadmium, copper, and zinc content during the twentieth century, Atmospheric Environment, 33, 1535-1541. 
Wolff, E. W., A. M. Rankin, and R. Röthlisberger (2003), An ice core indicator of Antarctic sea ice production?, Geophysical Research Letters, 30, doi:10.1029/2003gl018454.

Wolff, E. W., et al. (2006), Southern Ocean sea ice extent, productivity and iron flux over the past eight glacial cycles, Nature, 440, 491-496.

Wu, G., C. Zhang, S. Gao, T. Yao, L. Tian, and D. Xia (2009), Element composition of dust from a shallow Dunde ice core, Northern China, Global and Planetary Change, 67, 186192.

Yan, Y., P. A. Mayewski, S. Kang, and E. A. Meyerson (2005), An ice-core proxy for Antarctic circumpolar zonal wind intensity, Annals of Glaciology, 41, 121-130.

Yuan, X., and D. G. Martinson (2000), Antarctic sea ice extent variability and its global connectivity, Journal of Climate, 13, 1697-1717.

Zhang, Y., Q. Liu, and C. Sun (2001), Sulphuric acid leaching of ocean manganese nodules using phenols as reducing agents, Minerals Engineering, 14, 525-537.

Zhou, T., and R. Yu (2004), Sea-surface temperature induced variability of the Southern Annular Mode in an atmospheric general circulation model, Geophysical Research Letters, 31, doi:10.1029/2004gl021473.

Zreda-Gostynska, G., P. R. Kyle, D. Finnegan, and K. M. Prestbo (1997), Volcanic gas emissions from Mount Erebus and their impact on the Antarctic environment, Journal of Geophysical Research, 102, 15039-15055.

Zwally, H. J., J. C. Comiso, C. L. Parkinson, D. J. Cavalieri, and P. Gloersen (2002), Variability of Antarctic sea ice 1979-1998, Journal of Geophysical Research, 107, doi:10.1029/2000JC000733. 


\section{Appendices}

\section{Appendix I: Mt Erebus Saddle 2004/05 snow pit data}

Major ion concentrations were determined by ion chromatography (IC) at the University of Maine on samples from the Mt Erebus Saddle (MES) $2 \mathrm{~m}$ snow pit (Table A1). $\delta^{18} \mathrm{O}$ values were determined at the Alfred Wegener Institute. The $\delta^{18} \mathrm{O}$ and $\mathrm{MS}^{-}$ data formed the basis of a Geophysical Research Letters paper presented in Chapter 3. The annual mean $\mathrm{MS}^{-}$concentrations of the five complete years incorporated by the snow pit record were regressed against both open water area and annual primary production (Fig. A1). 
Table A1: Stable isotope ratios $\left(\delta^{18} \mathrm{O}\right)$ and major ion concentrations for MES $04 / 05$ snow pit.

Concentrations given in ppb.

\begin{tabular}{|c|c|c|c|c|c|c|c|c|c|c|c|}
\hline Sample ID & Age Model & $\begin{array}{c}\text { Depth } \\
(\mathrm{cm})\end{array}$ & $\mathrm{Na}^{+}$ & $\mathrm{K}^{+}$ & $\mathrm{Mg}^{2+}$ & $\mathrm{Ca}^{2+}$ & $\mathrm{MS}^{-}$ & $\mathrm{Cl}^{-}$ & $\mathrm{NO}_{3}^{-}$ & $\mathrm{SO}_{4}{ }^{2-}$ & $\begin{array}{l}\delta^{18} 0 \\
(\%)\end{array}$ \\
\hline MES-04-05-001 & 1999.58 & 210 & 33.1 & 4.6 & 6.5 & 16.5 & 11.3 & 61.4 & 7.0 & 79.6 & -32.78 \\
\hline MES-04-05-002 & 1999.61 & 209 & 28.0 & 3.2 & 5.7 & 9.3 & 7.7 & 53.5 & 53.9 & 87.5 & -32.84 \\
\hline MES-04-05-003 & 1999.63 & 208 & 32.9 & 3.9 & 5.5 & 5.3 & 10.8 & 58.9 & 5.9 & 93.8 & -32.81 \\
\hline MES-04-05-004 & 1999.64 & 207 & 32.3 & 2.8 & 5.9 & 6.4 & 5.3 & 52.3 & 49.5 & 99.0 & -32.75 \\
\hline MES-04-05-005 & 1999.66 & 206 & 32.0 & 3.1 & 5.7 & 3.7 & 7.7 & 55.3 & 53.2 & 105.0 & -32.74 \\
\hline MES-04-05-006 & 1999.67 & 205 & 35.1 & 3.5 & 5.9 & 3.4 & 9.0 & 55.4 & 51.5 & 108.7 & -32.46 \\
\hline MES-04-05-007 & 1999.69 & 204 & 33.1 & 3.1 & 5.9 & 3.2 & 9.7 & 56.6 & 54.1 & 105.6 & -32.55 \\
\hline MES-04-05-008 & 1999.70 & 203 & 34.9 & 2.5 & 5.8 & 2.4 & 18.8 & 65.6 & 6.7 & 103.7 & -32.29 \\
\hline MES-04-05-009 & 1999.72 & 202 & 37.1 & 2.2 & 6.2 & 3.6 & 19.7 & 66.1 & 5.6 & 96.6 & -32.11 \\
\hline MES-04-05-010 & 1999.74 & 201 & 38.8 & 3.1 & 6.5 & 5.5 & 19.4 & 75.7 & 64.6 & 118.6 & -31.95 \\
\hline MES-04-05-011 & 1999.75 & 200 & 37.2 & 3.3 & 6.2 & 3.7 & 15.7 & 59.3 & 51.6 & 97.1 & -31.91 \\
\hline MES-04-05-012 & 1999.77 & 199 & 308.9 & 212.5 & 8.4 & 27.5 & 22.7 & 449.4 & 51.9 & 128.1 & -31.44 \\
\hline MES-04-05-013 & 1999.78 & 198 & 32.1 & 4.8 & 7.1 & 8.8 & 21.2 & 59.4 & 61.5 & 139.5 & -31.50 \\
\hline MES-04-05-014 & 1999.80 & 197 & 26.7 & 3.9 & 5.5 & 4.8 & 23.3 & 53.9 & 6.2 & 141.9 & -31.28 \\
\hline MES-04-05-015 & 1999.81 & 196 & 25.6 & 4.2 & 5.3 & 4.2 & 34.0 & 72.7 & 102.1 & 214.5 & -31.17 \\
\hline MES-04-05-016 & 1999.83 & 195 & 23.6 & 3.9 & 4.9 & 3.6 & 36.5 & 70.6 & 101.4 & 228.3 & -30.78 \\
\hline MES-04-05-017 & 1999.84 & 194 & 22.7 & 3.2 & 4.7 & 3.2 & 41.0 & 69.4 & 117.0 & 231.2 & -30.63 \\
\hline MES-04-05-018 & 1999.86 & 193 & 23.8 & 3.6 & 4.8 & 3.2 & 45.3 & 71.2 & 110.4 & 243.3 & -30.62 \\
\hline MES-04-05-019 & 1999.88 & 192 & 25.2 & 3.3 & 4.9 & 3.2 & 45.5 & 76.3 & 121.9 & 251.7 & -30.29 \\
\hline MES-04-05-020 & 1999.89 & 191 & 26.5 & 2.6 & 4.8 & 3.4 & 55.8 & 81.4 & 13.9 & 238.0 & -29.99 \\
\hline MES-04-05-021 & 1999.91 & 190 & 27.0 & 3.4 & 5.1 & 4.4 & 25.7 & 60.8 & 87.1 & 157.1 & -29.89 \\
\hline MES-04-05-022 & 1999.92 & 189 & 25.6 & 3.1 & 4.9 & 3.6 & 31.8 & 64.0 & 93.7 & 172.9 & -29.74 \\
\hline MES-04-05-023 & 1999.94 & 188 & 23.1 & 2.6 & 4.6 & 3.0 & 46.1 & 70.7 & 8.5 & 190.3 & -29.50 \\
\hline MES-04-05-024 & 1999.95 & 187 & 21.4 & 2.4 & 4.5 & 2.9 & 60.7 & 88.2 & 28.5 & 224.9 & -29.22 \\
\hline MES-04-05-025 & 1999.97 & 186 & 57.8 & 3.4 & 8.3 & 3.5 & 39.8 & 147.4 & 87.2 & 192.8 & -28.99 \\
\hline MES-04-05-026 & 1999.98 & 185 & 171.3 & 6.0 & 21.0 & 6.9 & 40.0 & 310.2 & 67.7 & 246.3 & -29.01 \\
\hline MES-04-05-027 & 2000.00 & 184 & 239.1 & 6.6 & 29.9 & 11.2 & 38.8 & 389.6 & 22.1 & 230.0 & -28.67 \\
\hline MES-04-05-028 & 2000.08 & 183 & 377.2 & 11.3 & 47.1 & 14.3 & 48.3 & 750.1 & 40.5 & 379.4 & -28.59 \\
\hline MES-04-05-029 & 2000.17 & 182 & 248.3 & 8.6 & 32.1 & 11.0 & 50.3 & 533.8 & 43.5 & 291.4 & -28.97 \\
\hline MES-04-05-030 & 2000.17 & 181 & 131.8 & 4.7 & 16.9 & 6.5 & 57.9 & 312.7 & 5.0 & 177.7 & -29.02 \\
\hline MES-04-05-031 & 2000.25 & 180 & 81.5 & 4.6 & 10.3 & 5.6 & 50.1 & 180.0 & 4.7 & 124.4 & -29.33 \\
\hline MES-04-05-032 & 2000.33 & 179 & 69.5 & 4.1 & 8.6 & 4.8 & 44.4 & 157.5 & 5.1 & 109.0 & -29.79 \\
\hline MES-04-05-033 & 2000.41 & 178 & 61.6 & 4.0 & 8.1 & 4.3 & 32.9 & 148.5 & 29.2 & 110.5 & -30.06 \\
\hline MES-04-05-034 & 2000.50 & 177 & 46.0 & 3.3 & 6.5 & 3.0 & 20.7 & 82.3 & 16.7 & 69.0 & -30.63 \\
\hline MES-04-05-035 & 2000.58 & 176 & 48.2 & 4.0 & 6.7 & 3.2 & 21.3 & 86.8 & 17.7 & 71.9 & -30.28 \\
\hline MES-04-05-036 & 2000.60 & 175 & 73.2 & 4.4 & 8.0 & 4.4 & 20.4 & 125.3 & 21.3 & 78.7 & -30.63 \\
\hline MES-04-05-037 & 2000.61 & 174 & 123.7 & 5.1 & 11.7 & 6.5 & 15.4 & 210.5 & 21.8 & 96.7 & -30.47 \\
\hline MES-04-05-038 & 2000.63 & 173 & 167.4 & 5.5 & 13.9 & 12.0 & 15.2 & 315.7 & 23.0 & 123.6 & -29.74 \\
\hline MES-04-05-039 & 2000.64 & 172 & 102.8 & 4.2 & 10.0 & 6.5 & 9.3 & 192.9 & 29.2 & 105.2 & -28.72 \\
\hline MES-04-05-040 & 2000.66 & 171 & 79.6 & 3.6 & 8.1 & 4.7 & 10.5 & 138.6 & 5.6 & 84.0 & -28.51 \\
\hline MES-04-05-041 & 2000.68 & 170 & 17.9 & 4.4 & 3.1 & 7.3 & 7.5 & 26.6 & 31.2 & 59.2 & -28.36 \\
\hline MES-04-05-042 & 2000.69 & 169 & 16.0 & 3.7 & 2.8 & 4.6 & 6.5 & 24.8 & 32.3 & 59.0 & -28.08 \\
\hline MES-04-05-043 & 2000.71 & 168 & 15.4 & 3.7 & 2.7 & 2.7 & n.a. & 24.3 & 34.0 & 56.6 & -28.25 \\
\hline MES-04-05-044 & 2000.73 & 167 & 19.3 & 4.0 & 3.0 & 4.0 & n.a. & 29.9 & 33.2 & 57.7 & -28.03 \\
\hline MES-04-05-045 & 2000.74 & 166 & 24.9 & 3.7 & 3.5 & 3.0 & n.a. & 37.5 & 30.1 & 55.5 & -28.18 \\
\hline MES-04-05-046 & 2000.76 & 165 & 33.9 & 3.8 & 4.6 & 5.3 & 5.9 & 49.4 & 25.4 & 50.0 & -28.03 \\
\hline MES-04-05-047 & 2000.77 & 164 & 35.5 & 3.8 & 4.6 & 3.4 & 8.2 & 53.1 & n.a. & 53.8 & -27.76 \\
\hline MES-04-05-048 & 2000.79 & 163 & 34.2 & 3.7 & 4.6 & 3.8 & 7.1 & 49.2 & 26.8 & 50.9 & -27.88 \\
\hline MES-04-05-049 & 2000.81 & 162 & 31.8 & 3.7 & 4.3 & 2.6 & 7.5 & 46.5 & 27.1 & 56.8 & -27.85 \\
\hline MES-04-05-050 & 2000.82 & 161 & 30.6 & 3.7 & 4.3 & 3.9 & 6.7 & 45.1 & 30.8 & 66.7 & -27.69 \\
\hline MES-04-05-051 & 2000.84 & 160 & 29.3 & 3.8 & 4.0 & 2.5 & 8.7 & 42.9 & 32.6 & 74.2 & -27.29 \\
\hline MES-04-05-052 & 2000.85 & 159 & 26.7 & 3.6 & 3.6 & 3.8 & 9.9 & 42.4 & 6.0 & 93.4 & -27.42 \\
\hline MES-04-05-053 & 2000.87 & 158 & 23.7 & 3.6 & 3.2 & 2.9 & 10.6 & 35.6 & 5.0 & 90.3 & -27.03 \\
\hline MES-04-05-054 & 2000.89 & 157 & 19.1 & 3.4 & 2.8 & 3.0 & 11.2 & 30.1 & n.a. & 85.6 & -26.92 \\
\hline
\end{tabular}




\begin{tabular}{|c|c|c|c|c|c|c|c|c|c|c|c|}
\hline Sample ID & Age Model & $\begin{array}{l}\text { Depth } \\
\text { (cm) }\end{array}$ & $\mathrm{Na}^{+}$ & $\mathrm{K}^{+}$ & $\mathrm{Mg}^{2+}$ & $\mathrm{Ca}^{2+}$ & MS $^{-}$ & $\mathrm{Cl}^{-}$ & $\mathrm{NO}_{3}^{-}$ & $\mathrm{SO}_{4}{ }^{2-}$ & $\begin{array}{l}\delta^{18} 0 \\
(\% o)\end{array}$ \\
\hline MES-04-05-055 & 2000.90 & 156 & 17.0 & 3.6 & 2.6 & 3.2 & 10.2 & 26.6 & 39.5 & 74.4 & -26.62 \\
\hline MES-04-05-056 & 2000.92 & 155 & 16.4 & 3.5 & 2.6 & 3.2 & 11.1 & 26.8 & 41.4 & 76.2 & -26.45 \\
\hline MES-04-05-057 & 2000.94 & 154 & 16.8 & 3.4 & 2.4 & 2.7 & 14.7 & 29.0 & 6.2 & 87.5 & -26.40 \\
\hline MES-04-05-058 & 2000.95 & 153 & 19.3 & 3.6 & 2.8 & 3.2 & 14.2 & 38.4 & 51.2 & 80.5 & -26.17 \\
\hline MES-04-05-059 & 2000.97 & 152 & 50.4 & 4.1 & 5.6 & 4.6 & 16.4 & 90.8 & 45.8 & 102.1 & -26.05 \\
\hline MES-04-05-060 & 2000.98 & 151 & 108.6 & 4.0 & 12.7 & 6.1 & 21.6 & 183.0 & n.a. & 146.8 & -25.72 \\
\hline MES-04-05-061 & 2001.00 & 150 & 206.5 & 6.7 & 26.0 & 8.4 & 25.6 & 340.6 & 36.5 & 169.9 & -25.93 \\
\hline MES-04-05-062 & 2001.03 & 149 & 544.1 & 15.5 & 64.3 & 21.5 & 37.3 & 851.0 & 43.9 & 309.7 & -25.79 \\
\hline MES-04-05-063 & 2001.06 & 148 & 239.3 & 7.0 & 29.8 & 11.9 & 34.0 & 442.1 & n.a. & 179.9 & -25.76 \\
\hline MES-04-05-064 & 2001.09 & 147 & 53.9 & 4.7 & 8.0 & 5.0 & 28.0 & 150.3 & 50.9 & 133.9 & -26.01 \\
\hline MES-04-05-065 & 2001.12 & 146 & 79.7 & 4.1 & 8.6 & 5.7 & 35.3 & 145.9 & 6.8 & 170.0 & -26.06 \\
\hline MES-04-05-066 & 2001.15 & 145 & 89.2 & 5.5 & 9.8 & 6.5 & 32.7 & 150.6 & 55.6 & 171.5 & -25.92 \\
\hline MES-04-05-067 & 2001.18 & 144 & 97.6 & 6.8 & 12.2 & 8.9 & 30.7 & 157.5 & 52.5 & 187.7 & -26.57 \\
\hline MES-04-05-068 & 2001.21 & 143 & 24.2 & 4.2 & 3.8 & 4.6 & 33.1 & 64.8 & 71.2 & 104.0 & -27.03 \\
\hline MES-04-05-069 & 2001.24 & 142 & 44.7 & 4.2 & 5.4 & 4.1 & 34.2 & 83.4 & 65.7 & 129.4 & -26.62 \\
\hline MES-04-05-070 & 2001.27 & 141 & 83.6 & 4.5 & 9.9 & 5.8 & 38.2 & 135.8 & 59.8 & 162.7 & -26.71 \\
\hline MES-04-05-071 & 2001.31 & 140 & 134.9 & 6.3 & 16.3 & 8.2 & 38.0 & 215.7 & 45.3 & 200.6 & -26.59 \\
\hline MES-04-05-072 & 2001.34 & 139 & 149.2 & 5.3 & 18.3 & 7.5 & 43.7 & 244.5 & 5.0 & 224.4 & -26.77 \\
\hline MES-04-05-073 & 2001.37 & 138 & 139.5 & 5.3 & 17.0 & 8.0 & 40.2 & 223.4 & 15.3 & 214.6 & -27.45 \\
\hline MES-04-05-074 & 2001.40 & 137 & 195.1 & 7.4 & 23.1 & 9.1 & 39.8 & 305.9 & 39.9 & 252.9 & -26.72 \\
\hline MES-04-05-075 & 2001.43 & 136 & 159.0 & 5.7 & 19.1 & 8.0 & 33.5 & 257.9 & 45.3 & 222.9 & -27.26 \\
\hline MES-04-05-076 & 2001.46 & 135 & 144.8 & 5.0 & 16.6 & 7.5 & 32.8 & 230.6 & 4.9 & 223.8 & -28.00 \\
\hline MES-04-05-077 & 2001.49 & 134 & 112.8 & 4.6 & 13.3 & 8.4 & 30.3 & 176.8 & 6.2 & 197.6 & -28.47 \\
\hline MES-04-05-078 & 2001.52 & 133 & 61.0 & 4.6 & 7.7 & 5.3 & 23.2 & 101.0 & 57.8 & 130.7 & -28.99 \\
\hline MES-04-05-079 & 2001.55 & 132 & 26.4 & 3.8 & 4.2 & 4.0 & 26.4 & 47.1 & 8.3 & 97.7 & -28.85 \\
\hline MES-04-05-080 & 2001.58 & 131 & 23.9 & 3.9 & 4.1 & 4.5 & 21.8 & 42.2 & 57.4 & 87.0 & -29.44 \\
\hline MES-04-05-081 & 2001.64 & 130 & 25.8 & 4.0 & 4.4 & 9.1 & 20.0 & 45.1 & 49.1 & 89.5 & -29.25 \\
\hline MES-04-05-082 & 2001.70 & 129 & 39.1 & 4.2 & 5.5 & 6.3 & 20.4 & 64.4 & 48.1 & 93.2 & -29.08 \\
\hline MES-04-05-083 & 2001.76 & 128 & 87.5 & 4.4 & 10.3 & 6.5 & 19.9 & 139.1 & 43.3 & 105.2 & -28.67 \\
\hline MES-04-05-084 & 2001.82 & 127 & 122.3 & 5.0 & 15.0 & 6.9 & 23.0 & 197.0 & 39.8 & 117.0 & -28.49 \\
\hline MES-04-05-085 & 2001.88 & 126 & 136.0 & 5.1 & 16.8 & 7.9 & 25.9 & 216.3 & 38.1 & 118.9 & -28.16 \\
\hline MES-04-05-086 & 2001.94 & 125 & 111.7 & 5.1 & 14.4 & 7.3 & 26.4 & 180.9 & 41.8 & 110.2 & -27.92 \\
\hline MES-04-05-087 & 2002.00 & 124 & 99.6 & 4.8 & 12.8 & 6.6 & 31.5 & 165.0 & 41.1 & 110.2 & -28.20 \\
\hline MES-04-05-088 & 2002.03 & 123 & 115.0 & 4.9 & 13.9 & 12.1 & 41.4 & 192.0 & n.a. & 113.0 & -28.07 \\
\hline MES-04-05-089 & 2002.05 & 122 & 120.9 & 4.9 & 14.7 & 7.5 & 48.7 & 202.9 & n.a. & 103.0 & -28.49 \\
\hline MES-04-05-090 & 2002.08 & 121 & 112.4 & 5.3 & 14.0 & 6.8 & 49.2 & 184.3 & 20.3 & 92.7 & -28.64 \\
\hline MES-04-05-091 & 2002.11 & 120 & 97.8 & 4.9 & 12.4 & 5.7 & 55.9 & 151.5 & 13.4 & 119.5 & -28.96 \\
\hline MES-04-05-092 & 2002.13 & 119 & 89.4 & 4.2 & 10.3 & 5.4 & 67.7 & 131.4 & n.a. & 148.1 & -29.32 \\
\hline MES-04-05-093 & 2002.16 & 118 & 83.8 & 4.8 & 10.2 & 5.6 & 67.9 & 118.3 & n.a. & 154.4 & -29.49 \\
\hline MES-04-05-094 & 2002.18 & 117 & 73.8 & 4.5 & 9.0 & 6.0 & 63.8 & 102.1 & 11.4 & 135.2 & -29.79 \\
\hline MES-04-05-095 & 2002.21 & 116 & 78.5 & 5.5 & 9.5 & 8.6 & 61.2 & 105.7 & 13.1 & 136.3 & -29.59 \\
\hline MES-04-05-096 & 2002.24 & 115 & 80.3 & 5.1 & 9.8 & 8.1 & 59.0 & 111.2 & 11.2 & 127.0 & -30.09 \\
\hline MES-04-05-097 & 2002.26 & 114 & 86.0 & 5.4 & 9.9 & 6.8 & 50.2 & 127.6 & 12.3 & 105.2 & -30.43 \\
\hline MES-04-05-098 & 2002.29 & 113 & 94.9 & 4.3 & 10.0 & 6.6 & 57.5 & 145.3 & n.a. & 100.9 & -30.43 \\
\hline MES-04-05-099 & 2002.32 & 112 & 94.8 & 5.2 & 11.0 & 6.5 & 42.4 & 151.9 & 13.2 & 81.9 & -30.83 \\
\hline MES-04-05-100 & 2002.34 & 111 & 97.2 & 4.2 & 10.1 & 5.1 & 46.7 & 153.2 & n.a. & 91.8 & -31.05 \\
\hline MES-04-05-101 & 2002.37 & 110 & 94.4 & 4.7 & 10.9 & 7.0 & 37.4 & 150.6 & 10.6 & 82.7 & -31.26 \\
\hline MES-04-05-102 & 2002.40 & 109 & 93.9 & 4.7 & 10.7 & 7.0 & 31.2 & 150.1 & 12.8 & 83.4 & -31.60 \\
\hline MES-04-05-103 & 2002.42 & 108 & 100.6 & 4.8 & 11.6 & 6.1 & 30.1 & 156.0 & 10.9 & 85.8 & -32.12 \\
\hline MES-04-05-104 & 2002.45 & 107 & 121.6 & 5.3 & 15.0 & 8.9 & 23.2 & 190.0 & 13.3 & 104.9 & -32.84 \\
\hline MES-04-05-105 & 2002.47 & 106 & 115.4 & 5.4 & 15.0 & 10.1 & 19.7 & 178.0 & 15.5 & 97.5 & -33.66 \\
\hline MES-04-05-106 & 2002.50 & 105 & 100.9 & 5.1 & 13.8 & 9.2 & 13.1 & 158.0 & 20.1 & 83.1 & -34.42 \\
\hline MES-04-05-107 & 2002.53 & 104 & 76.0 & 4.8 & 10.3 & 7.4 & 12.0 & 116.8 & 21.8 & 62.1 & -34.85 \\
\hline MES-04-05-108 & 2002.55 & 103 & 66.7 & 4.3 & 8.4 & 5.6 & 11.5 & 104.4 & n.a. & 61.0 & -35.32 \\
\hline MES-04-05-109 & 2002.58 & 102 & 69.9 & 4.5 & 9.7 & 6.4 & 7.6 & 106.5 & 23.9 & 55.0 & -35.28 \\
\hline MES-04-05-110 & 2002.61 & 101 & 65.5 & 4.3 & 8.9 & 5.8 & 4.8 & 99.9 & 27.7 & 51.3 & -35.08 \\
\hline MES-04-05-111 & 2002.63 & 100 & 58.0 & 4.2 & 7.9 & 5.5 & 5.0 & 89.9 & 28.0 & 51.9 & -34.54 \\
\hline MES-04-05-112 & 2002.66 & 99 & 53.5 & 4.2 & 7.3 & 5.1 & n.a. & 84.3 & 29.8 & 50.6 & -34.05 \\
\hline MES-04-05-113 & 2002.69 & 98 & 50.9 & 4.2 & 7.2 & 4.5 & 6.2 & 82.4 & 30.3 & 52.3 & -33.27 \\
\hline
\end{tabular}




\begin{tabular}{|c|c|c|c|c|c|c|c|c|c|c|c|}
\hline Sample ID & Age Model & $\begin{array}{c}\text { Depth } \\
(\mathrm{cm})\end{array}$ & $\mathrm{Na}^{+}$ & $\overline{K^{+}}$ & $\mathrm{Mg}^{2+}$ & $\mathrm{Ca}^{2+}$ & $\mathrm{MS}^{-}$ & $\mathrm{Cl}^{-}$ & $\mathrm{NO}_{3}$ & $\mathrm{SO}_{4}{ }^{2-}$ & $\begin{array}{l}\delta^{18} 0 \\
(\%)\end{array}$ \\
\hline MES-04-05-114 & 2002.71 & 97 & 47.7 & 4.2 & 6.4 & 4.2 & 6.9 & 73.6 & 29.9 & 65.8 & -32.48 \\
\hline MES-04-05-115 & 2002.74 & 96 & 38.4 & 4.2 & 5.5 & 4.3 & 7.1 & 59.7 & 32.0 & 87.9 & -31.49 \\
\hline MES-04-05-116 & 2002.76 & 95 & 33.9 & 4.4 & 4.8 & 4.5 & 7.8 & 53.2 & 27.6 & 91.4 & -30.87 \\
\hline MES-04-05-117 & 2002.79 & 94 & 25.0 & 4.0 & 3.9 & 3.6 & 8.6 & 38.1 & 22.6 & 90.4 & -30.26 \\
\hline MES-04-05-118 & 2002.82 & 93 & 15.2 & 4.0 & 3.1 & 3.9 & 10.0 & 24.0 & 18.0 & 73.4 & -29.77 \\
\hline MES-04-05-119 & 2002.84 & 92 & 11.9 & 3.7 & 2.3 & 2.0 & 9.8 & 19.6 & 14.0 & 68.1 & -29.32 \\
\hline MES-04-05-120 & 2002.87 & 91 & 12.7 & 3.7 & 2.2 & 2.7 & 9.3 & 19.9 & 13.9 & 70.9 & -28.94 \\
\hline MES-04-05-121 & 2002.90 & 90 & 13.1 & 4.2 & 2.7 & 8.6 & 10.1 & 17.8 & 11.5 & 77.9 & -28.71 \\
\hline MES-04-05-122 & 2002.92 & 89 & 14.0 & 3.8 & 2.7 & 5.6 & 10.1 & 18.7 & 9.2 & 79.3 & -28.79 \\
\hline MES-04-05-123 & 2002.95 & 88 & 18.5 & 3.9 & 2.7 & 3.7 & 10.4 & 21.8 & 9.7 & 81.4 & -28.29 \\
\hline MES-04-05-124 & 2002.97 & 87 & 17.8 & 3.7 & 2.9 & 4.0 & 10.6 & 25.1 & 12.5 & 80.7 & -28.09 \\
\hline MES-04-05-125 & 2003.00 & 86 & 18.5 & 3.7 & 3.0 & 3.4 & 11.1 & 25.5 & 11.0 & 77.8 & -28.16 \\
\hline MES-04-05-126 & 2003.03 & 85 & 18.9 & 3.6 & 3.0 & 3.6 & 12.1 & 27.2 & n.a. & 83.6 & -28.04 \\
\hline MES-04-05-127 & 2003.05 & 84 & 24.2 & 7.5 & 3.2 & 4.5 & 10.4 & 34.6 & 20.1 & 82.1 & -28.20 \\
\hline MES-04-05-128 & 2003.08 & 83 & 18.0 & 4.1 & 2.9 & 3.5 & 11.0 & 29.0 & 25.5 & 82.1 & -28.16 \\
\hline MES-04-05-129 & 2003.10 & 82 & 18.0 & 4.8 & 2.8 & 3.8 & 9.4 & 30.6 & 29.0 & 79.5 & -28.34 \\
\hline MES-04-05-130 & 2003.13 & 81 & 16.6 & 4.1 & 2.6 & 2.9 & 10.1 & 28.5 & 32.5 & 76.8 & -28.39 \\
\hline MES-04-05-131 & 2003.15 & 80 & 18.2 & 4.6 & 2.7 & 3.4 & 9.8 & 31.2 & 31.3 & 79.6 & -28.56 \\
\hline MES-04-05-132 & 2003.18 & 79 & 17.7 & 4.2 & 2.7 & 2.5 & 9.2 & 31.0 & 29.9 & 79.2 & -28.31 \\
\hline MES-04-05-133 & 2003.20 & 78 & 17.5 & 3.8 & 2.6 & 2.5 & 9.9 & 32.0 & 29.6 & 81.9 & -28.65 \\
\hline MES-04-05-134 & 2003.23 & 77 & 16.8 & 4.6 & 2.6 & 3.4 & 9.0 & 31.8 & 45.5 & 79.3 & -28.77 \\
\hline MES-04-05-135 & 2003.25 & 76 & 17.3 & 3.9 & 2.5 & 2.9 & 8.9 & 34.3 & 18.2 & 91.9 & -28.86 \\
\hline MES-04-05-136 & 2003.28 & 75 & 14.5 & 4.5 & 2.4 & 2.6 & 8.9 & 32.7 & 52.3 & 85.2 & -28.94 \\
\hline MES-04-05-137 & 2003.30 & 74 & 13.2 & 4.5 & 2.2 & 3.3 & 9.7 & 31.7 & 56.7 & 86.3 & -28.84 \\
\hline MES-04-05-138 & 2003.33 & 73 & 13.3 & 4.8 & 2.2 & 2.6 & 11.1 & 31.1 & 57.6 & 87.8 & -28.95 \\
\hline MES-04-05-139 & 2003.35 & 72 & 10.9 & 4.4 & 2.1 & 2.7 & 12.5 & 22.0 & 42.3 & 86.5 & -29.03 \\
\hline MES-04-05-140 & 2003.38 & 71 & 12.8 & 5.5 & 2.1 & 3.3 & 13.0 & 22.5 & 49.6 & 86.2 & -29.03 \\
\hline MES-04-05-141 & 2003.40 & 70 & 11.2 & 4.6 & 2.0 & 2.8 & 13.2 & 20.7 & 32.2 & 80.6 & -29.11 \\
\hline MES-04-05-142 & 2003.43 & 69 & 12.1 & 4.5 & 2.1 & 2.4 & 12.8 & 21.7 & 20.1 & 76.4 & -29.15 \\
\hline MES-04-05-143 & 2003.45 & 68 & 12.6 & 4.5 & 2.4 & 2.6 & 12.1 & 22.2 & 25.8 & 79.1 & -29.01 \\
\hline MES-04-05-144 & 2003.48 & 67 & 12.3 & 4.4 & 2.3 & 3.5 & 11.6 & 21.6 & 24.4 & 74.9 & -29.07 \\
\hline MES-04-05-145 & 2003.50 & 66 & 12.6 & 4.7 & 2.8 & 3.8 & 11.3 & 21.9 & 24.2 & 76.9 & -29.23 \\
\hline MES-04-05-146 & 2003.53 & 65 & 12.6 & 4.7 & 2.2 & 2.9 & 13.1 & 21.7 & 24.8 & 80.8 & -29.19 \\
\hline MES-04-05-147 & 2003.55 & 64 & 12.4 & 3.9 & 2.2 & 2.7 & 14.6 & 22.9 & 5.1 & 88.3 & -29.09 \\
\hline MES-04-05-148 & 2003.58 & 63 & 15.3 & 5.7 & 2.7 & 2.6 & 18.1 & 23.6 & 21.9 & 118.2 & -29.24 \\
\hline MES-04-05-149 & 2003.60 & 62 & 16.7 & 4.7 & 3.1 & 3.2 & 18.4 & 24.3 & 20.6 & 140.3 & -29.05 \\
\hline MES-04-05-150 & 2003.63 & 61 & 16.8 & 5.1 & 3.0 & 3.6 & 18.7 & 28.4 & 41.4 & 136.5 & -28.93 \\
\hline MES-04-05-151 & 2003.65 & 60 & 15.3 & 5.3 & 2.7 & 3.6 & 18.9 & 32.5 & 57.7 & 120.5 & -28.98 \\
\hline MES-04-05-152 & 2003.67 & 59 & 11.9 & 4.9 & 2.6 & 5.1 & 13.2 & 29.3 & 38.3 & 93.8 & -28.62 \\
\hline MES-04-05-153 & 2003.70 & 58 & 15.1 & 5.3 & 2.8 & 4.1 & 20.5 & 32.6 & 62.4 & 134.0 & -28.63 \\
\hline MES-04-05-154 & 2003.72 & 57 & 14.3 & 5.2 & 2.6 & 4.0 & 20.9 & 28.8 & 71.0 & 141.1 & -28.33 \\
\hline MES-04-05-155 & 2003.74 & 56 & 15.1 & 5.5 & 2.8 & 3.9 & 22.4 & 29.7 & 74.3 & 153.3 & -28.34 \\
\hline MES-04-05-156 & 2003.77 & 55 & 16.2 & 5.0 & 2.8 & 3.3 & 22.4 & 31.0 & 74.2 & 157.5 & -28.21 \\
\hline MES-04-05-157 & 2003.79 & 54 & 16.6 & 5.1 & 2.8 & 4.3 & 22.5 & 32.3 & 70.0 & 156.8 & -28.29 \\
\hline MES-04-05-158 & 2003.81 & 53 & 15.0 & 5.1 & 2.6 & 3.5 & 22.9 & 33.8 & 77.8 & 157.7 & -28.06 \\
\hline MES-04-05-159 & 2003.84 & 52 & 12.9 & 4.9 & 2.4 & 3.3 & 22.3 & 32.1 & 88.0 & 153.5 & -28.11 \\
\hline MES-04-05-160 & 2003.86 & 51 & 14.6 & 5.3 & 2.7 & 4.4 & 21.8 & 33.1 & 85.5 & 167.5 & -27.98 \\
\hline MES-04-05-161 & 2003.88 & 50 & 15.0 & 5.3 & 2.8 & 3.8 & 21.6 & 33.5 & 81.9 & 183.3 & -27.67 \\
\hline MES-04-05-162 & 2003.91 & 49 & 15.6 & 5.4 & 2.9 & 4.5 & 21.1 & 35.0 & 89.4 & 192.3 & -27.37 \\
\hline MES-04-05-163 & 2003.93 & 48 & 15.6 & 5.6 & 2.8 & 3.4 & 22.2 & 33.8 & 91.8 & 202.9 & -27.31 \\
\hline MES-04-05-164 & 2003.95 & 47 & 16.6 & 5.8 & 3.0 & 3.2 & 20.0 & 33.7 & 94.8 & 214.0 & -27.21 \\
\hline MES-04-05-165 & 2003.98 & 46 & 16.8 & 6.0 & 3.5 & 8.5 & 21.2 & 34.1 & 92.6 & 221.5 & -27.13 \\
\hline MES-04-05-166 & 2004.00 & 45 & 16.3 & 5.8 & 3.2 & 4.7 & 19.8 & 32.0 & 90.8 & 218.9 & -27.04 \\
\hline MES-04-05-167 & 2004.06 & 44 & 17.5 & 5.8 & 8.9 & 14.5 & 19.8 & 35.8 & 100.4 & 227.3 & -27.14 \\
\hline MES-04-05-168 & 2004.13 & 43 & 19.5 & 7.0 & 3.6 & 4.9 & 18.8 & 38.1 & 94.4 & 230.9 & -27.56 \\
\hline MES-04-05-169 & 2004.19 & 42 & 9.1 & 5.3 & 2.0 & 3.7 & 5.9 & 35.4 & 64.6 & 95.3 & -27.75 \\
\hline MES-04-05-170 & 2004.26 & 41 & 17.9 & 5.8 & 3.1 & 4.1 & 16.2 & 38.5 & 83.6 & 198.1 & -28.34 \\
\hline MES-04-05-171 & 2004.32 & 40 & 21.5 & 5.9 & 3.4 & 3.9 & 14.1 & 41.8 & 61.9 & 186.0 & -29.08 \\
\hline
\end{tabular}




\begin{tabular}{|c|c|c|c|c|c|c|c|c|c|c|c|}
\hline Sample ID & Age Model & $\begin{array}{c}\text { Depth } \\
\text { (cm) }\end{array}$ & $\mathrm{Na}^{+}$ & $\mathbf{K}^{+}$ & $\mathrm{Mg}^{2+}$ & $\mathrm{Ca}^{2+}$ & $\mathbf{M S}^{-}$ & $\mathrm{Cl}^{-}$ & $\mathrm{NO}_{3}^{-}$ & $\mathrm{SO}_{4}{ }^{2-}$ & $\begin{array}{l}\delta^{18} 0 \\
(\%)\end{array}$ \\
\hline MES-04-05-172 & 2004.39 & 39 & 14.8 & 5.9 & 2.8 & 4.1 & 12.8 & 28.4 & 54.5 & 166.3 & -29.41 \\
\hline MES-04-05-173 & 2004.45 & 38 & 10.3 & 5.0 & 2.1 & 2.5 & 13.0 & 20.1 & 7.8 & 150.4 & -29.92 \\
\hline MES-04-05-174 & 2004.52 & 37 & 9.2 & 5.2 & 2.1 & 2.5 & 10.5 & 20.6 & 18.4 & 141.9 & -30.44 \\
\hline MES-04-05-175 & 2004.58 & 36 & 9.3 & 5.4 & 2.8 & 2.6 & 9.0 & 21.5 & 18.9 & 132.7 & -30.53 \\
\hline MES-04-05-177 & 2004.60 & 34 & 7.5 & 5.1 & 1.7 & 2.8 & 6.8 & 15.8 & 10.0 & 78.5 & -30.17 \\
\hline MES-04-05-178 & 2004.61 & 33 & 5.1 & 4.8 & 1.5 & 2.6 & 6.3 & 12.7 & 5.4 & 60.9 & -30.13 \\
\hline MES-04-05-179 & 2004.63 & 32 & 4.1 & 3.9 & 1.3 & 2.3 & 4.3 & 10.8 & n.a. & 52.0 & -29.47 \\
\hline MES-04-05-180 & 2004.64 & 31 & 4.3 & 4.7 & 1.4 & 3.0 & 4.3 & 12.0 & 7.1 & 52.2 & -29.01 \\
\hline MES-04-05-181 & 2004.65 & 30 & 5.1 & 4.7 & 1.4 & 2.5 & 4.6 & 12.6 & 7.2 & 54.4 & -28.63 \\
\hline MES-04-05-185 & 2004.69 & 26 & 2.8 & 5.0 & 1.2 & 2.4 & 5.6 & 9.5 & 5.6 & 48.2 & -27.11 \\
\hline MES-04-05-186 & 2004.70 & 25 & 2.3 & 4.8 & 1.2 & 1.8 & 6.1 & 8.8 & 5.8 & 46.4 & -26.94 \\
\hline MES-04-05-187 & 2004.72 & 24 & 2.4 & 4.5 & 1.2 & 1.6 & 6.5 & 8.8 & 5.2 & 49.8 & -26.58 \\
\hline MES-04-05-188 & 2004.73 & 23 & 8.1 & 4.8 & 1.6 & 1.7 & 7.2 & 25.1 & 7.1 & 68.4 & -26.43 \\
\hline MES-04-05-189 & 2004.74 & 22 & 9.1 & 4.9 & 1.8 & 2.7 & 7.4 & 28.9 & 10.4 & 74.3 & -26.58 \\
\hline MES-04-05-190 & 2004.75 & 21 & 16.5 & 5.2 & 2.5 & 2.6 & 6.8 & 47.7 & 8.8 & 76.1 & -26.38 \\
\hline MES-04-05-191 & 2004.76 & 20 & 11.7 & 5.1 & 2.4 & 3.4 & 5.6 & 21.9 & 6.0 & 47.4 & -24.99 \\
\hline MES-04-05-192 & 2004.77 & 19 & 13.6 & 5.7 & 2.1 & 2.2 & 8.0 & 22.0 & 5.7 & 38.4 & -24.25 \\
\hline MES-04-05-193 & 2004.78 & 18 & 44.7 & 11.5 & 3.0 & 3.7 & 11.9 & 65.9 & 5.7 & 44.3 & -23.49 \\
\hline MES-04-05-194 & 2004.79 & 17 & 48.4 & 7.7 & 5.0 & 3.9 & 18.4 & 68.1 & 5.3 & 64.3 & -22.82 \\
\hline MES-04-05-201 & 2004.87 & 10 & 50.0 & 5.9 & 6.2 & 3.7 & 37.6 & 75.3 & 16.0 & 87.5 & -22.62 \\
\hline MES-04-05-202 & 2004.88 & 9 & 62.9 & 6.4 & 7.7 & 4.1 & 36.5 & 99.0 & 27.1 & 104.9 & -23.27 \\
\hline MES-04-05-203 & 2004.90 & 8 & 100.9 & 10.2 & 15.2 & 17.4 & 39.6 & 117.7 & 79.1 & 223.2 & -31.32 \\
\hline MES-04-05-204 & 2004.91 & 7 & 78.3 & 23.3 & 11.0 & 17.9 & 11.0 & 104.5 & 80.4 & 134.6 & -31.17 \\
\hline MES-04-05-205 & 2004.92 & 6 & 74.6 & 8.0 & 10.1 & 7.7 & 42.3 & 80.3 & 18.2 & 190.8 & -32.01 \\
\hline MES-04-05-206 & 2004.93 & 5 & 65.9 & 7.4 & 9.0 & 7.0 & 32.1 & 70.4 & 38.2 & 158.7 & -31.57 \\
\hline MES-04-05-207 & 2004.94 & 4 & 80.6 & 9.3 & 11.1 & 8.3 & 44.9 & 83.9 & 44.3 & 203.4 & -31.61 \\
\hline
\end{tabular}

n.a. = not available 

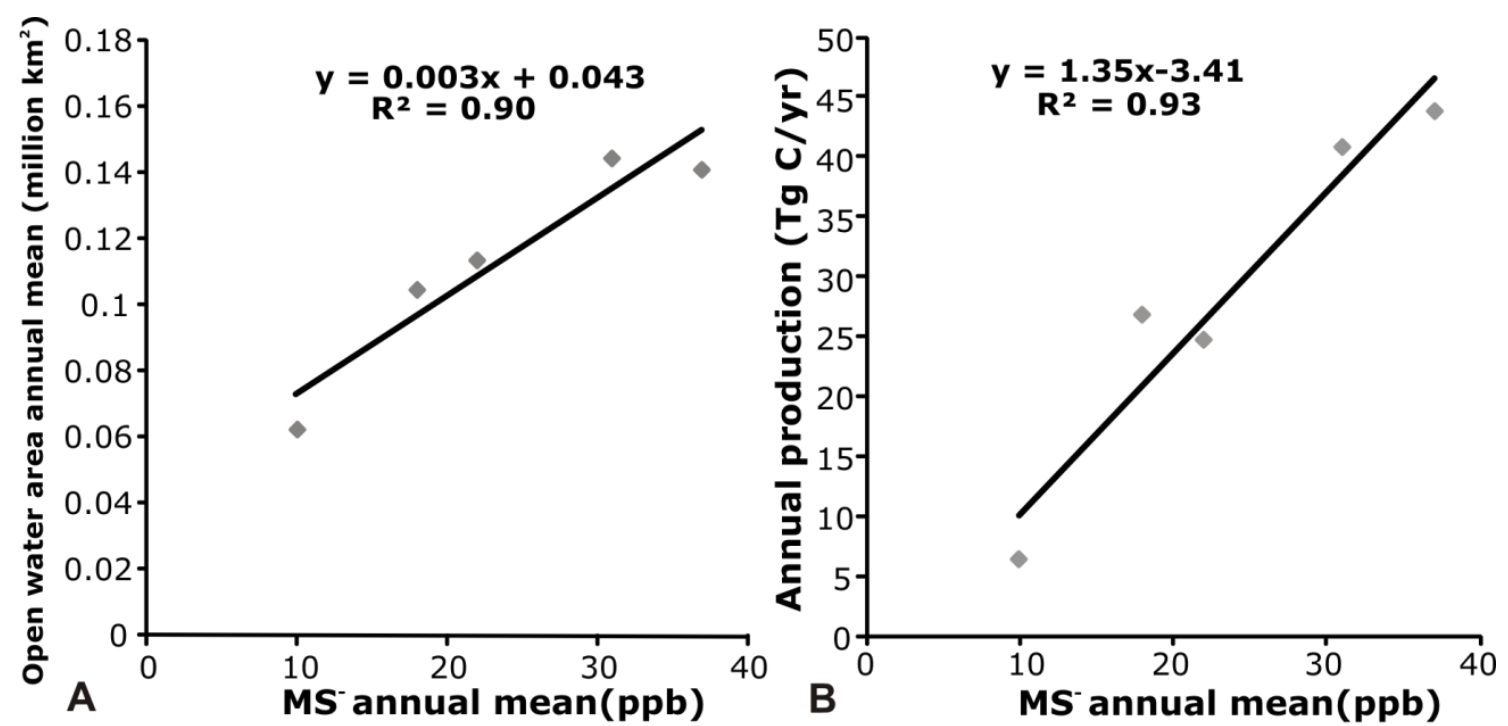

Figure A1: Scatterplots of annual mean $\mathrm{MS}^{-}$values against A) annual mean open water area and B) annual production. The equations of the linear trendlines are displayed. Correlations are significant at 95\% (A) and 99\% (B) levels. Using Isoplot software (version 3.0, K. R. Ludwig, Berkeley Geochronology Centre, (2003)) errors on the slope and intercept of each linear trendline at $95 \%$ confidence level are: A) slope \pm 0.0018 , intercept \pm 0.046 ; B) slope \pm 0.70 , intercept \pm 18 . 
Appendix II: Procedural blanks for Mt Erebus Saddle ice core processing and sampling.

Ultra-pure water (> 18.2 M $\Omega$ ) was frozen in $500 \mathrm{~mL}$ Nalgene jars to create mock ice core. This core was then cut in the cold laboratory and sampled using the continuous melter system following the same procedure as for the MES ice core. The procedural blanks were treated as ice core samples during analysis and data processing. Any background contribution from the analytical instrument, ultra-pure water or acid added to the procedural blanks has therefore been corrected for. Blanks for ICP-MS and IC were sampled concurrently from the same section of mock ice core so ICP-MS and IC blanks with the same blank I.D. are directly comparable. Concentrations of trace elements in the procedural blanks determined by ICP-MS are provided in Table $\mathrm{A} 2$ and major ion concentrations determined by ion chromatography are provided in Table A3. Due to time constraints not all procedural blanks were analysed by ICP-MS and only blanks 1 to 34 have been analysed by IC to date. Procedural blanks were sampled at the beginning of each day the melter system was used. 
Table A2: Concentrations of trace elements determined by ICP-MS in the procedural blanks. Blanks that are in bold and italicised had problems that were noted down in melting log book which adversely affected chemical concentrations (see footnotes pg. 192). Concentrations are given in ppt.

\begin{tabular}{|c|c|c|c|c|c|c|c|c|c|c|c|c|c|c|c|c|c|c|c|c|c|c|c|}
\hline Blank I.D. & elted & la & Mg & Al & $\mathrm{Ca}$ & $\mathrm{Ti}$ & V & Mn & As & b & $\mathrm{Sr}$ & $\mathbf{Y}$ & $\mathrm{Zr}$ & Cs & $\mathrm{Ba}$ & La & Ce & $\mathrm{Pr}$ & TI & b & $3 \mathbf{i}$ & Th & $\mathbf{U}$ \\
\hline MES Blk 1 & 007 & 499 & 1967 & 1758 & 170913 & 35.49 & 2.20 & 1.73 & 1.32 & -0.52 & -0.11 & 1.24 & -0.15 & -0.17 & 78.98 & 0.33 & 0.37 & 0.14 & 0.03 & 12.94 & 0.03 & 0.00 & 0.09 \\
\hline MES BIk 3 & $16 / 10 / 2007$ & 231 & 261 & 170 & 45937 & 9.00 & 0.88 & 1.01 & 0.63 & 0.58 & 21.68 & 0.31 & 0.08 & -0.01 & 7.48 & 0.09 & 0.07 & 0.02 & -0.04 & 2.05 & 0.17 & 0.03 & 0.08 \\
\hline MES Blk 4 & $16 / 10 / 2007$ & -42 & 126 & 184 & 14990 & 5.20 & 0.98 & 6.46 & 0.05 & 0.23 & 5.35 & 0.10 & 0.11 & 0.02 & 3.92 & 0.05 & 0.06 & 0.01 & -0.03 & 1.78 & 0.10 & -0.12 & 0.22 \\
\hline MES Blk 8 & $18 / 10 / 2007$ & 204 & 118 & 109 & 642 & -6.39 & 0.31 & 0.06 & 0.15 & 0.17 & 1.17 & 0.03 & 0.22 & 0.01 & 1.29 & 0.04 & 0.06 & 0.01 & -0.01 & 1.23 & -0.01 & 0.00 & 0.01 \\
\hline MES Blk 10 & $18 / 10 / 2007$ & 62 & 236 & 324 & 96457 & 7.90 & 0.80 & 15.98 & 0.04 & 0.20 & 22.15 & 0.69 & 0.02 & 0.00 & 4.09 & 0.20 & 0.11 & 0.04 & -0.06 & 0.60 & 0.01 & -0.04 & 0.12 \\
\hline MES Blk 12 & $18 / 10 / 2007$ & 157 & 263 & 307 & 9647 & 16.07 & 1.82 & 7.24 & 1.22 & 0.38 & 8.61 & 0.10 & 0.29 & 0.02 & 15.68 & 0.26 & 0.42 & 0.04 & 0.03 & 2.22 & 0.08 & 0.06 & 0.04 \\
\hline MES Blk 14 & $5 / 02 / 2008$ & -86 & 156 & 193 & 13575 & 7.87 & 0.53 & 17.38 & -0.27 & 0.25 & 7.75 & 0.08 & 0.14 & 0.02 & 11.15 & 0.03 & 0.04 & -0.03 & -0.01 & 2.29 & 0.04 & 0.08 & 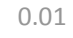 \\
\hline MES Blk 16 & $5 / 02 / 2008$ & 88 & 116 & 556 & 11214 & 28.53 & 0.21 & 6.59 & -0.72 & 0.14 & 6.90 & 0.11 & 0.06 & 0.02 & 7.55 & 0.03 & .02 & 0.00 & 0.03 & 1.73 & -0.01 & 0.06 & 0.04 \\
\hline MES Blk 17 & $5 / 02 / 2$ & 139 & 132 & 127 & 15123 & 15.00 & 0.63 & 12.28 & 2.32 & 0.28 & 7.03 & 0.12 & 0.06 & 0.05 & 11.66 & 0.09 & 10 & 0.02 & 0.05 & 34 & 15 & -0.01 & -0.0 \\
\hline MES Blk 18 & 8 & 367 & 151 & 150 & 17992 & 13.87 & 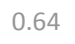 & 14.46 & 2.99 & 0.44 & 8.26 & 0.19 & -0.02 & 0.05 & 13.57 & 0.10 & 22 & 0.03 & 0.08 & 41 & 02 & -0.01 & 0 \\
\hline MES Blk 20 & $8 / 02 / 2007$ & 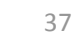 & 1 & & 49755 & 13.56 & 0.59 & 1 & 0.40 & 0.16 & 12.73 & 0.31 & 0.12 & 0.02 & 4.28 & 0.07 & 03 & 0.02 & -0.04 & 61 & 04 & 0.00 & $-0 . C$ \\
\hline MES Blk 21 & $8 / 02 / 2007$ & -150 & 65 & 124 & 6543 & 19.91 & 0. & & -0.41 & 0.12 & & 0.04 & 0.13 & 0.01 & 4.82 & 0.03 & 05 & 0.00 & 0.07 & 42 & 12 & 00 & 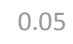 \\
\hline MES Blk 23 & $13 / 02 / 2008$ & 15 & 8 & 101 & 3975 & 13.13 & 0.30 & & -0.54 & 0.23 & & 0.09 & 0.20 & -0.01 & 4.31 & 0.07 & 06 & 0.00 & 0.00 & 88 & 08 & 06 & 0. \\
\hline MES Blk 24 & /02/2008 & & 4 & 72 & 146 & 7.88 & & & -0.75 & 0. & & 0.04 & 0.04 & 0.00 & 79 & 0. & 5 & 0.00 & 0.05 & 33 & 09 & 01 & 0. \\
\hline MES Blk 25 & 2008 & 4635 & 597 & 85 & 17375 & 18.17 & & 10.39 & 0.63 & 1.83 & & 0.11 & 0.50 & 0.01 & 6.27 & 2.5 & 75 & 0.00 & 0.09 & 84 & 10 & 06 & 0.10 \\
\hline MES Blk 26 & 008 & & 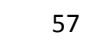 & 5 & & 4. & & & & 0. & & 0.05 & 0.26 & 0.00 & 70 & 0. & 99 & 0 & 0.09 & 51 & 03 & -0.02 & 0.0 \\
\hline MES Blk 29 & 2008 & 243 & 9 & 506 & 3676 & 1.43 & .22 & 31 & & 0.31 & 6.81 & 0.03 & 0.33 & 0.03 & 1.48 & 0.1 & 29 & 0.00 & 0.02 & 2.73 & -0.02 & -0.03 & 0.02 \\
\hline MES Blk 30 & 008 & 119 & 1 & 405 & 4 & -0.48 & 0.11 & -0.35 & 0.00 & 0.08 & 2.02 & 0.02 & -0.01 & 0.00 & 0.69 & 0.05 & 10 & 0.00 & 0.01 & .27 & 0.03 & -0.02 & 0.0 \\
\hline MES Blk 31 & 08 & 76 & 25 & 460 & 2754 & 0.95 & 12 & 0.50 & 1.46 & 0.07 & 3.32 & 0.02 & 0.07 & 0.01 & 0.65 & 0.05 & .09 & 0.00 & 0.04 & .03 & -0.01 & -0.02 & 0.0 \\
\hline MES Blk 32 & 08 & 91 & 2 & 13 & 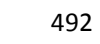 & 0 & 15 & 4.16 & 0.14 & 0.23 & 2.61 & 0.05 & 0.19 & 0.03 & 3.17 & 0.08 & .14 & 0.00 & 0.00 & .56 & 0.05 & -0.04 & 0.0 \\
\hline MES Blk 33 & 08 & 165 & 761 & 487 & 2376 & 3.09 & 0.19 & 22.00 & 2.07 & 0.19 & 3.61 & 0.08 & 0.24 & 0.03 & 3.67 & 0.30 & 0.50 & 0.00 & -0.01 & 3.12 & -0.06 & -0.05 & -0.05 \\
\hline MES Blk 34 & & 4 & 33 & 169 & 552 & -0.66 & 0.04 & 1.42 & 0.21 & 0.05 & 3.38 & 0.02 & -0.03 & 0.03 & 3.66 & 0.05 & .09 & 0.00 & 0.03 & 1.00 & 0.00 & -0.04 & -0.0 \\
\hline MES Blk 35 & & 103 & 4 & 93 & 64 & 13.55 & .07 & 0. & 1.45 & 0.05 & 3.56 & 0.04 & -0.02 & 0.01 & 1.03 & 0.04 & .09 & 0.00 & 0.03 & .49 & 0.01 & -0.07 & -0.0 \\
\hline MES Blk 36 & & 107 & 163 & 573 & 4178 & -0.34 & 0.10 & 4.38 & 0.27 & 0.10 & 4.26 & 0.05 & 0.04 & 0.02 & 2.33 & 0.05 & 08 & 0.00 & 0.01 & 3.37 & 0.01 & -0.03 & -0.0 \\
\hline MES Blk 37 & $26 / 03 / 2008$ & 54 & 50 & 38 & 261 & 0.04 & 0.15 & 1.41 & 0.32 & 0.05 & 3.05 & 0.02 & -0.02 & 0.01 & 0.66 & 0.04 & 0.07 & 0.00 & 0.00 & 0.26 & 0.00 & -0.05 & 0.03 \\
\hline MES Blk 38 & $2 / 04 / 2008$ & 105 & 2720 & 9171 & 90884 & 193.16 & 1.90 & 45.58 & 0.74 & 1.48 & 66.56 & 1.17 & 25.78 & 0.14 & 46.18 & 0.70 & 1.32 & 0.14 & 0.03 & 98.25 & 0.54 & 0.02 & 0.15 \\
\hline MES Blk 39 & $2 / 04 / 2008$ & 64 & 109 & 134 & 1126 & 4.27 & 0.48 & 2.22 & 0.35 & 0.17 & 1.26 & 0.04 & 0.23 & 0.03 & 1.92 & 0.07 & 0.14 & 0.03 & 0.12 & 1.66 & 0.05 & 0.00 & 0.0 \\
\hline MES Blk 40 & $2 / 04 / 2008$ & -117 & 123 & 217 & 2451 & 11.89 & 0.21 & 4.30 & 0.00 & 0.16 & 1.69 & 0.04 & 0.10 & 0.03 & 1.94 & 0.08 & 0.10 & 0.00 & -0.08 & 4.24 & .02 & 0.05 & 0.0 \\
\hline MES Blk 41 & $9 / 04 / 2008$ & 217 & 86 & 120 & 1458 & 12.55 & 0.43 & 6.97 & 1.40 & 0.20 & 2.33 & 0.03 & 0.10 & 0.03 & 3.51 & 0.12 & 0.12 & 0.00 & -0.06 & 2.30 & .04 & 0.09 & 0.05 \\
\hline MES Blk 42 & $9 / 04 / 2008$ & 279 & 81 & 100 & 2967 & 6.79 & 0.31 & 6.57 & -0.53 & 0.12 & 2.71 & 0.10 & 0.30 & 0.02 & 2.27 & 0.05 & 0.09 & 0.01 & 0.00 & 1.76 & 0.00 & 0.08 & 0.07 \\
\hline MES Blk 43 & $9 / 04 / 2008$ & 448 & 87 & 119 & 2133 & 6.09 & 0.26 & 2.97 & -0.23 & 0.25 & .74 & 0.01 & 0.14 & 0.00 & 3.14 & 0.10 & 0.12 & 0.00 & -0.07 & 1.55 & -0.12 & 0.08 & $0 . c$ \\
\hline
\end{tabular}




\begin{tabular}{|c|c|c|c|c|c|c|c|c|c|c|c|c|c|c|c|c|c|c|c|c|c|c|c|}
\hline Blank I.D. & Date melted & $\mathrm{Na}$ & $\mathrm{Mg}$ & $\mathrm{Al}$ & $\mathrm{Ca}$ & $\mathrm{Ti}$ & V & $\mathrm{Mn}$ & As & $\mathbf{R b}$ & $\mathrm{Sr}$ & $\bar{Y}$ & $\mathrm{Zr}$ & Cs & $\mathrm{Ba}$ & La & $\mathrm{Ce}$ & $\mathrm{Pr}$ & $\mathrm{TI}$ & $\mathrm{Pb}$ & $\mathrm{Bi}$ & Th & U \\
\hline MES Blk 49 & $29 / 05 / 2008$ & 356 & 206 & 303 & 50325 & 2.02 & 1.44 & 40.21 & 0.76 & 0.41 & 15.01 & 0.44 & 0.10 & 0.02 & 8.06 & 0.12 & 0.11 & 0.01 & 0.02 & 2.41 & 0.01 & -0.02 & 0.02 \\
\hline MES Blk 51 & $4 / 06 / 2008$ & 16 & 34 & 55 & 718 & -2.41 & 0.18 & .79 & -0.02 & 0.12 & 0.77 & 0.04 & 0.24 & 0.01 & 0.98 & 0.01 & 0.03 & 0.01 & -0.03 & 0.95 & 0.02 & -0.01 & 0.01 \\
\hline MES Blk 52 & $4 / 06 / 2008$ & 265 & 177 & 335 & 4172 & 23.47 & 1.04 & 89.28 & 3.28 & 0.25 & 2.54 & 0.09 & 1.06 & 0.05 & 3.57 & 0.09 & 0.18 & 0.03 & 0.03 & 1.41 & 0.01 & 0.01 & 0.01 \\
\hline MES Blk 54 & $17 / 09 / 2008$ & 362 & 332 & 1666 & 21466 & 22.16 & 0.45 & 13.47 & 0.49 & 0.39 & 9.17 & 0.28 & 4.35 & 0.01 & 5.45 & 0.12 & 0.16 & 0.01 & -0.01 & 3.93 & 0.03 & 0.01 & 0.02 \\
\hline MES Blk 55 & $17 / 09 / 2008$ & 90 & 195 & 143 & 10057 & -5.34 & 0.06 & 3.73 & 0.14 & 0.22 & 3.74 & 0.40 & 2.20 & 0.01 & 1.37 & 0.13 & 0.13 & 0.03 & -0.01 & 6.70 & 0.01 & 0.00 & 0.02 \\
\hline MES Blk 57 & $25 / 09 / 2008$ & 202 & 111 & 348 & 1818 & -4.67 & 0.18 & 1.18 & 0.22 & 0.12 & 1.00 & 0.31 & 12.32 & 0.02 & 2.79 & 0.11 & 0.10 & 0.02 & 0.03 & 0.47 & 0.05 & -0.01 & -0.02 \\
\hline MES Blk 58 & $25 / 09 / 2008$ & 51 & 26 & 220 & 169 & 2.57 & 0.00 & -1.01 & 0.02 & 0.09 & 0.45 & 0.29 & 3.23 & 0.01 & 2.82 & 0.01 & 0.03 & 0.01 & -0.02 & 0.34 & 0.00 & -0.03 & -0.03 \\
\hline MES Blk 60 & $25 / 09 / 2008$ & 122 & 181 & 162 & 2035 & -1.42 & 0.10 & 5.13 & 0.35 & 0.10 & 1.75 & 0.05 & 1.36 & 0.01 & 2.74 & 0.15 & 0.18 & 0.02 & -0.03 & 0.38 & -0.01 & 0.00 & -0.02 \\
\hline MES Blk 60A & $1 / 10 / 2008$ & 52 & 31 & 45 & 804 & -1.49 & 0.07 & 0.01 & 0.26 & 0.28 & 1.23 & 0.01 & 0.06 & 0.02 & 1.38 & 0.01 & 0.03 & 0.01 & 0.02 & 0.69 & -0.01 & 0.00 & -0.03 \\
\hline MES Blk 63 & $6 / 10 / 2008$ & 82 & 25 & 40 & 393 & -5.14 & 0.06 & -1.61 & 0.22 & 0.10 & 0.56 & 0.02 & 0.59 & 0.01 & 0.73 & 0.00 & 0.01 & 0.00 & -0.01 & 0.28 & 0.01 & -0.01 & -0.02 \\
\hline MES BIk 64 & $6 / 10 / 2008$ & 9 & 55 & 56 & 1267 & 18.16 & 0.04 & -0.65 & 0.22 & 0.11 & 0.73 & 0.46 & 0.40 & 0.01 & 1.04 & 0.00 & 0.02 & 0.01 & 0.02 & 0.38 & 0.01 & 0.00 & -0.02 \\
\hline MES Blk 66 & $7 / 10 / 2008$ & 60 & 30 & 68 & 400 & -0.99 & 0.17 & -2.17 & 0.03 & 0.08 & 0.60 & 0.03 & 0.01 & 0.00 & 0.64 & 0.02 & 0.02 & 0.00 & -0.04 & 0.19 & -0.02 & 0.02 & 0.00 \\
\hline MES Blk 67 & $13 / 10 / 2008$ & 12050 & 357 & 209 & 1466 & 123.64 & 0.19 & 29.30 & 1.76 & 1.43 & 5.61 & 0.31 & 2.02 & 0.07 & 18.29 & 0.75 & 1.67 & 0.18 & -0.04 & 4.69 & -0.05 & 0.15 & 0.06 \\
\hline MES Blk 68 & $13 / 10 / 2008$ & 4719 & 3601 & 36584 & 22761 & 3674.94 & 6.60 & 1112.01 & 0.26 & 1.44 & 81.93 & 0.67 & 11.87 & 0.42 & 116.32 & 0.98 & 11.02 & 0.30 & 0.04 & 112.12 & 0.11 & 0.83 & 0.84 \\
\hline MES Blk 69 & $16 / 10 / 2008$ & 183 & 320 & 183 & 1319 & 62.39 & 0.21 & 20.49 & 0.30 & 0.13 & 6.62 & 0.21 & 0.49 & 0.04 & 6.24 & 0.05 & 0.39 & 0.02 & -0.06 & 3.93 & -0.07 & 0.03 & 0.00 \\
\hline MES Blk 70 & $16 / 10 / 2008$ & 248 & 151 & 1261 & 1169 & 13.84 & 0.16 & 0.28 & 0.40 & 0.12 & 1.20 & 0.40 & 1.49 & 0.03 & 2.73 & 0.05 & 0.37 & 0.02 & -0.01 & 3.35 & -0.02 & 0.09 & 0.01 \\
\hline MES Blk 72 & $20 / 10 / 2008$ & 235 & 37 & 68 & 648 & -5.53 & 0.32 & 0.03 & 0.15 & 0.16 & 0.57 & 0.05 & 0.89 & 0.02 & 1.27 & 0.06 & 0.08 & 0.02 & -0.02 & 0.56 & -0.03 & 0.04 & 0.00 \\
\hline MES BIk 75 & $13 / 11 / 2008$ & 14271 & 66 & 358 & 2797 & 7.98 & 0.15 & 8.67 & 0.20 & 0.30 & 3.04 & 0.05 & 0.49 & 0.16 & 3.64 & 0.05 & 0.09 & 0.03 & -0.02 & 1.66 & 0.00 & 0.03 & -0.01 \\
\hline MES BIk 76 & $13 / 11 / 2008$ & -440 & 105 & 137 & 6836 & 16.21 & 0.14 & 10.02 & 0.34 & 0.45 & 5.22 & 0.04 & 1.39 & 0.02 & 4.70 & 0.05 & 0.09 & 0.01 & -0.01 & 5.55 & 0.07 & 0.10 & 0.00 \\
\hline MES Blk 77 & $18 / 11 / 2008$ & -312 & 104 & 139 & 3145 & 12.30 & 0.16 & 8.60 & 0.06 & 0.23 & 2.75 & 0.10 & 0.33 & 0.02 & 3.10 & 0.04 & 0.08 & 0.01 & 0.00 & 1.22 & -0.01 & 0.02 & 0.01 \\
\hline MES Blk 78 & $18 / 11 / 2008$ & 39597 & 2948 & 4961 & 13907 & 2675.44 & 5.71 & 25.36 & 0.37 & 0.83 & 14.46 & 1.07 & 47.10 & 0.43 & 42.15 & 0.78 & 9.97 & 0.26 & 0.05 & 107.67 & 0.11 & 0.71 & 0.71 \\
\hline MES Blk 80 & $20 / 11 / 2008$ & 3734 & 65 & 105 & 1875 & 8.52 & 0.13 & 15.02 & -0.40 & 0.18 & 2.59 & 0.04 & 0.09 & 0.03 & 3.01 & 0.05 & 0.07 & 0.02 & 0.04 & 1.47 & 0.00 & 0.01 & 0.01 \\
\hline MES Blk 81 & $16 / 07 / 2009$ & 9730 & 10805 & 69361 & 73365 & 9580.48 & 17.96 & 74.29 & -0.23 & 1.77 & 495.91 & 2.13 & 36.18 & 0.96 & 161.69 & 3.20 & 23.27 & 1.11 & 0.13 & 216.08 & 2.13 & 1.85 & 2.43 \\
\hline MES Blk 82 & $16 / 07 / 2009$ & 23 & 32 & 135 & 1939 & 11.06 & 0.00 & 4.94 & -0.33 & 0.11 & 1.39 & 0.02 & 2.71 & 0.01 & 2.08 & 0.03 & 0.05 & 0.01 & -0.02 & 3.07 & 0.03 & 0.02 & 0.02 \\
\hline MES Blk 83 & $16 / 07 / 2009$ & 105 & 161 & 2710 & 2736 & 263.86 & 0.60 & 4.44 & -0.51 & 0.15 & 3.98 & 0.05 & 0.81 & 0.03 & 4.15 & 0.10 & 0.86 & 0.02 & -0.08 & 11.09 & -0.01 & 0.04 & 0.07 \\
\hline MES BIk 84 & $20 / 07 / 2009$ & 623 & 189 & 1647 & 3899 & 317.38 & 0.76 & 26.02 & 0.13 & 0.42 & 4.92 & 0.06 & 1.81 & 0.07 & 7.86 & 0.11 & 0.61 & 0.04 & -0.06 & 9.83 & 0.01 & 0.26 & 0.07 \\
\hline MES Blk 85 & $20 / 07 / 2009$ & 47 & 40 & 93 & 1691 & 4.89 & 0.14 & 4.43 & -0.40 & 0.12 & 1.36 & 0.02 & 0.55 & 0.01 & 3.62 & 0.04 & 0.07 & 0.01 & -0.11 & 2.55 & -0.01 & 0.03 & 0.02 \\
\hline MES BIk 86 & $20 / 07 / 2009$ & -28 & 23 & 181 & 1014 & 25.44 & 0.24 & 4.38 & 0.06 & 0.10 & 1.39 & 0.01 & 2.19 & 0.02 & 23.91 & 0.03 & 0.07 & 0.01 & 0.00 & 2.16 & -0.06 & 0.24 & 0.01 \\
\hline MES Blk 87 & $28 / 07 / 2009$ & 300 & 91 & 134 & 2721 & 102.52 & 0.49 & 23.66 & 0.70 & 0.52 & 3.58 & 0.09 & 1.61 & 0.03 & 4.71 & 0.09 & 0.21 & 0.03 & -0.03 & 4.91 & 0.02 & 0.02 & 0.02 \\
\hline MES Blk 88 & $28 / 07 / 2009$ & 723 & 167 & 235 & 3985 & 86 & 1. & 78.99 & 1.92 & 0.80 & 5.05 & 0.15 & 2.46 & 0.03 & 8.25 & 0.13 & 0.20 & 0.03 & -0.03 & 7.36 & 0.01 & 0.12 & 0.02 \\
\hline MES Blk 89 & 2009 & 1198 & 1097 & 9831 & 13212 & 8 & 2 & 76 & 0.59 & 0.81 & 12.59 & 0.49 & 3.90 & 0.38 & 11.26 & 0.59 & 3.87 & 0.10 & 0.00 & 22.96 & 0.21 & 0.17 & 0.24 \\
\hline MES Blk 90 & 009 & 842 & 621 & 5319 & 5224 & 1224.32 & & 13.95 & 0.44 & 0.59 & 5.25 & 0.18 & 1.52 & 0.10 & 6.69 & 0.31 & 3.36 & 0.06 & 0.05 & 27.16 & 0.06 & 0.19 & 0.33 \\
\hline MES Blk 91 & & 156 & 64 & 126 & 774 & & & & 0.25 & 0.31 & 1.09 & 0.05 & 0.10 & 0.03 & 3.39 & 0.10 & 0.22 & 0.02 & 0.03 & 2.28 & 0.06 & 0.03 & 0.01 \\
\hline MES Blk 92 & $30 / 07 / 2009$ & 14442 & 4592 & 2820 & 8772 & 94.17 & 20.23 & 88.11 & 1.60 & 8.15 & 7.36 & 26.76 & 11.05 & 1.25 & 20.79 & 42.53 & 89.51 & 12.48 & 0.13 & 6.00 & 0.02 & 3.93 & 0.65 \\
\hline MES BIk 93 & $31 / 07 / 2009$ & 669 & 308 & 644 & 11058 & 134.48 & 0.95 & 41.21 & 1.08 & 1.60 & 13.64 & 0.19 & 0.88 & 0.08 & 11.07 & 0.36 & 0.69 & 0.69 & -0.07 & 9.70 & 0.03 & 0.05 & 0.09 \\
\hline MES BIk 94 & $31 / 07 / 2009$ & 685 & 262 & 978 & 11737 & 162.82 & 1.55 & 65.30 & 1.46 & 1.62 & 14.88 & 0.31 & 3.23 & 0.11 & 24.35 & 0.39 & 0.84 & 0.10 & -0.06 & 11.40 & 0.59 & 0.08 & 0.11 \\
\hline MES Blk 95 & $31 / 07 / 2009$ & 1066 & 240 & 99 & 5952 & 55.22 & 0.62 & 26.41 & 0.91 & 1.09 & 8.89 & 0.54 & 16.98 & 0.06 & 11.63 & 0.14 & 0.29 & 0.03 & 0.03 & 5.47 & -0.02 & 0.02 & 0.01 \\
\hline MES Blk 96 & $2 / 06 / 2010$ & 3843 & 1637 & 329 & 8102 & 53.67 & 0.26 & 25.17 & -1.83 & -0.30 & -0.29 & 0.11 & -0.46 & -0.12 & 14.19 & 0.12 & 0.19 & 0.00 & 0.01 & 6.61 & 1.32 & -0.19 & 0.02 \\
\hline
\end{tabular}




\begin{tabular}{|c|c|c|c|c|c|c|c|c|c|c|c|c|c|c|c|c|c|c|c|c|c|c|c|}
\hline Blank I.D. & Date melted & $\mathrm{Na}$ & $\mathrm{Mg}$ & $\mathrm{Al}$ & $\mathrm{Ca}$ & $\mathrm{Ti}$ & $\mathrm{V}$ & $\mathrm{Mn}$ & As & $\mathrm{Rb}$ & $\mathrm{Sr}$ & $Y$ & $\mathrm{Zr}$ & Cs & $\mathrm{Ba}$ & La & $\mathrm{Ce}$ & $\mathrm{Pr}$ & TI & $\mathrm{Pb}$ & $\mathrm{Bi}$ & Th & $U$ \\
\hline MES Blk 97 & $2 / 06 / 2010$ & 5380 & 933 & 495 & 11518 & 130.37 & 0.73 & 29.90 & -1.74 & -0.32 & -0.24 & 0.84 & -0.48 & -0.12 & 27.93 & 0.19 & 0.38 & 0.00 & 0.00 & 16.33 & 0.47 & -0.18 & 0.03 \\
\hline AES Blk 98 & $2 / 06 / 2010$ & 114 & 859 & 304 & 12183 & 44.28 & 0.43 & 7.65 & 1.05 & 3.61 & 13.13 & 0.35 & 2.17 & 0.18 & 17.86 & 0.11 & 0.26 & 0.00 & 0.00 & 9.99 & 0.23 & 0.03 & 0.01 \\
\hline MES Blk 101 & $3 / 06 / 2010$ & 1091 & 537 & 937 & 10498 & 86.28 & 1.82 & 2.52 & $\mathrm{~nm}$ & 1.41 & 12.16 & 0.17 & 3.36 & 0.20 & 7.47 & 0.08 & 0.12 & 0.02 & 0.00 & 20.31 & 0.14 & 0.03 & 0.00 \\
\hline AES Blk 102 & $3 / 06 / 2010$ & 497 & 28 & 277 & 3264 & 71.63 & 0.35 & 1.58 & $\mathrm{~nm}$ & 1.22 & 3.56 & 0.06 & 0.65 & 0.05 & 6.91 & 0.10 & 0.29 & 0.03 & 0.01 & 5.51 & 0.10 & 0.03 & -0.01 \\
\hline MES Blk 104 & $4 / 06 / 2010$ & 735 & 145 & 541 & 2894 & 39.96 & 0.60 & 14.61 & $\mathrm{~nm}$ & 1.65 & 4.06 & 0.21 & 1.43 & 0.07 & 9.48 & 0.45 & 0.90 & 0.11 & 0.00 & 7.16 & 3.25 & 0.13 & 0.04 \\
\hline MES Blk 105 & $4 / 06 / 2010$ & 655 & 395 & 208 & 3237 & 33.09 & 0.40 & 13.75 & $\mathrm{~nm}$ & 0.91 & 5.60 & 0.04 & 0.68 & 0.04 & 7.50 & 0.34 & 0.13 & 0.01 & 0.03 & 4.42 & 0.54 & 0.00 & -0.01 \\
\hline MES Blk 106 & $8 / 06 / 2010$ & 141 & 164 & 681 & 5418 & 38.45 & 0.15 & 5.53 & $\mathrm{~nm}$ & 0.48 & 3.89 & 0.06 & 0.35 & 0.03 & 3.80 & 0.07 & 0.12 & 0.02 & -0.01 & 2.67 & 0.10 & -0.01 & 0.00 \\
\hline MES Blk 108 & $8 / 06 / 2010$ & 33 & 117 & 265 & 3896 & 1.96 & 0.14 & 4.50 & $\mathrm{~nm}$ & $\mathrm{~nm}$ & $\mathrm{~nm}$ & 0.04 & $\mathrm{~nm}$ & $\mathrm{~nm}$ & 2.17 & 0.06 & 0.15 & 0.02 & -0.02 & 1.96 & 0.00 & 0.00 & 0.00 \\
\hline MES Blk 110 & $11 / 06 / 2010$ & 35 & 683 & 132 & 10521 & 3.78 & 0.19 & 10.87 & $\mathrm{~nm}$ & 1.16 & 4.66 & 0.13 & 24.05 & 0.02 & 0.63 & 0.03 & 0.07 & 0.00 & 0.02 & 0.23 & 0.03 & 0.00 & 0.02 \\
\hline MES Blk 111 & $11 / 06 / 2010$ & 5 & 35 & 100 & 286 & 6.99 & 0.05 & 4.74 & $\mathrm{~nm}$ & 0.06 & 0.16 & 0.00 & 0.17 & 0.01 & 0.24 & -0.01 & 0.01 & -0.01 & 0.02 & 0.10 & 0.03 & 0.01 & 0.01 \\
\hline MES Blk 112 & $14 / 06 / 2010$ & 7 & 1277 & 190 & 2972 & 12.52 & 0.05 & 17.45 & $\mathrm{~nm}$ & $\mathrm{~nm}$ & $\mathrm{~nm}$ & 3.14 & 72.60 & $\mathrm{~nm}$ & 1.12 & $\mathrm{~nm}$ & 0.04 & -0.01 & 0.00 & 0.74 & 0.00 & 0.00 & 0.01 \\
\hline MES Blk 114 & $14 / 06 / 2010$ & 9 & 49 & 860 & 1046 & 5.15 & 0.25 & 4.19 & $\mathrm{~nm}$ & $\mathrm{~nm}$ & $\mathrm{~nm}$ & 1.30 & 31.45 & $\mathrm{~nm}$ & 2.33 & $\mathrm{~nm}$ & 0.22 & 0.03 & 0.03 & 2.17 & 0.00 & 0.00 & 0.00 \\
\hline MES Blk 116 & $15 / 06 / 2010$ & 49 & 25 & 169 & 1058 & 1.75 & 0.04 & -0.74 & $\mathrm{~nm}$ & $\mathrm{~nm}$ & $\mathrm{~nm}$ & 0.03 & 3.40 & $\mathrm{~nm}$ & 2.78 & 0.00 & 0.02 & 0.01 & 0.00 & 0.46 & 0.00 & 0.00 & 0.02 \\
\hline MES Blk 117 & $15 / 06 / 2010$ & 24 & 26 & 148 & 986 & -1.18 & 0.15 & 1.06 & $\mathrm{~nm}$ & $\mathrm{~nm}$ & $\mathrm{~nm}$ & 0.01 & 0.52 & $\mathrm{~nm}$ & 0.45 & 0.02 & 0.05 & 0.01 & -0.02 & 1.26 & 0.00 & 0.00 & 0.01 \\
\hline MES Blk 118 & $16 / 06 / 2010$ & 106 & 33 & 132 & 1121 & 3.80 & 0.02 & -0.39 & $\mathrm{~nm}$ & $\mathrm{~nm}$ & $\mathrm{~nm}$ & 0.01 & 1.53 & $\mathrm{~nm}$ & 0.71 & 0.01 & 0.02 & 0.00 & 0.00 & 0.19 & 0.00 & 0.00 & -0.02 \\
\hline MES Blk 119 & $16 / 06 / 2010$ & 29 & 20 & 118 & 696 & 1.16 & 0.12 & 0.38 & $\mathrm{~nm}$ & 0.06 & 0.44 & 0.01 & 0.40 & -0.01 & 0.41 & 0.05 & 0.10 & 0.00 & -0.02 & 0.46 & 0.02 & -0.01 & 0.02 \\
\hline MES Blk 121 & $21 / 06 / 2010$ & 66 & 38 & 240 & 1487 & 2.99 & 0.11 & 0.55 & $\mathrm{~nm}$ & 0.21 & 0.87 & 0.05 & -0.02 & 0.01 & 0.82 & 0.08 & 0.20 & 0.03 & -0.03 & 1.66 & 0.04 & -0.01 & 0.01 \\
\hline MES Blk 122 & $22 / 06 / 2010$ & 82 & -18 & 141 & 1181 & 5.27 & 0.11 & 2.13 & $\mathrm{~nm}$ & 0.25 & 0.85 & 0.05 & 0.16 & 0.02 & 1.21 & 0.10 & 0.17 & 0.02 & 0.00 & 1.40 & 0.04 & -0.02 & 0.01 \\
\hline MES Blk 125 & $23 / 06 / 2010$ & 210 & 429 & 515 & 3567 & 1.18 & -0.06 & 8.21 & $\mathrm{~nm}$ & $\mathrm{~nm}$ & $\mathrm{~nm}$ & 0.04 & 0.13 & $\mathrm{~nm}$ & 2.15 & 0.08 & 0.14 & 0.04 & 0.01 & 6.38 & 0.00 & 0.00 & 0.02 \\
\hline MES Blk 126 & $28 / 06 / 2010$ & 26 & -35 & 141 & 348 & 1.79 & -0.06 & 0.01 & $\mathrm{~nm}$ & 0.04 & 0.24 & 0.01 & 0.11 & 0.00 & 0.16 & 0.02 & 0.03 & 0.01 & 0.00 & 0.05 & -0.01 & -0.02 & 0.00 \\
\hline MES Blk 127 & $28 / 06 / 2010$ & 22 & 127 & 144 & 1451 & 0.28 & -0.06 & 1.97 & $\mathrm{~nm}$ & 0.05 & 0.61 & 0.02 & 0.09 & 0.01 & 0.23 & 0.02 & 0.01 & 0.01 & 0.00 & 0.10 & 0.01 & -0.01 & 0.03 \\
\hline \multirow{2}{*}{\multicolumn{2}{|c|}{$\begin{array}{l}\text { Mean procedural blank } \\
\text { Mean procedural blank } \\
\text { (excl. bold, italicised values) }\end{array}$}} & 1558 & 478 & 2075 & 10649 & 217.20 & 0.98 & 25.60 & 0.39 & 0.55 & 12.07 & 0.52 & 3.73 & 0.06 & 10.51 & 0.66 & 1.68 & 0.18 & 0.00 & 9.36 & 0.12 & 0.10 & 0.08 \\
\hline & & 1127 & 290 & 561 & 25 & .50 & 0.70 & 90 & 0.33 & 0.47 & 4.54 & 0.50 & 3.03 & 0.05 & 5.39 & 0.66 & 1.42 & 0.17 & .00 & 4.68 & 0.09 & 0.07 & 0.04 \\
\hline
\end{tabular}

$\mathrm{nm}=$ element not measured. Values in grey are below the detection limit.

Problems noted down in melting log book for bold, italicised blanks:

MES Blank $1=1^{\text {st }}$ blank to be sampled on continuous melter at New Zealand Ice Core Laboratory.

MES Blank 6 = Pump for outer line suction was not working so blank would have received material from outer section of mock core.

MES Blank 38 = Pump for outer line suction was not working so blank would have received material from outer section of mock core.

MES Blanks $67,68=$ Mock ice core cut too narrow so that it barely covered the inner circle of melt disk.

MES Blanks 75, $76=$ New melter head used for first time.

MES Blank $81=1^{\text {st }}$ blank to be run through melter head after it was anodised.

MES Blanks 93, 94, 95 = Small piece of mock ice did not sit well over inner circle of melt disk. 
Table A3: Concentrations of major ions (ppb) determined by IC in the procedural blanks.

\begin{tabular}{|c|c|c|c|c|c|c|c|c|}
\hline Blank I.D. & $\mathrm{Na}^{+}$ & $\mathbf{K}^{+}$ & $\mathrm{Mg}^{2+}$ & $\mathrm{Ca}^{2+}$ & $\mathbf{M S}^{-}$ & $\mathrm{Cl}^{-}$ & $\mathrm{SO}_{4}{ }^{2-}$ & $\mathrm{NO}_{3}^{-}$ \\
\hline MES Blk 1 & 1.05 & 0.17 & 1.99 & 41.9 & n.a. & 29.0 & 12.7 & 9.55 \\
\hline MES Blk 2 & 0.16 & 0.10 & 1.32 & 22.8 & n.a. & 26.2 & n.a. & 5.80 \\
\hline MES Blk 3 & 0.15 & 0.07 & 1.10 & 19.0 & n.a. & 26.0 & n.a. & 6.17 \\
\hline MES Blk 4 & 0.11 & 0.04 & 0.78 & 12.0 & n.a. & 25.5 & n.a. & 6.05 \\
\hline MES Blk 5 & 0.16 & 0.06 & 0.70 & 18.8 & n.a. & 25.7 & n.a. & 5.72 \\
\hline MES Blk 6 & 1.00 & 0.10 & 0.90 & 34.9 & n.a. & 27.5 & 12.2 & 7.99 \\
\hline MES Blk 7 & 0.82 & 0.10 & 0.85 & 30.3 & n.a. & 26.6 & 12.2 & 6.24 \\
\hline MES Blk 8 & 0.20 & 0.07 & 0.62 & 21.5 & n.a. & 25.5 & n.a. & 6.08 \\
\hline MES Blk 9 & 0.08 & 0.07 & 0.57 & 12.9 & n.a. & 25.4 & n.a. & 5.69 \\
\hline MES BIk 10 & 0.09 & 0.07 & 0.51 & 9.8 & n.a. & 25.7 & n.a. & 6.06 \\
\hline MES Blk 11 & 0.29 & 0.06 & 0.67 & 12.6 & n.a. & 25.9 & 13.4 & 6.08 \\
\hline MES BIk 12 & 0.19 & 0.34 & 0.54 & 10.6 & n.a. & 25.9 & 12.4 & 5.72 \\
\hline MES Blk 13 & 0.12 & 0.05 & 0.48 & 7.7 & n.a. & 25.6 & 12.1 & 5.76 \\
\hline MES Blk 14 & 0.42 & 0.09 & 0.61 & 25.3 & n.a. & 26.6 & n.a. & 7.78 \\
\hline MES BIk 15 & 0.11 & n.a. & 0.54 & 17.0 & n.a. & 27.0 & n.a. & 5.65 \\
\hline MES Blk 16 & 0.12 & n.a. & 0.53 & 15.5 & n.a. & 26.7 & n.a. & 5.93 \\
\hline MES BIk 17 & 0.24 & 0.20 & 0.55 & 19.1 & n.a. & 27.6 & n.a. & 6.40 \\
\hline MES BIk 18 & 0.31 & 0.10 & 0.51 & 17.5 & n.a. & 26.9 & n.a. & 6.46 \\
\hline MES blk 19 & 2.53 & 0.07 & 0.59 & 19.4 & n.a. & 26.4 & 14.2 & 7.08 \\
\hline MES Blk 20 & 0.30 & 0.07 & 0.57 & 21.8 & n.a. & 26.7 & n.a. & 5.94 \\
\hline MES Blk 21 & 0.16 & 0.12 & 0.54 & 21.3 & n.a. & 26.1 & n.a. & 6.29 \\
\hline MES blk 22 & 0.09 & 0.15 & 0.47 & 19.0 & n.a. & 26.7 & n.a. & 5.65 \\
\hline MES Blk 23 & 0.11 & 0.17 & 0.48 & 25.1 & n.a. & 27.4 & n.a. & 5.84 \\
\hline MES Blk 24 & 0.09 & 0.10 & 0.52 & 19.3 & n.a. & 26.7 & n.a. & 5.89 \\
\hline MES Blk 25 & 0.16 & 0.07 & n.a. & 13.3 & n.a. & 27.3 & n.a. & 5.66 \\
\hline MES BIk 26 & 0.44 & 0.08 & 0.51 & 29.0 & n.a. & 26.9 & 15.4 & 5.69 \\
\hline MES Blk 27 & 0.12 & 0.07 & 0.49 & 27.1 & n.a. & 25.8 & n.a. & 5.72 \\
\hline MES Blk 28 & 0.09 & 0.08 & 0.47 & 21.0 & n.a. & 26.0 & n.a. & 6.07 \\
\hline MES Blk 29 & 1.03 & 0.19 & 0.69 & 27.1 & n.a. & 28.3 & 12.2 & 8.10 \\
\hline MES Blk 30 & 0.14 & 0.08 & 0.61 & 23.5 & n.a. & 26.3 & n.a. & 5.65 \\
\hline MES Blk 31 & 0.10 & 0.08 & 0.52 & 12.2 & n.a. & 26.0 & n.a. & 5.88 \\
\hline MES Blk 32 & 0.09 & 0.09 & 0.47 & 19.2 & n.a. & 26.1 & 12.3 & 6.02 \\
\hline MES BIk 33 & 0.22 & 0.09 & 0.66 & 26.8 & n.a. & 28.6 & 11.9 & 5.67 \\
\hline MES BIk 34 & 0.42 & 0.08 & 0.58 & 16.6 & n.a. & 26.6 & 12.2 & 7.00 \\
\hline $\begin{array}{l}\text { Mean } \\
\text { procedural } \\
\text { blank }\end{array}$ & 0.34 & 0.10 & 0.66 & 20.3 & 0.00 & 26.6 & 4.5 & 6.27 \\
\hline
\end{tabular}


Appendix III: Accuracy, precision and detection limits of major ion concentration measurements

The detection limits of the ion chromatography method are displayed in Table A4. Table A5 displays the accuracy and precision of major ion determinations made by myself during a visit to the University of Maine in late February to March 2010. These are the only analytical sessions for which external standard data has been made available. The external standard is ION-92 (Environment Canada). As the concentrations of major ions vary by several orders of magnitude in the ice core samples, ION-92 was measured at two dilutions (x100 and x1000) during each analytical session.

Table A4: Detection limits (ppb) of major ions determined by IC. Data courtesy of Sharon Sneed, University of Maine.

\begin{tabular}{cccccccc}
\hline $\mathrm{Na}^{+}$ & $\mathrm{K}^{+}$ & $\mathrm{Mg}^{2+}$ & $\mathrm{Ca}^{2+}$ & $\mathrm{MS}^{-}$ & $\mathrm{NO}_{3}{ }^{-}$ & $\mathrm{Cl}^{-}$ & $\mathrm{SO}_{4}{ }^{2-}$ \\
\hline 0.16 & 0.33 & 0.51 & 0.08 & 0.32 & 0.35 & 0.76 & 0.43 \\
\hline
\end{tabular}


Table A5: Concentrations of major ions (ppb) determined in two dilutions of the external standard ION-92 and the accuracy and precision of measurements. $\mathrm{NO}_{3}{ }_{3}^{-}$is not detectable in external standard.

\begin{tabular}{|c|c|c|c|c|c|c|c|c|c|c|c|c|c|c|}
\hline $\begin{array}{l}\text { Analysis date } \\
\text { (ddmmyy) }\end{array}$ & $\mathrm{Na}^{+}$ & $\mathrm{Na}^{+}$ & $\mathrm{K}^{+}$ & $\mathbf{K}^{+}$ & $\mathrm{Mg}^{2+}$ & $\mathrm{Mg}^{2+}$ & $\mathrm{Ca}^{2+}$ & $\mathrm{Ca}^{2+}$ & $\mathrm{MS}^{-}$ & MS $^{-}$ & $\mathrm{Cl}^{-}$ & $\mathrm{Cl}^{-}$ & $\mathrm{SO}_{4}{ }^{2-}$ & $\mathrm{SO}_{4}{ }^{2-}$ \\
\hline 240210 & 25.6 & 208 & 1.41 & 4.33 & 10.3 & 97.3 & 45.8 & 434 & 17.5 & 38.7 & 107 & 1048 & 34.3 & 351 \\
\hline 240210 & 27.5 & 220 & 1.21 & 5.04 & 13.6 & 104 & 49.6 & 459 & 20.1 & 36.7 & 110 & 1051 & 39.9 & 353 \\
\hline 250210 & 27.7 & 221 & 1.17 & 5.04 & 11.5 & 104 & 46.8 & 459 & 17.8 & 42.2 & 109 & 1063 & 33.9 & 345 \\
\hline 250210 & 29.8 & 226 & 1.67 & 6.27 & 12.1 & 106 & 49.3 & 469 & 22.5 & 51.2 & 117 & 1098 & 40.4 & 365 \\
\hline 260210 & 29.0 & 227 & 1.20 & 4.97 & 11.3 & 105 & 47.1 & 469 & 22.1 & 46.7 & 115 & 1100 & 36.4 & 360 \\
\hline 260210 & 29.0 & 227 & 1.20 & 4.97 & 11.3 & 105 & 47.1 & 469 & 22.1 & 46.7 & 115 & 1100 & 36.4 & 360 \\
\hline 270210 & 14.0 & 185 & 0.85 & 3.61 & 9.50 & 90.8 & 41.0 & 407 & 29.4 & 50.6 & 112 & 1088 & 41.2 & 362 \\
\hline 270210 & 15.8 & 193 & 0.94 & 4.43 & 8.79 & 93.0 & 46.3 & 421 & 21.3 & 49.2 & 117 & 1126 & 43.4 & 370 \\
\hline 010310 & 14.0 & 185 & 0.85 & 3.61 & 9.50 & 90.8 & 41.0 & 407 & 29.4 & 50.6 & 112 & 1088 & 41.2 & 362 \\
\hline 010310 & 15.8 & 193 & 0.94 & 4.43 & 8.79 & 93.0 & 46.3 & 421 & 21.3 & 49.2 & 117 & 1126 & 43.4 & 370 \\
\hline 020310 & 6.85 & 182 & n.a. & n.a. & 9.29 & 92.4 & 35.0 & 420 & 19.9 & 43.7 & 110 & 1078 & 40.6 & 361 \\
\hline 020310 & 7.40 & 188 & n.a. & n.a. & 8.47 & 94.7 & 40.5 & 436 & 28.8 & 48.1 & 112 & 1105 & 42.9 & 372 \\
\hline 030310 & 8.97 & 185 & n.a. & n.a. & 8.49 & 93.8 & 34.2 & 430 & 24.5 & 49.9 & 126 & 1149 & 47.4 & 379 \\
\hline 030310 & 9.04 & 189 & n.a. & n.a. & 9.11 & 95.1 & 44.6 & 442 & 28.7 & 57.2 & 121 & 1195 & 46.7 & 387 \\
\hline 040310 & 5.99 & 178 & n.a. & n.a. & 8.25 & 87.1 & 35.0 & 408 & 25.8 & 57.0 & 114 & 1082 & 41.2 & 367 \\
\hline 040310 & 7.07 & 185 & n.a. & n.a. & 8.66 & 90.6 & 40.7 & 424 & 35.2 & 74.1 & 121 & 1158 & 45.3 & 379 \\
\hline 110310 & 17.5 & 180 & 0.38 & 1.84 & 8.98 & 86.0 & 41.0 & 393 & n.a. & 42.3 & n.a. & 1018 & 38.5 & 341 \\
\hline 110310 & 19.4 & 181 & 0.92 & 2.99 & 10.0 & 81.0 & n.a. & 356 & 42.1 & 70.3 & 114 & 1072 & 41.8 & 358 \\
\hline 090310 & 18.3 & 183 & 0.63 & 2.64 & 9.39 & 88.2 & n.a. & n.a. & 28.0 & 50.5 & 113 & 1003 & 42.9 & 343 \\
\hline 090310 & 17.4 & 188 & 0.56 & 3.17 & 8.71 & 87.0 & n.a. & n.a. & 24.8 & 58.4 & 107 & 1059 & 39.8 & 361 \\
\hline 100310 & 17.0 & 178 & 0.37 & 2.26 & 8.83 & 86.2 & 39.7 & 384 & 16.9 & 44.1 & 106 & 1005 & 37.9 & 343 \\
\hline 100310 & 17.7 & 181 & 0.39 & 2.49 & 9.12 & 87.7 & 44.8 & 399 & 20.2 & 49.3 & 107 & 1026 & 42.6 & 349 \\
\hline 160310 & 16.6 & 182 & 0.43 & 2.59 & 9.69 & 88.5 & 41.7 & 398 & 28.7 & 51.4 & 110 & 1060 & 39.6 & 352 \\
\hline 160310 & 17.9 & 187 & 1.10 & 4.26 & 8.76 & 91.2 & 45.5 & 432 & 38.0 & 66.1 & 117 & 1115 & 44.3 & 364 \\
\hline 180310 & 16.8 & 181 & 1.36 & 5.95 & 9.21 & 88.3 & 41.2 & 400 & 28.0 & 46.9 & 112 & 1056 & 39.8 & 356 \\
\hline 180310 & 17.1 & 183 & 1.93 & 7.29 & 8.96 & 89.5 & 43.0 & 406 & 24.3 & 41.8 & 111 & 1040 & 42.5 & 356 \\
\hline 230310 & 18.8 & 186 & 18.8 & n.a. & 1.48 & n.a. & 10.1 & n.a. & 19.2 & 51.3 & 115 & 1113 & 40.8 & 361 \\
\hline
\end{tabular}




\begin{tabular}{|c|c|c|c|c|c|c|c|c|c|c|c|c|c|c|}
\hline $\begin{array}{l}\text { Analysis date } \\
\text { (ddmmyy) }\end{array}$ & $\mathrm{Na}^{+}$ & $\mathrm{Na}^{+}$ & $\mathrm{K}^{+}$ & $\mathrm{K}^{+}$ & $\mathrm{Mg}^{2+}$ & $\mathrm{Mg}^{2+}$ & $\mathrm{Ca}^{2+}$ & $\mathrm{Ca}^{2+}$ & $\mathrm{MS}^{-}$ & $\mathrm{MS}^{-}$ & $\mathrm{Cl}^{-}$ & $\mathrm{Cl}^{-}$ & $\mathrm{SO}_{4}{ }^{2-}$ & $\mathrm{SO}_{4}{ }^{2-}$ \\
\hline 230310 & 19.5 & 189 & 19.5 & n.a. & 2.13 & $\overline{\text { n.a. }}$ & 10.6 & n.a. & 28.5 & 53.4 & 118 & 1164 & 45.8 & 376 \\
\hline 240310 & 18.2 & 185 & 0.94 & 3.51 & 9.30 & 89.5 & 40.5 & 404 & 22.6 & 46.6 & 113 & 1141 & 40.9 & 363 \\
\hline 240310 & 19.2 & 191 & 1.30 & 4.80 & 10.8 & 89.2 & 46.8 & 395 & 15.4 & 46.1 & 119 & 1185 & 48.6 & 383 \\
\hline 300310 & 21.2 & 192 & 1.85 & 5.09 & 10.4 & 92.6 & 42.1 & 413 & 24.8 & 54.8 & 113 & 1063 & 38.3 & 356 \\
\hline 300310 & 25.4 & 220 & 2.40 & 6.26 & 13.3 & 108 & 53.7 & 475 & 24.4 & 55.9 & 118 & 1104 & 46.0 & 373 \\
\hline 010410 & 24.4 & 216 & 1.63 & 4.85 & 12.2 & 108 & 50.2 & 468 & 30.8 & 50.2 & 113 & 1071 & 37.5 & 353 \\
\hline 010410 & 26.8 & 221 & 2.58 & 7.41 & 21.1 & 112 & 78.7 & 490 & 41.6 & 62.3 & 116 & 1094 & 62.1 & 367 \\
\hline Long-term mean & 18.3 & 195 & 2.45 & 4.4 & 9.74 & 94.2 & 42.6 & 426 & 25.6 & 51.0 & 114 & 1089 & 41.9 & 362 \\
\hline $2 S D$ & 13.6 & 33.1 & 9.52 & 3.0 & 6.20 & 15.8 & 23.1 & 63.8 & 13.3 & 16.5 & 9.34 & 95.94 & 10.1 & 22.9 \\
\hline Certified & 19.3 & 193 & 0.90 & 9.00 & 9.60 & 96.0 & 42.8 & 428 & 20.0 & 50.0 & 106 & 1055 & 37.0 & 370 \\
\hline $2 \mathrm{SD}$ & 4.80 & 48.0 & 0.40 & 4.00 & 2.20 & 22.0 & 8.0 & 80.0 & & & 24.6 & 246.0 & 9.80 & 98.0 \\
\hline Precision 2 RSD (\%) & 37.0 & 8.50 & 194 & 34.1 & 31.8 & 8.40 & 27.1 & 7.5 & 25.9 & 11.2 & 4.10 & 4.40 & 12.0 & 3.17 \\
\hline Accuracy (\% error) & 5.12 & 0.84 & 172 & 51.2 & 1.51 & 1.85 & 0.5 & 0.39 & 28.0 & 2.0 & 7.96 & 3.27 & 13.2 & 2.24 \\
\hline
\end{tabular}




\section{Appendix IV: Stable isotope data for Mt Erebus Saddle 2006/07 ice core}

All stable isotope ratios of oxygen and hydrogen and the derived $d$-excess values are provided in Table A6. The stable isotope ratios of a small number of samples had to be removed from analysis because they were anomalously heavy (Table A7). This was the result of ethanol or ultra-pure water contamination within the melter system.

The instrument used for stable isotope ratio determination changed from a GVI mass spectrometer to a LGR Liquid-Water Isotope Analyser at $92 \mathrm{~m}$ depth in the ice core. To ascertain whether comparable measurements were produced, a batch of samples (MES06/07_ISO_3783 to MES06/07_ISO_3921 and MES06/07_ISO_4858 to MES06/07_ISO_4905) was measured using both instruments (Table A8). Comparisons of the stable isotope ratios measured on the two instruments show offsets (Figs. A2 and $A 3)$, most notably for $\delta D$, which for only the lightest (most negative) values, are greater than the combined analytical error of both instruments. The mean difference between measurements on the GVI mass spectrometer and LGR Liquid-Water Isotope Analyser was $-0.14 \%$ o for $\delta^{18} \mathrm{O}$ and $-2.86 \%$ for $\delta \mathrm{D}$, which resulted in a mean difference of $-1.84 \%$ o for $d$-excess. For several samples tested, the difference between the $d$ excess derived from the GVI mass spectrometer and the LGR Liquid-Water Isotope Analyser data is greater than the analytical uncertainty (Fig. A4). Therefore, the $\delta D$ and $\delta^{18} \mathrm{O}$ values measured on the LGR Liquid-Water Isotope Analyser were corrected to make them comparable to the GVI mass spectrometer values using the linear relationships established by analysing samples on both instruments (Figs. A2 and A3).

$\left.\delta D_{\text {mass spec. equiv. }}=\left(\delta D_{\text {laser }}+1.6576\right) / 0.9809\right)$

$\left.\delta^{18} \mathrm{O}_{\text {mass spec. equiv. }}=\left(\delta^{18} \mathrm{O}_{\text {laser }}-0.1577\right) / 1.0034\right)$

Deuterium excess values were then calculated from the corrected $\delta D$ and $\delta^{18} O$ datasets. A revised analytical uncertainty $(u)$ for d-excess, which takes into account the errors on both instruments, is calculated as: $\sqrt{1.3^{2}+1.7^{2}}=2.14 \%$. The $\delta \mathrm{D}$ and d-excess records of the MES ice core before and after the above corrections were applied are displayed in Figure A5.

Tables A6 and A7 are located on the enclosed data disk 
Table A8: Comparison of the stable isotope ratios $\left(\delta^{18} O\right.$ and $\left.\delta D\right)$ of selected MES ice core samples

determined by GVI mass spectrometer (Mass spec.) and LGR Liquid-Water Isotope Analyser

(Laser). Difference between mass spec. and laser measurements $(\Delta)$ and analytical precision $(\sigma=$

1 standard deviation) of samples is provided.

\begin{tabular}{|c|c|c|c|c|c|c|c|c|c|c|c|}
\hline \multirow{2}{*}{$\begin{array}{l}\text { Internal } \\
\text { sample } \\
\text { I.D. }\end{array}$} & \multirow{2}{*}{$\begin{array}{c}\text { Depth } \\
\text { (m) }\end{array}$} & \multirow[b]{2}{*}{$\begin{array}{l}\text { Mass } \\
\text { spec. }\end{array}$} & \multicolumn{3}{|c|}{$\delta^{18} \mathrm{O}(\% \circ)$} & \multirow[b]{2}{*}{$\Delta$} & \multirow[b]{2}{*}{$\begin{array}{l}\text { Mass } \\
\text { spec. }\end{array}$} & \multicolumn{3}{|c|}{$\delta D(\%)$} & \multirow[b]{2}{*}{$\Delta$} \\
\hline & & & $\bar{\sigma}$ & Laser & $\bar{\sigma}$ & & & $\bar{\sigma}$ & Laser & $\bar{\sigma}$ & \\
\hline MES0607_ISO_3783 & 77.02 & -26.95 & & -26.64 & 0.06 & -0.31 & -210.37 & 0.43 & -205.77 & 0.24 & -4.60 \\
\hline MES0607_ISO_3784 & 77.03 & -28.60 & & -28.27 & 0.05 & -0.33 & -225.37 & 0.41 & -220.07 & 0.39 & -5.30 \\
\hline MES0607_ISO_3785 & 77.04 & -29.18 & & -28.95 & 0.11 & -0.23 & -230.77 & 0.07 & -225.51 & 0.47 & -5.26 \\
\hline MES0607_ISO_3786 & 77.06 & -26.41 & & -26.32 & 0.05 & -0.09 & -206.83 & 0.04 & -202.90 & 0.09 & -3.93 \\
\hline MES0607_ISO_3787 & 77.07 & -27.20 & & -27.13 & 0.08 & -0.07 & -213.64 & 0.72 & -209.06 & 0.24 & -4.58 \\
\hline MES0607_ISO_3788 & 77.08 & -28.70 & & -28.73 & 0.08 & 0.03 & -226.23 & 0.03 & -221.37 & 0.17 & -4.86 \\
\hline MES0607_ISO_3789 & 77.09 & -29.15 & & -29.19 & 0.09 & 0.04 & -229.79 & 0.54 & -224.53 & 0.28 & -5.26 \\
\hline MES0607_ISO_3790 & 77.10 & -27.64 & & -27.73 & 0.04 & 0.10 & -214.15 & 0.81 & -210.26 & 0.17 & -3.88 \\
\hline MES0607_ISO_3791 & 77.11 & -26.19 & & -26.21 & 0.04 & 0.02 & -200.29 & 0.60 & -196.42 & 0.14 & -3.87 \\
\hline MES0607_ISO_3792 & 77.12 & -26.14 & & -25.99 & 0.12 & -0.16 & -198.57 & 0.64 & -195.11 & 1.19 & -3.46 \\
\hline MES0607_ISO_3793 & 77.13 & -26.10 & & -26.13 & 0.09 & 0.03 & -199.46 & 0.26 & -195.86 & 0.25 & -3.60 \\
\hline MES0607_ISO_3794 & 77.15 & -26.44 & & -26.43 & 0.03 & -0.01 & -202.67 & 0.26 & -199.31 & 0.26 & -3.36 \\
\hline MES0607_ISO_3795 & 77.16 & -26.76 & & -26.80 & 0.07 & 0.03 & -206.98 & 0.40 & -202.88 & 0.13 & -4.09 \\
\hline MES0607_ISO_3796 & 77.17 & -26.94 & & -26.94 & 0.05 & -0.01 & -208.08 & 0.38 & -204.47 & 0.09 & -3.60 \\
\hline MES0607_ISO_3797 & 77.18 & -27.45 & & -27.42 & 0.07 & -0.03 & -213.61 & 0.40 & -210.04 & 0.09 & -3.57 \\
\hline MES0607_ISO_3798 & 77.19 & -27.96 & & -27.91 & 0.05 & -0.05 & -218.06 & 0.30 & -215.13 & 0.19 & -2.93 \\
\hline MES0607_ISO_3799 & 77.20 & -28.39 & & -28.47 & 0.07 & 0.08 & -223.11 & 0.51 & -219.43 & 0.11 & -3.68 \\
\hline MES0607_ISO_3800 & 77.21 & -28.71 & & -28.78 & 0.10 & 0.07 & -226.11 & 0.34 & -222.36 & 0.06 & -3.75 \\
\hline MES0607_ISO_3801 & 77.22 & -29.03 & & -29.05 & 0.04 & 0.02 & -228.77 & 1.03 & -225.90 & 0.11 & -2.88 \\
\hline MES0607_ISO_3802 & 77.24 & -29.37 & & -29.23 & 0.01 & -0.14 & -231.76 & 0.04 & -227.79 & 0.12 & -3.97 \\
\hline MES0607_ISO_3803 & 77.25 & -29.47 & & -29.38 & 0.03 & -0.09 & -231.90 & 0.13 & -228.42 & 0.16 & -3.48 \\
\hline MES0607_ISO_3804 & 77.26 & -29.47 & 0.02 & -29.19 & 0.06 & -0.27 & -231.63 & 0.12 & -227.96 & 0.06 & -3.67 \\
\hline MES0607_ISO_3805 & 77.27 & -29.45 & & -29.17 & 0.08 & -0.29 & -229.75 & 0.45 & -227.17 & 0.12 & -2.59 \\
\hline MES0607_ISO_3806 & 77.28 & -28.57 & & -28.26 & 0.07 & -0.31 & -220.80 & 0.65 & -217.47 & 0.09 & -3.33 \\
\hline MES0607_ISO_3807 & 77.29 & -27.43 & & -27.26 & 0.02 & -0.16 & -208.47 & 0.54 & -205.50 & 0.09 & -2.97 \\
\hline MES0607_ISO_3808 & 77.30 & -26.99 & & -26.78 & 0.07 & -0.21 & -201.62 & 0.37 & -199.71 & 0.19 & -1.91 \\
\hline MES0607_ISO_3809 & 77.31 & -26.72 & & -26.61 & 0.02 & -0.10 & -199.76 & 0.28 & -197.12 & 0.11 & -2.64 \\
\hline MES0607_ISO_3810 & 77.33 & -26.50 & & -26.20 & 0.11 & -0.30 & -198.46 & 0.11 & -195.34 & 0.11 & -3.12 \\
\hline MES0607_ISO_3811 & 77.34 & -25.93 & & -25.58 & 0.05 & -0.35 & -193.42 & 0.60 & -189.34 & 0.22 & -4.08 \\
\hline MES0607_ISO_3812 & 77.35 & -25.76 & & -25.57 & 0.12 & -0.19 & -190.99 & 0.06 & -187.09 & 0.97 & -3.90 \\
\hline MES0607_ISO_3813 & 77.36 & -25.79 & & -25.66 & 0.08 & -0.13 & -191.05 & 0.37 & -188.03 & 0.10 & -3.02 \\
\hline MES0607_ISO_3814 & 77.37 & -25.98 & & -25.80 & 0.04 & -0.18 & -193.51 & 0.46 & -190.54 & 0.16 & -2.97 \\
\hline MES0607_ISO_3815 & 77.38 & -26.25 & & -26.10 & 0.07 & -0.15 & -196.64 & 0.49 & -193.48 & 0.07 & -3.16 \\
\hline MES0607_ISO_3816 & 77.39 & -26.45 & & -26.20 & 0.08 & -0.25 & -199.42 & 0.29 & -195.83 & 0.13 & -3.59 \\
\hline MES0607_ISO_3817 & 77.40 & -26.88 & & -26.64 & 0.06 & -0.25 & -203.99 & 0.41 & -200.83 & 0.02 & -3.17 \\
\hline MES0607_ISO_3818 & 77.42 & -27.24 & & -26.96 & 0.09 & -0.28 & -207.90 & 0.18 & -204.39 & 0.12 & -3.50 \\
\hline MES0607_ISO_3819 & 77.43 & -27.63 & & -27.40 & 0.02 & -0.23 & -211.57 & 0.18 & -208.45 & 0.07 & -3.12 \\
\hline MES0607_ISO_3820 & 77.44 & -27.98 & & -27.78 & 0.08 & -0.20 & -214.95 & 0.06 & -212.29 & 0.23 & -2.66 \\
\hline MES0607_ISO_3821 & 77.45 & -28.32 & & -28.25 & 0.10 & -0.07 & -218.76 & 0.66 & -216.33 & 0.13 & -2.43 \\
\hline MES0607_ISO_3822 & 77.46 & -28.84 & & -28.88 & 0.04 & 0.04 & -224.14 & 0.14 & -220.53 & 0.23 & -3.61 \\
\hline MES0607_ISO_3823 & 77.47 & -29.15 & & -29.30 & 0.09 & 0.15 & -227.26 & 0.22 & -223.91 & 0.11 & -3.34 \\
\hline MES0607_ISO_3824 & 77.48 & -29.50 & & -29.55 & 0.06 & 0.05 & -229.59 & 0.14 & -227.15 & 0.02 & -2.44 \\
\hline MES0607_ISO_3825 & 77.49 & -29.85 & & -29.96 & 0.03 & 0.12 & -232.84 & 0.44 & -230.27 & 0.16 & -2.56 \\
\hline MES0607_ISO_3826 & 77.51 & -30.14 & & -30.23 & 0.01 & 0.09 & -236.19 & 0.08 & -233.01 & 0.10 & -3.19 \\
\hline MES0607_ISO_3827 & 77.52 & -30.44 & & -30.45 & 0.03 & 0.01 & -238.09 & 1.06 & -235.37 & 0.26 & -2.72 \\
\hline MES0607_ISO_3828 & 77.53 & -30.68 & & -30.66 & 0.03 & -0.02 & -238.52 & 0.92 & -237.09 & 0.22 & -1.43 \\
\hline MES0607_ISO_3829 & 77.54 & -30.91 & & -30.86 & 0.03 & -0.05 & -242.49 & 0.08 & -239.10 & 0.23 & -3.39 \\
\hline MES0607_ISO_3830 & 77.55 & -31.19 & 0.01 & -31.00 & 0.05 & -0.19 & -244.70 & 0.06 & -240.66 & 0.10 & -4.04 \\
\hline MES0607_ISO_3831 & 77.56 & -31.30 & & -31.15 & 0.08 & -0.15 & -245.83 & 0.16 & -242.05 & 0.14 & -3.78 \\
\hline MES0607_ISO_3832 & 77.57 & -31.37 & & -31.16 & 0.10 & -0.22 & -245.77 & 0.14 & -242.09 & 0.96 & -3.68 \\
\hline MES0607_ISO_3833 & 77.58 & -31.48 & & -31.28 & 0.03 & -0.19 & -247.08 & 0.72 & -242.58 & 0.17 & -4.50 \\
\hline
\end{tabular}

198 


\begin{tabular}{|c|c|c|c|c|c|c|c|c|c|c|c|}
\hline \multirow{2}{*}{$\begin{array}{l}\text { Internal } \\
\text { sample } \\
\text { I.D. }\end{array}$} & \multirow{2}{*}{$\begin{array}{c}\text { Depth } \\
\text { (m) }\end{array}$} & \multirow[b]{2}{*}{$\begin{array}{l}\text { Mass } \\
\text { spec. }\end{array}$} & \multicolumn{3}{|c|}{$\delta^{18} 0(\%)$} & \multirow[b]{2}{*}{$\Delta$} & \multirow[b]{2}{*}{$\begin{array}{l}\text { Mass } \\
\text { spec. }\end{array}$} & \multicolumn{3}{|c|}{$\delta D(\%)$} & \multirow[b]{2}{*}{$\Delta$} \\
\hline & & & $\sigma$ & Laser & $\sigma$ & & & $\sigma$ & Laser & $\sigma$ & \\
\hline MES0607_ISO_3834 & 77.60 & -31.52 & & -31.31 & 0.03 & -0.20 & -246.95 & 0.57 & -242.75 & 0.22 & -4.20 \\
\hline MES0607_ISO_3835 & 77.61 & -31.38 & & -31.31 & 0.10 & -0.06 & -246.60 & 0.29 & -242.15 & 0.13 & -4.45 \\
\hline MES0607_ISO_3836 & 77.62 & -31.28 & & -31.15 & 0.05 & -0.13 & -244.96 & 0.34 & -241.45 & 0.15 & -3.51 \\
\hline MES0607_ISO_3837 & 77.63 & -30.82 & & -30.73 & 0.01 & -0.09 & -242.19 & 0.67 & -238.00 & 0.24 & -4.19 \\
\hline MES0607_ISO_3838 & 77.64 & -27.50 & & -27.32 & 0.06 & -0.18 & -214.57 & 0.25 & -211.46 & 0.05 & -3.11 \\
\hline MES0607_ISO_3839 & 77.65 & -25.09 & & -25.06 & 0.09 & -0.02 & -194.20 & 1.14 & -192.07 & 0.18 & -2.13 \\
\hline MES0607_ISO_3840 & 77.66 & -24.70 & & -24.63 & 0.05 & -0.07 & -190.54 & 0.74 & -188.81 & 0.10 & -1.73 \\
\hline MES0607_ISO_3841 & 77.67 & -24.58 & & -24.54 & 0.01 & -0.04 & -189.59 & 0.54 & -187.84 & 0.15 & -1.75 \\
\hline MES0607_ISO_3842 & 77.69 & -24.51 & & -24.56 & 0.03 & 0.05 & -189.21 & 0.64 & -187.34 & 0.22 & -1.87 \\
\hline MES0607_ISO_3843 & 77.70 & -24.40 & & -24.49 & 0.07 & 0.09 & -188.71 & 0.92 & -186.24 & 0.19 & -2.47 \\
\hline MES0607_ISO_3844 & 77.71 & -23.94 & & -24.10 & 0.08 & 0.16 & -183.85 & 0.17 & -182.00 & 0.17 & -1.85 \\
\hline MES0607_ISO_3845 & 77.72 & -23.76 & & -23.89 & 0.07 & 0.13 & -181.95 & 0.60 & -180.22 & 0.16 & -1.73 \\
\hline MES0607_ISO_3846 & 77.73 & -23.79 & & -23.88 & 0.04 & 0.09 & -181.99 & 0.04 & -179.96 & 0.14 & -2.03 \\
\hline MES0607_ISO_3847 & 77.74 & -23.78 & & -23.84 & 0.08 & 0.06 & -181.75 & 0.36 & -180.09 & 0.02 & -1.65 \\
\hline MES0607_ISO_3848 & 77.75 & -23.89 & & -23.95 & 0.11 & 0.06 & -181.70 & 0.46 & -180.73 & 0.14 & -0.96 \\
\hline MES0607_ISO_3849 & 77.76 & -23.93 & & -23.95 & 0.05 & 0.02 & -183.03 & 0.28 & -181.33 & 0.03 & -1.70 \\
\hline MES0607_ISO_3850 & 77.78 & -23.99 & & -23.94 & 0.10 & -0.04 & -184.31 & 0.19 & -182.03 & 0.11 & -2.28 \\
\hline MES0607_ISO_3851 & 77.79 & -24.12 & & -24.00 & 0.05 & -0.12 & -185.69 & 1.14 & -182.86 & 0.22 & -2.83 \\
\hline MES0607_ISO_3852 & 77.80 & -24.27 & 0.01 & -24.05 & 0.06 & -0.22 & -187.25 & 0.03 & -183.58 & 0.87 & -3.67 \\
\hline MES0607_ISO_3853 & 77.81 & -24.41 & & -24.27 & 0.06 & -0.14 & -188.36 & 0.88 & -185.50 & 0.12 & -2.86 \\
\hline MES0607_ISO_3854 & 77.82 & -24.59 & & -24.48 & 0.06 & -0.11 & -189.40 & 1.03 & -187.44 & 0.06 & -1.96 \\
\hline MES0607_ISO_3855 & 77.83 & -24.76 & & -24.55 & 0.11 & -0.21 & -191.43 & 0.27 & -188.87 & 0.09 & -2.56 \\
\hline MES0607_ISO_3856 & 77.84 & -24.84 & & -24.60 & 0.07 & -0.23 & -192.66 & 0.99 & -189.91 & 0.28 & -2.75 \\
\hline MES0607_ISO_3857 & 77.85 & -25.05 & & -24.84 & 0.10 & -0.21 & -194.38 & 0.21 & -191.58 & 0.11 & -2.80 \\
\hline MES0607_ISO_3858 & 77.87 & -25.17 & & -24.93 & 0.06 & -0.24 & -194.54 & 0.17 & -192.67 & 0.15 & -1.87 \\
\hline MES0607_ISO_3859 & 77.88 & -25.18 & & -25.03 & 0.06 & -0.16 & -195.63 & 0.23 & -193.07 & 0.29 & -2.56 \\
\hline MES0607_ISO_3860 & 77.89 & -25.31 & & -25.26 & 0.09 & -0.05 & -196.12 & 0.09 & -194.05 & 0.15 & -2.07 \\
\hline MES0607_ISO_3861 & 77.90 & -25.39 & & -25.22 & 0.05 & -0.17 & -197.26 & 0.68 & -194.73 & 0.17 & -2.54 \\
\hline MES0607_ISO_3862 & 77.91 & -25.47 & & -25.37 & 0.05 & -0.10 & -197.95 & 0.85 & -195.23 & 0.17 & -2.72 \\
\hline MES0607_ISO_3863 & 77.92 & -25.53 & & -25.51 & 0.06 & -0.02 & -197.24 & 0.22 & -195.76 & 0.14 & -1.48 \\
\hline MES0607_ISO_3864 & 77.93 & -25.56 & & -25.40 & 0.05 & -0.15 & -198.30 & 0.01 & -195.75 & 0.11 & -2.55 \\
\hline MES0607_ISO_3865 & 77.94 & -25.58 & & -25.46 & 0.04 & -0.12 & -197.82 & 0.59 & -195.71 & 0.15 & -2.11 \\
\hline MES0607_ISO_3866 & 77.96 & -25.59 & & -25.39 & 0.07 & -0.21 & -197.79 & 0.02 & -195.16 & 0.25 & -2.64 \\
\hline MES0607_ISO_3867 & 77.97 & -26.07 & & -26.01 & 0.05 & -0.06 & -198.83 & 0.07 & -196.74 & 0.36 & -2.09 \\
\hline MES0607_ISO_3868 & 77.98 & -26.18 & & -26.07 & 0.07 & -0.10 & -198.81 & 0.54 & -197.08 & 0.14 & -1.74 \\
\hline MES0607_ISO_3869 & 77.99 & -26.37 & & -26.28 & 0.05 & -0.10 & -200.98 & 0.13 & -198.55 & 0.20 & -2.43 \\
\hline MES0607_ISO_3870 & 78.00 & -26.67 & & -26.53 & 0.03 & -0.14 & -203.51 & 0.02 & -200.90 & 0.13 & -2.62 \\
\hline MES0607_ISO_3871 & 78.01 & -26.83 & & -26.67 & 0.06 & -0.16 & -206.19 & 0.86 & -202.70 & 0.23 & -3.49 \\
\hline MES0607_ISO_3872 & 78.02 & -27.08 & & -26.84 & 0.05 & -0.24 & -207.54 & 0.62 & -204.31 & 0.99 & -3.23 \\
\hline MES0607_ISO_3873 & 78.04 & -27.17 & & -26.90 & 0.03 & -0.27 & -208.80 & 0.40 & -205.94 & 0.23 & -2.86 \\
\hline MES0607_ISO_3874 & 78.05 & -27.53 & & -27.30 & 0.08 & -0.23 & -212.32 & 0.23 & -209.21 & 0.26 & -3.11 \\
\hline MES0607_ISO_3875 & 78.06 & -27.90 & & -27.77 & 0.06 & -0.13 & -216.18 & 0.47 & -213.18 & 0.03 & -3.01 \\
\hline MES0607_ISO_3876 & 78.07 & -28.26 & & -28.05 & 0.04 & -0.21 & -219.53 & 0.23 & -216.17 & 0.38 & -3.35 \\
\hline MES0607_ISO_3877 & 78.08 & -28.43 & & -28.41 & 0.05 & -0.02 & -220.80 & 0.37 & -218.60 & 0.28 & -2.20 \\
\hline MES0607_ISO_3878 & 78.09 & -28.55 & 0.01 & -28.47 & 0.06 & -0.08 & -221.59 & 0.41 & -219.85 & 0.27 & -1.74 \\
\hline MES0607_ISO_3879 & 78.11 & -28.82 & & -28.66 & 0.06 & -0.16 & -225.00 & 0.65 & -222.43 & 0.33 & -2.57 \\
\hline MES0607_ISO_3880 & 78.12 & -29.06 & & -28.84 & 0.08 & -0.23 & -227.43 & 0.33 & -224.69 & 0.21 & -2.74 \\
\hline MES0607_ISO_3881 & 78.13 & -29.43 & & -29.17 & 0.07 & -0.26 & -229.65 & 0.39 & -227.77 & 0.38 & -1.88 \\
\hline MES0607_ISO_3882 & 78.14 & -29.66 & & -29.57 & 0.09 & -0.09 & -231.81 & 0.60 & -228.78 & 0.25 & -3.02 \\
\hline MES0607_ISO_3883 & 78.15 & -29.68 & & -29.61 & 0.04 & -0.07 & -232.21 & 0.34 & -229.07 & 0.07 & -3.14 \\
\hline MES0607_ISO_3884 & 78.16 & -29.71 & & -29.68 & 0.10 & -0.03 & -232.51 & 0.46 & -229.64 & 0.21 & -2.86 \\
\hline MES0607_ISO_3885 & 78.18 & -29.65 & & -29.58 & 0.10 & -0.07 & -230.73 & 0.06 & -228.39 & 0.18 & -2.34 \\
\hline MES0607_ISO_3886 & 78.19 & -29.57 & & -29.55 & 0.03 & -0.02 & -230.28 & 0.71 & -227.63 & 0.38 & -2.65 \\
\hline MES0607_ISO_3887 & 78.20 & -29.42 & & -29.31 & 0.06 & -0.11 & -226.72 & 0.38 & -225.72 & 0.28 & -1.00 \\
\hline MES0607_ISO_3888 & 78.21 & -28.48 & & -28.44 & 0.10 & -0.04 & -216.71 & 0.12 & -216.04 & 0.09 & -0.66 \\
\hline MES0607_ISO_3889 & 78.22 & -27.83 & & -27.73 & 0.07 & -0.10 & -211.14 & 0.52 & -208.70 & 0.25 & -2.43 \\
\hline MES0607_ISO_3890 & 78.24 & -27.33 & & -27.28 & 0.06 & -0.04 & -205.77 & 0.20 & -203.13 & 0.20 & -2.63 \\
\hline MES0607_ISO_3891 & 78.25 & -26.86 & & -26.75 & 0.05 & -0.11 & -201.15 & 0.37 & -198.47 & 0.25 & -2.67 \\
\hline MES0607_ISO_3892 & 78.26 & -26.29 & & -26.27 & 0.06 & -0.02 & -195.64 & 0.03 & -191.32 & 0.80 & -4.32 \\
\hline
\end{tabular}




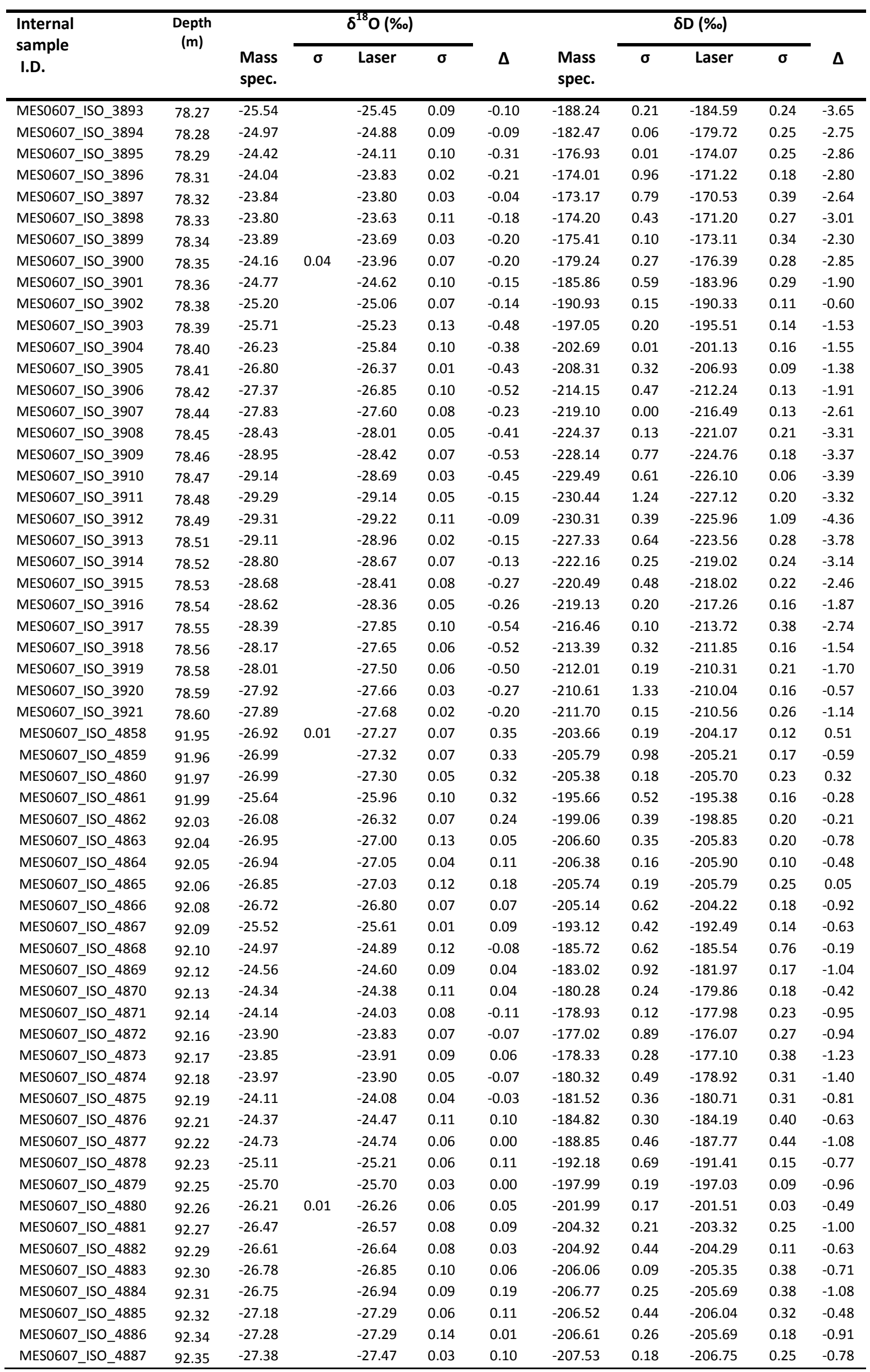




\begin{tabular}{|c|c|c|c|c|c|c|c|c|c|c|c|}
\hline \multirow{2}{*}{$\begin{array}{l}\text { Internal } \\
\text { sample } \\
\text { I.D. }\end{array}$} & \multirow{2}{*}{$\begin{array}{c}\text { Depth } \\
\text { (m) }\end{array}$} & \multirow[b]{2}{*}{$\begin{array}{l}\text { Mass } \\
\text { spec. }\end{array}$} & \multicolumn{3}{|c|}{$\delta^{18} 0(\%)$} & \multirow[b]{2}{*}{$\Delta$} & \multirow[b]{2}{*}{$\begin{array}{l}\text { Mass } \\
\text { spec. }\end{array}$} & \multicolumn{3}{|c|}{$\delta D(\%)$} & \multirow[b]{2}{*}{$\Delta$} \\
\hline & & & $\sigma$ & Laser & $\sigma$ & & & $\sigma$ & Laser & $\sigma$ & \\
\hline MES0607_ISO_4888 & 92.36 & -27.46 & & -27.50 & 0.07 & 0.04 & -206.94 & 0.33 & -206.66 & 0.83 & -0.28 \\
\hline MES0607_ISO_4889 & 92.38 & -27.62 & & -27.94 & 0.02 & 0.32 & -209.30 & 0.00 & -208.31 & 0.16 & -1.00 \\
\hline MES0607_ISO_4890 & 92.39 & -27.79 & & -28.15 & 0.02 & 0.36 & -211.45 & 0.45 & -210.18 & 0.15 & -1.27 \\
\hline MES0607_ISO_4891 & 92.40 & -27.95 & & -28.50 & 0.08 & 0.55 & -213.08 & 0.35 & -212.11 & 0.17 & -0.96 \\
\hline MES0607_ISO_4892 & 92.42 & -28.21 & & -28.71 & 0.07 & 0.50 & -215.40 & 0.77 & -214.41 & 0.15 & -0.99 \\
\hline MES0607_ISO_4893 & 92.43 & -28.47 & & -28.98 & 0.08 & 0.51 & -217.90 & 0.63 & -217.01 & 0.19 & -0.89 \\
\hline MES0607_ISO_4894 & 92.44 & -28.88 & & -29.27 & 0.08 & 0.39 & -221.86 & 0.05 & -221.05 & 0.18 & -0.81 \\
\hline MES0607_ISO_4895 & 92.45 & -29.21 & & -29.65 & 0.05 & 0.44 & -225.54 & 0.02 & -224.36 & 0.19 & -1.18 \\
\hline MES0607_ISO_4896 & 92.47 & -29.95 & & -30.30 & 0.08 & 0.35 & -232.42 & 0.52 & -231.44 & 0.42 & -0.99 \\
\hline MES0607_ISO_4897 & 92.48 & -30.55 & & -30.83 & 0.06 & 0.28 & -238.10 & 0.33 & -237.66 & 0.19 & -0.43 \\
\hline MES0607_ISO_4898 & 92.49 & -30.84 & & -30.85 & 0.11 & 0.01 & -240.33 & 0.39 & -239.12 & 0.17 & -1.22 \\
\hline MES0607_ISO_4899 & 92.51 & -31.18 & & -31.19 & 0.08 & 0.00 & -244.14 & 0.28 & -242.29 & 0.16 & -1.84 \\
\hline MES0607_ISO_4900 & 92.52 & -31.38 & & -31.48 & 0.07 & 0.10 & -246.81 & 0.60 & -244.66 & 0.13 & -2.15 \\
\hline MES0607_ISO_4901 & 92.53 & -31.50 & & -31.69 & 0.14 & 0.20 & -247.19 & 0.48 & -245.77 & 0.21 & -1.43 \\
\hline MES0607_ISO_4902 & 92.55 & -31.51 & & -31.62 & 0.05 & 0.11 & -247.54 & 0.24 & -245.70 & 0.12 & -1.84 \\
\hline MES0607_ISO_4903 & 92.56 & -31.06 & & -31.21 & 0.10 & 0.15 & -243.74 & 0.62 & -241.64 & 0.09 & -2.10 \\
\hline MES0607_ISO_4904 & 92.57 & -29.59 & & -29.80 & 0.15 & 0.21 & -228.95 & 0.40 & -227.62 & 0.17 & -1.33 \\
\hline MES0607_ISO_4905 & 92.58 & -29.09 & & -29.04 & 0.09 & -0.05 & -224.07 & 0.55 & -222.58 & 0.29 & -1.50 \\
\hline Average $=$ & & -27.25 & 0.01 & -27.18 & 0.07 & -0.06 & -209.54 & 0.40 & -207.19 & 0.23 & -2.35 \\
\hline
\end{tabular}




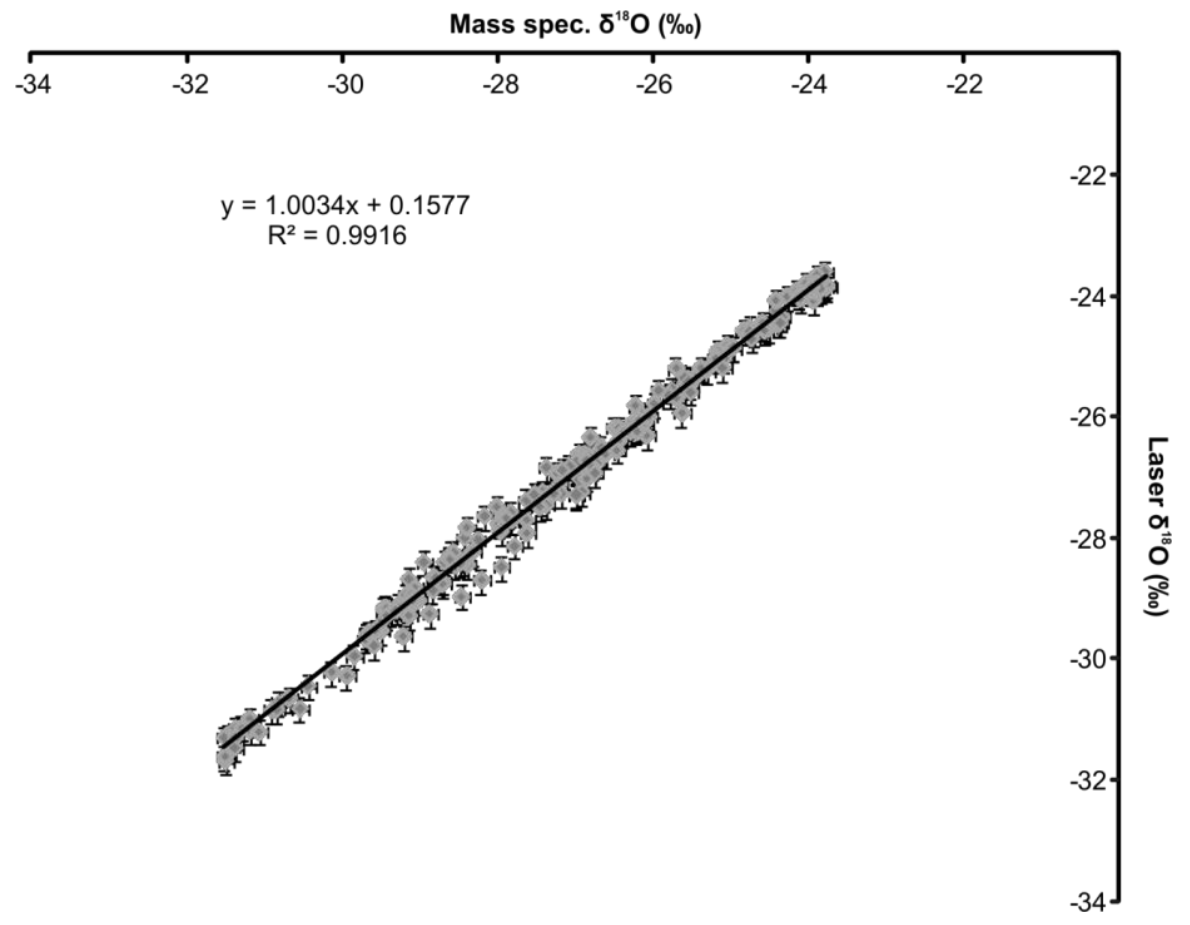

Figure A2: $\delta^{18} \mathrm{O}$ measured on GVI mass spectrometer and LGR Liquid-Water Isotope Analyser (Laser). Error bars are $2 \sigma$.

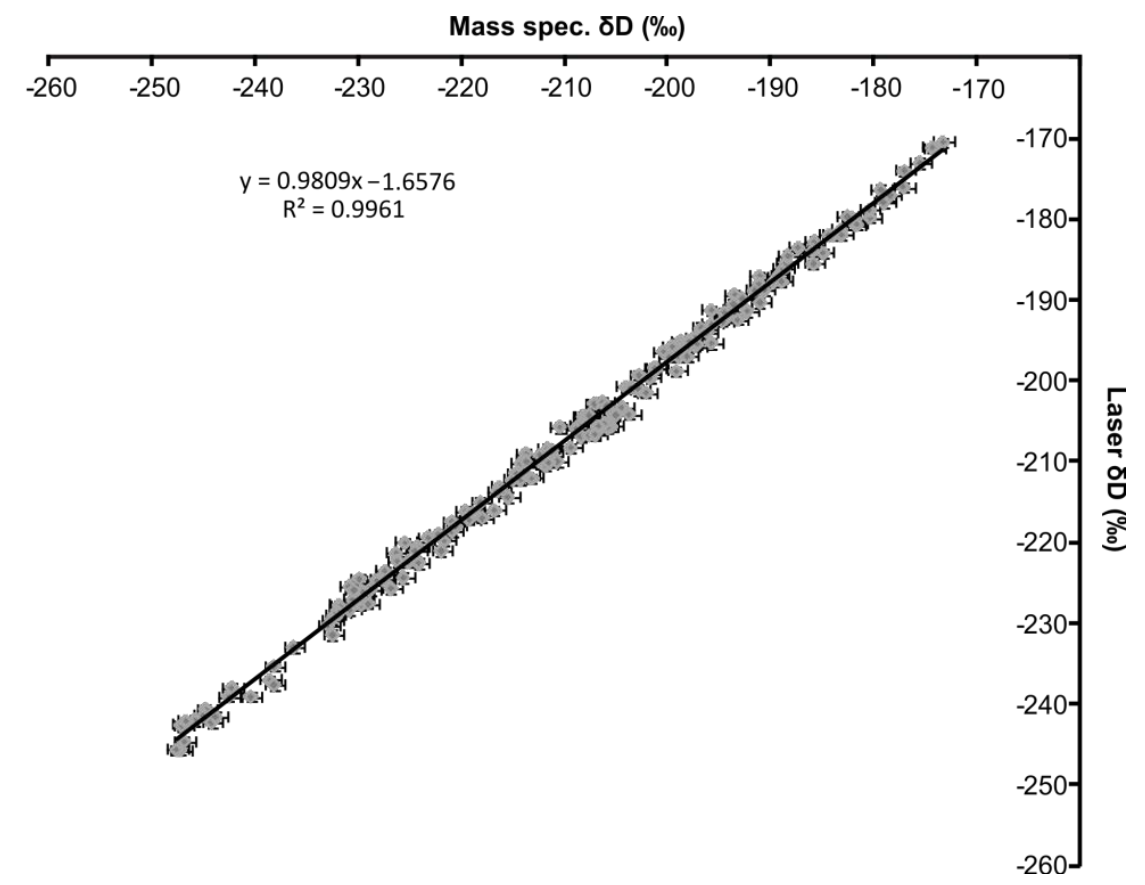

Figure A3: $\delta D$ measured on GVI mass spectrometer and LGR Liquid-Water Isotope Analyser (Laser). Error bars are $2 \sigma$. 


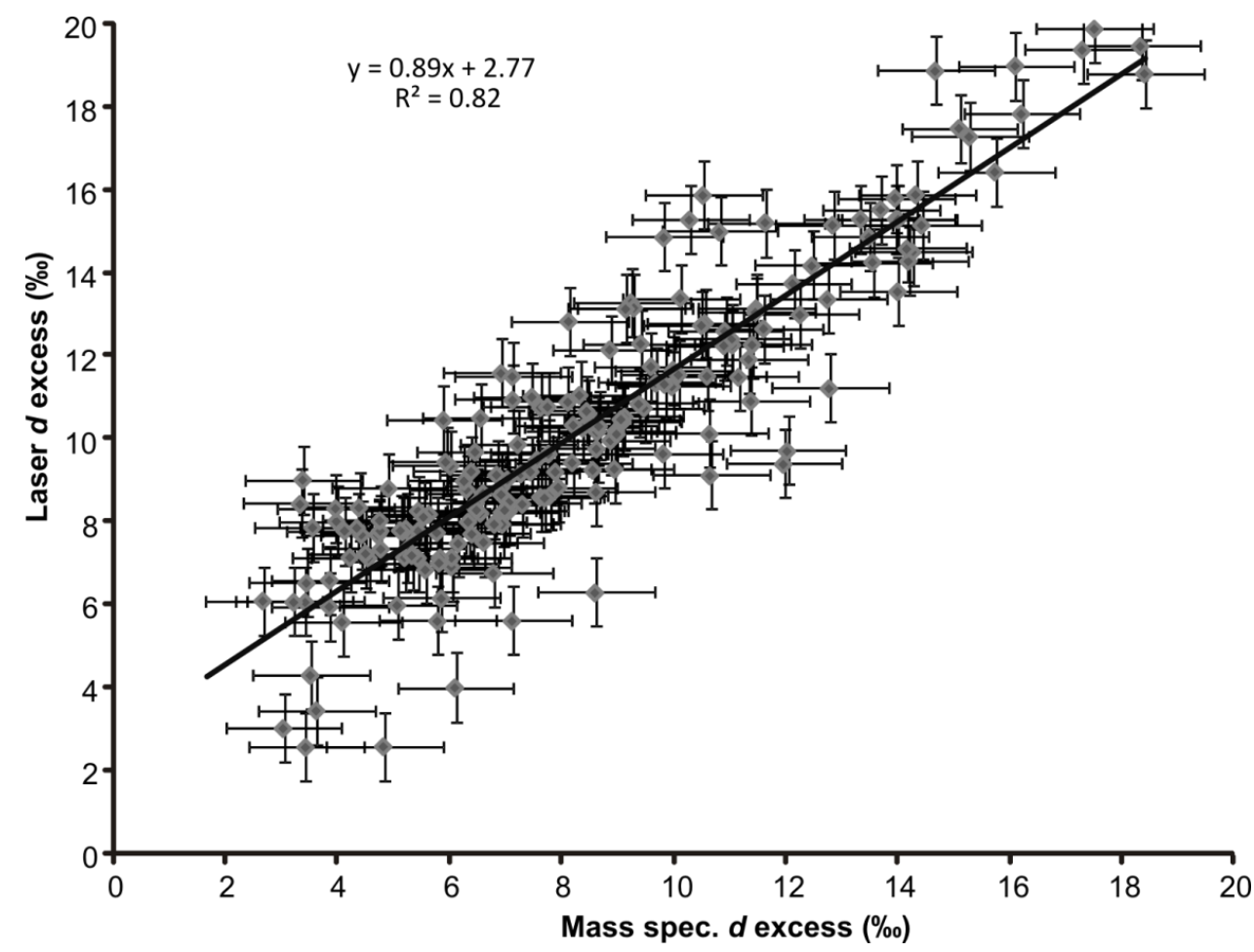

Figure A4: Deuterium excess calculated from $\delta^{18} \mathrm{O}$ and $\delta \mathrm{D}$ values measured on GVI mass spectrometer and LGR Liquid-Water Isotope Analyser (Laser). Error bars are $u$ ( $u=$ analytical uncertainty (Section 4.2.1)). 


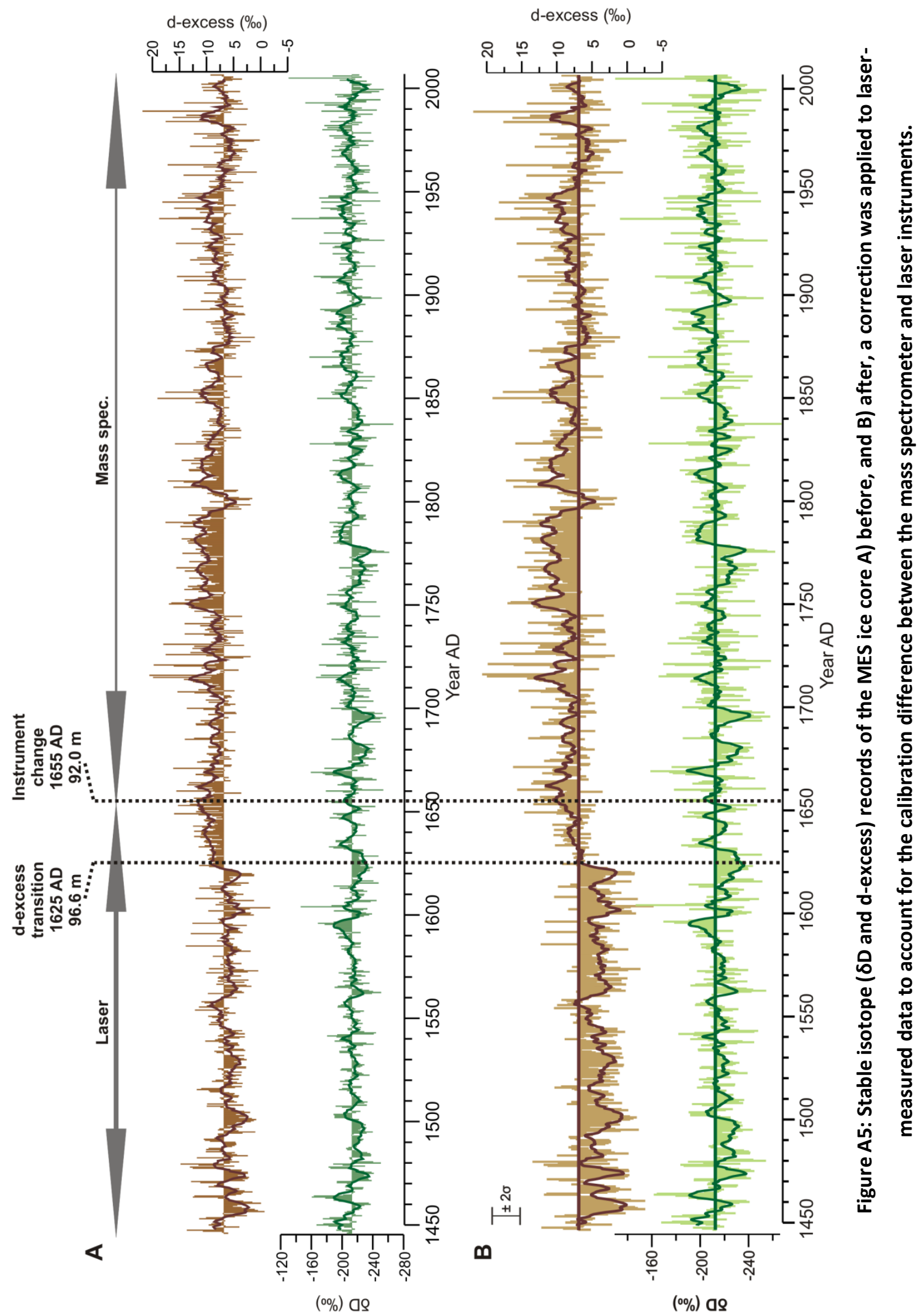




\section{Appendix V: Dansgaard-Johnsen glacial flow model}

A Dansgaard-Johnsen glacial flow model was applied to the MES ice core by HansChristian Steen Larsen from the Center for Ice and Climate, University of Copenhagen. This glacial flow model assumes that the horizontal velocity of the ice at the drill site is constant down to a specified depth. After this depth is exceeded the horizontal velocity decreases linearly with depth because it is attenuated by friction with the bedrock. This makes the Dansgaard-Johnsen glacial model suitable for use on coldbased glaciers which have little basal sliding [Dansgaard and Johnsen, 1969].

The following parameters were input into the model:

Density-depth profile of ice core: Table A15

Site annual temperature: $-25.6^{\circ} \mathrm{C}$

Site elevation: $1600 \mathrm{~m}$ above sea level

Depth to bedrock: $220 \mathrm{~m}$

Annual accumulation rate: $0.252 m\left(\mathrm{H}_{2} \mathrm{O}\right.$ equivalent) $\mathrm{yr}^{-1}$ (1950-2000 mean)

The profile of the annual layer thickness produced takes into account the compression of layers resulting from densification and thinning due to strain (Table A9). The modelled depth-age profile of the MES ice core is provided in Table A10.

Tables $\mathrm{A} 9$ and $\mathrm{A} 10$ are located on the enclosed data disk. 
Appendix VI: Back-diffusion of Mt Erebus Saddle 2006/07 ice core stable isotope ratios

Ice core stable isotopic records are affected by diffusion of water molecules in the firn layer and below the firn-ice transition [Johnsen et al., 2000]. This effectively smoothes the record by filtering out high frequency signals, making annual cycles difficult to identify [Dansgaard et al., 1973]. However, an estimation of the original signal, including high frequencies, can be obtained by back-diffusion or deconvolution, which is the inverse of filtering.

The back-diffusion method of Johnsen et al. [2000] was employed by Hans-Christian Steen Larsen from the Center for Ice and Climate, University of Copenhagen on the MES ice core stable isotopic record. This method takes into account diffusion during the post-depositional processes of densification of snow into firn then ice and also thinning of glacial ice due to strain. It differs from other models because diffusion is assumed to take place in a porous media, as opposed to only the vapour phase, meaning that molecules can diffuse and be re-adsorbed in the pore space. The main effect of this is that diffusion has a greater relative effect on $\delta^{18} \mathrm{O}$ profiles than $\delta D$ profiles, which is in agreement with ice core stable isotope profiles (Johnsen et al., 2000).

Back-diffusion must be performed on evenly spaced data so the raw $\delta^{18} \mathrm{O}$ and $\delta D$ records were re-sampled (Table A11). The diffusion lengths of $\delta^{18} \mathrm{O}$ and $\delta \mathrm{D}$ (Table A12) were calculated using the results of the Dansgaard-Johnsen flow model (Appendix V) [Dansgaard and Johnsen, 1969], because diffusion is temperature sensitive [Johnsen et al. 2000], and a Herron-Langway densification model [Herron and Langway, 1980] (Table A13). The densification model used an initial density of $0.370 \mathrm{~g} \mathrm{~cm}^{-3}$ and a critical density of $550 \mathrm{~g} \mathrm{~cm}^{-3}$, and the parameters $f_{0}$ and $f_{1}$ were respectively scaled by the factors 0.95 and 1.00 . The back-diffused $\delta^{18} \mathrm{O}$ and $\delta \mathrm{D}$ profiles produced are provided in Table A14. An additional set of stable isotopic profiles was produced using the same back-diffusion method but with increased diffusion lengths to aid in the identification of annual layers (Table A15).

Table A11 to A15 are located on the enclosed data disk. 


\section{Appendix VII: Mt Erebus Saddle tritium $\left({ }^{3} \mathrm{H}\right)$ measurements}

${ }^{3} \mathrm{H}$ measurements were carried out at the GNS Science Tritium and Water Dating Laboratory, Lower Hutt, New Zealand (Table A16). Sample depths for ${ }^{3} \mathrm{H}$ analysis were selected according to an early ice core age model based on annual layer counting of raw $\delta^{18} \mathrm{O}$ and $\delta \mathrm{D}$ time series. Once a back-diffused stable isotope time series had been produced the accuracy of the age model improved significantly. For this reason, although the intention was to sample an entire year, often the samples did not incorporate all four seasons. As tritium content is known to show a seasonal cycle in Antarctic ice, with a peak during winter [Jouzel et al., 1979], the bias towards summertime sampling which is shown here could cause the tritium content measured to be depleted relative to the annual average.

Table A16: Six tritium content measurements conducted on samples from selected depths in the ice core.

\begin{tabular}{|c|c|c|c|c|c|c|c|}
\hline Drill Date & $\begin{array}{c}\text { Tritium } \\
\text { content } \\
\text { (TU) }\end{array}$ & $\begin{array}{c}\sigma \\
(\mathrm{TU})\end{array}$ & $\begin{array}{c}\text { Start } \\
\text { depth } \\
\text { (m) }\end{array}$ & $\begin{array}{c}\text { End } \\
\text { depth } \\
(\mathrm{m})\end{array}$ & $\begin{array}{l}\text { Start } \\
\text { year }\end{array}$ & $\begin{array}{l}\text { End } \\
\text { year }\end{array}$ & Months sampled \\
\hline $20 / 12 / 2006$ & 1.87 & 1.86 & 11.0 & 11.2 & 1983.15 & 1983.51 & February to June \\
\hline $20 / 12 / 2006$ & 7.91 & 1.94 & 16.0 & 16.1 & 1971.98 & 1972.18 & December to March \\
\hline $20 / 12 / 2006$ & 8.80 & 1.95 & 17.0 & 17.4 & 1968.89 & 1969.54 & November to July \\
\hline $20 / 12 / 2006$ & 13.21 & 2.01 & 17.9 & 18.2 & 1966.40 & 1967.09 & May to February \\
\hline $20 / 12 / 2006$ & 15.59 & 2.04 & 19.0 & 19.1 & 1964.09 & 1964.36 & February to May \\
\hline $20 / 12 / 2006$ & 3.20 & 1.82 & 21.1 & 21.3 & 1958.90 & 1959.39 & November to May \\
\hline
\end{tabular}

$\mathrm{TU}=$ tritium units; $\sigma=1$ standard deviation 
Appendix VIII: Mt Erebus Saddle 2006/07 ice core density measurements

Density values for each metre-length of core calculated by weighing each section in the field are presented in Table A17. A mean density of $0.382 \mathrm{~g} \mathrm{~cm}^{-3}$ is used in this study for the top metre of snow. This value was produced by dual-energy $x$-ray (DEXA) scanning of the core. 
Table A17: Field density measurements for the MES ice core. Bag number refers to the depth of each metre-length section i.e., Bag number 3 refers to the section of core between 2 and $3 \mathrm{~m}$ core depth.

\begin{tabular}{|c|c|c|c|c|c|}
\hline $\begin{array}{c}\text { Bag } \\
\text { number }\end{array}$ & $\begin{array}{l}\text { Density } \\
\left(\mathrm{g} / \mathrm{cm}^{3}\right)\end{array}$ & $\begin{array}{c}\text { Bag } \\
\text { number }\end{array}$ & $\begin{array}{l}\text { Density } \\
\left(\mathrm{g} / \mathrm{cm}^{3}\right)\end{array}$ & Bag number & $\begin{array}{l}\text { Density } \\
\left(\mathrm{g} / \mathrm{cm}^{3}\right)\end{array}$ \\
\hline 3 & 0.413 & 55 & 0.796 & 107 & 0.877 \\
\hline 4 & 0.442 & 56 & 0.803 & 108 & 0.884 \\
\hline 5 & 0.460 & 57 & 0.781 & 109 & 0.868 \\
\hline 6 & 0.468 & 58 & 0.823 & 110 & 0.874 \\
\hline 7 & 0.496 & 59 & 0.809 & 111 & 0.863 \\
\hline 8 & 0.505 & 60 & 0.814 & 112 & 0.887 \\
\hline 9 & 0.524 & 61 & 0.772 & 113 & 0.877 \\
\hline 10 & 0.523 & 62 & 0.814 & 114 & 0.868 \\
\hline 11 & 0.532 & 63 & 0.841 & 115 & 0.872 \\
\hline 12 & 0.534 & 64 & 0.839 & 116 & $\mathrm{~nm}$ \\
\hline 13 & 0.549 & 65 & 0.791 & 117 & 0.887 \\
\hline 14 & 0.549 & 66 & 0.846 & 118 & 0.865 \\
\hline 15 & 0.565 & 67 & 0.852 & 119 & 0.851 \\
\hline 16 & 0.576 & 68 & 0.845 & 120 & 0.861 \\
\hline 17 & 0.582 & 69 & 0.829 & 121 & 0.879 \\
\hline 18 & 0.586 & 70 & 0.847 & 122 & 0.853 \\
\hline 19 & 0.597 & 71 & $\mathrm{~nm}$ & 123 & 0.875 \\
\hline 20 & 0.611 & 72 & 0.852 & 124 & 0.839 \\
\hline 21 & $\mathrm{~nm}$ & 73 & 0.813 & 125 & $\mathrm{~nm}$ \\
\hline 22 & 0.614 & 74 & 0.819 & 126 & 0.863 \\
\hline 23 & 0.623 & 75 & 0.866 & 127 & 0.864 \\
\hline 24 & 0.612 & 76 & 0.845 & 128 & 0.870 \\
\hline 25 & 0.652 & 77 & 0.858 & 129 & 0.875 \\
\hline 26 & 0.637 & 78 & 0.840 & 130 & 0.868 \\
\hline 27 & 0.635 & 79 & 0.849 & 131 & 0.868 \\
\hline 28 & 0.644 & 80 & 0.860 & 132 & 0.873 \\
\hline 29 & 0.654 & 81 & 0.840 & 133 & 0.870 \\
\hline 30 & $\mathrm{~nm}$ & 82 & 0.871 & 134 & 0.842 \\
\hline 31 & 0.652 & 83 & 0.853 & 135 & 0.859 \\
\hline 32 & 0.667 & 84 & 0.872 & 136 & 0.863 \\
\hline 33 & 0.673 & 85 & 0.872 & 137 & 0.852 \\
\hline 34 & 0.679 & 86 & 0.865 & 138 & 0.852 \\
\hline 35 & 0.681 & 87 & 0.866 & 139 & 0.869 \\
\hline 36 & 0.690 & 88 & 0.861 & 140 & 0.858 \\
\hline 37 & 0.698 & 89 & 0.846 & 141 & 0.844 \\
\hline 38 & 0.701 & 90 & 0.867 & 142 & 0.862 \\
\hline 39 & 0.711 & 91 & 0.856 & 143 & 0.862 \\
\hline 40 & 0.696 & 92 & 0.821 & 144 & 0.834 \\
\hline 41 & 0.716 & 93 & 0.872 & 145 & 0.828 \\
\hline 42 & 0.724 & 94 & 0.870 & 146 & 0.841 \\
\hline 43 & 0.724 & 95 & 0.863 & 147 & 0.787 \\
\hline 44 & 0.730 & 96 & 0.865 & 148 & 0.799 \\
\hline 45 & 0.732 & 97 & 0.877 & 149 & 0.843 \\
\hline 46 & 0.724 & 98 & 0.859 & 150 & 0.811 \\
\hline 47 & 0.745 & 99 & 0.890 & 151 & 0.873 \\
\hline 48 & 0.765 & 100 & 0.859 & 152 & 0.829 \\
\hline 49 & 0.756 & 101 & 0.882 & 153 & 0.829 \\
\hline 50 & 0.764 & 102 & 0.876 & 154 & 0.716 \\
\hline 51 & 0.765 & 103 & 0.883 & 155 & 0.778 \\
\hline 52 & 0.793 & 104 & 0.874 & 156 & 0.710 \\
\hline 53 & 0.787 & 105 & 0.873 & & \\
\hline 54 & 0.788 & 106 & 0.839 & $\mathrm{~nm}=$ not measured & \\
\hline
\end{tabular}




\section{Appendix IX: Supplementary data tables for dust leaching investigation}

Tables A18 to A27 were included as a Supplementary Information section in the submission of the paper "Experimental investigation of the effects of mineral dust on the reproducibility and accuracy of ice core trace element analysis" to Chemical Geology (Chapter 6). Tables A18 to A25 present the trace element concentrations measured in the mineral dust leachates. Tables A18 to A24 include some duplicate leachates measurements. Table A26 contains data relating to procedural blanks and Table A27 contains REE ratios of the leachates. 
Table A18: Concentrations of trace elements (ppt) in leachates of BHVO-2 at 10 ppm dust concentration.

\begin{tabular}{|c|c|c|c|c|c|c|c|c|c|c|c|c|c|c|c|c|c|c|c|c|c|c|c|c|c|c|c|c|c|}
\hline $\begin{array}{c}\text { Acidi- } \\
\text { fcation } \\
\text { time (hr) }\end{array}$ & Li & $\mathrm{Na}$ & $\mathrm{Mg}$ & Al & $\mathrm{Ca}$ & $\mathrm{Ti}$ & v & $\mathrm{Cr}$ & $M n$ & $\mathrm{Cu}$ & $\mathrm{Zn}$ & As & $\mathbf{R b}$ & $\mathrm{Sr}$ & $Y$ & $\mathrm{Zr}$ & Cs & $\mathrm{Ba}$ & La & $\mathrm{Ce}$ & $\mathrm{Pr}$ & Gd & $\mathrm{Er}$ & $\mathrm{Yb}$ & $\mathrm{TI}$ & $\mathrm{Pb}$ & $\mathrm{Bi}$ & Th & u \\
\hline 0.167 & 2.6 & 2000 & 1869 & 6670 & 8539 & 266 & 7.7 & 17.7 & 125.4 & 121.4 & nd & ndS & 0.5 & 52.4 & 32.9 & 13.0 & nd & 15.3 & 31.7 & 75.5 & 10.3 & 8.9 & $\mathrm{~nm}$ & $\mathrm{~nm}$ & ndS & nd & ndS & 1.8 & 0.4 \\
\hline 1 & 4.0 & 2443 & 3779 & 8936 & 14089 & 378 & 9.6 & 20.4 & 187.2 & 169.5 & nd & ndS & 0.6 & 70.4 & 50.1 & 22.3 & nd & 18.9 & 48.2 & 115 & 15.8 & 14.1 & $\mathrm{~nm}$ & $\mathrm{~nm}$ & ndS & nd & ndS & 2.8 & 0.7 \\
\hline 2 & 1.3 & 2887 & 5240 & 11553 & 14397 & 495 & 11.5 & 22.7 & 221.3 & 228.6 & nd & ndS & 0.6 & 84.3 & 52.9 & 26.2 & nd & 21.2 & 50.6 & 122 & 16.5 & 14.9 & $\mathrm{~nm}$ & $\mathrm{~nm}$ & ndS & nd & ndS & 3.0 & 0.8 \\
\hline 4 & 2.2 & 2874 & 7670 & 12928 & 14566 & 599 & 12.2 & 25.5 & 265.5 & 214.2 & nd & ndS & 0.6 & 91.5 & 54.2 & 28.2 & nd & 22.3 & 52.0 & 125 & 16.9 & 14.6 & $\mathrm{~nm}$ & $\mathrm{~nm}$ & ndS & nd & ndS & 3.0 & 0.8 \\
\hline 8 & 5.2 & 4590 & 12598 & 17262 & 18829 & 771 & 15.4 & 31.2 & 349.5 & 249.9 & nd & ndS & 0.8 & 115 & 54.4 & 32.5 & nd & 27.1 & 51.3 & 124 & 16.8 & 15.2 & $\mathrm{~nm}$ & $\mathrm{~nm}$ & ndS & nd & ndS & 3.0 & 0.9 \\
\hline 12 & 3.3 & 4950 & 15194 & 19538 & 19712 & 868 & 16.4 & 32.1 & 383.9 & 258.5 & nd & ndS & 0.8 & 125 & 53.2 & 33.3 & nd & 27.8 & 50.8 & 122 & 16.6 & 14.3 & $\mathrm{~nm}$ & $\mathrm{~nm}$ & ndS & nd & ndS & 3.1 & 0.8 \\
\hline 24 & 3.0 & 6867 & 21797 & 28411 & 25342 & 1176 & 20.0 & 36.7 & 462.9 & 341.9 & nd & ndS & 0.9 & 173 & 52.6 & 38.2 & nd & 34.6 & 50.5 & 121 & 16.5 & 14.5 & $\mathrm{~nm}$ & $\mathrm{~nm}$ & ndS & nd & ndS & 3.1 & 0.8 \\
\hline 36 & 3.7 & 7947 & 26693 & 35022 & 29177 & 1384 & 22.2 & 40.3 & 511.7 & 745.5 & nd & ndS & 0.9 & 208 & 52.2 & 40.2 & nd & 38.7 & 49.9 & 120 & 16.5 & 14.3 & $\mathrm{~nm}$ & $\mathrm{~nm}$ & ndS & nd & ndS & 3.1 & 0.9 \\
\hline 48 & 4.2 & 9489 & 29747 & 41219 & 33255 & 1622 & 25.0 & 46.4 & 549.9 & 313.4 & nd & ndS & 1.0 & 250 & 52.9 & 41.7 & nd & 43.2 & 50.0 & 120 & 16.4 & 14.9 & $\mathrm{~nm}$ & $\mathrm{~nm}$ & ndS & nd & ndS & 3.2 & 0.8 \\
\hline 72 & 3.9 & 11910 & 33673 & 53817 & 39040 & 1979 & 28.6 & 50.6 & 587.3 & 315.7 & nd & ndS & 1.1 & 317 & 52.1 & 44.1 & nd & 52.0 & 49.4 & 119 & 16.1 & 14.7 & $\mathrm{~nm}$ & $\mathrm{~nm}$ & ndS & nd & ndS & 3.0 & 0.8 \\
\hline 120 & 4.3 & 16726 & 38095 & 76806 & 52059 & 2700 & 35.4 & 53.9 & 646.1 & 346.2 & nd & ndS & 1.2 & 445 & 51.9 & 48.3 & nd & 69.3 & 50.1 & 120 & 16.3 & 14.9 & $\mathrm{~nm}$ & $\mathrm{~nm}$ & ndS & nd & ndS & 3.1 & 0.8 \\
\hline 168 & 4.9 & 19558 & 38817 & 91562 & 59598 & 3177 & 39.3 & 56.5 & 660.8 & 346.4 & nd & ndS & 1.2 & 529 & 51.4 & 49.5 & nd & 78.9 & 49.5 & 118 & 16.2 & 15.0 & $\mathrm{~nm}$ & $\mathrm{~nm}$ & ndS & nd & ndS & 3.2 & 0.8 \\
\hline 336 & 10.0 & 27818 & 41066 & 147185 & 89880 & 4921 & 59.0 & $\mathrm{~nm}$ & 773.5 & 406.8 & nd & ndS & 1.5 & 834 & 51.8 & 59.4 & nd & 119.6 & 50.1 & 120 & 16.4 & 14.5 & $\mathrm{~nm}$ & $\mathrm{~nm}$ & ndS & nd & ndS & 3.2 & 0.9 \\
\hline 528 & 5.7 & 42536 & 42005 & 199299 & 118901 & 7460 & 82 & 75 & 841 & 425 & nd & ndS & 2.0 & 1161 & 55.6 & 54.2 & nd & 163 & 53.3 & 128 & 17.5 & 15.1 & $\mathrm{~nm}$ & nd & ndS & nd & ndS & 3.4 & 1.0 \\
\hline 672 & 9.4 & 47737 & 42142 & 222249 & 132413 & 8720 & 95 & 78 & 883 & 433 & nd & ndS & 2.3 & 1304 & 55.6 & 59.1 & nd & 185 & 53.8 & 128 & 17.5 & 14.9 & $\mathrm{~nm}$ & nd & ndS & nd & ndS & 3.3 & 1.0 \\
\hline 1296 & 8.7 & 65953 & 44145 & 295276 & 175479 & 13869 & 146 & 95 & 1117 & 485 & nd & ndS & 2.9 & 1760 & 59.1 & 67.9 & nd & 259 & 57.1 & 135 & 18.3 & 16.8 & $\mathrm{~nm}$ & nd & ndS & nd & ndS & 3.2 & 0.9 \\
\hline 1848 & 11.3 & 77118 & 46190 & 341658 & 201681 & 18157 & 191 & 110 & 1291 & 506 & nd & ndS & 3.5 & 2056 & 62.1 & 88.1 & nd & 309 & 60.2 & 143 & 19.1 & 17.5 & $\mathrm{~nm}$ & nd & ndS & nd & ndS & 3.3 & 1.0 \\
\hline 12 & 2.60 & 4924 & 15124 & 19690 & 19424 & 862 & 16.2 & 29.9 & 378 & 257 & nd & ndS & 0.75 & 125 & 52.3 & 33.3 & nd & 28.2 & 50.2 & 120 & 16.5 & 14.5 & $\mathrm{~nm}$ & $\mathrm{~nm}$ & ndS & nd & ndS & 3.1 & 0.8 \\
\hline 120 & 4.15 & 16705 & 38075 & 77189 & 52051 & 2671 & 35.5 & 55.5 & 643 & 398 & nd & ndS & 1.16 & 446 & 51.9 & 49.0 & nd & 69.2 & 50.0 & 120 & 16.5 & 14.4 & $\mathrm{~nm}$ & $\mathrm{~nm}$ & ndS & nd & ndS & 3.3 & 0.8 \\
\hline
\end{tabular}

$\stackrel{ }{\longmapsto}$ 
Table A19: Concentrations of trace elements (ppt) in leachates of W-2 at $10 \mathrm{ppm}$ dust concentration.

\begin{tabular}{|c|c|c|c|c|c|c|c|c|c|c|c|c|c|c|c|c|c|c|c|c|c|c|c|c|c|c|c|c|c|}
\hline $\begin{array}{l}\text { Acidi- } \\
\text { fication } \\
\text { time(hr) }\end{array}$ & Li & $\mathrm{Na}$ & Mg & Al & $\mathrm{Ca}$ & $\mathrm{Ti}$ & v & $\mathrm{Cr}$ & $M n$ & $\mathrm{Cu}$ & $\mathrm{Zn}$ & As & $\mathbf{R b}$ & $\mathrm{Sr}$ & $Y$ & $\mathrm{Zr}$ & Cs & $\mathrm{Ba}$ & La & $\mathrm{Ce}$ & $\operatorname{Pr}$ & Gd & $\mathrm{Er}$ & $\mathrm{Yb}$ & $\mathrm{Tl}$ & $\mathrm{Pb}$ & $\mathbf{B i}$ & Th & U \\
\hline 0.167 & 8.7 & 6408 & 8288 & 8424 & 31560 & 827 & 46.8 & 9.7 & 179 & 340 & nd & nd & 36.2 & 80.1 & 26.1 & 2.47 & 4.13 & 135 & 39.4 & 80.3 & 9.27 & 7.12 & 2.17 & 1.39 & nd & 35.4 & nd & 4.25 & 0.65 \\
\hline 1 & 11.3 & 6591 & 10726 & 10428 & 32730 & 1106 & 57.9 & 12.2 & 192 & 248 & nd & nd & 41.3 & 92.2 & 26.6 & 2.52 & 4.58 & 152 & 40.4 & 82.4 & 9.50 & 7.03 & 2.19 & 1.40 & nd & 36.8 & nd & 5.40 & 0.71 \\
\hline 2 & 14.0 & 7064 & 11953 & 11653 & 34962 & 1191 & 61.6 & 12.9 & 238 & 255 & nd & nd & 42.3 & 101 & 26.5 & 3.03 & 4.97 & 163 & 40.4 & 82.0 & 9.53 & 7.17 & 2.31 & 1.52 & nd & 37.3 & nd & 5.79 & 0.71 \\
\hline 4 & 13.8 & 8843 & 13081 & 14270 & 40849 & 1225 & 65.3 & 12.6 & 242 & 272 & nd & nd & 42.9 & 124 & 26.5 & 3.23 & 4.77 & 179 & 40.2 & 81.2 & 9.31 & 7.43 & 2.31 & 1.45 & nd & 38.9 & nd & 6.08 & 0.80 \\
\hline 8 & 15.5 & 11172 & 14611 & 17587 & 48435 & 1368 & 73.0 & 17.4 & 355 & 323 & nd & nd & 45.0 & 158 & 27.1 & 4.18 & 5.11 & 201 & 41.1 & 83.2 & 9.61 & 7.17 & 2.20 & 1.33 & 0.36 & 38.2 & nd & 6.54 & 0.82 \\
\hline 12 & 16.9 & 13500 & 16042 & 21434 & 55553 & 1474 & 77.3 & 16.8 & 370 & 320 & nd & nd & 44.6 & 188 & 26.5 & 3.91 & 5.05 & 216 & 40.8 & 82.3 & 9.40 & 7.25 & 2.10 & 1.51 & 0.28 & 38.5 & nd & 6.72 & 0.88 \\
\hline 24 & 19.9 & 18377 & 18472 & 29241 & 70760 & 1719 & 85.7 & 18.4 & 383 & 323 & nd & nd & 44.2 & 253 & 25.8 & 4.17 & 4.97 & 244 & 40.2 & 80.3 & 9.14 & 6.89 & 2.12 & 1.34 & nd & 39.1 & nd & 6.98 & 0.91 \\
\hline 36 & 23.1 & 21367 & 20279 & 33798 & 80563 & 1866 & 92.4 & 19.8 & 403 & 328 & nd & nd & 44.1 & 294 & 25.4 & 4.27 & 4.96 & 261 & 39.8 & 79.6 & 9.07 & 6.79 & 2.17 & 1.39 & nd & 38.3 & nd & 6.93 & 0.95 \\
\hline 48 & 28.1 & 23741 & 21483 & 37537 & 88609 & 2051 & 99.6 & 24.3 & 431 & 341 & nd & nd & 45.5 & 334 & 26.2 & 5.75 & 4.99 & 276 & 40.1 & 79.5 & 9.10 & 6.98 & 2.16 & 1.38 & 0.31 & 37.0 & nd & 6.78 & 0.93 \\
\hline 72 & 33.5 & 29326 & 24623 & 46224 & 107030 & 2333 & 108.7 & 25.9 & 470 & 347 & nd & nd & 45.2 & 403 & 25.7 & 5.80 & 4.93 & 307 & 40.3 & 80.7 & 9.09 & 6.96 & 2.21 & 1.45 & nd & 38.6 & nd & 7.07 & 1.02 \\
\hline 120 & 34.2 & 37141 & 26969 & 57599 & 128250 & 2786 & 124.2 & 29.4 & 527 & 370 & nd & nd & 46.8 & 505 & 26.2 & 6.47 & 5.08 & 357 & 41.6 & 82.4 & 9.42 & 6.97 & 2.22 & 1.42 & nd & 39.9 & nd & 7.43 & 1.03 \\
\hline 168 & 38.3 & 43212 & 28278 & 64399 & 145117 & 3165 & 139.5 & 33.1 & 539 & 406 & nd & nd & 49.7 & 592 & 27.5 & 7.86 & 5.17 & 399 & 43.3 & 85.1 & 9.69 & 6.93 & 2.38 & 1.69 & nd & 40.6 & nd & 7.24 & 1.10 \\
\hline 384 & 22.4 & 62347 & 28781 & 349374 & 188604 & 4106 & 164.7 & 37.6 & 570 & 440 & nd & nd & 53.9 & 805 & 29.4 & 8.43 & 5.28 & 510 & 46.3 & 89.1 & 10.19 & 7.35 & 2.51 & 1.66 & 0.31 & 41.3 & nd & 7.27 & 1.34 \\
\hline 528 & 24.7 & 69483 & 29790 & 385505 & 208959 & 4516 & 179.5 & 39.5 & 609 & 456 & nd & nd & 56.3 & 896 & 30.0 & 9.36 & 5.34 & 560 & 47.8 & 91.1 & 10.51 & 7.70 & 2.61 & 1.91 & 0.39 & 42.0 & nd & 7.34 & 1.35 \\
\hline 672 & 37.9 & 82571 & 31508 & 445465 & 256383 & 5291 & 215.3 & 48.0 & 718 & 487 & nd & nd & 61.8 & 1091 & 31.8 & 13.38 & 5.21 & 679 & 51.1 & 95.0 & 10.66 & 8.31 & 2.83 & 2.12 & 0.41 & 44.7 & nd & 6.89 & 1.31 \\
\hline 1128 & 39.4 & 91016 & 33020 & 481133 & 276823 & 5701 & 243.3 & 56.3 & 798 & 503 & nd & nd & 64.6 & 1186 & 33.1 & 15.66 & 5.01 & 742 & 52.5 & 96.9 & 10.95 & 8.89 & 2.99 & 2.28 & 0.44 & 46.8 & nd & 7.47 & 1.46 \\
\hline 1680 & 37.7 & 70991 & 29887 & 393223 & 226498 & 4672 & 187.3 & 42.1 & 630 & 463 & nd & nd & 58.1 & 966 & 30.2 & 10.72 & 5.36 & 600 & 48.5 & 93.0 & 10.43 & 8.16 & 2.45 & 2.02 & 0.36 & 44.4 & nd & 7.00 & 1.22 \\
\hline 0.167 & 7.6 & 4544 & 7597 & 28239 & 28168 & 733 & 43.3 & 8.74 & 200 & 240 & nd & nd & 35.3 & 66.7 & 25.8 & 2.23 & 4.01 & 126 & 38.8 & 79.1 & 9.19 & 6.92 & 2.24 & 1.36 & 0.17 & 35.0 & nd & 4.10 & 0.6 \\
\hline 4 & 14.5 & 9004 & 13188 & 58001 & 42176 & 1254 & 66.3 & 12.5 & 235 & 270 & nd & nd & 43.2 & 128 & 26.5 & 2.82 & 4.86 & 180 & 40.0 & 81.5 & 9.37 & 7.34 & 2.27 & 1.33 & 0.20 & 38.4 & nd & 6.01 & 0.75 \\
\hline 12 & 18.7 & 13594 & 15952 & 86192 & 55891 & 1457 & 76.2 & 15.5 & 340 & 313 & nd & nd & 43.8 & 188 & 26.0 & 3.57 & 4.99 & 215 & 40.0 & 80.6 & 9.35 & 7.28 & 2.14 & 1.46 & 0.26 & 38.4 & nd & 6.50 & 0.86 \\
\hline 120 & 33.2 & 38276 & 26865 & 230806 & 132434 & 2829 & 125 & 27.5 & 521 & 377 & nd & nd & 47.9 & 520 & 27.0 & 6.64 & 5.12 & 366 & 42.5 & 83.6 & 9.43 & 7.12 & 2.30 & 1.57 & 0.24 & 40.0 & nd & 7.02 & 1.07 \\
\hline
\end{tabular}


Table A20: Concentrations of trace elements (ppt) in leachates of JG-2 at 10 ppm dust concentration.

\begin{tabular}{|c|c|c|c|c|c|c|c|c|c|c|c|c|c|c|c|c|c|c|c|c|c|c|c|c|c|c|c|c|c|}
\hline $\begin{array}{l}\text { Acidi- } \\
\text { fication } \\
\text { time (hr) }\end{array}$ & Li & $\mathrm{Na}$ & $\mathrm{Mg}$ & Al & $\mathrm{Ca}$ & $\mathrm{Ti}$ & v & $\mathrm{Cr}$ & $\mathrm{Mn}$ & $\mathrm{Cu}$ & $\mathrm{Zn}$ & As & $\mathbf{R b}$ & $\mathrm{Sr}$ & $Y$ & $\mathrm{Zr}$ & Cs & $\mathrm{Ba}$ & La & $\mathrm{Ce}$ & $\mathrm{Pr}$ & Gd & $\mathrm{Er}$ & $\mathrm{Yb}$ & TI & $\mathrm{Pb}$ & $\mathrm{Bi}$ & Th & u \\
\hline 0.167 & 106 & 4205 & 2011 & 15424 & 7325 & 647 & 9.7 & nd & 388 & nd & 39.0 & nd & 189 & 21.0 & 345 & 9.2 & 20.7 & 144 & 17.0 & 40.1 & 5.7 & 22.1 & $\mathrm{~nm}$ & $\mathrm{~nm}$ & 1.1 & 44.4 & 7.6 & 50.9 & 33.2 \\
\hline 1 & 131 & 5145 & 2524 & 17638 & 9096 & 764 & 11.8 & nd & 468 & nd & 117.2 & nd & 213 & 23.5 & 417 & 11.9 & 24.8 & 167 & 21.1 & 48.9 & 7.0 & 27.1 & $\mathrm{~nm}$ & $\mathrm{~nm}$ & 1.3 & 68.6 & 8.0 & 60.0 & 36.4 \\
\hline 2 & 141 & 5128 & 2487 & 18221 & 7853 & 806 & 10.2 & nd & 478 & nd & nd & nd & 216 & 20.8 & 435 & 9.5 & 25.4 & 165 & 21.7 & 50.6 & 7.3 & 27.7 & $\mathrm{~nm}$ & $\mathrm{~nm}$ & 1.3 & 38.6 & 7.4 & 63.0 & 37.7 \\
\hline 4 & 147 & 3681 & 2331 & 18654 & 7870 & 841 & 10.9 & nd & 499 & nd & nd & nd & 220 & 20.0 & 454 & 9.5 & 26.8 & 169 & 22.6 & 52.3 & 7.4 & 28.2 & $\mathrm{~nm}$ & $\mathrm{~nm}$ & 1.3 & 39.7 & 7.3 & 68.0 & 39.7 \\
\hline 8 & 155 & 3754 & 2492 & 19653 & 7776 & 880 & 10.5 & nd & 526 & nd & nd & 1.15 & 224 & 20.4 & 455 & 10.3 & 28.0 & 177 & 22.9 & 53.2 & 7.5 & 28.8 & $\mathrm{~nm}$ & $\mathrm{~nm}$ & 1.3 & 39.8 & 7.0 & 72.3 & 42.1 \\
\hline 12 & 157 & 4184 & 2763 & 20219 & 8711 & 901 & 11.7 & nd & 546 & nd & 44.3 & 1.57 & 230 & 21.7 & 458 & 11.4 & 28.7 & 181 & 22.8 & 53.7 & 7.6 & 28.5 & $\mathrm{~nm}$ & $\mathrm{~nm}$ & 1.2 & 38.2 & 6.4 & 73.9 & 41.9 \\
\hline 24 & 170 & 4404 & 2814 & 22014 & 8345 & 932 & 12.6 & nd & 590 & nd & 26.7 & 1.43 & 234 & 21.5 & 447 & 11.6 & 29.3 & 188 & 23.1 & 53.9 & 7.6 & 28.6 & $\mathrm{~nm}$ & $\mathrm{~nm}$ & 1.2 & 39.4 & 6.4 & 81.0 & 45.6 \\
\hline 36 & 180 & 4418 & 3011 & 22998 & 8056 & 963 & 13.1 & nd & 623 & nd & 25.9 & 1.56 & 235 & 21.7 & 442 & 11.1 & 29.5 & 191 & 23.2 & 54.0 & 7.6 & 28.3 & $\mathrm{~nm}$ & $\mathrm{~nm}$ & 1.3 & 38.4 & 6.3 & 84.6 & 46.7 \\
\hline 48 & 184 & 4919 & 3586 & 23961 & 9369 & 890 & 14.5 & nd & 657 & nd & 35.5 & 1.43 & 241 & 23.5 & 440 & 12.6 & 29.5 & 192 & 23.3 & 54.2 & 7.5 & 28.9 & $\mathrm{~nm}$ & $\mathrm{~nm}$ & 1.3 & 41.2 & 6.2 & 86.0 & 46.4 \\
\hline 72 & 187 & 5434 & 3197 & 26194 & 7954 & 921 & 14.6 & nd & 701 & nd & nd & 1.58 & 247 & 22.8 & 438 & 12.0 & 29.6 & 197 & 23.6 & 55.1 & 7.6 & 28.3 & $\mathrm{~nm}$ & $\mathrm{~nm}$ & 1.3 & 39.5 & 6.3 & 92.1 & 48.6 \\
\hline 120 & 197 & 10095 & 5850 & 31069 & 15420 & 935 & 15.5 & nd & 752 & nd & 200.8 & 1.68 & 265 & 30.7 & 440 & 20.3 & 29.7 & 208 & 24.9 & 58.1 & 8.0 & 28.8 & $\mathrm{~nm}$ & $\mathrm{~nm}$ & 1.5 & 43.7 & 6.6 & 102.6 & 52.4 \\
\hline 168 & 199 & 7661 & 3570 & 33109 & 7954 & 929 & 14.7 & nd & 757 & nd & 26.7 & 1.59 & 267 & 23.7 & 432 & 13.0 & 29.3 & 200 & 25.0 & 58.4 & 8.0 & 28.7 & $\mathrm{~nm}$ & $\mathrm{~nm}$ & 1.5 & 41.0 & 6.3 & 105.2 & 53.0 \\
\hline 336 & 211 & 3302 & 3978 & 43467 & 10329 & 1097 & 17.7 & nd & 816 & nd & 70.9 & 2.43 & 317 & 28.0 & 461 & 16.9 & 30.9 & 214 & 29.1 & 67.6 & 9.2 & 29.8 & 29.7 & 37.0 & 1.7 & 46.5 & 6.6 & 122.9 & 55.8 \\
\hline 1296 & 218 & 25949 & 1398 & 80209 & 10744 & 1220 & 19.7 & nd & 827 & nd & 26.5 & 4.77 & 496 & 38.5 & 475 & 21.4 & 33.8 & 243 & 37.6 & 87.1 & 11.5 & 31.9 & 31.5 & 40.9 & 2.7 & 64.0 & 6.9 & 157.8 & 61.6 \\
\hline 1848 & 216 & 32164 & 2381 & 94719 & 15552 & 1272 & 18.0 & nd & 822 & nd & 143.3 & 4.12 & 560 & 45.5 & 466 & 24.7 & 35.1 & 256 & 39.5 & 92.0 & 12.3 & 30.7 & 32.5 & 40.3 & 3.3 & 70.0 & 8.2 & 155.7 & 59.3 \\
\hline 12 & 158 & 4264 & 2408 & 20488 & 7898 & 891 & 11.7 & nd & 542 & nd & 21.6 & 1.65 & 228 & 20.8 & 454 & 11.0 & 28.6 & 180 & 22.8 & 53.6 & 7.5 & 28.2 & $\mathrm{~nm}$ & $\mathrm{~nm}$ & 1.28 & 38.60 & 6.22 & 75.42 & 43.11 \\
\hline 36 & 176 & 4621 & 2885 & 23444 & 8051 & 977 & 13.4 & nd & 630 & nd & 27.2 & 1.81 & 238 & 21.7 & 446 & 11.6 & 29.8 & 193 & 23.2 & 54.8 & 7.67 & 28.3 & $\mathrm{~nm}$ & $\mathrm{~nm}$ & 1.28 & 39.6 & 6.41 & 85.4 & 46.8 \\
\hline
\end{tabular}

$\mathrm{nd}=$ not detected; $\mathrm{nm}=$ not measured 


\begin{tabular}{|c|c|c|c|c|c|c|c|c|c|c|c|c|c|c|c|c|c|c|c|c|c|c|c|c|c|c|c|c|c|}
\hline $\begin{array}{l}\text { Acidi- } \\
\text { fication } \\
\text { time (hr) }\end{array}$ & Li & $\mathrm{Na}$ & Mg & Al & $\mathrm{Ca}$ & $\mathrm{Ti}$ & v & $\mathrm{Cr}$ & $\mathrm{Mn}$ & $\mathrm{Cu}$ & $\mathrm{Zn}$ & As & $\mathbf{R b}$ & Sr & $Y$ & $\mathrm{Zr}$ & Cs & $\mathrm{Ba}$ & La & $\mathrm{Ce}$ & $\mathrm{Pr}$ & Gd & Er & $\mathrm{Yb}$ & TI & $\mathbf{P b}$ & $\mathrm{Bi}$ & Th & U \\
\hline 0.166667 & 954 & 130367 & 56799 & 20606 & 174190 & 2835 & 1147 & 5.9 & 84554 & 45314 & 9095 & 120 & 36.3 & 4611 & 501 & 136 & 1.8 & 6863 & 555 & 612 & 171 & 164 & 67.2 & 59.9 & 2.2 & 200 & 0.21 & 14.6 & 24.9 \\
\hline 1 & 1033 & 129215 & 81243 & 32894 & 180640 & 4444 & 1522 & 8.0 & 95960 & 60989 & 11234 & 144 & 44.1 & 4995 & 579 & 179 & 2.3 & 9772 & 668 & 856 & 205 & 195 & 81.0 & 72.5 & 3.3 & 248 & 0.28 & 19.8 & 28.3 \\
\hline 2 & 1054 & 127882 & 92376 & 40381 & 178997 & 5273 & 1688 & 8.7 & 103987 & 66238 & 11819 & 155 & 47.0 & 5044 & 598 & 209 & 2.6 & 10898 & 695 & 949 & 214 & 203 & 84.6 & 76.1 & 4.1 & 245 & 0.31 & 22.4 & 28.8 \\
\hline 4 & 1068 & 126251 & 103137 & 48923 & 178817 & 6319 & 1866 & 10.0 & 103169 & 71602 & 12509 & 156 & 51.2 & 5112 & 627 & 226 & 2.8 & 12251 & 732 & 1074 & 224 & 212 & 89.2 & 81.2 & 3.8 & 256 & 0.27 & 26.6 & 29.9 \\
\hline 8 & 1083 & 123758 & 112995 & 57904 & 178488 & 7499 & 2058 & 12.0 & 100596 & 76282 & 13125 & 153 & 56.7 & 5204 & 657 & 236 & 3.4 & 13845 & 771 & 1222 & 237 & 223 & 95.0 & 85.8 & 3.1 & 275 & 0.30 & 32.9 & 30.4 \\
\hline 12 & 1086 & 123334 & 118832 & 63683 & 177539 & 8318 & 2184 & 13.4 & 107790 & 78619 & 13454 & 154 & 60.7 & 5200 & 670 & 249 & 3.7 & 14754 & 787 & 1318 & 242 & 228 & 97.6 & 89.2 & 4.1 & 303 & 0.32 & 40.0 & 30.6 \\
\hline 24 & 1066 & 119363 & 122567 & 70077 & 173295 & 9316 & 2307 & 15.6 & 97766 & 79557 & 13428 & 145 & 62.7 & 5079 & 670 & 257 & 3.9 & 15444 & 788 & 1407 & 242 & 228 & 99.0 & 89.9 & 4.4 & 287 & 0.26 & 49.6 & 29.9 \\
\hline 36 & 1040 & 115504 & 123262 & 73310 & 169907 & 9877 & 2339 & 17.7 & 105609 & 78418 & 13367 & 144 & 64.5 & 4917 & 655 & 262 & 4.3 & 15636 & 773 & 1451 & 237 & 225 & 97.1 & 88.4 & 6.6 & 323 & 0.38 & 56.4 & 29.0 \\
\hline 48 & 997 & 111106 & 118220 & 71820 & 161385 & 9859 & 2319 & 18.9 & 98417 & 76521 & 12752 & 143 & 64.2 & 4768 & 638 & 260 & 4.2 & 15382 & 751 & 1439 & 230 & 218 & 96.9 & 88.4 & 5.4 & 303 & 0.42 & 59.3 & 28.3 \\
\hline 72 & 982 & 109738 & 119586 & 75139 & 163107 & 10458 & 2383 & 20.5 & 98560 & 76785 & 12760 & 143 & 67.5 & 4738 & 637 & 264 & 4.5 & 15653 & 753 & 1492 & 229 & 218 & 96.2 & 88.4 & 5.6 & 311 & 0.48 & 65.1 & 27.6 \\
\hline 120 & 983 & 108159 & 121276 & 79866 & 159055 & 11168 & 2442 & 24.2 & 96349 & 77265 & 12732 & 147 & 73.5 & 4692 & 633 & 267 & 5.0 & 15979 & 751 & 1551 & 228 & 219 & 96.4 & 89.2 & 8.6 & 323 & 0.41 & 71.8 & 27.7 \\
\hline 168 & 961 & 106165 & 120680 & 81546 & 155838 & 11398 & 2450 & 27.0 & 101591 & 76723 & 12633 & 153 & 76.8 & 4634 & 627 & 283 & 5.3 & 16004 & 746 & 1563 & 226 & 215 & 96.3 & 89.6 & 17.6 & 322 & 0.75 & 74.3 & 27.4 \\
\hline 384 & 1054 & 108187 & 130294 & 95021 & 156317 & 12334 & 2518 & 32.6 & 121926 & 77405 & 12713 & 162 & 88.5 & 4654 & 630 & 324 & 6.3 & 17282 & 794 & 1730 & 240 & 233 & 103.1 & 99.3 & 11.9 & 385 & 0.50 & 94.9 & 31.6 \\
\hline 528 & 1055 & 107917 & 129451 & 96720 & 155067 & 12270 & 2487 & 33.8 & 111734 & 76820 & 12613 & 158 & 90.6 & 4631 & 629 & 320 & 6.7 & 17436 & 799 & 1762 & 243 & 234 & 103.0 & 100.7 & 7.4 & 362 & 0.38 & 98.1 & 33.0 \\
\hline 672 & 912 & 98147 & 118418 & 91726 & 147439 & 11771 & 2374 & 33.4 & 139041 & 71773 & 11585 & 159 & 84.3 & 4234 & 576 & 314 & 5.8 & 14753 & 689 & 1530 & 209 & 206 & 88.3 & 83.5 & 32.8 & 324 & 1.28 & 78.4 & 25.0 \\
\hline 1128 & 890 & 96813 & 116853 & 96036 & 143871 & 11754 & 2351 & 35.3 & 165479 & 70604 & 11320 & 169 & 87.7 & 4134 & 559 & 348 & 6.2 & 14483 & 672 & 1519 & 203 & 199 & 87.0 & 82.4 & 32.2 & 354 & 1.81 & 78.0 & 24.3 \\
\hline 1680 & 901 & 98307 & 118188 & 101623 & 144467 & 12012 & 2381 & 39.2 & 168812 & 70819 & 11342 & 171 & 91.4 & 4140 & 559 & 397 & 6.0 & 14507 & 667 & 1524 & 203 & 200 & 85.4 & 82.8 & 5.6 & 323 & 1.10 & 79.2 & 23.6 \\
\hline 4 & 1060 & 125933 & 103210 & 49031 & 179333 & 6359 & 1869 & 11.0 & 111308 & 71585 & 12511 & 157 & 51.4 & 5117 & 626 & 235 & 2.87 & 12218 & 730 & 1078 & 224 & 212 & 89.3 & 80.6 & 3.98 & 271 & 0.3 & 26.6 & 29.3 \\
\hline 12 & 1091 & 124167 & 119208 & 63647 & 179852 & 8345 & 2198 & 13.3 & 103853 & 79284 & 13569 & 154 & 60.1 & 5243 & 673 & 250 & 3.7 & 14776 & 790 & 1317 & 243 & 229 & 98.4 & 88.9 & 4.38 & 292 & 0.29 & 38.9 & 30.5 \\
\hline 120 & 972 & 107623 & 120941 & 79467 & 158871 & 11209 & 2436 & 24.1 & 94471 & 76821 & 12713 & 147 & 72.9 & 4667 & 633 & 266 & 5.1 & 15914 & 747 & 1542 & 227 & 216 & 96.2 & 88.8 & 8.85 & 318 & 0.44 & 71.7 & 27.5 \\
\hline
\end{tabular}


Table A22: Concentrations of trace elements (ppt) in leachates of W-2 at $50 \mathrm{ppm}$ dust concentration.

\begin{tabular}{|c|c|c|c|c|c|c|c|c|c|c|c|c|c|c|c|c|c|c|c|c|c|c|c|c|c|c|c|c|c|}
\hline $\begin{array}{l}\text { Acidi- } \\
\text { fication } \\
\text { time(hr) }\end{array}$ & Li & $\mathrm{Na}$ & Mg & Al & $\mathrm{Ca}$ & $\mathrm{Ti}$ & v & $\mathrm{Cr}$ & $\mathrm{Mn}$ & $\mathrm{Cu}$ & $\mathrm{Zn}$ & As & $\mathbf{R b}$ & $\mathrm{Sr}$ & $Y$ & $\mathrm{Zr}$ & Cs & $\mathrm{Ba}$ & La & $\mathrm{Ce}$ & $\mathrm{Pr}$ & Gd & Er & $\mathrm{Yb}$ & TI & $\mathrm{Pb}$ & Bi & Th & u \\
\hline 0.167 & 59.0 & 43002 & 47053 & 249328 & 194228 & 4856 & 265 & $\mathrm{~nm}$ & 1025 & 1251 & 154 & 12.8 & 188 & 575 & 136 & 9.0 & 20.6 & 780 & 210 & 423 & 48.8 & 37.7 & 11.3 & 7.2 & 1.23 & 199 & 0.67 & 23.0 & 3.42 \\
\hline 1 & 66.3 & 40234 & 61154 & 271454 & 203206 & 5982 & 324 & $\mathrm{~nm}$ & 1191 & 1418 & 203 & 13.5 & 218 & 608 & 141 & 9.7 & 23.2 & 887 & 219 & 440 & 51.1 & 39.0 & 11.9 & 7.5 & 1.38 & 214 & 0.75 & 28.4 & 3.81 \\
\hline 2 & 69.2 & 38757 & 64611 & 281270 & 207949 & 6227 & 339 & $\mathrm{~nm}$ & 1217 & 1482 & 218 & 14.5 & 230 & 627 & 143 & 9.4 & 24.6 & 923 & 219 & 443 & 51.5 & 38.7 & 12.0 & 7.5 & 1.38 & 216 & 1.31 & 30.6 & 3.90 \\
\hline 4 & 72.7 & 45207 & 70626 & 334421 & 232960 & 6647 & 364 & $\mathrm{~nm}$ & 1328 & 1535 & 230 & 14.9 & 234 & 733 & 142 & 9.4 & 25.3 & 995 & 218 & 441 & 51.0 & 38.8 & 11.8 & 7.5 & 1.44 & 217 & 0.86 & 31.4 & 4.06 \\
\hline 8 & 82.2 & 65342 & 78425 & 422780 & 282863 & 7289 & 398 & $\mathrm{~nm}$ & 1464 & 1644 & 270 & 16.7 & 241 & 946 & 143 & 9.4 & 26.3 & 1120 & 221 & 444 & 51.3 & 39.1 & 11.9 & 7.7 & 1.44 & 220 & 1.03 & 32.7 & 4.22 \\
\hline 12 & 87.3 & 72366 & 82417 & 475295 & 305220 & 7552 & 411 & $\mathrm{~nm}$ & 1525 & 1656 & 285 & 17.1 & 241 & 1050 & 142 & 9.5 & 26.3 & 1172 & 221 & 445 & 51.0 & 39.4 & 12.0 & 7.9 & 1.42 & 223 & 1.01 & 33.5 & 4.25 \\
\hline 24 & 101 & 91413 & 92726 & 596321 & 367387 & 8474 & 455 & $\mathrm{~nm}$ & 1709 & 1722 & 309 & 18.2 & 248 & 1310 & 144 & 9.8 & 27.0 & 1310 & 226 & 453 & 52.0 & 39.7 & 12.3 & 8.0 & 1.54 & 229 & 1.05 & 34.7 & 4.41 \\
\hline 36 & 115 & 110850 & 102612 & 716683 & 432924 & 9318 & 496 & $\mathrm{~nm}$ & 1886 & 1792 & 350 & 19.3 & 253 & 1581 & 146 & 9.2 & 27.4 & 1439 & 229 & 459 & 52.4 & 40.0 & 12.5 & 8.1 & 1.53 & 231 & 1.05 & 35.3 & 4.64 \\
\hline 48 & 127 & 126782 & 110105 & 812093 & 485329 & 10184 & 529 & $\mathrm{~nm}$ & 2043 & 1885 & 672 & 19.9 & 257 & 1799 & 148 & 10.3 & 27.4 & 1552 & 232 & 464 & 52.8 & 40.1 & 12.6 & 8.3 & 1.63 & 237 & 1.26 & 35.8 & 4.85 \\
\hline 72 & 148 & 156134 & 124030 & 970877 & 562312 & 11520 & 579 & $\mathrm{~nm}$ & 2252 & 1931 & 440 & 20.7 & 260 & 2136 & 149 & 10.4 & 27.4 & 1687 & 236 & 471 & 53.6 & 39.9 & 12.8 & 8.3 & 1.72 & 237 & 0.82 & 36.4 & 5.14 \\
\hline 120 & 179 & 200621 & 141060 & 1227617 & 698976 & 14107 & 670 & $\mathrm{~nm}$ & 2607 & 2049 & 464 & 21.1 & 271 & 2718 & 154 & 11.9 & 28.0 & 1969 & 245 & 487 & 55.3 & 40.7 & 13.6 & 9.1 & 1.70 & 244 & 0.89 & 37.9 & 5.44 \\
\hline 168 & 187 & 230136 & 149055 & 1400123 & 787942 & 15747 & 736 & $\mathrm{~nm}$ & 2849 & 2107 & 482 & 22.6 & 278 & 3082 & 157 & 15.5 & 28.1 & 2148 & 250 & 494 & 56.2 & 41.2 & 13.6 & 8.8 & 1.76 & 247 & 0.89 & 38.5 & 5.81 \\
\hline 336 & 214 & 326756 & 163602 & 1865842 & 1064413 & 19771 & 919 & 206 & 3298 & 2422 & 548 & 27.4 & 312 & 4411 & 175 & 12.1 & 30.8 & 2874 & 283 & 552 & 62.4 & 47.7 & 15.0 & 9.7 & 1.92 & 285 & 1.81 & 43.5 & 6.90 \\
\hline 504 & 227 & 368008 & 170948 & 2082679 & 1186039 & 21815 & 1001 & 224 & 3550 & 2514 & 586 & 27.0 & 324 & 4850 & 178 & 15.6 & 30.7 & 3115 & 289 & 560 & 63.9 & 47.0 & 15.8 & 10.1 & 2.01 & 284 & 2.15 & 42.9 & 7.15 \\
\hline 672 & 218 & 390678 & 169775 & 2165124 & 1229036 & 24848 & 1057 & 237 & 3619 & 2571 & 489 & 25.7 & 326 & 5145 & 177 & 17.1 & 29.2 & 3192 & 281 & 544 & 61.2 & 46.5 & 15.3 & 10.3 & 2.12 & 276 & 1.20 & 37.4 & 6.97 \\
\hline 1104 & 221 & 447514 & 177957 & 2423672 & 1375383 & 28146 & 1214 & 269 & 4041 & 2679 & 496 & 28.7 & 350 & 5872 & 186 & 22.2 & 30.1 & 3648 & 298 & 571 & 64.1 & 48.4 & 16.8 & 11.9 & 2.47 & 285 & 1.27 & 40.4 & 7.44 \\
\hline 1656 & 223 & 492314 & 185689 & 2610496 & 1485990 & 30774 & 1366 & 306 & 4490 & 2776 & 513 & 28.4 & 364 & 6384 & 195 & 32.7 & 30.6 & 4017 & 308 & 587 & 65.6 & 50.9 & 17.8 & 12.4 & 2.40 & 296 & 1.24 & 40.9 & 8.07 \\
\hline 4 & 76.6 & 47640 & 71451 & 89026 & 241493 & 6864 & 370 & $\mathrm{~nm}$ & 1357 & 1550 & 248 & 15.5 & 236 & 785 & 142 & 9.23 & 25.4 & 1023 & 220 & 443 & 50.9 & 38.6 & 11.7 & 7.61 & 1.39 & 219 & 0.83 & 31.9 & 4.11 \\
\hline 12 & 86.3 & 70599 & 81315 & 116163 & 294525 & 7546 & 410 & $\mathrm{~nm}$ & 1511 & 1639 & 272 & 17.3 & 239 & 1035 & 142 & 9.19 & 26.1 & 1166 & 220 & 443 & 50.9 & 38.6 & 12.0 & 7.73 & 1.44 & 221 & 0.97 & 33.2 & 4.32 \\
\hline 168 & 191 & 232083 & 150694 & 353716 & 782176 & 15951 & 740 & $\mathrm{~nm}$ & 2830 & 2132 & 492 & 22.8 & 279 & 3091 & 157 & 14.4 & 28.3 & 2155 & 250 & 494 & 56.2 & 42.1 & 13.3 & 9.06 & 1.88 & 249 & 0.91 & 38.5 & 6.17 \\
\hline
\end{tabular}

$\mathrm{nm}=$ not measured

$\stackrel{N}{v}$ 


\begin{tabular}{|c|c|c|c|c|c|c|c|c|c|c|c|c|c|c|c|c|c|c|c|c|c|c|c|c|c|c|c|c|c|}
\hline $\begin{array}{l}\text { Acidi- } \\
\text { fication } \\
\text { time (hr) }\end{array}$ & Li & $\mathrm{Na}$ & Mg & Al & $\mathrm{Ca}$ & $\mathrm{Ti}$ & v & $\mathrm{Cr}$ & Mn & $\mathrm{Cu}$ & $\mathrm{Zn}$ & As & $\mathbf{R b}$ & $\mathrm{Sr}$ & $\mathbf{Y}$ & $\mathrm{Zr}$ & Cs & $\mathrm{Ba}$ & La & $\mathrm{Ce}$ & $\mathrm{Pr}$ & Gd & Er & $\mathrm{Yb}$ & TI & $\mathrm{Pb}$ & $\mathrm{Bi}$ & Th & u \\
\hline 0.167 & 403 & 241361 & 364062 & 1486963 & 1397446 & 33958 & 2076 & $\mathrm{~nm}$ & 7927 & 10845 & 1364 & 111 & 1584 & 3558 & 1249 & 34.8 & 162 & 6237 & 1919 & 3896 & 451 & 346 & 104 & 64.5 & 10.4 & 1944 & 6.4 & 208 & 30.6 \\
\hline 1 & 547 & 299339 & 518381 & 1980345 & 1652616 & 46808 & 2786 & $\mathrm{~nm}$ & 10974 & 12790 & 1862 & 138 & 1928 & 4456 & 1371 & 33.8 & 186 & 7661 & 2110 & 4284 & 496 & 377 & 115 & 74.8 & 11.6 & 2444 & 7.5 & 276 & 36.1 \\
\hline 2 & 615 & 386816 & 589144 & 2554579 & 1944614 & 53165 & 3093 & $\mathrm{~nm}$ & 12453 & 13629 & 2480 & 149 & 2040 & 5716 & 1392 & 35.3 & 195 & 8633 & 2143 & 4354 & 501 & 384 & 118 & 74.6 & 12.6 & 2511 & 8.5 & 293 & 37.4 \\
\hline 4 & 679 & 471838 & 662021 & 3101405 & 2224540 & 58407 & 3421 & $\mathrm{~nm}$ & 14431 & 14321 & 2260 & 156 & 2131 & 6923 & 1415 & 40.5 & 203 & 9607 & 2178 & 4420 & 506 & 386 & 121 & 75.9 & 12.7 & 2555 & 8.5 & 309 & 38.9 \\
\hline 8 & 754 & 563168 & 730261 & 3767238 & 2572730 & 61489 & 3664 & $\mathrm{~nm}$ & 16204 & 14976 & 2513 & 164 & 2150 & 8385 & 1424 & 32.2 & 206 & 10485 & 2192 & 4439 & 511 & 389 & 120 & 77.4 & 13.1 & 2591 & 8.3 & 321 & 40.0 \\
\hline 12 & 798 & 655977 & 784569 & 4307035 & 2842003 & 65072 & 3938 & $\mathrm{~nm}$ & 17896 & 15408 & 2618 & 173 & 2183 & 9579 & 1429 & 34.2 & 209 & 11072 & 2193 & 4420 & 507 & 384 & 121 & 76.6 & 13.1 & 2552 & 7.9 & 318 & 40.8 \\
\hline 24 & 935 & 864179 & 924658 & 5623643 & 3543918 & 78614 & 4535 & $\mathrm{~nm}$ & 21158 & 16228 & 3015 & 192 & 2264 & 12313 & 1443 & 73.5 & 217 & 12650 & 2233 & 4484 & 515 & 388 & 123 & 80.1 & 14.0 & 2643 & 7.6 & 336 & 43.6 \\
\hline 36 & 1057 & 1046366 & 988728 & 6791888 & 4138624 & 83210 & 4803 & $\mathrm{~nm}$ & 21845 & 16813 & 3278 & 226 & 2297 & 14768 & 1457 & 62.6 & 219 & 13696 & 2258 & 4555 & 520 & 390 & 122 & 79.8 & 14.0 & 2680 & 8.0 & 343 & 46.0 \\
\hline 48 & 1129 & 1150771 & 1038098 & 7440062 & 4456695 & 88236 & 5055 & $\mathrm{~nm}$ & 22855 & 17090 & 3368 & 213 & 2328 & 16184 & 1468 & 50.9 & 221 & 14390 & 2283 & 4584 & 525 & 397 & 125 & 80.9 & 14.4 & 2700 & 8.0 & 352 & 47.6 \\
\hline 72 & 1301 & 1383878 & 1129610 & 8874845 & 5199137 & 94111 & 5343 & $\mathrm{~nm}$ & 24336 & 17515 & 3750 & 219 & 2328 & 19498 & 1463 & 26.3 & 221 & 15713 & 2306 & 4626 & 530 & 397 & 127 & 82.2 & 14.0 & 2755 & 8.4 & 354 & 49.7 \\
\hline 120 & 1618 & 1818801 & 1351232 & 11435366 & 6584822 & 120778 & 6489 & $\mathrm{~nm}$ & 28845 & 18920 & 4379 & 229 & 2457 & 24932 & 1527 & 53.2 & 227 & 18332 & 2403 & 4797 & 549 & 410 & 131 & 87.1 & 15.8 & 2808 & 7.9 & 367 & 54.0 \\
\hline 168 & 1766 & 2073927 & 1412452 & 12895095 & 7314193 & 131249 & 6864 & $\mathrm{~nm}$ & 30119 & 19164 & 4579 & 234 & 2457 & 28093 & 1526 & 50.1 & 226 & 19657 & 2423 & 4809 & 549 & 408 & 132 & 86.2 & 15.8 & 2823 & 8.1 & 374 & 55.4 \\
\hline 336 & 2109 & 2991356 & 1667826 & 17409733 & 10561986 & 170567 & 9089 & 2330 & 36810 & 22531 & 5564 & 271 & 2784 & 39615 & 1698 & 83.6 & 246 & 26054 & 2726 & 5349 & 608 & 454 & 152 & 97.7 & 17.5 & 3142 & 18.7 & 408 & 65.0 \\
\hline 504 & 2206 & 3379704 & 1722474 & 19410920 & 11842108 & 207854 & 10123 & 2551 & 38924 & 23830 & 5516 & 277 & 2935 & 44735 & 1766 & 97.7 & 252 & 28798 & 2828 & 5528 & 626 & 467 & 158 & 103.3 & 18.4 & 3242 & 20.2 & 421 & 69.3 \\
\hline 672 & 2044 & 3402770 & 1589608 & 19295224 & 11029783 & 200642 & 9853 & 2392 & 36550 & 23362 & 4904 & 263 & 2724 & 45530 & 1672 & 57.6 & 235 & 27871 & 2681 & 5208 & 585 & 447 & 149 & 99.1 & 18.3 & 3023 & 12.6 & 366 & 65.6 \\
\hline 1104 & 2120 & 3926980 & 1667805 & 21797024 & 12492536 & 229596 & 11400 & 2733 & 39424 & 24999 & 5079 & 262 & 2847 & 51620 & 1745 & 55.2 & 238 & 31269 & 2799 & 5410 & 607 & 468 & 157 & 107.7 & 20.0 & 3143 & 12.5 & 386 & 72.3 \\
\hline 1656 & 2135 & 4323404 & 1727528 & 23536276 & 13523269 & 250931 & 12891 & 3026 & 42579 & 26241 & 5207 & 272 & 2934 & 56487 & 1824 & 61.5 & 241 & 34199 & 2883 & 5550 & 628 & 477 & 166 & 117.5 & 19.2 & 3194 & 11.8 & 395 & 76.3 \\
\hline 4 & 698 & 502631 & 688233 & 823696 & 2299170 & 63158 & 3608 & $\mathrm{~nm}$ & 15055 & 14420 & 2309 & 158 & 2150 & 7378 & 1419 & 52.5 & 205 & 9898 & 2185 & 4423 & 513 & 388 & 120 & 77.4 & 13.2 & 2573 & 8.28 & 311 & 38.4 \\
\hline 12 & 827 & 702096 & 819051 & 1138137 & 2950371 & 69869 & 4152 & $\mathrm{~nm}$ & 18670 & 15633 & 2673 & 174 & 2222 & 10079 & 1446 & 92.4 & 213 & 11453 & 2219 & 4489 & 515 & 391 & 120 & 78.2 & 13.5 & 2617 & 8.23 & 327 & 40.6 \\
\hline
\end{tabular}

$\mathrm{nm}=$ not measured 
Table A24: Concentrations of trace elements (ppt) in leachate of BHVO-2 after $12 \mathrm{hr}$ acidification following storage under different conditions.

\begin{tabular}{|c|c|c|c|c|c|c|c|c|c|c|c|c|c|c|c|c|c|c|c|c|c|c|c|c|c|c|c|c|c|}
\hline $\begin{array}{l}\text { Dust } \\
\text { concen- } \\
\text { tration } \\
\text { (ppm) }\end{array}$ & $\begin{array}{c}\text { Storage } \\
\text { option }\end{array}$ & Li & $\mathrm{Na}$ & $\mathrm{Mg}$ & Al & $\mathrm{Ca}$ & $\mathrm{Ti}$ & v & $\mathrm{Cr}$ & $\mathrm{Mn}$ & $\mathrm{Cu}$ & As & $\mathbf{R b}$ & $\mathrm{Sr}$ & $Y$ & $\mathrm{Zr}$ & Cs & $\mathrm{Ba}$ & La & $\mathrm{Ce}$ & $\operatorname{Pr}$ & Gd & $\mathrm{Er}$ & $\mathrm{Yb}$ & TI & $\mathrm{Pb}$ & $\mathrm{Bi}$ & Th & U \\
\hline 63.132 & $\mathrm{AF}$ & 14.8 & 27978 & 143363 & 114921 & 118452 & 6219 & 116 & 240 & 2849 & 1638 & ndS & 4.73 & 757 & 322 & 159 & nd & 169 & 307 & 735 & 101 & 89.0 & 29.8 & 21.4 & ndS & nd & ndS & 14.4 & 4.42 \\
\hline 62.055 & $\mathrm{AF}$ & 14.9 & 33269 & 141415 & 119642 & 123000 & 6468 & 120 & 215 & 2769 & 1569 & ndS & 5.46 & 790 & 342 & 172 & nd & 174 & 327 & 785 & 108 & 94.5 & 31.8 & 22.8 & ndS & nd & nds & 16.0 & 5.18 \\
\hline 62.750 & $\mathrm{AF}$ & 14.3 & 27365 & 150301 & 109814 & 114535 & 6155 & 117 & 243 & 3040 & 1660 & ndS & 4.93 & 734 & 333 & 172 & nd & 166 & 319 & 766 & 105 & 91.9 & 31.2 & 23.0 & ndS & nd & ndS & 16.0 & 4.90 \\
\hline 64.757 & UF & 14.4 & 36004 & 101391 & 127462 & 128547 & 5664 & 114 & 184 & 2296 & 1572 & nds & 6.36 & 845 & 351 & 135 & nd & 189 & 337 & 806 & 111 & 96.3 & 33.1 & 23.8 & ndS & nd & nds & 16.9 & 5.05 \\
\hline 64.726 & UF & 15.6 & 45822 & 102258 & 118838 & 135631 & 5128 & 103 & 179 & 2463 & 1495 & nds & 6.81 & 819 & 338 & 128 & nd & 181 & 326 & 779 & 107 & 94.1 & 31.6 & 22.7 & ndS & nd & nds & 16.5 & 4.97 \\
\hline 63.092 & UF & 17.5 & 43324 & 98652 & 117419 & 121154 & 4909 & 103 & 211 & 2360 & 1529 & nds & 6.71 & 787 & 328 & 119 & nd & 173 & 314 & 751 & 103 & 90.0 & 30.4 & 22.0 & ndS & nd & nds & 15.8 & 4.82 \\
\hline 63.664 & $\mathrm{NF}$ & 19.0 & 43318 & 114036 & 136736 & 140444 & 5996 & 116 & 221 & 2583 & 1623 & nds & 6.50 & 901 & 367 & 115 & nd & 196 & 349 & 841 & 115 & 98.8 & 33.8 & 24.2 & ndS & nd & nds & 17.2 & 5.37 \\
\hline 63.080 & $\mathrm{NF}$ & 15.6 & 39749 & 105888 & 128810 & 132560 & 5532 & 107 & 194 & 2467 & 1495 & nds & 6.14 & 849 & 346 & 113 & nd & 188 & 331 & 798 & 109 & 93.4 & 32.3 & 23.2 & ndS & nd & nds & 16.1 & 5.04 \\
\hline 61.906 & NF & 14.3 & 32392 & 110562 & 129515 & 131952 & 5562 & 113 & 227 & 2755 & 1680 & nds & 5.70 & 860 & 350 & 123 & nd & 190 & 335 & 808 & 111 & 94.8 & 32.3 & 23.3 & ndS & nd & nds & 17.1 & 5.02 \\
\hline
\end{tabular}




\begin{tabular}{|c|c|c|c|c|c|c|c|c|c|c|c|c|c|c|c|c|c|c|c|c|c|c|c|c|c|c|c|c|c|c|}
\hline $\begin{array}{c}\text { Dust } \\
\text { concen- } \\
\text { tration }\end{array}$ & $\begin{array}{l}\text { Storage } \\
\text { option }\end{array}$ & Li & $\mathrm{Na}$ & Mg & Al & $\mathrm{Ca}$ & $\mathrm{Ti}$ & v & $\mathrm{Cr}$ & $\mathrm{Mn}$ & $\mathrm{Cu}$ & $Z n$ & As & $\mathbf{R b}$ & Sr & $\mathrm{Y}$ & $\mathrm{Zr}$ & Cs & $\mathrm{Ba}$ & La & $\mathrm{Ce}$ & $\mathrm{Pr}$ & Gd & $\mathrm{Er}$ & $\mathbf{Y b}$ & $\mathrm{TI}$ & $\mathrm{Pb}$ & $\mathrm{Bi}$ & Th & u \\
\hline 63.132 & $\mathrm{AF}$ & 1272 & 35054 & 980 & 174245 & 27917 & 6582 & 100 & nd & 3366 & nd & 74.5 & 11.7 & 1568 & 156 & 3739 & 163.6 & 196 & 1487 & 192 & 446 & 61.8 & 224.1 & 244.0 & 299 & nd & 261 & 46.5 & 953 & 384 \\
\hline 62.055 & $\mathrm{AF}$ & 1296 & 26899 & 973 & 157196 & 23620 & 7018 & 103 & nd & 3498 & nd & 74.5 & 10.9 & 1694 & 139 & 3326 & 133.9 & 225 & 1370 & 181 & 427 & 59.6 & 206.3 & 224.1 & 276 & nd & 281 & 21.5 & 1467 & 459 \\
\hline 62.750 & $\mathrm{AF}$ & 1404 & 28916 & 1018 & 167747 & 34949 & 7300 & 104 & nd & 3773 & nd & 75.3 & 21.1 & 1721 & 146 & 4509 & 180.4 & 229 & 1452 & 207 & 476 & 66.3 & 260.2 & 286.3 & 351 & nd & 273 & 24.7 & 2143 & 428 \\
\hline 64.757 & UF & 931 & 24650 & 1417 & 118643 & 28797 & 5107 & 74 & nd & 2720 & nd & 84.2 & 8.7 & 1362 & 121 & 2621 & 81.9 & 170 & 1188 & 137 & 316 & 44.1 & 166.3 & 168.4 & 210 & nd & 265 & 19.9 & 648 & 287 \\
\hline 64.726 & UF & 1034 & 25743 & 1347 & 127947 & 38840 & 5214 & 129 & nd & 2946 & nd & 86.6 & 9.6 & 1432 & 131 & 3417 & 100.8 & 184 & 1250 & 164 & 381 & 53.7 & 210.2 & 218.0 & 277 & nd & 326 & 26.0 & 624 & 309 \\
\hline 63.092 & UF & 1073 & 28804 & 1190 & 138679 & 35313 & 5664 & 78 & nd & 3115 & nd & 512.3 & 9.7 & 1532 & 149 & 3017 & 97.4 & 207 & 1382 & 159 & 367 & 51.0 & 191.9 & 192.1 & 242 & nd & 268 & 28.1 & 676 & 329 \\
\hline 63.664 & $\mathrm{NF}$ & 983 & 31224 & 1575 & 132273 & 30997 & 5397 & 74 & nd & 2895 & nd & 87.6 & 10.9 & 1411 & 142 & 3242 & 84.4 & 184 & 1364 & 161 & 375 & 52.4 & 204.8 & 208.1 & 262 & nd & 232 & 24.6 & 658 & 391 \\
\hline 63.080 & $\mathrm{NF}$ & 1223 & 27857 & 8826 & 143995 & 53659 & 7056 & 102 & nd & 4089 & nd & 261.4 & 24.5 & 1713 & 142 & 2951 & 91.3 & 204 & 1309 & 155 & 363 & 51.6 & 194.2 & 186.7 & 239 & nd & 360 & 21.9 & 599 & 320 \\
\hline 61.906 & NF & 1196 & 24147 & 6937 & 131116 & 50193 & 7647 & 99 & nd & 3925 & nd & 232.2 & 13.7 & 1510 & 125 & 3278 & 84.4 & 172 & 1157 & 144 & 334 & 47.2 & 196.0 & 197.6 & 259 & nd & 228 & 18.6 & 523 & 308 \\
\hline
\end{tabular}


Table A26: Concentrations of trace elements recorded in freezing experiment procedural blanks (vials containing $8 \mathrm{~mL}$ of ultra-pure water or $1 \% \mathrm{HNO}_{3}$ (Seastar) which were treated as samples).

\begin{tabular}{|c|c|c|c|c|c|c|}
\hline & $\mathrm{H}_{2} \mathrm{O}$ & $\mathrm{H}_{2} \mathrm{O}$ & $\mathrm{H}_{2} \mathrm{O}$ & $\mathrm{HNO}_{3}$ & $\mathrm{HNO}_{3}$ & $\mathrm{HNO}_{3}$ \\
\hline $\mathrm{Li}$ & 0.95 & 0.32 & 0.33 & -0.04 & -0.06 & -0.03 \\
\hline $\mathrm{Na}$ & -216.87 & -127.21 & 2878.78 & -319.96 & -326.02 & -335.10 \\
\hline $\mathrm{Mg}$ & 503.48 & 315.11 & 569.47 & 442.95 & 262.04 & -62.85 \\
\hline $\mathrm{Al}$ & 90.02 & 42.48 & 15.75 & 100.19 & 67.66 & 66.56 \\
\hline $\mathrm{Ca}$ & 696.91 & 275.42 & 2466.22 & 731.32 & -284.79 & 25.04 \\
\hline $\mathrm{Ti}$ & 34.43 & -5.77 & 55.81 & 8.43 & -13.60 & -8.06 \\
\hline V & -0.48 & -0.52 & -0.11 & -0.91 & -1.06 & -0.64 \\
\hline $\mathrm{Cr}$ & 2.50 & 0.94 & 3.31 & -1.07 & -1.84 & 1.37 \\
\hline $\mathrm{Mn}$ & 38.50 & 24.43 & 11.84 & 12.82 & 5.03 & -5.92 \\
\hline $\mathrm{Cu}$ & -0.35 & -0.46 & 20.13 & -4.51 & -4.92 & -2.24 \\
\hline As & ndS & ndS & ndS & ndS & ndS & ndS \\
\hline $\mathrm{Rb}$ & -0.20 & -0.07 & 1.71 & -0.10 & -0.10 & -0.19 \\
\hline $\mathrm{Sr}$ & -0.25 & -0.09 & 6.49 & 0.94 & -0.23 & -0.07 \\
\hline Y & 0.00 & -0.02 & -0.01 & 0.10 & 0.04 & 0.06 \\
\hline $\mathrm{Zr}$ & 0.32 & 0.05 & 0.01 & -0.13 & -0.21 & -0.28 \\
\hline Cs & -0.01 & -0.04 & 0.00 & -0.01 & 0.01 & -0.01 \\
\hline $\mathrm{Ba}$ & 0.22 & 1.94 & -1.19 & -1.40 & -2.41 & -2.12 \\
\hline La & -0.04 & -0.03 & 0.01 & -0.04 & -0.01 & 0.00 \\
\hline $\mathrm{Ce}$ & -0.06 & -0.05 & -0.05 & -0.03 & -0.02 & -0.04 \\
\hline $\mathrm{Pr}$ & 0.00 & 0.00 & 0.02 & 0.01 & 0.00 & -0.01 \\
\hline $\mathrm{Gd}$ & 0.00 & 0.06 & -0.09 & -0.09 & -0.11 & 0.03 \\
\hline $\mathrm{Er}$ & 0.01 & 0.04 & 0.08 & -0.08 & -0.01 & 0.02 \\
\hline $\mathrm{Yb}$ & -0.05 & 0.09 & 0.07 & 0.18 & 0.04 & 0.08 \\
\hline $\mathrm{TI}$ & ndS & ndS & ndS & ndS & ndS & ndS \\
\hline $\mathrm{Pb}$ & -1.23 & -1.21 & 142.50 & 0.25 & 0.18 & -0.07 \\
\hline $\mathrm{Bi}$ & ndS & ndS & ndS & ndS & ndS & ndS \\
\hline Th & -0.07 & -0.06 & -0.14 & -0.16 & -0.16 & -0.12 \\
\hline U & -0.01 & -0.04 & 0.04 & -0.01 & -0.04 & 0.02 \\
\hline
\end{tabular}


Table A27: LREE/MREE and LREE/HREE ratios of BHVO-2, JG-2 and W-2 leachates and rock standards.

Ratios are of chondrite-normalised concentrations. (LREE= light rare earth elements $\mathrm{La}, \mathrm{Ce}, \mathrm{Pr}$;

MREE= medium rare earth elements $\mathrm{Gd}$ ); HREE= heavy rare earth elements $\mathrm{Er}, \mathrm{Gd}$ ).

\begin{tabular}{|c|c|c|c|c|c|}
\hline $\begin{array}{c}\text { Acidification } \\
\text { time (hr) }\end{array}$ & $\begin{array}{c}\text { BHVO-2 } \\
\text { LREE/MREE }\end{array}$ & $\begin{array}{c}\text { JG-2 } \\
\text { LREE/MREE }\end{array}$ & $\begin{array}{c}\text { JG-2 } \\
\text { LREE/HREE }\end{array}$ & $\begin{array}{c}\text { W-2 } \\
\text { LREE/MREE }\end{array}$ & $\begin{array}{c}\text { W-2 } \\
\text { LREE/HREE }\end{array}$ \\
\hline 0.167 & 2.74 & 0.60 & $\mathrm{~nm}$ & 3.70 & 12.3 \\
\hline 1 & 2.65 & 0.60 & $\mathrm{~nm}$ & 3.74 & 11.9 \\
\hline 2 & 2.62 & 0.60 & $\mathrm{~nm}$ & 3.72 & 11.9 \\
\hline 4 & 2.75 & 0.61 & $\mathrm{~nm}$ & 3.75 & 11.9 \\
\hline 8 & 2.62 & 0.61 & $\mathrm{~nm}$ & 3.75 & 11.9 \\
\hline 12 & 2.76 & 0.62 & $\mathrm{~nm}$ & 3.78 & 11.9 \\
\hline 24 & 2.69 & 0.62 & $\mathrm{~nm}$ & 3.81 & 11.8 \\
\hline 36 & 2.71 & 0.63 & $\mathrm{~nm}$ & 3.84 & 12.0 \\
\hline 48 & 2.61 & 0.61 & $\mathrm{~nm}$ & 3.81 & 11.8 \\
\hline 72 & 2.60 & 0.64 & $\mathrm{~nm}$ & 3.85 & 11.7 \\
\hline 120 & 2.59 & 0.66 & $\mathrm{~nm}$ & 3.86 & 11.7 \\
\hline 168 & 2.55 & 0.66 & $\mathrm{~nm}$ & 3.90 & 11.7 \\
\hline 336 & 2.67 & 0.74 & 0.53 & 3.91 & 11.5 \\
\hline 528 & 2.74 & $\mathrm{~nm}$ & $\mathrm{~nm}$ & 3.94 & 11.3 \\
\hline 672 & 2.77 & $\mathrm{~nm}$ & $\mathrm{~nm}$ & 3.88 & 11.3 \\
\hline 1104 & $\mathrm{~nm}$ & $\mathrm{~nm}$ & $\mathrm{~nm}$ & 3.85 & 11.0 \\
\hline 1296 & 2.60 & 0.88 & 0.63 & $\mathrm{~nm}$ & $\mathrm{~nm}$ \\
\hline 1656 & $\mathrm{~nm}$ & $\mathrm{~nm}$ & $\mathrm{~nm}$ & 3.89 & 10.6 \\
\hline 1848 & 2.62 & 0.97 & 0.66 & $\mathrm{~nm}$ & $\mathrm{~nm}$ \\
\hline Rock standard & 1.94 & 1.81 & 1.59 & 1.79 & 2.48 \\
\hline
\end{tabular}




\section{Appendix X: Antarctic Little Ice Age climate}

In order to rapidly consider the Little Ice Age climate record, developed from the MES ice core, in the context of that of the entire Antarctic continent, a graphical summary of the available paleoclimate data is displayed (Fig. A6). 

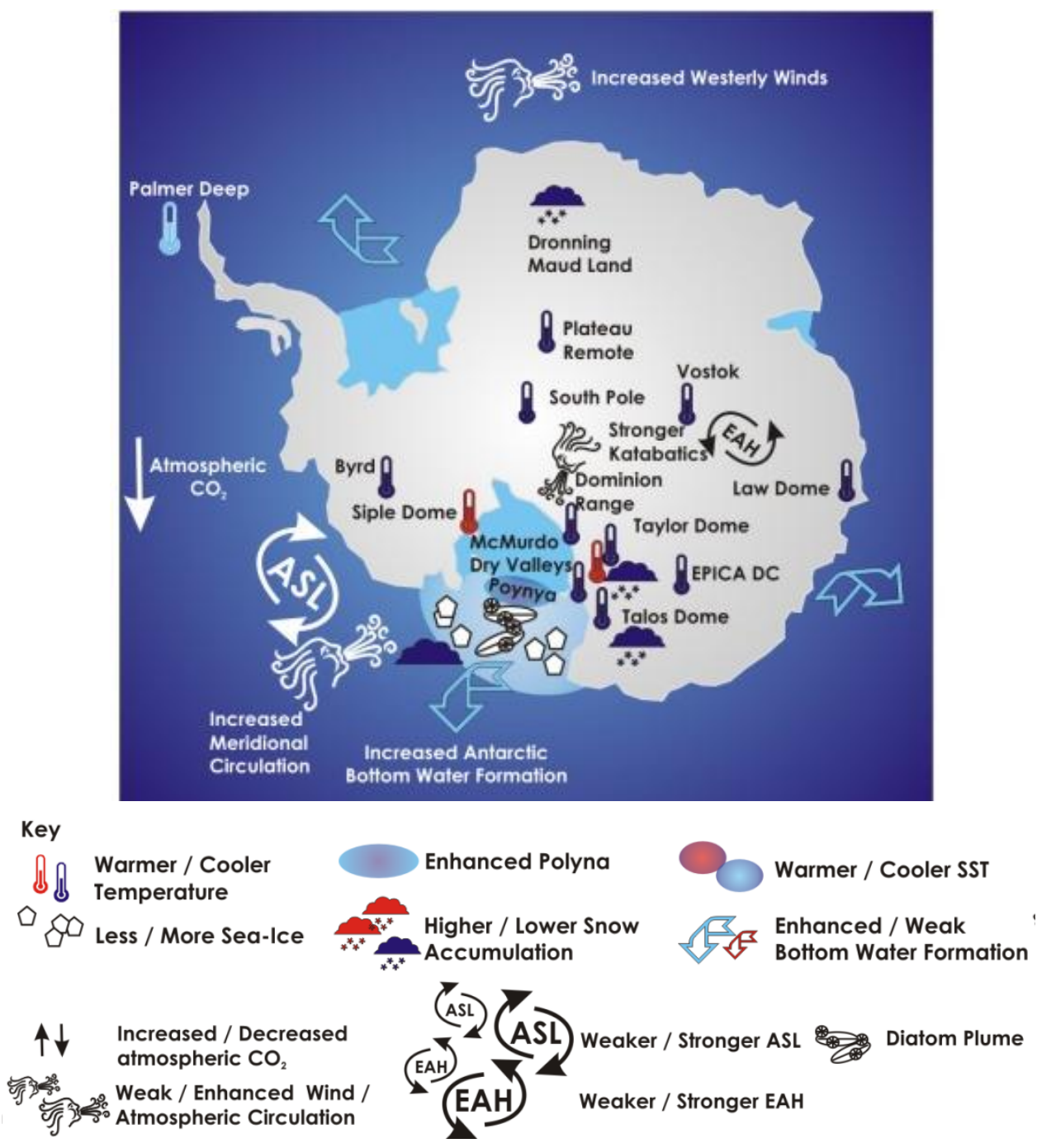

Figure A6: Summary of conditions across Antarctica during the Little Ice Age (modified after Bertler et al. [in press]). Datasets included are: McMurdo Dry Valleys temperature, Ross Sea sea surface temperature (SST), humidity, and sea-ice extent from ice core records [Bertler et al., in press]; temperature data for Law Dome, Dome C, Vostok, Dominion Range, Byrd, and Plateau Remote from stable isotopic records [Masson et al., 2000]; temperature data for Talos Dome, EPICA Dome C, South Pole, and Taylor Dome from stable isotopic records and snow accumulation data for Talos Dome [Stenni et al., 2002]; temperature data from Taylor Dome borehole measurements referred to by Broecker [2000]; Antarctic Bottom Water formation rates [Broecker, 2000]; katabatic flow, diatom plume, polyna size, and sea ice from diatom data [Leventer and Dunbar, 1988]; Amundsen Sea Low strength from geochemical ice core data [Kreutz et al., 2000]; East Antarctic High from geochemical ice core data [Mayewski et al., 2004]; Southern Hemisphere Westerlies from geochemical ice core data [Yan et al., 2005]; SST from magnetic susceptibility at Palmer Deep [Domack and Mayewski, 1999]; snow accumulation data for Dronning Maud Land [Karlöf et al., 2000]; and atmospheric $\mathrm{CO}_{2}$ concentration [Etheridge et al., 1996; Indermuhle et al., 1999]. 


\section{Appendix XI: Mt Erebus Saddle 2006/07 soluble chemistry data}

Concentration data for the elements $\mathrm{Na}, \mathrm{Mg}, \mathrm{Al}, \mathrm{Ca}, \mathrm{Ti}, \mathrm{V}, \mathrm{Mn}, \mathrm{As}, \mathrm{Rb}, \mathrm{Sr}, \mathrm{Y}, \mathrm{Zr}, \mathrm{Cs}, \mathrm{Ba}$, La, $\mathrm{Ce}, \mathrm{Pr}, \mathrm{TI}, \mathrm{Pb}, \mathrm{Bi}$, Th and $\mathrm{U}$ for all the ice core samples analysed by ICP-MS are provided in Table A28. A small batch of samples were analysed by ICP-MS in collision cell mode using a hydrogen-flushed collision cell to remove polyatomic interferences. Concentration data for the elements $\mathrm{Na}, \mathrm{Mg}, \mathrm{Al}, \mathrm{Ca}, \mathrm{Mn}, \mathrm{Fe}$ and $\mathrm{Ba}$ for these samples are provided in Table A29.

The major ion data for all ice core samples analysed by IC at the University of Maine are provided in Table A30. Concentrations of $\mathrm{Na}^{+}$and $\mathrm{Mg}^{2+}$ determined by IC were compared to the $\mathrm{Na}$ and $\mathrm{Mg}$ concentrations determined in corresponding samples by ICP-MS and significant discrepancies were found. Approximately $5 \%$ of the samples analysed by IC showed anomalously high concentrations of $\mathrm{Na}^{+}$and $\mathrm{Mg}^{2+}$ and were also characterised by high concentrations of all the other cations and anions measured (Figure A7A). One possible cause of these anomalous data points is that air may have been drawn into the chromatograph during sample uptake. Once these data points were removed, the $\mathrm{Na}^{+}$ record determined by IC and the Na record determined by ICP-MS corresponded well (Figure A7B) and showed a strong positive correlation $\left(R^{2}=0.69\right)$. The major ion dataset with the anomalous values removed is displayed in Table A31.

Tables A28 to A31 are located on the enclosed data disk. 


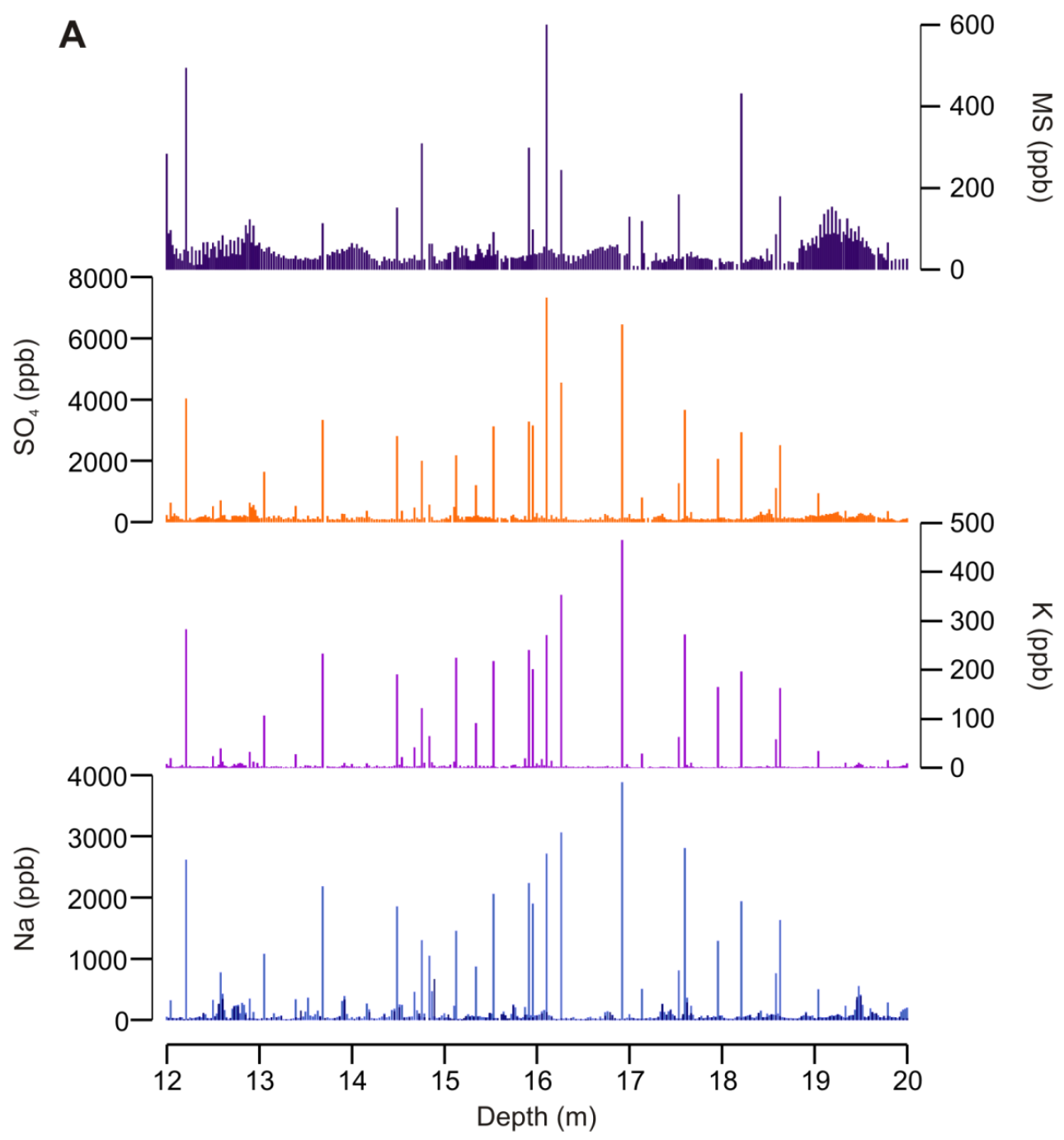

B

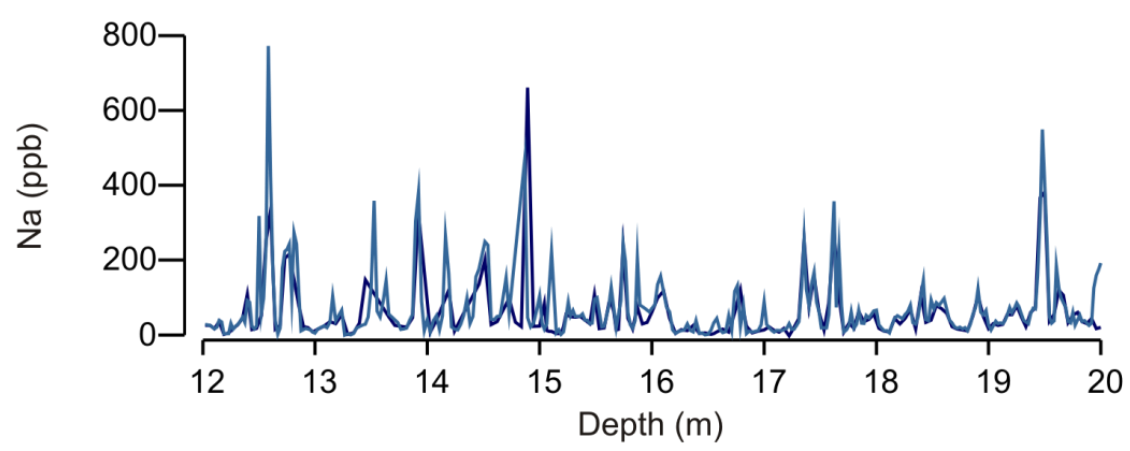

Figure A7: Identification and removal of anomalous IC data points. (A) Data for all cations ( $\mathrm{Na}^{+}$and $\mathrm{K}^{+}$shown) and anions ( $\mathrm{SO}_{4}{ }^{2-}$ and $\mathrm{MS}^{-}$shown) exhibit anomalously high concentrations determined by IC on several samples throughout the MES record. The segment from 12 to $20 \mathrm{~m}$ depth is displayed here to illustrate this. Comparison of the Na record determined by IC (light blue) with that determined by ICP-MS (dark blue) suggests that the concentrations determined by IC on these samples are unreliable. (B) Removal of the IC data for these samples results in an IC Na record similar to the ICP-MS Na record. 


\section{Appendix XII: Mt Erebus Saddle ice core age model}

The results of the annual layer count are provided here in Table A32. The depth at which $\delta D$ occurs in each annual cycle dates to January $1^{\text {st }}$. Below $110 \mathrm{~m}$ depth the age-depth relationship produced by the polynomial extrapolation of the annual layer count is given. This age model can be applied to any of the stable isotope or soluble chemistry parameters displayed in Tables A6, A14 and A28 to A21 by using an interpolation function. As the ice core age model could be subject to improvement in the future, age is not included in the raw data tables. 
Table A32: MES ice core age model.

\begin{tabular}{|c|c|c|c|c|c|c|c|}
\hline $\begin{array}{l}\text { Age } \\
\text { (yr) }\end{array}$ & $\begin{array}{c}\text { Depth } \\
\text { (m) }\end{array}$ & $\begin{array}{l}\text { Age } \\
\text { (yr) }\end{array}$ & $\begin{array}{c}\text { Depth } \\
\text { (m) }\end{array}$ & $\begin{array}{l}\text { Age } \\
\text { (yr) }\end{array}$ & $\begin{array}{c}\text { Depth } \\
\text { (m) }\end{array}$ & $\begin{array}{l}\text { Age } \\
\text { (yr) }\end{array}$ & $\begin{array}{c}\text { Depth } \\
\text { (m) }\end{array}$ \\
\hline 2007 & 0.00 & 1964 & 19.14 & 1921 & 33.42 & 1878 & 45.66 \\
\hline 2006 & 0.40 & 1963 & 19.48 & 1920 & 33.83 & 1877 & 46.00 \\
\hline 2005 & 0.96 & 1962 & 20.02 & 1919 & 34.19 & 1876 & 46.20 \\
\hline 2004 & 1.73 & 1961 & 20.48 & 1918 & 34.48 & 1875 & 46.48 \\
\hline 2003 & 2.21 & 1960 & 20.86 & 1917 & 34.88 & 1874 & 46.72 \\
\hline 2002 & 2.91 & 1959 & 21.27 & 1916 & 35.15 & 1873 & 46.98 \\
\hline 2001 & 3.23 & 1958 & 21.63 & 1915 & 35.52 & 1872 & 47.15 \\
\hline 2000 & 3.69 & 1957 & 21.97 & 1914 & 35.84 & 1871 & 47.44 \\
\hline 1999 & 4.12 & 1956 & 22.20 & 1913 & 36.10 & 1870 & 47.67 \\
\hline 1998 & 4.59 & 1955 & 22.56 & 1912 & 36.43 & 1869 & 47.97 \\
\hline 1997 & 5.00 & 1954 & 23.05 & 1911 & 36.71 & 1868 & 48.22 \\
\hline 1996 & 5.48 & 1953 & 23.30 & 1910 & 37.01 & 1867 & 48.48 \\
\hline 1995 & 5.98 & 1952 & 23.57 & 1909 & 37.41 & 1866 & 48.87 \\
\hline 1994 & 6.64 & 1951 & 23.90 & 1908 & 37.63 & 1865 & 49.11 \\
\hline 1993 & 7.16 & 1950 & 24.23 & 1907 & 37.92 & 1864 & 49.51 \\
\hline 1992 & 7.63 & 1949 & 24.65 & 1906 & 38.25 & 1863 & 49.78 \\
\hline 1991 & 7.93 & 1948 & 24.98 & 1905 & 38.52 & 1862 & 50.08 \\
\hline 1990 & 8.22 & 1947 & 25.23 & 1904 & 38.81 & 1861 & 50.24 \\
\hline 1989 & 8.79 & 1946 & 25.59 & 1903 & 39.03 & 1860 & 50.61 \\
\hline 1988 & 9.11 & 1945 & 25.98 & 1902 & 39.25 & 1859 & 50.88 \\
\hline 1987 & 9.47 & 1944 & 26.21 & 1901 & 39.45 & 1858 & 51.23 \\
\hline 1986 & 9.99 & 1943 & 26.43 & 1900 & 39.79 & 1857 & 51.44 \\
\hline 1985 & 10.38 & 1942 & 26.72 & 1899 & 40.06 & 1856 & 51.67 \\
\hline 1984 & 10.72 & 1941 & 26.97 & 1898 & 40.48 & 1855 & 51.99 \\
\hline 1983 & 11.29 & 1940 & 27.27 & 1897 & 40.76 & 1854 & 52.27 \\
\hline 1982 & 11.74 & 1939 & 27.72 & 1896 & 40.99 & 1853 & 52.61 \\
\hline 1981 & 12.18 & 1938 & 28.03 & 1895 & 41.26 & 1852 & 52.84 \\
\hline 1980 & 12.88 & 1937 & 28.30 & 1894 & 41.51 & 1851 & 53.05 \\
\hline 1979 & 13.19 & 1936 & 28.69 & 1893 & 41.81 & 1850 & 53.30 \\
\hline 1978 & 13.62 & 1935 & 28.90 & 1892 & 42.03 & 1849 & 53.55 \\
\hline 1977 & 13.94 & 1934 & 29.33 & 1891 & 42.34 & 1848 & 53.71 \\
\hline 1976 & 14.46 & 1933 & 29.64 & 1890 & 42.74 & 1847 & 53.96 \\
\hline 1975 & 14.80 & 1932 & 30.00 & 1889 & 42.90 & 1846 & 54.13 \\
\hline 1974 & 15.14 & 1931 & 30.27 & 1888 & 43.20 & 1845 & 54.33 \\
\hline 1973 & 15.55 & 1930 & 30.60 & 1887 & 43.42 & 1844 & 54.51 \\
\hline 1972 & 16.10 & 1929 & 30.94 & 1886 & 43.68 & 1843 & 54.75 \\
\hline 1971 & 16.49 & 1928 & 31.25 & 1885 & 43.95 & 1842 & 54.95 \\
\hline 1970 & 16.76 & 1927 & 31.58 & 1884 & 44.23 & 1841 & 55.20 \\
\hline 1969 & 17.37 & 1926 & 31.99 & 1883 & 44.44 & 1840 & 55.40 \\
\hline 1968 & 17.65 & 1925 & 32.30 & 1882 & 44.77 & 1839 & 55.69 \\
\hline 1967 & 17.94 & 1924 & 32.72 & 1881 & 45.04 & 1838 & 55.91 \\
\hline 1966 & 18.39 & 1923 & 32.90 & 1880 & 45.19 & 1837 & 56.18 \\
\hline 1965 & 18.75 & 1922 & 33.13 & 1879 & 45.46 & 1836 & 56.39 \\
\hline
\end{tabular}




\begin{tabular}{|c|c|c|c|c|c|c|c|}
\hline $\begin{array}{l}\text { Age } \\
\text { (yr) }\end{array}$ & $\begin{array}{l}\text { Depth } \\
\text { (m) }\end{array}$ & $\begin{array}{l}\text { Age } \\
\text { (yr) }\end{array}$ & $\begin{array}{c}\text { Depth } \\
\text { (m) }\end{array}$ & $\begin{array}{l}\text { Age } \\
\text { (yr) }\end{array}$ & $\begin{array}{c}\text { Depth } \\
\text { (m) }\end{array}$ & $\begin{array}{l}\text { Age } \\
\text { (yr) }\end{array}$ & $\begin{array}{c}\text { Depth } \\
\text { (m) }\end{array}$ \\
\hline 1835 & 56.60 & 1790 & 67.32 & 1745 & 75.74 & 1700 & 84.66 \\
\hline 1834 & 56.97 & 1789 & 67.49 & 1744 & 75.96 & 1699 & 84.85 \\
\hline 1833 & 57.16 & 1788 & 67.72 & 1743 & 76.14 & 1698 & 85.01 \\
\hline 1832 & 57.41 & 1787 & 67.90 & 1742 & 76.28 & 1697 & 85.22 \\
\hline 1831 & 57.64 & 1786 & 68.13 & 1741 & 76.44 & 1696 & 85.39 \\
\hline 1830 & 57.84 & 1785 & 68.26 & 1740 & 76.65 & 1695 & 85.61 \\
\hline 1829 & 58.11 & 1784 & 68.56 & 1739 & 76.83 & 1694 & 85.75 \\
\hline 1828 & 58.37 & 1783 & 68.77 & 1738 & 76.94 & 1693 & 85.95 \\
\hline 1827 & 58.60 & 1782 & 68.98 & 1737 & 77.13 & 1692 & 86.09 \\
\hline 1826 & 58.82 & 1781 & 69.19 & 1736 & 77.34 & 1691 & 86.26 \\
\hline 1825 & 59.09 & 1780 & 69.38 & 1735 & 77.49 & 1690 & 86.50 \\
\hline 1824 & 59.28 & 1779 & 69.52 & 1734 & 77.68 & 1689 & 86.60 \\
\hline 1823 & 59.54 & 1778 & 69.71 & 1733 & 77.85 & 1688 & 86.79 \\
\hline 1822 & 59.79 & 1777 & 69.91 & 1732 & 78.02 & 1687 & 86.95 \\
\hline 1821 & 60.00 & 1776 & 70.06 & 1731 & 78.31 & 1686 & 87.09 \\
\hline 1820 & 60.27 & 1775 & 70.28 & 1730 & 78.58 & 1685 & 87.23 \\
\hline 1819 & 60.46 & 1774 & 70.50 & 1729 & 78.78 & 1684 & 87.43 \\
\hline 1818 & 60.70 & 1773 & 70.70 & 1728 & 78.96 & 1683 & 87.53 \\
\hline 1817 & 60.96 & 1772 & 70.83 & 1727 & 79.14 & 1682 & 87.74 \\
\hline 1816 & 61.23 & 1771 & 70.99 & 1726 & 79.35 & 1681 & 87.87 \\
\hline 1815 & 61.49 & 1770 & 71.13 & 1725 & 79.52 & 1680 & 88.16 \\
\hline 1814 & 61.69 & 1769 & 71.37 & 1724 & 79.69 & 1679 & 88.33 \\
\hline 1813 & 61.87 & 1768 & 71.59 & 1723 & 79.83 & 1678 & 88.50 \\
\hline 1812 & 62.09 & 1767 & 71.77 & 1722 & 80.05 & 1677 & 88.57 \\
\hline 1811 & 62.24 & 1766 & 71.99 & 1721 & 80.34 & 1676 & 88.75 \\
\hline 1810 & 62.50 & 1765 & 72.15 & 1720 & 80.48 & 1675 & 88.93 \\
\hline 1809 & 62.67 & 1764 & 72.38 & 1719 & 80.72 & 1674 & 89.06 \\
\hline 1808 & 62.93 & 1763 & 72.57 & 1718 & 80.98 & 1673 & 89.24 \\
\hline 1807 & 63.19 & 1762 & 72.74 & 1717 & 81.08 & 1672 & 89.39 \\
\hline 1806 & 63.45 & 1761 & 72.92 & 1716 & 81.32 & 1671 & 89.54 \\
\hline 1805 & 63.63 & 1760 & 73.08 & 1715 & 81.62 & 1670 & 89.72 \\
\hline 1804 & 64.05 & 1759 & 73.27 & 1714 & 81.88 & 1669 & 89.87 \\
\hline 1803 & 64.37 & 1758 & 73.49 & 1713 & 82.15 & 1668 & 90.05 \\
\hline 1802 & 64.65 & 1757 & 73.66 & 1712 & 82.28 & 1667 & 90.20 \\
\hline 1801 & 64.82 & 1756 & 73.83 & 1711 & 82.53 & 1666 & 90.37 \\
\hline 1800 & 65.04 & 1755 & 74.04 & 1710 & 82.68 & 1665 & 90.56 \\
\hline 1799 & 65.24 & 1754 & 74.21 & 1709 & 82.89 & 1664 & 90.69 \\
\hline 1798 & 65.48 & 1753 & 74.41 & 1708 & 83.09 & 1663 & 90.81 \\
\hline 1797 & 65.82 & 1752 & 74.54 & 1707 & 83.26 & 1662 & 90.99 \\
\hline 1796 & 66.16 & 1751 & 74.82 & 1706 & 83.41 & 1661 & 91.14 \\
\hline 1795 & 66.41 & 1750 & 74.98 & 1705 & 83.61 & 1660 & 91.33 \\
\hline 1794 & 66.56 & 1749 & 75.08 & 1704 & 83.79 & 1659 & 91.49 \\
\hline 1793 & 66.76 & 1748 & 75.22 & 1703 & 84.05 & 1658 & 91.64 \\
\hline 1792 & 66.92 & 1747 & 75.38 & 1702 & 84.18 & 1657 & 91.79 \\
\hline 1791 & 67.14 & 1746 & 75.56 & 1701 & 84.35 & 1656 & 91.93 \\
\hline
\end{tabular}




\begin{tabular}{|c|c|c|c|c|c|c|c|}
\hline $\begin{array}{l}\text { Age } \\
\text { (yr) }\end{array}$ & $\begin{array}{c}\text { Depth } \\
\text { (m) }\end{array}$ & $\begin{array}{l}\text { Age } \\
\text { (yr) }\end{array}$ & $\begin{array}{c}\text { Depth } \\
\text { (m) }\end{array}$ & $\begin{array}{l}\text { Age } \\
\text { (yr) }\end{array}$ & $\begin{array}{c}\text { Depth } \\
\text { (m) }\end{array}$ & $\begin{array}{l}\text { Age } \\
\text { (yr) }\end{array}$ & $\begin{array}{c}\text { Depth } \\
(\mathrm{m})\end{array}$ \\
\hline 1655 & 92.13 & 1610 & 98.90 & 1565 & 105.39 & 1520 & 111.24 \\
\hline 1654 & 92.28 & 1609 & 99.03 & 1564 & 105.53 & 1519 & 111.36 \\
\hline 1653 & 92.40 & 1608 & 99.18 & 1563 & 105.64 & 1518 & 111.49 \\
\hline 1652 & 92.59 & 1607 & 99.32 & 1562 & 105.79 & 1517 & 111.61 \\
\hline 1651 & 92.72 & 1606 & 99.47 & 1561 & 105.92 & 1516 & 111.74 \\
\hline 1650 & 92.89 & 1605 & 99.65 & 1560 & 106.03 & 1515 & 111.86 \\
\hline 1649 & 93.13 & 1604 & 99.86 & 1559 & 106.23 & 1514 & 111.99 \\
\hline 1648 & 93.27 & 1603 & 100.09 & 1558 & 106.36 & 1513 & 112.11 \\
\hline 1647 & 93.42 & 1602 & 100.28 & 1557 & 106.48 & 1512 & 112.24 \\
\hline 1646 & 93.61 & 1601 & 100.41 & 1556 & 106.61 & 1511 & 112.36 \\
\hline 1645 & 93.77 & 1600 & 100.56 & 1555 & 106.72 & 1510 & 112.48 \\
\hline 1644 & 93.91 & 1599 & 100.68 & 1554 & 106.84 & 1509 & 112.61 \\
\hline 1643 & 94.08 & 1598 & 100.81 & 1553 & 107.01 & 1508 & 112.73 \\
\hline 1642 & 94.25 & 1597 & 100.93 & 1552 & 107.11 & 1507 & 112.85 \\
\hline 1641 & 94.37 & 1596 & 101.07 & 1551 & 107.26 & 1506 & 112.98 \\
\hline 1640 & 94.48 & 1595 & 101.21 & 1550 & 107.34 & 1505 & 113.10 \\
\hline 1639 & 94.62 & 1594 & 101.32 & 1549 & 107.45 & 1504 & 113.22 \\
\hline 1638 & 94.83 & 1593 & 101.44 & 1548 & 107.55 & 1503 & 113.34 \\
\hline 1637 & 94.94 & 1592 & 101.56 & 1547 & 107.72 & 1502 & 113.47 \\
\hline 1636 & 95.11 & 1591 & 101.72 & 1546 & 107.85 & 1501 & 113.59 \\
\hline 1635 & 95.22 & 1590 & 101.87 & 1545 & 108.02 & 1500 & 113.71 \\
\hline 1634 & 95.38 & 1589 & 101.97 & 1544 & 108.16 & 1499 & 113.83 \\
\hline 1633 & 95.52 & 1588 & 102.12 & 1543 & 108.32 & 1498 & 113.95 \\
\hline 1632 & 95.64 & 1587 & 102.22 & 1542 & 108.47 & 1497 & 114.07 \\
\hline 1631 & 95.81 & 1586 & 102.38 & 1541 & 108.59 & 1496 & 114.20 \\
\hline 1630 & 95.92 & 1585 & 102.51 & 1540 & 108.73 & 1495 & 114.32 \\
\hline 1629 & 96.05 & 1584 & 102.67 & 1539 & 108.81 & 1494 & 114.44 \\
\hline 1628 & 96.22 & 1583 & 102.77 & 1538 & 108.94 & 1493 & 114.56 \\
\hline 1627 & 96.36 & 1582 & 102.93 & 1537 & 109.07 & 1492 & 114.68 \\
\hline 1626 & 96.51 & 1581 & 103.12 & 1536 & 109.20 & 1491 & 114.80 \\
\hline 1625 & 96.62 & 1580 & 103.25 & 1535 & 109.32 & 1490 & 114.92 \\
\hline 1624 & 96.77 & 1579 & 103.37 & 1534 & 109.45 & 1489 & 115.04 \\
\hline 1623 & 96.91 & 1578 & 103.50 & 1533 & 109.58 & 1488 & 115.16 \\
\hline 1622 & 97.03 & 1577 & 103.62 & 1532 & 109.71 & 1487 & 115.28 \\
\hline 1621 & 97.19 & 1576 & 103.76 & 1531 & 109.84 & 1486 & 115.39 \\
\hline 1620 & 97.30 & 1575 & 103.87 & 1530 & 109.97 & 1485 & 115.51 \\
\hline 1619 & 97.44 & 1574 & 103.98 & 1529 & 110.10 & 1484 & 115.63 \\
\hline 1618 & 97.60 & 1573 & 104.12 & 1528 & 110.22 & 1483 & 115.75 \\
\hline 1617 & 97.70 & 1572 & 104.32 & 1527 & 110.35 & 1482 & 115.87 \\
\hline 1616 & 97.96 & 1571 & 104.48 & 1526 & 110.48 & 1481 & 115.99 \\
\hline 1615 & 98.17 & 1570 & 104.62 & 1525 & 110.60 & 1480 & 116.10 \\
\hline 1614 & 98.33 & 1569 & 104.75 & 1524 & 110.73 & 1479 & 116.22 \\
\hline 1613 & 98.50 & 1568 & 104.96 & 1523 & 110.86 & 1478 & 116.34 \\
\hline 1612 & 98.61 & 1567 & 105.13 & 1522 & 110.98 & 1477 & 116.46 \\
\hline 1611 & 98.76 & 1566 & 105.28 & 1521 & 111.11 & 1476 & 116.57 \\
\hline
\end{tabular}




\begin{tabular}{cc}
\hline $\begin{array}{c}\text { Age } \\
\text { (yr) }\end{array}$ & $\begin{array}{c}\text { Depth } \\
(\mathbf{m})\end{array}$ \\
\hline 1475 & 116.69 \\
1474 & 116.81 \\
1473 & 116.92 \\
1472 & 117.04 \\
1471 & 117.16 \\
1470 & 117.27 \\
1469 & 117.39 \\
1468 & 117.50 \\
1467 & 117.62 \\
1466 & 117.73 \\
1465 & 117.85 \\
1464 & 117.96 \\
1463 & 118.08 \\
1462 & 118.19 \\
1461 & 118.31 \\
1460 & 118.42 \\
1459 & 118.54 \\
1458 & 118.65 \\
1457 & 118.76 \\
1456 & 118.88 \\
1455 & 118.99 \\
1454 & 119.10 \\
1453 & 119.22 \\
1452 & 119.33 \\
1451 & 119.44 \\
1450 & 119.56 \\
1449 & 119.67 \\
1448 & 119.78 \\
1447 & 119.89 \\
1446 & 120.00 \\
\hline
\end{tabular}




\section{References for appendices}

Bertler, N. A. N., P. Mayewski, and L. Carter (in press), Cold conditions in Antarctica during the Little Ice Age - Implications for abrupt climate change mechanisms, Earth and Planetary Science Letters.

Broecker, W. S., 2000b. Was a change in thermohaline circulation responsible for the Little Ice Age? Procedings of the National Academy of Science U. S. A. 97, 1339-1342.

Dansgaard, W., and S. J. Johnsen (1969), A flow model and a time scale for the ice core from Camp Century, Greenland, Journal of Glaciology, 8, 215-223.

Dansgaard, W., S. J. Johnsen, and H. Clausen (1973), Stable isotope glaciology, Meddelelser om Grønland, 197, 1-53.

Domack, E.W., Mayewski, P.A., (1999), Bi-polar ocean linkages: evidence from lateHolocene Antarctic marine and Greenland ice-core records, Holocene, 9, 247-251.

Etheridge, D.M., Steele, L.P., Langenfelds, R.L., Francey, R.J., Barnola, J.M.,Morgan, V.I., (1996), Natural and anthropogenic changes in atmospheric $\mathrm{CO}_{2}$ over the last 1000 years from air in Antarctic ice and firn, Journal of Geophysical Research, 101, 4115-4128.

Herron and Langway (1980), Firn densification: an empirical model, Journal of Glaciology, $25,373-385$.

Indermuhle, A., Stocker, T. F., Joos, F., Fischer, H., Smith, H. J., Wahlen, M., Deck, B., Mastroianni, D., Tschumi, J., Blunier, T., Meyer, R., Stauffer, B., (1999), Holocene carboncycle dynamics based on $\mathrm{CO}_{2}$ trapped in ice at Taylor Dome, Antarctica, Nature, 398, $121-126$.

Johnsen, S. J., H. B. Clausen, K. M. Cuffey, G. Hoffmann, J. Schwander, and T. Creyts (2000), Diffusion of stable isotopes in polar firn and ice: the isotope effect in firn diffusion, Physics of Ice Core Records, 121-140. 
Jouzel, J. L. Merlivat, M. Pourchet, and C. Lorius (1979), A continuous record of artificial tritium fallout at the South Pole (1954-1978), Earth and Planetary Science Letters, 45, 188-200.

Karlöf, L., Winther, J. G., Isaksson, E., Kohler, J., Pinglot, J.F., Wilhelms, F., Hansson, M., Holmlund, P., Nyman, M., Pettersson, R., Stenberg, M., Thomassen, M. P. A., van der Veen, C., van de Wal, R. S. W., (2000), A 1500 year record of accumulation at Amundsenisen western Dronning Maud Land, Antarctica, derived from electrical and radioactive measurements on a 120 m ice core, Journal of Geophysical Research, 105, 12471-12483.

Kreutz, K. J., Mayewski, P., Pittalwala, I. I., Meeker, L. D., Twickler, M. S., Whitlow, S. I., (2000), Sea level pressure variability in the Amundsen Sea region inferred from a West Antarctic glaciochemical record, Journal of Geophysical Research, 105, 4047-4059.

Leventer, A., Dunbar, R. B., (1988), Recent Diatom Record of McMurdo Sound, Antarctica: implications for history of sea ice extent, Paleoceanography, 3, 259-274.

Masson, V., Vimeux, F., Jouzel, J., Morgan, V., Delmotte, M., Ciais, P., Hammer, C., Johnsen, S., Lipenkov, V. Y., Mosley-Thompson, E., Petit, J.-R., Steig, E .J., Stievenard, M., Vaikmae, R., (2000), Holocene climate variability in Antarctica based on 11 ice-core isotopic records, Quaternary Research, 54, 348-358.

Mayewski, P., Maasch, K. A., White, J. W. C., Steig, E. J., Meyerson, E., Goodwin, I., Morgan, V. I., van Ommen, T., Curran, M. A. J., Souney, J., Kreutz, K., (2004), A 700 year record of Southern Hemisphere extratropical climate variability, Annals of Glaciology, 39, $127-132$.

Stenni, B., Proposito, M., Gragnani, R., Flora, O., Jouzel, J., Falourd, S., Frezzotti, M., (2002), Eight centuries of volcanic signal and climate change at Talos Dome (East Antarctica), Journal of Geophysical Research, 107, 4076.

Yan, Y., Mayewski, P.A., Kang, S., Meyerson, E., (2005), An ice-core proxy for Antarctic circumpolar zonal wind intensity, Annals of Glaciology, 41, 121-130. 